ASSIS RODRIGUES ABBUD VILLELA

\title{
ESTUDO DE CAMADA DE BASE ASFÁLTICA DE MÓDULO ELEVADO PARA RESTAURAÇÃO DE RODOVIAS DE TRÁFEGO MUITO PESADO
}



ASSIS RODRIGUES ABBUD VILLELA

\section{ESTUDO DE CAMADA DE BASE ASFÁLTICA DE MÓDULO ELEVADO PARA RESTAURAÇÃO DE RODOVIAS DE TRÁFEGO MUITO PESADO}

Tese apresentada à Escola Politécnica da Universidade de São Paulo para obtenção do Título de Doutor em Engenharia

Área de Concentração:

Engenharia de Transportes

Orientadora:

Professora Titular, Doutora Liedi Légi Bariani Bernucci 
Este exemplar foi revisado e alterado em relação à versão original, sob responsabilidade única do autor e com a anuência de seu orientador.

São Paulo, 15 de fevereiro de 2012.

Assinatura do autor

Assinatura do orientador

\section{FICHA CATALOGRÁFICA}

Villela, Assis Rodrigues Abbud

Estudo de camada de base asfáltica de módulo elevado para restauração de rodovias de tráfego muito pesado / A.R.A. Villela. -- São Paulo, 2012.

$206 \mathrm{p}$.

Tese (Doutorado) - Escola Politécnica da Universidade de São Paulo. Departamento de Engenharia de Transportes.

1. Pavimentação 2. Pavimentação asfáltica 3. Tráfego rodoviário 4. Módulos I. Universidade de São Paulo. Escola Politécnica. Departamento de Engenharia de Transportes II. t. 


\section{FICHA DE APROVAÇÃO}

ASSIS RODRIGUES ABBUD VILLELA

\section{ESTUDO DE CAMADA DE BASE ASFÁlTICA DE MÓdULO ElEVADO PARA RESTAURAÇÃO DE RODOVIAS DE TRÁFEGO MUITO PESADO}

Texto apresentado à Escola Politécnica da Universidade de São Paulo para obtenção do Título de Doutor

Área de concentração: Engenharia de Transportes

Aprovado em:

\section{BANCA EXAMINADORA}

Professora Titular, Doutora Liedi Légi Bariani Bernucci

Escola Politécnica da Universidade de São Paulo (USP)

Professor Doutor Carlos Yukio Suzuki

Escola Politécnica da Universidade de São Paulo (USP)

Professora Doutora Laura Maria Goretti da Motta Universidade Federal do Rio de Janeiro (UFRJ / COPPE)

Doutora Leni Figueiredo Mathias Leite

Centro de Pesquisas e Desenvolvimento Leopoldo Américo Miguez de Mello (CENPES / Petrobras) 

Ao João e à Helô, pelos incontáveis desenhos que criamos e colorimos juntos ao longo do desenvolvimento desta tese. Nossa geladeira é uma verdadeira galeria de arte! 

Embora muito da produção de uma tese resulte de horas solitárias diante de folhas preenchidas ou a preencher, nada se faz sozinho. É sempre no diálogo com os outros que se constroem as ideias e se realiza o trabalho. Agradecer-Ihes é reconhecer sua importância em minhas realizações. Por isso minha profunda gratidão:

- A Deus, pela graça da vida, pela saúde, pelos dons e meios concedidos à realização e conclusão de mais uma jornada.

- Ao João e à Helô pelo amor, respeito e pela presença, fundamentais em toda essa minha trajetória. Sobretudo, por compreender minhas dificuldades e minhas ausências, com constantes palavras de ânimo e total confiança no meu sucesso. Fortalece-me o simples fato de saber que vocês existem em minha vida.

- Ao meu pai Luiz (in memoriam) e a minha mãe Rosa Alice, que me incentivaram em toda possível curiosidade, na busca constante do conhecimento e na dedicação aos estudos. O que talvez vocês não tivessem adivinhado ou previsto é que eu faria da curiosidade, do desejo de tudo conhecer, de experimentar toda novidade, um doce complemento de minha profissão. Aos meus irmãos, Anthuza e Juliano, que me estimularam nesse longo período de estudo.

- À minha família (Abbud, Bruel, Gemin, Villela), o fato de saber que posso contar com vocês me permite progredir constantemente no caminho que escolhi. Em diversos momentos da vida encontrei na família meu porto seguro, que se revelou imprescindível mesmo quando teimei em achar o contrário. À tia Angelina que, dentre tantos conselhos e conversas prazerosas, ao redor de uma bela mesa de café tipicamente mineira, teve a coragem de indicar um garoto de 18 anos de idade, que recém havia ingressado na engenharia, para lecionar aulas de matemática. Sua generosidade e todo aquele aprendizado naqueles anos letivos resultaram nesta tese.

- À minha orientadora Professora Liedi, por permitir este convívio, uma das experiências determinantes de minha formação acadêmica, profissional e pessoal. Neste período, aprendi a confiar na racionalidade e ainda mais na capacidade de aprimoramento técnico. Ao admirá-la, mantenho a esperança de que a vida pode e deve ser mais leve e agradável.

- Ao Professor Suzuki, pela valiosa contribuição dada a esta tese, incentivando-me a reformular o estudo paramétrico e presenteando-me com excelentes sugestões durante o exame de qualificação e, em outras oportunidades, em seu escritório.

- À Professora Laura, pelo estímulo ainda nos primeiros anos de mestrado quando visitava a COPPE. Nunca me esquecerei de sua generosidade em compartilhar os mais recentes artigos técnicos, num tempo em que não eram disponibilizados pela internet. Por toda contribuição e pelo constante interesse no desenvolvimento de minha tese.

- À Doutora Leni, pela oportunidade de interlocução, tendo aceitado participar da banca examinadora desta tese e principalmente por ter viabilizado o CAP duro para execução do Trecho Experimental.

- Ao Professor Ceratti, pela arguição atenta e ricas sugestões oferecidas no exame de qualificação. Saiba que suas contribuições são enriquecedoras, desde o tempo do mestrado. 
- Aos docentes do Programa de Pós-Graduação em Engenharia de Transportes: Professor Balbo, Professor Hugo, pela competência com que ministraram as disciplinas. Em especial ao Professor Quintanilha, pelas inúmeras horas que generosamente concedeu-me para o auxilio a análise estatística desta tese.

- À amiga Elieni (in memoriam). Não sou realmente capaz de expressar a sorte e alegria de, contigo, ter convivido em tantos e significativos momentos. Mas, se aqui todos os agradecimentos serão necessariamente insuficientes, que essas palavras sirvam pelo menos para relembrar quão fantástico foi tê-la conhecido.

- À amiga Márcia Aps, por ter me recebido ainda nos tempos de IPT e acreditado nas minhas intenções, no processo de trabalho e na construção de conhecimento que propus por meio do plano de trabalho ainda na fase embrionária desta tese. Amizade assim não se pode retribuir com palavras. Deixo somente o registro do meu mais total apreço, na certeza de que esta tese coroa este relacionamento fraternal.

- Ao amigo Cláudio Renato, companheiro de muitas reflexões e destinos, comparsa de toda jornada para a execução, madrugada adentro, do Trecho Experimental. Sem seu apoio, dezenas de situações teriam sido difíceis e, sem dúvida, esta tese não seria a mesma.

- Aos velhos amigos da época da UFSC Cássio, Geralci, Renato e Rodolfo, que mesmo distantes são para mim exemplos da amizade incondicional e perene. Floripa não é mais a mesma!

- Ao Laboratório e seus mais do que inestimáveis (e eternos) membros: Amanda, Ana, Diomária, Edson Moura, Erasmo, Kamilla, Kendi, Manuela, Mary, Renato, Rosângela, Rosely, Sérgio, Tiago. Sem vocês a tarefa de terminar este doutorado teria certamente passado de difícil a improvável.

- A Camila, Edson Silva, Luciana, Patrícia, Simone, e todo o pessoal da secretaria do PTR. O trabalho de "bastidores" que vocês realizam pode ser, a muitos olhos, invisível. Mas certamente só é invisível quando bem feito. E ele é extremamente bem feito.

- À ANTT, pelos incentivos à pesquisa por meio de Recursos de Desenvolvimento Tecnológico (RDT).

- Às empresas que colaboraram para a execução e monitoramento do Trecho Experimental desta tese: CENPES, em nome de Leni e Luiz Nascimento; Cibermétrica, em nome de Rodrigo Barella; COPAVEL, em nome de Luciano e Rodrigo Vasconcelos; EPT, em nome de Ricardo Ishikawa; Grupo CCR, em nome de Barba, Burê, Décio, Escudeiro e Paulo Rangel; LENC, em nome de Debora Targas e Joel; RACUM Tecnologia, em nome de Ronaldo Racum; SERVENG CIVILSAN, em nome de Adilson, Calil e Fred.

Enfim agradeço a todos que, mesmo que não soubessem, me fizeram fazer esta tese. 
"Nunca haverá uma porta, e te achas dentro e esse alcáçar abarca o universo e não tem nem anverso, nem reverso, nem muro externo, nem secreto centro. Não cuides que o rigor de teu caminho, que tenazmente se bifurca em outro, que tenazmente se bifurca em outro, terá fim $[\ldots]^{\prime \prime}$ 



\section{RESUMO}

A partir dos anos 1980, iniciou-se na França o uso de misturas asfálticas de módulo elevado (EME - Enrobé à Module Éleve) em intervenções de pavimentos para a restauração de vias urbanas e de trechos de rodovias sujeitas a tráfego pesado e intenso. Estas experiências tiveram como principais finalidades reduzir a deformabilidade e as espessuras das camadas do pavimento, elevando sua rigidez e melhorando seu comportamento mecânico quanto à deformação permanente e à vida de fadiga, em comparação com outros materiais convencionais. Com base nos estudos paramétricos, esta pesquisa analisa as deflexões, tensões e deformações atuantes nas diversas camadas da estrutura de um pavimento, a fim de estudar o comportamento de camadas de EME empregadas nos serviços de restauração. Desde que sejam conhecidas as condições estruturais do pavimento existente e do futuro tráfego, pode-se definir rapidamente as características geométricas e mecânicas das misturas de EME a serem empregadas nas camadas sobrejacentes das restaurações de pavimentos. São apresentados os ensaios laboratoriais com misturas de EME para definição do projeto de mistura, comportamento mecânico, Prensa de Cisalhamento Giratória (PCG - Presse à Cisaillement Giratoire) e deformação permanente, cujos resultados atenderam às especificações técnicas. Esta pesquisa conta com a execução de um Trecho Experimental na rodovia Presidente Dutra, localizado no município de Jacareí/SP, que é sujeita a tráfego pesado e intenso. Durante a sua execução, não foram verificadas dificuldades adicionais de usinagem e de execução em pista. Neste trecho composto de três diferentes seções experimentais, variandose a espessura da camada de base de módulo elevado, foi avaliado e comprovado 0 bom comportamento estrutural do pavimento com mistura de EME como base asfáltica para restauração do pavimento de rodovia com tráfego muito pesado. 


\section{ABSTRACT}

Since 80's it has started in France the use of high modulus asphalt concrete (EME Enrobé à Module Éleve) in pavement interventions for the restoration of urban roads and some sections of highways with heavy and high traffic. Those experiences had the main purpose of reducing deformability and decreasing layers' thicknesses of the pavement, which could raise its strength and improve its mechanical behavior, concerning rutting and fatigue life, in comparison to other conventional materials. Based on a parametric studies, this research analyses deflections, tensions and deformations that act in all pavement structure for studying the behavior of EME layers in restorations. Since structural conditions of the existing pavement and the future traffic are known, it can be rapidly defined the geometrical and mechanical characteristics of EME mixtures for being used as wearing courses in pavement restorations. Laboratory tests were carried out with EME in terms of mixture design, mechanical behavior, French gyratory compaction (PCG - Presse à Cisaillement Giratoire) and rutting and the results were in compliance with technical specifications. This research includes a trial section on Presidente Dutra highway in Jacareí city/SP, which is a heavy and high trafficked road. During the construction, no additional difficulties in mixing and laydown operations were found. This test track composed of three sections with different thicknesses of EME as a base layer was evaluated, and proved the good structural behavior of EME mixture as an asphalt base layer for pavement rehabilitation of a very high trafficked road. 


\section{SUMÁRIO}

1. CONSIDERAÇÕES INICIAIS 11

1.1. RELEVÂNCIA DA PESQUISA E CONTEXTUALIZAÇÃO DO PROBLEMA 11

1.2. ENQUADRAMENTO DA PESQUISA 12

1.3. DELIMITAÇÕES E PRESSUPOSTOS DA PESQUISA

$\begin{array}{ll}\text { 1.4. HIPÓTESE } & 14\end{array}$

1.5. OBJETIVO 14

1.6. DESCRIÇÃO SUMÁRIA DOS CAPÍTULOS - ESTRUTURA DO TRABALHO 15

2. MISTURAS ASFÁLTICAS DE MÓDULO ELEVADO (EME) 17

2.1. INTRODUÇÃO 17

2.2. CARACTERÍSTICAS DAS MISTURAS DE MÓDULO ELEVADO (EME) 20

2.3. EXPERIÊNCIAS ANTERIORES COM PAVIMENTOS CONSTITUÍDOS DE

2.3.1. Experiências Francesas 26

2.3.2. Experiências Espanholas $\quad 30$

2.3.3. Experiência Suíça 31

2.3.4. Experiências Portuguesas $\quad 32$

2.3.5. Experiência Polonesa 34

2.3.6. Experiência Italiana $\quad 35$

2.3.7. Experiências Brasileiras 36

3. TRECHO EXPERIMENTAL 45

3.1. LOCALIZAÇÃO DO TRECHO EXPERIMENTAL 45

$\begin{array}{lllllll}\text { 3.2. CLIMA E TRÁFEGO ATUANTES NA REGIÃO DO TRECHO } & \\ \text { EXPERIMENTAL } & & & & & 46\end{array}$

3.2.1. Clima Atuante na Região do Trecho Experimental 46

3.2.2. Tráfego Atuante na Região do Trecho Experimental 48

3.2.3. Velocidades dos Veículos na Região do Trecho Experimental 48

3.3. SONDAGENS NO TRECHO EXPERIMENTAL

3.4. DEFINIÇÃO DO TRECHO EXPERIMENTAL

3.5. ESTUDOS LABORATORIAIS 56

3.5.1. Distribuição Granulométrica do EME 56

3.5.2. Caracterização do Ligante do EME 56

3.5.3. Projeto da Mistura do EME 57

3.5.4. Propriedades Mecânicas do EME- Deformação Permanente e PCG 61

3.6. USINAGEM E EXECUÇÃO DO TRECHO EXPERIMENTAL 62

3.6.1. Usinagem do Trecho Experimental 62

3.6.2. Execução do Trecho Experimental 66

3.6.2.1. Preparo da Superfície 66

3.6.2.2. Distribuição e Compactação do EME 66 
3.6.2.3. Sistema de Drenagem 67

3.6.2.4. Controle da Execução 67

3.6.2.5. Execução da Camada de Rolamento 68

4. ESTUDOS PARAMÉTRICOS 69

4.1. ESTUDOS PARAMÉTRICOS ANTECEDENTES 69

4.2. ESTUDOS PARAMÉTRICOS PARA ESTRUTURAS DE PAVIMENTO RESTAURADAS COM CAMADA DE BASE EM EME 71

4.2.1. Dimensionamento de Estruturas de Restauração de $\begin{array}{ll}\text { Pavimentos } & 71\end{array}$

4.2.2. Descrição das etapas para o Desenvolvimento do Estudo Paramétrico 72

5. ANÁLISE DOS RESULTADOS 103

5.1. ANÁLISES MECANÍSTICAS 103

5.1.1. Levantamento Deflectométrico 103

5.1.2. Análise da Linearidade do Sistema Estrutural Multicamadas 106

5.1.3. Análise das Medidas de Deflexões 111

5.1.3.1. Análise das Medidas de Deflexões entre Seções de Comportamentos Similares 111

5.1.3.2. Análise das Medidas de Deflexões ao longo do Trecho Experimental

5.1.4. Retroanálises dos Módulos de resiliência das Camadas de EME

5.2. AVALIAÇÃO DA CONCENTRAÇÃO DE DEFEITOS 125

5.3. AVALIAÇÃO ESTRUTURAL PELO DNER PRO-11/79 127

5.3.1. Modelos Propostos para Misturas Asfálticas de Módulo Elevado (EME) 129

5.3.1.1. Fator de Redução K de Deflexão para EME 129

5.3.1.2. Modelos Empíricos para EME 132

6. CONCLUSÕES 138

REFERÊNCIAS BIBLIOGRÁFICAS

$\begin{array}{ll}\text { ANEXOS } & 151\end{array}$

Modelos Desenvolvidos 153

$\begin{array}{ll}\text { Levantamentos Deflectométricos } & 167\end{array}$ 


\section{RELAÇÃO DE FIGURAS}

Figura 2.1 - Estruturas do pavimento para a temperatura de $15^{\circ} \mathrm{C}$ e $10 \mathrm{~Hz}$, estudadas por QUINTERO (2011)

Figura 2.2 - Estruturas do pavimento para a temperatura de $30^{\circ} \mathrm{C}$ e $10 \mathrm{~Hz}$, estudadas por QUINTERO (2011)

Figura 3.1 - Localização do Trecho Experimental (imagem extraída no Google Earth)

Figura 3.2 - Localização dos Sensores a laço indutivo para classificação e identificação e identificação da velocidade dos veículos, km 170+360

Figura 3.3 - Distribuição dos veículos em relação à velocidade trafegada

Figura 3.4 - Estaca 170+420: Grau de trincamento da superfície do pavimento

Figura 3.5 - Estaca 170+260: Grau de trincamento de superfície do pavimento e deficiência do dispositivo de drenagem

Figura 3.6 - Estaca 170+260: Poço de Inspeção P05 e materiais extraídos

Figura 3.8 - Perfil longitudinal com a estrutura do pavimento no local do Trecho Experimental

Figura 3.10 - Curva granulométrica da mistura de EME estuda

Figura 3.11 - Massa específica aparente $\left(\mathrm{g} / \mathrm{cm}^{3}\right)$

Figura 3.12 - Massa específica teórica $\left(\mathrm{g} / \mathrm{cm}^{3}\right)$

60

Figura 3.13 - Volume de vazios (\%)

60

Figura 3.14 - Vazios do agregado mineral (\%) 60

Figura 3.15 - Relação betume/vazios (\%)

60

Figura 3.16 - Resistência à tração (MPa)

Figura 3.17 - Aptidão de compactação para o ensaio na Prensa de Cisalhamento Giratória (PCG)

Figura 3.19 - Deformação permanente em trilha de roda no simulador LCP

Figura 3.18 - Usina Gravimétrica Jambeiro Serveng-Civilsan

Figura 3.19 - Tela de controle das atividades da Usina Gravimétrica

Figura 3.20 - Acabamento da superfície de EME

Figura 4.1 - Fluxograma de representação dos Estudos Paramétricos

Figura 4.2 - Pavimento tipo com camadas de revestimento e EME como restauração

Figura 4.3 - Desenho esquemático da distribuição do carregamento para simulação com FWD

Figura 4.4 - Desenho esquemático da distribuição do carregamento para simulação com VBK

Figura 4.5 - Análise dos resíduos para os Indicadores Estruturais e para os Indicadores de Curvatura

Figura 4.6 - Comparação dos modelos em função MRREM e DoREM ante ao عteme Retroanalisados 
Figura 4.7 - Comparação dos modelos em função MRREM e DoREM ante ao otemE Retroanalisados

Figura 4.8 - Comparação dos modelos em função MRREM e DoREM ante ao EVREM Retroanalisados

Figura 4.9 - Ajuste do modelo EvREM em relação aos modelos em função MRREM e DOREM

Figura 5.1 - Estágios dos levantamentos deflectométricos

Figura 5.2 - Distribuição das deflexões máximas (Do) e seus coeficientes de determinação em cada seção experimental na Estrutura Primitiva

Figura 5.3 - Distribuição dos valores de SCI e seus coeficientes de determinação em cada seção experimental na Estrutura Primitiva

Figura 5.4 - Distribuição das deflexões máximas $\left(D_{0}\right)$ e seus coeficientes de determinação em cada seção experimental no Fundo de Caixa Fresada

Figura 5.5 - Distribuição dos valores de SCI e seus coeficientes de determinação em cada seção experimental no Fundo da Caixa Fresada

Figura 5.6 - Distribuição das deflexões máximas $\left(D_{0}\right)$ e seus coeficientes de determinação em cada seção experimental na Camada de EME

Figura 5.7 - Distribuição dos valores de SCI e seus coeficientes de determinação em cada seção experimental na Camada de EME

Figura 5.8 - Distribuição das deflexões máximas (Do) e seus coeficientes de determinação em cada seção experimental no Topo do Revestimento

Figura 5.9 - Distribuição dos valores de SCI e seus coeficientes de determinação em cada seção experimental no Topo do Revestimento

Figura 5.10 - Bacias de deflexões na seção de $140 \mathrm{~mm}$ de EME da pista experimental, com intensidade de carregamento de $2,1 \mathrm{tf}$

Figura 5.11 - Bacias de deflexões na seção de $110 \mathrm{~mm}$ de EME da pista experimental, com intensidade de carregamento de $2,1 \mathrm{tf}$

Figura 5.12 - Bacias de deflexões na seção de $80 \mathrm{~mm}$ de EME da pista experimental, com intensidade de carregamento de $2,1 \mathrm{tf}$

Figura 5.13 - Bacias de deflexões na seção de $140 \mathrm{~mm}$ de EME da pista experimental, com intensidade de carregamento de 4,1 tf

Figura 5.14 - Bacias de deflexões na seção de $110 \mathrm{~mm}$ de EME da pista experimental, com intensidade de carregamento de 4,1 tf

Figura 5.15 - Bacias de deflexões na seção de $80 \mathrm{~mm}$ de EME da pista experimental, com intensidade de carregamento de 4,1 tf

Figura 5.16 - Bacias de deflexões na seção de $140 \mathrm{~mm}$ de EME da pista experimental, com intensidade de carregamento de $6,5 \mathrm{tf}$

Figura 5.17 - Bacias de deflexões na seção de $110 \mathrm{~mm}$ de EME da pista experimental, com intensidade de carregamento de $6,5 \mathrm{tf}$

Figura 5.18 - Bacias de deflexões na seção de $80 \mathrm{~mm}$ de EME da pista experimental, com intensidade de carregamento de 6,5 tf

Figura 5.19 - Medidas de deflexão máxima ao longo do Trecho Experimental, nos diversos Estágios

Figura 5.20 - Módulo de resiliência da Camada de EME, levantamento no Estágio 2 (final da obra do EME) 
Figura 5.21 - Módulo de resiliência da Camada de EME, levantamento no Estágio 3120

Figura 5.22 - Módulo de resiliência da Camada de EME, levantamento no Estágio $4 \quad 121$

Figura 5.23 - Condição de saturação das camadas do pavimento 122

Figura 5.24 - Execução dos dispositivos de drenagem 122

Figura 5.25 - Fator de redução da deflexão K (PRO 11) 131

Figura 5.26 - Potencial de redução da espessura de reforço em EME $(K=27)$ em comparação com o CBUQ convencional ( $K=40)$

Figura 5.27 - Características geométricas e mecânicas adotadas para a simulação

Figura 5.28 - Valores da deflexão máxima e do módulo de resiliência mínimo admissíveis no topo do remanescente, com seus graus de confiabilidade 


\section{RELAÇÃO DE TABELAS}

Tabela 2.1 - Faixas Granulométricas para a mistura de módulo elevado adotadas em camada de base em Portugal (JAE, 1998 e BRANCO et al, 2006)

Tabela 2.2 - Características dos ligantes duros (CAP 10-20 e CAP 15-25) adaptada de ECS (2006)

Tabela 2.3 - Características das misturas de elevado módulo (EME 1 e EME 2) adaptada de AFNOR (1999) CORTÉ e SERFASS (2000) e CORTÉ (2001)

Tabela 2.4 - Coeficientes estruturais de camadas novas, usadas na França para dimensionamento de pavimentos de aeroportos (PARIZÉ et al, 1998)

Tabela 2.5 - Coeficientes estruturais das novas misturas BBME e EME determinados para dimensionamento de pavimentos de aeroportos na França (PARIZÉ et al, 1998)

Tabela 2.6 - Características mecânicas das misturas estudadas por MAGALHÃES (2004)

Tabela 2.7 - MR e RT das misturas estudadas por FREITAS (2007) 38

Tabela 3.1 - Contribuição da precipitação $(\mathrm{mm})$, ao longo das estações do ano 46

Tabela 3.2 - Contribuição da temperatura do $\operatorname{ar}\left({ }^{\circ} \mathrm{C}\right)$, ao longo das estações do ano 47

Tabela 3.3 - Dados de tráfego 48

Tabela 3.4 - Localização dos Poços de Inspeção 50

Tabela 3.5 - Localização das Sondagens Rotativas 52

Tabela 3.6 - Constituição geral do Trecho Experimental

Tabela 3.7 - Caracterização do ligante fornecido pela Petrobras

Tabela 3.8 - Características Técnicas da Usina Jambeiro

Tabela 3.9 - Valor dos módulos de riqueza das amostras

Tabela 3.10 - Espessuras de fresagem nas seções experimentais

Tabela 3.11 - Temperatura ambiente na de execução do trecho experimental

Tabela 4.1 - Parâmetros investigados nos estudos paramétricos antecedentes

Tabela 4.2 - Parâmetros considerados para o plano fatorial de modelagem

Tabela 4.3 - Coeficientes e parâmetros de análises para indicadores estruturais da VBK

Tabela 4.4 - Coeficientes e parâmetros de análises para indicadores de curvatura da VBK 
Tabela 4.5 - Coeficientes e parâmetros de análises para indicadores estruturais do FWD

Tabela 4.6 - Coeficientes e parâmetros de análises para indicadores de curvatura do FWD

Tabela 4.7 - Valores dos coeficientes de determinação $\left(R^{2}\right)$ para cada modelo

Tabela 4.8 - Coeficientes e parâmetros de análises para indicadores de curvatura para VBK, exceto Q

Tabela 4.9 - Coeficientes e parâmetros de análises para indicadores de curvatura para FWD, exceto Q

Tabela 4.10 - Valores de Dorem correspondentes a cada MRREM

Tabela 4.11 - Coeficientes e parâmetros de análises para indicadores estruturais da VBK

Tabela 4.12 - Coeficientes e parâmetros de análises para indicadores de curvatura da VBK

Tabela 4.13 - Coeficientes e parâmetros de análises para indicadores de curvatura da FWD

Tabela 4.14 - Coeficientes e parâmetros de análises para indicadores de curvatura do FWD

Tabela 4.15 - Comparativo dos coeficientes de determinação entre os indicadores estruturais

Tabela 4.16 - Comparativo dos coeficientes de determinação entre os indicadores de curvatura

Tabela 4.17 - Principais parâmetros para controle dos Indicadores Estruturais (IE)

Tabela 4.18 - Equações de Correlação entre os Esforços Solicitantes e Do e os Indicadores de Curvatura, a partir dos estudos paramétricos em função de MRREM

Tabela 4.19 - Equações de Correlação entre os Esforços Solicitantes e Do e os Indicadores de Curvatura, a partir dos estudos paramétricos em função de Dorem

Tabela 5.1 - Dia da Realização do levantamento e respectivo Estágio

Tabela 5.2 - Relação das faixas de valores deflectométricos para os substratos remanescentes 
Tabela 5.3 - Análise de variância dos MReme para os carregamentos do FWD Estágio 2

Tabela 5.4 - Análise de variância dos MREME para os carregamentos do FWD Estágio 3

Tabela 5.5 - Análise de variância dos MREME para os carregamentos do FWD Estágio 4 125

Tabela 5.6 - Evolução da condição geral da superfície do pavimento 126

Tabela 5.7 - Solicitações do tráfego no Trecho Experimental

Tabela 5.8 - Modelos empíricos para EME, comparados com CBUQ e Asfalto Borracha

Tabela 5.9 - Valores da deflexão máxima e do módulo de resiliência mínimo admissíveis para a estrutura remanescente atingir até DadmREV $=30\left(10^{-2} \mathrm{~mm}\right)$ 


\section{CONSIDERAÇõES INICIAIS}

\subsection{RELEVÂNCIA E CONTEXTUALIZAÇÃo DO PROBLEMA}

O pavimento constitui parte de maior custo na infraestrutura de transportes de uma rede rodoviária ou urbana, representando um patrimônio cujo gerenciamento, manutenção e conservação adequados são vitais para a minimização do custo global envolvido no transporte.

Além desse fato, verifica-se no Brasil uma oferta insuficiente de infraestrutura de transporte rodoviário, tanto em extensão quanto na qualidade de suas vias. A má conservação das rodovias impacta negativamente na economia do País, além de gerar um processo de "antieconomia", ou seja, o volume poupado em serviços de manutenção no momento adequado resulta em acréscimos em gastos futuros com obras de reconstrução e em custos adicionais para os usuários (BARTHOLOMEU, 2006).

Desse modo, cabe à pesquisa em pavimentação o desenvolvimento de tecnologias que possibilitem a construção de rodovias com uma maior durabilidade, proporcionando a postergação de intervenções de reabilitação e a diminuição na frequência de atividades de manutenção (NEVES FILHO, 2004).

Com base nessas evidências, estabelece-se o seguinte questionamento como motivação para o desenvolvimento desta tese: Pode-se desenvolver uma camada de base capaz de compor uma estrutura de pavimento que resista às trincas por fadiga e à deformação permanente nas trilhas de roda, em um determinado período de vida útil, como estruturas convencionais de reconstrução e que seja de rápida execução? 


\subsection{ENQUADRAMENTO DA PESQUISA}

Visando melhorar o desempenho mecânico e em contrapartida reduzir as espessuras das camadas asfálticas durante serviços de recuperação de pavimentos urbanos e restauração de rodovias, foram desenvolvidas na França, na década de 80 , as chamadas misturas asfálticas de módulo elevado $\left(\mathrm{EME}^{1}\right)$. Essas misturas apresentam rigidez superior à das misturas asfálticas convencionais e se caracterizam pelo uso de granulometria contínua e ligantes duros, com penetração a $25^{\circ} \mathrm{C}$ entre 10 e $20\left(10^{-1}\right.$ $\mathrm{mm}$ ) e temperatura de amolecimento anel e bola $\geq 55^{\circ} \mathrm{C}$ (BROSSEAUD, 2002).

As misturas asfálticas de módulo elevado (EME) são usadas nas camadas de base ou de ligação e especificadas de acordo com a norma francesa NF P 98-140 (AFNOR, 1999). São misturas asfálticas com elevado desempenho e durabilidade que permitem a redução de até $25 \%$ de espessura nas camadas de pavimento ante as constituídas com materiais convencionais (BROSSEAUD, 2002; 2006).

Pelo exposto, este trabalho busca trazer contribuições no estudo do comportamento de misturas asfálticas de EME, submetidas a tráfego pesado e intenso executadas em escala real. Outras pesquisas nacionais, descritas no capítulo a seguir, abordaram este mesmo tema sob o enfoque da análise das características físicas e mecânicas em laboratório (MAGALHÃES, 2004; FREITAS, 2007 e QUINTERO, 2011) ou da avaliação de comportamento estrutural em pista teste submetida a carregamentos acelerados com simulador de tráfego (ROHDE, 2007).

Propõe-se nesta pesquisa adaptar a tecnologia francesa de misturas asfálticas de EME para as condições brasileiras de dimensionamento, execução e avaliação de desempenho. Pretende-se ainda discutir, a partir do EME, uma nova tecnologia de restauração de pavimentos que propicie maior rigidez e que apresente bom comportamento em relação à vida à fadiga além de minimizar, o quanto possível, os

\footnotetext{
${ }^{1}$ Neste trabalho, optou-se por utilizar a sigla EME que é comumente utilizada na literatura técnica rodoviária para designar misturas asfálticas de módulo elevado, sendo suas iniciais derivadas da expressão francesa: enrobé à module élevé.
} 
transtornos para o usuário por meio de sua rápida execução. Como assinala BROSSEAUD (2002; 2006) ao utilizar ligantes de consistência mais elevada, apesar de teores relativamente maiores, em torno de $6 \%$, e de misturas com baixos volumes de vazios, na ordem de 3 a $6 \%$, consegue-se manter um bom comportamento em relação à fadiga, possibilitando pavimentos de menores espessuras e com características mecânicas superiores a de estruturas convencionais.

\subsection{DELIMITAÇÕES E PRESSUPOSTOS DA PESQUISA}

Alguns pressupostos adotados na pesquisa são essenciais para a delimitação das fronteiras do trabalho de investigação, tornando mais clara a formulação e compreensão do objetivo desta tese.

Previamente, faz-se necessário estabelecer que o objeto de estudo é a mistura asfáltica de módulo elevado (EME) com finalidade de restauração, ou seja, como parte integrante da estrutura de um pavimento remanescente deteriorado em decorrência da solicitação do tráfego ao longo dos anos.

A base dos conceitos e técnicas utilizadas nesta pesquisa são a associação e a integração entre quatro etapas fundamentais: $[i]$ as características dos materiais que compõem a mistura de $\mathrm{EME}_{\text {; }}[i i]$ a análise do comportamento mecânico das estruturas com camada de base em EME sob a ação das cargas do tráfego, por meio de processos mecanísticos-empíricos no desenvolvimento de estudos paramétricos; [iii] as etapas e o processo de construção do Trecho Experimental e $[i v]$ o seu comportamento mecânico mensurado in situ. 


\subsection{HIPÓTESE}

Tem-se como hipótese da pesquisa que a adoção de um cimento de asfáltico de petróleo (CAP) de baixa penetração, a $25^{\circ} \mathrm{C}$, entre 10 e $20 \times 10^{-1} \mathrm{~mm}$ e temperatura de ponto de amolecimento anel e bola $\geq 55^{\circ} \mathrm{C}^{2}$, na composição de misturas asfálticas pode servir como contribuição para inserção de mais uma técnica dentre às comumente utilizadas na pavimentação rodoviária brasileira para situações de estruturas de pavimento submetidas a tráfego pesado e intenso.

Atualmente a fabricação deste CAP no Brasil está em estágio incipiente pelas produtoras de ligantes asfálticos, não representando ainda um volume significativo de produção. Todavia, acredita-se ser propícia sua adoção em escala comercial no Brasil por considerar que haverá demanda nas vias de tráfego pesado e intenso, além de ser uma alternativa para: aeroportos (pista de pouso e decolagem e de taxiamento), terminais e corredores exclusivos de ônibus, praças de pedágios, balanças de controle de pesagem para veículos comerciais, pátios e estacionamentos de manobras de veículos comerciais, em curvas de raios curtos que proporcionam forte esforço tangencial e em vias com rampas acentuadas, principalmente, as ascendentes.

\subsection{OBJETIVO}

O presente trabalho tem como objetivo estudar a tecnologia francesa para execução de camada de base constituída de EME e adaptá-la para as condições brasileiras a fim de possibilitar a análise de seu comportamento em laboratório e em campo por meio do Trecho Experimental submetido ao tráfego real da rodovia Presidente Dutra (BR-116), no estado de São Paulo.

\footnotetext{
${ }^{2}$ As demais características do CAP duro bem como da mistura asfáltica de módulo elevado (EME) serão apresentadas no item 2.2 desta tese.
} 
A partir do objetivo descrito, desdobram-se as etapas a serem cumpridas, que envolvem:

- Discutir por meio do estudo bibliográfico e principalmente pela execução de Trecho Experimental as características dos materiais, o processo de produção e a execução da camada asfáltica de EME;

- Analisar as características e o funcionamento mecânico do pavimento constituído de camada de EME sob a influência dos parâmetros que podem afetar o seu desempenho estrutural;

- Avaliar as etapas e os processos para a construção do Trecho Experimental;

- Analisar o comportamento de campo do Trecho Experimental; e,

- Propor um conjunto de indicadores que contribua para a definição de uma metodologia de dimensionamento de pavimento brasileiro para camada asfáltica de $E M E$, considerando: faixa de valores de módulo de resiliência $\left(M_{E M E}\right)$ e fator de redução de deflexão estrutural ${ }^{3}(K)$ admissíveis para projeto de reforço.

\subsection{DESCRIÇÃO SUMÁRIA DOS CAPÍTULOS - ESTRUTURA DO TRABALHO}

Além deste primeiro capítulo que apresentou a relevância do tema, o enquadramento temático da tese, o objetivo da pesquisa e as etapas programadas para alcançá-lo; a tese será dividida por mais cinco capítulos apresentados conforme descrição sumária a seguir:

O segundo capítulo compreende a apresentação da literatura a respeito do tema, incluindo informações sobre o histórico de aplicações de Misturas Asfálticas de Módulo Elevado (EME) em diversos Países, suas propriedades, os materiais empregados, produção, execução e ensaios de controle.

\footnotetext{
3 O fator de redução de deflexão $\mathrm{K}$ é preconizado pelo procedimento de restauração de pavimentos DNER-PRO 011/79.
} 
É apresentada no terceiro capítulo a descrição do Trecho Experimental, contemplando suas características geométricas, climáticas e de tráfego. A seleção e caracterização dos materiais utilizados para a produção da mistura de EME estudada, a dosagem, o comportamento mecânico e ainda a execução do trecho do Trecho Experimental, são também abordados neste capítulo.

No quarto capítulo, são apresentadas as características e o funcionamento da estrutura constituída de EME como camada de base na estrutura de pavimento, a partir do estudo paramétrico desenvolvido nesta tese.

A análise dos resultados dos levantamentos deflectométricos, a partir de todos os Estágios em que foram executados é apresentada no quinto capítulo.

Finalmente, no sexto capítulo, são descritas as principais conclusões acerca dos estudos realizados que sintetizam as contribuições desta pesquisa, abordando também as limitações pertinentes ao trabalho desenvolvido, e sugerindo algumas recomendações para pesquisas futuras com a finalidade de aperfeiçoar os critérios de projeto, a produção da mistura, o controle de campo e a avaliação de desempenho do tipo de estrutura proposto na presente tese.

No conjunto de anexos são apresentados os modelos desenvolvidos e os levantamentos executados em campo no Trecho Experimental. 


\section{MISTURAS ASFÁLTICAS DE MÓdULO ELEVADO (EME)}

\subsection{INTRODUÇÃO}

O desenvolvimento das misturas asfálticas de módulo elevado (EME) se deu como consequência da crise do petróleo ocorrida na década de 1970. A crise do petróleo estimulou a busca por soluções que permitissem a redução da quantidade de asfalto e que mantivesse o mesmo desempenho das misturas tradicionais francesas. A produção de ligantes duros (CAP 10/20) tinha como objetivo reduzir a espessura das camadas de concreto asfáltico por meio do aumento de sua rigidez (elevado módulo de deformabilidade), diminuindo assim a demanda por cimento asfáltico (FEE, 2002). Neste sentido, iniciou-se a execução de misturas de EME como camada de base sobre sub-bases granulares ou em base e sub-base de pavimentos a fim de garantir um melhor desempenho da estrutura.

Mas foi a partir de 1980, na França, que as primeiras experiências com misturas asfálticas de módulo elevado (EME) ocorreram, sendo estudada e desenvolvida uma nova família de misturas asfálticas para camadas estruturais de pavimentos rodoviários, apresentando um comportamento superior às misturas tradicionalmente usadas face aos mecanismos de ruína considerados no dimensionamento: trincamento por fadiga e deformação permanente (CAPITÃO, 2003).

Com dificuldades em empregar soluções convencionais de manutenção de estruturas em pavimento de rodovias submetidas a tráfego elevado e intenso e em vias urbanas (com restrições altimétricas, em virtude às interferências de redes de utilidade pública de abastecimento, limitações de calçadas e guias), os franceses propuseram a adoção de mistura de EME, como camada de base em reforços com ou sem fresagem ou escavação parcial do pavimento antigo, empregando camadas mais esbeltas (CAROFF e CORTÉ, 1994; CORTÉ, 2001; BROSSEAUD, 2006). 
Após 1985, verificou-se o uso de misturas asfálticas de módulo elevado (EME) em situações nas quais as misturas betuminosas tradicionais não apresentavam comportamento adequado. O CAP duro foi utilizado nas misturas com agregados de baixa qualidade a fim de produzir misturas de bom desempenho. Na maioria dos casos usaram-se estas misturas em camadas de base associadas a uma camada de rolamento delgada sem funções estruturais, proporcionando assim uma redução na espessura total de camadas asfálticas (VÉRHÉE et al, 1991; CORTÉ 2001). Esta redução, proporcionada pela substituição de uma camada asfáltica tradicional por outra constituída de EME, permitiu uma considerável economia de materiais e de tempo de construção dos pavimentos.

A partir de 1990, iniciou-se a aplicação de betumes duros, em geral modificados, no desenvolvimento de misturas de módulo elevado destinadas à camada de rolamento pelo fato de desempenharem um papel estrutural importante quanto à resistência à formação de trilha de roda. Nesse sentido, questionando-se sobre a necessidade da utilização das duas camadas com funções distintas, uma de base constituída de mistura de EME e outra de rolamento, LESAGE (1993) e LESAGE et al (1993) apresentaram uma mistura que proporcionasse as duas funções. Esta mistura é denominada concreto betuminoso de módulo elevado na França de béton bitumineux à module élevé (BBME) e especificada pela norma NF P 98-141 (AFNOR, 1992).

Segundo DELORME et al (1996), para o desenvolvimento destas novas concepções de misturas com ligantes de baixa penetração, foi necessário não só um grande número de ensaios de laboratório, para a comparação entre o desempenho das misturas tradicionais e das novas, mas também foram essenciais os testes destas misturas no Simulador de Tráfego Circular de Nantes, além da observação de trechos experimentais por 10 a 15 anos. Dessa forma, embora iniciado na década de 1980, só em 1992 foi possível propor uma primeira especificação francesa para misturas asfálticas de módulo elevado (EME).

Com a finalidade de reduzir os riscos de deformação permanente o uso de misturas asfálticas de módulo elevado (EME) tem sido frequentemente acompanhado pelo uso 
de misturas asfálticas delgadas descontínuas usinadas a quente (Béton Bitumineux Trés Mince - BBTM) como camada de rolamento com finalidade estritamente funcional. O uso conjunto dessas soluções, camada de rolamento delgada e mistura de EME, tem mostrado as seguintes vantagens:

- baixa porcentagem de vazios e alta rigidez das misturas de módulo elevado que fornece proteção para a camada subjacente quanto à fadiga e à deformação permanente;

- alta textura superficial do BBTM devido a sua granulometria descontínua que proporciona elevada resistência à derrapagem.

As misturas de módulo elevado foram normalizadas em outubro de 1992 pela AFNOR com a denominação NF P 98-140 e em 1993 com a denominação NF P 98-141 para as misturas do tipo EME e BBME respectivamente (CORTÉ, 2001).

As misturas BBME eram utilizadas em menor escala em comparação com as misturas EME até a década de 1993 (MARSOT, 1993). Existem algumas experiências com esse tipo de mistura, como podem ser citados os trabalhos de GLITA et al (2000) e JAMOIS et al (2002). Também na França (KOBISH et al, 1997; JAMOIS et al, 2000), foram estudadas misturas ainda mais rígidas que as EME, denominadas misturas asfálticas de módulo muito elevado (EMTE), utilizadas como camada de base e constituídas de CAP mais consistentes, com penetrações a $25^{\circ} \mathrm{C}$ inferiores a $10 \times 10^{-1}$ $\mathrm{mm}$.

Tanto as misturas de BBME quanto as de EMTE não fazem parte de objeto de estudo deste trabalho.

Após os estudos desenvolvidos para a avaliação do comportamento mecânico em laboratório, aplicação e desempenho em campo das misturas asfálticas de módulo elevado (EME) na França, outros Países também realizaram pesquisas com esta tecnologia a fim de comprovarem as vantagens da tecnologia francesa nas condições 
construtivas e de solicitação locais. No item 2.3 deste capítulo, serão apresentadas de forma sucinta algumas dessas experiências.

\subsection{CARACTERÍSTICAS DAS MISTURAS DE MÓdULO ELEVADO (EME)}

As misturas asfálticas de módulo elevado (EME) utilizadas na França são empregadas em pavimentos asfálticos de estrutura plena (do tipo full depth) ou estruturas mistas. São também muito utilizadas na execução de restauração de pavimentos, ou seja, com a presença de um substrato remanescente que, portanto, sofreu ações do tráfego ao longo de sua vida de serviço.

A adoção desta técnica pode ainda resultar em redução da espessura final do pavimento de $25 \%$, resultando em economia de agregados e ligante asfáltico (SETRA, 1998 e RGRA, 2005).

Essas misturas são caracterizadas pelo uso de ligantes duros, granulometria contínua e apresentam faixa de valores de módulos de resiliência bem superiores aos encontrados nas misturas convencionais. São misturas densas, de granulometria contínua (30\% a $35 \%$ passante na peneira de $2 \mathrm{~mm}$ e $7 \%$ a $8 \%$ de fíler) e possuindo em sua formulação agregados com diâmetro máximo de $10 \mathrm{~mm}, 14 \mathrm{~mm}$ ou $20 \mathrm{~mm}$., sendo aplicado em camadas variando de 60 a $150 \mathrm{~mm}$ de espessura. Possuem alto teor de asfalto em torno de $6 \%$ (razão entre o peso do asfalto e o peso do agregado), maior quando comparado ao concreto asfáltico comumente utilizado. $\mathrm{Na}$ França, o mais usual é EME 0/14.

Quanto às características de deformabilidade das misturas asfálticas de módulo elevado, o uso de um asfalto duro como ligante aumenta a rigidez da mistura asfáltica (CORTÉ, 2001). Portanto, a dureza do CAP empregado confere elevado módulo de deformabilidade à mistura asfáltica permitindo, com igual espessura, reduzir os esforços transmitidos ao subleito. Além disso, o alto do teor de asfalto possibilita o aumento da compacidade da mistura e da sua resistência à fadiga. 
As misturas de módulo elevado estão divididas em dois tipos de acordo com sua aplicação seja para camada de ligação (binder) ou camada de base (enrobé à module élevé- EME ) ou camada de rolamento (béton bitumineux à module élevéBBME ). As normas NF P 98-140, estabelecida para EME e NF P 98-141, estabelecida para BBME são frutos de mais de 10 anos de aplicação em obras e acompanhamento do desempenho de trechos experimentais e análises laboratoriais.

A mistura de EME é divida em duas classes: EME 1 - introduzida somente em 1988, devido ao reduzido teor de asfalto, próximos das camadas de base tradicionais francesas denominadas grave-bitume (GB), apresenta baixa durabilidade e resistência à fadiga, sendo usada preferencialmente em camadas sujeitas à compressão; e o EME 2 - correspondente a primeira geração deste material, com maior teor de ligante e apresentando maior durabilidade e resistência a fadiga (CORTÉ, 2001).

A mistura de módulo elevado conhecida como EME 2, associada a uma camada de rolamento em concreto asfáltico delgado ( 20 a $30 \mathrm{~mm}$ ) constitui uma das técnicas de manutenção mais frequentes para os pavimentos de tráfego pesado e intenso além da elevada resistência a formação de afundamento de trilhas de roda e boa manutenção da macrotextura (aderência e rugosidade). Para conciliar duas propriedades como a rigidez elevada (módulo rigidez a $15^{\circ} \mathrm{C}-10 \mathrm{~Hz}$ maior que $14.000 \mathrm{MPa})$ e a resistência elevada à fadiga ( $\varepsilon_{6} \geq 130 \mu$ def, EME2) é necessário, além de outras características ${ }^{4}$, usar um asfalto duro (baixa penetração, a $25^{\circ} \mathrm{C}$, entre 10 e $20 \times 10^{-1} \mathrm{~mm}$ e temperatura de ponto de amolecimento anel e bola $\geq 55^{\circ} \mathrm{C}$ ). Essa consistência elevada permite uma dosagem relativamente alta em ligante (em torno de 6\%, para o EME2), sem que a resistência à afundamento de trilhas de roda seja afetada, mesmo o material apresentando uma baixa porcentagem de vazios, variando de 3 a $6 \%$ para o EME 2 (BROSSEUAD, 2002).

\footnotetext{
${ }^{4}$ As demais características do CAP duro bem como da mistura asfáltica de módulo elevado (EME) serão apresentadas na Tabela 2.2 desta tese.
} 
Segundo BROUSSEAUD (2002), nas normas francesas não existem faixas granulométricas a serem seguidas. Todo o projeto de dosagem da mistura é baseado no produto final a ser alcançado ou no desempenho requerido da mistura, confirmado pelos ensaios mecânicos.

Há, entretanto, nas normas portuguesas indicação da faixa granulométrica que a mistura de EME 0/205 deve se enquadrar (JAE, 1998 e BRANCO et. al., 2006).

\section{Tabela 2.1 - Faixas Granulométricas para a mistura de módulo elevado adotadas em camada de base em Portugal} (JAE, 1998 e BRANCO et al, 2006)

\begin{tabular}{l|r|r|r}
\hline \multicolumn{1}{c}{$\begin{array}{c}\text { Abertura das malhas } \\
\text { das peneiras ASTM }\end{array}$} & \multicolumn{2}{|c}{ \% passante } \\
\hline \multicolumn{1}{c|}{$(\mathbf{m m})$} & \multicolumn{1}{c|}{$\mathbf{n}^{\mathbf{0}}$} & $\begin{array}{c}\text { Limite } \\
\text { superior }\end{array}$ & $\begin{array}{c}\text { Limite } \\
\text { inferior }\end{array}$ \\
\hline 25 & $1 "$ & 100 & 100 \\
\hline 19 & $3 / 4^{\prime \prime}$ & 100 & 90 \\
\hline 12,5 & $1 / 2^{\prime \prime}$ & 90 & 70 \\
\hline 9,5 & $3 / 8^{\prime \prime}$ & 80 & 60 \\
\hline 4,75 & $\mathrm{n}^{0} 4$ & 62 & 44 \\
\hline 2,36 & $\mathrm{n}^{0} 8$ & 44 & 30 \\
\hline 0,85 & $\mathrm{n}^{0} 20$ & 30 & 16 \\
\hline 0,425 & $\mathrm{n}^{0} 40$ & 21 & 10 \\
\hline 0,18 & $\mathrm{n}^{0} 80$ & 14 & 7 \\
\hline 0,075 & $\mathrm{n}^{0} 200$ & 10 & 6 \\
\hline
\end{tabular}

Quanto aos ligantes, embora as normas francesas não façam restrições às suas características, que tanto pode ser um ligante puro, modificado com polímeros ou com aditivos (fibras), a dosagem mínima em asfalto é fixada por meio do "módulo de riqueza" que representa uma espessura mínima de filme de asfalto sobre o agregado (BROSSEAUD, 2002).

A partir da escolha de uma determinada curva granulométrica, define-se o teor de ligante em função da superfície específica e do tipo de mistura a partir do módulo de riqueza k, conforme a equação 2.1:

\footnotetext{
${ }^{5}$ BRANCO et. al. (2006) citam que, em Portugal, as misturas asfálticas de módulo elevado (EME) utilizadas na execução de camadas de base é de granulometria 0/20, como nas misturas convencionais.
} 
Teor de ligante $=k \cdot \alpha \cdot \sqrt[5]{\Sigma}$

Na equação 2.1,

k é o módulo de riqueza;

$\alpha$ é o coeficiente de correção em função da densidade do agregado, segundo a equação 2.2;

$\alpha=\left(\frac{2,65}{D_{e f}}\right)$

Na equação 2.2,

$D_{\text {ef }}$ é a densidade efetiva da mistura de agregados;

$\Sigma$ é a superfície específica calculada, segundo a equação 2.3;

$\Sigma=0,25 G+2,3 S+12 s+135 f$

Na equação 2.3,

$\mathrm{G}$ é a porcentagem de agregados com diâmetro superior a $6,3 \mathrm{~mm}$;

$S$ é a porcentag em de agregados com diâmetro entre 6,3 e 0,315 mm;

s é a porcentagem de agregados com diâmetro entre 0,315 e 0,075 mm;

f é a porcentagem de agregados com diâmetro inferior a 0,075 mm.

A partir da determinação do teor mínimo de ligante, espera-se que haja o recobrimento total dos agregados e consequentemente maior durabilidade da mistura.

Segundo SERFASS et. al. (1997) as misturas de módulo elevado podem ser dividas em duas categorias quanto ao módulo de riqueza k: 
- misturas ricas: que têm módulo de riqueza maior que 3,2; apresentando teor de ligante entre 5,5\% e 6,2\% com excelente desempenho mecânico em termos de rigidez, deformação permanente e vida de fadiga comprovada pelo monitoramento de vários trechos, desde 1992. Essas misturas apresentam maior aptidão à compactação, menor porcentagem de vazios, maior resistência à água (ensaio Duriez), maior resistência à fadiga e pequena diferença na resistência à deformação permanente em relação às misturas pobres ou fracas;

- misturas pobres ou fracas: com módulo de riqueza entre 2,5 e 3,2; apresentando teor de ligante entre $4,0 \%$ e 5,4\%, foram extensivamente desenvolvidas com propósitos essencialmente econômicos.

A Tabela 2.2, adaptada de ECS (2006), e a Tabela 2.3, adaptada de AFNOR (1999) CORTÉ e SERFASS (2000) e CORTÉ (2001), apresentam as especificações com os desempenhos mecânicos mínimos e parâmetros exigidos para o ligante duro e para as misturas de alto módulo utilizadas na Europa.

Tabela 2.2 - Características dos ligantes duros (CAP 10-20 e CAP 15-25) adaptada de ECS (2006)

\begin{tabular}{l|r|r}
\hline \multicolumn{1}{c|}{ Parâmetro } & \multicolumn{2}{|c}{ Ligante duro } \\
\cline { 2 - 3 } & CAP 10-20 & CAP 15-25 \\
\hline Penetração a $25^{\circ} \mathrm{C}, 5 \mathrm{~s}, 100 \mathrm{~g}\left(10^{-1} \mathrm{~mm}\right)$ & $10-20$ & $15-25$ \\
\hline $\begin{array}{l}\text { Temperatura de ponto de amolecimento } \\
\text { anel e bola }\end{array}$ & $60-76^{\circ} \mathrm{C}$ & $55-71^{\circ} \mathrm{C}$ \\
\hline $\begin{array}{l}\text { Variação de massa, após RTFOT, } \\
\text { máxima }\end{array}$ & $0,5 \%$ & $0,5 \%$ \\
\hline Penetração retida, após RTFOT, mínima & $55 \%$ & $55 \%$ \\
\hline $\begin{array}{l}\text { Aumento da temperatura de } \\
\text { amolecimento após RTFOT, máximo }\end{array}$ & $10^{\circ} \mathrm{C}$ & $10^{\circ} \mathrm{C}$ \\
\hline $\begin{array}{l}\text { Índice de penetração antes do ensaio } \\
\text { (no ligante original) }\end{array}$ & $-1,5 \mathrm{a}+0,7$ & $-1,5 \mathrm{a}+0,7$ \\
\hline Viscosidade cinemática a $135^{\circ} \mathrm{C}$, mínima & $700 \mathrm{~mm}^{2} / \mathrm{s}$ & $600 \mathrm{~mm}^{2} / \mathrm{s}$ \\
\hline Temperatura de inflação, mínima & $245^{\circ} \mathrm{C}$ & $245^{\circ} \mathrm{C}$ \\
\hline Solubilidade, máxima & $99 \%$ & $99 \%$ \\
\hline
\end{tabular}


Tabela 2.3 - Especificações para misturas de elevado módulo (EME 1 e EME 2) adaptada de AFNOR (1999) CORTÉ e SERFASS (2000) e CORTÉ (2001)

\begin{tabular}{|c|c|c|c|c|}
\hline \multirow{2}{*}{$\begin{array}{l}\text { Parâmetro } \\
\text { Granulometria }\end{array}$} & \multicolumn{2}{|r|}{ EME 1} & \multicolumn{2}{|r|}{ EME 2} \\
\hline & & contínua & & contínua \\
\hline Módulo de riqueza (k) & & $2,5-3,3$ & & $\geq 3,4$ \\
\hline \multirow{3}{*}{$\begin{array}{l}\text { Diâmetro máximo } \\
\text { dos agregados (0/D) e } \\
\text { espessura das camadas }\end{array}$} & $0 / 10$ & 60 a $100 \mathrm{~mm}$ & $0 / 10$ & 60 a $100 \mathrm{~mm}$ \\
\hline & $0 / 14$ & 70 a $120 \mathrm{~mm}$ & $0 / 14$ & 70 a $120 \mathrm{~mm}$ \\
\hline & $0 / 20$ & 100 a $150 \mathrm{~mm}$ & $0 / 20$ & 100 a $150 \mathrm{~mm}$ \\
\hline$\%$ Ligante, para $0 / 10$ & & $4,0-5,0$ & & $5,2-6,2$ \\
\hline \% Ligante, para 0/14 & & $3,8-4,8$ & & $5,0-6,0$ \\
\hline \% Ligante, para 0/20 & & $3,6-4,6$ & & $4,9-5,8$ \\
\hline Nível de compactação (\%) & & $94-98$ & & $94-98$ \\
\hline $\begin{array}{l}\text { Ensaio Duriez } \\
\left(18^{\circ} \mathrm{C}\right) \mathrm{NF} P \text { 98-251-1 }\end{array}$ & & $\geq 0,70$ & & $\geq 0,70$ \\
\hline $\begin{array}{l}\text { Deformação Permanente } \\
\left(60^{\circ} \mathrm{C}, 30.000 \text { ciclos }\right) \\
\text { NF P 98-253-1 }\end{array}$ & & $\begin{aligned} \leq 7,5 \% \\
\text { (vazios entre } 7 \text { e } 10 \%)\end{aligned}$ & & $\begin{array}{r}\leq 7,5 \% \\
(\text { vazios entre } 3 \text { e } 6 \%)\end{array}$ \\
\hline $\begin{array}{l}\text { Módulo Rigidez } \\
\left(15^{\circ} \mathrm{C}, 10 \mathrm{~Hz}\right) \mathrm{MPa} \\
\text { NF P 98-280-2 }\end{array}$ & & $\begin{array}{r}\geq 14.000 \\
(\text { vazios entre } 7 \text { e } 10 \%)\end{array}$ & & $\begin{array}{r}\geq 14.000 \\
(\text { vazios entre } 3 \text { e } 6 \%)\end{array}$ \\
\hline $\begin{array}{l}\text { Tração Direta } \\
\text { MPa NF P 98-260-1 }\end{array}$ & & $\begin{array}{r}\geq 14.000 \\
(\text { vazios entre } 7 \text { e } 10 \%)\end{array}$ & & $\begin{array}{r}\geq 14.000 \\
(\text { vazios entre } 3 \text { e } 6 \%)\end{array}$ \\
\hline $\begin{array}{l}\text { Ensaio de Fadiga } \varepsilon_{6}\left(10^{-6}\right) \\
\left(15^{\circ} \mathrm{C}, 25 \mathrm{~Hz}\right) \text {, em } 1 \text { milhão de } \\
\text { ciclos NF P 98-260-1 }\end{array}$ & & $\begin{array}{r}\geq 100 \mu \mathrm{def} \\
(\text { vazios entre } 7 \text { e } 10 \%)\end{array}$ & & $\begin{array}{r}\geq 130 \mu \mathrm{de} \\
(\text { vazios entre } 3 \text { e } 6 \%)\end{array}$ \\
\hline PCG Volume de vazios (\%) & & $\leq 10$ & & $\leq 6$ \\
\hline
\end{tabular}

Além da realização de ensaios laboratoriais, que tem por finalidade simular as condições de serviço dos materiais de pavimentação, a caracterização do comportamento de pavimentos com EME foi feita também por meio da construção e monitoramento de pistas experimentais. Outro procedimento habitual é monitorar trechos executados em estradas da rede viária. Em ambos os casos, o objetivo fundamental é caracterizar melhor o desempenho em serviço dos materiais. No item a seguir serão apresentadas de forma sucinta algumas dessas experiências. 


\subsection{EXPERIÊNCIAS ANTERIORES COM PAVIMENTOS CONSTITUÍDOS COM MISTURAS ASFÁLTICAS DE MÓDULO ELEVADO (EME)}

Algumas experiências foram desenvolvidas com a execução de estruturas de pavimentos e submetendo-as a carregamentos simulados, outras com trecho de pavimento executado em vias submetidas a tráfego real. Em ambos os casos, sendo avaliado o seu comportamento mecânico. Outras ainda foram desenvolvidas estritamente com simulação de tráfego laboratorial a fim de conhecer o comportamento mecânico da mistura de EME em comparação com misturas asfálticas convencionais.

Apresentam-se a seguir algumas pesquisas que relatam as experiências na utilização de EME na França e em alguns outros Países, inclusive no Brasil.

\subsubsection{Experiências Francesas}

\section{- VIVIER e DEGUINES (1986)}

Tem-se como referência em diversos outros estudos sobre misturas asfálticas de módulo elevado a pesquisa de VIVIER e DEGUINES (1986).

Segundo essa pesquisa, o projeto previa originalmente um pavimento constituído por $270 \mathrm{~mm}$ de camadas asfálticas. A falta de material pétreo de boa qualidade na região e a abundância de agregados aluvionares ${ }^{6}$ foram determinantes para a adoção de EME. Assim, as camadas estruturais foram realizadas com misturas asfálticas de módulo elevado proporcionando uma redução significativa nos custos da obra em decorrência da diminuição da espessura das camadas do pavimento e, por haver grande quantidade de seixo na região, proporcionando redução no custo transporte do material e na sua produção.

\footnotetext{
${ }^{6}$ Agregados aluvionares são materiais pétreos (seixos) transportados por águas correntes e, por conseqüência, submetidos à erosão pluvial, sendo muitas vezes de forma arredondada.
} 


\section{- LAUTIER et al (1991)}

LAUTIER et al (1991) apresentam em seu trabalho a execução de um trecho constituído de EME na RD 570, em Bouches-du-Rhône. O projeto em sua concepção original previa a construção de uma camada de $700 \mathrm{~mm}$ de material britado assente em geotêxtil nos trechos de pavimento novo, e de 200 a $300 \mathrm{~mm}$ se colocada sobre o pavimento existente; uma camada asfáltica de $240 \mathrm{~mm}$ além de uma camada de rolamento em concreto asfáltico com $60 \mathrm{~mm}$ de espessura.

A alternativa proposta manteve as camadas granulares, alterando apenas as camadas asfálticas para: $25 \mathrm{~mm}$ de rolamento; $120 \mathrm{~mm}$ de concreto betuminoso e $90 \mathrm{~mm}$ de EME. Tal alteração resultou em uma redução na espessura total das camadas asfálticas superior a $20 \%$, que apresentou um bom comportamento em serviço.

\section{- CORTÉ et al (1994)}

CORTÉ et al (1994) estudaram a deformação permanente de camadas de rolamento por meio do simulador de tráfego circular do LCPC (Laboratoire Central des Ponts et Chaussées) e ensaios de laboratório (simulador LPC e ensaios de creep estático e dinâmico). Nesta pesquisa, foram estudadas misturas com 4 tipos diferentes de ligantes, sendo 3 com mesma classe de penetração 50/70: um convencional, outro modificado por SBS e o Shell Multigrade (de baixa sensibilidade térmica); e um ligante duro com penetração 10/20.

As estruturas analisadas apresentaram as mesmas espessuras e características para todas as camadas, exceto a composta pelo ligante duro, que além de $80 \mathrm{~mm}$ de mistura como as demais, apresentava também um revestimento de $25 \mathrm{~mm}$ de camada asfáltica constituída de ligante modificado por SBS. Após 202.000 ciclos de carregamento no simulador circular, as maiores deformações encontradas, superiores a $12 \mathrm{~mm}$, ocorreram nas misturas com o ligante convencional 50/70, no 
modificado por SBS e no Shell Multigrade variaram de 5 e $7 \mathrm{~mm}$ e enquanto que as menores, de 3 a $5 \mathrm{~mm}$, ocorreram com o ligante duro.

\section{- SETRA (1997)}

Segundo a SETRA (1997), foi desenvolvida na França uma avaliação de desempenho de 47 trechos de pavimentos construídos no início dos anos oitenta com idades de 2 a 14 anos. Nesta pesquisa as misturas asfálticas de módulo elevado (EME) demonstraram-se bem sucedidas. Os trechos foram implantados em rodovias francesas, do tipo autoestradas e vias urbanas expressas, compreendendo diversas faixas de volumes tráfego com idades distintas. As extensões dos trechos experimentais variaram entre menor que $1 \mathrm{~km}$ (21 trechos), entre 1 e $5 \mathrm{~km}$ (19 trechos) e maior que $5 \mathrm{~km}$ (7 trechos).

Os trechos estudados foram distribuídos entre trechos novos e restaurados, sendo a maioria (36 trechos) executada com uma camada de rolamento do tipo concreto betuminoso delgado ou muito delgado (BBM ou BBTM). Este estudo conclui que os trechos com idade entre 2 e 6 anos não apresentaram degradação nem fissuras incipientes; os trechos com idade entre 6 e 10 anos apresentaram certa porcentagem de fissuras, porém de baixa a moderada severidade; e, os trechos com mais de 10 anos apresentaram uma tendência similar sem, no entanto, requererem intervenções de restauração significativas. Nenhum dos trechos deste estudo apresentou necessidade de reconstrução.

\section{- PARIZÉ et al (1998)}

PARIZÉ et al (1998) descrevem o estudo que permitiu o emprego de misturas de módulo elevado em aeroportos franceses, com a introdução do "coeficiente de equivalência estrutural " (CE) deste material em relação aos tradicionais. Esta pesquisa teve como motivação o método de dimensionamento de pavimentos de aeroportos usado pelos franceses para aeroportos que, naquela época, baseava-se 
no método do $\mathrm{CBR}$, que tem como princípio calcular uma estrutura equivalente total em termos de camada granular.

Para dividir a espessura total do pavimento em camadas de materiais diferentes, segundo o método do CBR, é preciso trabalhar com o conceito de coeficiente de equivalência estrutural. Os coeficientes de equivalência estrutural comumente utilizados naquela época na França, para os materiais novos de uso em aeroportos são apresentados na Tabela 2.4.

\begin{tabular}{l|c}
\multicolumn{1}{c}{$\begin{array}{c}\text { Tabela 2.4 - Coeficientes estruturais de } \\
\text { camadas novas, adotadas na França para } \\
\text { dimensionamento de pavimentos de } \\
\text { aeroportos (PARIZE et al, 1998) }\end{array}$} \\
\hline \multicolumn{1}{c}{ Material } & $\begin{array}{c}\text { Coeficiente } \\
\text { estrutural (CE) }\end{array}$ \\
\hline $\begin{array}{l}\text { Concreto Betuminoso Usinado } \\
\text { a Quente (CBUQ) }\end{array}$ & 2,00 \\
\hline $\begin{array}{l}\text { Agregado Betume (Grave } \\
\text { Bitume - GR) }\end{array}$ & 1,50 \\
\hline $\begin{array}{l}\text { Brita Graduada Tratada com } \\
\text { Cimento (BGTC) }\end{array}$ & 1,50 \\
\hline Agregado Emulsão (AE) & 1,20 \\
\hline Brita Graduada Simples (BGS) & 1,00 \\
\hline $\begin{array}{l}\text { Areia Tratada com Cimento } \\
\text { (ATC) }\end{array}$ & 0,75 \\
\hline Bica Corrida (BC) & 0,50 \\
\hline
\end{tabular}

Na determinação de cada coeficiente de equivalência estrutural para o BBME e para o EME, foram executados trechos experimentais com estes materiais e com os convencionais. Estes trechos foram solicitados por carregamentos em serviço variando de 18 tf a 24 tf. Com estes experimentos foram obtidos os coeficientes de equivalência mostrados na Tabela 2.5. Tais valores foram verificados por meio do programa computacional ALIZÈ. 


\begin{tabular}{|c|c|c|}
\hline Material & $\begin{array}{l}\text { Coeficiente de } \\
\text { equivalência (CE) }\end{array}$ & Tipo de camada \\
\hline $\begin{array}{l}\text { Concreto Asfáltico de } \\
\text { Módulo Elevado } \\
\text { (BBME) classe } 1 \\
\text { (NF 98-141) }\end{array}$ & 2,50 & rolamento \\
\hline $\begin{array}{l}\text { Mistura Asfáltica de } \\
\text { Módulo Elevado } \\
\text { (EME) classe } 2 \\
\text { (NF P 98-140) }\end{array}$ & 1,90 & base \\
\hline
\end{tabular}

\subsubsection{Experiências Espanholas}

\section{- ROCHA (1992)}

Na Espanha, o interesse por materiais de alto desempenho surgiu no final dos anos 1980. ROCHA (1992) apresenta a experiência realizada na Espanha, onde foram executados trechos experimentais a fim de estudar uma estrutura alternativa com mistura asfáltica de módulo elevado e investigar seu comportamento em serviço. Foi executada parte destes trechos com misturas asfálticas convencionais cujas espessuras foram definidas no projeto original e outra construída com EME e sofrendo reduções de espessura variando cerca de 0 a $40 \%$.

Os resultados de três levantamentos deflectométricos nos trechos experimentais mostraram aceitáveis reduções de espessura em até $25 \%$ em relação às misturas convencionais. Obtiveram-se deflexões mais elevadas nos trechos realizados com EME nos casos onde a redução de espessura foi superior a 30\%.

\section{- VAL MELÚS (1996)}

VAL MELÚS (1996) apresenta os resultados de um estudo desenvolvido sobre camadas de base constituídas de misturas asfálticas de módulo elevado entre 1991 e 1993 na Universidade Politécnica de Madri, com a finalidade de adaptar o uso destes materiais à realidade espanhola. Nesta pesquisa, foram dosadas misturas segundo o 
método Marshall utilizando quatro tipos de ligante asfáltico com penetrações a $25^{\circ} \mathrm{C}$ variando entre 21 e $29 \times 10^{-1} \mathrm{~mm}$.

Ainda é descrito pelo autor que, a partir de 1992, foram executados na Espanha alguns trechos experimentais empregando camadas de base de misturas asfálticas de módulo elevado (EME), tanto em pavimentos novos quanto em reforço de pavimentos antigos em rodovias com baixo volume de tráfego ( $<300$ veículos pesados, por dia, por faixa).

De acordo com a experiência espanhola, VAL MELÚS (1996) indica valores de 175 a $185^{\circ} \mathrm{C}$ no final da operação da mistura. Durante a compactação a temperatura mínima deve variar entre $140^{\circ} \mathrm{C}$ e $150^{\circ} \mathrm{C}$. A compactação combina normalmente rolos vibratórios e de pneus e pode ser mais simples devido ao alto teor de ligante proporcionar um efeito lubrificante. Em geral, as espessuras das camadas de mistura de módulo elevado variam entre 80 e 160 mm, sendo aconselhável executar em duas camadas quando exceder $130 \mathrm{~mm}$.

\subsubsection{Experiência Suíça}

\section{- PERRET et al (2004)}

Na Suíça, anteriormente à introdução das misturas asfálticas de módulo elevado nas especificações para pavimentação, um projeto experimental foi desenvolvido com a construção de três trechos experimentais solicitados por um simulador de tráfego a fim de avaliar o comportamento dos materiais sob diferentes carregamentos e temperaturas (PERRET et al, 2004).

Dois trechos incluíram em sua estrutura EME classe 1 e 2 nas camadas de base, seguindo as especificações francesas. O terceiro trecho, de referência, foi executado com base asfáltica seguindo as recomendações locais. Os três trechos avaliados foram projetados para apresentar resistências à fadiga equivalentes. 
A partir da avaliação do desempenho das estruturas para diferentes tipos de carregamento em diferentes temperaturas, concluiu-se que a mistura do tipo EME classe 1 avaliada não proporcionou redução significativa na espessura das camadas de base de pavimentos, enquanto que a mistura EME classe 2 permitiu redução de $30 \%$ em relação à mistura convencional.

\subsubsection{Experiências Portuguesas}

\section{- PAUl e SOUZA (1999)}

PAUL e SOUZA (1999) apresentam os resultados de um experimento com uma mistura asfáltica de módulo elevado projetada para a recuperação de uma rodovia portuguesa denominada EN-106 com um tráfego médio diário estimado em 2.000 veículos comerciais. O pavimento original tem uma estrutura constituída por $180 \mathrm{~mm}$ de camada asfáltica e $120 \mathrm{~mm}$ de macadame hidráulico assente sobre solos com CBR da ordem de $12 \%$.

Nesta pesquisa, a solução para recuperação previa a fresagem de $160 \mathrm{~mm}$ e recomposição com uma mistura de módulo elevado e posterior recapeamento com uma camada de desgaste convencional com $60 \mathrm{~mm}$ de espessura.

A dosagem volumétrica da mistura foi efetuada a partir do método Marshall tomando como referência alguns parâmetros de dosagem para a mistura EME $2(0 / 20)$, tais como: módulo de riqueza maior que 3,4 e vazios menor que $6 \%$.

O teor de projeto adotado foi de 5,5\%. Os resultados de módulo de resiliência e de fadiga foram obtidos por meio de ensaio de dois cutelos. Este ensaio foi realizado à deformação controlada com temperatura de ensaio de $23^{\circ} \mathrm{C}$ e uma frequência de $10 \mathrm{~Hz}$ que, segundo os autores, corresponde a uma velocidade estimada de $60 \mathrm{~km} / \mathrm{h}$ dos veículos comerciais. 
Como resultados obtiveram-se que, para o teor de $4,5 \%$ de ligante, o módulo de resiliência foi de $19.532 \mathrm{MPa}$; para 5,0\%, foi de $17.405 \mathrm{MPa}$ e; para 5,5\%, foi de 16.811 MPa. As curvas de fadiga apresentam valores de deformações inferiores aos admissíveis, comprovando o bom desempenho.

\section{- CAPITÃO (2003)}

A pesquisa desenvolvida por CAPITÃO (2003) teve como objetivo avaliar e modelar o comportamento mecânico de misturas asfálticas de módulo elevado a partir de ensaios capazes de representar as condições climáticas portuguesas. O estudo buscou ainda apresentar indicadores de desempenho a fim de permitir 0 desenvolvimento de especificações técnicas locais para misturas asfálticas de módulo elevado.

Na pesquisa, foi executado um trecho experimental de restauração com $16 \mathrm{~km}$ de extensão na rodovia EM-14, constituído de camada estrutural de mistura asfáltica de módulo elevado de $160 \mathrm{~mm}$ de espessura. A partir da avaliação de características volumétricas e de propriedades mecânicas, foram definidas duas misturas de agregados diferentes: uma com $2 \%$ de fíler calcário (mistura $A$ ) e outra com $5 \%$ de fíler calcário (mistura B), cada uma delas fabricada com três teores diferentes de ligante $(4,8 ; 5,3$ e $5,8 \%)$.

Foram executados trechos experimentais aplicando dois níveis de compactação diferentes para cada uma das seis composições estudadas: N1 e N2, correspondentes a 30 passagens ( 20 com rolo de pneus e $10 \mathrm{com}$ rolo de chapa) e 22 passagens (16 com rolo de pneus e 6 com rolo de chapa) do equipamento compactador, respectivamente.

Após a construção dos trechos experimentais, foram recolhidos corpos-de-prova cilíndricos e retangulares, de cada uma das doze composições volumétricas em análise, para a realização de estudo laboratorial das características de deformabilidade e da resistência à fadiga das misturas. 
Foram realizados ensaios de flexão de cargas repetidas em corpos-de-prova prismáticos, ensaios em simulador de tráfego do tipo LCPC e ensaios de compressão uniaxial de cargas repetidas em corpos-de-prova cilíndricos. Além das amostras extraídas dos trechos experimentais, foram também ensaiadas amostras moldadas em laboratório.

A partir dos resultados obtidos, foram propostos modelos de previsão para as características de deformabilidade das misturas asfálticas de módulo elevado EME, em função das condições de solicitação, e dos parâmetros de composição das misturas. Em relação à resistência à fadiga e à deformação permanente, chegou-se a um conjunto de modelos que permite estimar alguns indicadores de comportamento, para situações de solicitação previsíveis no território português. Estes parâmetros podem ser adotados para estabelecer critérios de dosagem e elaborar especificações técnicas relativas às misturas asfálticas de módulo elevado (EME).

\subsubsection{Experiência Polonesa}

\section{- BROSSEAUD et al (2003)}

Na Polônia, um estudo em conjunto entre o Laboratório de Estradas de Poznan e o LCPC avaliou a possibilidade de empregar a solução de restauração constituída de BBTM como camada de rolamento, sobre uma camada de EME (BROSSEAUD et al, 2003)

Durante os ensaios laboratoriais, foi avaliada uma mistura EME empregando um ligante com penetração a $25^{\circ} \mathrm{C}$ de $25 \times 10^{-1} \mathrm{~mm}$ e ponto de amolecimento anel e bola de $58^{\circ} \mathrm{C}$. A dosagem Marshall resultou em uma mistura com 5,3\% de ligante e volume de vazios de $3,7 \%$; a estabilidade e a fluência medidas a $60^{\circ} \mathrm{C}$ foram de $14 \mathrm{kN}$ e $4 \mathrm{~mm}$, respectivamente. De posse da mistura projetada, foi executado um trecho experimental composto por $120 \mathrm{~mm}$ de EME e $30 \mathrm{~mm}$ de BBTM. 
Os autores concluíram que estruturas de pavimento constituídas de camadas asfálticas com EME e BBTM como camada de rolamento pode resultar na modernização dos projetos de pavimentos novos e de reforços estruturais, proporcionando maior segurança e conforto aos usuários das rodovias.

\subsubsection{Experiência Italiana}

\section{- MONTEPARA e TEBALDI (1999)}

MONTEPARA e TEBALDI (1999) apresentam os resultados de uma pesquisa que avaliou o desempenho de misturas asfálticas de módulo elevado (EME) para aplicação em rodovias italianas em substituição às camadas de base cimentada.

Foram preparadas quatro misturas moldadas com o compactador Marshall e com o compactador giratório, variando-se o teor de polímero SBS, sendo que nenhum dos ligantes adotados na pesquisa apresentou penetração dentro dos parâmetros estabelecidos nas normas francesas para elaboração de misturas asfálticas de módulo elevado. Os valores de penetração variaram de 34 a $57 \times 10^{-1} \mathrm{~mm}$, temperatura anel e bola de 75,4 a $82,6^{\circ} \mathrm{C}$ e com viscosidade a $60^{\circ} \mathrm{C}$ de 1730 a 825 Pa.s. Os teores de betume foram da faixa de 4,1 e $4,8 \%$.

As misturas foram executadas em trechos experimentais na pista sul da Autostrada del Brennero A22, com um tráfego médio diário correspondente à 21.374 veículos comerciais, no ano de 1997. A estrutura executada foi de $50 \mathrm{~mm}$ de camada asfáltica de rolamento, $50 \mathrm{~mm}$ de camada asfáltica convencional, $180 \mathrm{~mm}$ de base com mistura asfáltica de módulo elevado e uma manta de geotêxtil sobre uma sub-base de agregado bem graduado com $350 \mathrm{~mm}$.

As misturas preparadas com o compactador giratório apresentaram características mecânicas muito semelhantes das amostras extraídas do trecho experimental, diferentemente daquelas preparadas com o compactador Marshall. 
Os autores concluíram que as misturas asfálticas de EME ensaiadas apresentaram uma resistência à fadiga três vezes maior do que as misturas convencionais por eles utilizadas.

\subsubsection{Experiências Brasileiras}

Até então, no Brasil, foram desenvolvidas as seguintes pesquisas envolvendo misturas asfálticas de módulo elevado (EME):

- MAGALHÃES (2004) - dissertação de mestrado desenvolvida na COPPE, Rio de Janeiro;

- FREITAS (2007) - dissertação de mestrado desenvolvida na COPPE, Rio de Janeiro;

- ROHDE (2007) - tese de doutorado desenvolvida na UFRGS, Rio Grande do Sul;

- QUINTERO (2011) - dissertação de mestrado desenvolvida na UFSC, Santa Catarina, e,

- MOTTA et al (2011) - pesquisa em desenvolvimento na COPPE, Rio de Janeiro.

\section{- MAGALHÃES (2004)}

MAGALHÃES (2004) comparou duas misturas asfálticas de módulo elevado com ligante modificado por EVA (AMP EVA) e um resíduo asfáltico de petróleo (RASF) e uma mistura com CAP 20, preparadas com agregado de natureza mineral granítica. As misturas preparadas com ligantes especiais apresentaram módulo de resiliência até três vezes maiores que a mistura convencional. A Tabela 2.6 apresenta os valores de módulo de resiliência (MR), resistência à tração (RT) e da relação MR/RT.

Tabela 2.6 - Características mecânicas das misturas estudadas por MAGALHÃES (2004)

\begin{tabular}{|c|c|c|c|}
\hline Mistura & MR $25^{\circ} \mathrm{C}(\mathrm{MPa})$ & RT $25^{\circ} \mathrm{C}(\mathrm{MPa})$ & MR / RT \\
\hline CAP 20 & 6603 & 1,58 & 4183 \\
\hline AMP EVA & 10982 & 2,25 & 4874 \\
\hline RASF & 16341 & 3,50 & 4676 \\
\hline
\end{tabular}


O autor destaca ainda que as misturas asfálticas de módulo elevado preparadas com ligantes especiais apresentaram excelente comportamento à deformação permanente, com afundamentos na trilha de roda em simulador do tipo LCPC entre 3 e 4,5\%. Com base em curvas de fadiga e em análises paramétricas, o autor conclui que a mistura preparada com RASF apresentou desempenho superior quando comparado com a mistura de AMP EVA, com relação à vida de fadiga para um $\mathrm{N}$ maior que $10^{8}$.

A partir de uma análise mecanística, MAGALHÃES (2004) concluiu que as misturas asfálticas de módulo elevado atendem aos valores críticos de diferença de tensões quando aplicadas como camada de ligação apoiadas sobre camadas cimentadas com espessuras em torno de 100 a 120 mm, devido a redução das tensões de tração na fibra inferior das misturas asfálticas de módulo elevado proporcionada pela camada cimentada. Sobre camadas granulares de menor rigidez, por exemplo brita graduada, a espessura mínima de mistura asfáltica de módulo elevado sugerida pelo autor é $150 \mathrm{~mm}$.

\section{- FREITAS (2007)}

FREITAS (2007) estudou a possibilidade do uso de uma escória de aciaria como agregado em misturas asfálticas de módulo elevado. A autora empregou uma única curva granulométrica, constituída por $97 \%$ de escória e $3 \%$ de cal, e três tipos de ligantes (CAP 30/45, Resíduo de Vácuo e CAP 30/45 com 4\% de SASOBIT) para as misturas em estudo. Foram dosadas misturas de referência com a mesma granulometria sem uso de escória FREITAS e MOTTA (2008). Todas as misturas foram caracterizadas mecanicamente por meio de ensaios de módulo de resiliência, resistência à tração estática por compressão diametral, fadiga por compressão diametral à tensão controlada e compressão axial estática (creep estático). A Tabela 2.7 apresenta o MR e a RT obtidos pela pesquisadora para as misturas com escória e teor de ligante de projeto de $7 \%$ e com agregado convencional e $5 \%$ de ligante. 
Tabela 2.7 - MR e RT das misturas estudadas por FREITAS (2007)

\begin{tabular}{l|r|r|r|r}
\hline \multirow{2}{*}{ Ligante asfáltico } & \multicolumn{2}{|c|}{ Escória } & \multicolumn{2}{c}{ Convencional } \\
\cline { 2 - 5 } & MR (MPa) & RT (MPa) & MR (MPa) & RT (MPa) \\
\hline Resíduo de vácuo & 8062 & 1,76 & 7121 & 1,62 \\
\hline CAP 30/45 + SASOBIT & 9173 & 1,79 & 9080 & 1,89 \\
\hline CAP 30/45 & 8608 & 1,92 & 7082 & 1,68 \\
\hline
\end{tabular}

A partir de resultados de estudos mecanísticos utilizando o programa computacional FEPAVE2, a autora concluiu que a utilização de misturas asfálticas de módulo elevado (EME) formuladas com escória de aciaria e CAP 30/45 + 4\% de SASOBIT pode resultar em pavimentos com espessuras de camadas mais esbeltas. 0 desempenho mecânico das misturas com escória foi superior ao das misturas produzidas com agregado convencional, embora com teor ligeiramente maior de ligante.

\section{- ROHDE (2007)}

Com o objetivo caracterizar misturas asfálticas de módulo elevado, ROHDE (2007) desenvolveu sua tese empregando procedimentos laboratoriais e testes acelerados por meio da utilização do simulador de tráfego da UFRGS.

No estudo laboratorial foram desenvolvidas misturas de módulo elevado empregando os ligantes RASF, AMP EVA e também foi utilizado um CAP 30/45 modificado por 1,2\% de ácido polifosfórico (PPA 30/45) no projeto de misturas asfálticas de módulo elevado. Além destes ligantes, como referência, foi utilizado o CAP 50/70 puro.

Outra etapa foi dedicada ao projeto, execução e monitoramento de uma seção experimental com mistura asfáltica de módulo elevado submetida ao tráfego imposto pelo simulador linear UFRGS-DAER/RS. 
Pelo fato de, naquela ocasião ${ }^{7}$, não serem produzidos em escala comercial ligantes asfálticos com as características necessárias para a formulação de EME (penetração, a $25^{\circ} \mathrm{C}$, entre 10 e $20 \times 10^{-1} \mathrm{~mm}$ e temperatura de ponto de amolecimento anel e bola entre $60 \mathrm{e} 85^{\circ} \mathrm{C}$ ), esta pesquisa analisou materiais alternativos para garantir $\mathrm{o}$ desempenho esperado. No desenvolvimento do projeto da mistura asfáltica para a execução da pista experimental foram analisadas as seguintes possibilidades, considerando-se o emprego de materiais em disponibilidade no Estado do Rio Grande do Sul:

- Um CAP 50/70 modificado por $2 \%$ de ácido polifosfórico, modificado no Laboratório de Pavimentação da UFRGS, denominado PPA 50/70;

- Um ligante asfáltico modificado em escala laboratorial por asfaltita fornecido pela Petrobras Distribuidora S. A., denominado CAPPLUS 106B; e,

- Um resíduo asfáltico proveniente do beneficiamento do petróleo em torre de vácuo, produzido na Refinaria Alberto Pasqualini, localizada na região metropolitana de Porto Alegre (Canoas/RS).

Para a dosagem da mistura asfáltica empregando o ligante modificado por ácido polifosfórico (PPA 50/70) a composição granulométrica foi avaliada, buscando minimizar a utilização de areia e cal hidratada. Foi constatada na pesquisa que, tendo em vista o desempenho esperado para misturas asfálticas de módulo elevado, a presença de cal hidratada resultou na redução do efeito modificador proporcionado pelo ácido polifosfórico, revelando valores de módulo de resiliência (MR) abaixo dos preconizados na literatura internacional (MR $>10.000 \mathrm{MPa}$ ). Portanto, foi possível concluir que a utilização de ligante modificado por este tipo de aditivo não é adequada em misturas asfálticas contendo cal hidratada em sua composição. Neste sentido, as misturas modificadas com ligante PPA 50/70 não foram satisfatórias e, portanto, descartada sua utilização na execução da pista experimental.

\footnotetext{
${ }^{7}$ Até o momento, a produção do ligante consistente (ou com modificação para proporcionar seu endurecimento) encontra-se em estágio incipiente no Brasil, mas há um grande potencial para sua utilização em larga escala, como relatado no item 1.4 desta tese.
} 
A mistura asfáltica dosada com CAPPLUS 106B foi considerada a solução mais adequada para a execução da pista experimental, visto que os resultados alcançados pela mistura formulada com RV foram superiores, porém a impossibilidade de fornecimento do ligante por parte da Refinaria levou ao abandono da alternativa.

O concreto asfáltico formulado com RV apresentou as características adequadas ao emprego como mistura de módulo elevado. A modificação do CAP 50/70 empregando ácido polifosfórico (PPA) reduz a penetração e eleva o ponto de amolecimento do ligante, permitindo a formulação de material adequado à utilização em misturas asfálticas de módulo elevado (EME).

A pista experimental projetada foi composta de dois subtrechos: um com $160 \mathrm{~mm}$ de camada de rachão; $120 \mathrm{~mm}$ de brita graduada simples; $120 \mathrm{~mm}$ de EME e o outro manteve todas as camadas do pavimento da anterior alterando-se apenas a camada de EME para $80 \mathrm{~mm}$. Muito embora seja preconizada pela literatura técnica (BROUSSEAUD, 2002), uma mistura asfáltica delgada a quente como camada de rolamento, sobre a camada de módulo elevado (EME) foi executada uma camada de microrrevestimento asfáltico a frio.

Durante o período de operação do simulador de tráfego, foram aplicados inicialmente 100.000 ciclos de carga de 100 kN e pressão de inflação dos pneumáticos de 0,62 $\mathrm{MPa}$ (90 psi). Posteriormente, houve um incremento do carregamento e da pressão de inflação dos pneumáticos para $120 \mathrm{kN}$ e 0,69 MPa (100 psi), respectivamente. 0 emprego de carregamento superior ao especificado para o eixo padrão (82 kN) objetivou acelerar a degradação da seção de teste.

Após análises estruturais efetuadas por meio de avaliações deflectométricas com viga Benkelman (VBK) e Falling Weight Deflectometer (FWD), foi selecionada a região da trilha de roda externa do subtrechos constituído de $80 \mathrm{~mm}$ de EME para os ensaios acelerados. A escolha deste local ocorreu por ser a região de melhor condição estrutural dentre toda a área da pista experimental. 
Durante o período de operação do simulador de tráfego, foi monitorada a evolução da degradação do pavimento da pista experimental com $80 \mathrm{~mm}$ de EME em função das solicitações de carregamento impostas e a variação de parâmetros ambientais como temperatura do ar e precipitações pluviométricas.

Apesar de as deformações máximas terem atingido $8 \mathrm{~mm}$ no final do experimento, concluiu-se que as misturas modificadas para a formulação de EME têm melhor desempenho que a mistura de referência adotada (CAP 50/70 puro).

Ao final ROHDE (2007) cita que a execução de misturas asfálticas de módulo elevado (EME) em camadas estruturais de pavimentos poderá contribuir para o aumento da vida útil das rodovias.

\section{- QUINTERO (2011)}

A pesquisa de QUINTERO (2011) foi desenvolvida a partir da comparação de desempenho laboratorial de duas misturas asfálticas francesas, uma referente a uma mistura denominada grave-bitume dosada com ligante convencional (CAP 30/45) e outra mistura asfáltica de módulo elevado (EME) dosada com CAP de baixa penetração, a $25^{\circ} \mathrm{C}, 10 \times 10^{-1} \mathrm{~mm}$.

$\mathrm{Na}$ formulação das duas misturas asfálticas, foram abordadas as características dos materiais, as curvas granulométricas e a descrição dos ensaios realizados em cada nível de formulação segundo a metodologia francesa (LCPC, 2007): verificação da habilidade da mistura asfáltica à compacidade no ensaio de compactação por cisalhamento giratório PCG (AFNOR, 1999), a sensibilidade à água no ensaio de Duriez (AFNOR, 1995), a resistência à deformação permanente (AFNOR, 1993a), o módulo complexo (AFNOR, 1992) e a resistência à fadiga (AFNOR, 1993b).

No ensaio de fadiga a $30^{\circ} \mathrm{C}$ e $25 \mathrm{~Hz}$, a deformação correspondente a 1 milhão de ciclos mudou de $240 \mu$ def a $10^{\circ} \mathrm{C}$ e $25 \mathrm{~Hz}$ para $173 \mu$ def a $10^{\circ} \mathrm{C}$ e $25 \mathrm{~Hz}$, e consequentemente as respectivas deformações admissíveis de 112,9 $\mu$ def para 82,5 
$\mu$ def. Este fato apontou que a mistura asfáltica de módulo elevado possui características mecânicas superiores, sendo pouco suscetível à variação de temperatura.

A partir dos dados adquiridos no desempenho laboratorial, as duas misturas foram combinadas em três estruturas para o dimensionamento segundo as diretrizes da metodologia francesa (SETRA-LCPC, 1994 e 1997). Tal dimensionamento foi realizado com o programa ViscoRoute, considerando o modelo reológico de HuetSayegh. As estruturas adotadas estão indicadas na Figura 2.1.

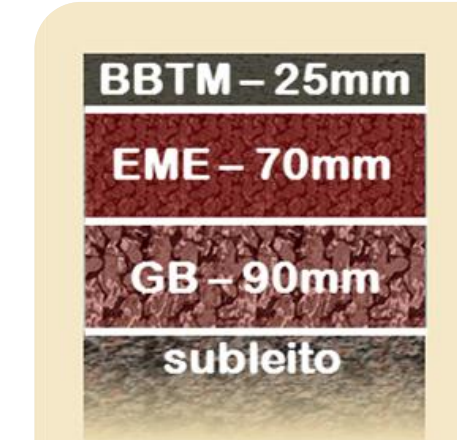

\section{Alternativa 1}

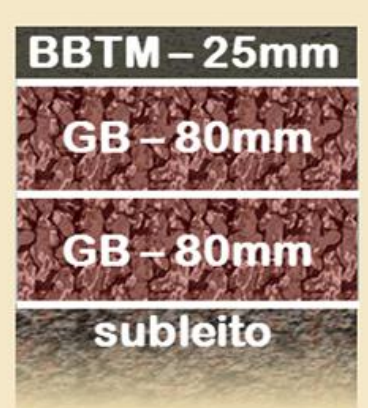

Alternativa 2

\section{BBTM-25mm \\ EME $-70 \mathrm{~mm}$}

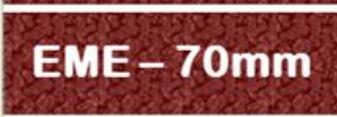

subleito

\section{Alternativa 3}

Figura 2.1 - Estruturas do pavimento para a temperatura de $15^{\circ} \mathrm{C} \mathrm{e} 10 \mathrm{~Hz}$, estudadas por QUINTERO (2011)

Para as três primeiras estruturas de pavimento, considerando a deformação admissível para as misturas adotadas à temperatura de $10^{\circ} \mathrm{C}$ e $25 \mathrm{~Hz}$ e temperatura equivalente de $15^{\circ} \mathrm{C}$, não se encontrou variação significativa nas espessuras das camadas.

A fim de analisar o efeito da temperatura no dimensionamento, além das três estruturas, uma quarta foi dimensionada considerando para a mistura asfáltica de módulo elevado o valor de deformação admissível correspondente à temperatura de $30^{\circ} \mathrm{C}$. A estrutura adotada é apresentada na Figura 2.2. 


\section{BBTM-25mm}

EME $-70 \mathrm{~mm}$

\section{EME $-120 \mathrm{~mm}$}

\section{subleito}

Figura 2.2 - Nova estrutura do pavimento para a temperatura de $30^{\circ} \mathrm{C} \mathrm{e} 10 \mathrm{~Hz}$, estudadas por QUINTERO (2011)

Verificou-se nesta pesquisa, portanto, que a mistura de EME obteve comportamento superior em relação à grave-bitume, tanto nos ensaios laboratoriais realizados quanto na comparação das estruturas de pavimento dimensionadas.

\section{- MOTTA et al (2011)}

O objetivo desta pesquisa foi planejar e executar dois trechos experimentais ${ }^{8}$. Os trechos foram executados próximos do km 57 da rodovia BR-040, entre os dias 10 a 13 de dezembro de 2010. O primeiro trecho experimental de referência, executado com mistura asfáltica convencional (CAP 50/70) ${ }^{9}$, encontra-se entre as estacas 5649+10 m e 5659+000, com extensão de $190 \mathrm{~m}$. O segundo, com mistura asfáltica de módulo elevado (EME), encontra-se entre as estacas 5639+10 m e 5649+10 m, com 200 m de extensão.

Após a fresagem total do revestimento antigo de $110 \mathrm{~mm}$ de espessura, os dois trechos foram executados em duas camadas asfálticas: $60 \mathrm{~mm}$ (camada inferior) e $50 \mathrm{~mm}$ (camada superior), recompondo os $110 \mathrm{~mm}$ fresados. Essa remoção total do revestimento asfáltico antigo foi em decorrência do elevado grau de trincamento existente na superfície do pavimento e das deflexões máximas médias na ordem de $110 \times 10^{-2} \mathrm{~mm}$ encontrados na estrutura primitiva (antes das intervenções previstas).

\footnotetext{
${ }^{8}$ Esta pesquisa encontra-se ainda em desenvolvimento pela UFRJ/COPPE e por esta razão haverá a execução de um novo segmento com asfalto morno, além do estudo do tráfego visando à previsão do crescimento e pontos de interesse de mudança de Volume de Tráfego Diário para fins de dimensionamento dos pavimentos.

${ }^{9}$ O CAP utilizado no trecho de referência da rodovia BR-040 (CAP 50/70) difere do ligante utilizado no trecho de referência desta tese (CAP 30/45), embora ambos sejam comumente utilizados nos serviços de recuperação e restauração no Brasil.
} 
Embora enfatizassem que esta pesquisa encontra-se em fase insipiente e que, por esta razão, seria prematuro traçar conclusões definitivas acerca do comportamento dos trechos estudados, os autores apresentaram um balanço das atividades realizadas até aquele momento, com as seguintes considerações:

- Apesar do pouco tempo de exposição ao tráfego (cerca de 2 meses), os dois trechos experimentais apresentaram afundamentos de trilha de roda em $90 \%$ das estacas avaliadas. Em ambos os trechos os valores de afundamentos de trilha de roda variaram de 1 a $5 \mathrm{~mm}$, embora os resultados no trecho de módulo elevado (EME) apresentassem em geral resultados menores que os do trecho de mistura convencional, excetuando-se em dois pontos (estacas 5648 e 5649);

- Os pontos levantados com pêndulo britânico revelaram valores de resistência à derrapagem (VRD) para a mistura asfáltica de módulo elevado (EME) entre 54 e 72, sendo classificados como rugosos a medianamente rugosos, assim como o trecho experimental convencional, cujos valores apresentaram-se ligeiramente mais baixos;

- Nos levantamentos de macrotextura pôde-se observar que a maior parte dos resultados obtidos no levantamento do trecho de EME se enquadrou entre os valores de HS de 0,81 e 1,20, que representa uma macrotextura grossa. Entretanto, os valores encontrados no trecho convencional foram inferiores aos da mistura de EME, em sua maior parte enquadrada na faixa de classificação de macrotextura média, variando HS de 0,41 a 0,80;

- Os valores deflectométricos foram considerados elevados mesmo após a remoção do revestimento antigo totalmente trincado e substituído por camadas asfálticas novas. Embora o trecho de referência em asfalto convencional (CAP 50/70) tivesse apresentado valores deflectométricos, na ordem de 38 a $102 \times 10^{-2} \mathrm{~mm}$, inferiores a determinados segmentos do trecho com mistura de EME (entre 69 e $95 \times 10^{-2} \mathrm{~mm}$ ), apresentou mais defeitos em sua superfície ${ }^{10}, 18,7 \%$ em média de área com defeitos em comparação a $13,8 \%$ no trecho com mistura de EME.

\footnotetext{
${ }^{10}$ Os valores percentuais das áreas de defeito foram estimados segundo as figuras apresentadas no trabalho de MOTTA et al, 2011.
} 


\section{TRECHO EXPERIMENTAL}

\subsection{LOCALIZAÇÃO DO TRECHO EXPERIMENTAL}

O Trecho Experimental encontra-se localizado na Rodovia Presidente Dutra, entre os quilômetros 171 e 170 (sentido Rio de Janeiro) no município de Jacareí/SP, na região do Vale do rio Paraíba do Sul, conforme ilustrado na Figura 3.1. O segmento contém duas faixas de tráfego, tendo sido executado o Trecho Experimental na faixa de veículos pesados (faixa da direita).

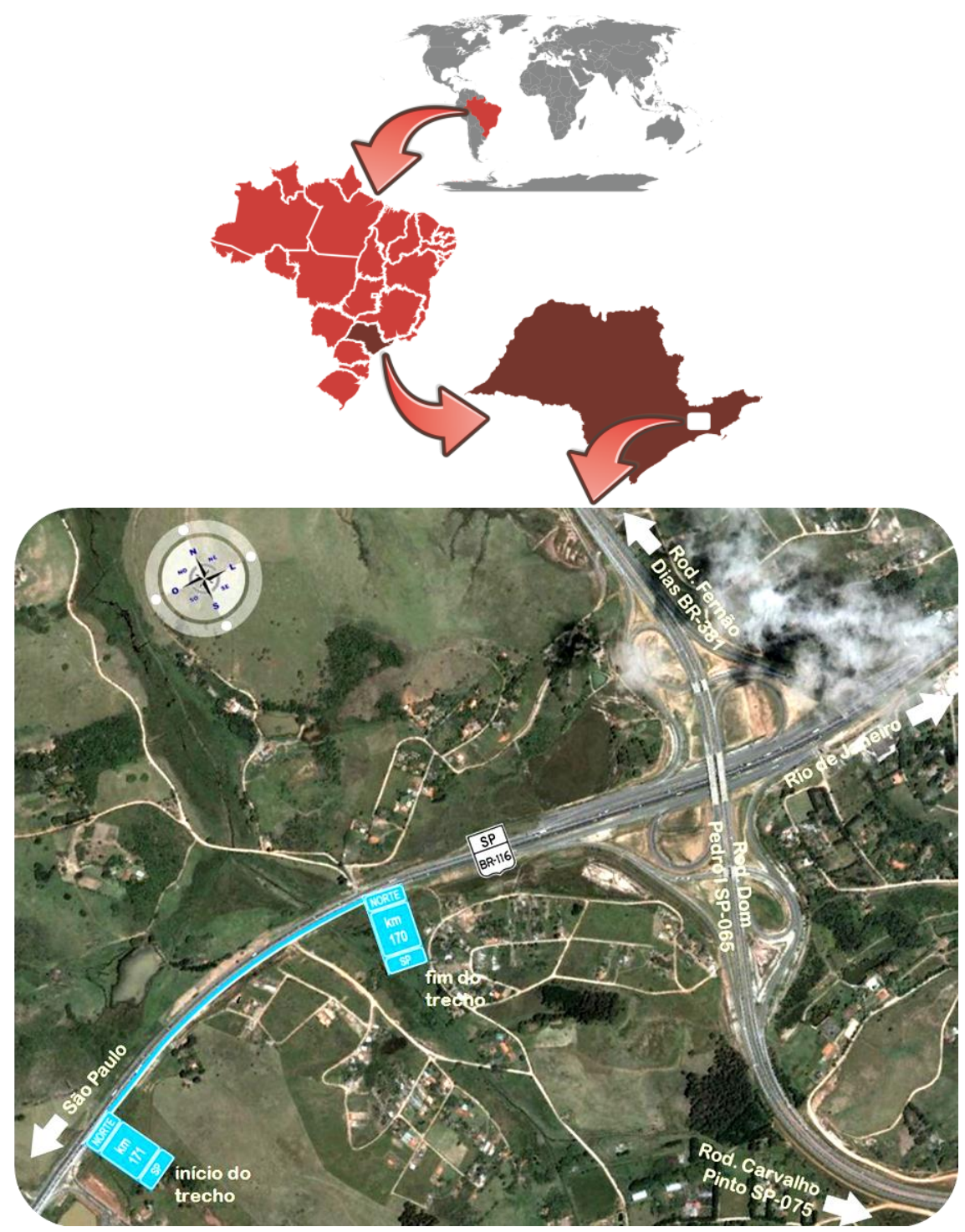

Figura 3.1 - Localização do Trecho Experimental (imagem extraída do Google Earth) 


\subsection{CLIMA E TRÁFEGO ATUANTES NA REGIÃO DO TRECHO EXPERIMENTAL}

\subsubsection{Clima Atuante na Região do Trecho Experimental}

O Trecho Experimental está compreendido entre duas estações meteorológicas. São elas:

- Estação Climatológica de Guarulhos: aberta em 1943, localizada a 44,5km do início do Trecho Experimental.

- Estação Climatológica de Taubaté: aberta em 1983, localizada a 60,5 km do final do Trecho Experimental.

Por se encontrar mais próxima, adotaram-se como representativos da região do Trecho Experimental os valores climatológicos extraídos da Estação de Guarulhos. 0 período analisado foi de janeiro de 2000 a dezembro de 2009. Os valores das temperaturas e das precipitações podem ser observados na Tabela 3.1 e 3.2.

Tabela 3.1 - Contribuição da precipitação $(\mathrm{mm})$, ao longo das estações do ano

\begin{tabular}{|c|c|c|c|c|c|c|c|c|c|c|c|c|c|}
\hline \multirow{2}{*}{ Parâmetros } & \multicolumn{3}{|c|}{ Estações do ano } & \multicolumn{2}{|c|}{ VERÃO } & \multicolumn{3}{|c|}{ OUTONO } & \multicolumn{2}{|c|}{ INVERNO } & \multicolumn{3}{|c|}{ PRIMAVERA } \\
\hline & & & & \begin{tabular}{|l|l|} 
DEZ & JA \\
\end{tabular} & \begin{tabular}{|l|l|} 
I FEV \\
\end{tabular} & MAR & ABR & MAI & \begin{tabular}{|l|l|} 
JUN & JUL \\
\end{tabular} & AGO & SET & OUT & NOV \\
\hline \multirow{7}{*}{$\begin{array}{l}\text { precipitação } \\
(\mathrm{mm})\end{array}$} & & & édia & & 13,5 & & & 10,5 & & 6,6 & & & 9,5 \\
\hline & $\begin{array}{c}\mathrm{m} \\
\text { (mê }\end{array}$ & $\begin{array}{l}\text { áxima m } \\
\text { s de má }\end{array}$ & $\begin{array}{l}\text { insal } \\
\text { ima) }\end{array}$ & & $\begin{array}{l}256.0 \\
(\mathrm{JAN})\end{array}$ & & & $\begin{array}{r}200.0 \\
(M A R)\end{array}$ & & $\begin{array}{r}60.0 \\
\text { (JUL) }\end{array}$ & & & $\begin{array}{l}162.0 \\
\text { (NOV) }\end{array}$ \\
\hline & & nédia m & $\begin{array}{l}\text { nsal } \\
\mathrm{nm})\end{array}$ & & 230,0 & & & 117,0 & & 39,7 & & & 117,0 \\
\hline & $\begin{array}{r}m \\
(m e\end{array}$ & $\begin{array}{l}\text { ínima m } \\
\text { s de mír }\end{array}$ & $\begin{array}{l}\text { nsal } \\
\text { ima) }\end{array}$ & & $\begin{array}{l}202.0 \\
\text { (FEV) }\end{array}$ & & & $\begin{array}{r}66.0 \\
(\mathrm{MAI})\end{array}$ & & $\begin{array}{r}28.0 \\
(A G O)\end{array}$ & & & $\begin{array}{r}61.0 \\
(\mathrm{SET})\end{array}$ \\
\hline & & $\begin{array}{l}\text { tot } \\
\text { eríodo }\end{array}$ & $\begin{array}{l}\text { no } \\
\mathrm{nm})\end{array}$ & & 690,0 & & & 351,0 & & 119,0 & & & 351,0 \\
\hline & & $\begin{array}{l}\text { stribuiç } \\
\text { período }\end{array}$ & $\begin{array}{l}\text { o no } \\
(\%)\end{array}$ & & 46,0 & & & 23,0 & & 8,0 & & & 23,0 \\
\hline & $n^{\circ}$ & $\begin{array}{r}\text { nédio de } \\
\text { chu }\end{array}$ & $\begin{array}{l}\text { dias } \\
\text { osos }\end{array}$ & & 17 & & & 11 & & 5 & & & 12 \\
\hline \multicolumn{14}{|l|}{ Legenda: } \\
\hline $\mathrm{DEZ}=\mathrm{de}$ & \multirow{3}{*}{$\begin{array}{l}\text { dezembro } \\
\text { janeiro } \\
\text { fevereiro }\end{array}$} & MAR & $=$ & março & & JUN & $=$ & junho & & SET & $=$ & & embro \\
\hline $\mathrm{JAN}=$ ja & & ABR & $=$ & abril & & JUL & $=$ & julho & & OUT & $=$ & & utubro \\
\hline$F E V=f e$ & & MAI & $=$ & maio & & AGO & $=$ & agostc & & NOV & $=$ & & embro \\
\hline
\end{tabular}


3.2 - Contribuição da temperatura do ar $\left({ }^{\circ} \mathrm{C}\right)$, ao longo das estações do ano

\begin{tabular}{|c|c|c|c|c|c|c|c|c|c|c|c|c|c|}
\hline \multirow{2}{*}{ Parâmetros } & \multirow{2}{*}{\multicolumn{3}{|c|}{ Estações do ano }} & \multicolumn{2}{|c|}{ VERÃO } & \multicolumn{3}{|c|}{ OUTONO } & \multicolumn{2}{|c|}{ INVERNO } & \multicolumn{3}{|c|}{ PRIMAVERA } \\
\hline & & & & \begin{tabular}{|l|l|} 
DEZ & J \\
\end{tabular} & JAN FEV & MAR & ABR & MAI & \begin{tabular}{|l|l|} 
JUN & JUL \\
\end{tabular} & AGO & SET & OUT & NOV \\
\hline \multirow{3}{*}{$\begin{array}{l}\text { temperatura } \\
\text { do ar } \\
\left({ }^{\circ} \mathrm{C}\right)\end{array}$} & (mê & $\begin{array}{r}\text { má } \\
\text { de máx }\end{array}$ & $\begin{array}{l}\text { xima } \\
\text { ima) }\end{array}$ & & $\begin{array}{l}29,28 \\
\text { (FEV) }\end{array}$ & & & $\begin{array}{r}29,05 \\
\text { (MAR) }\end{array}$ & & $\begin{array}{r}25,21 \\
(\mathrm{AGO})\end{array}$ & & & $\begin{array}{r}27,75 \\
\text { (NOV) }\end{array}$ \\
\hline & & & $\begin{array}{l}\text { édia } \\
\left({ }^{\circ} \mathrm{C}\right)\end{array}$ & & 23,90 & & & 22,30 & & 18,90 & & & 21,80 \\
\hline & $(m$ & mí & $\begin{array}{l}\text { hima } \\
\text { ima) }\end{array}$ & & $\begin{array}{l}18,17 \\
\text { (DEZ) }\end{array}$ & & & $\begin{array}{l}14,22 \\
\text { (MAI) }\end{array}$ & & $\begin{array}{l}12,02 \\
\text { (JUL) }\end{array}$ & & & $\begin{array}{l}14,54 \\
\text { (SET) }\end{array}$ \\
\hline \multicolumn{14}{|l|}{ Legenda: } \\
\hline $\mathrm{DEZ}=$ & ibro & MAR & $=$ & março & & JUN & $=$ & junho & & SET & $=$ & & tembro \\
\hline $\mathrm{JAN}=\mathrm{jc}$ & & ABR & $=$ & abril & & JUL & $=$ & julho & & OUT & $=$ & & outubro \\
\hline $\mathrm{FEV}=\mathrm{fel}$ & & MAI & $=$ & maio & & AGO & $=$ & agostc & & NOV & $=$ & nov & vembro \\
\hline
\end{tabular}

De acordo com a classificação climática proposta por KÖPPEN (1931) o clima da região do município de Jacareí é do tipo Cwa. A classificação Cwa corresponde ao clima temperado chuvoso (mesotérmico) com inverno seco e verão chuvoso; e subtropical, com inverno seco e temperatura do mês mais quente superior a $22,0^{\circ} \mathrm{C}$.

O clima da região que compreende o Trecho Experimental apresenta duas estações bem definidas: uma iniciando-se em novembro e estende-se até o início de abril do ano seguinte, com temperaturas mais elevadas e maiores precipitações pluviométricas, e outra de abril a outubro, mais fria e com menor presença de chuvas.

A temperatura média anual do ar correspondeu a $21,7^{\circ} \mathrm{C}$, variando entre um mínimo de $12,02^{\circ} \mathrm{C}$, em julho (inverno) e um máximo de $29,28^{\circ} \mathrm{C}$, em fevereiro (verão).

Da análise da distribuição da precipitação anual, pelas estações do ano, pode-se observar que aproximadamente $46 \%$ da precipitação anual ocorrem no verão, enquanto o inverno é a estação menos chuvosa do ano, com cerca de $8 \%$ do total da precipitação anual. As estações de transição, primavera e outono, contribuem com os $46 \%$ restantes da precipitação total, distribuídos de maneira equitativa.

A precipitação pluviométrica é o elemento climatológico de maior variabilidade temporal, destacando-se os meses de janeiro, mês mais chuvoso, $256 \mathrm{~mm}$ e março 
com 200 mm, caracterizando na região uma estação chuvosa bem definida quanto à distribuição de chuva. 0 mês de julho apresentou o menor valor de precipitação (60 $\mathrm{mm})$.

\subsubsection{Tráfego Atuante na Região do Trecho Experimental}

A partir do estudo de tráfego (Grupo CCR, 2009), são apresentados na Tabela 3.3 de forma resumida os dados de tráfego atuante no Trecho Experimental.

Tabela 3.3 - Dados de tráfego

\begin{tabular}{|c|c|c|c|c|c|c|}
\hline \multirow{2}{*}{\multicolumn{2}{|c|}{$\begin{array}{c}\text { Taxa de Crescimento } \\
\text { Anual (\%) }\end{array}$}} & \multirow{2}{*}{ TMDAсом } & \multicolumn{4}{|c|}{ Fator de Veículo } \\
\hline & & & \multicolumn{2}{|c|}{ AASHTO } & \multicolumn{2}{|c|}{ USACE } \\
\hline \multicolumn{2}{|c|}{$3 \%$} & \multirow{3}{*}{$\begin{array}{r}8328 \\
\text { TMDA }_{\text {сом }} \text { Acum. }\end{array}$} & & 2,6 & & 9,2 \\
\hline \multirow{2}{*}{\multicolumn{2}{|c|}{ Ano }} & & \multicolumn{2}{|c|}{ Número "N" AASHTO } & \multicolumn{2}{|c|}{ Número "N" USACE } \\
\hline & & & Ano & Acum & Ano & Acum. \\
\hline & 2009 & 8328 & $7,90 \mathrm{E}+06$ & - & $2,79 E+07$ & - \\
\hline 1 & 2010 & 8578 & $8,14 \mathrm{E}+06$ & $8,14 \mathrm{E}+06$ & $2,88 \mathrm{E}+07$ & $2,88 \mathrm{E}+07$ \\
\hline 2 & 2011 & 8835 & $8,38 \mathrm{E}+06$ & $1,65 E+07$ & $2,96 \mathrm{E}+07$ & $5,84 \mathrm{E}+07$ \\
\hline 3 & 2012 & 9100 & $8,64 \mathrm{E}+06$ & $2,52 \mathrm{E}+07$ & $3,05 E+07$ & $8,90 \mathrm{E}+07$ \\
\hline 4 & 2013 & 9373 & $8,89 E+06$ & $3,41 \mathrm{E}+07$ & $3,14 \mathrm{E}+07$ & $1,20 E+08$ \\
\hline 5 & 2014 & 9654 & $9,16 \mathrm{E}+06$ & $4,32 \mathrm{E}+07$ & $3,24 \mathrm{E}+07$ & $1,53 E+08$ \\
\hline 6 & 2015 & 9944 & $9,44 E+06$ & $5,27 \mathrm{E}+07$ & $3,34 \mathrm{E}+07$ & $1,86 \mathrm{E}+08$ \\
\hline 7 & 2016 & 10242 & $9,72 E+06$ & $6,24 \mathrm{E}+07$ & $3,44 \mathrm{E}+07$ & $2,21 E+08$ \\
\hline 8 & 2017 & 10550 & $1,00 \mathrm{E}+07$ & 7,24E+07 & $3,54 \mathrm{E}+07$ & $2,56 E+08$ \\
\hline \multicolumn{7}{|l|}{$\begin{array}{l}\text { TMDA }_{\text {сOм }} \\
\text { Acum } \\
\text { AASHTO } \\
\text { USACE }\end{array}$} \\
\hline
\end{tabular}

Segundo os dados de tráfego da Tabela 3.3 o número de eixos padrão de 8,2tf (N) para um período de projeto de 8 anos representa, para o Fator de Veículo AASHTO $7,24 \times 10^{7}$ e para o Fator de Veículo USACE 2,56 x $10^{8}$.

\subsubsection{Velocidades dos Veículos na Região do Trecho Experimental}

No km 170+360 do Trecho Experimental, existem sensores a laço indutivo para classificação e identificação da velocidade dos veículos (Figura 3.2). 


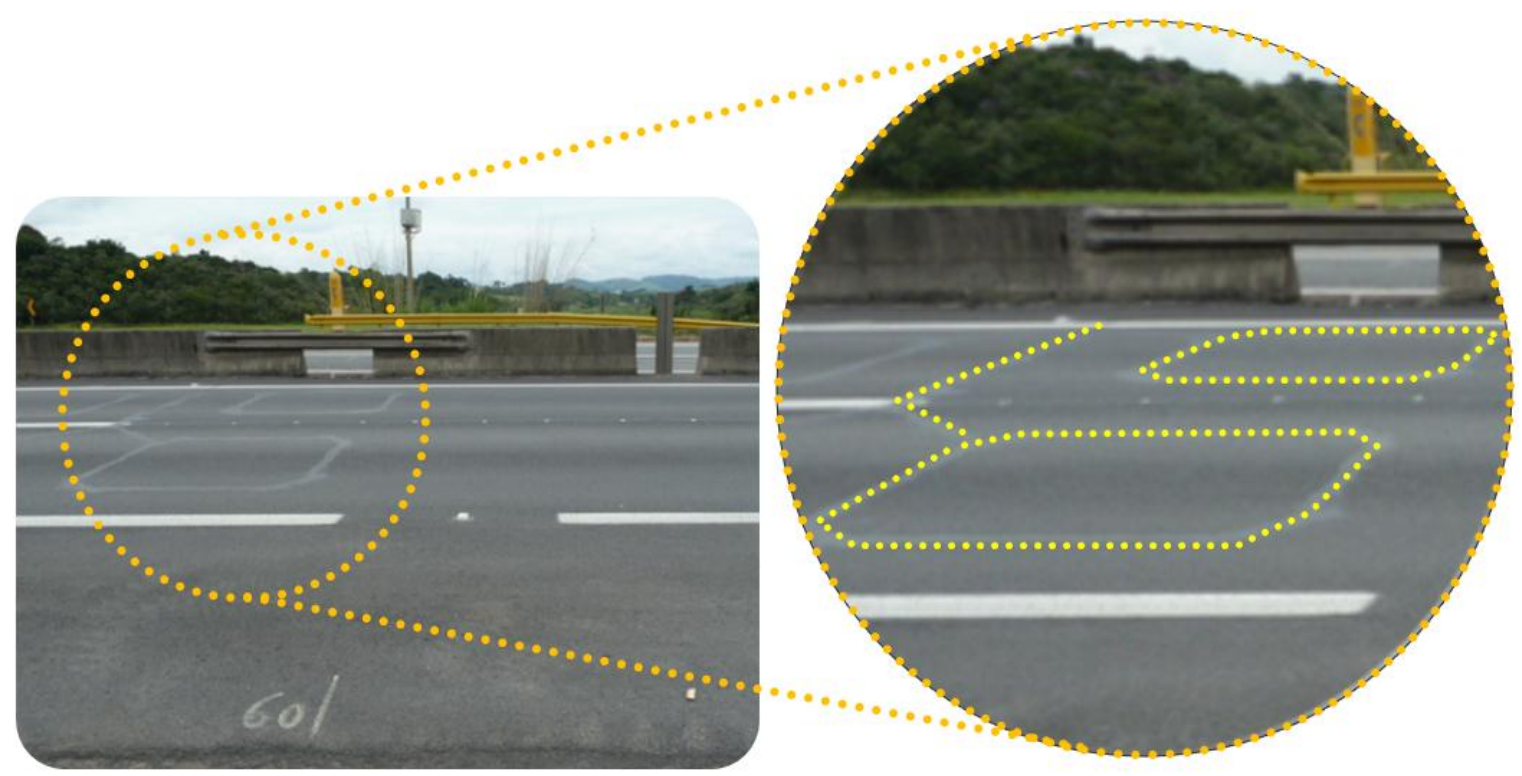

Figura 3.2 - Localização e detalhe dos sensores a laço indutivo para classificação e identificação da velocidade dos veículos, km 170+360

A Figura 3.3 representa de forma ilustrativa a distribuição percentual dos veículos de acordo com a velocidade trafegada, no período de março de 2010 a março de 2011.

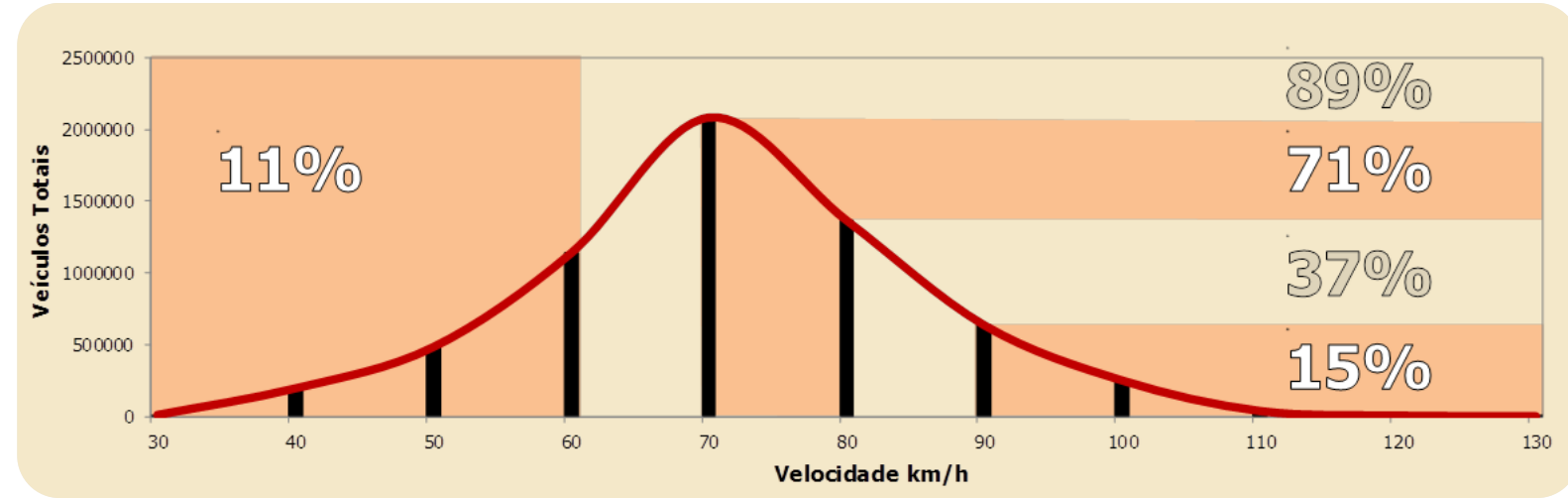

Figura 3.3 - Distribuição das velocidades dos veículos no Trecho Experimental

Percebe-se, na Figura 3.3, que 71\% dos veículos trafegam a velocidade superior a $70 \mathrm{~km} / \mathrm{h}$ e que $89 \%$ trafegam a velocidade superior a $60 \mathrm{~km} / \mathrm{h}$. Neste sentido, é possível considerar representativos os levantamentos deflectométricos com o Falling Weight Deflectometer (FWD ${ }^{11}$, pelo fato deste equipamento produzir pulsos de carga com duração de 25 a 30 milissegundos correspondendo a velocidades de veículos comerciais entre 60 e $80 \mathrm{~km} / \mathrm{h}$.

\footnotetext{
${ }^{11}$ Todas as análises deflectométricas desenvolvidas nos capítulos 4 e 5 desta tese foram realizadas por meio de levantamentos gerados pelo Falling Weight Deflectometer (FWD).
} 


\subsection{SONDAGENS NO TRECHO EXPERIMENTAL}

Para efeito de avaliação das condições das camadas do pavimento foram efetuadas prospecções dos seguintes tipos:

- Abertura de seis poços de inspeção;

- Extração de dezoito testemunhos por sondagem rotativa.

Em cada caso, inspeções in loco das condições das camadas executadas foram efetuadas, assim como ensaios laboratoriais, conforme é descrito a seguir. Todas as prospecções foram realizadas em maio de 2010.

- Abertura de Poços de Inspeção

Poços de sondagem foram efetuados em seis locais, na trilha de roda externa da faixa de tráfego mais solicitada, conforme relação apresentada na Tabela 3.4. Nela são relacionadas as espessuras das camadas do pavimento conforme medidas de cada poço de inspeção

Tabela 3.4 - Localização dos Poços de Inspeção

\begin{tabular}{r|r|r|r|r|r|r}
\hline \multirow{2}{*}{ Estaca } & $\begin{array}{c}\text { Poço de } \\
\text { inspeção }\end{array}$ & \multicolumn{3}{|c|}{$\begin{array}{c}\text { Espessura dos Materiais Encontrados no } \\
\text { Pavimento Anterior a Intervenção (cm) }\end{array}$} \\
\cline { 3 - 7 } & & $\begin{array}{c}\text { Material } \\
\text { Betuminoso }\end{array}$ & BGS & Cascalho & Areia & \multicolumn{1}{c|}{ Argila } \\
\hline $170+940$ & P01 & 27 & 7 & 15 & 34 & 69 \\
\hline $170+780$ & P02 & 35 & 26 & & & 89 \\
\hline $170+600$ & P03 & 30 & & 36 & 64 \\
\hline $170+420$ & P04 & 30 & & 40 & 60 \\
\hline $170+260$ & P05 & 24 & 13 & 33 & 55 \\
\hline $170+120$ & P06 & 26 & 10 & 40 & \\
\hline
\end{tabular}

Os aspectos principais de campo anotados foram os seguintes:

- Subleito: em argila com aparência firme e estável. Indícios de umidade, sem comprometimento da sua resistência, nos poços P01, P02, P03 e P06; com capacidade de suporte superior a $5 \%$ e expansão inferior a $1,4 \%$. Os poços P04 e P05 apresentam maior incidência de umidade, com capacidade de suporte igual a $4 \%$ e expansão superior a $2,9 \%$. O poço P04 encontra-se 
localizado na região de corte e o poço P05 encontra-se em um ponto baixo. Ambos sendo evidenciados por uma superfície muito deteriorada e, no caso do poço P04, pela alta concentração de água na região de sarjeta. As Figuras 3.4 e 3.5 representam tais situações.

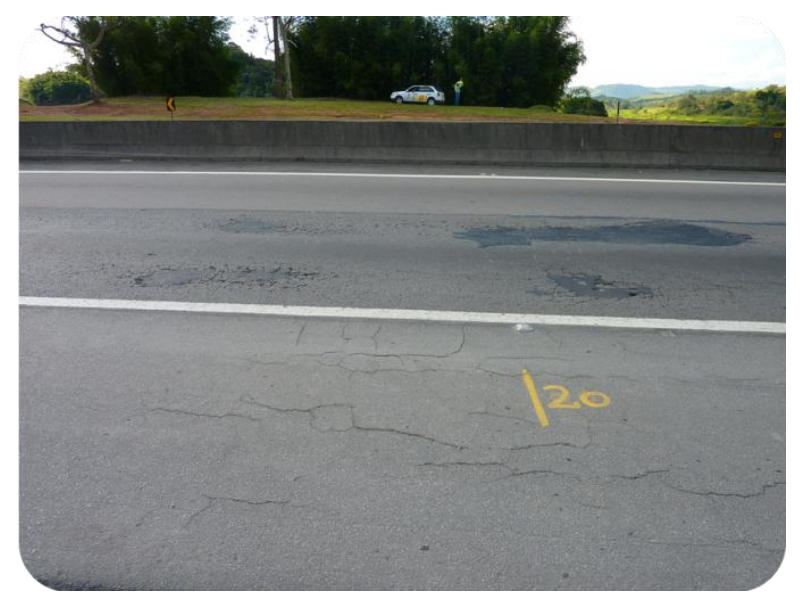

Figura 3.4 - Estaca 170+420: Grau de trincamento da superfície do pavimento

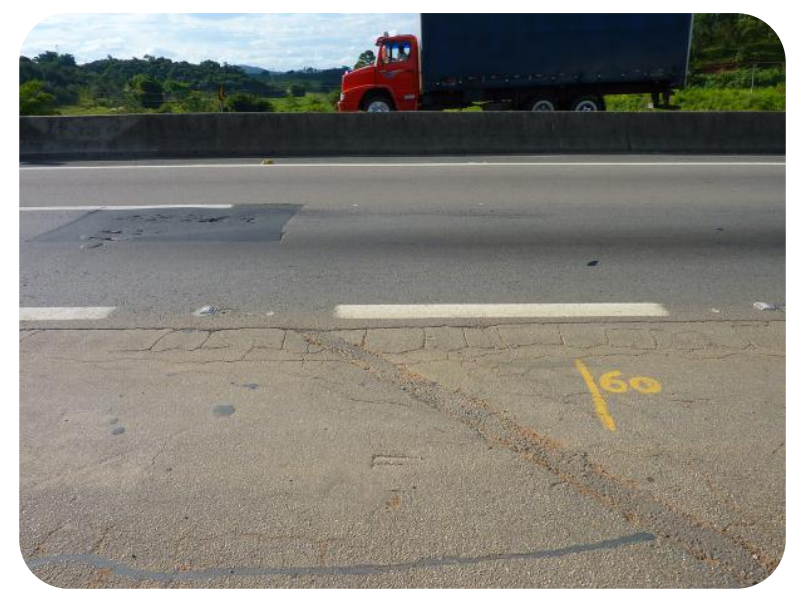

Figura 3.5 - Estaca 170+260: Grau de trincamento de superfície do pavimento e deficiência do dispositivo de drenagem

- Sub-base: em cascalho com aparência úmida, de modo geral, porém íntegra e estável em todos os poços.

- Base: em brita graduada simples (BGS) aparentando contaminada com material da camada de sub-base; aparentando certa umidade devido à infiltração de água pelas trincas da superfície. Tal situação pode ser observada, por exemplo, nas Figuras 3.6 e 3.7 do Poço de Inspeção P05.

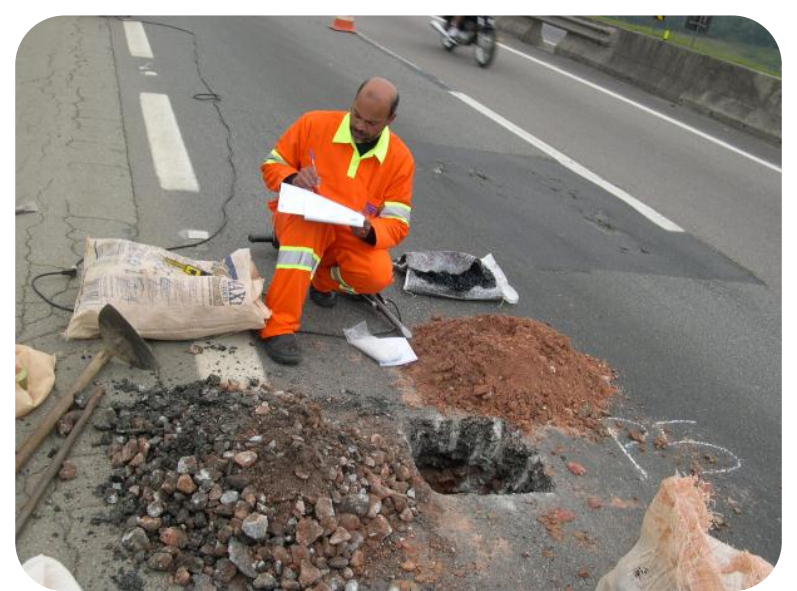

Figura 3.6 - Estaca 170+260: Poço de Inspeção P05 e matérias extraídos

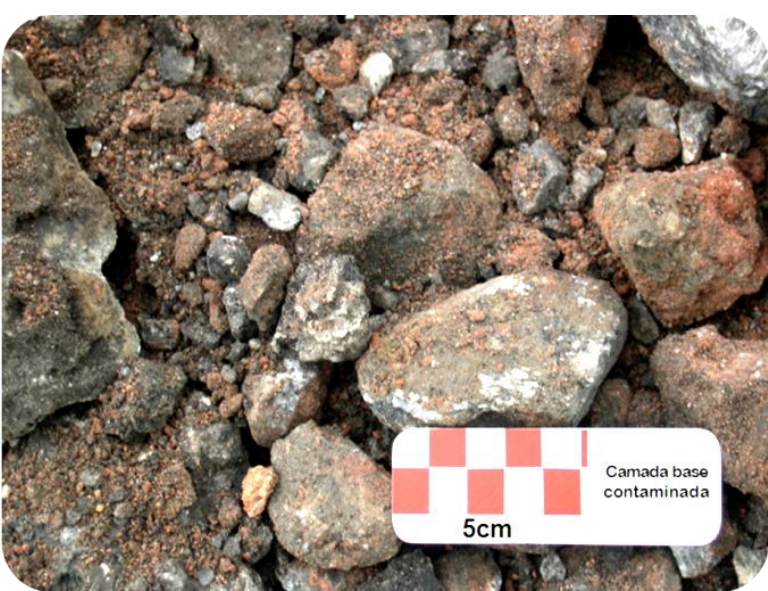

Figura 3.7 - Estaca 170+260: detalhe da camada de base contaminada 
Foram sacados das camadas do pavimento dezoito testemunhos localizados na trilha de roda externa da faixa de rolamento de veículos pesados, conforme relacionados na Tabela 3.5. Salienta-se que a camada de material betuminoso foi extraída por meio de sondagem rotativa e as demais camadas por meio de sondagem a trado.

Tabela 3.5 - Localização das Sondagens Rotativas

\begin{tabular}{|c|c|c|c|c|c|c|}
\hline \multirow{2}{*}{ Estaca } & \multirow{2}{*}{$\begin{array}{l}\text { Sondagem } \\
\text { Rotativa }\end{array}$} & \multicolumn{5}{|c|}{$\begin{array}{l}\text { Espessura dos Materiais Encontrados no } \\
\text { Pavimento Anterior a Intervenção }(\mathbf{c m})\end{array}$} \\
\hline & & $\begin{array}{c}\text { Material } \\
\text { Betuminoso }\end{array}$ & BGS & Cascalho & Areia & Argila \\
\hline $170+960$ & R01 & 20 & 15 & 11 & 7 & \\
\hline $170+900$ & R02 & 18 & 15 & 34 & & \\
\hline $170+840$ & R03 & 21,6 & 10,4 & 23 & 13 & \\
\hline $170+800$ & R04 & 11,5 & 15,5 & 33 & & \\
\hline $170+740$ & R05 & 23,5 & 9 & 29,5 & & \\
\hline $170+700$ & R06 & 23 & 6 & 31 & & \\
\hline $170+660$ & R07 & 12 & 15 & 34 & & \\
\hline $170+620$ & R08 & 17 & 9 & 35 & & \\
\hline $170+580$ & R09 & 19 & 28 & 42 & & \\
\hline $170+520$ & R10 & 17 & 11 & 39 & & \\
\hline $170+460$ & R11 & 34,5 & & 25,5 & & \\
\hline $170+380$ & R12 & 23 & 11 & 26 & & \\
\hline $170+340$ & R13 & 20,5 & 10 & 39,5 & & \\
\hline $170+300$ & R14 & 22,5 & 13,5 & 24 & & \\
\hline $170+220$ & R15 & 25 & 7 & 28 & & \\
\hline $170+200$ & R16 & 23 & 10 & 27 & & \\
\hline $170+080$ & R17 & 24 & 12 & 24 & & \\
\hline $170+040$ & R18 & 22 & 17 & 23 & & \\
\hline
\end{tabular}

As investigações detectaram estruturas com variações de espessura nas camadas denotando heterogeneidade na estrutura. Estas sondagens são apresentadas resumidamente na Figura 3.8. 


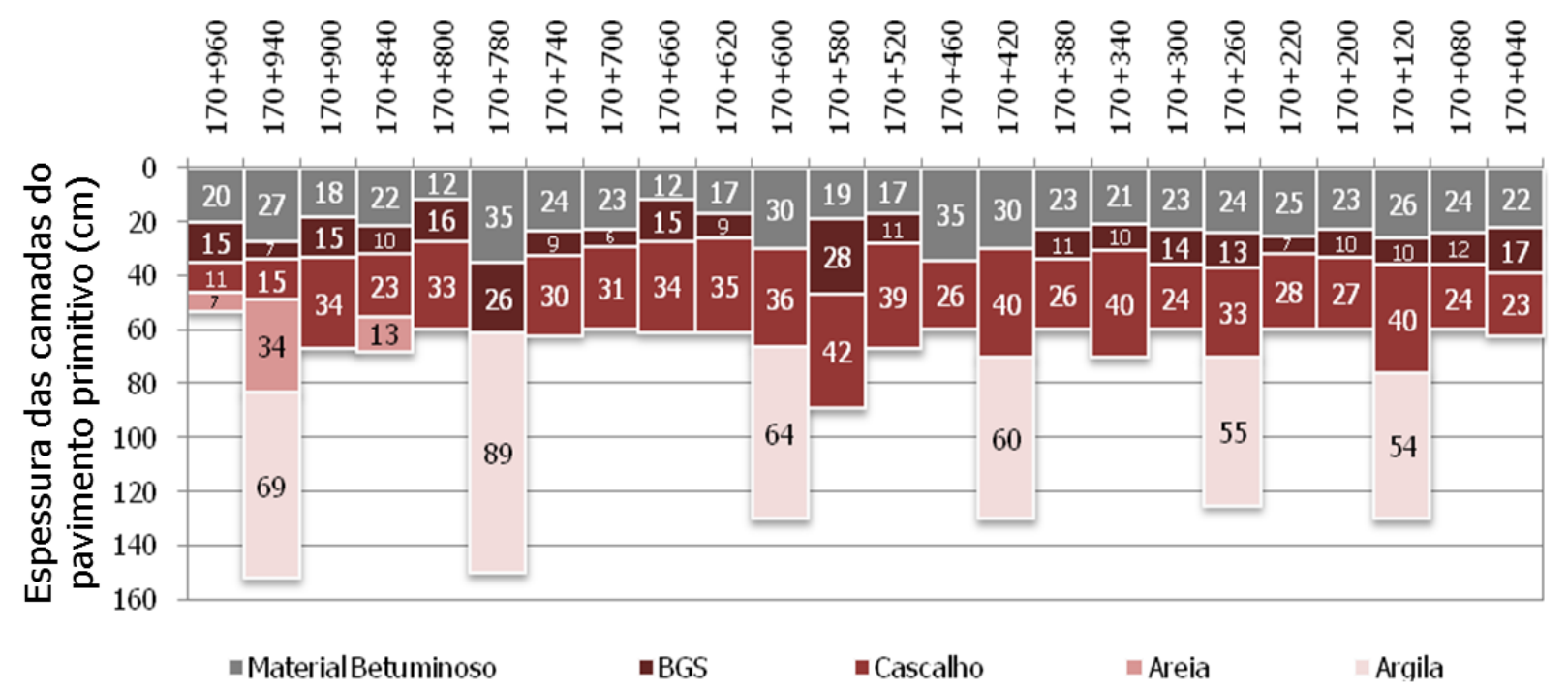

Figura 3.8 - Perfil longitudinal com a estrutura do pavimento no local do Trecho Experimental

A maioria dos solos ocorrentes é do tipo argiloso (A-7-6), para os poços P02, P03, P04 e P05; e argilo-siltoso (A-6), para os poços P01 e P06.

Nos poços P01, P02, P03 e P06; é apresentada capacidade de suporte superior a 5\% e expansão inferior a 1,4\%. Os poços P04 e P05 apresentam capacidade de suporte igual a $4 \%$ e expansão superior a $2,9 \%$.

Os valores da capacidade de suporte do subleito indicaram muita variação não apresentando nenhuma relação com a classificação do tipo de solo indicado anteriormente. Nos poços P01, P02, P03 e P06; é apresentada capacidade de suporte a $5 \%$ e expansão inferior a $1,4 \%$. os poços p04 e p05 apresentam capacidade de suporte igual a $4 \%$ e expansão superior a $2,9 \%$. 


\subsection{DEFINIÇÃO DO TRECHO EXPERIMENTAL}

O Trecho Experimental é constituído de cinco Seções, duas de referência e três experimentais, a saber:

- Primeira Seção de Referência (SRf-01): seção de reconstrução total até o subleito;

- Primeira Seção Experimental (SEx-01): seção de $140 \mathrm{~mm}$ de fresagem e recomposição em EME em duas camadas de 70 mm;

- Segunda Seção Experimental (SEx-02): seção de $110 \mathrm{~mm}$ de fresagem e recomposição em EME em duas camadas, a inferior de $60 \mathrm{~mm}$ e a superior de $50 \mathrm{~mm}$;

- Terceira Seção Experimental (SEx-03): seção de $80 \mathrm{~mm}$ de fresagem e recomposição em EME, em uma única camada de $80 \mathrm{~mm}$; e,

- Segunda Seção de Referência (SRf-02): seção de $80 \mathrm{~mm}$ de fresagem e recomposição em CBUQ com CAP 30-45 convencional, em uma única camada de $80 \mathrm{~mm}$.

A Tabela 3.6 e a Figura 3.9 apresentam o local onde foi executada cada Seção do Trecho Experimental.

Tabela 3.6 - Constituição geral do Trecho Experimental

\begin{tabular}{c|c|r|r|r}
\hline \multicolumn{2}{c|}{ km } & Extensão & \multicolumn{1}{|c|}{ Largura } & \multicolumn{1}{|c}{ Intervenção } \\
\hline Inicial & Final & \multicolumn{1}{|c|}{$(\mathbf{m})$} & (m) & \\
\hline $171+000$ & $170+800$ & 200 & 4,0 & Reconstrução \\
\hline $170+800$ & $170+600$ & 200 & 4,0 & EME $-140 \mathrm{~m}$ \\
\hline $170+600$ & $170+400$ & 200 & 4,0 & EME $-110 \mathrm{~mm}$ \\
\hline $170+400$ & $170+160$ & 240 & 4,0 & EME $-80 \mathrm{~mm}$ \\
\hline $170+160$ & $170+020$ & 140 & 4,0 & CAP $30-45-80 \mathrm{~mm}$ \\
\hline
\end{tabular}



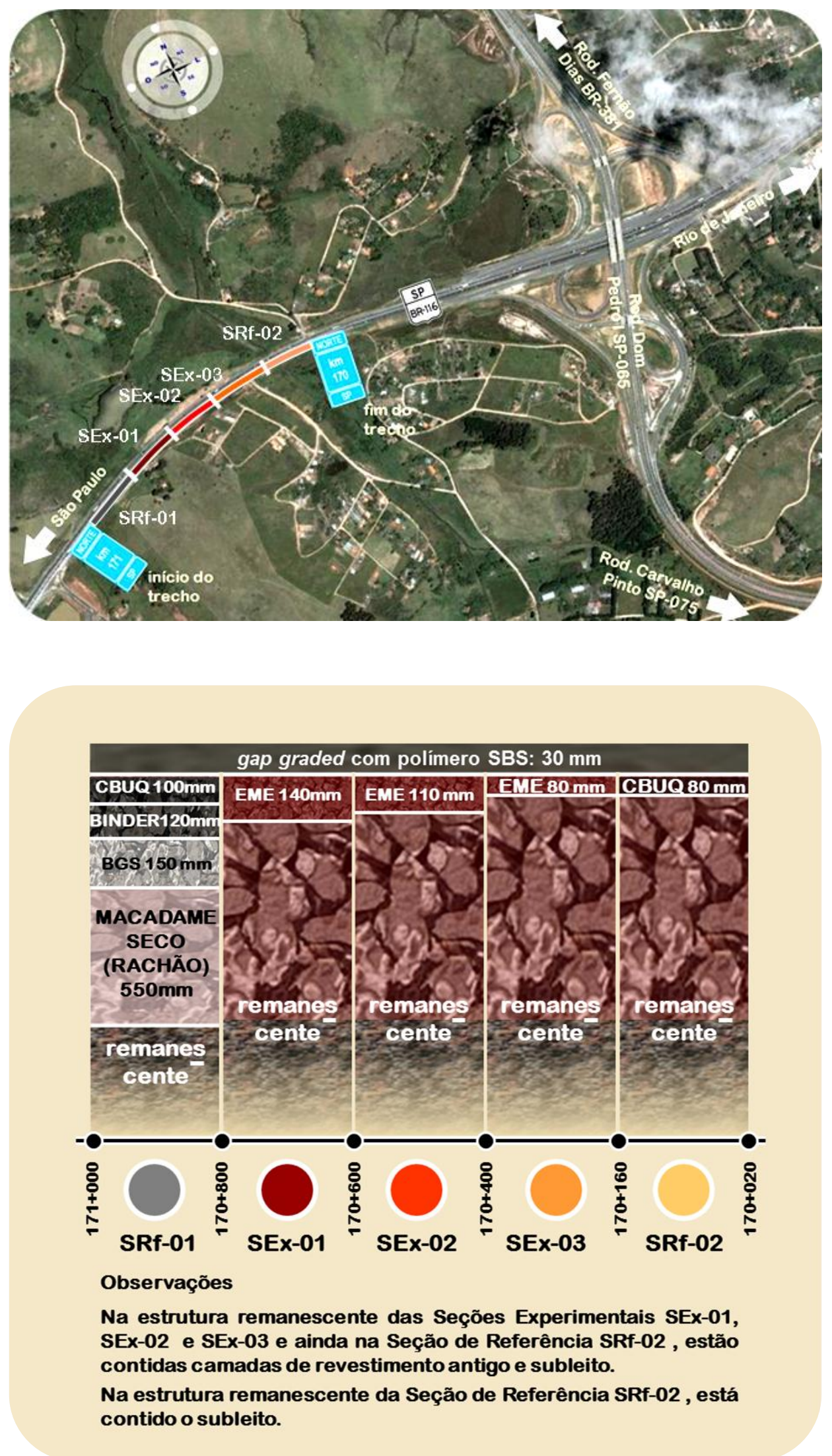

Figura 3.9 - Localização de cada Seção do Trecho Experimental 


\subsection{ESTUDOS LABORATORIAIS}

\subsubsection{Distribuição Granulométrica do EME}

A mistura de módulo elevado é caracterizada por uma curva de granulometria contínua. A curva de granulometria contínua possui em sua composição todas as frações de agregado de maneira que agregados miúdos caibam nos vazios dos graúdos. São materiais que, quando bem compactados, atingem altas densidades e, em conseqüência, maior resistência

A composição granulométrica projetada para a mistura asfáltica com o CAP endurecido pela PETROBRAS com ácido polifosfórico é constituída de $11 \%$ de Brita 1 , $28 \%$ de pedrisco, $61 \%$ de pó de pedra. A comparação entre a curva granulométrica resultante e a curva de máxima densidade é apresentada na Figura 3.10, confrontando também as faixas granulométricas definidas na Espanha (VAL MÉLUS, 1996) e em Portugal (JAE, 1998 e BRANCO et al, 2006) ${ }^{12}$.

A composição estudada resulta em uma curva granulométrica contínua, porém desviando-se dos limites superiores nas peneiras número 10 e 40, mostrando excesso de material nas frações mais grossas da granulometria. As demais peneiras encontram-se dentro das faixas granulométricas ou muito próximas de seus limites superiores.

\footnotetext{
${ }^{12}$ Por serem muito próximas, foi apresentada no gráfico apenas a faixa granulométrica da Espanha (VAL MÉLUS, 1996).
} 


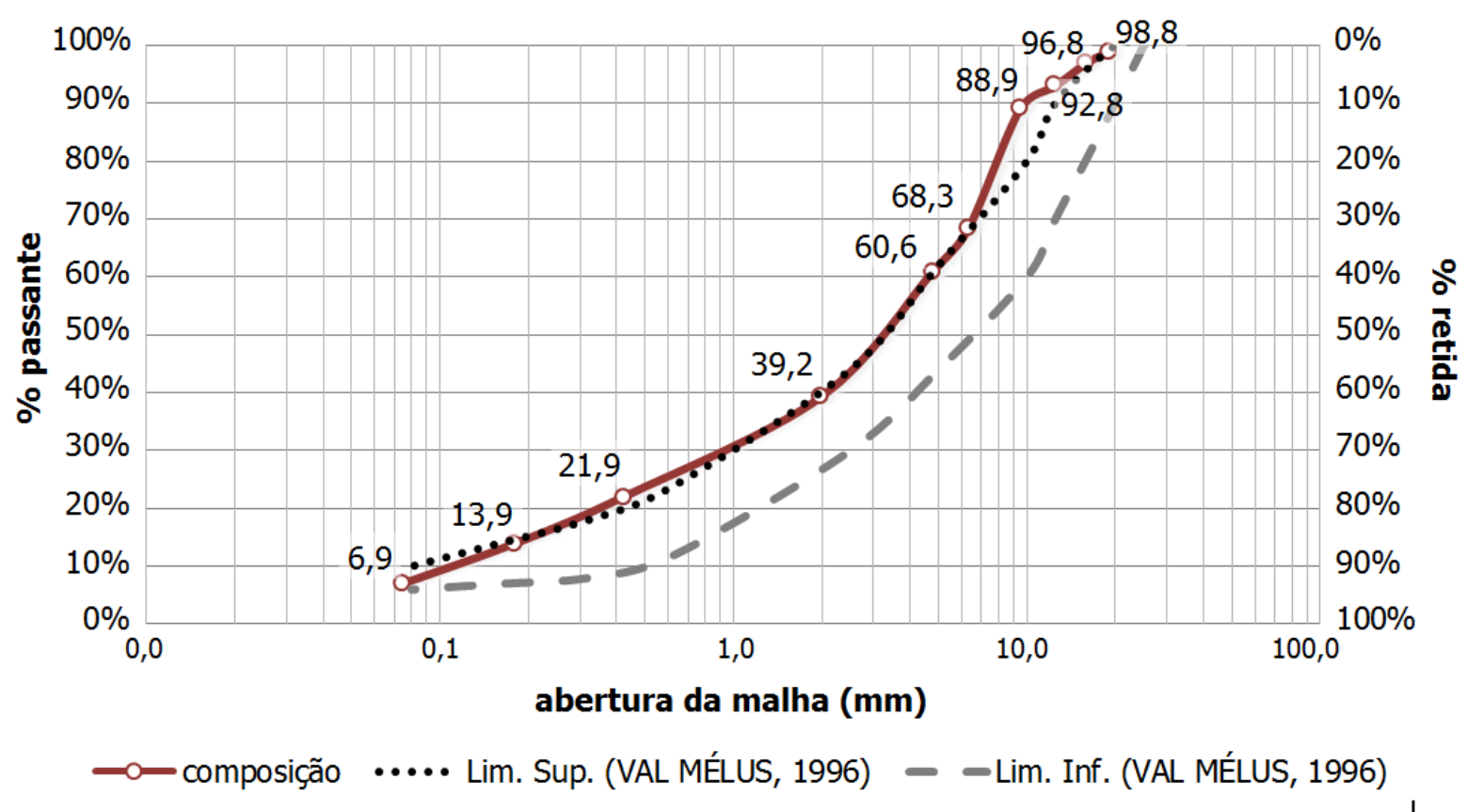

Figura 3.10 - Curva granulométrica da mistura de EME estudada

Como já mencionando no Capítulo 2, segundo BROUSSEAUD (2002), nas normas francesas não existem faixas granulométricas a serem seguidas. Entretanto, são apresentadas peneiras de controle para a composição da curva granulométrica contínua:

- $\%$ passante na peneira $\mathrm{n}^{\circ} 10(2 \mathrm{~mm}): 30 \%$ a $35 \%$; e

- $\%$ passante na peneira $n^{\circ} 200: 7 \%$ a $8 \%$.

A partir das peneiras de controle pode-se observar que a curva granulométrica definida encontra-se superior na fração passante na peneira $n^{\circ} 10$, excedendo $4,2 \%$ no seu limite superior e aproximadamente no limite inferior de fíler, com 6,9\%.

\subsubsection{Caracterização do Ligante do EME}

De acordo com os dados do controle tecnológico de recebimento do ligante na Usina Jambeiro, foram informadas as características apresentadas na Tabela 3.7. 


\begin{tabular}{|c|c|c|c|}
\hline Parâmetro & Unidade & Resultado & Método \\
\hline Penetração & $\mathrm{dmm}$ & 15 & NBR-6576 \\
\hline $\begin{array}{l}\text { Ponto de } \\
\text { amolecimento }\end{array}$ & ${ }^{\circ} \mathrm{C}$ & 79 & NBR-6560 \\
\hline $\begin{array}{l}\text { Recuperação } \\
\text { Elástica }\end{array}$ & $\%$ & 79,5 & DNER-ME 382/99 \\
\hline \multicolumn{2}{|c|}{$\begin{array}{l}\text { Viscosidade Brookfield, } 135^{\circ} \mathrm{C} \\
(6 \mathrm{rpm}, \mathrm{sp} 31)\end{array}$} & 4995 & \multirow{3}{*}{ NBR-15184 } \\
\hline \multicolumn{2}{|c|}{$\begin{array}{l}\text { Viscosidade Brookfield, } 150^{\circ} \mathrm{C} \\
(6 \mathrm{rpm}, \mathrm{sp} 31)\end{array}$} & 2190 & \\
\hline \multicolumn{2}{|c|}{$\begin{array}{l}\text { Viscosidade Brookfield, } 175^{\circ} \mathrm{C} \\
(6 \mathrm{rpm}, \mathrm{sp} 31)\end{array}$} & 910 & \\
\hline
\end{tabular}

As faixas de temperaturas para usinagem e compactação também foram fornecidas pela Petrobras:

- Temperatura de usinagem: $175^{\circ} \mathrm{C}-180^{\circ} \mathrm{C}$;

- Temperatura de compactação: $160^{\circ} \mathrm{C}-165^{\circ} \mathrm{C} ;$.

Para a confecção da mistura de EME, o ligante endurecido com ácido polifosfórico da Petrobras foi classificado como um CAP 10-20.

Segundo a metodologia SUPERPAVE o ligante foi classificado de acordo com o seu grau de desempenho (performance grade) como PG 82-10. 


\subsubsection{Projeto da Mistura do EME}

A partir da distribuição granulométrica selecionada foi realizado o projeto de mistura para o ligante endurecido com ácido polifosfórico da Petrobras. O compactador Marshall foi empregado para produzir corpos de prova para determinar:

- A massa específica aparente e a massa específica máxima teórica;

- As características volumétricas das misturas como volume de vazios (Vv), relação betume vazios (RBV) e vazios no agregado mineral (VAM);

- A resistência à tração por compressão diametral (RT).

A Figuras 3.11 a 3.16 apresentam os parâmetros da mistura estudada.

Segundo as literaturas (CAPITÃO, 2003; AFNOR, 1999; CORTÉ e SERFASS, 2000 e CORTÉ, 2001), as misturas de módulo elevado devem apresentar volume de vazios entre 3 a $6 \%$, vazios do agregado mineral (VAM) superior a 13\%, módulo de riqueza (k) superior ou igual a 3,4. Da mistura definida, o volume de vazios foi de 3,6\% e VAM igual a $16,1 \%$.

A partir das equações $2.1,2.2$ e 2.3 , pode ser estimado o módulo de riqueza baseando-se no teor de betume do projeto de mistura definido em 5,8\%. O valor do módulo de riqueza foi estimado em 3,54 e, além de ser superior ao valor estabelecido pela literatura $(3,40)$, segundo SERFASS et al (1997) indica uma mistura com excelente desempenho mecânico em termos de rigidez e deformação permanente.

O teor de vazios é um dos fatores que tem maior influência no desempenho mecânico (deformação permanente) das misturas asfálticas. Existe um intervalo de teor de vazios, de $3 \%$ a $7 \%$, para o qual as misturas asfálticas densas são mais estáveis (BROSSEAUD et al, 1993). Para mistura asfáltica de módulo elevado EME 2, o volume de vazio limite superior é igual a $6 \%$ inferior igual a $3 \%$. 


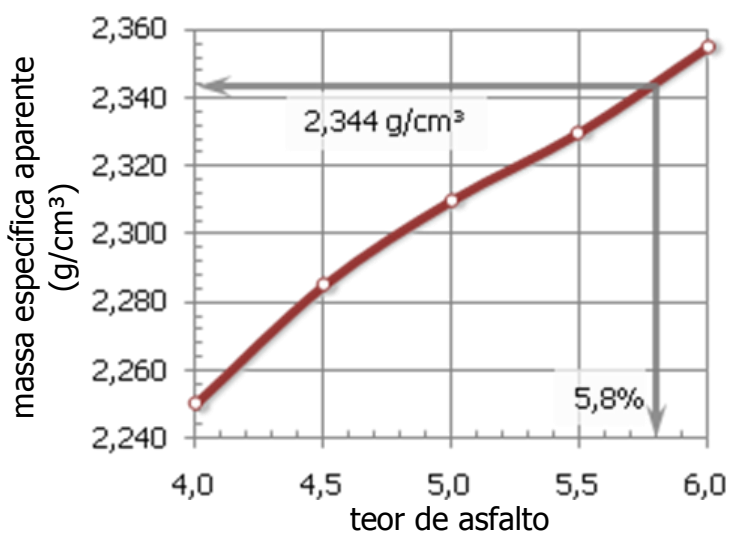

(\%)

Figura 3.11 - Massa específica aparente $\left(\mathrm{g} / \mathrm{cm}^{3}\right)$

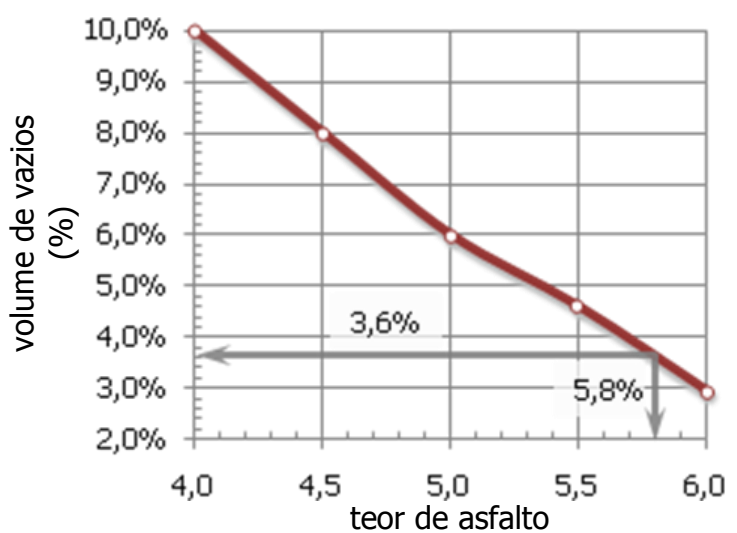

(\%)

Figura 3.13 - Volume de vazios (\%)

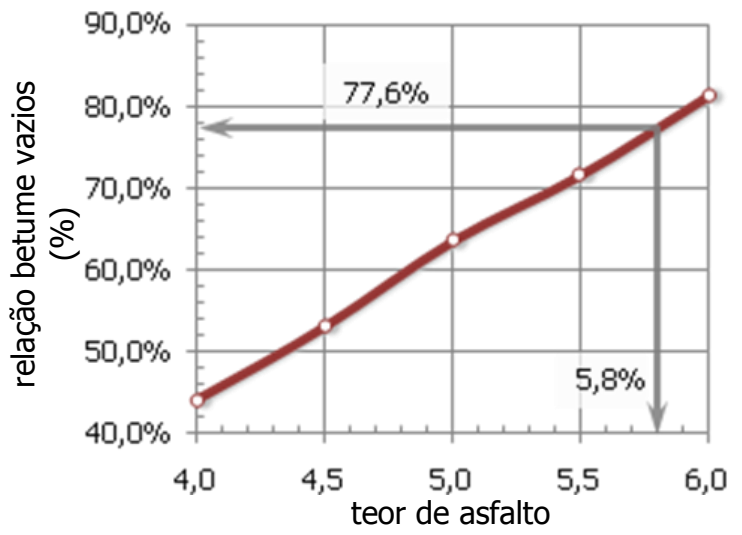

(\%)

Figura 3.15 - Relação betume/vazios (\%)

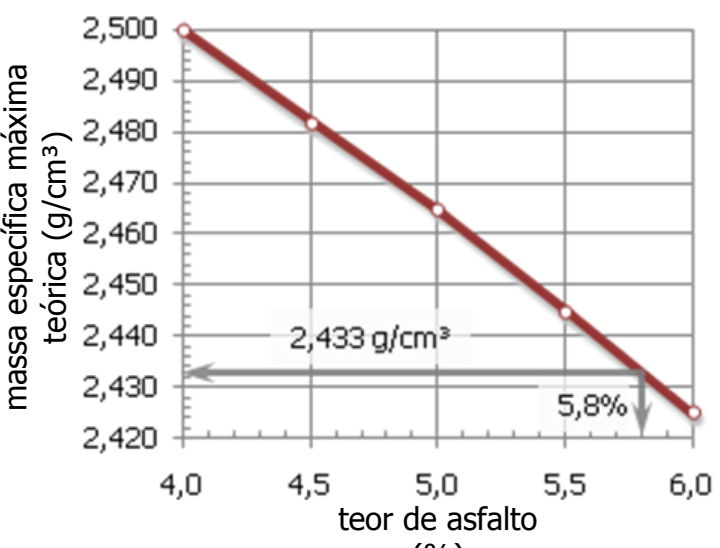

(\%)

Figura 3.12 - Massa específica máxima teórica $\left(\mathrm{g} / \mathrm{cm}^{3}\right)$

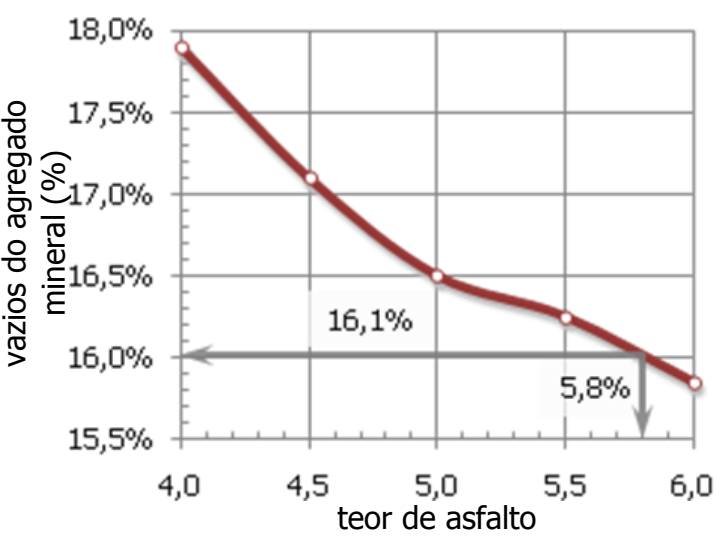

(\%)

Figura 3.14 - Vazios do agregado mineral (\%)

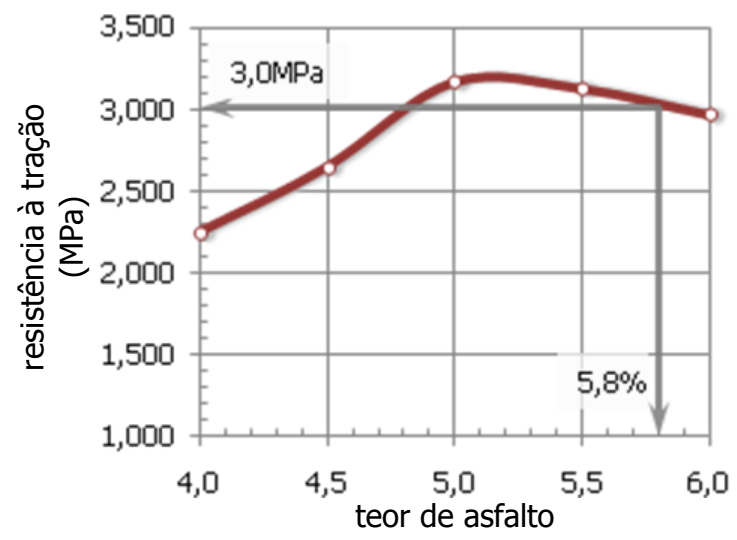

(\%)

Figura 3.16 - Resistência à tração (MPa) 


\subsubsection{Propriedades Mecânicas do EME - Deformação Permanente e PCG}

Nas misturas betuminosas densas, o controle dos vazios busca a obtenção de uma camada com resistência à deformação permanente. A literatura estabelece que, nos ensaios realizados no simulador francês (AFNOR, 1993b), o volume de vazios deve permanecer entre 3 e $6 \%$ e ao deformação permanente inferior a 7,5\%.

As Figuras 3.17 e 3.18 demonstram que, tanto para a PCG quanto para o ensaio de deformação permanente, a mistura definida teve um bom desempenho. Na Figura 3.17, para o ensaio na Prensa de Cisalhamento Giratória (PCG), a mistura se comportou com 4,5\% inferior ao máximo recomendado de $6 \%$ para 100 giros. $\mathrm{Na}$ Figura 3.18, para o ensaio no simulador tipo LCP, o valor da deformação permanente foi de $1,2 \%$ inferior ao limite preconizado de $7,5 \%$ para 30.000 ciclos.

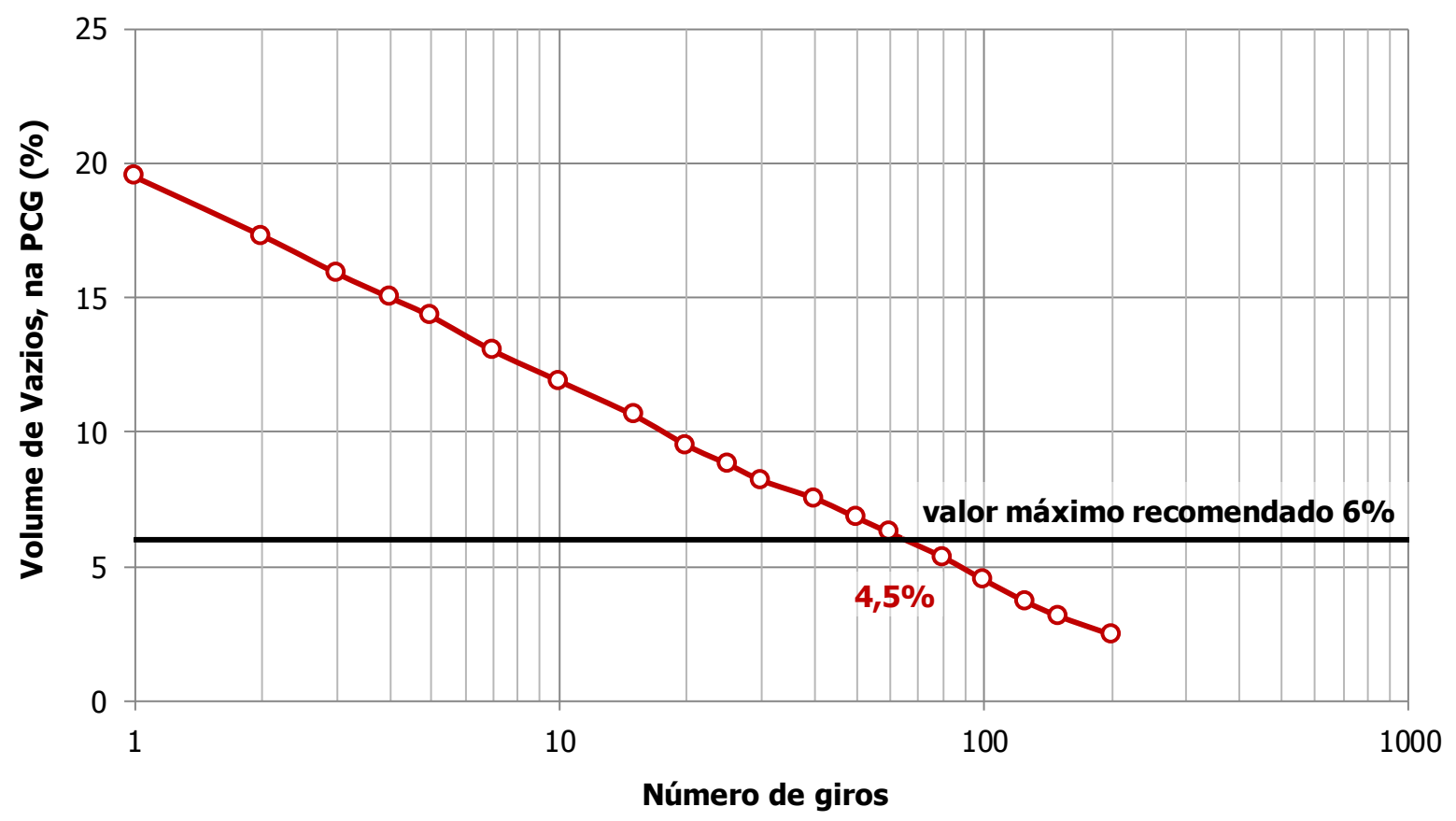

Figura 3.17 - Aptidão de compactação para o ensaio na Prensa de Cisalhamento Giratória (PCG) 


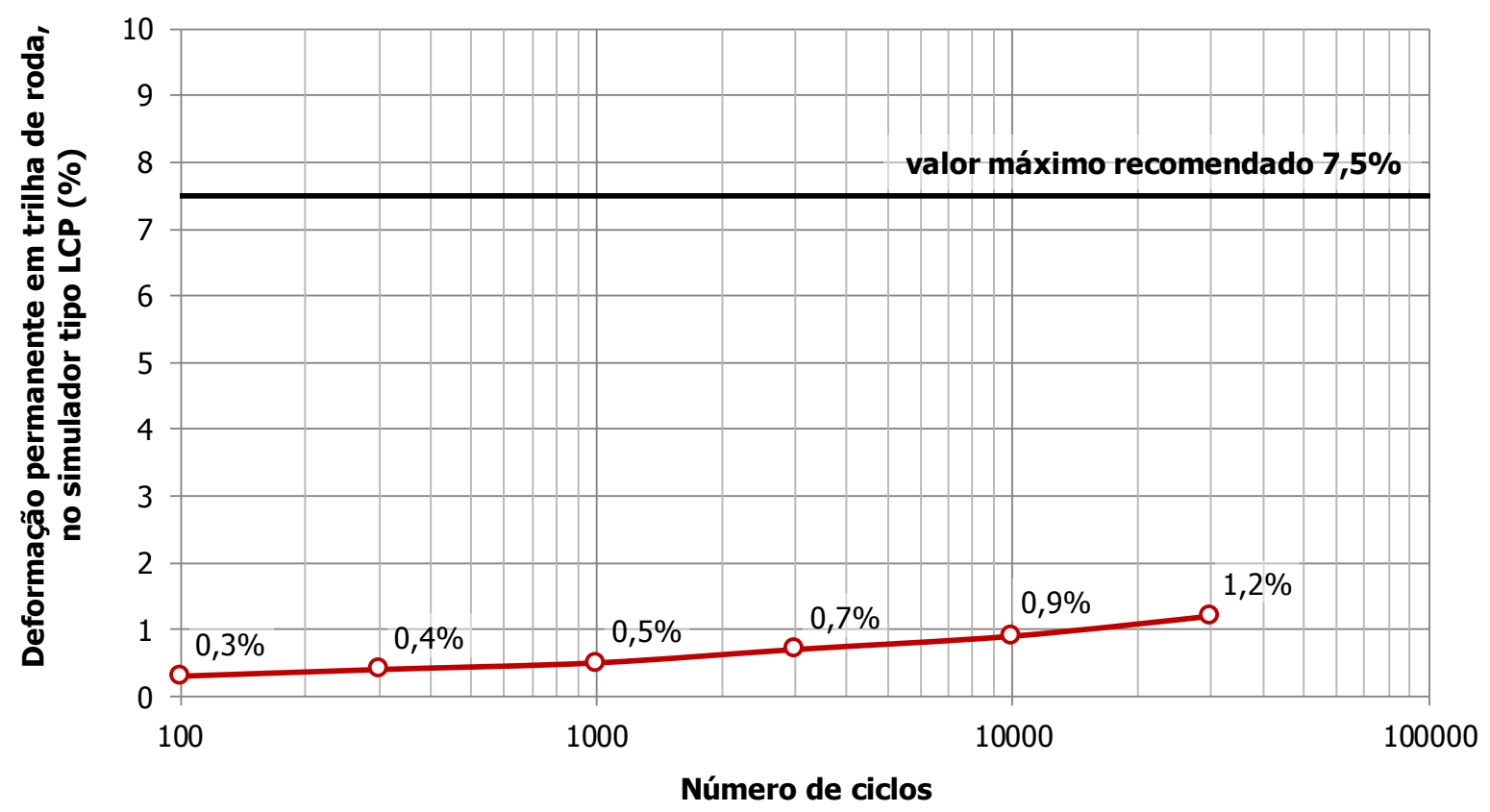

Figura 3.18 - Deformação permanente em trilha de roda, no simulador tipo LCP

Os resultados estão de acordo com as especificações francesas mostrando que o projeto de mistura foi adequado e com bom desempenho em laboratório.

\subsection{USINAGEM E EXECUÇÃO DO TRECHO EXPERIMENTAL}

A partir da caracterização dos agregados e do ligante de baixa penetração, foi possível projetar uma mistura asfáltica com a finalidade de emprego na execução do Trecho Experimental proposto nesta tese. Como mencionado no terceiro capítulo desta pesquisa, O Trecho Experimental foi construído na Rodovia Presidente Dutra, entre os quilômetros 171 e 170 (sentido Rio de Janeiro) no município de Jacareí/SP.

\subsubsection{Usinagem do Trecho Experimental}

O ligante foi entregue pela Petrobras, em um caminhão tanque apropriado para o seu transporte dotado de agitador e controlador de temperatura, na Usina Jambeiro. A adição do material foi realizada por bombeamento para um tanque apropriado da usina também dotado de agitador e controlador de temperatura. 
A partir do projeto de mistura a Usina Jambeiro foi calibrada para produzir a mistura de EME.

A mistura de EME foi produzida em uma usina gravimétrica (Figura 3.19) automatizada e controlada por um programa computacional (Figura 3.20), onde se percebe qualquer alteração na temperatura, tempo de mistura e alimentação dos agregados, ligantes asfálticos e aditivos. A Tabela 3.8 apresenta as características técnicas da Usina Jambeiro.

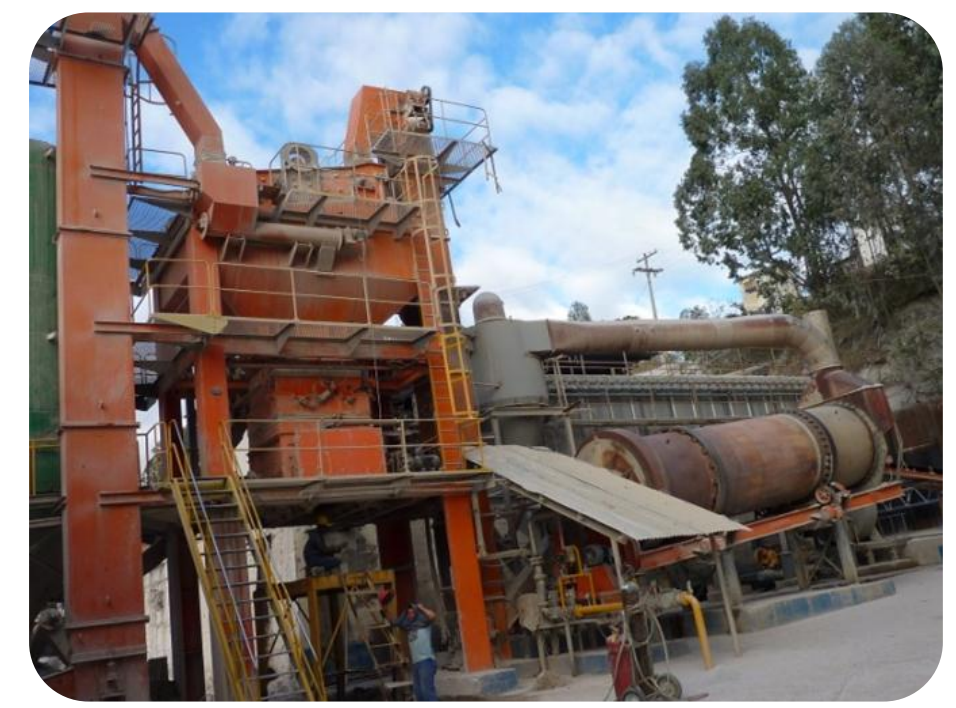

Figura 3.19 - Usina Gravimétrica Jambeiro Serveng-Civilsan

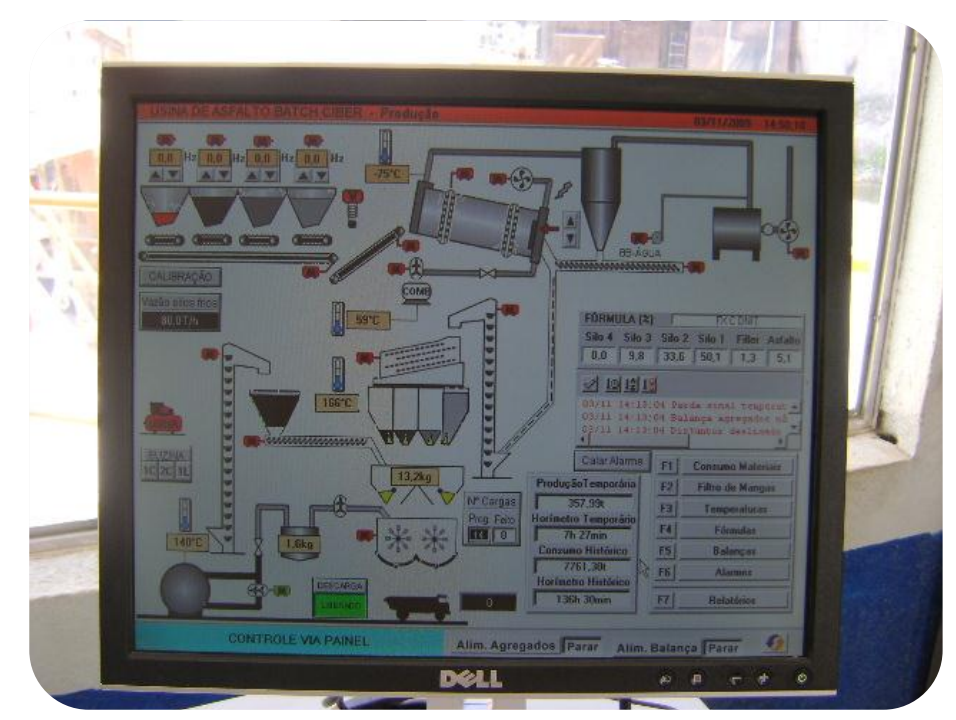

Figura 3.20 - Tela de controle das atividades da Usina Gravimétrica 
Tabela 3.8 - Características Técnicas da Usina Jambeiro

\begin{tabular}{|c|c|c|c|c|}
\hline \multirow{2}{*}{\multicolumn{3}{|c|}{ Pedreira }} & Característica & $\begin{array}{l}\text { usina com pedreira própria, instalada na } \\
\text { mesma planta de beneficiamento }\end{array}$ \\
\hline & & & Material pétreo & Gnaisse \\
\hline \multicolumn{4}{|c|}{ Tipo da Usina } & Gravimétrica \\
\hline \multicolumn{4}{|c|}{ Marca da Usina } & CIBER \\
\hline \multicolumn{4}{|c|}{ Mobilidade de Instalação da Usina } & dosador, secador/filtro e torre estacionários \\
\hline \multicolumn{4}{|c|}{ Data de Fabricação da Usina } & fevereiro de 2001 \\
\hline \multicolumn{4}{|c|}{ Produção da Usina $(t / h)^{1}$} & $100-140 \mathrm{t} / \mathrm{h}$ \\
\hline \multirow{2}{*}{\multicolumn{3}{|c|}{ Silos Dosadores (Silos Frios) ${ }^{2}$}} & Quantidade & 4 \\
\hline & & & Característica & $6 \mathrm{~m}$ de altura por pilha \\
\hline \multirow{25}{*}{ 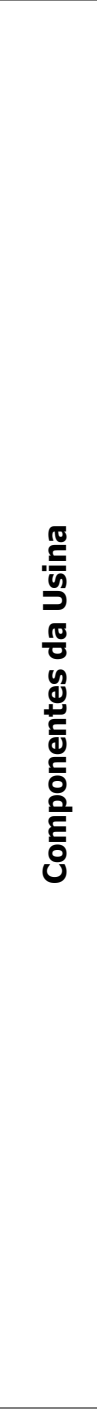 } & \multirow{6}{*}{ Secador } & \multicolumn{2}{|l|}{ Tipo } & Contrafluxo com aletas \\
\hline & & \multirow{2}{*}{ Dimensão } & Diâmetro (m) & 1,9 \\
\hline & & & Comprimento (m) & 7,5 \\
\hline & & \multirow{3}{*}{ Queimador } & Tipo & CIBER MC-10" - Chama Modulada \\
\hline & & & \multirow{2}{*}{ Potência } & $11,6 \mathrm{MW}$ \\
\hline & & & & $10.000 .000 \mathrm{kcal} / \mathrm{h}$ \\
\hline & \multirow{7}{*}{$\begin{array}{l}\text { Sistema de } \\
\text { exaustão }\end{array}$} & \multirow[b]{2}{*}{ Pré Coletor } & Tipo & Separador Estático \\
\hline & & & Eficiência & $\begin{array}{r}80 \% \text { a } 90 \% \text {, para material retido na } \\
\text { peneira } \# 200\end{array}$ \\
\hline & & \multirow{5}{*}{$\begin{array}{l}\text { Purificação e } \\
\text { Recuperação } \\
\text { de Finos }\end{array}$} & Tipo & Filtro de mangas \\
\hline & & & Quantidade de Mangas & 216 \\
\hline & & & $\begin{array}{l}\text { Eficiência do Filtro de } \\
\text { Mangas }\end{array}$ & $99,50 \%$ \\
\hline & & & Área Filtrante & $1.080 \mathrm{~m}^{2}$ \\
\hline & & & $\begin{array}{l}\text { Emissão máxima de } \\
\text { material particulado }\end{array}$ & $50 \mathrm{mg} / \mathrm{Nm}^{3}$ \\
\hline & \multicolumn{2}{|l|}{ Elevador } & Tipo & Vertical, de canecas para misturas quentes \\
\hline & \multirow{9}{*}{ Torre } & Deck & Quantidade & 4 (brita 2 , brita 1 pedrisco e pó de pedra) \\
\hline & & \multirow{2}{*}{$\begin{array}{l}\text { Sistema de } \\
\text { Peneiramento }\end{array}$} & Quantidade & 4 \\
\hline & & & Classificação & Gravimétrica \\
\hline & & Silos Quentes & Quantidade & 4 \\
\hline & & $\begin{array}{l}\text { Dosagem de } \\
\text { CAP }\end{array}$ & Característica & $\begin{array}{r}\text { Por meio de balança com recipiente } \\
\text { aquecido }\end{array}$ \\
\hline & & \multirow{3}{*}{ Misturador } & Tipo & Pug-mill \\
\hline & & & Característica & $\begin{array}{l}\text { Eixo duplo. Simétricos e sincronizados, de } \\
\text { rotação oposta, com injeção direta de CAP }\end{array}$ \\
\hline & & & Abertura & Inferior \\
\hline & & Descarga & Característica & $\begin{array}{r}\text { Diretamente efetuada sobre caçamba do } \\
\text { caminhão }\end{array}$ \\
\hline & \multirow{2}{*}{\multicolumn{2}{|c|}{$\begin{array}{l}\text { Bomba de Transferência de } \\
\text { Asfalto }\end{array}$}} & Diâmetro & $2,5 "$ \\
\hline & & & Fluxo (I/min) & 600 \\
\hline \multicolumn{3}{|c|}{ Produção de Mistura Usinada } & Quantidade & $1,5 \mathrm{t} /$ batelada \\
\hline
\end{tabular}

Notas:

1 Produção média da Usina 100t/h. Esta produção é variável e depende dos seguintes fatores: umidade dos agregados, percentual de finos da mistura, temperatura da mistura e peso específico dos agregados

2 O depósito de material é em pilhas que alimentam diretamente na usina por meio de correias transportadoras 
O controle tecnológico da mistura usinada pela Jambeiro foi realizado segundo os parâmetros:

- Teor de ligante - forno NCAT;

- Densidade Máxima de Mistura - Rice; e,

- Granulometria.

Em relação ao teor de ligante, apenas na seção experimental de $110 \mathrm{~mm}$, verificouse teor de ligante $0,1 \%$ abaixo dos limites aceitáveis (5,6 a 6\%). Apesar desta constatação, até abril de 2011 apenas uma pequena área de $1,5 \mathrm{~m}^{2}$ foi identificada com defeitos nesta seção. Tal análise será abordada no item 5.2.

Quanto à granulometria verificaram-se desvios na porção de finos, mostrando que a mistura estava acima do limite superior estabelecido. 0 módulo de riqueza do projeto de mistura foi calculado em 3,54. Pelos resultados obtidos no controle tecnológico e apresentados na Tabela 3.9, verificou-se que apenas uma amostra entre quatro (certificado 00738) apresentou um valor ligeiramente abaixo para a classificação de mistura rica $(k=3,03 ;<3,2)$, segundo SERFASS et al (1997).

Tabela 3.9 - Valor dos módulos de riqueza das amostras

\begin{tabular}{l|r|r}
\hline Certificado da amostra & Teor de Ligante (\%) & Módulo de Riqueza (k) \\
\hline 00699 & 5,9 & 3,43 \\
\hline 00737 & 5,7 & 3,18 \\
\hline 00738 & 5,5 & 3,03 \\
\hline 00788 & 6,0 & 3,56 \\
\hline
\end{tabular}

Esta amostra (certificado 00738) de k menor foi extraída na mesma que apresentou teor de asfalto inferior ao aceitável. Sendo assim, durante o monitoramento periódico do trecho representativo desta amostra estas informações devem ser levadas em consideração.

A mistura saiu da usina com temperatura entre 170 e $185^{\circ} \mathrm{C}$. 


\subsubsection{Execução do Trecho Experimental}

\subsubsection{Preparo da Superfície}

Para as três seções experimentais (SEx-01, SEx-02 e SEx-03), foram removidas as camadas asfálticas nas cotas estabelecidas na Tabela 3.10. Estas remoções foram executadas por meio de fresagens.

\begin{tabular}{c|c|c|c|r}
\multicolumn{2}{c}{ Tabela 3.10 - Espessuras de fresagem nas seções experimentais } \\
\hline $\begin{array}{c}\text { Seção } \\
\text { experimental }\end{array}$ & \multicolumn{2}{|c|}{ km } & $\begin{array}{c}\text { Extensão } \\
\text { (m) }\end{array}$ & $\begin{array}{c}\text { Espessura } \\
\text { de fresagem }\end{array}$ \\
\cline { 2 - 5 } Inicial & Final & 200 & $140 \mathrm{~mm}$ \\
\hline SEx-01 & $170+800$ & $170+600$ & 200 & $110 \mathrm{~mm}$ \\
\hline SEx-02 & $170+600$ & $170+400$ & 240 & $80 \mathrm{~mm}$ \\
\hline SEx-03 & $170+400$ & $170+160$ & &
\end{tabular}

Para a seção de referência SRf-01, foi necessária a remoção de toda a estrutura do pavimento atingido a cota de $920 \mathrm{~mm}$. Na seção de referência SRf-02, foi removida parte da camada asfáltica, na cota de $80 \mathrm{~mm}$, também com emprego de fresadora.

Após a fresagem, a superfície foi varrida manualmente e limpa com escova mecânica, eliminando todo o material solto no fundo da caixa.

\subsubsection{Distribuição e Compactação do EME}

O transporte da mistura de EME produzida foi realizado por caminhões basculantes cobertos por lona com a finalidade de reduzir a perda de temperatura durante seu transporte. $O$ espalhamento da mistura nas seções experimentais foi executado por vibro acabadora sobre superfície fresada de estrutura remanescente com pintura de ligação RR-1C realizada com caminhão espargidor.

O processo de compactação da mistura de EME foi o mesmo adotado por JAMOIS et al (1998). A compactação iniciou com rolo de pneus e prosseguiu com rolo liso vibratório. Tal processo foi adotado pelo fato das seções experimentais terem sido executadas a noite a uma temperatura ambiente baixa, de $11^{\circ} \mathrm{C}$ em média, o que acelera a perda de calor da massa asfáltica, o que dificulta a compactação. Cabe 
ressaltar que para misturas asfálticas de módulo elevado EME 2, o volume de vazios máximo é de $6 \%$.

A Tabela 3.11 relaciona a temperatura ambiente no dia em que cada seção experimental foi executada.

Tabela 3.11 - Temperatura ambiente na data de execução do Trecho Experimental

\begin{tabular}{l|c|c|c|c|c|r}
\hline \multirow{2}{*}{ Intervenção } & \multicolumn{2}{|c|}{ km } & Extensão & Data & Período & $\begin{array}{r}\text { Temp. } \\
\text { do Ar }\end{array}$ \\
\cline { 2 - 6 } & Inicial & Final & $(\mathbf{m})$ & & & \\
Reconstrução & $171+000$ & $170+800$ & 200 & $13 / 08 / 2010$ & diurno & $22^{\circ} \mathrm{C}$ \\
\hline EME $-140 \mathrm{~mm}$ & $170+800$ & $170+600$ & 200 & $01 / 07 / 2010$ & noturno & $9^{\circ} \mathrm{C}$ \\
\hline EME $-110 \mathrm{~mm}$ & $170+600$ & $170+400$ & 200 & $02 / 07 / 2010$ & noturno & $12^{\circ} \mathrm{C}$ \\
\hline EME $-80 \mathrm{~mm}$ & $170+400$ & $170+160$ & 240 & $07 / 07 / 2010$ & noturno & $11^{\circ} \mathrm{C}$ \\
\hline CAP30/45- $80 \mathrm{~mm}$ & $170+160$ & $170+020$ & 140 & $13 / 08 / 2010$ & diurno & $22^{\circ} \mathrm{C}$ \\
\hline
\end{tabular}

A temperatura de compactação variou de 160 a $175^{\circ} \mathrm{C}$.

As camadas mais espessas de EME foram executadas em etapas. No caso da seção experimental de $140 \mathrm{~mm}$, foram executadas duas camadas de $70 \mathrm{~mm}$ e para a seção experimental de $110 \mathrm{~mm}$, foi executada uma primeira camada de $60 \mathrm{~mm}$ e logo após outra de $50 \mathrm{~mm}$. A seção experimental de $80 \mathrm{~mm}$ foi executada em uma única camada.

\subsubsection{Sistema de Drenagem}

Na seção de referência com estrutura de reconstrução, foi executado o dreno de fundo de caixa. Ao longo das demais seções, com as soluções de fresagem e recomposição, foi executado o dreno longitudinal de pavimento.

Para as seções experimentais com EME, foi executado também um dreno longitudinal profundo de proteção, na região em Corte, no final de agosto de 2010.

\subsubsection{Controle da Execução}

O trecho foi executado segundo as premissas estabelecidas neste estudo. Foram respeitadas as espessuras definidas e a porcentagem de vazios ficou inferior a $6 \%$, conforme descrito no item 3.5.3. 
A porcentagem de vazios encontrada inferior a $6 \%$ reforça a definição do processo de execução, onde a eliminação da primeira etapa de conformação de material com o rolo liso não prejudicou o resultado do processo de compactação nem mesmo o acabamento final da superfície. A Figura 3.21 mostra o acabamento da superfície de EME.

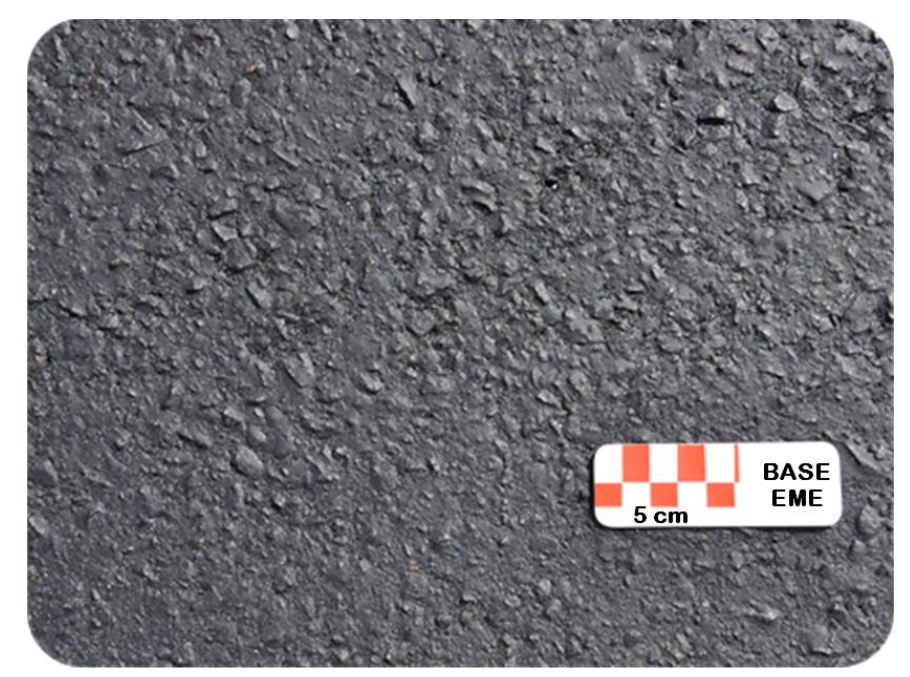

Figura 3.21 - Acabamento da superfície de EME

\subsubsection{Execução da Camada de Rolamento}

Após a conclusão de todas as seções experimentais, foi executada a camada de rolamento constituída de uma mistura asfáltica de granulometria descontínua modificada com polímero SBS, denominada gap-graded. Embora não apresente funções estruturais tão elevadas quanto a camada de EME, esta camada é fundamental para a composição da estrutura. A camada de EME por ser muito densa e com alto teor de ligante não resulta em uma superfície adequada ao tráfego. Para suprir esta deficiência funcional da camada de EME executou-se a camada de rolamento em gap-graded modificado com polímero SBS que, devido a sua macrotextura elevada, é responsável por uma boa aderência pneu-pavimento proporcionando segurança e conforto ao usuário.

Nas Seções de Referência SRf-01 e SRf-02 foi executada a mesma camada de rolamento gap-graded modificado com polímero SBS. 


\section{ESTUDOS PARAMÉTRICOS}

\subsection{ESTUDOS PARAMÉTRICOS ANTECEDENTES}

Os estudos paramétricos são ferramentas que possibilitam inferir rapidamente a resposta mecânica da estrutura de pavimento em análise e também predizer a influência das variáveis intervenientes nos modelos e seus graus de responsabilidades ante as demais.

A Tabela 4.1 sintetiza o histórico dos parâmetros investigados nos estudos paramétricos desenvolvidos por diversos autores e instituições. Destacam-se as pesquisas desenvolvidas pela Escola Politécnica da USP (SUZUKI, 1992; NAGAO, 2001 e VILLELA et al, 2009), instituição onde vários estudos foram elaborados, incluindo neste escopo também a iniciativa da Prefeitura de São Paulo (PMSP, 2002) que preconiza tais modelos em suas Instruções de Projeto.

No item 4.2, são apresentados os estudos paramétricos investigados por VILLELA et al (2009) de forma detalhada. Tais estudos foram elaborados especialmente para 0 desenvolvimento desta tese. 
Tabela 4.1 - Parâmetros investigados nos estudos paramétricos antecedentes

\begin{tabular}{|c|c|c|c|c|c|}
\hline \multirow{2}{*}{$\begin{array}{l}\text { Tipo de } \\
\text { estrutura de } \\
\text { pavimento }\end{array}$} & \multicolumn{2}{|c|}{$\begin{array}{l}\text { Parâmetros analisados } \\
\text { (variável dependente) }\end{array}$} & \multirow{2}{*}{$\begin{array}{c}\text { Parâmetros } \\
\text { intervenientes } \\
\text { (variável independente) }\end{array}$} & \multirow{2}{*}{ Instituição } & \multirow{2}{*}{ Fonte } \\
\hline & $\begin{array}{l}\text { Indicadores } \\
\text { estruturais }\end{array}$ & $\begin{array}{l}\text { Indicadores } \\
\text { de curvatura }\end{array}$ & & & \\
\hline \multirow{2}{*}{ Flexível } & $\varepsilon_{\mathrm{tCBUQ}}$ & - & $\begin{array}{c}\mathrm{h}_{\mathrm{CBUQ}} ; \mathrm{h}_{\mathrm{BGTC}} ; \mathrm{h}_{\mathrm{BGS}} ; \mathrm{MR}_{\text {subleito; }} ; \\
\mathrm{Q}_{\mathrm{ESRD}}\end{array}$ & PMSP & $\begin{array}{l}\text { PMSP } \\
(2002)\end{array}$ \\
\hline & $\mathrm{D}_{0}$ & $\begin{array}{l}\mathrm{R} ;(\mathrm{R} / \mathrm{DO}) ; \\
\quad(\mathrm{RxDO})\end{array}$ & $\begin{array}{c}\varepsilon_{\mathrm{t}} ; \varepsilon_{\mathrm{v}} ; \mathrm{MR}_{\text {subleito; }} \mathrm{SN} ; \mathrm{D}_{1200} ; \\
\left(\mathrm{D}_{0}-\mathrm{D}_{250}\right)\end{array}$ & USP & $\begin{array}{l}\text { NAGAO } \\
(2001)\end{array}$ \\
\hline \multirow{2}{*}{ Semi-rígido } & $\sigma_{\mathrm{tBGTC}} ; \mathrm{D}_{0}$ & - & $\begin{array}{c}\mathrm{h}_{\mathrm{CBUQ}} ; \mathrm{h}_{\mathrm{BGTC}} ; \mathrm{h}_{\mathrm{BGS}} ; \mathrm{MR}_{\mathrm{CBUQ}} ; \\
\mathrm{MR}_{\mathrm{BGTC}} ; \mathrm{MR}_{\text {subleito; }} \mathrm{Q}_{\mathrm{ESRD}}\end{array}$ & PMSP & $\begin{array}{l}\text { PMSP } \\
(2002)\end{array}$ \\
\hline & $\sigma_{\mathrm{tBGTC}}$ & - & $\begin{array}{l}\mathrm{h}_{\mathrm{CBUQ}} ; \mathrm{h}_{\mathrm{BGTC}} ; \mathrm{h}_{\mathrm{BGS}} ; \mathrm{MR}_{\mathrm{CBUQ}} ; \\
\mathrm{MR}_{\mathrm{BGTC}} ; \mathrm{MR}_{\mathrm{BGS}} ; \mathrm{MR}_{\text {subleito }}\end{array}$ & USP & $\begin{array}{l}\text { SUZUKI } \\
(2001)\end{array}$ \\
\hline \multirow{2}{*}{ Invertido } & $\varepsilon_{\mathrm{tCBUQ}} ; \sigma_{\mathrm{tBGTC}}$ & - & $\begin{array}{c}\mathrm{h}_{\mathrm{CBUQ}} ; \mathrm{h}_{\mathrm{BGTC}} ; \mathrm{h}_{\mathrm{BGS}} ; \mathrm{MR}_{\mathrm{CBUQ}} ; \\
\mathrm{MR}_{\mathrm{BGTC}} ; \mathrm{MR}_{\text {subleito }}\end{array}$ & PMSP & $\begin{array}{l}\text { PMSP } \\
(2002)\end{array}$ \\
\hline & $\begin{array}{c}\mathrm{D}_{0} ; \varepsilon_{\mathrm{tCBUQ}} ; \sigma_{\mathrm{tBGTC}} ; \\
\varepsilon_{\text {vsubleito }}\end{array}$ & - & $\begin{array}{c}\mathrm{h}_{\mathrm{CBUQ}} ; \mathrm{h}_{\mathrm{BGS}} ; \mathrm{h}_{\mathrm{BGTC}} ; \mathrm{MR}_{\mathrm{CBUQ}} ; \\
\mathrm{MR}_{\mathrm{BGS}} ; \mathrm{MR}_{\mathrm{BGTC}} ; \mathrm{MR}_{\text {subleito }}\end{array}$ & USP & $\begin{array}{l}\text { SUZUKI } \\
(2001)\end{array}$ \\
\hline PPT & $\begin{array}{c}\mathrm{D}_{0} ; \mathrm{D}_{300} ; \mathrm{D}_{600} ; \\
\mathrm{D}_{900} ; \sigma_{\text {vsubleito; }} \\
\varepsilon_{\mathrm{tSMA}} ; \varepsilon_{\mathrm{tPPT}} ; \varepsilon_{\mathrm{tCAmodif}}\end{array}$ & - & $\begin{array}{l}\mathrm{h}_{\mathrm{SMA}} ; \mathrm{h}_{\mathrm{PPT}} ; \mathrm{h}_{\text {CAmodif; }} ; \mathrm{MR}_{\mathrm{SMA}} ; \\
\mathrm{MR}_{\mathrm{PPT}} ; \mathrm{MR}_{\text {CAmodif }} ; \mathrm{MR}_{\text {subleito }}\end{array}$ & USP & $\begin{array}{l}\text { RODOLFO } \\
\text { e BALBO } \\
\text { (2004) }\end{array}$ \\
\hline EME & $\begin{array}{c}\mathrm{D}_{0} ; \varepsilon_{\mathrm{tEME}} ; \sigma_{\mathrm{tEME}} ; \\
\varepsilon_{\mathrm{vREM}}\end{array}$ & $\begin{array}{c}\mathrm{S} ; \mathrm{R} ; \\
\left(\mathrm{Rx} \mathrm{D}_{0}\right) ; \mathrm{SCI}\end{array}$ & $\begin{array}{c}\mathrm{h}_{\mathrm{REV}} ; \mathrm{h}_{\text {EME }} ; \mathrm{MR}_{\mathrm{REV}} ; \mathrm{MR}_{\mathrm{EME}} ; \\
\mathrm{MR}_{\mathrm{REM}} ; \mathrm{Q}\end{array}$ & USP & $\begin{array}{l}\text { VILLELA et } \\
\text { al (2009) }\end{array}$ \\
\hline
\end{tabular}

Notas:

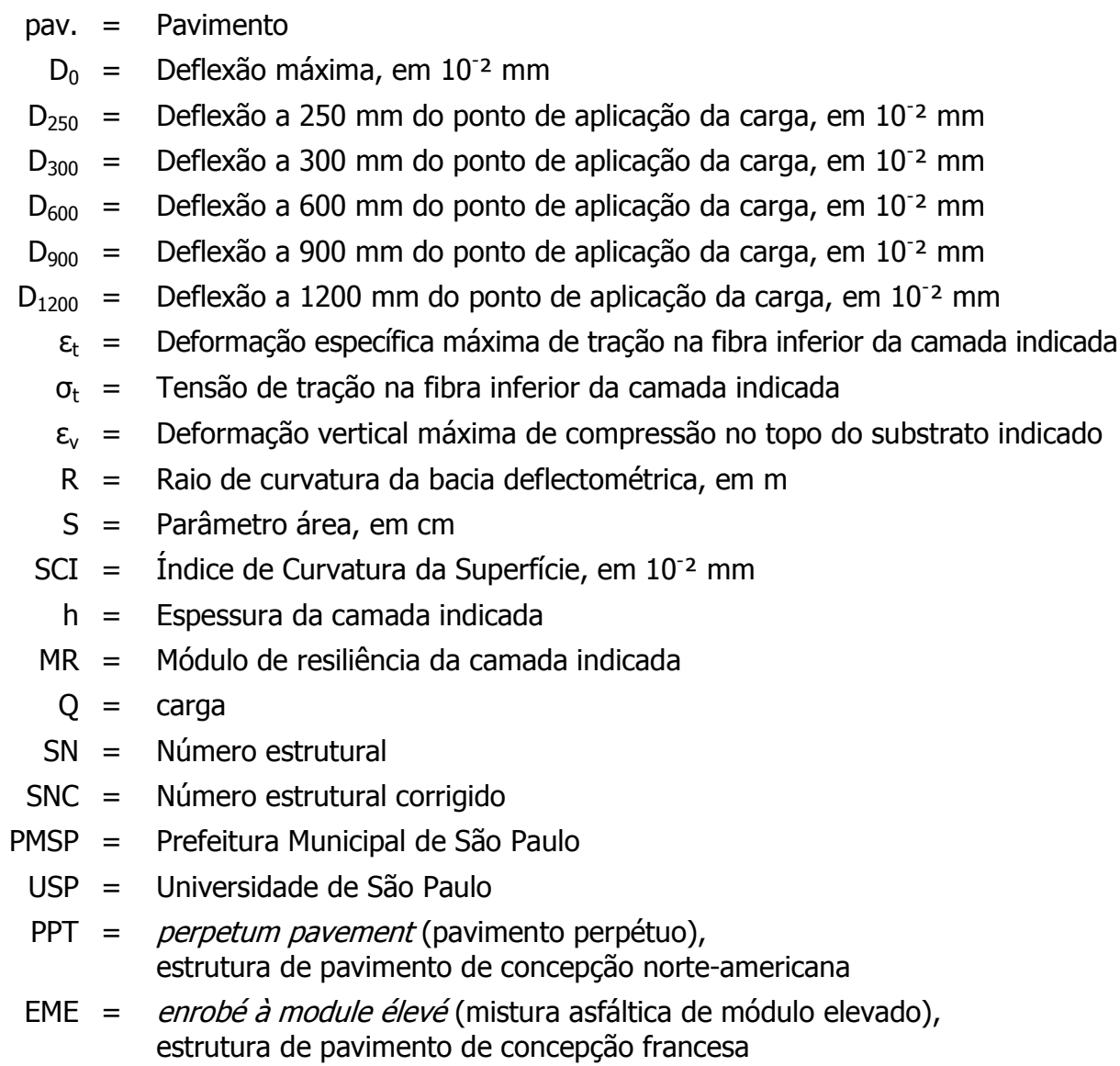




\subsection{ESTUdOS PARAMÉTRICOS PARA ESTRUTURAS DE PAVIMENTO RESTAURADAS COM CAMADA DE BASE EM EME}

\subsubsection{Dimensionamento de Estruturas de Restauração de Pavimentos}

Os pavimentos flexíveis são estruturas multicamadas com a finalidade de suportar esforços de uma combinação entre a ação das cargas do tráfego e os efeitos do clima com variações de temperatura e umidade ao longo do tempo (YODER e WITCZAC, 1975; HASS e HUDSON, 1978; MEDINA e MOTTA, 2005). Os principais defeitos que ocorrem em pavimentos asfálticos se refletem no revestimento asfáltico e permitem identificar dois modos distintos de solicitação mecânica nesta camada, que são os mais importantes até o momento ${ }^{13}$ a serem considerados: [i] flexão, proveniente das ações repetidas do carregamento, responsável pela fadiga da camada asfáltica; e [ii] compressão simples, que conduz ao acúmulo de deformações permanentes para a formação de trilha de roda.

Para a elaboração do dimensionamento de uma estrutura de pavimento asfáltico, de modo geral, deve-se compreender como ela atinge sua condição de ruína. Tal análise tem como princípio a adoção de cálculos das tensões e deformações, por meio da Teoria da Elasticidade, usando programas computacionais para facilidade e rapidez de cálculos, a partir da representação numérica de um sistema de camadas elásticas de espessuras finitas assentes sobre o subleito, semi-espaço infinito isotrópico, com seus respectivos valores de módulo de resiliência (MR) e coeficiente de Poisson $(\mu)$.

Quanto às respostas de solicitações mecânicas envolvidas nas estruturas, cada tipo de camada se comporta de maneira diferenciada em função de seus materiais constituintes (HUANG, 2004):

\footnotetext{
${ }^{13}$ Salienta-se que outros tipos de esforços podem também causar defeitos ao pavimento, como: cisalhamento, podendo ocasionar quebra dos agregados da mistura asfáltica; esforços tangenciais, proporcionando tensões horizontais e esforços de frenagem dos veículos.
} 
- para subleitos são calculadas as deformações verticais $\left(\varepsilon_{\mathrm{v}}\right)$ na sua superfície;

- para camadas asfálticas são avaliadas as tensões de tração $\left(\sigma_{t}\right)$ e deformações de tração na sua fibra inferior $\left(\varepsilon_{t}\right)$ e os deslocamentos plásticos que levam a deformações permanentes;

- para camadas estabilizadas quimicamente com aglomerantes hidráulicos, limitam-se as tensões de tração na sua fibra inferior $\left(\sigma_{t}\right)$.

Utilizar um critério de ruína, a partir de modelos consagrados, não significa simplesmente comparar determinados esforços atuantes com os valores admissíveis para determinado tráfego, mas compreender para qual nível de ruína cada modelo foi concebido e estabelecer a partir de que intensidade de defeito a estrutura atingirá seu término de vida de serviço.

\subsubsection{Descrição das Etapas para o Desenvolvimento do Estudo Paramétrico}

A análise e verificação do comportamento estrutural e deflectométrico do pavimento partiu do estudo paramétrico conjugado de um fatorial envolvendo simulações de estruturas compostas de camada de base em mistura asfáltica de módulo elevado $(E M E)$, assentes a um substrato remanescente (que, portanto, se deteriorou em decorrência das ações do tráfego ao longo de sua vida de serviço). O revestimento destas estruturas é constituído por uma camada de rolamento de mistura asfáltica delgada com atribuição principalmente funcional.

A Figura 4.1 apresenta de forma esquemática as três Etapas demonstrando como o Estudo Paramétrico foi desenvolvido. 


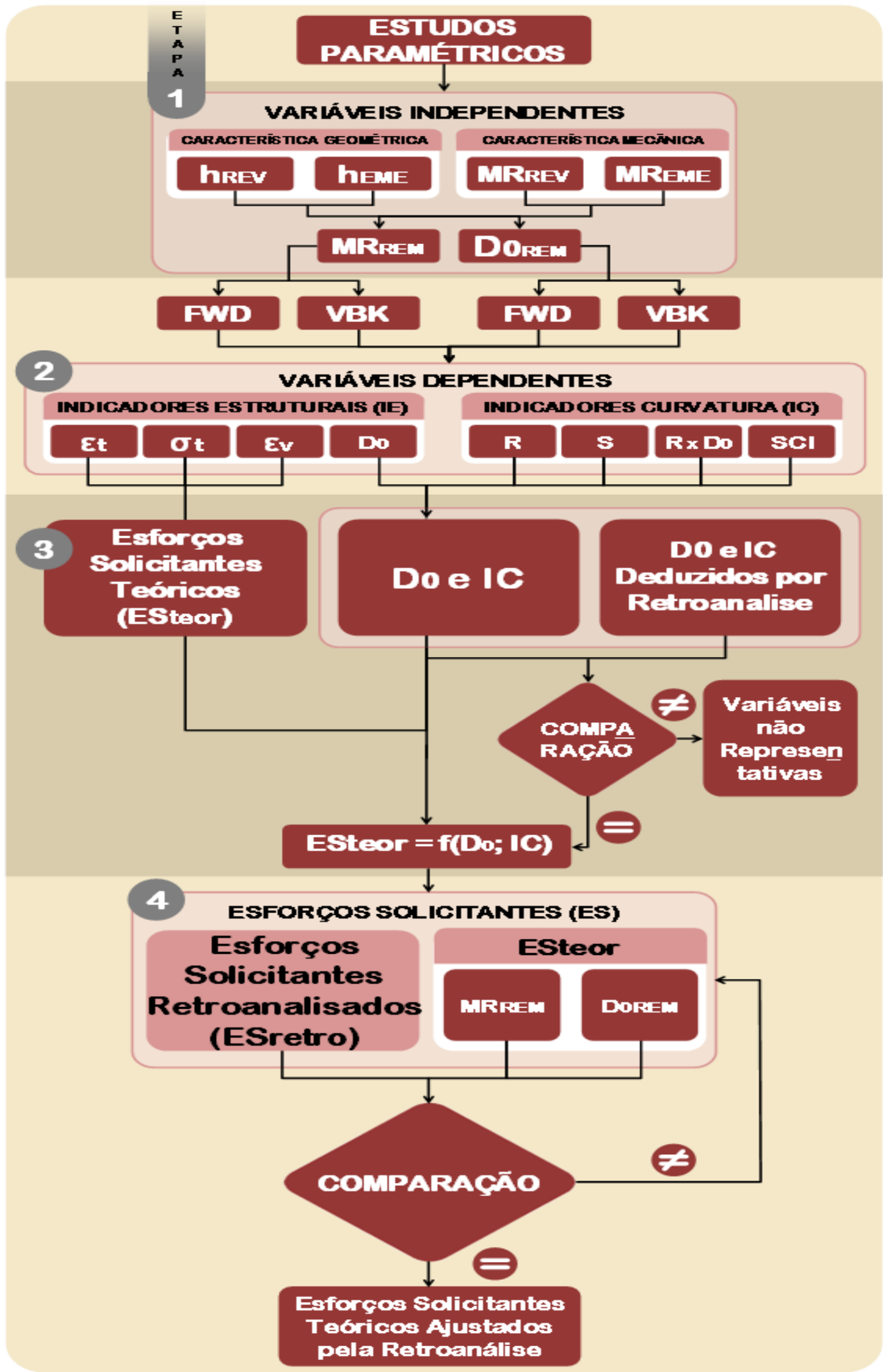

Figura 4.1 Fluxograma de representação dos Estudos Paramétricos 


\section{- Primeira Etapa: Variáveis Independentes}

Nesta primeira etapa, foram definidas as variáveis independentes para a estruturação do plano fatorial.

Para o Estudo Paramétrico, as variáveis independentes foram distribuídas em duas características da estrutura tipo proposta: [i] característica geométrica, onde foram variadas as espessuras das camadas restauradas (de base e de rolamento); e, [ii] característica mecânica, que apresenta os diversos valores de módulo de resiliência para as camadas restauradas e também para a estrutura remanescente.

Como na utilização prática dos estudos paramétricos o módulo de resiliência da estrutura remanescente deverá ser determinado por retroanálise, entendeu ser coerente estudar outros modelos paramétricos contendo como variável independente a deflexão máxima do topo da estrutura remanescente ( $\left.D_{\text {OREM }}\right)$.

A Figura 4.2 ilustra a estrutura tipo proposta com os valores estabelecidos para as características geométrica e mecânica que compuseram o plano fatorial do estudo.

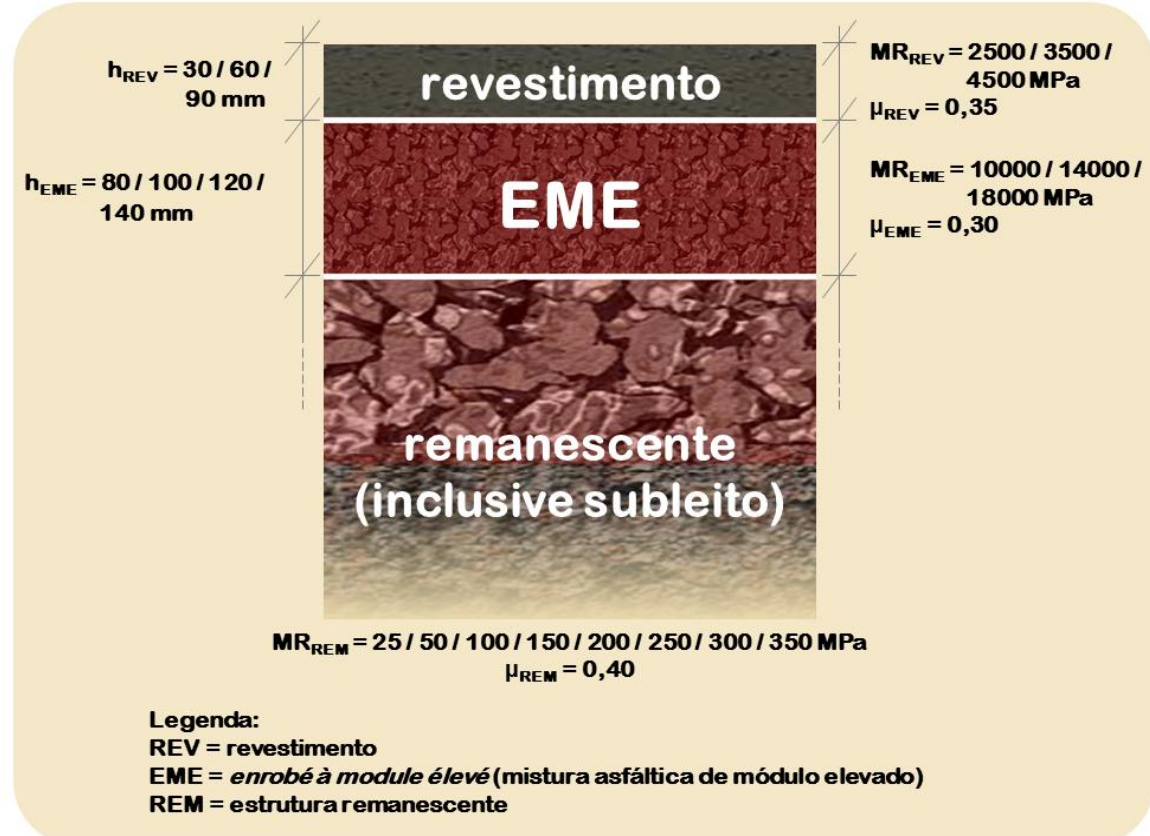

Figura 4.2 - Pavimento tipo com camadas de revestimento e EME como restauração 
Cabe salientar que tais valores para as características geométrica e mecânica da estrutura tipo, indicados na Figura 4.2, serviram tão somente para a concepção da modelagem, não sendo, necessariamente valores considerados no dimensionamento das estruturas do Trecho Experimental.

Para a identificação do comportamento estrutural do pavimento, frente às diversas simulações de carregamento, foi utilizado o programa computacional de camadas elásticas lineares ELSYM-5, na versão FHWA (KOPPERMAN et al, 1986). O programa ELSYM-5 permite determinar as deflexões (deslocamentos recuperáveis), tensões e deformações, em qualquer ponto da estrutura, sob ação de várias cargas.

Nesta análise, as simulações de carregamento foram deduzidas a partir de dois equipamentos utilizados para finalidade de investigação estrutural do pavimento: Falling Weight Deflectometer (FWD) e viga Benkelman (VBK). Em ambos os casos, as simulações foram desenvolvidas tanto para o eixo padrão brasileiro $(82 \mathrm{kN})$, quanto para o eixo padrão francês ( $130 \mathrm{kN}$ ), pelo fato de ser o País de origem desta solução de mistura asfáltica de módulo elevado (EME).

Na simulação com o equipamento FWD, as duas cargas utilizadas para análise do efeito do eixo padrão brasileiro e francês foram equivalentes a 41 kN e 65 kN, respectivamente. As disposições geométricas destes esforços verticais obedeceram às coordenadas, em mm, apresentadas na Figura 4.3. 

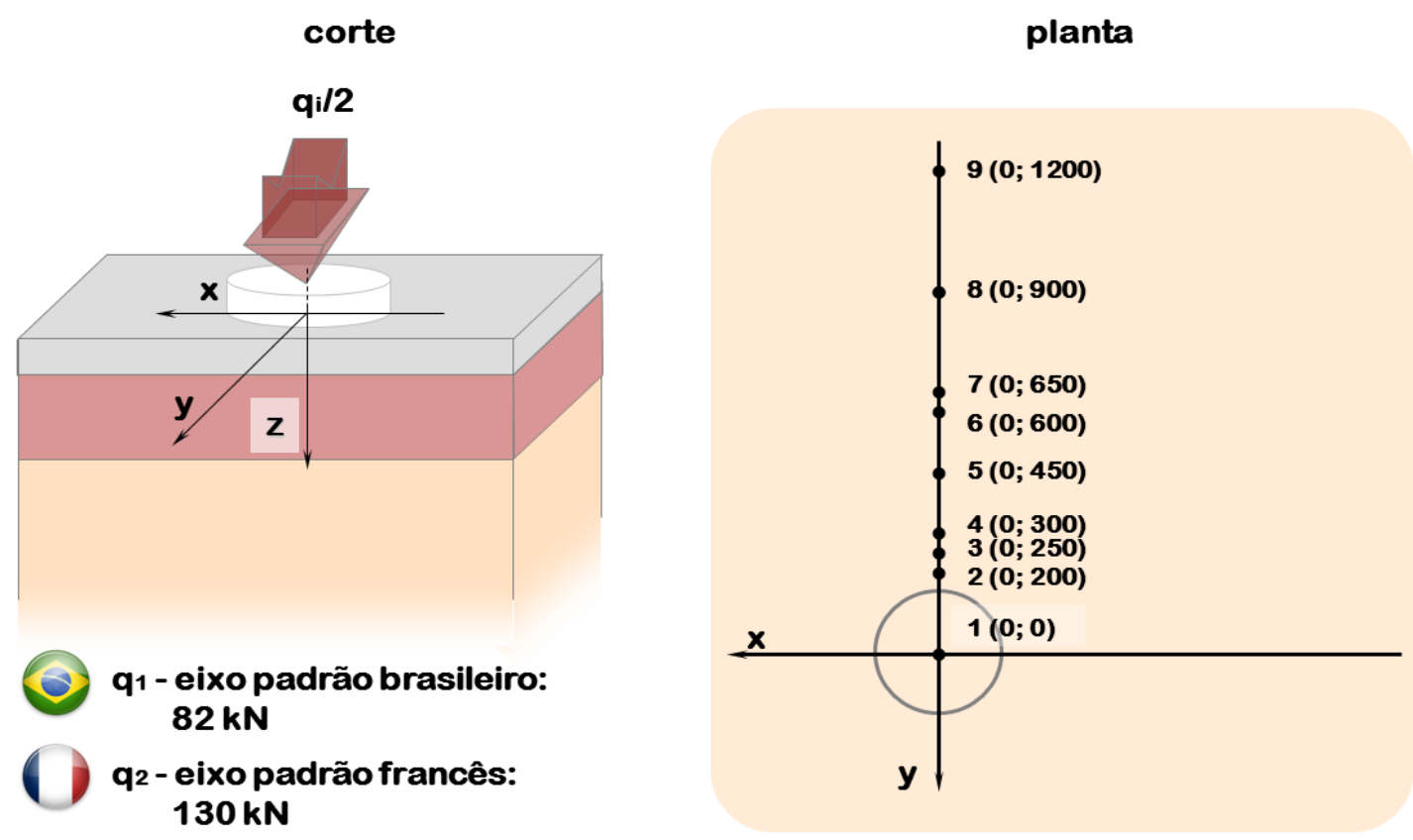

Figura 4.3 - Desenho esquemático da distribuição do carregamento para simulação com FWD

Para a VBK, no eixo simples de roda dupla ESRD simulado, foram utilizadas duas cargas por roda dupla, espaçadas de $340 \mathrm{~mm}$, sendo o número de cargas aplicadas caracterizada por quatro esforços verticais de $20,5 \mathrm{kN}$ (ou de $32,5 \mathrm{kN}$, conforme o caso do eixo padrão adotado) dispostos geometricamente a partir das coordenadas, em mm: $(0 ; 0),(340 ; 0),(1810 ; 0)$ e $(2150 ; 0)$. A Figura 4.4 representa tais informações.

Os demais parâmetros considerados para o plano fatorial de modelagem estão apresentados na Tabela 4.2. Tal plano fatorial resultou em 3456 interações das variáveis independentes. 

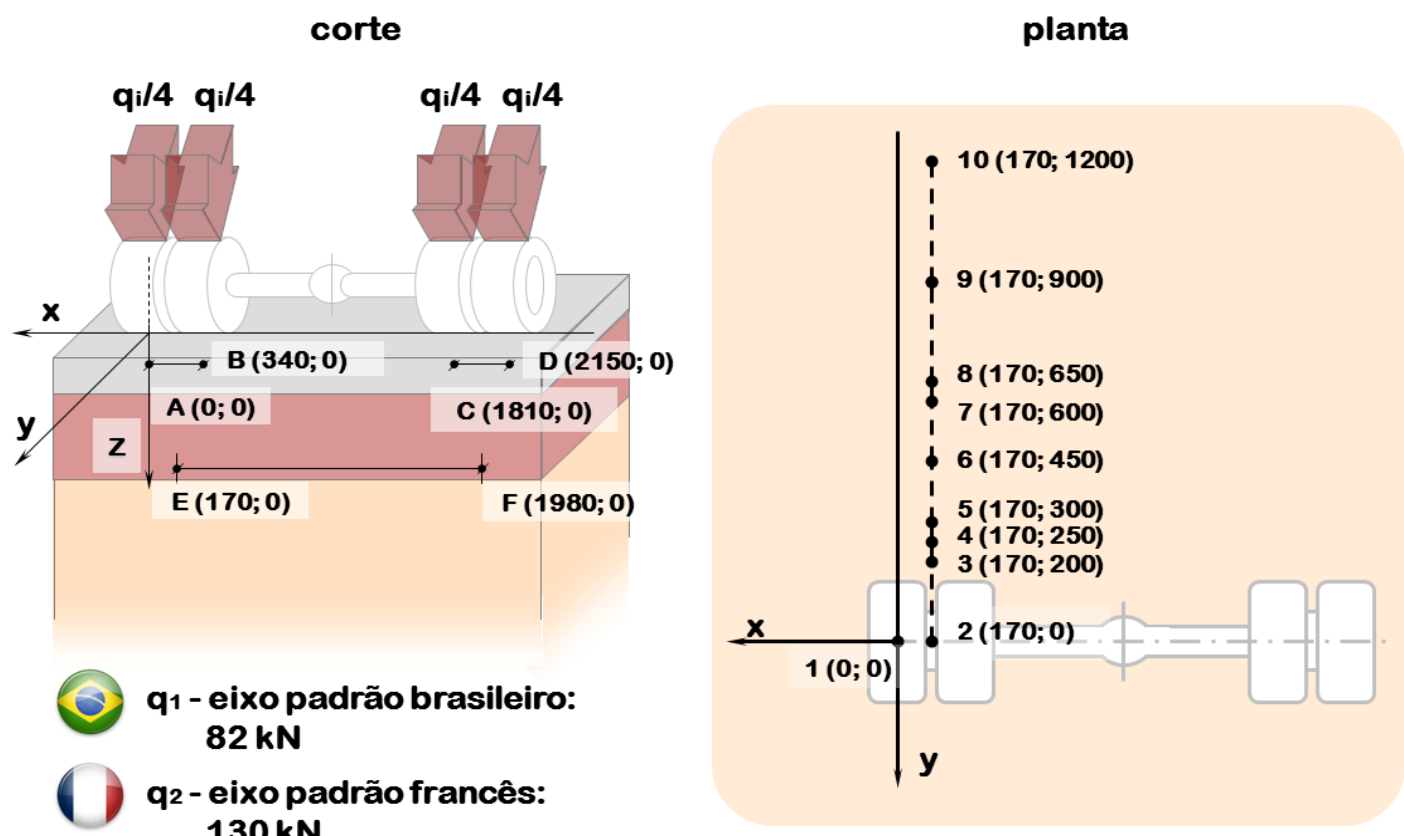

Figura 4.4 - Desenho esquemático da distribuição do carregamento para simulação com VBK 
Tabela 4.2 - Parâmetros considerados para o plano fatorial de modelagem Simulação de Estrutura

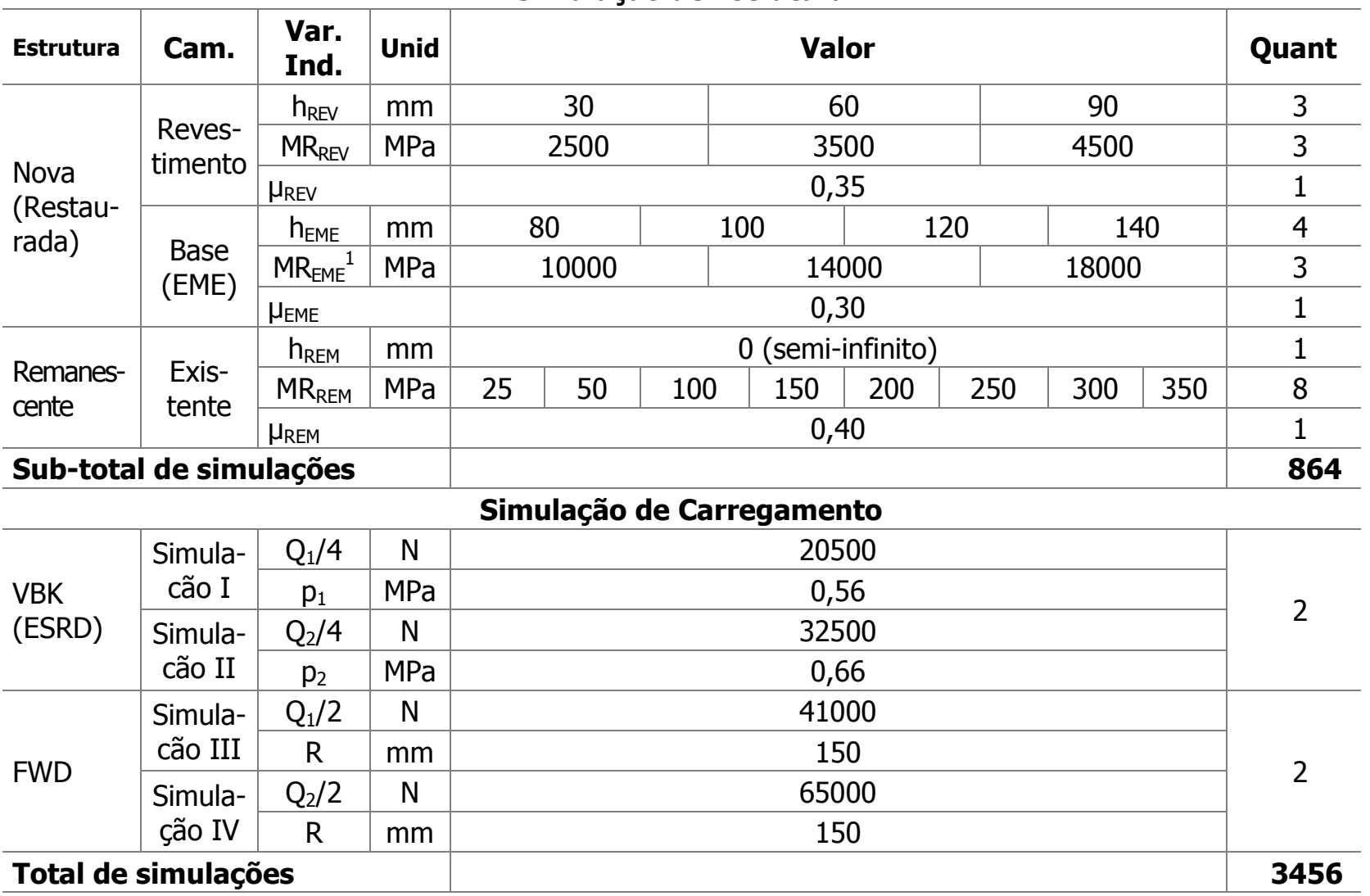

Legenda:

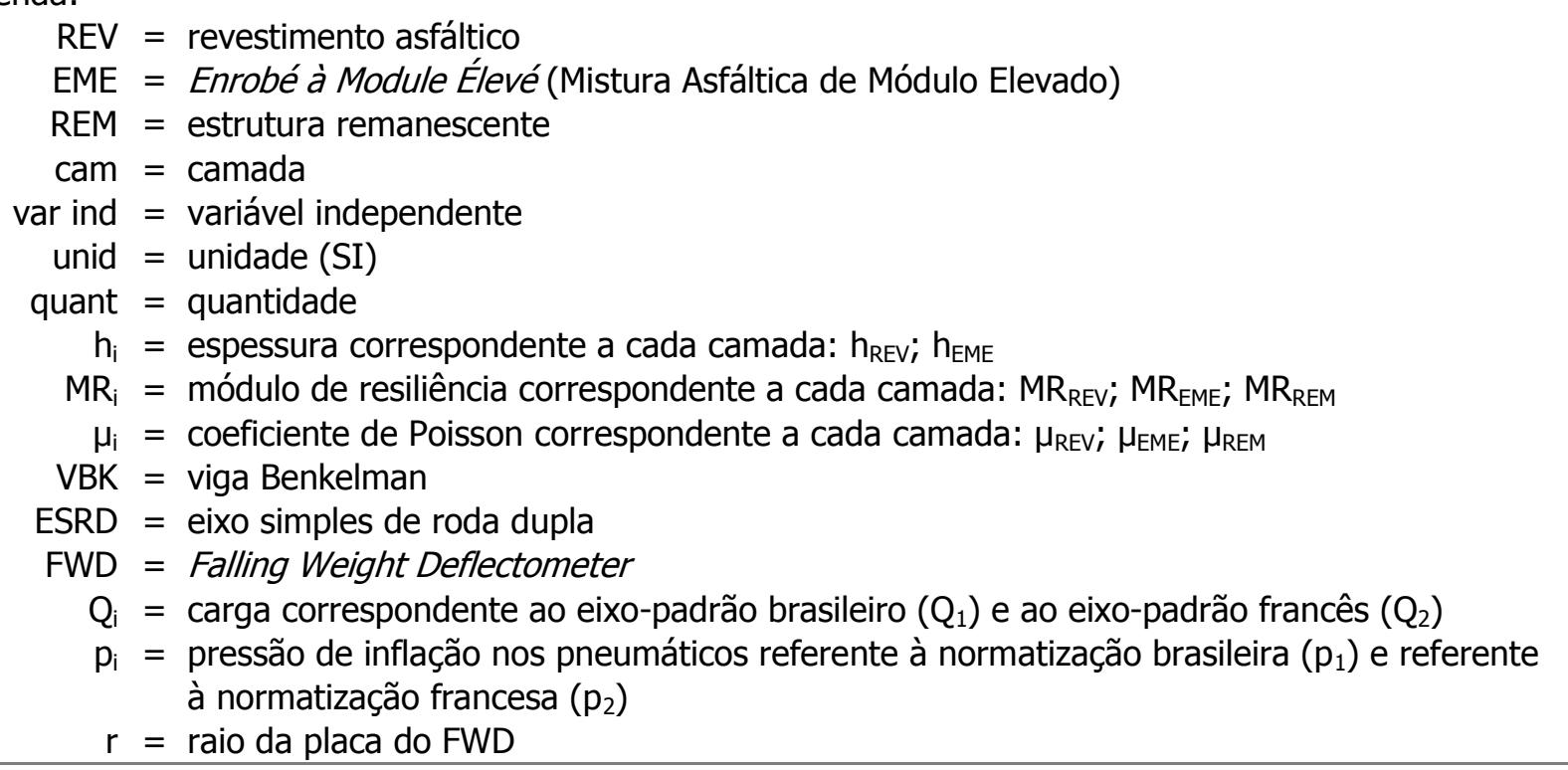
Nota:

1 O intervalo de valores de módulo de resiliência para a mistura asfáltica de módulo elevado (EME) compreende os encontrados por ROHDE (2007) e Magalhães (2004). Estes autores determinaram os módulos de resiliência para as misturas asfálticas de módulo elevado (EME) por meio de ensaio de compressão diametral a temperatura de $25^{\circ} \mathrm{C} \mathrm{e}$ freqüência de $1 \mathrm{~Hz}$, conforme preconizado pela norma ASTM D 7369-09 (ASTM, 2009) antiga NCHRP Project 1-28A (NCHRP, 2004). 


\section{- Segunda Etapa: Variáveis Dependentes}

O presente trabalho procurou estabelecer, como variáveis dependentes, apenas as respostas dos valores máximos dos Indicadores Estruturais (IE) correspondentes à fadiga da estrutura. A seguir, são relacionados os IE em seus respectivos pontos críticos de interesse:

- Deflexão máxima $\left(D_{0}\right)$, na superfície do pavimento;

- Deformação específica máxima de tração $\left(\varepsilon_{\mathrm{t}}\right)$, na fibra inferior da camada de EME para avaliação da fadiga;

- Tensão específica máxima de tração $\left(\sigma_{t}\right)$, na fibra inferior da camada de EME;

- Deformação vertical máxima de compressão $\left(\varepsilon_{\mathrm{v}}\right)$, no topo da camada remanescente.

Não estão sendo levados em conta, como parâmetros de dano, os acúmulos de deformações permanentes para a formação de trilha de roda nas camadas asfálticas, uma vez que os valores indicados no ensaio com o simulador de tráfego apresentaram-se muito inferiores ao preconizado na especificação francesa.

Considerando que o valor da deflexão máxima $\left(D_{0}\right)$ pode não ser suficiente para a avaliação estrutural do pavimento, quando analisado isoladamente, procurou-se utilizar indicadores complementares a partir das características da linha de deformação elástica da estrutura, quando submetida à ação de um carregamento. Assim sendo, além da magnitude das deflexões máximas, os seguintes Indicadores de Curvatura (IC) foram adotados como variáveis dependentes no estudo:

- Raio de Curvatura "R" (DNER,1979);

- Parâmetro Área "S" (AASHTO, 1993);

- produto entre o Raio e a Deflexão Máxima "R x D0"; 
- Índice de Curvatura da Superfície "SCI" (WSDOT, 1995; KIM et al, 2000).

Para o cálculo do Raio de Curvatura "R", no Brasil, é adotada a forma parabólica de representação da curvatura da bacia. Tal processo é preconizado pela norma DNERME 24/94 (DNER,1994a). A expressão matemática para o cálculo de "R" é apresentada a seguir:

$$
R=\frac{x^{2}}{20\left(D_{0}-D_{x}\right)}
$$

Na equação 4.1,

R é o Raio de Curvatura, $(m)$;

$\mathrm{x}$ é a distância radial do ponto de aplicação da carga, $(\mathrm{mm})$;

$\mathrm{D}_{0}$ é a deflexão no ponto de aplicação da carga, $\left(10^{-2} \mathrm{~mm}\right)$;

$D_{x} \quad$ é a deflexão à distância radial correspondente $\mathrm{a} \times(\mathrm{mm})$ do ponto de aplicação da carga. No Brasil, adota-se a distância radial a $250 \mathrm{~mm}$ do ponto de aplicação da carga, $\left(10^{-2} \mathrm{~mm}\right)$.

O Parâmetro Área "S" da bacia de deformação foi calculado a partir da expressão apresentada a seguir, segundo recomendações da AASHTO (1993):

$$
S=15\left[1+2\left(\frac{D_{300}}{D_{0}}\right)+2\left(\frac{D_{600}}{D_{0}}\right)+\left(\frac{D_{900}}{D_{0}}\right)\right]
$$

Na equação 4.2,

$\mathrm{S}$ é o Parâmetro Área, $(\mathrm{cm})$;

$D_{0}, D_{300}, D_{600}$ e $D_{900} \quad$ são as deflexões às distâncias radial correspondente a 0 , 300, 600 e $900 \mathrm{~mm}$, respectivamente, do ponto de aplicação da carga, $\left(10^{-2} \mathrm{~mm}\right)$.

O Índice de Curvatura da Superfície "SCI" (WSDOT, 1995; KIM et al, 2000) é representado pela diferença entre os valores de deflexão máxima $\left(D_{0}\right)$ e os valores 
de deflexão a $300 \mathrm{~mm}$ do ponto de aplicação da carga $\left(\mathrm{D}_{300}\right)$. O SCI, portanto, é representa pela equação a seguir:

$$
S C I=D_{0}-D_{300}
$$

Na equação 4.3,

SCI é o Índice de Curvatura da Superfície, $\left(10^{-2} \mathrm{~mm}\right)$;

$D_{0}, D_{300}$ são as deflexões às distâncias radial correspondente a 0 e $300 \mathrm{~mm}$, respectivamente, do ponto de aplicação da carga, $\left(10^{-2} \mathrm{~mm}\right)$.

Os resultados foram processados obtendo as equações de correlação entre os Indicadores Estruturais e os Indicadores de Curvatura da bacia de deformação. As Tabelas 4.3 e 4.4 apresentam resumidamente os coeficientes (Coef) dos modelos de regressão e parâmetros estatísticos de análise para os Indicadores Estruturais; tanto para VBK, quanto para FWD; respectivamente.

As Tabelas 4.5 e 4.6 apresentam resumidamente os coeficientes (Coef) dos modelos de regressão e parâmetros estatísticos de análise para os Indicadores de Curvatura; tanto para VBK, quanto para FWD; respectivamente.

Conforme o modelo genérico (4.4) apresentado a seguir, as equações empregadas foram funções potenciais:

VariávelDependente $=k \times\left(h_{\mathrm{REV}}{ }^{a} \times M R_{\mathrm{REV}}{ }^{b}\right) \times\left(h_{E M E}{ }^{c} \times M R_{E M E}{ }^{d}\right) \times M R_{R E M}{ }^{e} \times Q^{f}$ 
Tabela 4.3 - Coeficientes e parâmetros de análises para indicadores estruturais da VBK

\begin{tabular}{|c|c|c|c|c|c|c|c|c|c|c|}
\hline \multirow{3}{*}{ Coeficiente } & \multirow{2}{*}{\multicolumn{2}{|c|}{ Parâmetro }} & \multirow{2}{*}{\multicolumn{2}{|c|}{$D_{0}$}} & \multirow{2}{*}{\multicolumn{2}{|c|}{$\varepsilon_{\mathrm{tEME}}$}} & \multirow{2}{*}{\multicolumn{2}{|c|}{$\sigma_{\text {tEME }}$}} & \multirow{2}{*}{\multicolumn{2}{|c|}{$\varepsilon_{\text {vREM }}$}} \\
\hline & & & & & & & & & & \\
\hline & & & Coef & valor-P & Coef & valor-P & Coef & valor-P & Coef & valor-P \\
\hline \multicolumn{3}{|l|}{$\mathrm{k}$} & 7,881 & - & 0,003 & 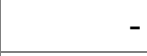 & 0,008 & - & 0,015 & 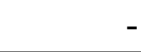 \\
\hline \multicolumn{3}{|l|}{ Inters } & 0,897 & 0,000 & $-2,475$ & 0,000 & $-2,116$ & 0,000 & $-1,810$ & 0,000 \\
\hline \multirow{2}{*}{$\begin{array}{l}\text { revesti- } \\
\text { mento }\end{array}$} & $h_{\text {REV }}$ & $a$ & $-0,157$ & 0,000 & $-0,309$ & 0,000 & $-0,318$ & 0,000 & $-0,331$ & 0,000 \\
\hline & $M R_{R E V}$ & $b$ & $-0,075$ & 0,000 & $-0,127$ & 0,000 & $-0,126$ & 0,000 & $-0,159$ & 0,000 \\
\hline \multirow{2}{*}{ base } & $h_{E M E}$ & C & $-0,477$ & 0,000 & $-0,850$ & 0,000 & $-0,875$ & 0,000 & $-1,021$ & 0,000 \\
\hline & $M R_{E M E}$ & d & $-0,132$ & 0,000 & $-0,560$ & 0,000 & 0,449 & 0,000 & $-0,409$ & 0,000 \\
\hline $\begin{array}{l}\text { remanes- } \\
\text { cente }\end{array}$ & $M R_{R E M}$ & e & $-0,785$ & 0,000 & $-0,290$ & 0,000 & $-0,295$ & 0,000 & $-0,415$ & 0,000 \\
\hline carga & C & f & 996 & 0,000 & 0,931 & 0,000 & 0,880 & 0,000 & 0,922 & 0,000 \\
\hline \multicolumn{3}{|l|}{$R^{2}$} & \multicolumn{2}{|r|}{0,999} & \multicolumn{2}{|r|}{0,990} & \multicolumn{2}{|r|}{0,988} & \multicolumn{2}{|r|}{0,992} \\
\hline \multicolumn{3}{|l|}{ Fischer (F) } & \multicolumn{2}{|r|}{375,420} & \multicolumn{2}{|r|}{29,309} & \multicolumn{2}{|r|}{24,593} & \multicolumn{2}{|r|}{37,915} \\
\hline
\end{tabular}

Tabela 4.4 - Coeficientes e parâmetros de análises para indicadores de curvatura da VBK

\begin{tabular}{|c|c|c|c|c|c|c|c|c|c|c|}
\hline \multirow{2}{*}{ Coeficiente } & \multicolumn{2}{|c|}{ Parâmetro } & \multicolumn{2}{|c|}{$\mathbf{s}$} & \multicolumn{2}{|c|}{$\mathbf{R}$} & \multicolumn{2}{|c|}{$\mathbf{R} \times \mathbf{D}_{\mathbf{0}}$} & \multicolumn{2}{|c|}{$S C I=D_{0}-D_{300}$} \\
\hline & $x^{2}+2+1$ & & Coef & valor-P & Coef & valor-P & Coef & valor-P & Coef & valor-P \\
\hline $\mathrm{k}$ & & & 10,563 & - & 1,268 & - & 9,996 & - & 2259,3 & - \\
\hline Inters & & & 1,024 & 0,000 & 0,103 & 0,000 & 1,000 & 0,000 & 3,354 & 0,000 \\
\hline \multirow{2}{*}{$\begin{array}{l}\text { revesti- } \\
\text { mento }\end{array}$} & $\mathrm{h}_{\mathrm{REV}}$ & $\mathrm{a}$ & 0,076 & 0,000 & 0,486 & 0,000 & 0,329 & 0,000 & $-0,472$ & 0,000 \\
\hline & $M R_{R E V}$ & b & 0,034 & 0,000 & 0,219 & 0,000 & 0,144 & 0,000 & $-0,216$ & 0,000 \\
\hline \multirow{2}{*}{ base } & $\mathrm{h}_{\mathrm{EME}}$ & C & 0,230 & 0,000 & 1,521 & 0,000 & 1,044 & 0,000 & $-1,464$ & 0,000 \\
\hline & $M R_{E M E}$ & d & 0,068 & 0,000 & 0,481 & 0,000 & 0,349 & 0,000 & $-0,454$ & 0,000 \\
\hline $\begin{array}{l}\text { remanes- } \\
\text { cente }\end{array}$ & $M R_{R E M}$ & e & $-0,099$ & 0,000 & 0,229 & 0,000 & $-0,557$ & 0,000 & $-0,272$ & 0,000 \\
\hline carga & $\mathrm{Q}$ & $f$ & 0,003 & 0,107 & $-0,989$ & 0,000 & 0,007 & 0,545 & 0,987 & 0,000 \\
\hline \multicolumn{3}{|l|}{$\mathrm{R}^{2}$} & \multicolumn{2}{|r|}{0,980} & \multicolumn{2}{|r|}{0,951} & \multicolumn{2}{|r|}{0,967} & \multicolumn{2}{|r|}{0,964} \\
\hline \multicolumn{3}{|l|}{ Fischer (F) } & \multicolumn{2}{|r|}{14,193} & \multicolumn{2}{|r|}{5,579} & \multicolumn{2}{|r|}{8,433} & & 7,600 \\
\hline
\end{tabular}


Tabela 4.5 - Coeficientes e parâmetros de análises para indicadores estruturais do FWD

\begin{tabular}{|c|c|c|c|c|c|c|c|c|c|c|}
\hline \multirow{2}{*}{ Coeficiente } & \multicolumn{2}{|c|}{ Parâmetro } & \multicolumn{2}{|c|}{$D_{0}$} & \multicolumn{2}{|c|}{$\varepsilon_{\mathrm{tEME}}$} & \multicolumn{2}{|c|}{$\sigma_{\text {tEME }}$} & \multicolumn{2}{|c|}{$\varepsilon_{\text {vREM }}$} \\
\hline & & & Coef & valor-P & Coef & valor-P & Coef & valor-P & Coef & valor-P \\
\hline k & & & 0,005 & - & $1,5 \mathrm{E}-06$ & - & $3,5 \mathrm{E}-06$ & - & $1,7 \mathrm{E}-05$ & - \\
\hline Inters & & & $-2,316$ & 0,000 & $-5,832$ & 0,000 & $-5,457$ & 0,000 & $-4,770$ & 0,000 \\
\hline \multirow{2}{*}{$\begin{array}{l}\text { revesti- } \\
\text { mento }\end{array}$} & $\mathrm{h}_{\mathrm{REV}}$ & $a$ & $-0,187$ & 0,000 & $-0,332$ & 0,000 & $-0,329$ & 0,000 & $-0,355$ & 0,000 \\
\hline & $\mathrm{MR}_{\mathrm{REV}}$ & $b$ & $-0,125$ & 0,000 & $-0,140$ & 0,000 & $-0,138$ & 0,000 & $-0,174$ & 0,000 \\
\hline \multirow{2}{*}{ base } & $h_{E M E}$ & C & $-0,629$ & 0,000 & $-0,945$ & 0,000 & $-0,932$ & 0,000 & $-1,113$ & 0,000 \\
\hline & $M R_{E M E}$ & d & $-0,186$ & 0,000 & $-0,589$ & 0,000 & 0,428 & 0,000 & $-0,451$ & 0,000 \\
\hline $\begin{array}{l}\text { remanes- } \\
\text { cente }\end{array}$ & $\mathrm{MR}_{\mathrm{REM}}$ & e & $-0,530$ & 0,000 & $-0,107$ & 0,000 & $-0,132$ & 0,000 & $-0,225$ & 0,000 \\
\hline carga & $\mathrm{Q}$ & $f$ & 1,668 & 0,000 & 1,614 & 0,000 & 1,553 & 0,000 & 1,542 & 0,000 \\
\hline \multicolumn{3}{|l|}{$\mathrm{R}^{2}$} & & 0,922 & & 0,895 & & 0,905 & & 0,920 \\
\hline \multicolumn{3}{|l|}{ Fischer (F) } & & 3,392 & & 2,434 & & 2,733 & & 3,282 \\
\hline
\end{tabular}

Tabela 4.6 - Coeficientes e parâmetros de análises para indicadores de curvatura do FWD

\begin{tabular}{|c|c|c|c|c|c|c|c|c|c|c|}
\hline \multirow{2}{*}{ Coeficiente } & \multicolumn{2}{|c|}{ Parâmetro } & \multicolumn{2}{|c|}{$\mathbf{S}$} & \multicolumn{2}{|c|}{$\mathbf{R}$} & \multicolumn{2}{|c|}{$\mathbf{R} \times \mathbf{D}_{\mathbf{0}}$} & \multicolumn{2}{|c|}{$S C I=D_{0}-D_{300}$} \\
\hline & & & Coef & valor-P & Coef & valor-P & Coef & valor-P & Coef & valor-P \\
\hline k & & & 4,745 & - & 5000 & - & 24,165 & - & 0,793 & . \\
\hline Inters & & & 0,676 & 0,000 & 3,699 & 0,000 & 1,383 & 0,000 & $-0,100$ & 0,439 \\
\hline \multirow{2}{*}{$\begin{array}{l}\text { revesti- } \\
\text { mento }\end{array}$} & $h_{\text {REV }}$ & a & 0,069 & 0,000 & 0,288 & 0,000 & 0,101 & 0,000 & $-0,327$ & 0,000 \\
\hline & $M R_{R E V}$ & b & 0,056 & 0,000 & 0,326 & 0,000 & 0,201 & 0,000 & $-0,306$ & 0,000 \\
\hline \multirow{2}{*}{ base } & $h_{E M E}$ & C & 0,254 & 0,000 & 1,247 & 0,000 & 0,618 & 0,000 & $-1,290$ & 0,000 \\
\hline & $\mathrm{MR}_{\mathrm{EME}}$ & d & 0,085 & 0,000 & 0,445 & 0,000 & 0,258 & 0,000 & $-0,444$ & 0,000 \\
\hline $\begin{array}{l}\text { remanes- } \\
\text { cente }\end{array}$ & $M R_{R E M}$ & e & $-0,129$ & 0,000 & 0,050 & 0,000 & $-0,480$ & 0,000 & $-0,072$ & 0,000 \\
\hline carga & $\mathrm{Q}$ & $f$ & 0,041 & 0,000 & $-1,517$ & 0,000 & 0,152 & 0,000 & 1,542 & 0,000 \\
\hline \multicolumn{3}{|l|}{$\mathrm{R}^{2}$} & \multicolumn{2}{|r|}{0,975} & \multicolumn{2}{|r|}{0,888} & \multicolumn{2}{|r|}{0,955} & \multicolumn{2}{|r|}{0,897} \\
\hline \multicolumn{3}{|l|}{ Fischer (F) } & \multicolumn{2}{|r|}{11,229} & \multicolumn{2}{|r|}{2,265} & \multicolumn{2}{|r|}{6,106} & \multicolumn{2}{|r|}{2,489} \\
\hline
\end{tabular}


Observa-se, nas Tabelas 4.3 e 4.5, que todos os coeficientes correspondentes às variáveis independentes estruturais (espessuras e módulos de resiliência das camadas) sempre apresentam valores negativos, ou seja, como eram esperadas, tais variáveis independentes são inversamente proporcionais aos Indicadores Estruturais estudados $\left(\varepsilon_{\mathrm{tEME}}, \sigma_{\mathrm{tEME}}, \varepsilon_{\mathrm{VREM}}\right.$ e $\left.\mathrm{D}_{0}\right)$.

Para obtenção de maior confiabilidade nos estudos realizados, os resultados das variáveis em estudo foram submetidos a uma análise de variância (ANOVA). Seu objetivo é identificar se os valores das variáveis dependentes diferem significativamente entre si, do ponto de vista estatístico. A técnica consiste em analisar grupos de observações, por meio da comparação da variabilidade das médias entre os diferentes grupos, com a variabilidade das observações dentro de cada grupo.

Dessa forma, calcularam-se parâmetros que demonstrassem numericamente se cada um dos quesitos analisados pelo programa ELSYM-5 satisfez a lei de formação dos modelos elaborados.

A partir disso, foi possível estabelecer a significância das variáveis independentes e das interações sobre a variável dependente, determinada por meio da análise de variância dos termos dos modelos obtidos. Também, são apresentados os coeficientes de determinação dos modelos de regressão entre as variáveis dependentes estudadas.

Segundo MONTGOMERY e RUNGER (1999), a significância estatística da variabilidade das médias entre grupos (isto é, o efeito de uma determinada variável independente sobre uma variável dependente) é determinada por meio de um teste que consiste em comparar valores calculados e tabelados, para um determinado nível de significância de uma função de distribuição da probabilidade $F$ (distribuição de Fisher). Neste processo, o nível de significância para as análises foi de 0,05, ou seja, ao aceitar a hipótese de que há influência significativa entre determinada variável 
independente e uma variável dependente há, no mínimo, uma probabilidade de $5 \%$ desta hipótese não ser verdadeira.

Com base neste raciocínio, a análise de distribuição de Fisher (F) demonstrou para todos os estudos apresentados nas Tabelas 4.3, 4.4, 4.5 e 4.6 que o efeito dos valores considerados foi significativo. A análise de variância (ANOVA) dos modelos resultou em coeficientes de determinação $\left(R^{2}\right)$ superiores a 0,888 , indicando que os modelos ajustaram-se de $88,8 \%$ a $99,9 \%$ às variáveis dependentes, como pode ser observado resumidamente na Tabela 4.7.

Tabela 4.7 - Valores dos coeficientes de determinação $\left(R^{2}\right)$ para cada modelo

\begin{tabular}{|c|c|c|c|c|c|c|c|c|c|c|}
\hline \multirow{2}{*}{ Parâmetro } & \multicolumn{8}{|c|}{ Variável dependente } & \multicolumn{2}{|c|}{ Valor } \\
\hline & $D_{0}$ & $\varepsilon_{\mathrm{tEME}}$ & $\sigma_{\mathrm{tEME}}$ & $\varepsilon_{\text {vREM }}$ & $\mathbf{s}$ & $\mathbf{R}$ & $\mathbf{R} \times \mathbf{D}_{\mathbf{0}}$ & SCI & máximo & mínimo \\
\hline VBK & 0,999 & 0,990 & 0,988 & 0,992 & 0,980 & 0,951 & 0,967 & 0,964 & 0,999 & 0,951 \\
\hline FWD & 0,922 & 0,895 & 0,905 & 0,920 & 0,975 & 0,888 & 0,955 & 0,897 & 0,975 & 0,888 \\
\hline
\end{tabular}

A influência individual de cada variável independente, nas variáveis dependentes, foi analisada por meio do valor-p.

Os resultados das Tabelas 4.3 e 4.4 indicam que as variáveis independentes ( $h_{R E V}$; $M R_{R E V} ; h_{E M E} ; M R_{E M E} ; M R_{R E M}$ e Q) são significativas ao nível de confiança de $99 \%$, porque apresentam valor $p<0,01$. Os modelos de comportamento previstos pela análise de regressão múltipla para os dados observados de deflexão máxima $\left(\mathrm{D}_{0}\right)$, na superfície do pavimento; de deformação específica máxima de tração $\left(\varepsilon_{\mathrm{t}}\right)$, na fibra inferior da camada de EME; de tensão específica máxima de tração $\left(\sigma_{t}\right)$, na fibra inferior da camada de EME; e de deformação vertical máxima de compressão $\left(\varepsilon_{\mathrm{v}}\right)$, no topo da camada remanescente; são apresentados conforme o modelo genérico (4.3) e seus respectivos coeficientes nas tabelas indicadas.

A mesma situação se repete para os casos dos Indicadores de Curvatura (Tabelas 4.5 e 4.6), exceto para a simulação com VBK, nos parâmetros área " $S$ " e produto " $R$ $x$ D0", onde a variável independente "carga" (Q) apresentou valor $p>>0,01$. Tal 
situação denota que a variável independente $Q$, nestes modelos, não é estatisticamente significativa ao nível de confiança de $99 \%$. Portanto, os modelos de comportamento para estes parâmetros foram novamente estudados e suprimindo-se a variável Q. Para efeito comparativo, foram também calculados novamente modelos de comportamento para estes parâmetros e sem a "carga" (Q) para a simulação com FWD.

As Tabelas 4.8 e 4.9 apresentam as equações de correlação dos parâmetros área "S" e produto "R x D0" para as simulações com VBK e, para efeito de comparação, com FWD. Observa-se que, nos casos onde foram identificados que a variável independente Q não se apresentou estatisticamente significativa, a análise destes modelos resultou em coeficientes de determinação $\left(R^{2}\right)$ de 0,967 a 0,980 ; indicando que os modelos ajustaram-se de $96,7 \%$ a $98,0 \%$ às variáveis dependentes.

Tabela 4.8 - Coeficientes e parâmetros de análises para indicadores de curvatura para VBK, exceto $Q$

\begin{tabular}{|c|c|c|c|c|c|c|}
\hline \multirow{2}{*}{\multicolumn{3}{|c|}{ Coeficiente }} & \multicolumn{2}{|c|}{$\mathbf{S}_{\mathrm{VBK}}$} & \multicolumn{2}{|c|}{$\left(R \times D_{0}\right)_{\mathrm{VBK}}$} \\
\hline & & & Coef & valor-P & Coef & valor-P \\
\hline \multicolumn{3}{|l|}{$\mathrm{k}$} & 10,839 & - & 10,679 & - \\
\hline \multicolumn{3}{|l|}{ Inters } & 1,035 & 0,000 & 1,029 & 0,000 \\
\hline \multirow{2}{*}{$\begin{array}{l}\text { revesti- } \\
\text { mento }\end{array}$} & $h_{R E V}$ & $a$ & 0,076 & 0,000 & 0,329 & 0,000 \\
\hline & $M R_{\text {REV }}$ & $b$ & 0,034 & 0,000 & 0,144 & 0,000 \\
\hline \multirow{2}{*}{ base } & $h_{E M E}$ & C & 0,230 & 0,000 & 1,044 & 0,000 \\
\hline & $M R_{E M E}$ & d & 0,068 & 0,000 & 0,349 & 0,000 \\
\hline $\begin{array}{l}\text { remanes- } \\
\text { cente }\end{array}$ & $M R_{R E M}$ & e & $-0,099$ & 0,000 & $-0,557$ & 0,000 \\
\hline \multicolumn{3}{|l|}{$\mathrm{R}^{2}$} & \multicolumn{2}{|r|}{0,980} & \multicolumn{2}{|r|}{0,967} \\
\hline \multicolumn{3}{|l|}{ Fischer (F) } & \multicolumn{2}{|r|}{17015} & \multicolumn{2}{|r|}{10123} \\
\hline
\end{tabular}


Tabela 4.9 - Coeficientes e parâmetros de análises para indicadores de curvatura para FWD, exceto $Q$

\begin{tabular}{|c|c|c|c|c|c|c|}
\hline \multirow{2}{*}{ Coeficiente } & \multirow{2}{*}{\multicolumn{2}{|c|}{ Parâmetro }} & \multicolumn{2}{|c|}{$S_{\text {FWD }}$} & \multicolumn{2}{|c|}{$\left(R \times D_{0}\right)_{F W D}$} \\
\hline & & & Coef & valor-P & Coef & valor-P \\
\hline \multicolumn{3}{|l|}{$\mathrm{k}$} & 7,375 & - & 125,579 & - \\
\hline \multicolumn{3}{|l|}{ Inters } & 0,868 & 0,000 & 2,099 & 0,000 \\
\hline \multirow{2}{*}{$\begin{array}{l}\text { revesti- } \\
\text { mento }\end{array}$} & $h_{\text {REV }}$ & $a$ & 0,069 & 0,000 & 0,101 & 0,000 \\
\hline & $M R_{R E V}$ & $b$ & 0,056 & 0,000 & 0,201 & 0,000 \\
\hline \multirow{2}{*}{ base } & $h_{\text {EME }}$ & C & 0,254 & 0,000 & 0,618 & 0,000 \\
\hline & $M R_{E M E}$ & d & 0,085 & 0,000 & 0,258 & 0,000 \\
\hline $\begin{array}{l}\text { remanes- } \\
\text { cente }\end{array}$ & $M R_{R E M}$ & e & $-0,129$ & 0,000 & $-0,480$ & 0,000 \\
\hline \multicolumn{3}{|l|}{$\mathrm{R}^{2}$} & \multicolumn{2}{|r|}{0,970} & \multicolumn{2}{|r|}{0,949} \\
\hline \multicolumn{3}{|l|}{ Fischer (F) } & \multicolumn{2}{|r|}{11158} & \multicolumn{2}{|r|}{6444} \\
\hline
\end{tabular}

Como já mencionado na primeira etapa, em campo, a forma mais prática e rápida de obter o resultado estrutural do pavimento se dá por meio de ensaios deflectométricos, ou seja, ensaios não-destrutivos. Por esta razão, todos os estudos paramétricos em função do $M R_{R E M}$, anteriormente apresentados, foram novamente estudados com a adoção da deflexão máxima no topo da camada remanescente ( $D_{\text {OREM }}$ ) de uma estrutura que irá receber um reforço estrutural com camada de base de EME e uma camada asfáltica de rolamento delgada.

A substituição da variável $M R_{R E M}$ pela variável $D 0_{R E M}$ foi também desenvolvido por intermédio do programa computacional ELSYM-5. A Tabela 4.10 apresenta os valores de $\mathrm{D} 0_{\mathrm{REM}}$ correspondentes aos $\mathrm{MR}_{\mathrm{REM}}$ adotados no plano fatorial, para cada intensidade de carregamento de FWD e de VBK.

Tabela 4.10 - Valores de $D_{\text {OREM }}$ correspondentes a cada $M R_{\text {REM }}$

\begin{tabular}{|c|c|c|c|c|}
\hline \multirow{3}{*}{$\begin{array}{l}\mathrm{MR}_{\mathrm{REM}} \\
(\mathrm{MPa})\end{array}$} & \multicolumn{2}{|c|}{$\mathrm{DO}_{\mathrm{REM}}$, para VBK $\left(10^{-2} \mathrm{~mm}\right)$} & \multicolumn{2}{|c|}{$\mathrm{DO}_{\mathrm{REM}}$, para FWD $\left(10^{-2} \mathrm{~mm}\right)$} \\
\hline & Simulação I & Simulação II & Simulação III & Simulação IV \\
\hline & $Q_{1}=80 \mathrm{kN}$ & $Q_{2}=130 \mathrm{kN}$ & $Q_{1}=80 \mathrm{kN}$ & $Q_{2}=130 \mathrm{kN}$ \\
\hline 250 & 298 & 483 & 585 & 927 \\
\hline 500 & 149 & 242 & 292 & 463 \\
\hline 1000 & 74,5 & 121 & 146 & 232 \\
\hline 1500 & 49,6 & 80,6 & 97,4 & 154 \\
\hline 2000 & 37,2 & 60,4 & 73,1 & 116 \\
\hline 2500 & 29,8 & 48,3 & 58,5 & 92,7 \\
\hline 3000 & 24,8 & 40,3 & 48,7 & 77,2 \\
\hline 3500 & 21,3 & 34,5 & 41,8 & 66,2 \\
\hline
\end{tabular}


Essas novas equações são também funções potenciais conforme o modelo genérico apresentado a seguir:

VariávelDependente $=k \times\left(h_{R E V}{ }^{a} \times M R_{R E V}{ }^{b}\right) \times\left(h_{E M E}{ }^{c} \times M R_{E M E}{ }^{d}\right) \times D_{0 R E M}{ }^{e} \times Q^{f}$

Nas tabelas 4.11 e 4.12 , são apresentados os modelos em função da D OREM para VBK e, nas tabelas 4.13 e 4.14, os modelos em função da $D_{\text {OREM }}$ para FWD.

Tabela 4.11 - Coeficientes e parâmetros de análises para indicadores estruturais da VBK

\begin{tabular}{|c|c|c|c|c|c|c|c|c|c|c|}
\hline \multirow{2}{*}{ Coeficiente } & \multirow{2}{*}{\multicolumn{2}{|c|}{ Parâmetro }} & \multicolumn{2}{|c|}{$D_{0}$} & \multicolumn{2}{|c|}{$\varepsilon_{\text {tEME }}$} & \multicolumn{2}{|c|}{$\sigma_{\mathrm{tEME}}$} & \multicolumn{2}{|c|}{$\varepsilon_{\mathrm{vREM}}$} \\
\hline & & & Coef & valor-P & Coef & valor-P & Coef & valor-P & Coef & valor-P \\
\hline \multicolumn{3}{|l|}{ k } & 25,914 & - & 0,005 & - & $1,2 \mathrm{E}-02$ & - & $2,9 \mathrm{E}-02$ & - \\
\hline \multicolumn{3}{|l|}{ Inters } & 1,414 & 0,000 & $-2,284$ & 0,000 & $-1,922$ & 0,000 & $-1,537$ & 0,000 \\
\hline \multirow{2}{*}{$\begin{array}{l}\text { revesti- } \\
\text { mento }\end{array}$} & $\mathrm{h}_{\mathrm{REV}}$ & $a$ & $-0,157$ & 0,000 & $-0,309$ & 0,000 & $-0,318$ & 0,000 & $-0,331$ & 0,000 \\
\hline & $M R_{\text {REV }}$ & b & $-0,075$ & 0,000 & $-0,127$ & 0,000 & $-0,126$ & 0,000 & $-0,159$ & 0,000 \\
\hline \multirow{2}{*}{ base } & $\mathrm{h}_{\mathrm{EME}}$ & C & $-0,477$ & 0,000 & $-0,850$ & 0,000 & $-0,875$ & 0,000 & $-1,021$ & 0,000 \\
\hline & $M R_{E M E}$ & d & $-0,132$ & 0,000 & $-0,560$ & 0,000 & 0,449 & 0,000 & $-0,409$ & 0,000 \\
\hline $\begin{array}{l}\text { remanes- } \\
\text { cente }\end{array}$ & $\mathrm{D}_{\text {OREM }}$ & e & 0,785 & 0,000 & 0,290 & 0,000 & 0,295 & 0,000 & 0,415 & 0,000 \\
\hline carga & $\mathrm{Q}$ & $f$ & 0,171 & 0,000 & 0,627 & 0,000 & 0,570 & 0,000 & 0,486 & 0,000 \\
\hline \multicolumn{3}{|l|}{$\mathrm{R}^{2}$} & & 0,999 & & 0,990 & & 0,988 & & 0,992 \\
\hline \multicolumn{3}{|l|}{ Fischer (F) } & & 375241 & & 29337 & & 24614 & & 37932 \\
\hline
\end{tabular}

Tabela 4.12 - Coeficientes e parâmetros de análises para indicadores de curvatura da VBK

\begin{tabular}{|c|c|c|c|c|c|c|c|c|c|c|}
\hline \multirow{2}{*}{ Coeficiente } & \multicolumn{2}{|c|}{ Parâmetro } & \multicolumn{2}{|c|}{$\mathbf{S}$} & \multicolumn{2}{|c|}{$\mathbf{R}$} & \multicolumn{2}{|c|}{$R \times D_{0}$} & \multicolumn{2}{|c|}{$S C I=D_{0}-D_{300}$} \\
\hline & & & Coef & valor-P & Coef & valor-P & Coef & valor-P & Coef & valor-P \\
\hline $\mathrm{k}$ & & & 12,280 & - & 0,897 & - & 23,233 & - & 3412 & - \\
\hline Inters & & & 1,089 & 0,000 & $-0,047$ & 0,588 & 1,366 & 0,000 & 3,533 & 0,000 \\
\hline \multirow{2}{*}{$\begin{array}{l}\text { revesti- } \\
\text { mento }\end{array}$} & $\mathrm{h}_{\mathrm{REV}}$ & $a$ & 0,076 & 0,000 & 0,486 & 0,000 & 0,329 & 0,000 & $-0,472$ & 0,000 \\
\hline & $M R_{R E V}$ & b & 0,034 & 0,000 & 0,219 & 0,000 & 0,144 & 0,000 & $-0,216$ & 0,000 \\
\hline \multirow{2}{*}{ base } & $h_{\text {EME }}$ & C & 0,230 & 0,000 & 1,521 & 0,000 & 1,044 & 0,000 & $-1,464$ & 0,000 \\
\hline & $M R_{E M E}$ & d & 0,068 & 0,000 & 0,481 & 0,000 & 0,349 & 0,000 & $-0,454$ & 0,000 \\
\hline $\begin{array}{l}\text { remanes- } \\
\text { cente }\end{array}$ & $\mathrm{D}_{\text {OREM }}$ & e & 0,099 & 0,000 & $-0,229$ & 0,000 & 0,556 & 0,000 & 0,272 & 0,000 \\
\hline carga & $\mathrm{Q}$ & $f$ & $-0,102$ & 0,000 & $-0,749$ & 0,000 & $-0,578$ & 0,000 & 0,701 & 0,000 \\
\hline \multicolumn{3}{|l|}{$\mathrm{R}^{2}$} & & 0,980 & & 0,951 & & 0,967 & & 0,964 \\
\hline \multicolumn{3}{|l|}{ Fischer (F) } & & 14207 & & 5581 & & 8424 & & 7603 \\
\hline
\end{tabular}


Tabela 4.13 - Coeficientes e parâmetros de análises para indicadores de curvatura da FWD

\begin{tabular}{|c|c|c|c|c|c|c|c|c|c|c|}
\hline \multirow{3}{*}{ Coeficiente } & \multirow{2}{*}{\multicolumn{2}{|c|}{ Parâmetro }} & \multirow{2}{*}{\multicolumn{2}{|c|}{$D_{0}$}} & \multirow{2}{*}{\multicolumn{2}{|c|}{$\varepsilon_{\text {tEME }}$}} & \multirow{2}{*}{\multicolumn{2}{|c|}{$\sigma_{\text {tEME }}$}} & \multirow{2}{*}{\multicolumn{2}{|c|}{$\varepsilon_{\text {VREM }}$}} \\
\hline & & & & & & & & & & \\
\hline & & & Coef & valor-P & Coef & valor-P & Coef & valor-P & Coef & valor-P \\
\hline \multicolumn{3}{|l|}{$\mathrm{k}$} & 8,3E-03 & - & $1,6 \mathrm{E}-06$ & - & $4,0 \mathrm{E}-06$ & - & $2,1 \mathrm{E}-05$ & - \\
\hline \multicolumn{3}{|l|}{ Inters } & $-2,079$ & 0,000 & $-5,784$ & 0,000 & $-5,398$ & 0,000 & $-4,669$ & 0,000 \\
\hline \multirow{2}{*}{$\begin{array}{l}\text { revesti- } \\
\text { mento }\end{array}$} & $\mathrm{h}_{\mathrm{REV}}$ & $a$ & $-0,187$ & 0,000 & $-0,332$ & 0,000 & $-0,329$ & 0,000 & $-0,355$ & 0,000 \\
\hline & $M R_{\text {REV }}$ & $b$ & $-0,125$ & 0,000 & $-0,140$ & 0,000 & $-0,138$ & 0,000 & $-0,174$ & 0,000 \\
\hline \multirow{2}{*}{ base } & $h_{E M E}$ & C & $-0,629$ & 0,000 & $-0,945$ & 0,000 & $-0,932$ & 0,000 & $-1,113$ & 0,000 \\
\hline & $M R_{E M E}$ & d & $-0,186$ & 0,000 & $-0,589$ & 0,000 & 0,428 & 0,000 & $-0,451$ & 0,000 \\
\hline $\begin{array}{l}\text { remanes- } \\
\text { cente }\end{array}$ & $\mathrm{D}_{\text {OREM }}$ & e & 0,531 & 0,000 & 0,108 & 0,000 & 0,132 & 0,000 & 0,225 & 0,000 \\
\hline carga & $\mathrm{Q}$ & $f$ & 1,138 & 0,000 & 1,507 & 0,000 & 1,421 & 0,000 & 1,317 & 0,000 \\
\hline \multicolumn{3}{|l|}{$\mathrm{R}^{2}$} & & 0,922 & & 0,895 & & 0,905 & & 0,920 \\
\hline \multicolumn{3}{|l|}{ Fischer (F) } & & 3398 & & 2435 & & 2734 & & 3285 \\
\hline
\end{tabular}

Tabela 4.14 - Coeficientes e parâmetros de análises para indicadores de curvatura do FWD

\begin{tabular}{|c|c|c|c|c|c|c|c|c|c|c|}
\hline \multirow{2}{*}{ Coeficiente } & \multicolumn{2}{|c|}{ Parâmetro } & \multicolumn{2}{|c|}{$\mathbf{S}$} & \multicolumn{2}{|c|}{$\mathbf{R}$} & \multicolumn{2}{|c|}{$\mathbf{R} \times \mathbf{D}_{\mathbf{0}}$} & \multicolumn{2}{|c|}{$S C I=D_{0}-D_{300}$} \\
\hline & & & Coef & valor-P & Coef & valor-P & Coef & valor-P & Coef & valor-P \\
\hline k & & & $5,4 E+00$ & - & $4,7 E+03$ & - & 39,607 & - & $4,7 \mathrm{E}-01$ & - \\
\hline Inters & & & 0,734 & 0,000 & 3,677 & 0,000 & 1,598 & 0,000 & $-0,068$ & 0,601 \\
\hline \multirow{2}{*}{$\begin{array}{l}\text { revesti- } \\
\text { mento }\end{array}$} & $h_{\text {REV }}$ & a & 0,069 & 0,000 & 0,288 & 0,000 & 0,101 & 0,000 & $-0,327$ & 0,000 \\
\hline & $M R_{R E V}$ & $\mathrm{~b}$ & 0,056 & 0,000 & 0,326 & 0,000 & 0,201 & 0,000 & $-0,306$ & 0,000 \\
\hline \multirow{2}{*}{ base } & $h_{E M E}$ & C & 0,254 & 0,000 & 1,247 & 0,000 & 0,618 & 0,000 & $-1,290$ & 0,000 \\
\hline & $M R_{E M E}$ & d & 0,085 & 0,000 & 0,445 & 0,000 & 0,258 & 0,000 & $-0,444$ & 0,000 \\
\hline $\begin{array}{l}\text { remanes- } \\
\text { cente }\end{array}$ & $\mathrm{D}_{\text {OREM }}$ & e & 0,129 & 0,000 & $-0,050$ & 0,000 & 0,480 & 0,000 & 0,072 & 0,000 \\
\hline carga & $\mathrm{Q}$ & $f$ & $-0,088$ & 0,000 & $-1,466$ & 0,000 & $-0,328$ & 0,000 & 1,469 & 0,000 \\
\hline \multicolumn{3}{|l|}{$R^{2}$} & & 0,975 & & 0,888 & & 0,955 & & 0,897 \\
\hline \multicolumn{3}{|l|}{ Fischer (F) } & & 11221 & & 2265 & & 6116 & & 2489 \\
\hline
\end{tabular}

Como as duas variáveis $D_{\text {OREM }}$ e $M R_{R E M}$ são intrinsecamente relacionadas, os coeficientes de determinação dos modelos em função de DOrem mantiveram-se exatamente iguais aos estudados nos modelos paramétricos em função de $M R_{R E M}$, como pode ser observado nas Tabelas 4.15 e 4.16 . 
Tabela 4.15 - Comparativo dos coeficientes de determinação entre os indicadores estruturais

\begin{tabular}{l|r|r|r|r|r|r|r}
\hline \multirow{2}{*}{ Modelo } & \multirow{2}{*}{ Simulação } & \multicolumn{4}{|c|}{ Variável Dependente } & \multicolumn{2}{c}{ Valor } \\
\cline { 3 - 8 } & VBK & 0,999 & 0,990 & 0,988 & 0,992 & 0,999 & 0,988 \\
\hline em função de & FWD & 0,922 & 0,895 & 0,905 & 0,920 & 0,922 & 0,895 \\
\hline MR $_{\text {REM }}$ (equação 4.3) & VBK & 0,999 & 0,990 & 0,988 & 0,992 & 0,999 & 0,988 \\
\hline em função de & FWD & 0,922 & 0,895 & 0,905 & 0,920 & 0,922 & 0,895 \\
\hline$D_{\text {0REM }}$ (equação 4.4) & &
\end{tabular}

Tabela 4.16 - Comparativo dos coeficientes de determinação entre os indicadores de curvatura

\begin{tabular}{l|c|c|c|c|r|r|r}
\hline \multirow{2}{*}{ Modelo } & \multirow{2}{*}{ Simulação } & \multicolumn{3}{|c|}{ Variável Dependente } & \multicolumn{2}{c}{ Valor } \\
\cline { 3 - 8 } & & S & \multicolumn{1}{|c|}{ R } & R x DO & SCI & Máximo & Mínimo \\
\hline em função de & VBK & 0,980 & 0,951 & 0,967 & 0,964 & 0,980 & 0,951 \\
\hline MR $_{\text {REM (equação 4.3) }}$ & FWD & 0,975 & 0,888 & 0,955 & 0,897 & 0,975 & 0,888 \\
\hline em função de & VBK & 0,980 & 0,951 & 0,967 & 0,964 & 0,980 & 0,951 \\
\hline$D_{\text {OREM (equação 4.4) }}$ & FWD & 0,975 & 0,888 & 0,955 & 0,897 & 0,975 & 0,888 \\
\hline
\end{tabular}

Resumidamente, a Tabela 4.17 apresenta os principais parâmetros que influem nos Indicadores Estruturais.

Tabela 4.17- Principais parâmetros para controle dos Indicadores Estruturais (IE)

\begin{tabular}{|c|c|c|c|c|c|}
\hline \multirow{3}{*}{$\begin{array}{c}\text { Modelos } \\
\text { Paramétricos }\end{array}$} & \multirow{3}{*}{$\begin{array}{c}\text { Simulação } \\
\text { de } \\
\text { Carregamento }\end{array}$} & \multicolumn{4}{|c|}{ Principais parâmetros para controle dos IE } \\
\hline & & \multirow[t]{2}{*}{ DO } & \multicolumn{2}{|c|}{$\begin{array}{c}\text { Trincamento por } \\
\text { fadiga }\end{array}$} & \multirow{2}{*}{$\begin{array}{c}\text { Deformação } \\
\text { permanente } \\
\text { evREM }\end{array}$} \\
\hline & & & etEME & stEME & \\
\hline \multirow{2}{*}{$I E=f\left(h_{i}, M R_{i}, M R_{R E M}\right)$} & \multirow{2}{*}{ VBK } & $M R_{R E M}$ & $h_{E M E}$ & $\mathrm{~h}_{\mathrm{EME}}$ & $\mathrm{h}_{\mathrm{EME}}$ \\
\hline & & $\mathrm{h}_{\mathrm{EME}}$ & $M R_{E M E}$ & $M R_{\text {EME }}$ & $M R_{R E M}$ \\
\hline \multirow{2}{*}{$I E=f\left(h_{i}, M R_{i}, M R_{R E M}\right)$} & \multirow{2}{*}{ FWD } & $\mathrm{h}_{\mathrm{EME}}$ & $h_{E M E}$ & $\mathrm{~h}_{\mathrm{EME}}$ & $\mathrm{h}_{\mathrm{EME}}$ \\
\hline & & $M R_{R E M}$ & $M R_{E M E}$ & $M R_{\text {EME }}$ & $M R_{E M E}$ \\
\hline \multirow{2}{*}{$I E=f\left(h_{i}, M R_{i}, D 0_{R E M}\right)$} & \multirow{2}{*}{ VBK } & $\mathrm{D}_{\text {OREM }}$ & $h_{E M E}$ & $\mathrm{~h}_{\mathrm{EME}}$ & $\mathrm{h}_{\mathrm{EME}}$ \\
\hline & & $h_{E M E}$ & $M R_{E M E}$ & $M R_{\text {EME }}$ & $\mathrm{D}_{\text {OREM }}$ \\
\hline \multirow{2}{*}{$I E=f\left(h_{i}, M R_{i}, D 0_{R E M}\right)$} & \multirow{2}{*}{ FWD } & $\mathrm{h}_{\mathrm{EME}}$ & $h_{E M E}$ & $\mathrm{~h}_{\mathrm{EME}}$ & $\mathrm{h}_{\mathrm{EME}}$ \\
\hline & & $\mathrm{D}_{\text {OREM }}$ & $M R_{E M E}$ & $M R_{E M E}$ & $M R_{E M E}$ \\
\hline
\end{tabular}

Como é possível observar os principais parâmetros que definem as condições estruturais do pavimentos são: a capacidade de suporte da estrutura onde será executada o EME (MR $R_{R E M}$ ou $D_{O R E M}$ ) além das características geométricas e mecânicas do EME ( $h_{E M E}$ e $D_{0 E M E}$ ). Do ponto de vista prático, estes deverão ser os itens melhores controlados durante a fase construtiva. 
- Terceira Etapa: Esforços Atuantes em função de $D_{0}$ e dos Indicadores de Curvatura

Com intuito de tentar obter modelos paramétricos consistentes que determinassem os Esforços Atuantes na estrutura em estudo, a partir dos Indicadores de Curvatura e de $D_{0}$, foram desenvolvidos novos estudos.

Como são adotados quatro Indicadores de Curvatura e a deflexão máxima $D_{0}$, têmse, portanto cinco elementos a serem combinados, sem repetição, nos próximos modelos desta terceira etapa. Por análise combinatória, expressa pela equação 4.6, verifica-se que as combinações simples destes 5 elementos; tomados 1 a 1, tomados 2 a 2, tomados 3 a 3, tomados 4 a 4 e, por fim, tomados 5 a 5 , geraram 31 combinações para cada um dos 3 Esforços Atuantes $\left(\varepsilon_{\mathrm{t}}, \sigma_{\mathrm{t}}\right.$ e $\left.\varepsilon_{\mathrm{v}}\right)$.

$$
C_{1}^{5}+C_{2}^{5}+C_{3}^{5}+C_{4}^{5}+C_{5}^{5}=31 \text { combinações }
$$

Além disso, foram desenvolvidos modelos, tanto em função do $M R_{R E M}$ quanto da D0 $_{\text {REM, }}$ gerando um número duas vezes maior para serem analisados, ou seja 186 combinações.

Essas 186 combinações foram estudadas, tanto para carregamentos simulados com FWD quanto com VBK, totalizando 372 modelos. Neste estudo, as análises foram limitadas para os carregamentos simulados com FWD. Todos os modelos resultantes estão apresentados em anexo.

Para hierarquizar os modelos teóricos que melhor responderam aos Esforços Atuantes de Campo, primeiramente, cada um dos Indicadores de Curvatura ( $R, S, R$ $x D_{0}$ e $\left.S C I\right)$ e $D_{0}$ foram submetidos por uma análise estatística de resíduos com estes 
parâmetros deduzidos por retroanálise ${ }^{14}$, apresentados no capítulo 5 , conforme apresentado na Figura 4.5.

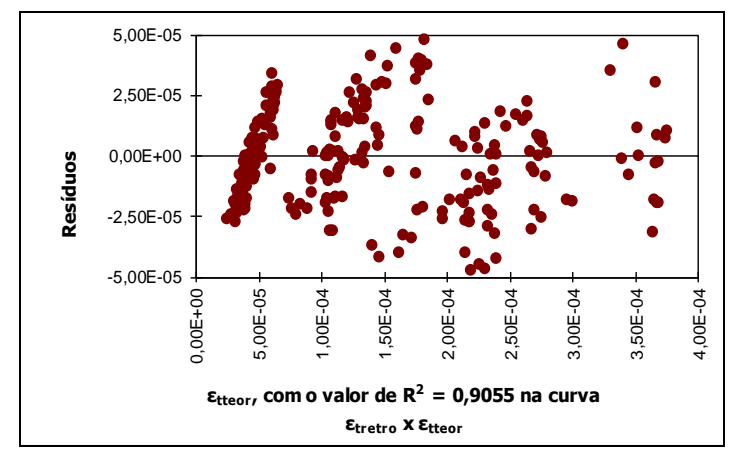

Figura 4.5a - Análise dos resíduos para $\varepsilon_{\text {tretro }} \times \varepsilon_{\text {tteor }}$

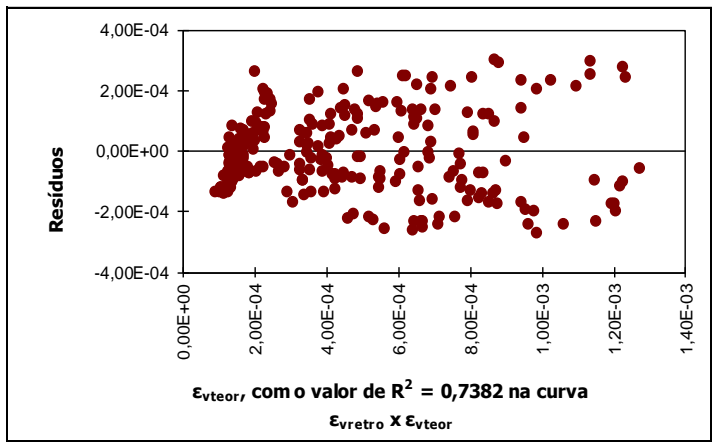

Figura 4.5c - Análise dos resíduos para $\varepsilon_{\text {vretro }} \times \varepsilon_{\text {vteo }}$

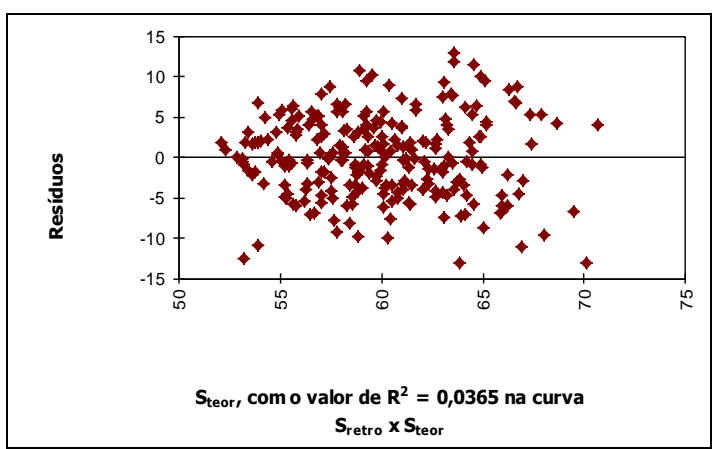

Figura 4.5e - Análise dos resíduos para $S_{\text {retro }} \times S_{\text {teor }}$

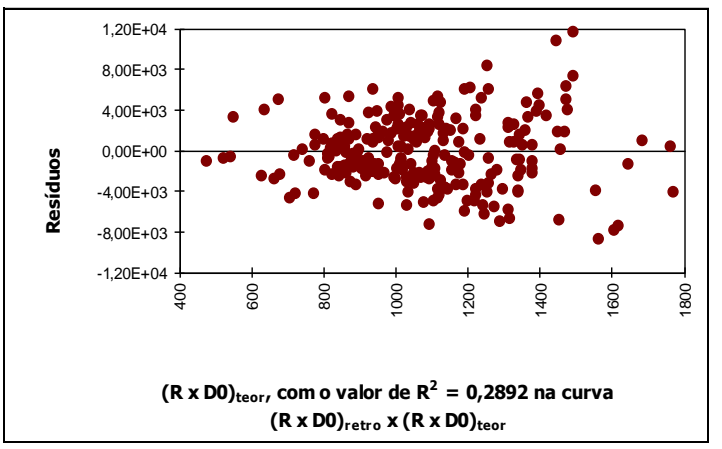

Figura 4.5g - Análise dos resíduos para $(\mathrm{R} \times \mathrm{DO})_{\text {retro }} \times(\mathrm{R} \times \mathrm{DO})_{\text {teor }}$

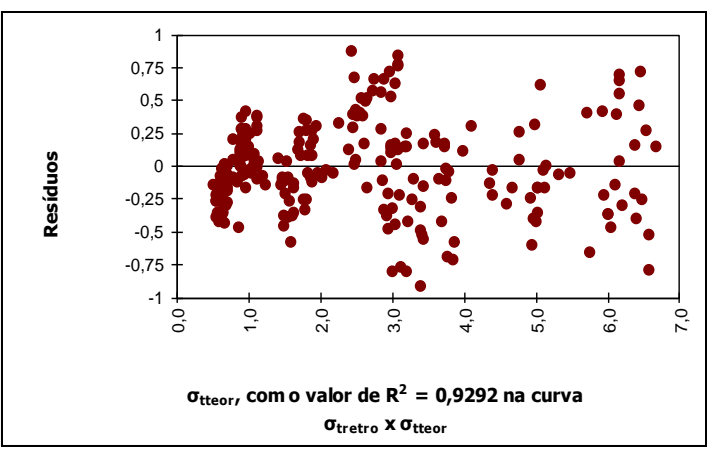

Figura 4.5b - Análise dos resíduos para $\sigma_{\text {tretro }} \times \sigma_{\text {tteor }}$

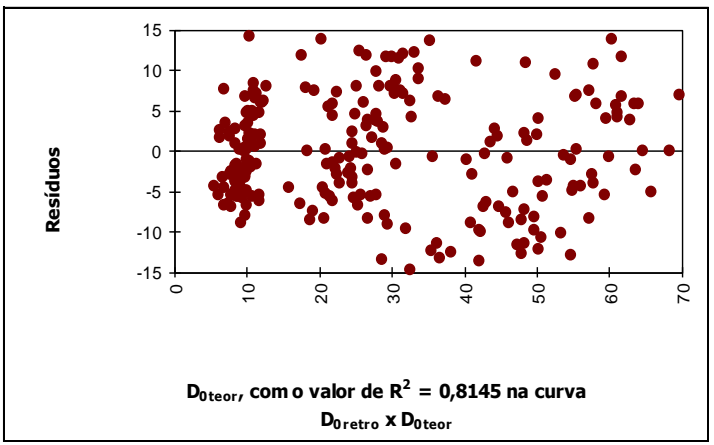

Figura 4.5d - Análise dos resíduos para $D_{0 \text { retro }} \times D_{0 \text { teor }}$

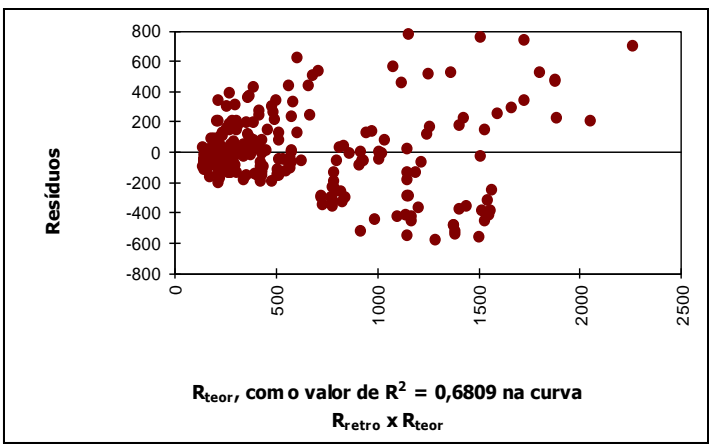

Figura 4.5f - Análise dos resíduos para $R_{\text {retro }} \times R_{\text {teor }}$

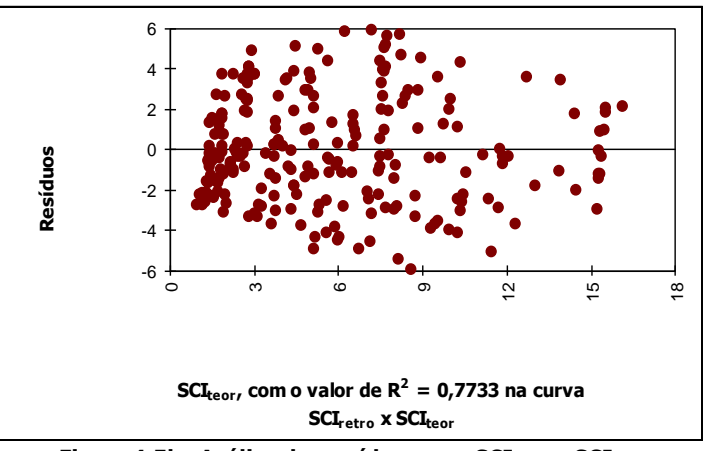

Figura 4.5h - Análise dos resíduos para $\mathrm{SCI}_{\text {retro }} \times \mathrm{SCI}_{\text {teor }}$

Figura 4.5 - Análise dos resíduos para os Indicadores Estruturais e para os Indicadores de Curvatura

${ }^{14}$ Todas as análises foram desenvolvidas com levantamentos deflectométricos efetuados com FWD. Antes da realização da análise das medidas de deflexões, todas as bacias foram normalizadas segundo o carregamento e a temperatura. 
A análise de resíduos foi executada para verificar a suposição de que os erros desempenhem aproximadamente um padrão segundo uma distribuição normal, de maneira aleatória, com valor médio nulo e variância constante caracterizando a hipótese de homocedasticidade. Para verificar tais condições, foram traçados os gráficos de resíduos versus valores previstos de cada variável independente dos modelos paramétricos.

Dos gráficos traçados, apresentados na figura 4.5, pode-se concluir que os resíduos para as variáveis independentes $S$ e $\mathrm{RxD}_{0}$ apresentam comportamentos que não foram tão bem captados pelos valores previstos quando contrapostos com os deduzidos por retroanálise, ou seja, tais modelos não explicam os valores retroanalisados. Isso pode ser verificado tanto na variância, que tende a aumentar para valores maiores das previsões, quanto por não se apresentarem totalmente aleatórios. Também são os dois casos onde seus coeficientes de determinação apresentaram-se com menor valor: 0,0365 e 0,2892, respectivamente. Os demais apresentam pontos distribuídos aleatoriamente em torno de uma reta que passa na origem, sem nenhum padrão definido, o que denota ser um indicador favorável à verificação da hipótese de homocedasticidade.

$\mathrm{Na}$ exclusão das varáveis independentes $\mathrm{S}$ e $\mathrm{RxD}_{0}$, percebe-se que o número de combinações reduz para 7, por esforço solicitante tanto em função de MRrem quanto em função de $D_{\text {OREM. }}$ Esses por sua vez podem ser hierarquizados, segundo seus respectivos coeficientes de determinação, da forma como são discriminados em ordem decrescente de valores de $\mathrm{R}^{2}$ nas Tabelas 4.18 e 4.19 . 
Tabela 4.18 - Equações de Correlação entre os Esforços Solicitantes e D0 e os Indicadores de Curvatura, a partir dos estudos paramétricos em função de $\mathbf{M R}_{\mathrm{REM}}$

\begin{tabular}{|c|c|c|c|c|c|c|c|c|c|c|c|c|}
\hline \multicolumn{2}{|c|}{$E S=f\left(D_{0} ; I C\right)$} & \multicolumn{9}{|c|}{ Equação de correlação } & \multirow{2}{*}{\begin{tabular}{c|}
$\mathbf{R}^{\mathbf{2}}$ \\
0,9724 \\
\end{tabular}} & \multirow{2}{*}{$\begin{array}{r}\text { eq. }\left(\mathbf{n}^{\circ}\right) \\
(4.7)\end{array}$} \\
\hline \multirow{7}{*}{$\varepsilon_{\text {tEME }}$} & $\mathrm{f}\left(\mathrm{D}_{0} ; \mathrm{R} ; \mathrm{SCI}\right)$ & $\varepsilon_{\mathrm{tEME}}=$ & $3,00 \mathrm{E}-04$ & $x$ & $\mathrm{D}_{0}$ & 0,126 & $x$ & $\mathrm{R}$ & $-0,372$ & $x$ SCI $\quad 0,482$ & & \\
\hline & $f\left(D_{0} ; S C I\right)$ & $\varepsilon_{\mathrm{tEME}}=$ & $1,46 \mathrm{E}-05$ & $\mathbf{x}$ & $\mathbf{D}_{0}$ & 0,1135 & $\mathbf{x}$ & SCI & 0,853 & & 0,9722 & $(4.8)$ \\
\hline & $f\left(D_{0} ; R\right)$ & $\varepsilon_{\mathrm{tEME}}=$ & $1,44 \mathrm{E}-01$ & $x$ & $\mathrm{D}_{0}$ & $-0,853$ & $x$ & $\mathrm{R}$ & 0,015 & & 0,9721 & $(4.9)$ \\
\hline & $\mathrm{f}(\mathrm{R} ; \mathrm{SCI})$ & $\varepsilon_{\mathrm{tEME}}=$ & 2,53E-09 & $x$ & $\mathrm{R}$ & 1,080 & $x$ & SCI & 2,002 & & 0,9647 & $(4.10)$ \\
\hline & $\mathrm{f}(\mathrm{SCI})$ & $\varepsilon_{\mathrm{tEME}}=$ & $2,00 \mathrm{E}-05$ & $x$ & $\mathrm{SCI}$ & 0,957 & & & & & 0,9619 & (4.11) \\
\hline & $f(R)$ & $\varepsilon_{\mathrm{tEME}}=$ & $5,78 \mathrm{E}-02$ & $x$ & $\mathrm{R}$ & $-0,984$ & & & & & 0,9543 & $(4.12)$ \\
\hline & $f\left(D_{0}\right)$ & $\varepsilon_{\mathrm{tEME}}=$ & $1,00 \mathrm{E}-05$ & $x$ & $\mathrm{D}_{0}$ & 0,600 & & & & & 0,6052 & $(4.13)$ \\
\hline \multirow{7}{*}{$\sigma_{\text {tEME }}$} & $\mathrm{f}\left(\mathrm{D}_{0} ; \mathrm{R} ; \mathrm{SCI}\right)$ & $\sigma_{\mathrm{tEME}}=$ & $1,06 \mathrm{E}-06$ & $x$ & $\mathrm{D}_{0}$ & 0,173 & $x$ & $\mathrm{R}$ & 1,538 & $x$ SCI $\quad 2,160$ & 0,8282 & $(4.14)$ \\
\hline & $f\left(D_{0} ; S C I\right)$ & $\sigma_{\mathrm{tEME}}=$ & 2,93E-01 & $\mathbf{x}$ & $\mathbf{D}_{\mathbf{0}}$ & 0,226 & $\mathbf{x}$ & SCI & 0,623 & & 0,8245 & $(4.15)$ \\
\hline & $f\left(D_{0} ; R\right)$ & $\sigma_{\mathrm{tEME}}=$ & $4,48 \mathrm{E}+01$ & $x$ & $\mathrm{D}_{0}$ & 0,251 & $x$ & $\mathrm{R}$ & $-0,618$ & & 0,8209 & $(4.16)$ \\
\hline & $\mathrm{f}(\mathrm{R} ; \mathrm{SCI})$ & $\sigma_{\mathrm{tEME}}=$ & $1,23 \mathrm{E}-13$ & $x$ & $\mathrm{R}$ & 3,523 & $x$ & $\mathrm{SCI}$ & 4,237 & & 0,8126 & $(4.17)$ \\
\hline & $\mathrm{f}(\mathrm{SCI})$ & $\sigma_{\mathrm{tEME}}=$ & 4,39E-01 & $x$ & $\mathrm{SCI}$ & 0,829 & & & & & 0,7801 & (4.18) \\
\hline & $f(R)$ & $\sigma_{\mathrm{tEME}}=$ & $4,65 E+02$ & $x$ & $\mathrm{R}$ & $-0,846$ & & & & & 0,7625 & $(4.19)$ \\
\hline & $f\left(D_{0}\right)$ & $\sigma_{\mathrm{tEME}}=$ & $2,90 \mathrm{E}-01$ & $x$ & $\mathrm{D}_{0}$ & 0,581 & & & & & 0,6130 & $(4.20)$ \\
\hline \multirow{7}{*}{$\varepsilon_{\mathrm{vREM}}$} & $\mathrm{f}\left(\mathrm{D}_{0} ; \mathrm{R} ; \mathrm{SCI}\right)$ & $\varepsilon_{\mathrm{VREM}}=$ & $3,94 \mathrm{E}-12$ & $x$ & $\mathrm{D}_{0}$ & 0,246 & $x$ & $\mathrm{R}$ & 1,958 & $x$ SCI $\quad 2,662$ & 0,9975 & $(4.21)$ \\
\hline & $\mathrm{f}\left(\mathrm{D}_{0} ; \mathrm{SCI}\right)$ & $\varepsilon_{\mathrm{vREM}}=$ & $3,30 \mathrm{E}-05$ & $\mathbf{x}$ & $D_{0}$ & 0,313 & $\mathbf{x}$ & SCI & 0,706 & & 0,9925 & $(4.22)$ \\
\hline & $f\left(D_{0} ; R\right)$ & $\varepsilon_{\mathrm{VREM}}=$ & $9,80 \mathrm{E}-03$ & $x$ & $\mathrm{D}_{0}$ & 0,342 & $x$ & $\mathrm{R}$ & $-0,699$ & & 0,9883 & $(4.23)$ \\
\hline & $\mathrm{f}(\mathrm{R} ; \mathrm{SCI})$ & $\varepsilon_{\mathrm{vREM}}=$ & $5,29 E-22$ & $x$ & $\mathrm{R}$ & 4,782 & $x$ & SCI & 5,618 & & 0,9713 & $(4.24)$ \\
\hline & $\mathrm{f}(\mathrm{SCI})$ & $\varepsilon_{\mathrm{VREM}}=$ & $6,00 \mathrm{E}-05$ & $x$ & $\mathrm{SCI}$ & 0,992 & & & & & 0,9219 & $(4.25)$ \\
\hline & $f(R)$ & $\varepsilon_{\mathrm{VREM}}=$ & $2,38 \mathrm{E}-01$ & $x$ & $\mathrm{R}$ & $-1,011$ & & & & & 0,8986 & $(4.26)$ \\
\hline & $f\left(D_{0}\right)$ & $\varepsilon_{\mathrm{vREM}}=$ & $3,00 \mathrm{E}-05$ & $x$ & $\mathrm{D}_{0}$ & 0,716 & & & & & 0,7683 & $(4.27)$ \\
\hline
\end{tabular}

Nota:

eq. = equação 
Tabela 4.19 - Equações de Correlação entre os Esforços Solicitantes e D0 e os Indicadores de Curvatura, a partir dos estudos paramétricos em função de $D_{\text {OREM }}$

\begin{tabular}{|c|c|c|c|c|c|c|c|c|c|c|c|c|}
\hline \multicolumn{2}{|c|}{$E S=f\left(D_{0} ; I C\right)$} & \multicolumn{9}{|c|}{ Equação de correlação } & \multirow{2}{*}{\begin{tabular}{c|}
$\mathbf{R}^{\mathbf{2}}$ \\
0,9724
\end{tabular}} & \multirow{2}{*}{ eq. $\left(n^{\circ}\right)$} \\
\hline \multirow{7}{*}{$\varepsilon_{\mathrm{tEME}}$} & $\mathrm{f}\left(\mathrm{D}_{0} ; \mathrm{R} ; \mathrm{SCI}\right)$ & $\varepsilon_{\mathrm{tEME}}=$ & $4,00 \mathrm{E}-04$ & $x$ & $\mathrm{D}_{0}$ & 0,126 & $x$ & $\mathrm{R}$ & $-0,371$ & x SCI $\quad 0,482$ & & \\
\hline & $f\left(D_{0} ; S C I\right)$ & $\varepsilon_{\mathrm{tEME}}=$ & 2,42E-05 & $\mathbf{x}$ & $D_{0}$ & 0,1135 & $\mathbf{x}$ & SCI & 0,853 & & 0,9722 & (4.29) \\
\hline & $f\left(D_{0} ; R\right)$ & $\varepsilon_{\mathrm{tEME}}=$ & $1,51 \mathrm{E}-02$ & $x$ & $\mathrm{D}_{0}$ & 0,144 & $x$ & $\mathrm{R}$ & $-0,853$ & & 0,9721 & $(4.30)$ \\
\hline & $\mathrm{f}(\mathrm{R} ; \mathrm{SCI})$ & $\varepsilon_{\mathrm{tEME}}=$ & $8,32 \mathrm{E}-09$ & $x$ & $\mathrm{R}$ & 1,080 & $x$ & SCI & 2,002 & & 0,9646 & $(4.31)$ \\
\hline & $\mathrm{f}(\mathrm{SCI})$ & $\varepsilon_{\mathrm{tEME}}=$ & $3,00 \mathrm{E}-05$ & $x$ & $\mathrm{SCI}$ & 0,957 & & & & & 0,9619 & $(4.32)$ \\
\hline & $f(R)$ & $\varepsilon_{\mathrm{tEME}}=$ & $5,78 \mathrm{E}-02$ & $x$ & $\mathrm{R}$ & $-0,984$ & & & & & 0,9543 & (4.33) \\
\hline & $f\left(D_{0}\right)$ & $\varepsilon_{\mathrm{tEME}}=$ & $1,00 \mathrm{E}-05$ & $x$ & $\mathrm{D}_{0}$ & 0,600 & & & & & 0,6052 & $(4.34)$ \\
\hline \multirow{7}{*}{$\sigma_{\text {tEME }}$} & $f\left(D_{0} ; R ; S C I\right)$ & $\sigma_{\text {tEME }}=$ & $3,85 \mathrm{E}-06$ & $x$ & $\mathrm{D}_{0}$ & 0,173 & $x$ & $\mathrm{R}$ & 1,539 & x SCI $\quad 2,160$ & 0,8282 & (4.35) \\
\hline & $f\left(D_{0} ; S C I\right)$ & $\sigma_{\mathrm{tEME}}=$ & $4,25 \mathrm{E}-01$ & $\mathbf{x}$ & $D_{0}$ & 0,226 & $\mathbf{x}$ & SCI & 0,623 & & 0,8245 & $(4.36)$ \\
\hline & $f\left(D_{0} ; R\right)$ & $\sigma_{\mathrm{tEME}}=$ & $4,48 \mathrm{E}+01$ & $x$ & $\mathrm{D}_{0}$ & 0,251 & $x$ & $\mathrm{R}$ & $-0,618$ & & 0,8209 & (4.37) \\
\hline & $\mathrm{f}(\mathrm{R} ; \mathrm{SCI})$ & $\sigma_{\mathrm{tEME}}=$ & $1,53 \mathrm{E}-12$ & $x$ & $\mathrm{R}$ & 3,524 & $x$ & $\mathrm{SCI}$ & 4,238 & & 0,8126 & (4.38) \\
\hline & $\mathrm{f}(\mathrm{SCI})$ & $\sigma_{\mathrm{tEME}}=$ & $7,19 \mathrm{E}-01$ & $x$ & $\mathrm{SCI}$ & 0,829 & & & & & 0,7801 & (4.39) \\
\hline & $f(R)$ & $\sigma_{\mathrm{tEME}}=$ & $4,65 \mathrm{E}+02$ & $x$ & $\mathrm{R}$ & $-0,846$ & & & & & 0,7625 & $(4.40)$ \\
\hline & $f\left(D_{0}\right)$ & $\sigma_{\mathrm{tEME}}=$ & $2,90 \mathrm{E}-01$ & $x$ & $\mathrm{D}_{0}$ & 0,581 & & & & & 0,6131 & (4.41) \\
\hline \multirow{7}{*}{$\varepsilon_{\mathrm{vREM}}$} & $\mathrm{f}\left(\mathrm{D}_{0} ; \mathrm{R} ; \mathrm{SCI}\right)$ & $\varepsilon_{\mathrm{vREM}}=$ & $1,93 \mathrm{E}-11$ & $x$ & $\mathrm{D}_{0}$ & 0,246 & $x$ & $\mathrm{R}$ & 1,958 & x SCI $\quad 2,662$ & 0,9975 & $(4.42)$ \\
\hline & $f\left(D_{0} ; S C I\right)$ & $\varepsilon_{\mathrm{vREM}}=$ & 5,02E-05 & $\mathbf{x}$ & $D_{0}$ & 0,313 & $\mathbf{x}$ & SCI & 0,706 & & 0,9925 & $(4.43)$ \\
\hline & $f\left(D_{0} ; R\right)$ & $\varepsilon_{\mathrm{vREM}}=$ & $9,80 \mathrm{E}-03$ & $x$ & $\mathrm{D}_{0}$ & 0,342 & $x$ & $\mathrm{R}$ & $-0,699$ & & 0,9883 & (4.44) \\
\hline & $\mathrm{f}(\mathrm{R} ; \mathrm{SCI})$ & $\varepsilon_{\mathrm{vREM}}=$ & $1,50 \mathrm{E}-20$ & $x$ & $\mathrm{R}$ & 4,782 & $x$ & $\mathrm{SCI}$ & 5,618 & & 0,9713 & $(4.45)$ \\
\hline & $\mathrm{f}(\mathrm{SCI})$ & $\varepsilon_{\mathrm{VREM}}=$ & $1,00 \mathrm{E}-04$ & $x$ & $\mathrm{SCI}$ & 0,992 & & & & & 0,9219 & $(4.46)$ \\
\hline & $f(R)$ & $\varepsilon_{\mathrm{vREM}}=$ & $2,38 \mathrm{E}-01$ & $x$ & $\mathrm{R}$ & $-1,011$ & & & & & 0,8986 & (4.47) \\
\hline & $f\left(D_{0}\right)$ & $\varepsilon_{\mathrm{vREM}}=$ & $3,00 \mathrm{E}-05$ & $x$ & $\mathrm{D}_{0}$ & 0,716 & & & & & 0,7683 & $(4.48)$ \\
\hline
\end{tabular}

Nota:

eq. = equação

Dessa hierarquização estabelecida nas Tabelas 4.18 e 4.19 pode-se deduzir que os parâmetros que melhor correlacionam com os esforços solicitantes são:

- Para $\varepsilon_{\mathrm{temE}}$ :

- em função de MREME: equações 4.7 e 4.8

- em função de $D_{0 E M E}:$ equações 4.28 e 4.29 
- Para $\sigma_{\text {teme: }}$

- em função de $M R_{E M E}:$ equações 4.14 e 4.15

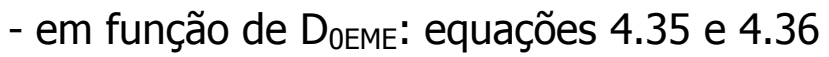

- Para $\varepsilon_{\mathrm{VREM}}$ :

- em função de MREME: equações 4.21 e 4.22

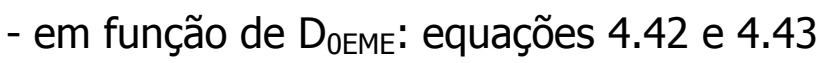

Entretanto, pode-se verificar que os valores de $\mathrm{R}^{2}$ da primeira para segunda equação são muito próximos, com uma diferença máxima de 0,0050. Por esta razão optou-se por adotar uma equação com o menor número de variáveis, mas com mesmo potencial de explicação do fenômeno em questão. Sendo assim, a equações adotadas foram as indicadas em negrito nas Tabelas 4.18 e 4.19 .

A partir dos modelos selecionados, percebe-se que a obtenção dos esforços solicitantes de uma estrutura constituída de camada de base em EME pode ser diretamente efetuada por meio dos modelos apresentados em função de parâmetros exclusivamente deflectométricos obtidos com equipamento tipo FWD. Segundo Lopes et al (2010), não utilizar características geométricas da estrutura pode ser necessário, uma vez que em campo sua determinação pode ser de difícil obtenção.

Da seleção apresentada nas Tabelas 4.18 e 4.19 pode-se também concluir que em todas as situações os modelos que obtiveram menor coeficiente de determinação foram aqueles em função somente da deflexão máxima. Todos os demais, em função dos Indicadores de Curvatura (IC), invariavelmente apresentaram melhores $\mathrm{R}^{2}$. Isto comprova que para a melhor explicação dos esforços solicitantes de uma estrutura deve-se necessariamente estudar o comportamento da bacia deflectométrica e não somente a sua deflexão máxima D0. 
- Quarta Etapa: Comparação entre os Esforços Solicitantes Teóricos e os Esforços Solicitantes Retroanalisados

Após a definição dos modelos paramétricos, foi possível compará-los com os valores dos esforços solicitantes retroanalisados ${ }^{15}$, por meio de uma nova análise estatística de resíduos, conforme apresentado na Figura 4.5. Desta comparação percebeu-se que, além de serem homocedásticos, os modelos apresentaram fortes coeficientes de determinação $\left(R^{2}\right)$ que variaram de 0,7132 a 0,9012 , conforme apresentados nas Figuras 4.6, 4.7 e 4.8 .

Nesta análise observou-se que os gráficos de distribuição de resíduos para os Esforços Solicitantes analisados são iguais, tanto em função de $M R_{R E M}$ quanto em função de $D_{O R E M}$. Este fato reforça a tese de que $M R_{R E M}$ e $D_{O R E M}$ são variáveis interdependentes, perceptível também pela comparação das Tabelas 4.18 e 4.19.

Para verificação dos modelos selecionados nas Tabelas 4.18 e 4.19, ante os Esforços Solicitantes retroanalisados, foram traçados os gráficos apresentados nas Figuras 4.9, 4.10 e 4.11 para $\varepsilon_{\text {tEME, }} \sigma_{\text {tEME }}$ e $\varepsilon_{\text {VREM }}$ respectivamente.

\footnotetext{
${ }^{15}$ A terminologia "esforços solicitantes retroanalisados" foi estabelecida para designar os esforços advindos das estruturas de pavimento cujas camadas foram retroanalisadas a partir do programa computacional EVERCALC.
} 


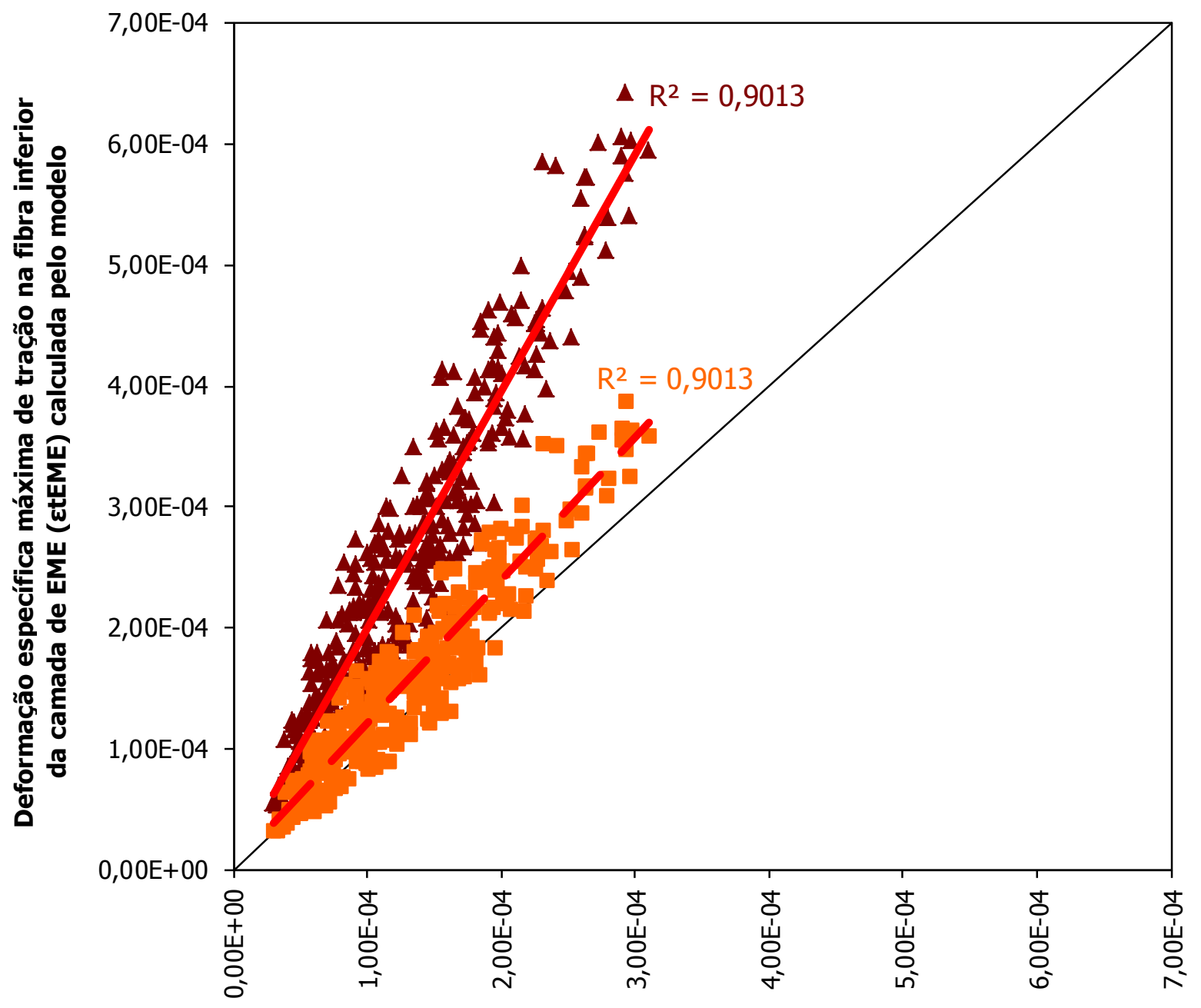

Deformação específica máxima de tração na fibra inferior da camada de EME ( $($ tEME) retroanalisada

- (ztEME)calc Dorem

- (EtEME)calc MRrem igualdade

Figura 4.6 - Comparação dos modelos em função $M R_{R E M}$ e $D_{\text {OREM }}$ ante ao $\varepsilon_{\mathrm{tEME}}$ Retroanalisados 


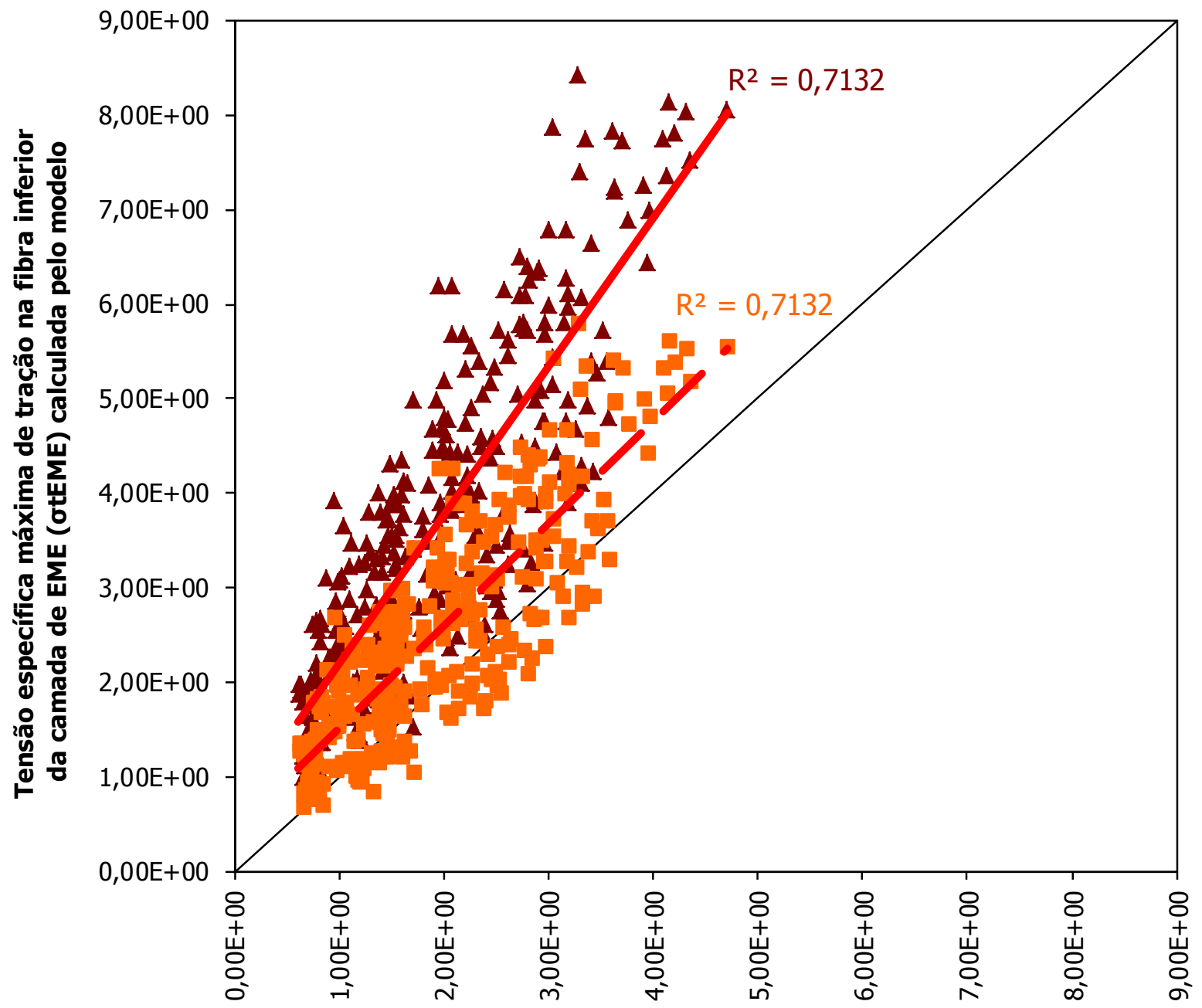

Tensão específica máxima de tração na fibra inferior da camada de EME (otEME) retroanalisada

- (otEME)calc D0rem

- (otEME)calc MRrem

— Igualdade

Figura 4.7 - Comparação dos modelos em função $M R_{\text {REM }}$ e $D_{\text {OREM }}$ ante ao $\sigma_{\text {tEME }}$ Retroanalisados 


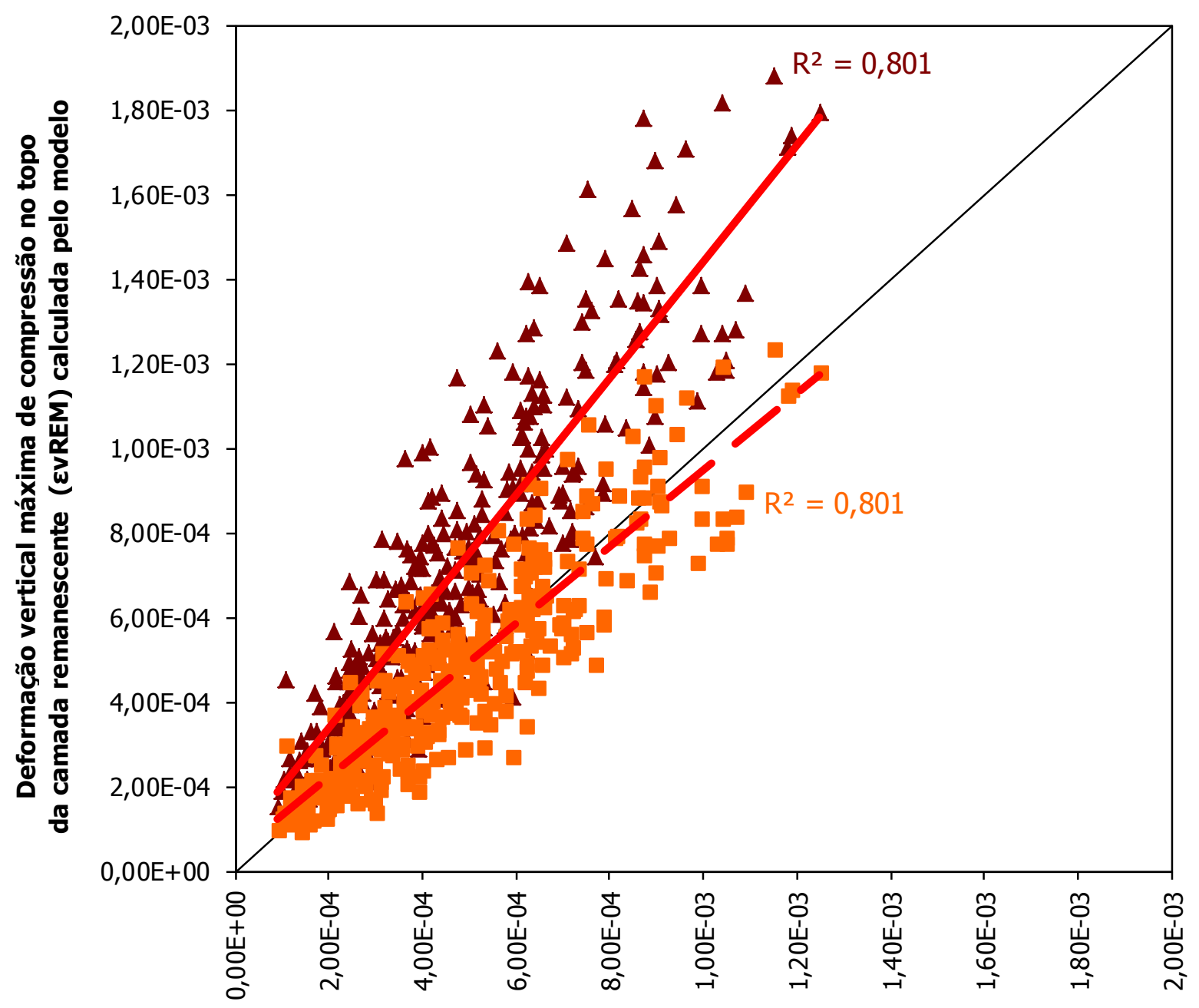

Deformação vertical máxima de compressão no topo da camada remanescente (EvREM) retroanalisada

\ (EvREM)calc DOrem - (EvREM)calc MRrem - igualdade

Figura 4.8 - Comparação dos modelos em função $M R_{R E M}$ e $D_{0 R E M}$ ante ao $\varepsilon_{\mathrm{vREM}}$ Retroanalisados

Nesta análise definiu-se que os modelos mais ajustados a fim de explicar os esforços $\varepsilon_{\text {tEME }}$ e $\sigma_{\text {tEME }}$ foram aqueles em função $M_{R_{R E M}}$ (Figuras 4.6 e 4.7 ), pois passaram ligeiramente acima da linha de igualdade.

Entretanto, para $\varepsilon_{V R E M}$ (Figura 4.8) verificou-se que o modelo em função do $M R_{R E M}$ apresentou-se inferior aos valores retroanalisados e no caso do modelo em função do $D_{\text {OREM }}$ superior. Desta forma, por meio da interpolação entre as constantes dos 
dois modelos, foi possível ajustar o modelo como é mostrado na Figura 4.9 que se apresentou muito próximo da linha de igualdade.

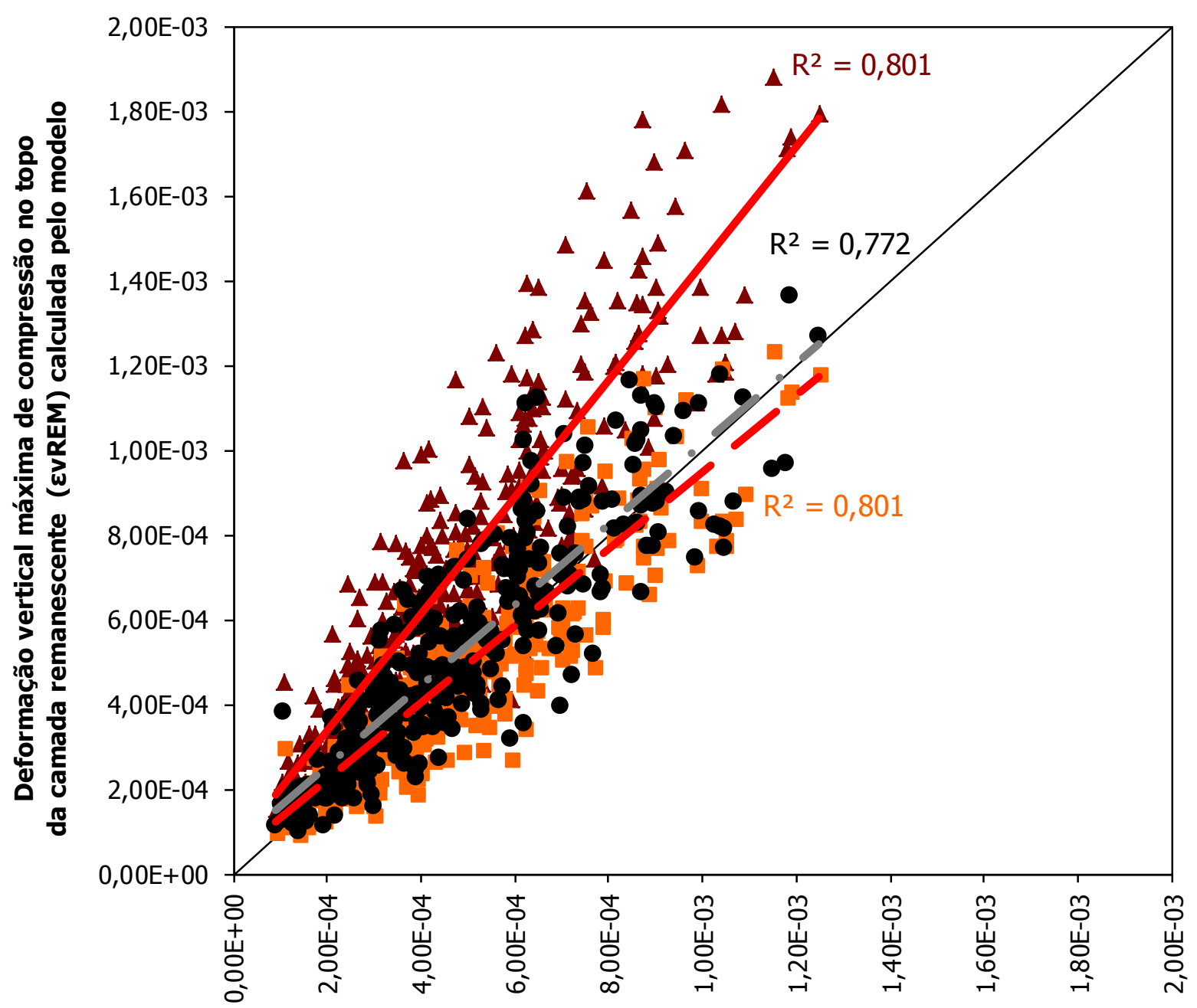

Deformação vertical máxima de compressão no topo da camada remanescente (EvREM) retroanalisada

- (EvREM)calc Dorem

- (EvREM)calc MRrem igualdade

- (EvREM)calc Ajustado

Figura 4.9 - Ajuste do modelo $\varepsilon_{\mathrm{VREM}}$ em relação aos modelos em função $M R_{\text {REM }}$ e $D_{\text {OREM }}$ 
Sendo assim, recomenda-se para a definição dos Esforços Solicitantes Teóricos (ESteor) os modelos a seguir apresentados:

- Para $\varepsilon_{\text {teme: }}$

$\varepsilon_{I E M E}=1,46 E-05 \times D_{0}^{0,1135} \times S C T^{0,853}, R^{2}=0,972$

- Para $\sigma_{\text {tEME: }}$ :

$\sigma_{t E M E}=2,93 E-01 \times D_{0}^{0,226} \times S C I^{0,623}, R^{2}=0,825$

- Para $\varepsilon_{\mathrm{VREM}}$ :

$\varepsilon_{\text {VREM }}=4,40 E-05 \times D_{0}^{0,313} \times S C I^{0,706}, R^{2}=0,993$

De acordo com LOPES et al (2010), modelos como estes podem determinar rapidamente os esforços solicitantes críticos na estrutura do pavimento somente por meio do levantamento deflectométrico e consequentemente estimar valores de número $\mathrm{N}$ por meio de modelos de fadiga correlacionando estas deformações e o número de solicitações do eixo padrão. 


\section{ANÁLISE DOS RESULTADOS}

\subsection{ANÁLISES MECANÍSTICAS}

\subsubsection{Levantamento Deflectométrico}

As deflexões no Trecho Experimental foram determinadas pelo equipamento FWD (Falling Weight Deflectometer) modelo Kuab em três intensidades distintas de carregamento: $2,1 \mathrm{tf} ; 4,1 \mathrm{tf}$ e $6,5 \mathrm{tf}$.

Foram adotadas essas intensidades de carga para observar se o Trecho Experimental encontra-se com suas respostas mecânicas de acordo com um comportamento elástico-linear, em todas as seções executadas ( $140 \mathrm{~mm}$ de EME, $110 \mathrm{~mm}$ de EME e $80 \mathrm{~mm}$ de EME), segundo a Teoria da Elasticidade.

Também as intensidades de carga de 4,1 tf e 6,5 tf foram adotadas para proporcionar, nas seções executadas, valores de esforços mecânicos atuantes como resposta aos carregamentos do eixo padrão brasileiro de 8,2 tf e o eixo padrão francês de 13 tf, respectivamente, auxiliando na análise mecanística do Trecho Experimental.

A Figura 5.1 representa de maneira esquemática os estágios que os levantamentos deflectométricos foram realizados. A Tabela 5.1 apresenta os dias em que as campanhas de levantamento das bacias de deflexão foram realizadas. Todos os levantamentos deflectométricos, em todos os Estágios, encontram-se em anexo. 


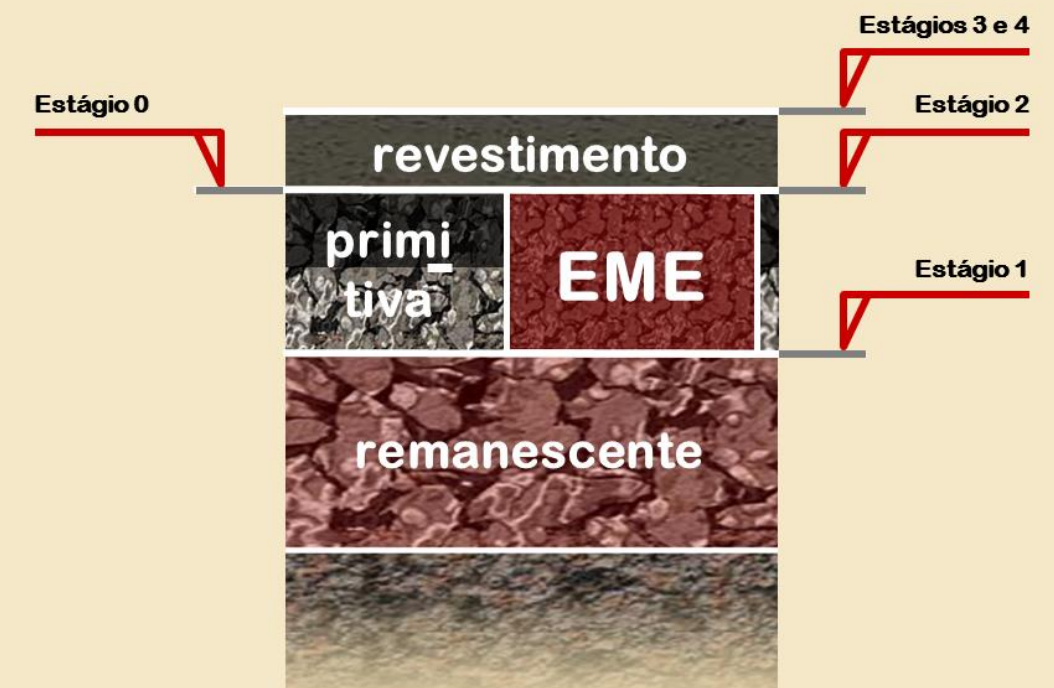

Estágio 0 - levantamento na Estrutura Primitiva - jun / 2010

Estágio 1 - levantamento no Remanescente - jun a ago / 2010

Estágio 2 - levantamento no EME - ago / 2010: final da obra de EME

Estágio 3 - levantamento no Revestimento - out/ 2010: final da estação seca

Estágio 4 - levantamento no Revestimento-abr / 2011: final da estação chuvosa

Figura 5.1 - Estágios dos levantamentos deflectométricos desta pesquisa 
Tabela 5.1 - Dia da Realização do levantamento e respectivo Estágio

\begin{tabular}{|c|c|c|}
\hline \multicolumn{2}{|r|}{ Levantamento e Respectivo Local de Execução } & dia \\
\hline $\mathbf{A}$ & $\begin{array}{l}\text { levantamento deflectométrico SRef 01; SExp 01; SExp 02; SExp } \\
03 \text { e SRef } 02 \text { - estrutura primitiva: Estágio } 0\end{array}$ & 29 / junho / 2010 \\
\hline B & $\begin{array}{l}\text { levantamento deflectométrico SExp 01; SExp } 02 \text { e SExp } 03 \text { - } \\
\text { fundo da caixa fresada: Estágio } 1\end{array}$ & 30 / junho / 2010 \\
\hline $\mathbf{C}$ & $\begin{array}{l}\text { levantamento deflectométrico SExp 01; SExp } 02 \text { e SExp } 03 \text { - } \\
\text { fundo da caixa fresada: Estágio } 1\end{array}$ & 1 / julho / 2010 \\
\hline D & $\begin{array}{l}\text { levantamento deflectométrico SExp 01; SExp } 02 \text { e SExp } 03 \text { - } \\
\text { fundo da caixa fresada: Estágio } 1\end{array}$ & 2 / julho / 2010 \\
\hline E & $\begin{array}{l}\text { levantamento deflectométrico SExp 01; SExp } 02 \text { e SExp } 03 \text { - } \\
\text { fundo da caixa fresada: Estágio } 1\end{array}$ & 7 / julho / 2010 \\
\hline $\mathbf{F}$ & reconstrução seção de referência SRef 01 & 13 / agosto / 2010 \\
\hline $\mathbf{G}$ & $\begin{array}{l}\text { levantamento deflectométrico SRef } 02 \text { - fundo da caixa fresada: } \\
\text { Estágio } 1\end{array}$ & 13 / agosto / 2010 \\
\hline $\mathbf{H}$ & $\begin{array}{l}\text { levantamento deflectométrico SRef 01; SExp 01; SExp 02; SExp } \\
03 \text { e SRef } 02 \text { - no topo do EME: Estágio } 2\end{array}$ & 19 / agosto / 2010 \\
\hline $\mathbf{I}$ & execução do gap graded - topo do Trecho Experimental & 23 / agosto / 2010 \\
\hline J & execução do dreno profundo & 26 / agosto / 2010 \\
\hline $\mathbf{K}$ & $\begin{array}{l}\text { levantamento deflectométrico SRef 01; SExp 01; SExp 02; SExp } \\
03 \text { e SRef } 02 \text { - no topo do Gap Graded (10 Levant.): Estágio } 3\end{array}$ & 19 / outubro / 2010 \\
\hline $\mathbf{L}$ & $\begin{array}{l}\text { levantamento deflectométrico SRef } 01 ; \text { SExp 01; SExp 02; SExp } \\
03 \text { e SRef } 02 \text { - no topo do Gap Graded (20 Levant.): Estágio } 4\end{array}$ & 26 / abril / 2011 \\
\hline \multicolumn{3}{|c|}{ Nota: } \\
\hline & $\begin{array}{l}\text { após a execução do levantamento deflector } \\
\text { a caixa fresada foi recomposta com o material e espessul }\end{array}$ & stágio \\
\hline
\end{tabular}

Antes da realização da análise das medidas de deflexões, todas as bacias foram normalizadas segundo o carregamento e a temperatura. Quanto ao carregamento, por meio da proporcionalidade ${ }^{16}$ do carregamento efetivamente realizado na superfície do pavimento com os carregamentos pré-definidos: 2,1tf; 4,1tf e 6,5tf. Quanto à temperatura, por meio da correção das medidas de deflexões segundo o AASHTO (1993), o qual fornece coeficientes que convertem a deflexão medida em campo, em diversas temperaturas, por deflexões a temperatura padrão de $20^{\circ} \mathrm{C}$.

\footnotetext{
${ }^{16}$ Embora o valor do carregamento não excedesse uma diferença de 5\%, todas as bacias foram ajustadas para os carregamentos pré-definidos: 2,1tf; 4,1tf e 6,5tf.
} 


\subsubsection{Análise da Linearidade do Sistema Estrutural de Multicamadas}

Um sistema estrutural de multicamadas pode ser estudado por diversos modelos estruturais. Os modelos estruturais são baseados em diversas abordagens de análise para determinar as respostas do pavimento (tensões, deformações e deflexões) em vários locais em um pavimento, devido à aplicação da carga de roda, sendo os mais comuns o modelo elástico-linear e o modelo visco-elático.

O modelo adotado neste trabalho é do tipo elástico linear. A adoção deste modelo se dá pelo fato que pretende-se analisar a eficiência dos estudos paramétricos elaborados, a partir de programas computacionais concebidos para o modelo eláticolinear (ELSYM-5 e EVERCALC), com os levantamentos realizados no Trecho Experimental. Ou seja, pretende-se comparar os valores encontrados nos estudos paramétricos (valores teóricos) com aqueles advindos de levantamentos de campo, a partir de estruturas de pavimentos conhecidas, e processados por programas computacionais (valores retroanalisados).

A abordagem de camadas elástico-lineares trabalha com modelos matemáticos relativamente simples que relaciona tensão, deformação e deflexão, com carga de roda e as propriedades mecânicas dos materiais estudados nas estruturas do pavimento (módulo de resiliências e coeficiente de Poisson) e suas respectivas características geométricas (espessuras).

A seguir, são apresentadas as Figuras 5.2 a 5.9 contendo gráficos do tipo box-plot a fim de explicar o efeito da linearidade entre as respostas dos deslocamentos verticais encontrados ante as diferentes intensidades de carga. Ainda nestas Figuras, são apresentados os coeficientes de determinação para cada uma das deflexões máximas $\left(D_{0}\right)$ e valores de SCI de acordo com cada intensidade de carga exercida nas seções do Trecho Experimental. 


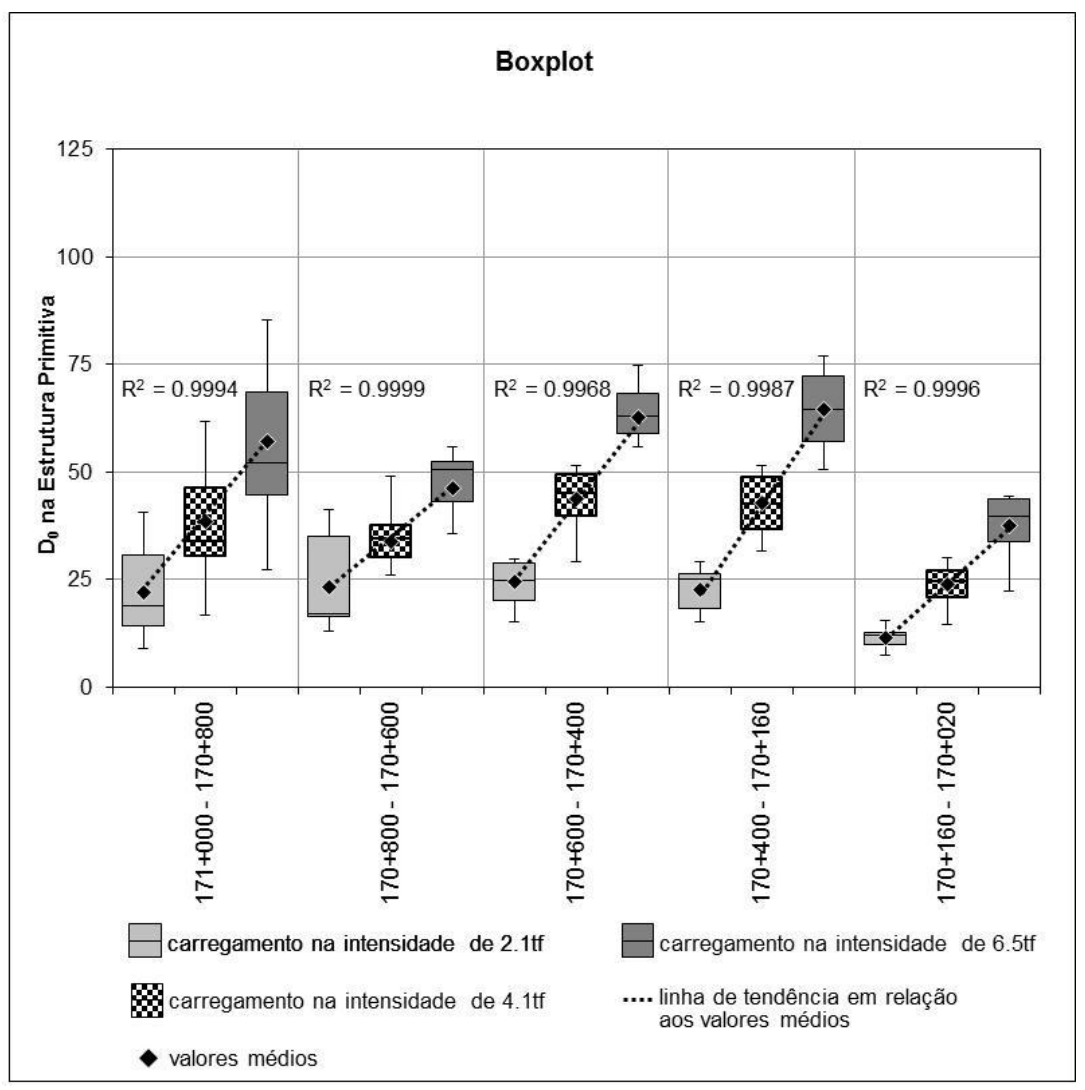

Figura 5.2 - Distribuição das deflexões máximas $\left(D_{0}\right)$ e seus coeficientes de determinação em cada seção experimental na Estrutura Primitiva

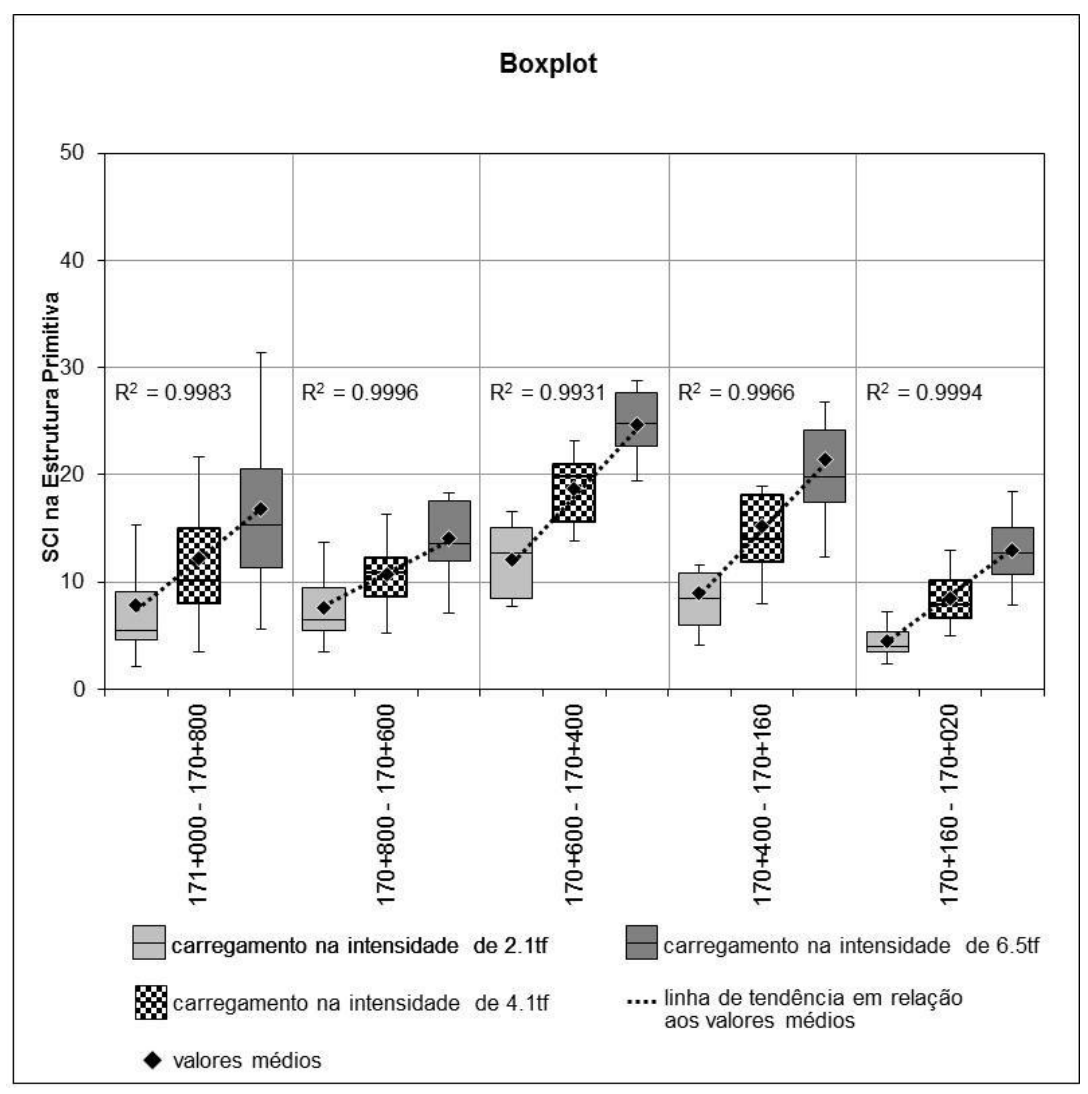

Figura 5.3 - Distribuição dos valores de SCI e seus coeficientes de determinação em cada seção experimental na Estrutura Primitiva 


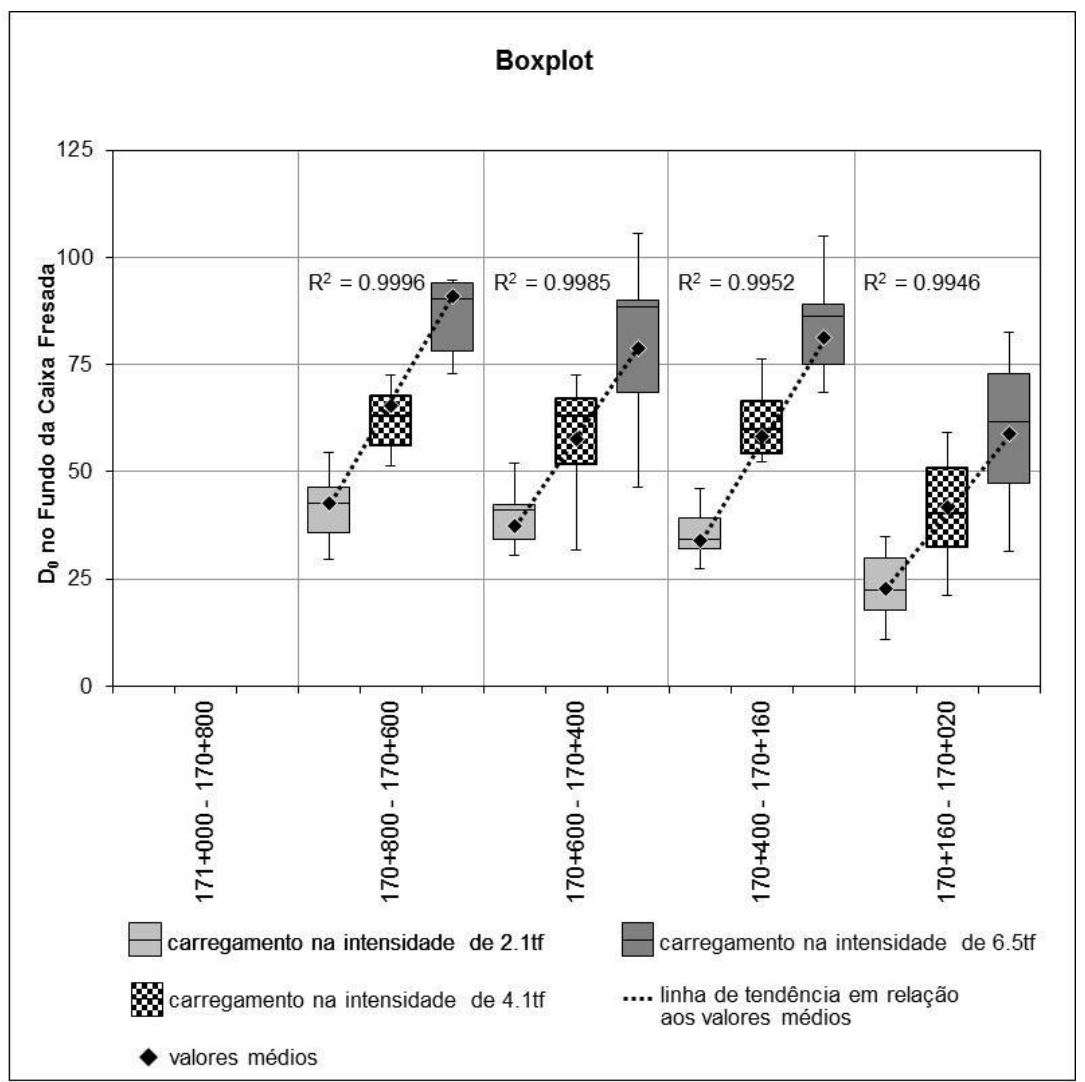

Figura 5.4 - Distribuição das deflexões máximas $\left(D_{0}\right)$ e seus coeficientes de determinação em cada seção experimental no Fundo da Caixa Fresada

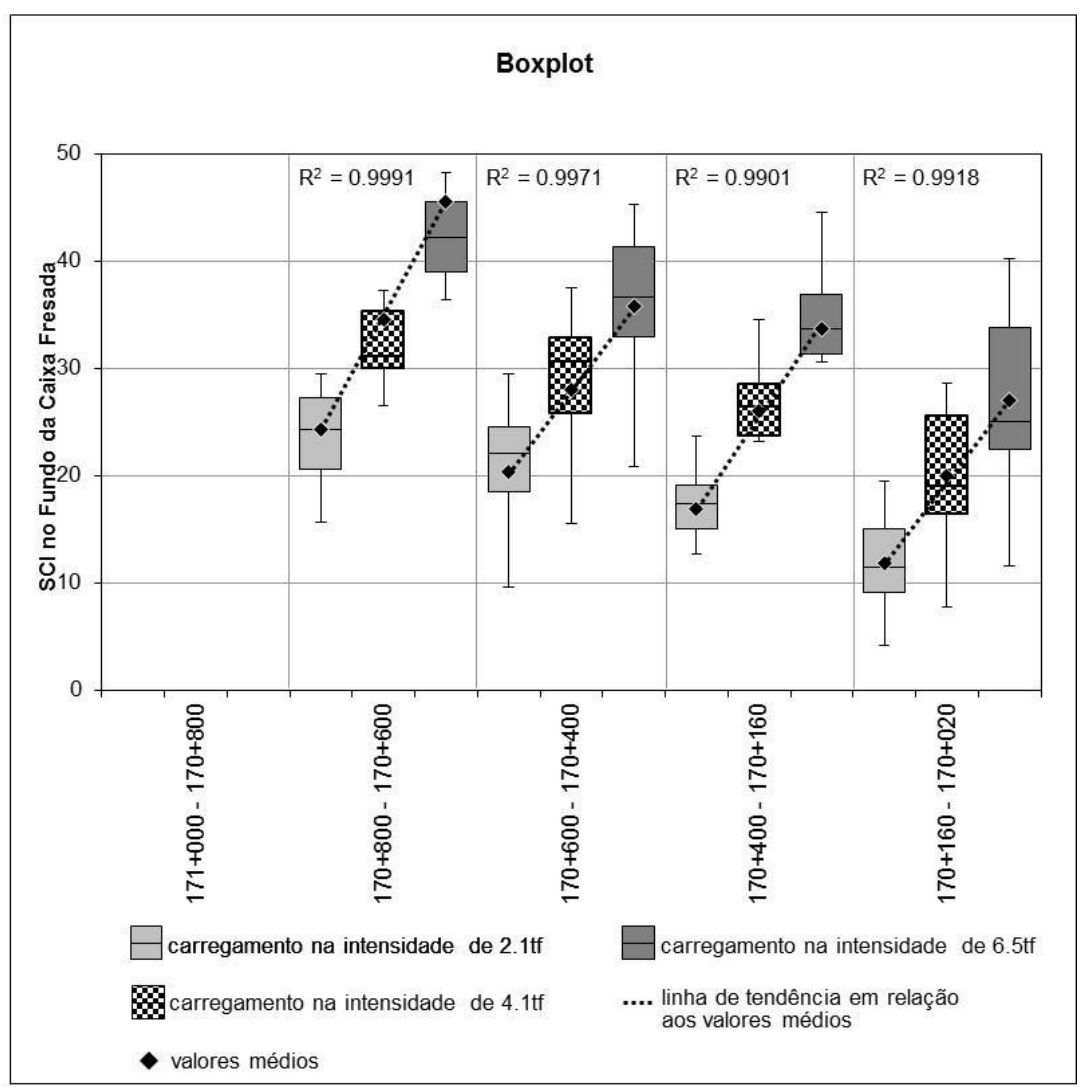

Figura 5.5 - Distribuição dos valores de SCI e seus coeficientes de determinação em cada seção experimental no Fundo da Caixa Fresada 


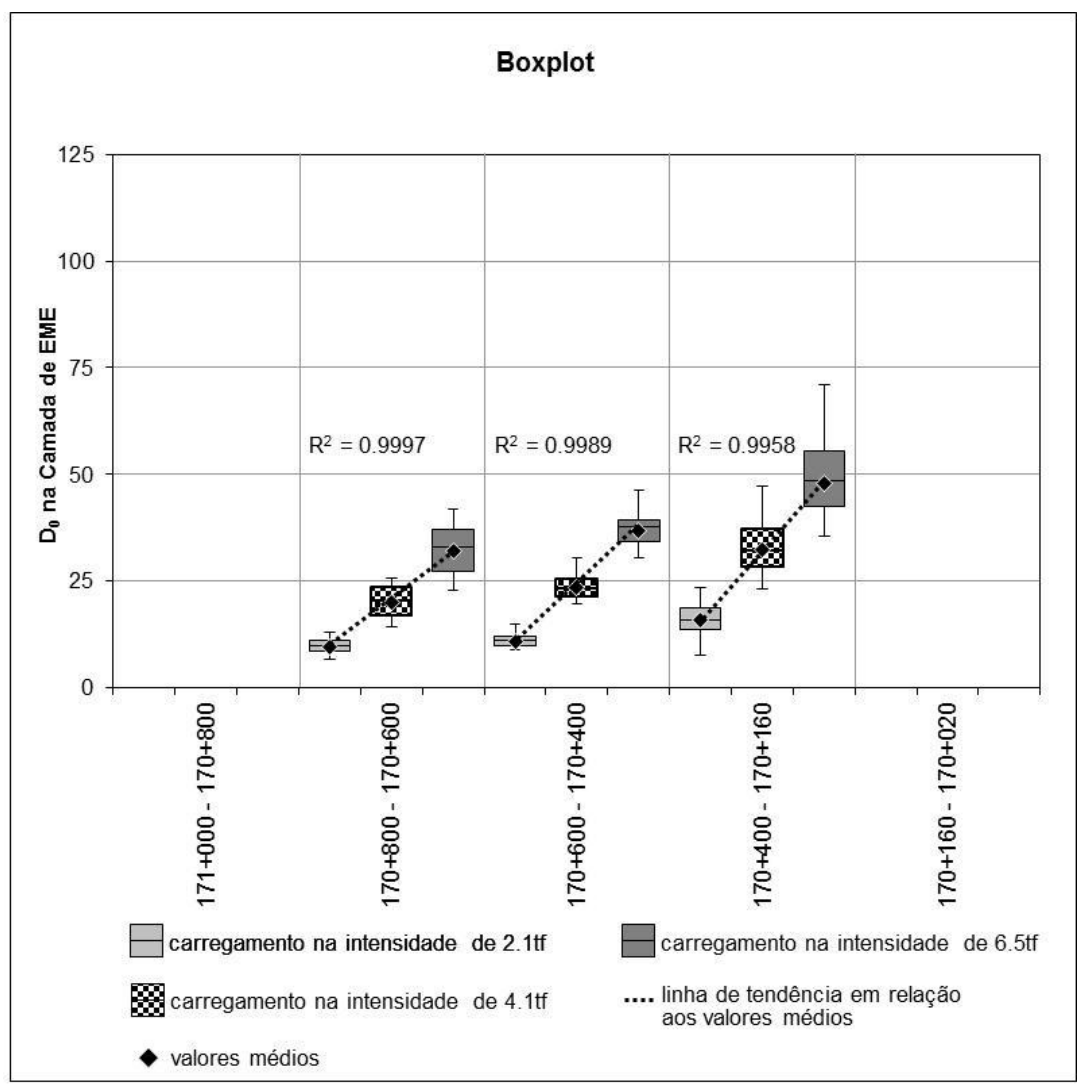

Figura 5.6 - Distribuição das deflexões máximas $\left(D_{0}\right)$ e seus coeficientes de determinação em cada seção experimental na Camada de EME

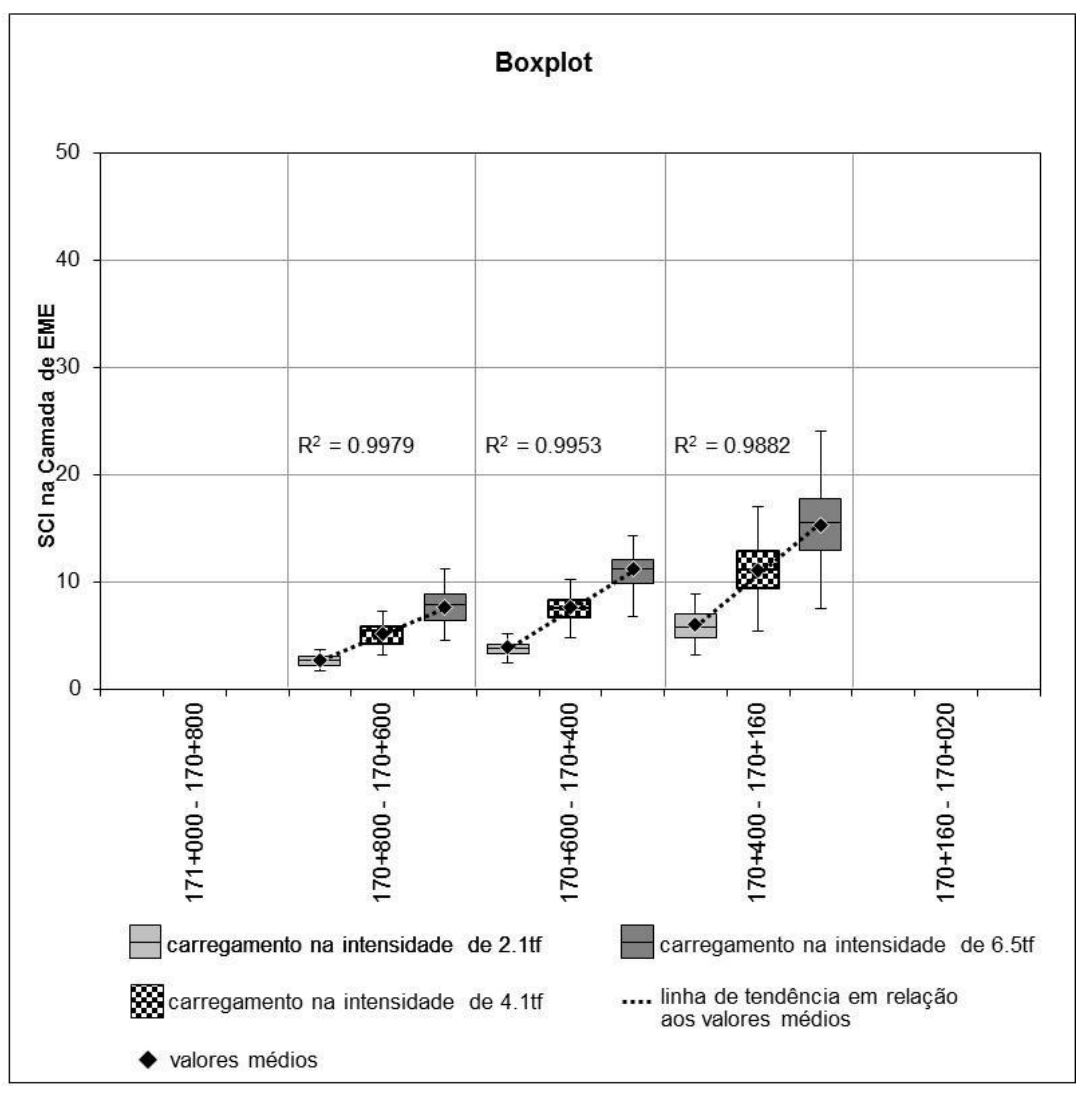

Figura 5.7 - Distribuição dos valores de SCI e seus coeficientes de determinação em cada seção experimental na Camada de EME 


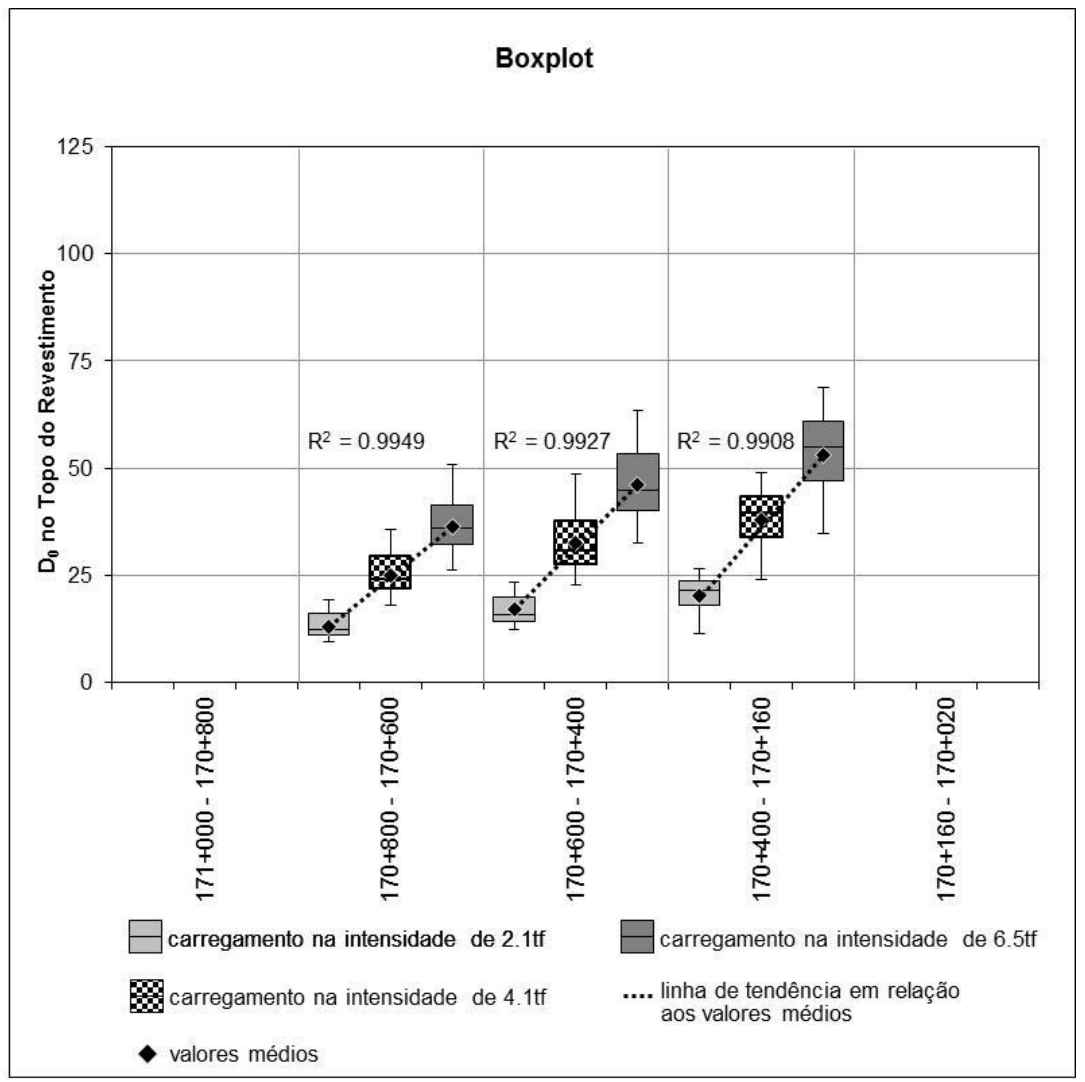

Figura 5.8 - Distribuição das deflexões máximas $\left(D_{0}\right)$ e seus coeficientes de determinação em cada seção experimental no Topo do Revestimento

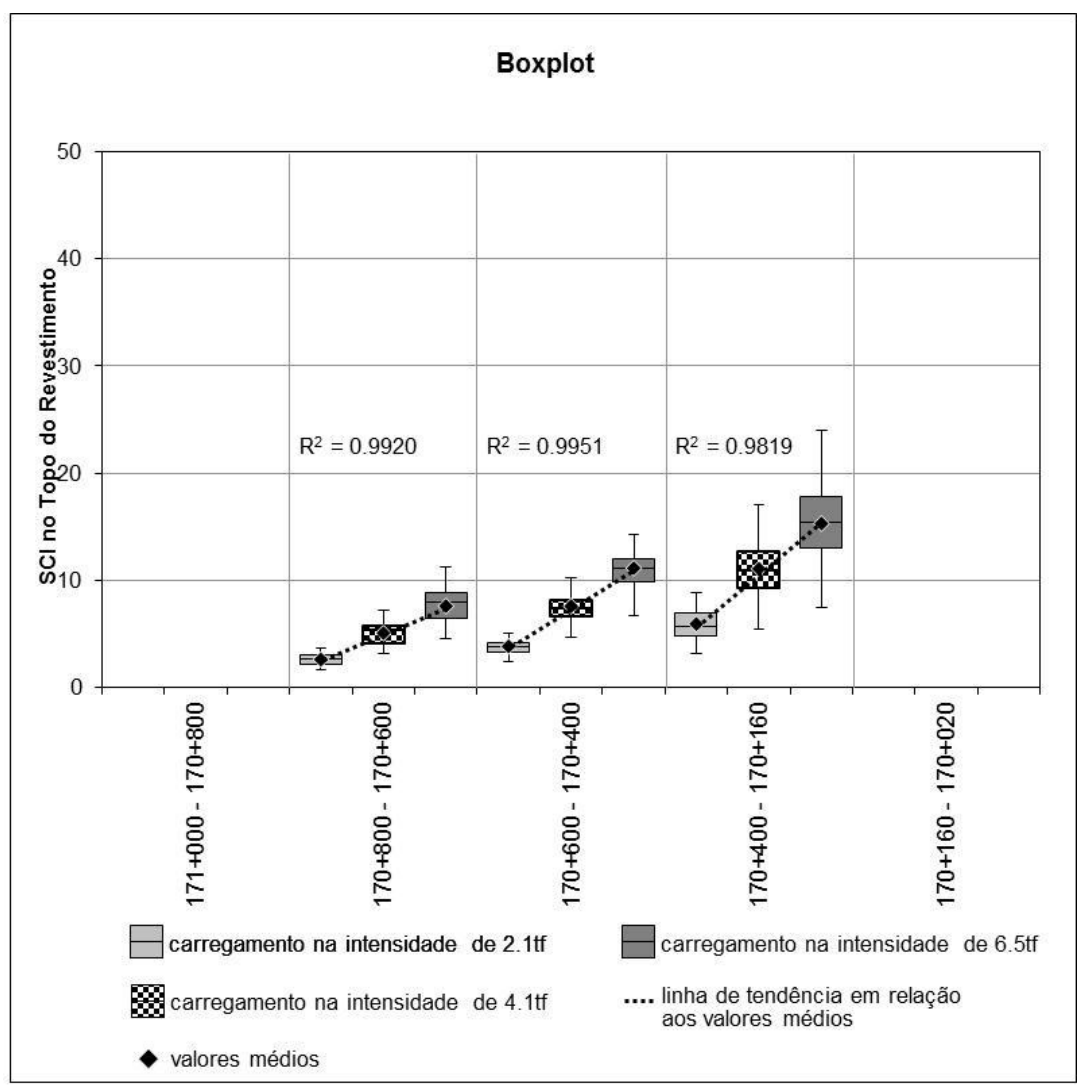

Figura 5.9 - Distribuição dos valores de SCI e seus coeficientes de determinação em cada seção experimental no Topo do Revestimento 
As Figuras 5.2 a 5.9 mostram que os dados apresentam linearidade, não sendo notadas variações significativas nas respostas às intensidades de carga a partir de suas alterações. Este fato pode ser corroborado com os valores encontrados nos coeficientes de determinação $\left(R^{2}\right)$ próximos a 1,0 para todos os casos. Estatisticamente, quanto mais próximo da unidade estiver $\circ \mathrm{R}^{2}$, tanto maior será a validade da regressão, neste caso, maior sua linearidade. Portanto, percebe-se uma significativa tendência linear dos valores de D0 e SCI.

\subsubsection{Análise das Medidas de Deflexões}

\subsubsection{Análise das Medidas de Deflexões entre Seções de Estruturas de Comportamentos Similares}

Para comparar os valores das medidas de deflexões no Trecho Experimental a fim de avaliar a influência das características do pavimento construído, como o substrato remanescente $^{17}$ à camada de EME, e as espessuras da camada de EME, foram elaborados gráficos para esclarecer se existem fatores intervenientes nas medidas de deflexões e como são suas repostas ante as estruturas executadas com camada de base em EME.

Primeiramente, é apresentada a Tabela 5.2 onde são definidas as faixas de valores deflectométricos que enquadram as deflexões dos substratos remanescentes com ordem de grandezas similares.

\footnotetext{
${ }^{17} \mathrm{O}$ substrato remanescente refere-se às camadas inferiores a de EME, inclusive subleito.
} 
Tabela 5.2 - Faixas de valores deflectométricos para os substratos remanescentes

\begin{tabular}{|c|c|}
\hline \multicolumn{2}{|c|}{ Faixa de Valor $\left(\times 10^{-2} \mathrm{~mm}\right)$} \\
\hline Mínimo & Máximo \\
\hline 10 & 30 \\
\hline 30 & 50 \\
\hline 50 & 70 \\
\hline 70 & 90 \\
\hline 90 & 110 \\
\hline & $>110$ \\
\hline
\end{tabular}

De posse destes valores, expõem-se as Figuras 5.10 a 5.18, onde são apresentadas as bacias deflectométricas em cada uma das seções executadas.

Distância dos sensores (cm)

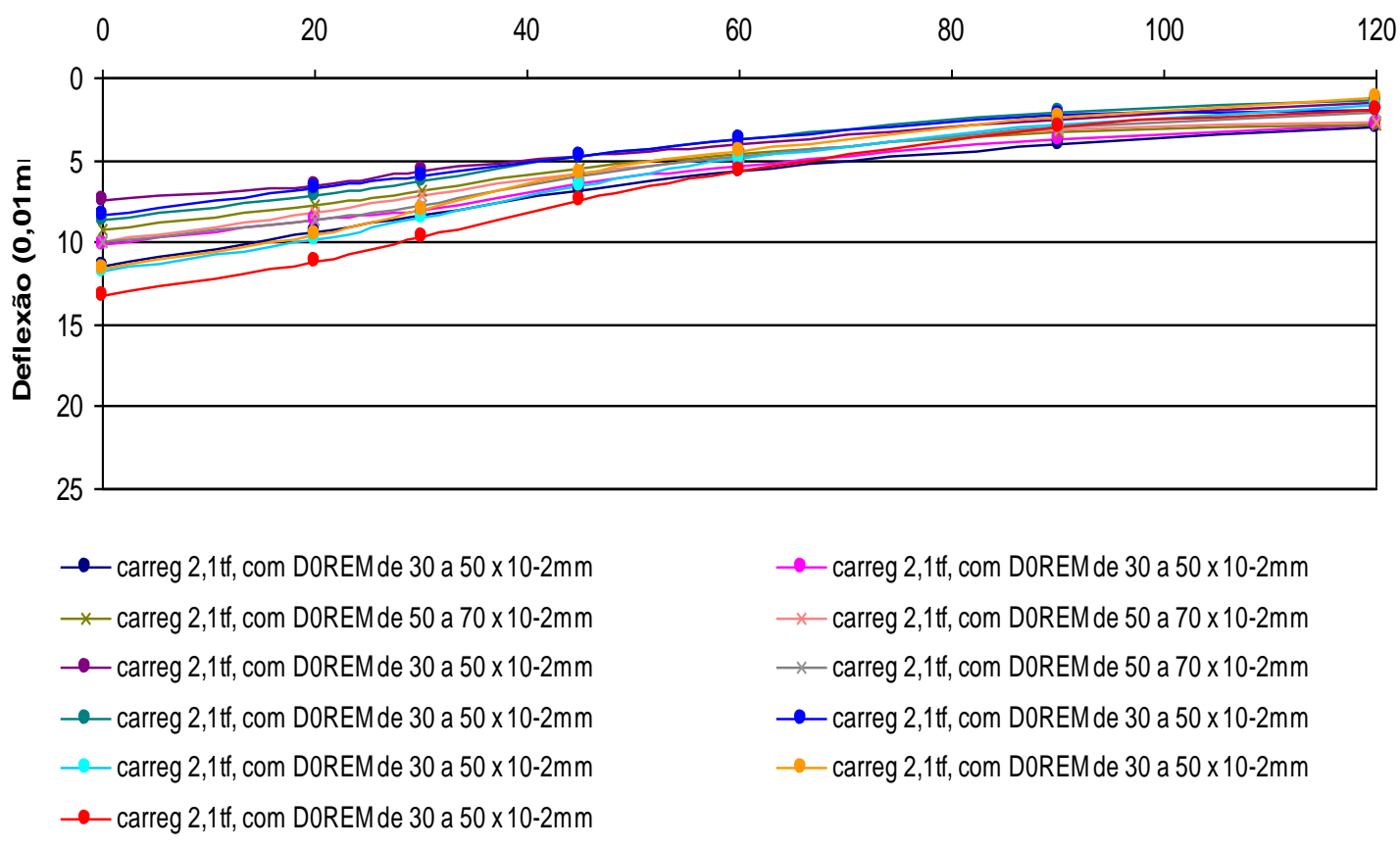

Figura 5.10 - Bacias de deflexões na seção de 140 mm de EME da pista experimental, com intensidade de carregamento de 2,1 tf 
Distância dos sensores (cm)

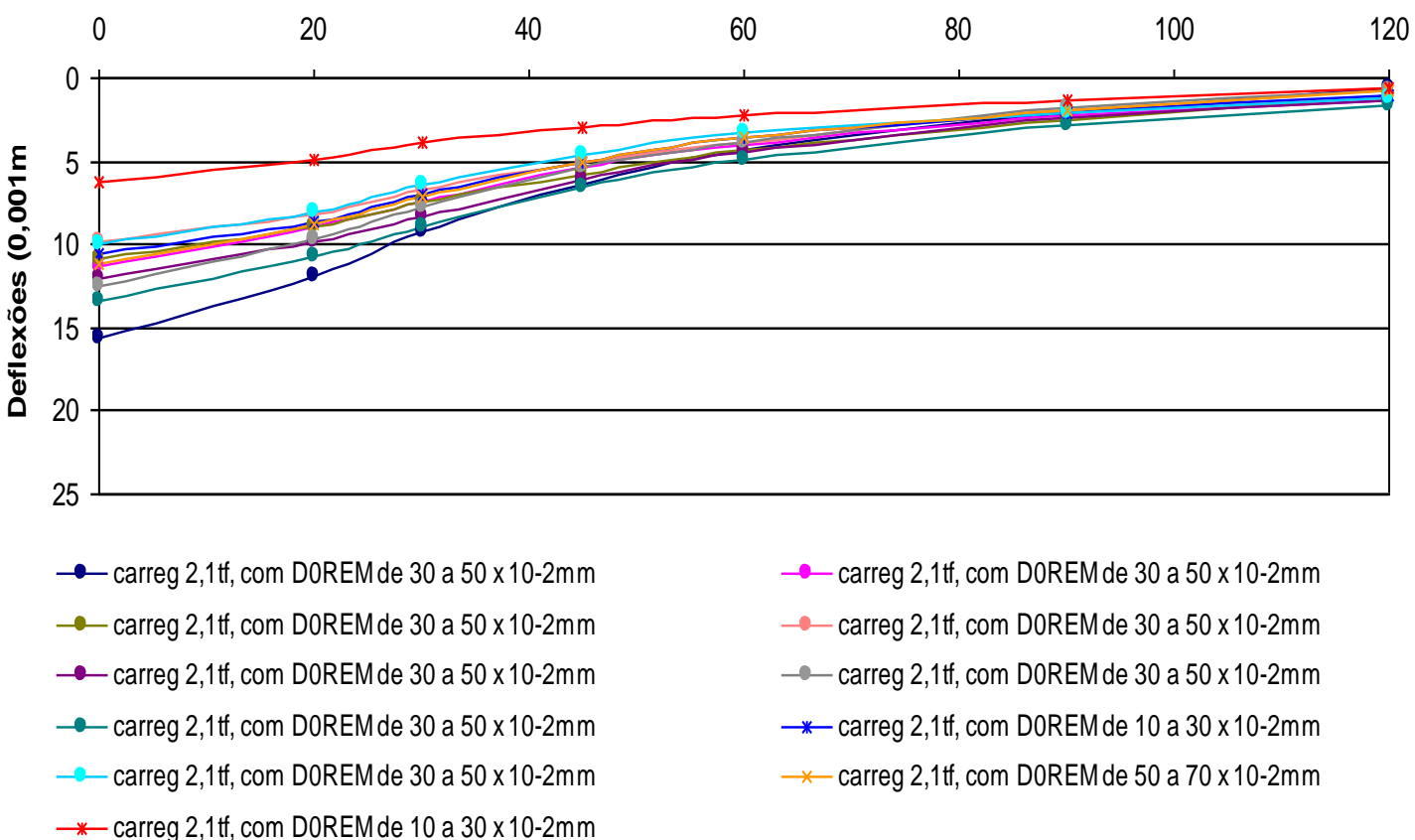

Figura 5.11 - Bacias de deflexões na seção de $110 \mathrm{~mm}$ de EME da pista experimental, com intensidade de carregamento de $2,1 \mathrm{tf}$

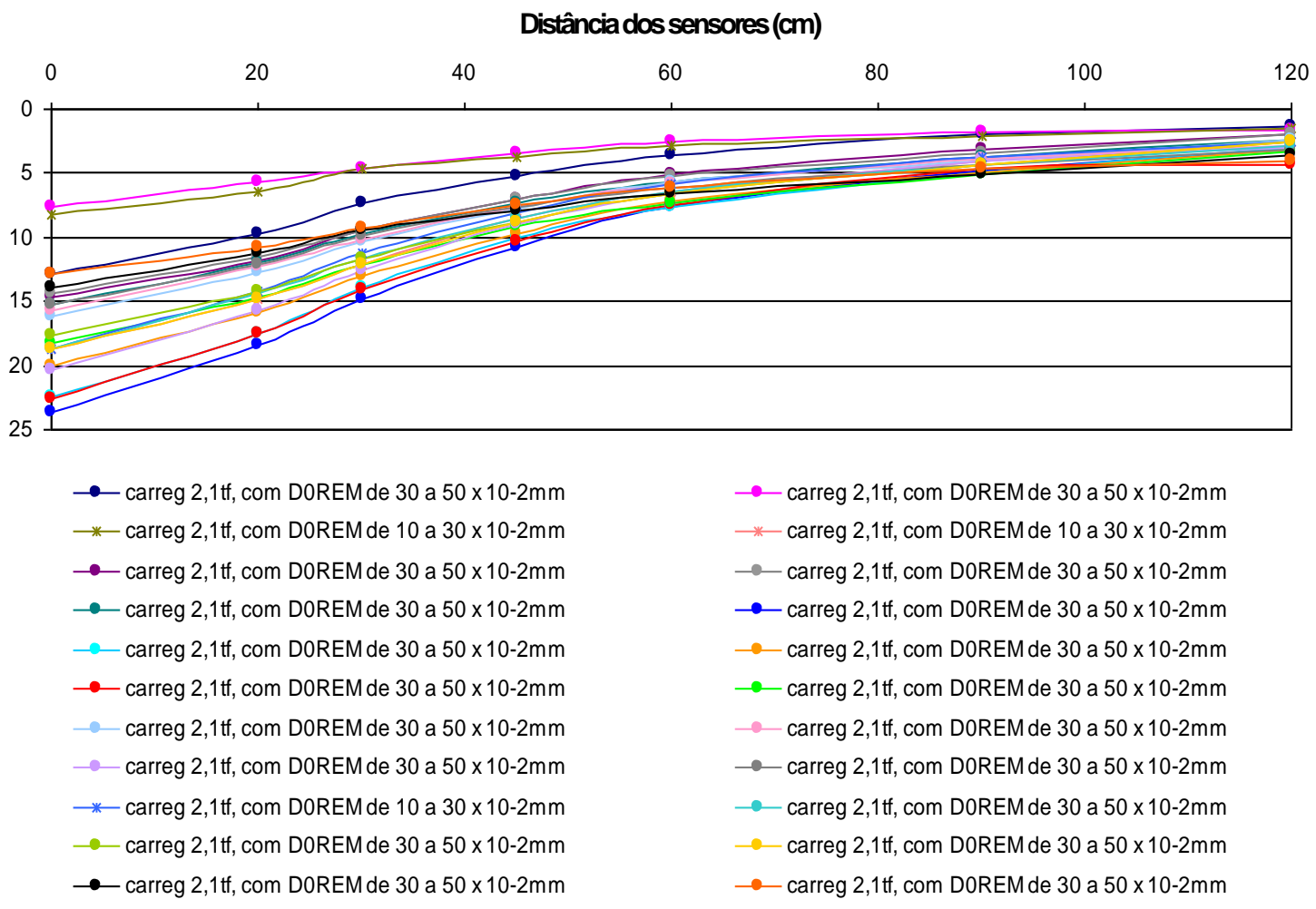

Figura 5.12 - Bacias de deflexões na seção de $80 \mathrm{~mm}$ de EME da pista experimental, com intensidade de carregamento de 2,1 tf 
Distância dos sensores (cm)

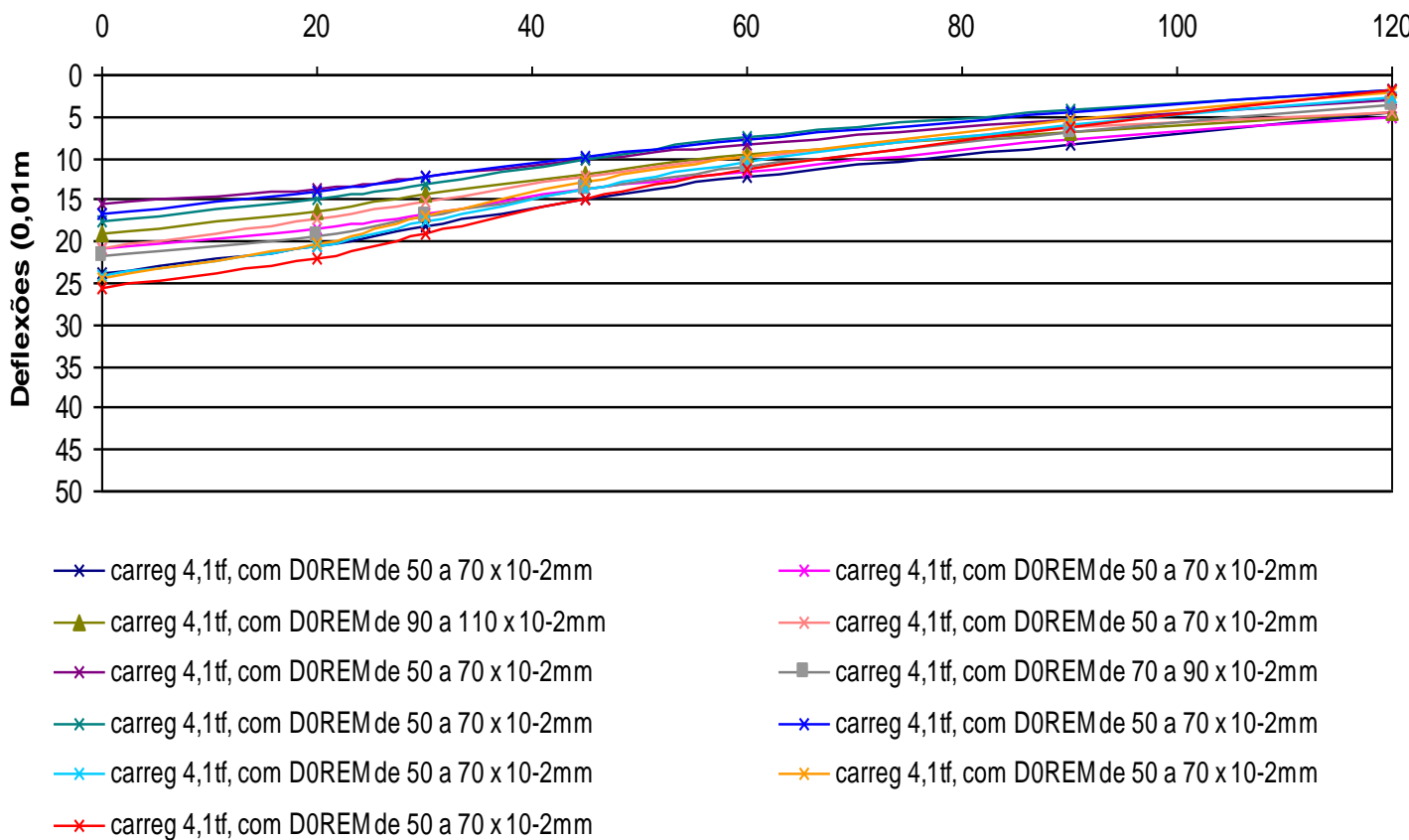

Figura 5.13 - Bacias de deflexões na seção de 140 mm de EME da pista experimental, com intensidade de carregamento de 4,1tf

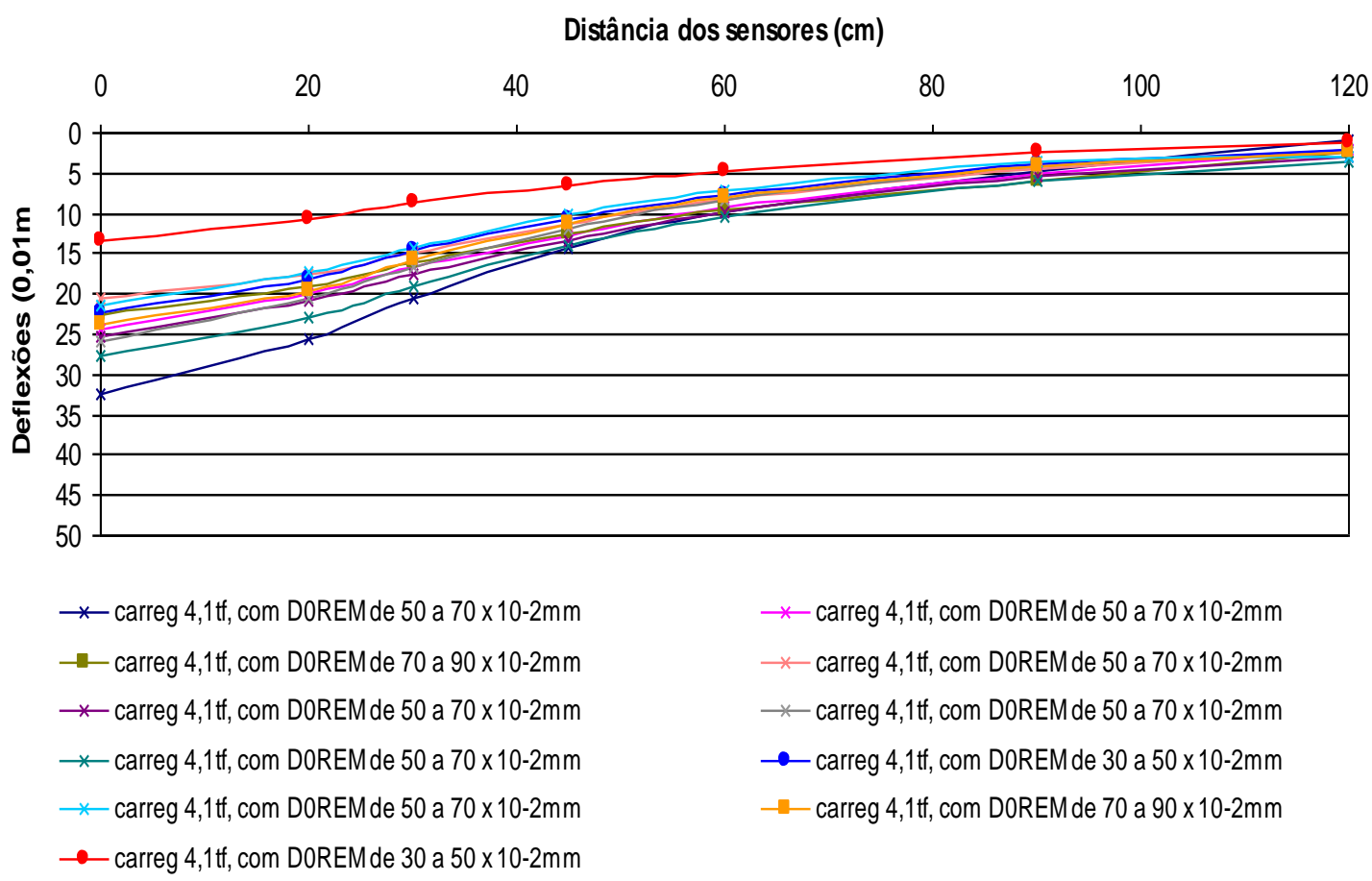

Figura 5.14 - Bacias de deflexões na seção de $110 \mathrm{~mm}$ de EME da pista experimental, com intensidade de carregamento de 4,1tf 
Distância dos sensores (cm)

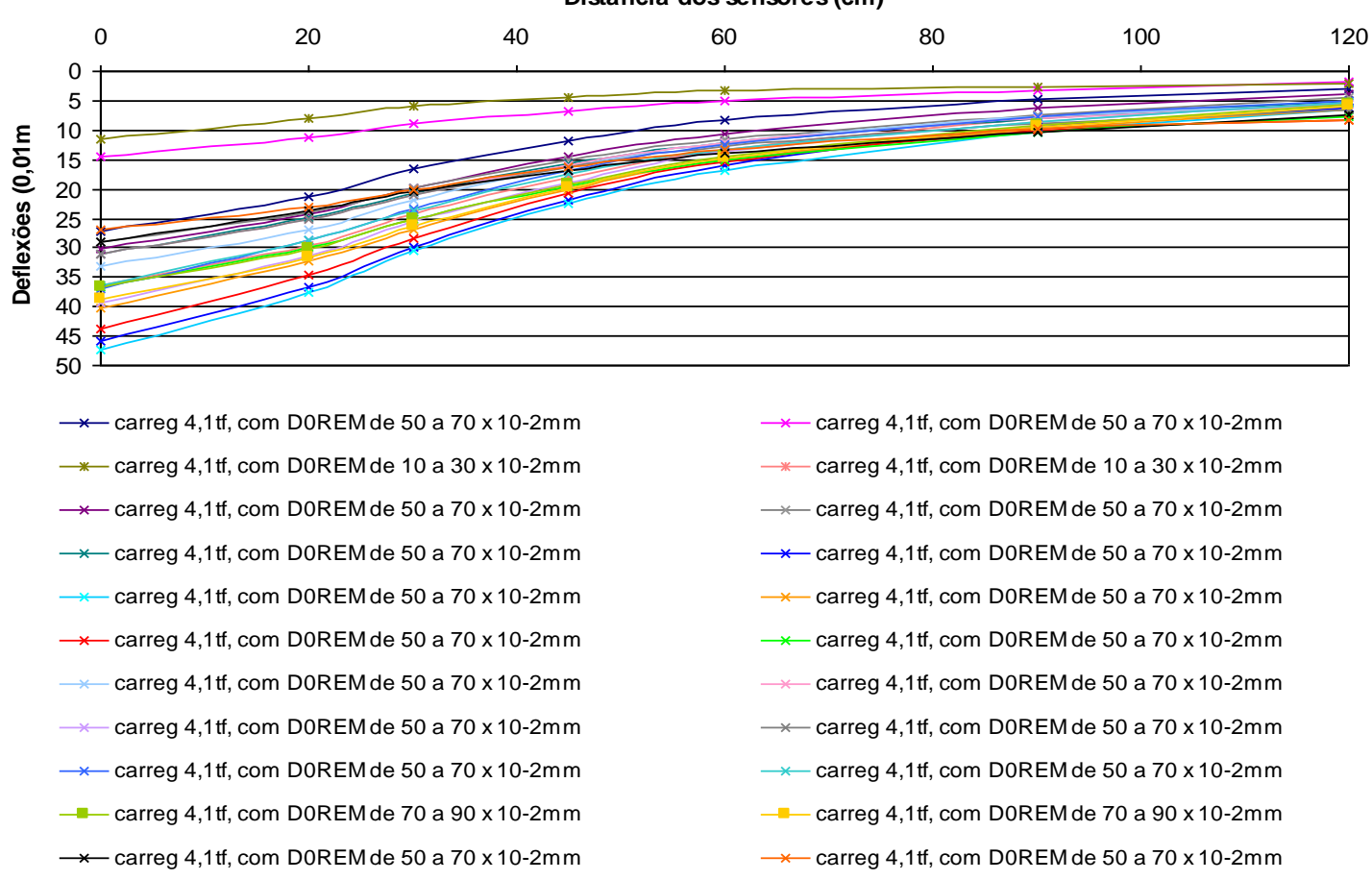

Figura 5.15 - Bacias de deflexões na seção de $80 \mathrm{~mm}$ de EME da pista experimental, com intensidade de carregamento de 4,1tf

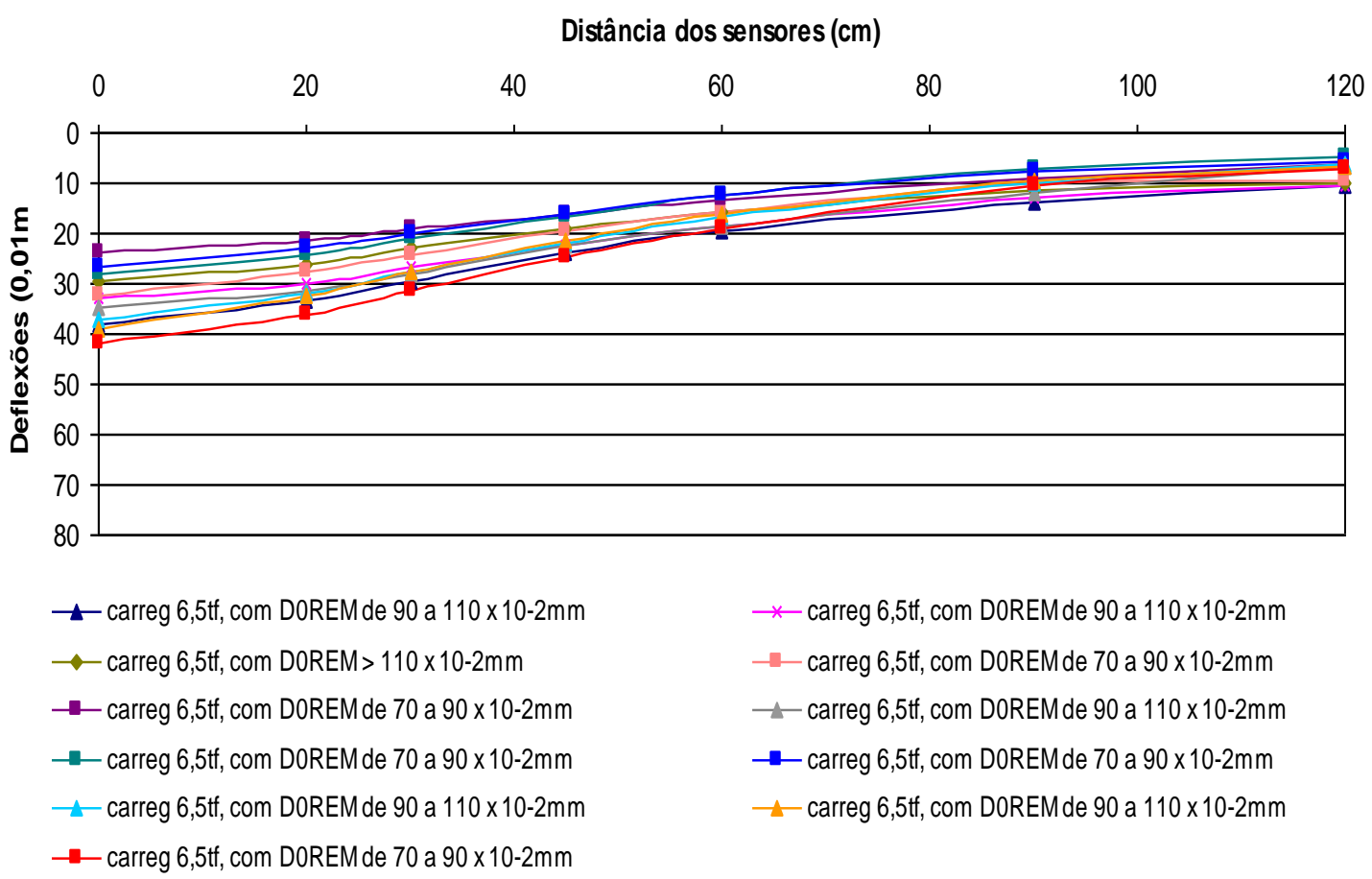

Figura 5.16 - Bacias de deflexões na seção de 140 mm de EME da pista experimental, com intensidade de carregamento de 6,5tf 
Distância dos sensores (cm)

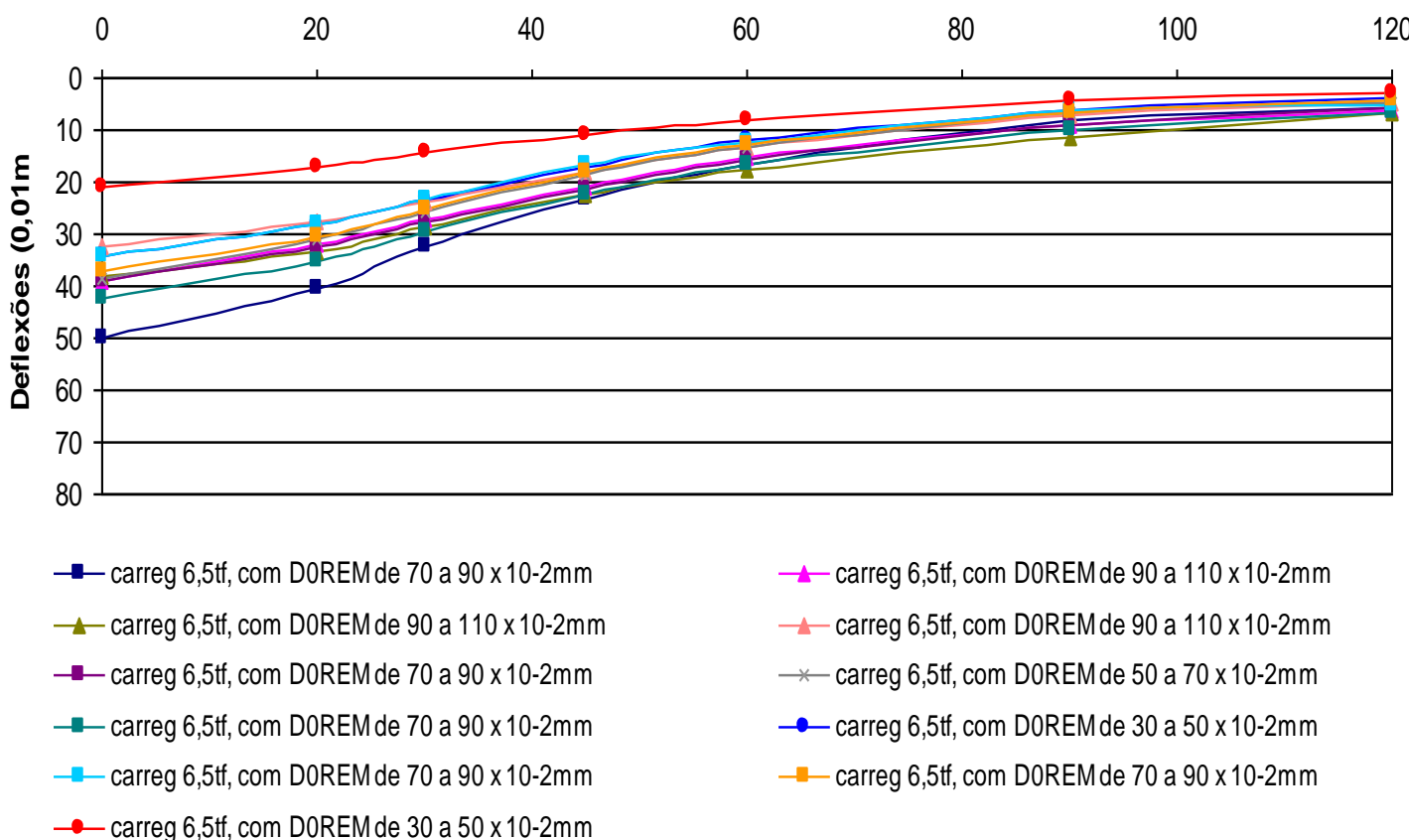

Figura 5.17 - Bacias de deflexões na seção de $110 \mathrm{~mm}$ de EME da pista experimental, com intensidade de carregamento de 6,5tf

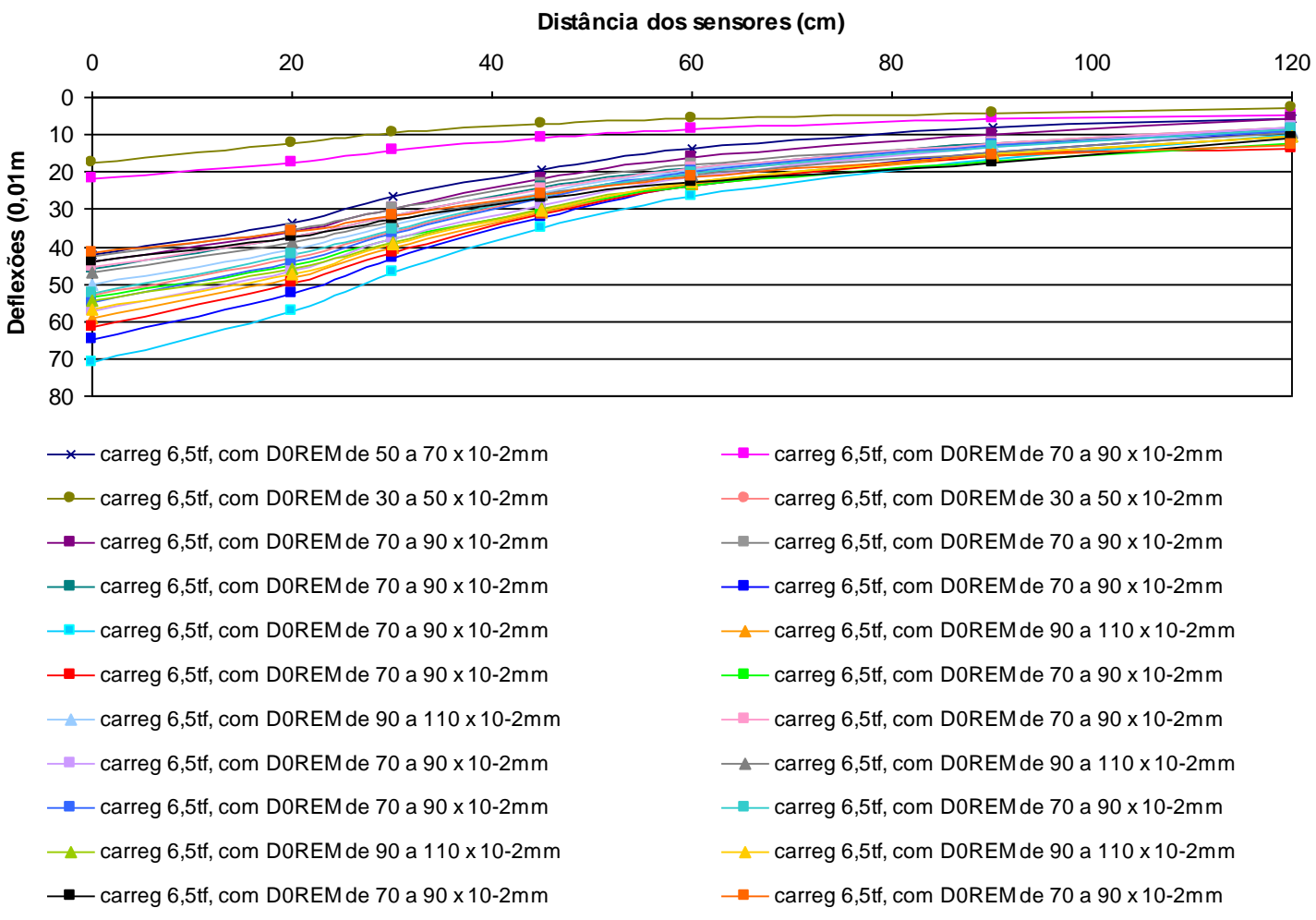

Figura 5.18 - Bacias de deflexões na seção de $80 \mathrm{~mm}$ de EME da pista experimental, com intensidade de carregamento de 6,5tf 
Ao comparar as medidas de deflexões nas camadas de EME assentadas em substratos remanescentes com mesma faixa de valores deflectométricos; ou seja, com capacidade de suporte equivalente; e diferentes espessuras (140, 110 e $80 \mathrm{~mm}$ ), nota-se que camadas de EME mais esbeltas sofrem maiores deslocamentos verticais que as mais espessas, como no caso das deflexões em camadas de EME onde a faixas de valores deflectométricos variam de 10 a $30 \times 10^{-2} \mathrm{~mm}$, para a carga de 2,1tf, nas Figuras 5.105 .11 e 5.12; como também nas faixas que variam de 30 a 50 $\times 10^{-2} \mathrm{~mm}$, para as cargas de 4,1tf e 6,5tf, nas Figuras de 5.13 a 5.18 .

Observa-se ainda, nas Figuras de 5.10 a 5.18, que para a mesma intensidade de carregamento os deslocamentos verticais nas camadas de EME não mantêm proporcionalidade em relação às faixas de deflexão do substrato remanescente. Este fato demonstra que a camada de EME é a responsável pelo controle dos esforços atuantes na estrutura do pavimento por ela constituído.

\subsubsection{Análise das Medidas de Deflexão ao longo do Trecho Experimental}

Para avaliar a evolução deflectométrica nos diversos Estágios de suas leituras é apresentada a Figura 5.19. 


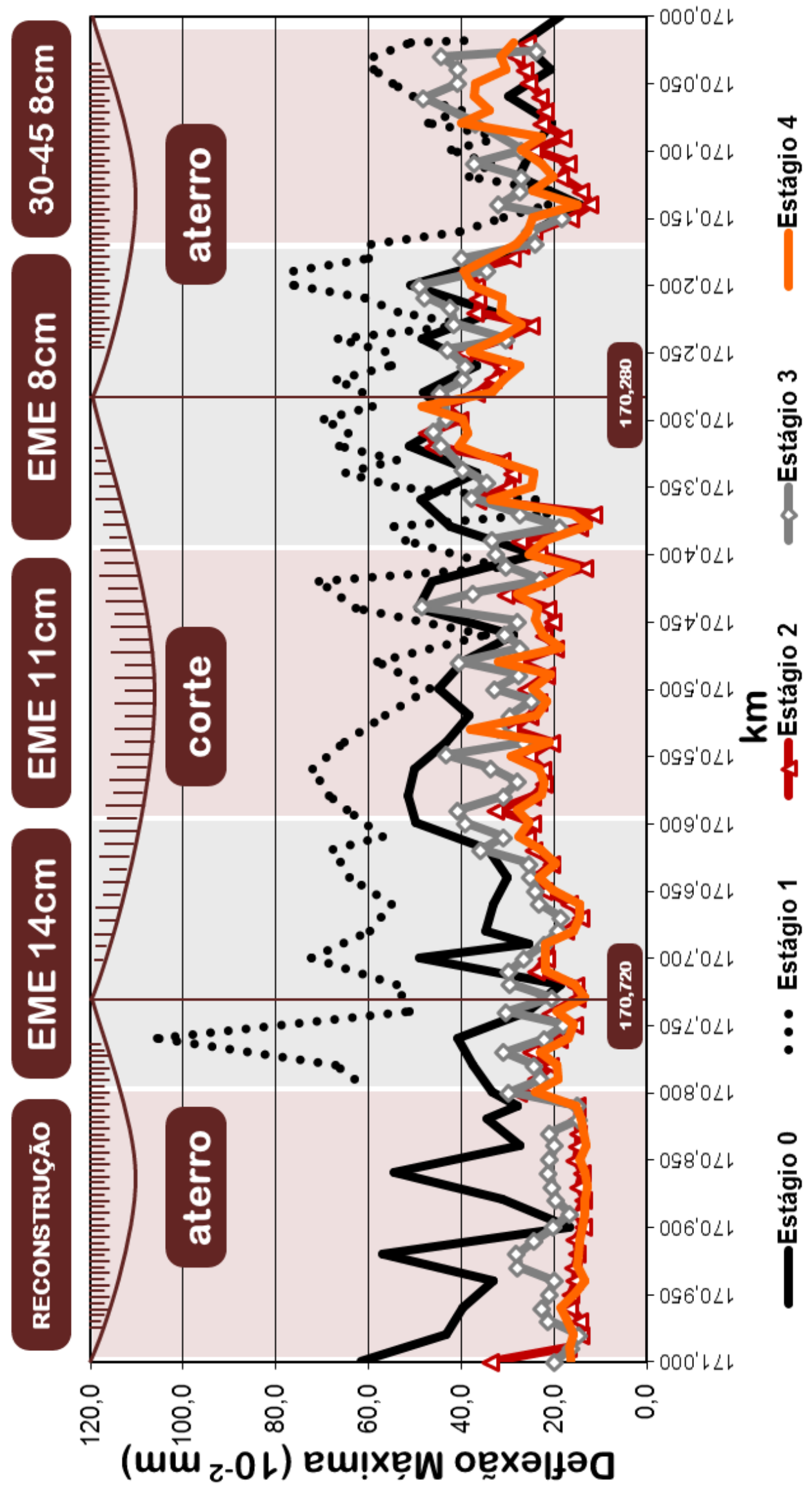

Figura 5.19 - Medidas de deflexão máxima ao longo do Trecho Experimental, nos diversos Estágios 
Observa-se na Figura 5.19 que de maneira geral as deflexões no Estágio 3 são superiores às do Estagio 4. Isto se deve ao fato que as deflexões no Estágio 3 foram executadas imediatamente após a execução da camada de rolamento e as deflexões no Estágio 4 após a execução do dreno de proteção e após seis meses da execução da camada de rolamento.

É possível observar também que; para a Seção de Referência SRf-01 e as Seções Experimentais SEx-01, SEx-02 e SEx-03; as deflexões após seis meses da execução da camada de rolamento alcançaram os mesmos níveis deflectométricos encontrados no Estágio 2 onde o levantamento deflectométrico foi executado no topo da camada de EME. Entretanto, na Seção de Referência SRf-02 foi observada uma evolução deflectométrica quando da comparação das deflexões do Estágio 2 com as do Estágio 4, revelando que, apesar de a Seção SRf-02 estar em situação de terraplenagem mais favorável (Aterro) que a Seção SEx-03 (parte em Corte e outra parte em Aterro), a camada de $80 \mathrm{~mm}$ de EME tem respondido melhor aos esforços solicitantes que a camada de $80 \mathrm{~mm}$ de CBUQ convencional (CAP 30-45).

\subsubsection{Retroanálises dos Módulos de Resiliência das Camadas de EME}

Nas Figura 5.20, 5.21 e 5.22 são apresentados os valores de módulo de resiliência das camadas de EME retroanalisados com as deflexões antes e após a execução do revestimento, respectivamente, a partir das cargas aplicadas nas seções experimentais. Recorda-se que, para proporcionar as leituras deflectométricas estudadas, os carregamentos foram efetuados a partir de três intensidades distintas de carregamento: 2,1tf; 4,1tf e 6,5tf.

Todas as bacias deflectométricas, em todos os Estágios e em todas as intensidades de carga, foram retroanalisadas pelo programa computacional EVERCALC. 


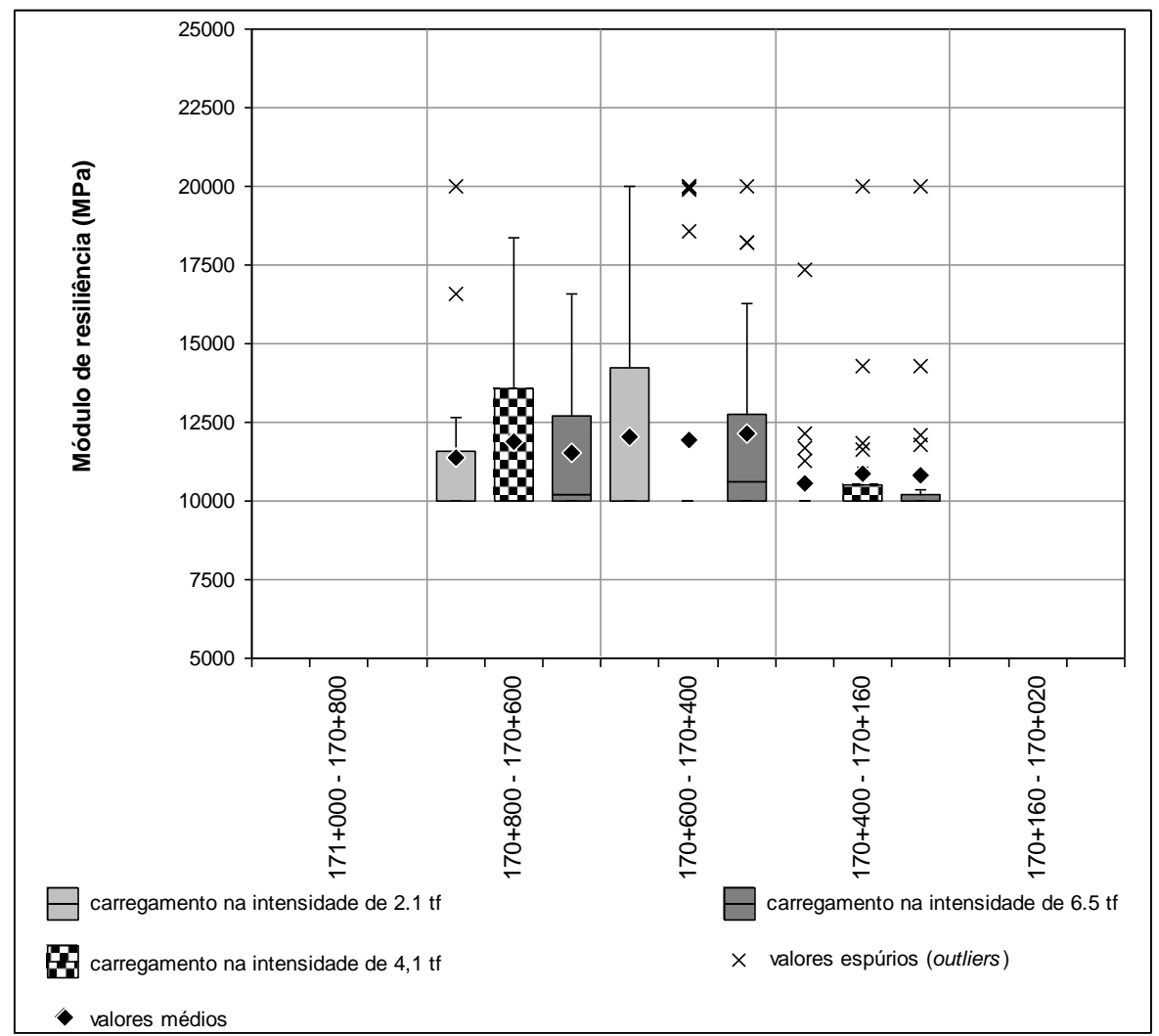

Figura 5.20 - Módulo de resiliência da Camada de EME, levantamento no Estágio 2 (final da obra do EME)

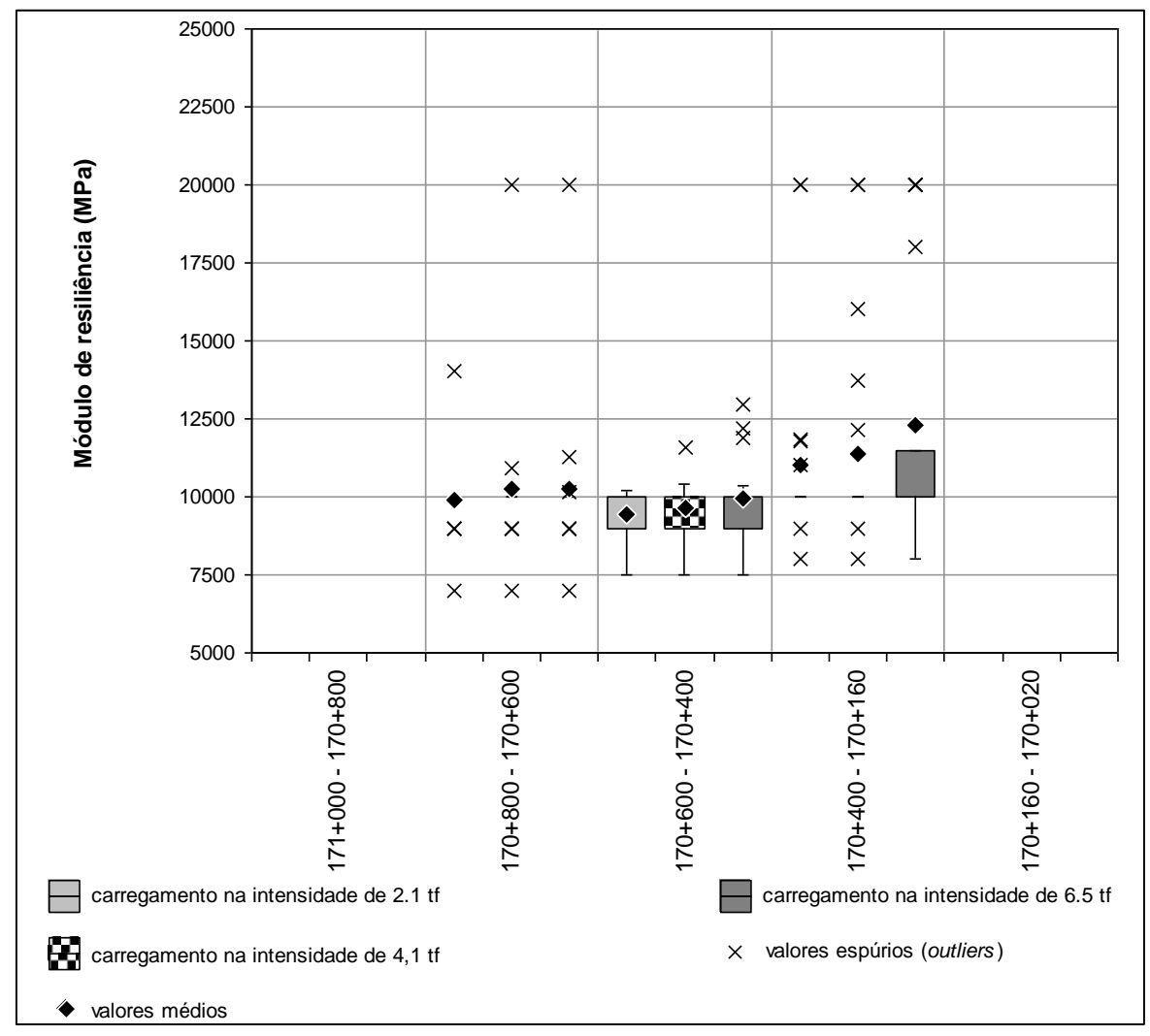

Figura 5.21 - Módulo de resiliência da Camada de EME, levantamento no Estágio 3 


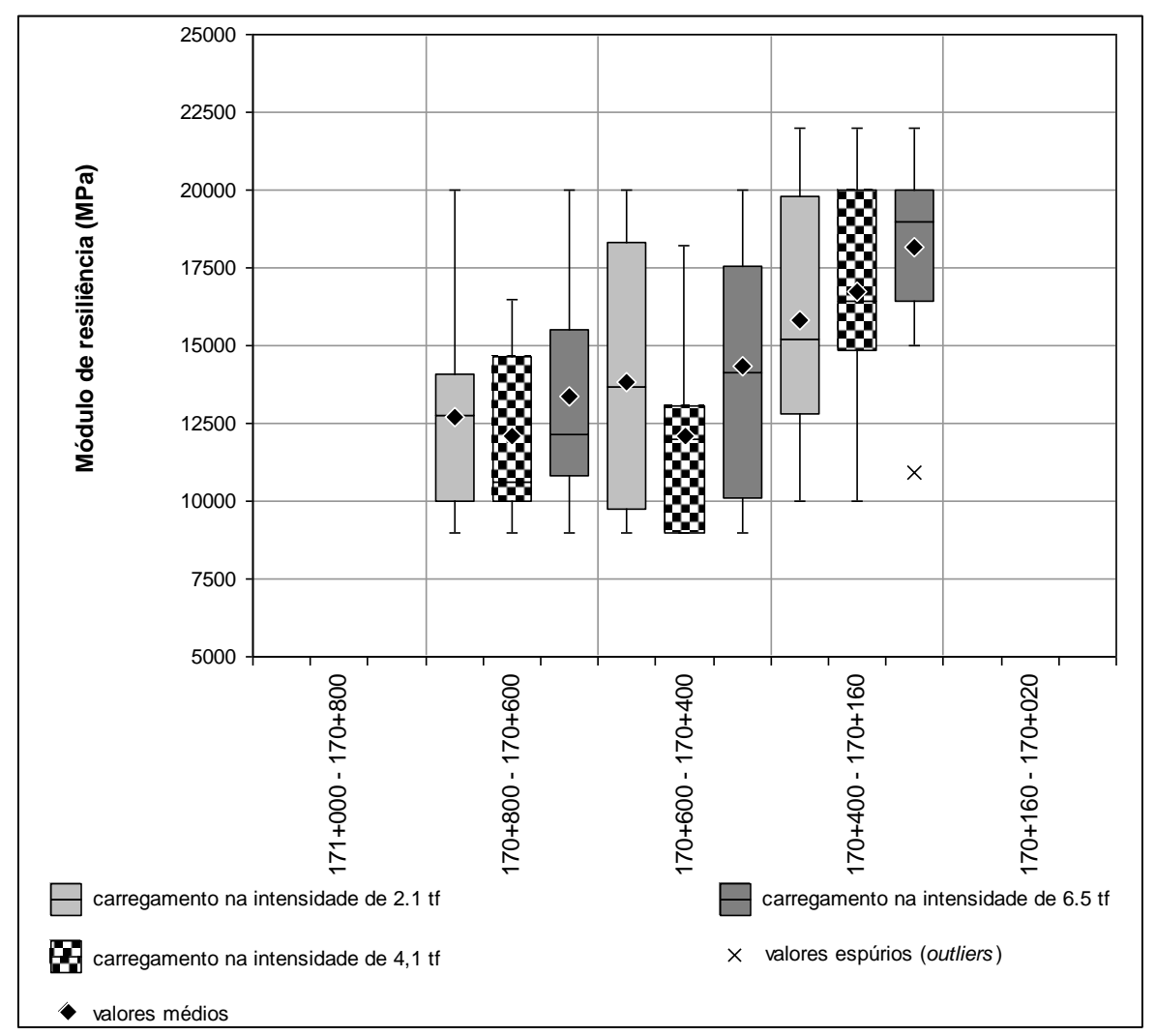

Figura 5.22 - Módulo de resiliência da Camada de EME, levantamento no Estágio 4

O módulo de resiliência do EME retroanalisado variou na faixa de 10.000 a 14.226 MPa, para a situação antes da execução do revestimento (Estágio 2), com o valor médio de $11.459 \mathrm{MPa}$. Para a situação imediatamente após a execução do

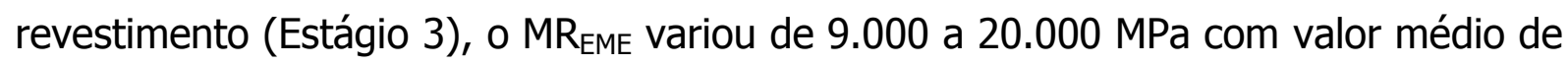
$M R_{E M E}$ de $10.461 \mathrm{MPa}$, valor inferior àquele encontrado na situação anterior à execução do revestimento (Estágio 2).

Ao serem comparados os valores modulares segundo o levantamento deflectométrico após seis meses da execução da camada de revestimento (Estágio 4), percebe-se a importância e a eficiência do dispositivo de drenagem executado. Tal dispositivo possibilitou controlar a água contida nas camadas remanescentes da estrutura do pavimento e recuperar os módulos de resiliência do $E M E$, atingindo um valor médio de $14.348 \mathrm{MPa}$. As Figuras 5.23 e 5.24 mostram a condição de saturação nas camadas remanescentes do pavimento e o dispositivo de drenagem executado, respectivamente. 


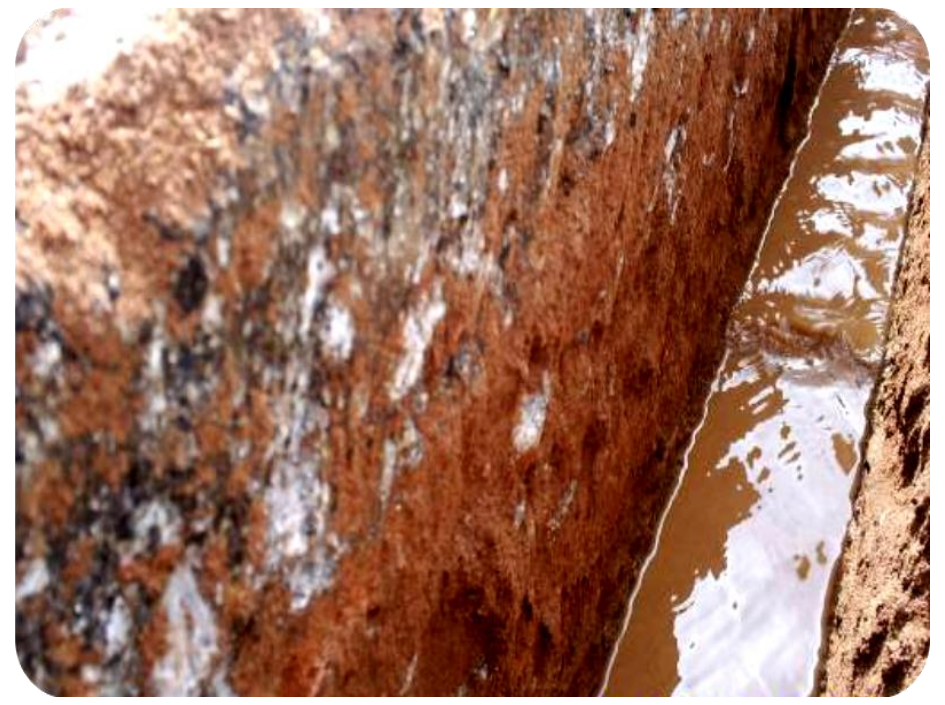

Figura 5.23 - Condição de saturação das camadas do pavimento, em agosto de 2010

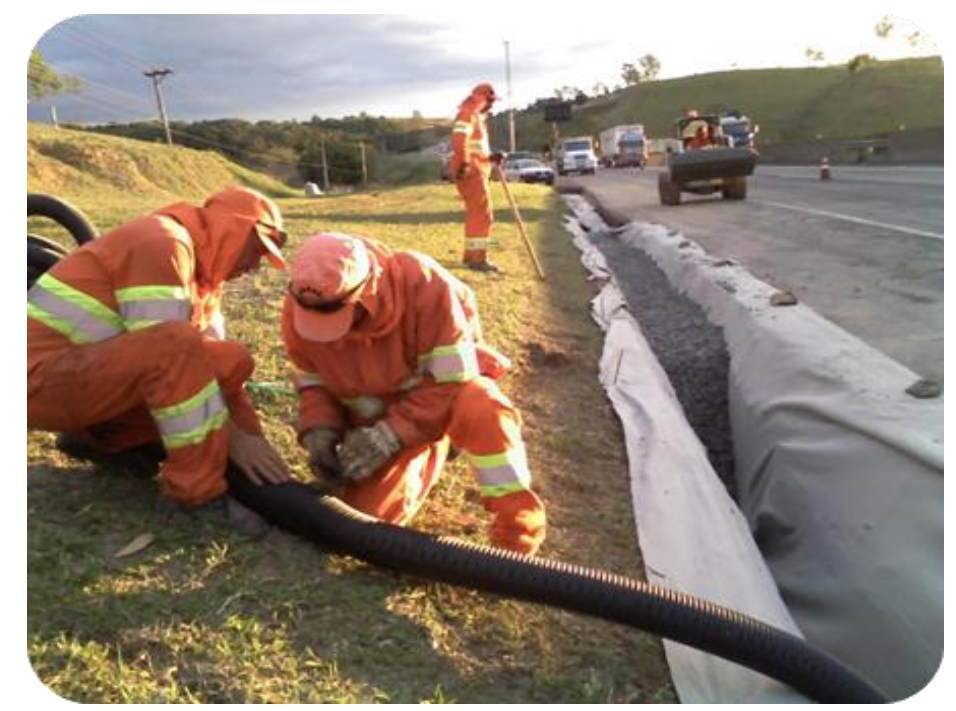

Figura 5.24 - Execução dos dispositivos de drenagem, em agosto de 2010

Dos resultados obtidos nas Figuras 5.20, 5.21 e 5.22, observa-se que os módulos de resiliência da camada de EME nos Estágios 2 e 4 resultaram em valores adequados para o desempenho de uma estrutura constituída de camada de base em EME principalmente quando comparados aos valores indicados nos estudos paramétricos preconizados por VILLELA et al (2009).

Ainda com relação aos valores de módulo de resiliência retroanalisados para diversas intensidades de carregamento pode-se verificar pela a análise de variância (ANOVA) e pela distribuição de Fisher (F), que para todos os estudos apresentados nas 
Tabelas 5.3, 5.4 e 5.5 não há diferença significativa entre os grupos, segundo uma confiabilidade de $95 \%$. A confiabilidade de $95 \%$ é fortemente representativa estatisticamente revelando indícios de que os valores modulares determinados por meio de retroanálise são satisfatórios. Essa questão reforça também a análise da linearidade do sistema estrutural de multicamadas, descrita no item 5.1.2.

O conceito de módulo de resiliência é expresso pela relação entre a tensão axial aplicada e a deformação recuperável que uma estrutura (ou camada) de pavimento está sujeita a partir de um carregamento cíclico nela solicitado.

Portanto, independentemente da intensidade de carregamento pode-se deduzir que o valor de módulo de resiliência será o mesmo uma vez que as tensões e deformações atribuídas na estrutura serão proporcionais ao carregamento nela solicitado. Isto ocorre segundo teoria da elasticidade, em uma estrutura de pavimento atuando como um semi-espaço infinito, isotrópico e homogêneo. 
Tabela 5.3 - Análise de variância dos MR $R_{\mathrm{EME}}$ para os carregamentos do FWD - Estágio 2 Seção Experimental SEx-01 - Estágio 2

\begin{tabular}{l|l|r|r|r|r|}
\hline \multicolumn{1}{|c|}{ Fonte da variação } & SQ & gl & MQ & F & F crítico \\
\hline Entre grupos & $2,83 \mathrm{E}+06$ & 2 & $1,42 \mathrm{E}+06$ & $\mathbf{0 , 2 4}$ & 3,16 \\
\hline Dentro dos grupos & $3,36 \mathrm{E}+08$ & 57 & $5,90 \mathrm{E}+06$ & & \\
\hline Total & $3,39 \mathrm{E}+08$ & 59 & & & \\
\hline
\end{tabular}

Seção Experimental SEx-02 - Estágio 2

\section{Fonte da variação}

Entre grupos

Dentro dos grupos

Total

\section{Seção Experimental SEx-03 - Estágio 2}

SQ

$6,92 \mathrm{E}+08$

$6,92 \mathrm{E}+08$

\section{gl}

2

2

57

59 \begin{tabular}{|c|c|c|} 
MQ & F & F crítico \\
\hline
\end{tabular}

\begin{tabular}{r|r|r|}
\hline $2,30 \mathrm{E}+05$ & $\mathbf{0 , 0 2}$ & 3,16 \\
\hline
\end{tabular}

$1,21 \mathrm{E}+07$

\begin{tabular}{l|l|l|l|}
\hline gl & MQ & F & F crítico \\
\hline
\end{tabular}

$1,42 \mathrm{E}+06$

$2,76 \mathrm{E}+08$

$2,77 \mathrm{E}+08$ gl

$2 \quad 7,12 \mathrm{E}+05$

$66 \quad 4,18 \mathrm{E}+06$

68

Total

is - Estágio 2

\begin{tabular}{l|l|r|r|r|r}
\hline \multicolumn{1}{|c|}{ Fonte da variação } & SQ & gl & MQ & F & F crítico \\
\hline Entre grupos & $1,98 \mathrm{E}+06$ & 2 & $9,88 \mathrm{E}+05$ & $\mathbf{0 , 1 3}$ & 3,04 \\
\hline Dentro dos grupos & $1,36 \mathrm{E}+09$ & 186 & $7,33 \mathrm{E}+06$ & & \\
\hline Total & $1,37 \mathrm{E}+09$ & 188 & & & \\
\hline
\end{tabular}

Notas:

$$
\begin{aligned}
\mathrm{SQ} & =\text { soma dos quadrados } \\
\mathrm{gl} & =\text { grau de liberdade } \\
\mathrm{MQ} & =\text { média quadrada }
\end{aligned}
$$

Tabela 5.4 - Análise de variância dos $M R_{E M E}$ para os carregamentos do FWD - Estágio 3 Seção Experimental SEx-01 - Estágio 3

\begin{tabular}{|l|l|r|r|r|r}
\multicolumn{1}{|c|}{ Fonte da variação } & SQ & \multicolumn{1}{|c|}{ gl } & MQ & F & F crítico \\
\hline Entre grupos & $1,69 \mathrm{E}+06$ & 2 & $8,43 \mathrm{E}+05$ & $\mathbf{0 , 1 9}$ & 3,16 \\
\hline Dentro dos grupos & $2,52 \mathrm{E}+08$ & 57 & $4,42 \mathrm{E}+06$ & & \\
\hline Total & $2,54 \mathrm{E}+08$ & 59 & & & \\
\hline
\end{tabular}

\section{Seção Experimental SEx-02 - Estágio 3}

\begin{tabular}{|l|l|r|r|r|r|}
\hline \multicolumn{1}{|c|}{ Fonte da variação } & SQ & \multicolumn{1}{|c|}{ gl } & MQ & F & F crítico \\
\hline Entre grupos & $2,30 \mathrm{E}+06$ & 2 & $1,15 \mathrm{E}+06$ & $\mathbf{1 , 1 2}$ & 3,16 \\
\hline Dentro dos grupos & $5,86 \mathrm{E}+07$ & 57 & $1,03 \mathrm{E}+06$ & & \\
\hline Total & $6,09 \mathrm{E}+07$ & 59 & & & \\
\hline Stal & & & & \\
\hline
\end{tabular}

\section{Seção Experimental SEx-03 - Estágio 3}

\begin{tabular}{l|l|r|l|l|r}
\hline \multicolumn{1}{|c|}{ Fonte da variação } & SQ & gl & MQ & F & F crítico \\
\hline Entre grupos & $1,85 \mathrm{E}+07$ & 2 & $9,27 \mathrm{E}+06$ & $\mathbf{0 , 7 2}$ & 3,15 \\
\hline Dentro dos grupos & $7,71 \mathrm{E}+08$ & 60 & $1,29 \mathrm{E}+07$ & & \\
\hline Total & $7,90 \mathrm{E}+08$ & 62 & & & \\
\hline
\end{tabular}

\section{Todas as Seções Experimentais - Estágio 3}

\begin{tabular}{|l|l|r|r|r|r|}
\hline \multicolumn{1}{|c|}{ Fonte da variação } & SQ & gl & MQ & F & F crítico \\
\hline Entre grupos & $1,59 \mathrm{E}+07$ & 2 & $7,95 \mathrm{E}+06$ & $\mathbf{1 , 1 8}$ & 3,05 \\
\hline Dentro dos grupos & $1,21 \mathrm{E}+09$ & 180 & $6,72 \mathrm{E}+06$ & & \\
\hline Total & $1,23 \mathrm{E}+09$ & 182 & & & \\
\hline
\end{tabular}

Notas:

$$
\begin{aligned}
\mathrm{SQ} & =\text { soma dos quadrados } \\
\mathrm{gl} & =\text { grau de liberdade } \\
\mathrm{MQ} & =\text { média quadrada }
\end{aligned}
$$


Tabela 5.5 - Análise de variância dos MR $R_{\mathrm{EME}}$ para os carregamentos do FWD - Estágio 4 Seção Experimental 01 SEx-01- Estágio 4

\begin{tabular}{|c|c|c|c|c|c|}
\hline Fonte da variação & SQ & gl & MQ & $\mathbf{F}$ & F crítico \\
\hline Entre grupos & $1,38 \mathrm{E}+07$ & 2 & $6,92 E+06$ & 0,80 & 3,19 \\
\hline Dentro dos grupos & $4,17 \mathrm{E}+08$ & 48 & $8,68 \mathrm{E}+06$ & & \\
\hline Total & $4,30 \mathrm{E}+08$ & 50 & & & \\
\hline \multicolumn{6}{|c|}{ Seção Experimental 02 SEx-02 - Estágio 4} \\
\hline Fonte da variação & SQ & gl & MQ & $\mathbf{F}$ & F crítico \\
\hline Entre grupos & $5,69 \mathrm{E}+07$ & 2 & $2,84 \mathrm{E}+07$ & 1,92 & 3,16 \\
\hline Dentro dos grupos & $8,44 \mathrm{E}+08$ & 57 & $1,48 \mathrm{E}+07$ & & \\
\hline Total & $9,01 \mathrm{E}+08$ & 59 & & & \\
\hline
\end{tabular}

Seção Experimental SEx-03 - Estágio 4

\begin{tabular}{l|l|l|l|l|r}
\hline \multicolumn{1}{c|}{ Fonte da variação } & SQ & gl & MQ & F & F crítico \\
\hline Entre grupos & $6,06 \mathrm{E}+07$ & 2 & $3,03 \mathrm{E}+07$ & $\mathbf{3 , 1 0}$ & 3,14 \\
\hline Dentro dos grupos & $6,15 \mathrm{E}+08$ & 63 & $9,77 \mathrm{E}+06$ & & \\
\hline Total & $6,76 \mathrm{E}+08$ & 65 & & & \\
\hline
\end{tabular}

Todas as Seções Experimentais - Estágio 4

\begin{tabular}{l|l|r|c|c|c}
\hline \multicolumn{1}{c|}{ Fonte da variação } & SQ & gl & MQ & F & F crítico \\
\hline Entre grupos & $8,79 \mathrm{E}+07$ & 2 & $4,40 \mathrm{E}+07$ & $\mathbf{3 , 0 2}$ & 3,05 \\
\hline Dentro dos grupos & $2,53 \mathrm{E}+09$ & 174 & $1,45 \mathrm{E}+07$ & & \\
\hline Total & $2,62 \mathrm{E}+09$ & 176 & & & \\
\hline
\end{tabular}

Notas:

$$
\begin{aligned}
\mathrm{SQ} & =\text { soma dos quadrados } \\
\mathrm{gl} & =\text { grau de liberdade } \\
\mathrm{MQ} & =\text { média quadrada }
\end{aligned}
$$

\subsection{AVALIAÇÃO DA CONCENTRAÇÃO DE DEFEITOS}

Para avaliar a condição de degradação da superfície do pavimento, nos vários estágios, foi realizado o mapeamento dos defeitos ao longo de toda a superfície do Trecho Experimental. Para tanto, foram seguidas as terminologias de defeitos de pavimento conforme a norma DNIT 005/2003 TER (DNIT, 2003). Os levantamentos tiveram também por base as normas DNIT 006/2003 PRO (DNIT, 2003b) e DNIT 007/2003 PRO (DNIT, 2003c).

A Tabela 5.6 apresenta a evolução da concentração de defeitos (\%) na superfície do pavimento, ao longo dos Estágios de levantamento: Estágio 0, Estágio 3 e Estágio 4. $\mathrm{Na}$ Tabela 5.7 tem-se as solicitações de tráfego as quais as estruturas estiveram sujeitas ao longo dos intervalos entre os Estágios. 
Tabela 5.6 - Evolução da condição geral da superfície do pavimento

\begin{tabular}{|c|c|c|c|c|c|c|c|c|c|c|}
\hline \multirow{2}{*}{\multicolumn{2}{|c|}{ km }} & \multicolumn{3}{|c|}{$\begin{array}{c}\text { Estágio } 0 \\
(26 / 06 / 2010)\end{array}$} & \multicolumn{3}{|c|}{$\begin{array}{c}\text { Estágio } 3 \\
(19 / 10 / 2010)\end{array}$} & \multicolumn{3}{|c|}{$\begin{array}{c}\text { Estágio } 4 \\
(26 / 04 / 2011)\end{array}$} \\
\hline & & \multicolumn{2}{|c|}{$\begin{array}{l}\text { Concentração } \\
\text { de defeitos }\end{array}$} & \multirow[t]{2}{*}{ IGG } & \multicolumn{2}{|c|}{$\begin{array}{c}\text { Concentração } \\
\text { de defeitos }\end{array}$} & \multirow[t]{2}{*}{ IGG } & \multicolumn{2}{|c|}{$\begin{array}{c}\text { Concentração } \\
\text { de defeitos }\end{array}$} & \multirow[t]{2}{*}{ IGG } \\
\hline Inicial & FInal & $\mathbf{m}^{2}$ & $\%$ & & $\mathbf{m}^{2}$ & $\%$ & & $\mathbf{m}^{2}$ & $\%$ & \\
\hline $171+000$ & $170+800$ & 446 & 62 & 164 & 0 & 0 & 0 & 0 & 0 & 0 \\
\hline $170+800$ & $170+600$ & 635 & 88 & 173 & 0 & 0 & 0 & 0 & 0 & 0 \\
\hline $170+600$ & $170+400$ & 684 & 95 & 187 & 0 & 0 & 0 & 3 & 0,76 & 17 \\
\hline $170+400$ & $170+160$ & 792 & 92 & 182 & 0 & 0 & 0 & 1,5 & 0,17 & 1 \\
\hline $170+160$ & $170+020$ & 342 & 68 & 167 & 0 & 0 & 0 & 41 & 8,13 & 63 \\
\hline
\end{tabular}

Tabela 5.7 - Solicitações do tráfego no Trecho Experimental

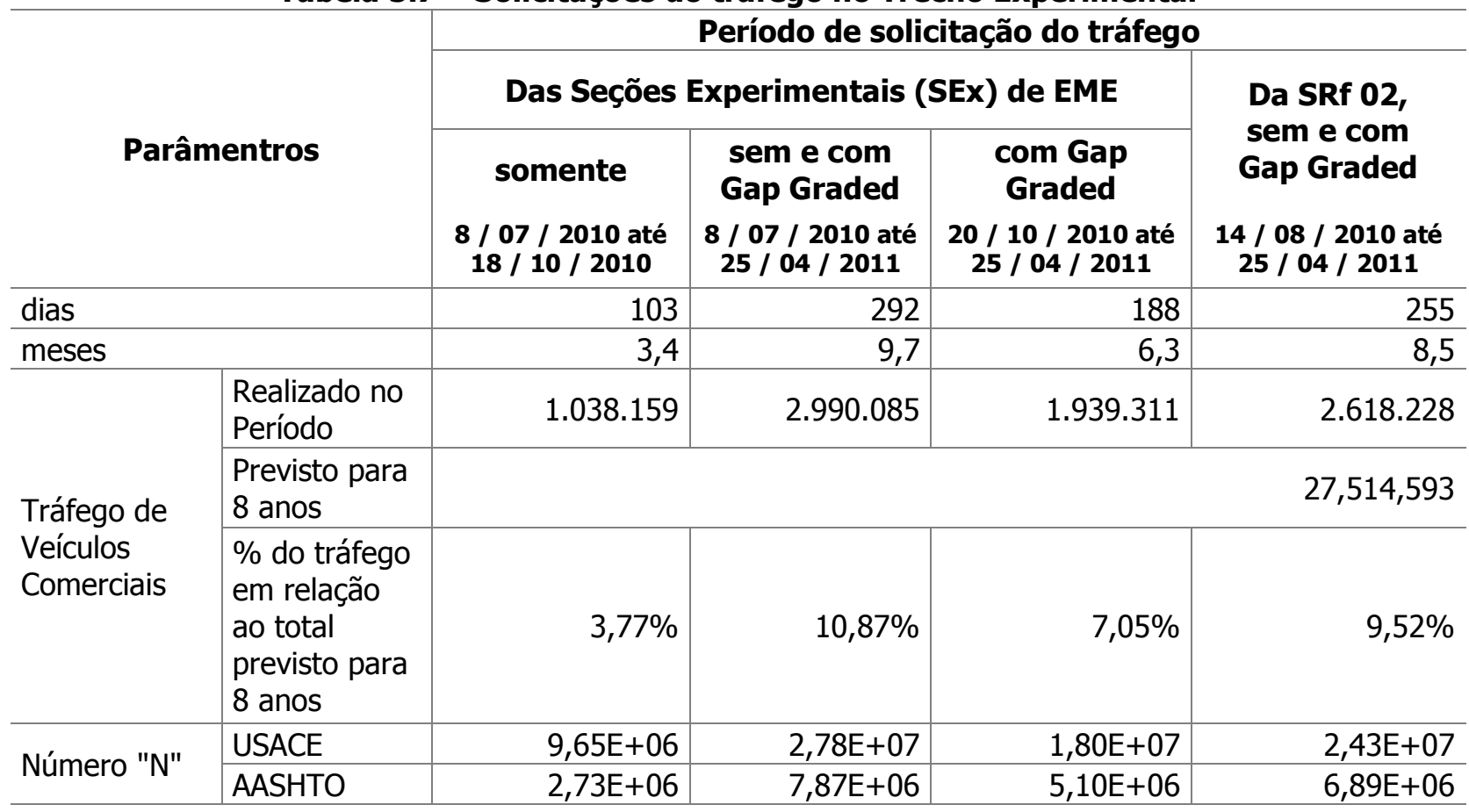

Demonstra-se nas Tabelas 5.6 e 5.7 que a última Seção (Seção de Referência SRf02); constituída de camada de $80 \mathrm{~mm}$ de CAP 30-45, com 2,6 milhões de solicitações de veículos comerciais ( $\mathrm{N}_{\text {USACE }}=2,43 \mathrm{E}+07$ e $\mathrm{N}_{\text {AASHTO }}=6,89 \mathrm{E}+06$ ); apresentou significativa concentração de defeitos $(8,13 \%$ e IGG=63). Em comparação com a Seção Experimental de mesma espessura com EME (SEx-03) cuja solicitação atingiu 2,9 milhões de veículos comerciais ( $\mathrm{N}_{\mathrm{USACE}}=2,78 \mathrm{E}+07$ e $\mathrm{N}_{\text {AASHTO }}=7,87 \mathrm{E}+06$ ), percebe-se um desempenho superior.

Por apresentar um afundamento localizado, a Seção Experimental SEx-02 foi penalizada no cálculo do IGG com um valor igual a 17. 
Salienta-se que os problemas localizados na Seção Experimental SEx-02 foram ocorridos por falta de capacidade estrutural das camadas remanescentes aliado a um possível problema de drenagem pelo fato deste ponto ser localizado em uma região de Corte. No caso da espessura de $80 \mathrm{~mm}$ de EME (SEx-03), o afundamento localizado possivelmente ocorreu por encontrar-se exatamente na transição de duas seções executadas (SEx-03 e SRf-02).

Ainda nas Tabelas 5.6 e 5.7 é possível notar que, com 2,9 milhões de veículos comerciais ( $\mathrm{N}_{\text {USACE }}=2,78 \mathrm{E}+07$ e $\mathrm{N}_{\text {AASHTO }}=7,87 \mathrm{E}+06$ ), a Seção Experimental (SEx 01) com $140 \mathrm{~mm}$ de EME não sofreu nenhum tipo de defeito tendo, até aquele momento desempenho comparável à Seção de Referência (SRf 01) com reconstrução total da estrutura do pavimento.

\subsection{AVALIAÇÃO ESTRUTURAL PELO DNER-PRO-11/79}

O procedimento PRO-11 (DNER, 1979) tem como objetivo calcular a vida remanescente ou o reforço necessário para um determinado número de solicitações do tráfego, durante o período de projeto. Baseia-se no critério de deformabilidade elástica, considerando que existe uma correlação entre as deflexões (deflexão anterior e após a execução da camada de reforço) e o aparecimento de trincas nos pavimentos asfálticos.

Segundo esse procedimento, para que não surjam trincas na camada de revestimento, deve-se manter a deflexão abaixo de um valor máximo admissível (Dadm) definido pela equação 5.1 .

$\log D_{d}=3,01-0,176 \log N$

Na equação 5.1,

$D_{d}$ é a deflexão admissível após a execução do reforço do pavimento (10-2 mm);

$\mathrm{N} \quad$ é o número " $\mathrm{N}$ " de repetições do eixo padrão brasileiro de $8,2 \mathrm{tf}$. 
A equação 5.1 é concebida para um pavimento constituído de revestimento asfáltico sobre camada de base granular, sendo solicitado por um determinado número " $\mathrm{N}$ " de repetições do eixo padrão brasileiro de $8,2 \mathrm{tf}$.

Considerando que o reforço seja constituído de concreto asfáltico, por meio do critério deflectométrico, seu cálculo emprega os seguintes modelos empíricos (equações 5.2; 5.3 e 5.4) para o dimensionamento de estruturas de comportamento flexível:

$$
\begin{aligned}
& h_{r e f}=K\left[\log \left(\frac{D_{a}}{D_{d}}\right)\right] \\
& D_{a}=1023 \cdot N^{-0,176} \\
& N=1,263 \cdot 10^{17} \cdot D_{a}^{-5,682}
\end{aligned}
$$

onde,

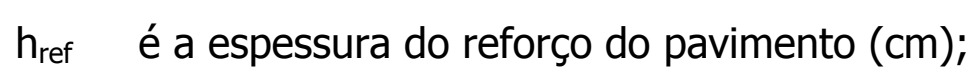

$\mathrm{K}$ é o fator de redução de deflexão, próprio do material usado no reforço;

$\mathrm{D}_{\mathrm{a}} \quad$ é a deflexão de projeto determinada na superfície do pavimento primitivo antes da execução do reforço, objeto do dimensionamento $\left(10^{-2} \mathrm{~mm}\right)$;

$D_{d} \quad$ é a deflexão admissível após a execução do reforço do pavimento $\left(10^{-2} \mathrm{~mm}\right)$;

$\mathrm{N} \quad$ é o número " $\mathrm{N}$ " de repetições do eixo padrão brasileiro de $8,2 \mathrm{tf}$.

Quando o reforço é constituído de camada asfáltica de CBUQ convencional o procedimento recomenda a adoção do valor de $K=40$. Entretanto, para o caso de verificar as características deflectométricas de um novo material a ser empregado no reforço estrutural, a partir da equação 5.2, tem-se uma nova equação (5.5) para o cálculo do valor de $\mathrm{K}$. 


$$
K=\frac{h_{r e f}}{\log \frac{D_{a}}{D_{d}}}
$$

onde,

$\mathrm{K}$ é o fator de redução de deflexão, próprio do material usado no reforço;

$\mathrm{h}_{\text {ref }}$ é a espessura do reforço do pavimento $(\mathrm{cm})$;

$D_{a} \quad$ é a deflexão de projeto determinada na superfície do pavimento primitivo antes da execução do reforço, objeto do dimensionamento $\left(10^{-2} \mathrm{~mm}\right)$;

$D_{d} \quad$ é a deflexão admissível após a execução do reforço do pavimento $\left(10^{-2} \mathrm{~mm}\right)$;

FONSECA et al (2007) desenvolveram modelos genéricos para a determinação da espessura de reforço em asfalto borracha. Os autores concluíram que o concreto asfáltico com ligante modificado apresenta um desempenho estrutural melhor se comparado ao concreto asfáltico convencional e, a partir dos estudos desenvolvidos, propuseram a utilização da constante $\mathrm{K}=35$ no lugar do valor 40 .

\subsubsection{Modelos Propostos para Misturas Asfálticas de Módulo Elevado (EME)}

\subsubsection{Fator de Redução K de Deflexão para EME}

Segundo FONSECA et al (2007), a partir do mesmo raciocínio desenvolvido para a elaboração dos modelos (5.3) e (5.4) é possível calcular os modelos genéricos para previsão da redução de deflexão após a execução do reforço e também para a estimativa da vida útil provável da nova estrutura.

Como mencionado anteriormente, todos os levantamentos deflectométricos para o estudo desta tese foram executados com FWD. Porém o procedimento PRO 11 (DNER, 1979) define que as deflexões sejam levantadas com VBK. Desta forma, foi tomado como ponto inicial o cálculo do valor de K para a Seção de Referência 2 (SRf 02), executada com asfalto convencional na espessura de $80 \mathrm{~mm}$. 
Nesta análise foi verificada para o eixo padrão brasileiro uma faixa de valores de $\mathrm{K}$ compreendida entre 30 e 54, em um grau de confiabilidade de 68,3\%, com o valor médio de $\mathrm{K}=42$. Como o valor médio encontrado é apenas $5 \%$ superior ao valor recomendado no procedimento PRO $11(K=40)$, tomou-se como satisfatório o levantamento deflectométrico com FWD para analisar o potencial de redução de deflexão que a camada de EME pode apresentar. Assim a Figura 5.25 apresenta as faixas dos valores de $\mathrm{K}$ encontrados para cada carregamento. 


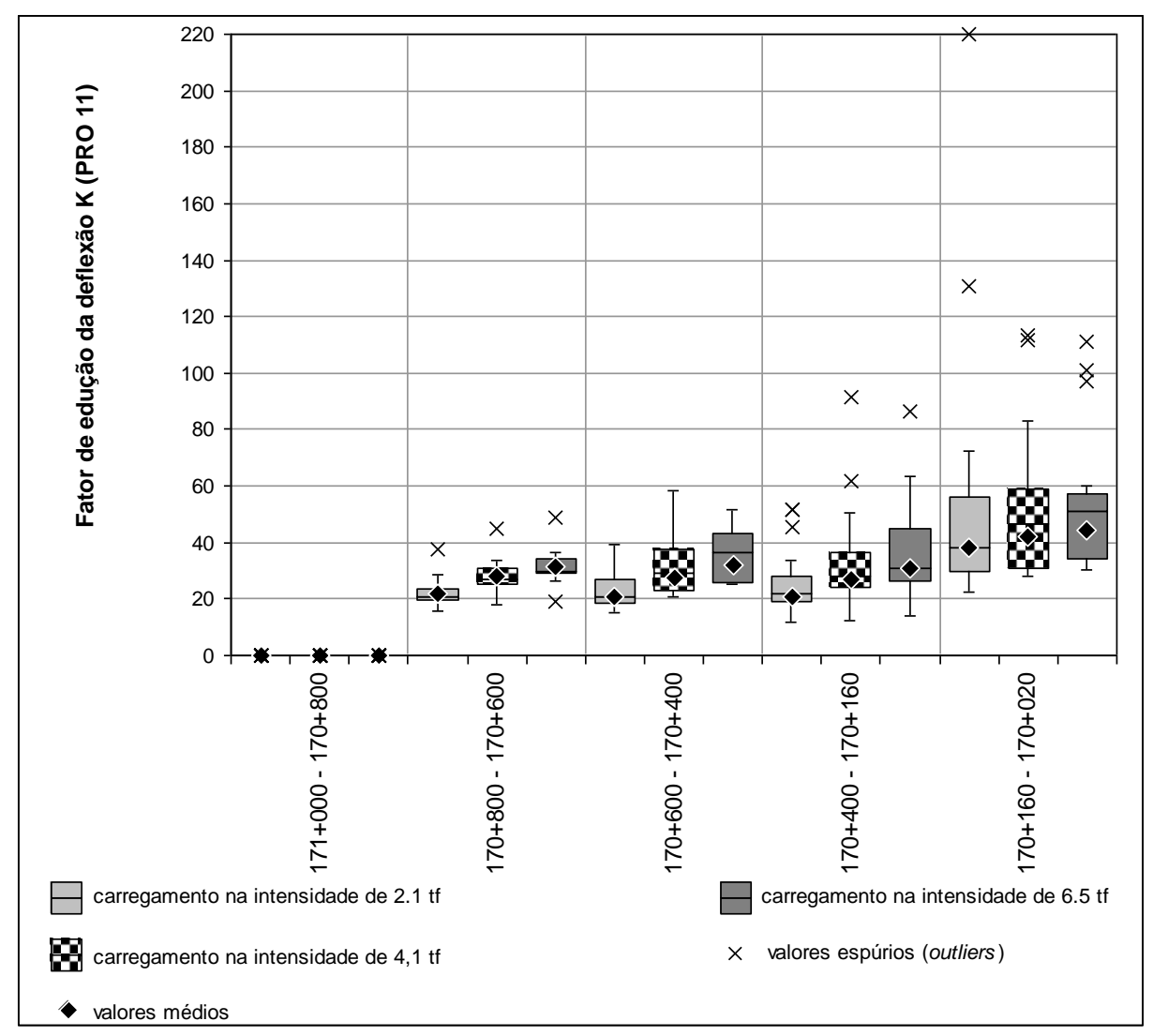

Figura 5.25 - Fator de redução da deflexão K (PRO 11)

Da Tabela 5.8 tem-se que a faixa de valor de K estabelecida para a camada de EME, ao longo de todos os valores encontrados nas 3 Seções Experimentais, varia de 20 a 34 para um grau de confiabilidade de $68,3 \%$, com um valor médio de $\mathrm{K}=27$.

O grau de confiabilidade de $68,3 \%$ foi definido a partir do limite de significância $\alpha$ para atingir o valor de $K=40$ no carregamento de 6,5tf; segundo a inequação 5.6. Tal critério foi atribuído por ser improvável que o material em análise (EME), cujo seu MR é superior ao do CBUQ convencional, tenha como fator de redução de deflexão um valor acima de 40, mesmo para uma condição de carregamento mais severo (eixo padrão francês) que a do eixo padrão brasileiro. 
$\overline{K_{6,5 t f}} \pm \alpha \sigma_{6,5 t f} \leq 40$

onde,

$\overline{K_{6,5 \text { tf }}}$ é a média do fator de redução de deflexão, para o carregamento correspondente ao eixo padrão francês $(6,5 \mathrm{tf})$;

$\alpha$ é a constante que determinará o nível de significância requerido no tratamento estatístico;

$\sigma_{6,5 t f}$ é o desvio-padrão do fator de redução de deflexão, para o carregamento correspondente ao eixo padrão francês $(6,5 \mathrm{tf})$.

\subsubsection{Modelos Empíricos para EME}

A partir da faixa de valores de $\mathrm{K}^{18}$ definida para a camada de $E M E$, pode-se desenvolver a calibração dos modelos apresentados no PRO 11. Contudo, é necessário analisar quantitativamente os benefícios na adoção da camada de EME com relação à deflexão encontrada e vida útil esperada (FONSECA et. al., 2007). Para tanto, com base nas equações 5.3 e 5.4 e baseando-se no trabalho de FONSECA et. al. (2007), é possível estabelecer outros modelos para o dimensionamento de reforços de estruturas com camada de EME. A Tabela 5.9 apresenta tais modelos, como também estabelece uma comparação com modelos de asfalto convencional e modificado com borracha.

\footnotetext{
${ }^{18}$ Salienta-se que o modelo definido por RUIZ foi concebido para pavimentos com camada de base granular e comportamento flexível, entretanto para efeito de comparação foi apresentado o valor do fator de redução de deflexão K para mistura asfáltica de EME a fim de demonstrar o potencial de redução das deflexões em relação às misturas do tipo CBUQ convencional e asfalto borracha.
} 
Tabela 5.8 - Modelos empíricos para EME, comparados com CBUQ e Asfalto Borracha

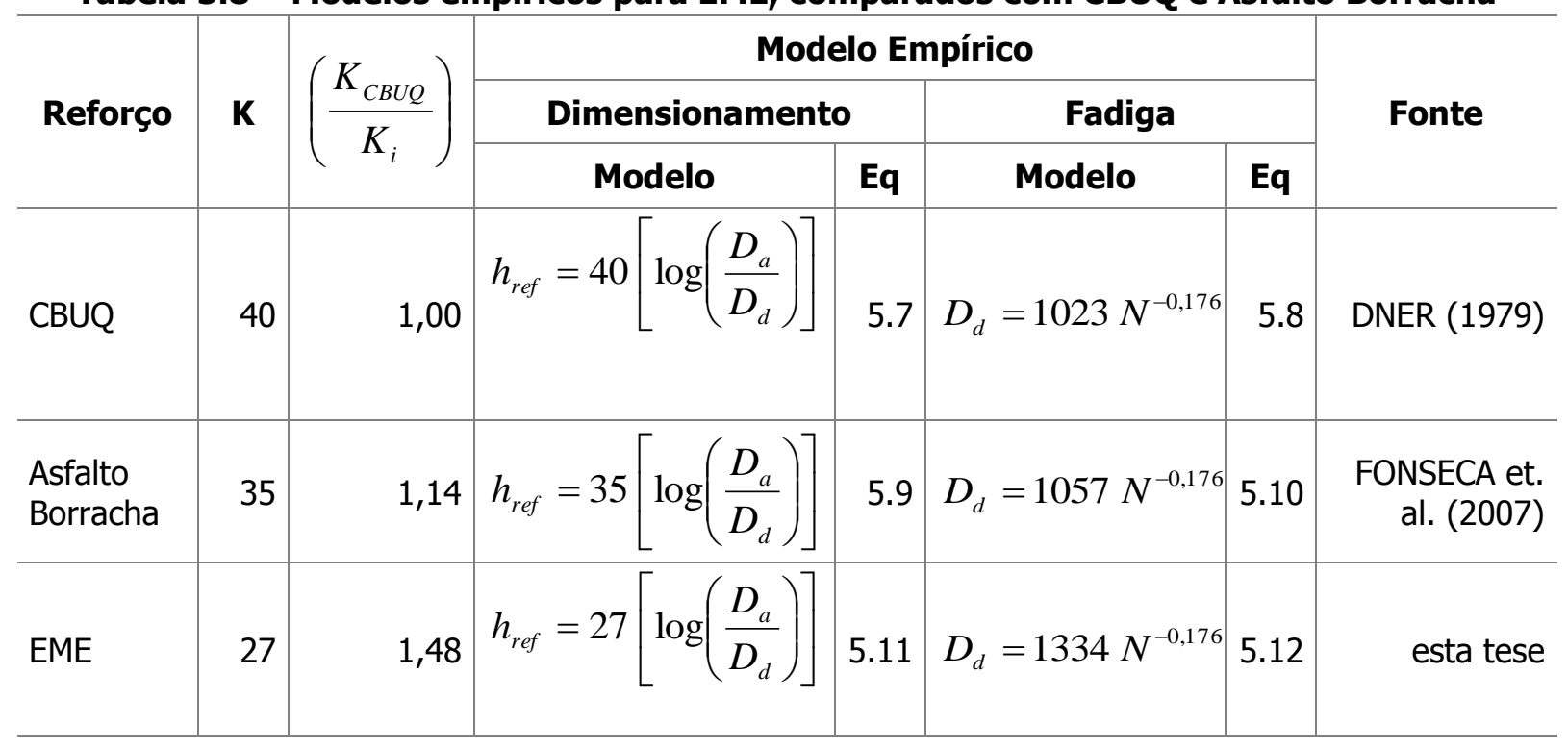

Nota:

$\mathrm{Eq}=$ ordem numérica da equação

$K_{i}=$ fator de redução de deflexão $K$ para outro material, que não seja o asfalto convencional $\left(\mathrm{K}_{\mathrm{CB} U \mathrm{O}}\right)$, deduzido em estudos citado nas fontes indicadas

Como ilustração, a partir do valor médio de $K=27$, a Figura 5.26 demonstra o potencial de redução das deflexões quando da execução de reforços constituídos de camada de EME. 

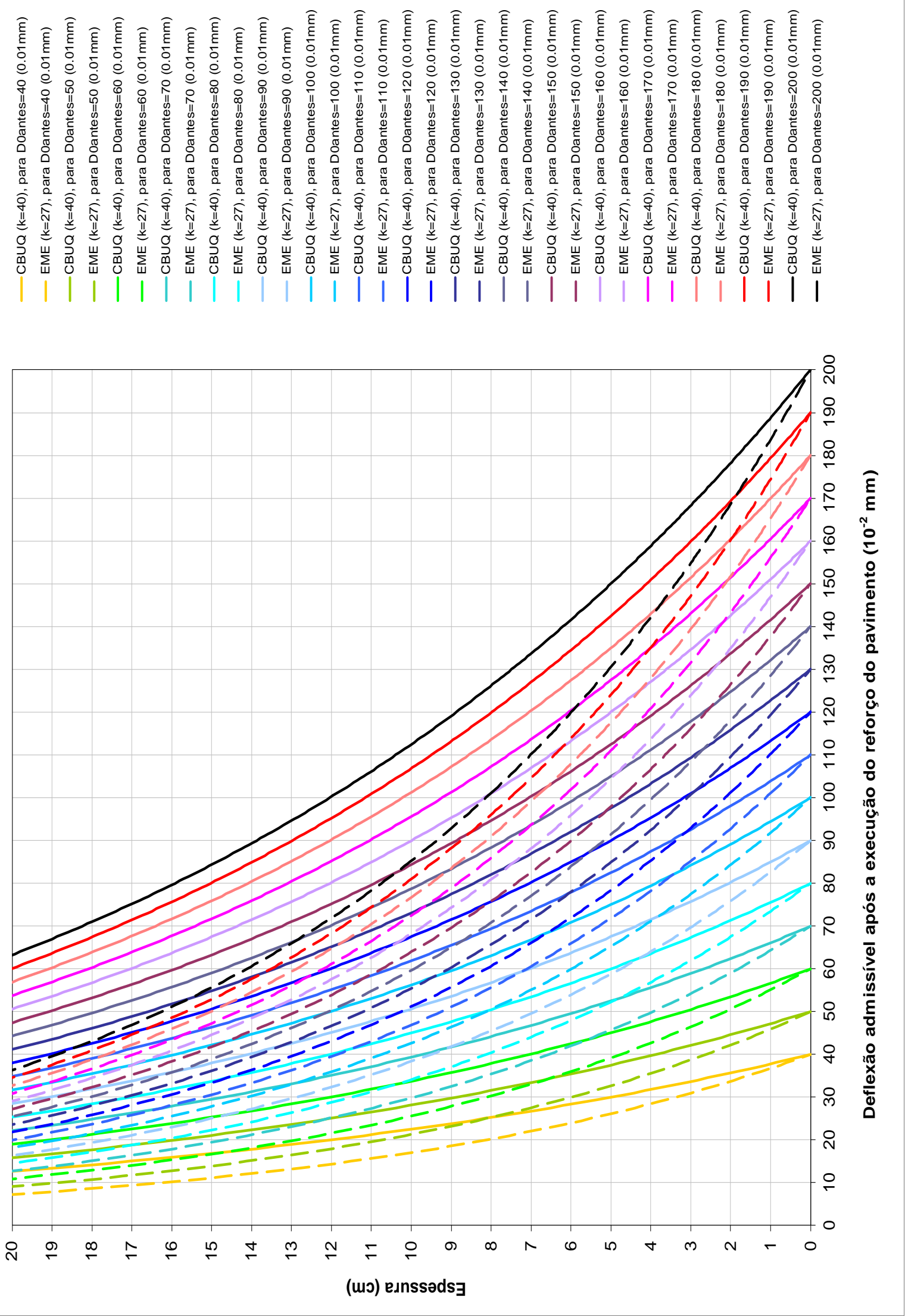

Figura 5.26 - Potencial de redução da espessura de reforço em EME $(K=27)$ em comparação com o CBUQ convencional $(K=40)$ 
É possível observar na Figura 5.25 a partir das condições estabelecidas $\left(\overline{K_{E M E}}=27 \mathrm{e}\right.$ $\left.K_{C B U Q}=40\right)$ que, independentemente da relação do valor deflectométrico medido na superfície do pavimento primitivo, antes da execução de um reforço de pavimento em EME, com a deflexão admissível após este reforço, tem-se que a espessura de EME reduz 30\% em relação à espessura de CBUQ convencional. Evidentemente esta condição é uma inferência teórica, pois para uma camada ser devidamente compactada ela deve receber o mínimo de reação do seu substrato, o suficiente para homogeneizá-la, e portanto merece ser analisada na prática como é o caso dos valores indicados na Tabela 5.10.

Na Figura 5.27 e na Tabela 5.10 são apresentados os valores da deflexão máxima e do módulo de resiliência mínimo admissíveis para a estrutura remanescente, de acordo com a simulação de carregamento com FWD para o eixo padrão brasileiro de 8,2tf. Tal análise do realizada com o programa computacional ELSYM 5.

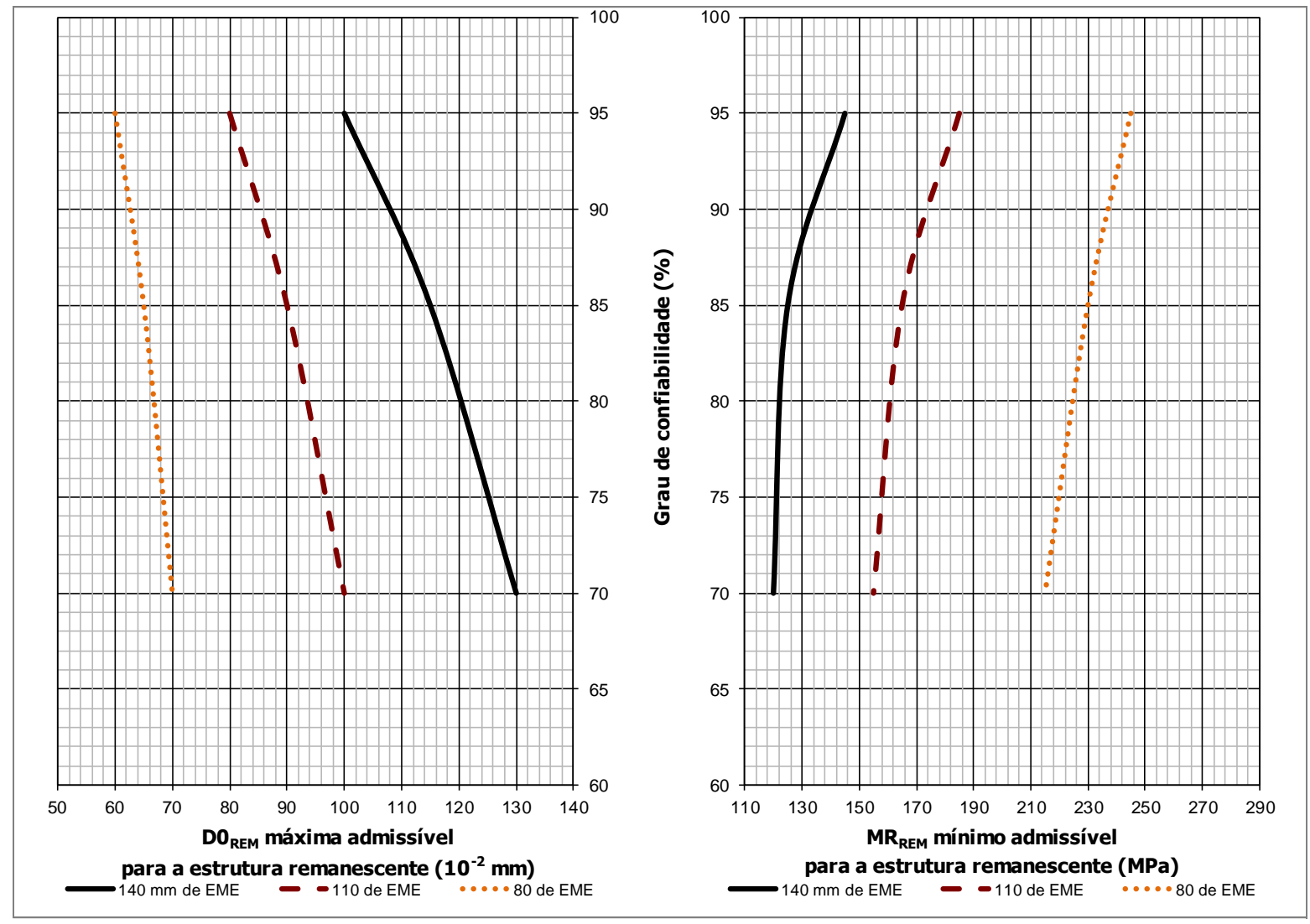

Figura 5.27 - Características geométricas e mecânicas adotadas para a simulação, válido para a estrutura atingir $\operatorname{Dadm}_{\mathrm{REV}}=\mathbf{3 0}\left(10^{-2} \mathrm{~mm}\right)$ 


\begin{tabular}{|c|c|c|c|}
\hline $\begin{array}{c}\text { Espessura de } \\
\text { EME }(\mathbf{m m})\end{array}$ & $\begin{array}{c}\mathrm{DO}_{\mathrm{REM}^{1}} \\
\left(10^{-2} \mathrm{~mm}\right)\end{array}$ & $\begin{array}{l}\mathrm{MR}_{\mathrm{REM}}{ }^{2} \\
(\mathrm{MPa})\end{array}$ & $\begin{array}{l}\text { Conf } \\
(\%)\end{array}$ \\
\hline \multirow{3}{*}{140} & 100 & 145 & 95 \\
\hline & 115 & 125 & 85 \\
\hline & 130 & 120 & 70 \\
\hline \multirow{3}{*}{110} & 80 & 185 & 95 \\
\hline & 90 & 165 & 85 \\
\hline & 100 & 155 & 70 \\
\hline \multirow{3}{*}{80} & 60 & 245 & 95 \\
\hline & 65 & 230 & 85 \\
\hline & 70 & 215 & 70 \\
\hline \multicolumn{4}{|c|}{$\begin{array}{l}\text { da deflexão má } \\
\text { a remanescente } \\
\text { do módulo } \\
\text { vel para a estrutur } \\
\text { au de confiabilidad }\end{array}$} \\
\hline
\end{tabular}

As características geométricas e mecânicas adotadas para tal simulação são apresentadas na Figura 5.27.

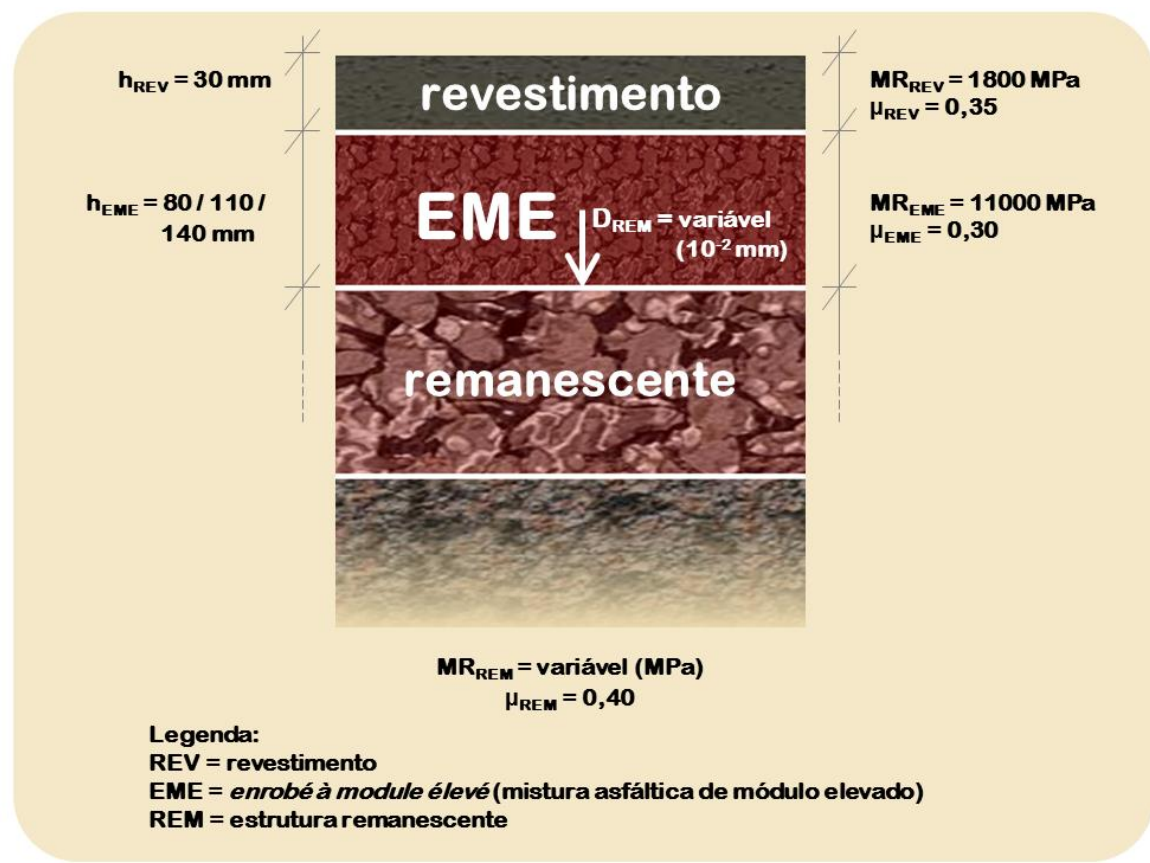

Figura 5.27 - Valores da deflexão máxima e do módulo de resiliência mínimo admissíveis no topo do remanescente, com seus graus de confiabilidade 
A partir da simulação gerada com o FWD e confrontando os valores retroanalisados da deflexão máxima e do módulo de resiliência mínimo admissíveis para a estrutura remanescente com os levantados em campo, observa-se na Figura 5.26 e na Tabela 5.10 que uma camada de EME com espessura igual a $140 \mathrm{~mm}$, por exemplo, para atingir a Dadm no topo de seu revestimento de $30\left(10^{-2} \mathrm{~mm}\right)$, é necessário um valor máximo de deflexão no topo da estrutura remanescente correspondente à $100\left(10^{-2}\right.$ $\mathrm{mm}$ ), para um grau de confiabilidade de $95 \%$, ou ainda um módulo de resiliência da estrutura remanescente no valor mínimo de $146 \mathrm{MPa}$, para o mesmo grau de confiabilidade.

É importante salientar que os valores encontrados na Figura 5.26 e na Tabela 5.10, para o grau de confiabilidade igual a $95 \%$, oferecem valores de deflexão máxima admissível à estrutura remanescente para cada uma das Seções Experimentais mais seguros para serem considerados.

Pelos valores encontrados, pode-se deduzir que se recupera em média de 3 a $4\left(10^{-2} \mathrm{~mm}\right)$ da deflexão admissível na estrutura remanescente para cada $\mathrm{cm}$ de CBUQ convencional, enquanto que em uma estrutura com EME, de 7 a $8\left(10^{-2} \mathrm{~mm}\right)$ a cada $\mathrm{cm}$. 


\section{CONCLUSÕES}

Neste trabalho, foi apresentada a tecnologia francesa de misturas asfálticas de módulo elevado (EME) como alternativa para restauração de pavimentos, considerando as circunstâncias dos projetos brasileiros. Os estudos desta tese contaram com a execução do primeiro Trecho Experimental no País submetido a tráfego muito pesado, localizado na rodovia Presidente Dutra.

Até a análise do último levantamento realizado no Trecho Experimental, entende-se que a estrutura constituída de camada de base em EME demonstrouse uma técnica adequada e de sucesso para restauração de pavimentos submetidos a tráfego muito pesado e intenso com um bom desempenho até então.

Os estudos desenvolvidos na presente tese permitem concluir acerca da viabilidade técnica da mistura asfáltica de módulo elevado (EME) que, quando bem dimensionada e executada, tal estrutura pode ficar com os seus níveis de deflexão, tensão e deformação aquém daqueles máximos admissíveis estabelecidos em projeto.

A viabilidade técnica deste tipo de alternativa de restauração é confirmada ainda pelos inúmeros exemplos já executados e em operação em diversos Países e também pelo Trecho Experimental, objeto de análise desta tese, cujos resultados das primeiras avaliações confirmam, até o momento, seu bom desempenho.

O material asfáltico adotado para a confecção do EME é condizente com as especificações francesas. Constata-se também ser possível executar a tecnologia francesa do EME com os recursos de usinas e equipamentos disponíveis no Brasil com boa qualidade. Sua usinagem e compactação foram efetuadas sem 
dificuldades adicionais, mesmo tendo sido executado durante a madrugada a uma temperatura que variou de 9 a $11^{\circ} \mathrm{C}$.

A partir dos estudos paramétricos, em função das características geométricas e mecânicas da estrutura de EME, foram desenvolvidos modelos a fim de determinar seus Esforços Solicitantes apenas com levantamentos deflectométricos, por meio da Deflexão Máxima $\left(D_{0}\right)$ e Indicadores de Curvatura. Foram desenvolvidos 372 modelos, destes os Esforços Solicitantes que melhor apresentaram seus coeficientes de determinação e com maior simplicidade de aplicação, por serem função apenas de dois parâmetros, foram aqueles em função de: $D_{0}$ e SCI. Seus coeficientes de determinação variaram de 82,45 a $99,25 \%$. Tais modelos demonstraram-se como uma ferramenta útil para avaliação dos ES, devido aos fortes coeficientes de determinação e da sua rápida aplicação, uma vez que em campo a investigação das características geométricas da estrutura pode ser de difícil obtenção.

Verificou-se por meio dos estudos paramétricos desenvolvidos que o principal parâmetro definidor para o dimensionamento deste tipo de alternativa é a capacidade estrutural do pavimento remanescente $\left(M R_{R E M}\right.$ ou $\left.D 0_{R E M}\right)$. Por esta razão é importante sempre que possível investigar, por meio de diversos poços de inspeção, a estrutura do pavimento a ser restaurado, avaliando as condições de homogeneidade das camadas e assim fornecendo subsídios importantes para a determinação da espessura da camada de EME e, consequentemente, sua viabilidade econômica.

Neste sentido, tem-se igual importância a investigação da condição do sistema de drenagem e, no caso de diagnosticada a sua inexistência ou insuficiência, deve-se prever um sistema de drenagem adequadamente dimensionado quanto aos aspectos hidráulicos, permitindo assim a rápida eliminação da água antes da ocorrência da saturação da estrutura remanescente e, consequentemente, a perda de resistência. 
É importante para o dimensionamento da estrutura de restauração com EME campanhas deflectométricas na estrutura primitiva para, em conjunto com as informações dos poços de inspeções, o desenvolvimento adequado de retroanálises e determinação do $M R_{R E M}$ e também no fundo da caixa fresada com intuito de determinar a $\mathrm{D} 0_{\mathrm{REM}}$.

Os dados dos levantamentos deflectométricos nas três intensidades de carregamento demonstram um comportamento linear da estrutura, não sendo notadas variações significativas nas resposta a tais intensidades de carga a partir de suas alterações. Este fato se confirma com os valores encontrados nos coeficientes de determinação próximos a um para todos os casos deste estudo: tanto D0 e SCI para os diversos Estágios de levantamento.

Ainda com relação aos levantamentos deflectométricos, este estudo apresentou que para a mesma intensidade de carregamento os deslocamentos verticais na camada de EME não se mantiveram proporcionais em relação à capacidade de suporte do pavimento remanescente. Por esta razão tem-se a camada de EME com responsável pelo controle dos esforços solicitantes na estrutura do pavimento por ela constituído.

Segundo as retroanálises efetuadas a partir dos levantamentos deflectométricos realizados, de modo geral, pode-se concluir que para os Estágios cujos levantamentos foram na camada de EME (Estágios 2, 3 e 4) a camada asfáltica de módulo elevado encontra-se com valor de módulo de resiliência variando de 9.000 a $14.226 \mathrm{MPa}$. Embora tenha havido valores discrepantes (de 7.000 a 20.000MPa), tal ordem grandeza é compatível com aqueles encontrados na literatura para este tipo de tecnologia.

A partir da avaliação da condição da superfície do pavimento, conclui-se que a Seção de Referência SRf-02 constituída de $80 \mathrm{~mm}$ de CBUQ convencional (CAP 30-45), com 2,6 milhões de solicitações de veículos comerciais (NUSACE = $2,43 \mathrm{E}+07$ e $\mathrm{N}_{\text {AASHTO }}=6,89 \mathrm{E}+06$ ); apresentou significativa concentração de 
defeitos (8,13\% e IGG=63). Comparando-se com a Seção Experimental de mesma espessura com EME (SEx-03) cuja solicitação atingiu 2,9 milhões de veículos comerciais ( $\mathrm{N}_{\mathrm{USACE}}=2,78 \mathrm{E}+07$ e $\mathrm{N}_{\mathrm{AASHTO}}=7,87 \mathrm{E}+06$ ), percebe-se um desempenho superior, apenas apresentando problemas localizados com concentração de defeitos de $0,17 \%$ e IGG=1. Apesar de problemas localizados terem sido encontrados nas Seções Experimentais de 110mm (SEx-02) e de $80 \mathrm{~mm}$ (SEx-03), deve-se atentar para a distinção de defeitos atribuídos pela camada do revestimento que possui valor médio de módulo de resiliência de 1.800MPa, com os da camada de base em EME que possui valores médios de 14.348MPa.

Com base na análise realizada empregando-se a metodologia PRO-11/79, verifica-se que, é possível reduzir em média de 7 a $8\left(10^{-2} \mathrm{~mm}\right)$ da deflexão admissível (após a execução do reforço) na estrutura remanescente para cada $\mathrm{cm}$ de EME executado, enquanto que em uma estrutura com CBUQ convencional de 3 a $4\left(10^{-2} \mathrm{~mm}\right)$ a cada $\mathrm{cm}$. Esta observação conduz à conclusão de que a mistura asfáltica de módulo elevado (EME) tende a apresentar um desempenho estrutural melhor se comparado ao concreto asfáltico convencional. Nesta fase do estudo, foi encontrada faixa de fatores de redução da deflexão (K) compreendida de 20 a 34 .

A deflexão máxima admissível no topo da camada remanescente dependerá do grau de confiabilidade requerido. Entretanto, segundo as condições desta tese, recomenda-se a adoção do grau de confiabilidade de $95 \%$, para um valor de D0 REM: para $140 \mathrm{~mm}$ de EME, equivalente a $100\left(10^{-2} \mathrm{~mm}\right)$; para $110 \mathrm{~mm}$ de $\mathrm{EME}$, equivalente a $80\left(10^{-2} \mathrm{~mm}\right)$; e para $80 \mathrm{~mm}$ de $E M E$, equivalente a $60\left(10^{-2} \mathrm{~mm}\right)$.

A execução de trechos com a adoção da técnica de $\mathrm{EME}$, bem como a análise de desempenho, encontram-se em fase incipiente no Brasil. Neste sentido, é importante a execução e o acompanhamento de novos trechos com ligantes duros, a exemplo da pesquisa desenvolvida por MOTTA et al (2011). Novas 
pesquisas possibilitarão efetuar a validação e a adoção dos modelos e procedimentos apresentados nesta tese para outras situações.

Para melhor entendimento do desempenho do Trecho Experimental desta tese há a necessidade de serem realizados novos levantamentos periódicos e análises complementares ao longo do período de vida útil da estrutura constituída de EME.

Pesquisas com a confecção de mistura asfáltica de módulo elevado (EME) morna e a reciclagem de camada de EME são interessantes serem desenvolvidas uma vez que a preocupação com meio ambiente tem sido cada vez mais evidente.

Com relação à reciclagem não se sabe ainda a possibilidade real de reciclagem da camada de EME produzido com ácido polifosfórico, como é o caso desta tese. Pode-se citar, portanto, mais uma pesquisa a ser desenvolvida para apresentar suas dificuldades e benefícios. 


\section{REFERÊNCIAS BIBLIOGRÁFICAS}

AASHTO - American Association of State Highway and Transportation Officials, 1993. Guide for Design of Pavement Structures. Washington, D.C.

THE ASPHALT INSTITUTE, 1982. Research and development of the asphalt institute's thickness design manual. Manual Series no 1, 9th ed. College Park.

AFNOR - Association Française de Normalisation, 1993a, NF P 98-252. Essais Relatifs aux Chaussées: Essai à la Presse à Cisaillement Giratoire (PCG), Association Française de Normalisation.

AFNOR - Association Française de Normalisation, 1993, NF T 98-253-1. Préparation des Mélanges Hydrocarbonés, Partie 1: Essai d'Orniérage.

AFNOR - Association Française de Normalisation, 1999, NF P 98-140, Enrobés Hidrocarbonés - Couches d'assises: Enrobés à Module Élevé (EME).

AFNOR - Association Française de Normalisation, 1999b, NF P 98-141, Enrobés Hidrocarbonés - Couches de roulement et couches de liaison: bétons bitumineux à module élevé (BBME).

ASTM - American Society for Testing and Materials, 2009. Standard Test Method for Determining the Resilient Modulus of Bituminous Mixtures by Indirect Tension Test: D 7369-09 West Conshohocken, PA.

BALBO, J.T.; RODOLFO, M. P., 2004. Estudo de deformações e tensões em pavimentos asfálticos perpétuos. In: 35a. Reunião Anual de Pavimentação, Rio de Janeiro. 35a RAPv, 2004. v. CD. 11 p.

BARTHOLOMEU, D. B., 2006, Quantificação dos impactos econômicos e ambientais decorrentes do estado de conservação das rodovias brasileiras, 200 p. Tese (Doutorado) - ESALQ, Escola Superior de Agricultura "Luiz de Queiroz" da Universidade de São Paulo, Piracicaba.

BRANCO, F. E.F.; PEREIRA, P. A. A.; PICADO-SANTOS, L. G., 2006. Pavimentos rodoviários. P. 388. Coimbra, Portugal. 
BROSSEAUD, Y; DELORME， J-L.; HIERNAUX, R., 1993. Study of Permanent Deformations in Asphalt with Help of the LCPC Wheel Tracking Rutting Tester: Evaluation and Future Prospects. In 72nd Annual Meeting of Transportations Research Board, USA.

BROSSEAUD,Y., 2002, "Les Enrobes Français: Panorama des Techniques Bitumineuses, Bilan de Comportement". $16^{\circ}$ Encontro de Asfalto, Rio de Janeiro, RJ, Dezembro.

BROSSEAUD,Y., 2006, "Les Enrobés à Module Eleve: Bilan de L' expérience de Française et Transfert de Technologie". 70 Congrès National de la Route, Maroc, Novembre.

BROSSEAUD,Y., BOGDANSKI, B., CARRÉ, D., 2003, Transfert de Technologie Réussi entre la France et la Pologne: Première Réalisation d'un Chantier de Reforcement Utilizant un Enrobé à Haut Module et un Béton Bituminex três Mince.

BROWN, S., BRUNTON, J., STOCK, A., 1985. The analytical design of bituminous pavements. Proceedings of Institution of Civil Engineering, vol. 79, Part 2, pp 131, London.

CAPITÃO, S., 2003. Caracterização mecânica de misturas betuminosas de alto módulo de deformabilidade. Tese de Doutorado, Departamento de Engenharia Civil, Faculdade de Ciências e Tecnologia da Universidade de Coimbra. Coimbra, Portugal.

CAROFF, G., CORTÉ, J. F. Les enrobés à module élevé. Revue Général des Routes et dês Aérodromes, Spécial chaussées d'autoroutes. Paris, 1994.

CORTÉ, J-F., SERFASS, J-P., 2000, The French Approach to Asphalt Mixtures Design: a Performance-Related System of Specifications. Communication au TRB, Washington

CORTÉ, J-F., 2001. Development and uses of hard grade asphalt and of high modulus asphalt mixes in France. Transportation Research Circular: Perpetual Bituminous Pavements, Washington, DC, n. 503, p. 12-31.

CORTÉ, J-F.; BROSSEAUD, Y.; SIMONCELLI, J-P.; CAROFF, G., 1994. Investigation of rutting of asphalt surface layers: influence of binder and of configuration of axle loading. Transportation Research Record, Washington, DC, n.1436. 
DELORME, J.L., GOYON, V. e GAVALDA, A., 1996. Asphaltic concrete with high modulus (EME): description, use, performance. In: Proceedings of 1st Eurasphalt \& Eurobitumie Congress.

DES CROIX, P. e PLANQUE, L., 2004. Experience with optimised hard grade bitumens in high modulus asphalt mixes. In: Eurasphalt \& Eurobitume Congress, 3, Viena, 2004. Proceedings... Bruxelas: EAPA, v.1, p.159-172.

DNER - Departamento Nacional de Rodagem, 1979. Avaliação estrutural dos pavimentos flexíveis, procedimento BÇ DNER-PRO 11/79.

DNER - Departamento Nacional de Rodagem, 1994a. Pavimento. Determinação das deflexões pela viga benkelman: DNER-ME 024/94.

DNER - Departamento Nacional de Rodagem, 1994b. Projeto de restauração de pavimentos flexíveis - TECNAPAV: DNER-PRO 269/94.

DNER - Departamento Nacional de Rodagem, 1979. Avaliação estrutural de pavimentos flexíveis - Procedimento-B: DNER-PRO 011/79.

DNIT - Departamento Nacional de Infraestrutura de Transportes, 2003a. Defeitos nos pavimentos flexíveis e semi-rígidos terminologia: DNIT 005/2003 TER.

DNIT - Departamento Nacional de Infraestrutura de Transportes, 2003b. Avaliação objetiva da superfície de pavimentos flexíveis e semi-rígidos - Procedimento: DNIT 006/2003 PRO.

DNIT - Departamento Nacional de Infraestrutura de Transportes, 2003c. Levantamento para avaliação da condição de superfície de subtrecho homogêneo de rodovias de pavimentos flexíveis e semi-rígidos para gerência de pavimentos e estudos e projetos - Procedimento: DNIT 007/2003 PRO.

FEE, F. (2002). Extended Life Asphalt Pavement: New Approaches to Increase Durability. Asphalt Review Online, Volume 21, No 1, May. Australian Asphalt Pavement Association (AAPA).

Disponível em: <http://www.aapa.asn.au/docs/review3.html/>. Acesso em: 08 de junho de 2008.

FONSECA, P. F. O.; SANTOS, C. R. G.; PEREIRA, A. C. O.; SUZUKI, C. Y., 2007. Avaliação estrutural de reforço em CBUQ modificado por borracha de pneus no trecho experimental da rodovia SP 300. In: CONINFRA - Congresso de Infraestrutura de Transportes, São Paulo. 11 p. 
FREITAS, H. B., 2007, Misturas Asfálticas de Módulo Elevado com uso de Escória de Aciaria como Agregado. Dissertação (Mestrado) - Universidade Federal do Rio de Janeiro.

FREITAS, H. B.; MOTTA, L. M. G., 2008, Uso de Escória de Aciaria em Misturas Asfálticas de Módulo Elevado. Transportes (Rio de Janeiro), v. 16, p. 16-25.

GLITA, S., MARCHAL, J-L., 2000. BBHR - béton bitumineux haute rigidité: Expérience en Belgique.

HAAS, R. e HUDSON, W. R., 1978. Pavement management systems. New York: McGraw Hill. 457 p.

HUANG, Y. H., 2004. Pavement Analysis and Design. 2nd Ed. Pearson Prentice Hall, $775 p$.

IBGE - Instituto Brasileiro de Geografia e Estatística, 2002. Base de Informações por Setor Censitário. Censo Demográfico 2000. Rio de Janeiro. CDrom.

JAE - JUNTA AUTONOMA DE ENGENHARIA, 1998. Caderno de encargos; 03 Pavimentação. Volume V, Almada

JAMOIS, D., VANISCOTE, J-C., JOLIVET, Y., MALOT, M., 2000. Development of a concept of very high modulus bituminous macadam for pavement base courses, 2nd Eurasphalt \& Eurobitume Congress,Vol. II, EAPA e Eurobitume, Barcelona. pp. 268-279.

JAMOIS, D., MALOT, M., BERGER, J., LEGREVE, A, 2002. Expérimentation d'enrobés bitumineux à hautes performances pour couches d'assisses et de roulements construction neuve sur le site d'une sation d'essence (E19-Nivelles).

KIM, Y.R., Lee, Y., RANJITHAN, S. R., 2000. Flexible pavement condition evaluation using deflection basin parameters and dynamic finite element analysis implemented by artificial neural networks. Nondestructive Testing of Pavements and Backcalculation of Moduli: Thrid Volume, ASTM STP 1375, S. D. Tayabji and E. O. Lukanen, Eds, American Society for Testing and Materials, West Conshohocken, PA, pp $514-530$. 
KOBISCH, R., GRAMSAMMER, J., KERZRÉHO, J-P., MALOT, M., JOLIVET, Y., VANISCOTE, J-C., "Modulotal TE2: Développement d'un bitume pour enrobé à module très élevé en assise de chaussée - Expérimentation. sur le manègede fatigue du LCPC, Revue Générale des Routes et des Aérodromes, Janeiro, No 747, RGRA, 1997, pp. 37-49.

KÖPPEN, W., 1931. Grundriss der Klimakunde. Walter D E Guyter \& Co. Berlin. 390p KOPPERMAN, S., TILLER, G., e TSENG, M., 1986. ELSYM-5: interactive microcomputer version user's manual: IBM PC and compatible version. Federal Highwal Administration, Report no. FHWA-TS-87-206, Final Report, dec. Washington, D.C.

LAUTIER, G., RENIÉ, E., VERHÉE, F., 1991. Exemple d'optimisation d'une structure souple: La RD 570 dans les Bouches-du-Rhône", Revue Général des Routes et des Aérodromes, No 684, Novembro, RGRA. pp. 80-81.

LESAGE, J., 1993. Intéret d'un liant de faible pénétration pour structurer les corps de chaussées en construction neuve ou en entretien: mode d'évaluation en laboratoire, 5th Eurobitume Symposium, Vol II, Estocolmo, pp. 536-45.

LESAGE, J., GRIMAUX, J. P. e HIERNAUX, R., 1993. Des couches de roulement épaisses, renforçantes et antiorniérantes, Revue Général des Routes et des Aérodromes, Maio, No 707, RGRA, pp. 35-41.

LOPES, F. M.; SANTOS, C. R. G.; FORTES, R. M.; FERRI, S.; SUZUKI, C. Y., 2010. Proposta de Metodologia para Avaliação de Pavimentos Asfálticos Utilizando Características da Bacia Deflectométrica. In: CONINFRA - Congresso de Infraestrutura de Transportes, São Paulo. $15 \mathrm{p}$.

MAGALHÃES, S., 2004, Misturas asfálticas de módulo elevado para pavimentos de alto desempenho. 197 f. Dissertação (Mestrado em Engenharia Civil) Universidade Federal do Rio de Janeiro.

MARSOT, A., 1993. Enrobés à haut module et liants modifiés. Revue Général des Routes et des Aérodromes, Outubro, No 711, RGRA, pp. 39-41.

MEDINA, J., MOTTA, L. M. G., 2005. Mecânica dos pavimentos. 2. ed. Rio de janeiro: UFRJ. 2005. $570 \mathrm{p}$. 
MONTEPARA, A., TEBALDI, G., 1999. Performance of high modulus bituminous mixtures for base courses. In: Proc. 3rd European Symposium. Performance and Durability of Bituminous Materials and Hidraulic Stabilised Comoposites. pp 221-238. Leeds, Inglaterra.

MONTGOMERY, D.C., RUNGER, G.C., 1999. Applied Statistics and Probability for Engineers. New York: John Wiley, 2nd Ed.

MOTTA, L. M. G.; FRITZEN, M. A.; VIANNA, A. A. D.; AVILA, G., GUIMARÃES, S. 2011. Avaliação do comportamento de dois tipos de revestimentos asfálticos, dosados pelo método SUPERPAVE, sob ação de tráfego real na Rodovia BR/040 - trecho Concessionária CONCER. In: IV WORKSHOP RDT - Recursos de Desenvolvimento Tecnológico nas Concessões Rodoviárias. p. 20-33.

NAGAO, E. M., 2001. Considerações de parâmetros de curvatura da bacia de deformação e do número estrutural no dimensionamento de reforço de pavimentos flexíveis. Dissertação de Mestrado em Engenharia Civil - Escola Politécnica da Universidade de São Paulo, São Paulo, 196 p.

NEVES FILHO, C. D., 2004, Avaliação Laboratorial de Misturas Asfálticas SMA Produzidas com Ligante Asfalto-Borracha. 67 f. Dissertação (Mestrado) Escola de Engenharia de São Carlos, Universidade de São Paulo, São Carlos.

NCHRP - National Cooperative Highway Research Program. Research Results Digest Number 285, 2004. Laboratory Determination of Resilient Modulus for Flexible Pavement Design.

PARIZÉ, E., BEZAVADA, V., DESMOULIN D., 1998, Emploi des matériaux à module élevé das les structures de chaussées aéroportuaires. RGRA n 767, novembro.

PAÚL, I., SOUSA, J., 1999. Formulação de uma mistura betuminosa de alto módulo com base em ensaios de performance, $10^{\circ}$ Congreso Ibero-Latinoamericano del Asfalto, Vol. I, Asociación Espanõla de la Carretera, Sevilha, pp. 443-454.

PERRET, J.; OULD-HENIA, M.; DUMONT, A.-G., 2004 High modulus pavement design using accelerated loading testing (ALT). In: Eurasphalt \& Eurobitume Congress, 3., 2004, Vienna. Proceedings. Vienna: EAPA. vol. 1, p. 203-212.

PMSP. Prefeitura Municipal de São Paulo. Secretaria de Infraestrutura Urbana, 2002. Instruções de projeto - Portaria 248/SIURB-G/2002. IP-08: Análise mecanistica à fadiga de estruturas do pavimento, pp. 173-183. 
QUINTERO, C. F. Q., 2011, Estudo de misturas asfálticas com ligantes de consistência elevada - Formulação e comportamento mecânico. Dissertação (Mestrado) Programa de Pós-Graduação em Engenharia Civil / Universidade Federal de Santa Catarina, Florianõpolis, 203p.

ROCHA, D., 1994. Experiencia española, Jornadas sobre Mezclas de Alto Modulo, Madrid.

RGRA - REVUE GÉNÉRAL DES ROUTES ET DES AÉRODROMES, 2005. Les Enrobés Bitumineux. vol. 2, 381 p. Paris : RGRA.

ROHDE, L., 2007. Estudo de misturas asfálticas de módulo elevado para camadas estruturais de pavimentos. Tese de Doutorado, PPGEC / Universidade Federal do Rio Grande do Sul, Porto Alegre, 246 p.

SERFASS, J-P., BENSE, P., PELLEVOISIN, P., 1997, Properties and New Developments of High Modulus Asphalt Concrete. In: $8^{0}$ Iternational Conference on Asphalt Pavements, v. 1, pp. 325-333, Seatle, Washington, USA. SETRA - Service d'Études Techniques des Routes et Autoroutes, 1997. Les enrobés à module élevé. Note d'information, Bagneux, n.96, 6p..

SETRA e LCPC - Service d'Études Techniques des Routes et Autoroutes e Laboratoire Central des Ponts et Chaussées, 1998. Catalogue des structures types de chaussées neuves. Bagneux : Ministère de L'Equipement, des Transports et du Logement.

SUZUKI, C. Y., 1992. Contribuição ao estudo de pavimentos rodoviários com estrutura invertida (sub-base cimentada). Tese de Doutorado em Engenharia Civil - Escola Politécnica da Universidade de São Paulo, São Paulo, 280 p.

VAL MELÚS, M. A., , 1996 Contribution à la mise au point d'un nouveau matérieu de construction des chaussées - L'enrobé bitumineux à haut module pour couche de base, Bulletin dês Liaisons du Laboratoire des Ponts et Chaussées, No. 204, Julho-Agosto, LCPC, pp. 43-52.

VÉRHÉE, F., DELORME, J., 1991. Enrobés classiques et à module élevé: bilan de comportement des enrobés à module élevé, Bulletin des Liaisons, n 172, LCPC, Março-Abril, pp.43-6. 
VILLELA, A.R.A.; SUZUKI, C. Y.; BERNUCCI, L. L. B.; QUINTANILHA, J.A.; ESCUDEIRO, M.S., 2009. Estudo de deflexões, tensões e deformações em estrutura com camada de módulo elevado: uma abordagem para projetos de restauração. In: XV CILA - Congresso Ibero-Latino-Americano do Asfalto, Lisboa, Portugal. v. 2. p. 863-872.

VIVIER, M., DEGUINES, J., 1986. Les enrobés à haut module: application à la rocade sud de salbris, Revue Général des Routes et des Aérodromes, No 633, Setembro, RGRA, 1986, pp. 31-40.

WSDOT - Washington State Department of Transportation. (1995). Pavement Guide for Design Evaluation and Rehabilitation.

YODER, E. J., e WITCZAK, M. W., 1975. Principles of pavement design. 2nd Ed. New York: John Wiley \& Sons, $711 \mathrm{p}$. 


\section{ANEXOS}






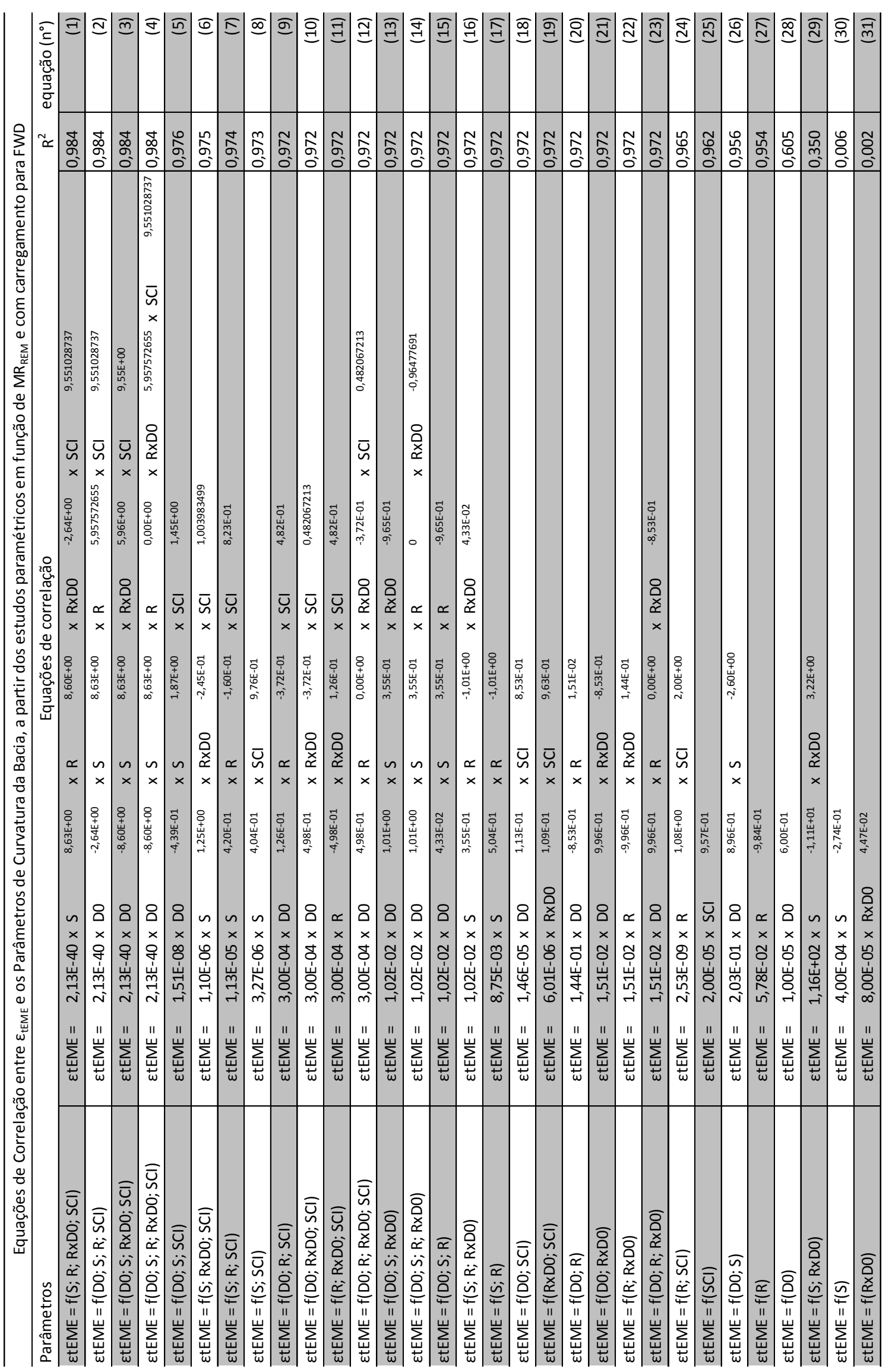




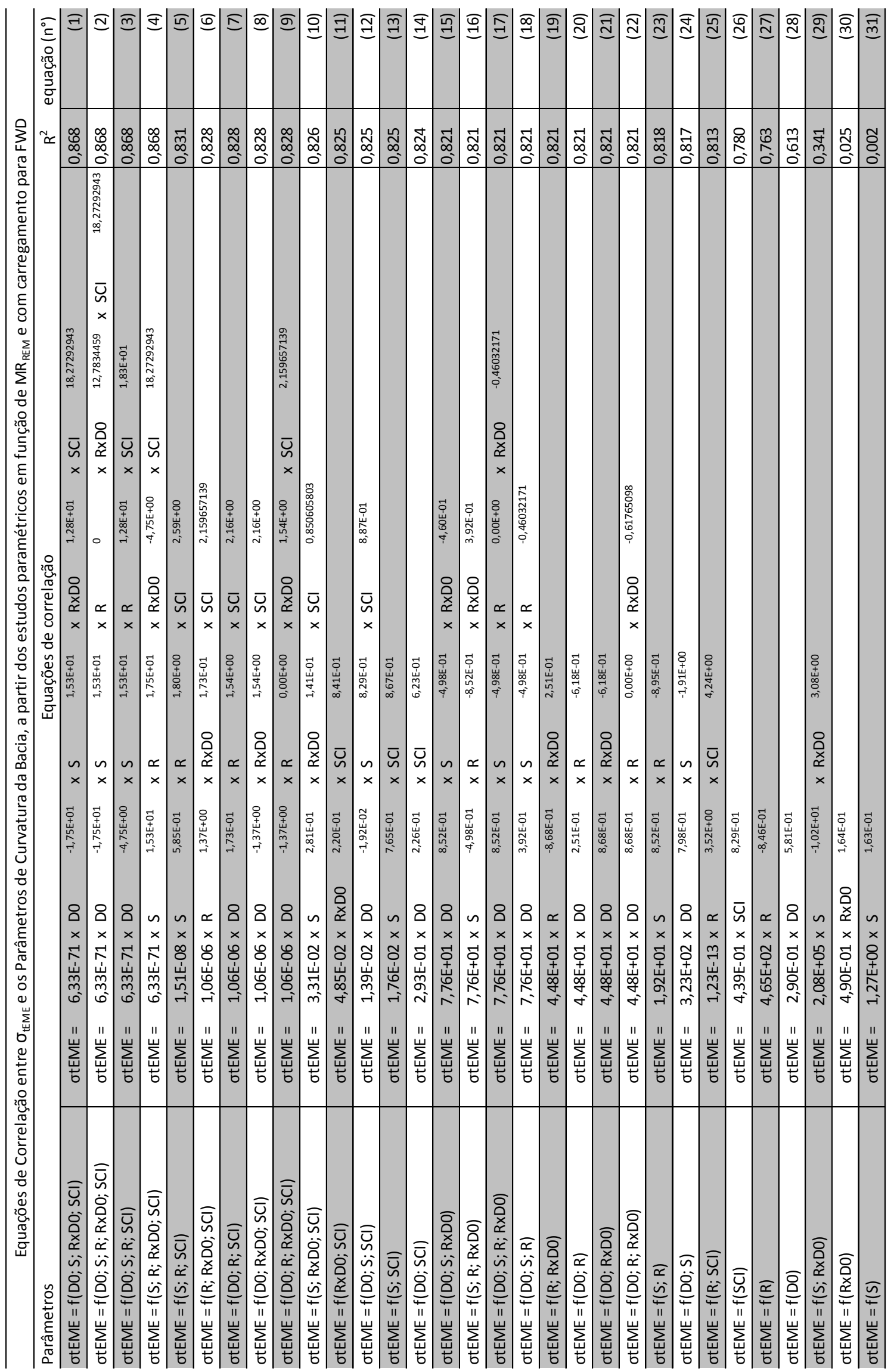




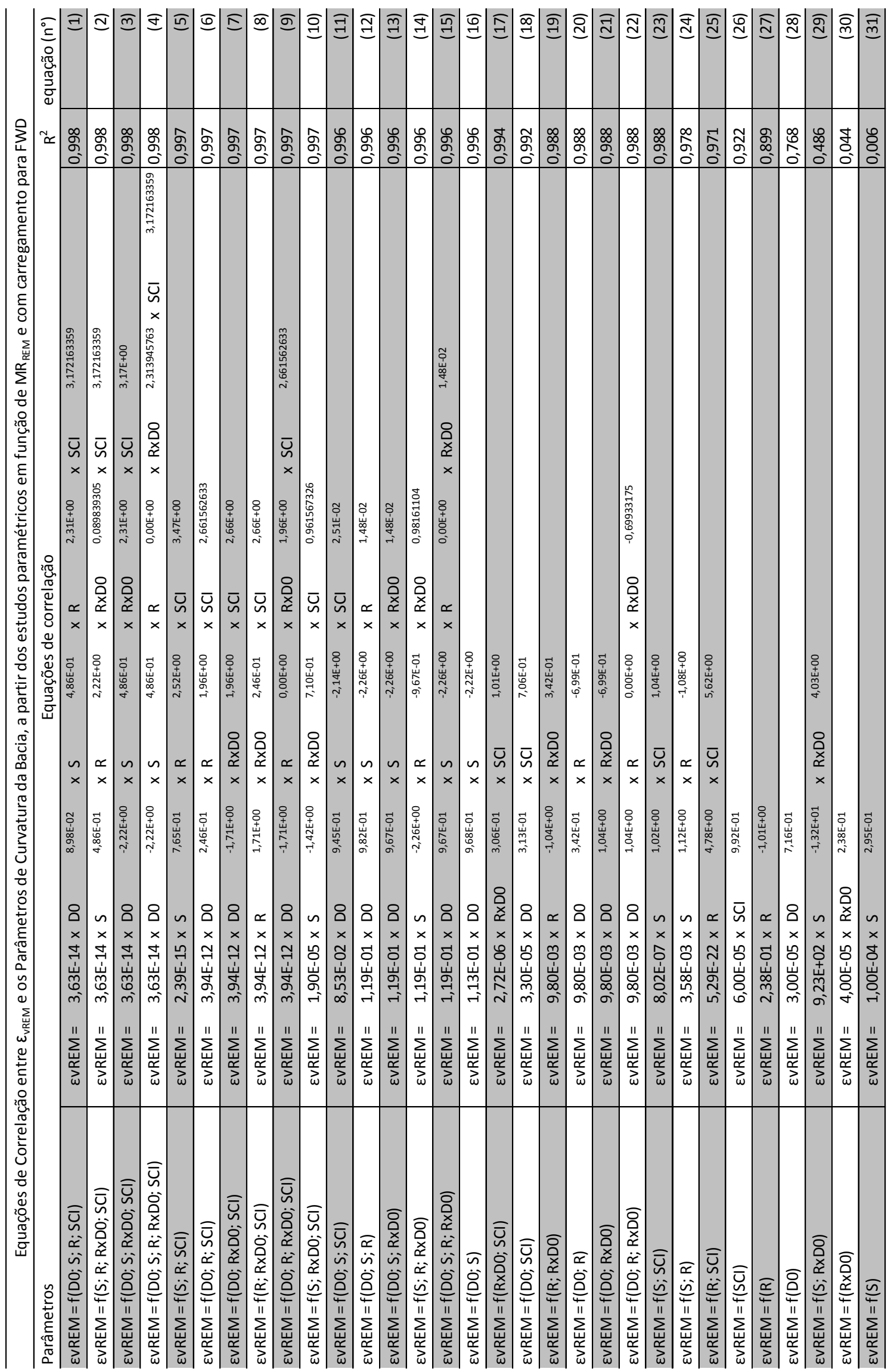




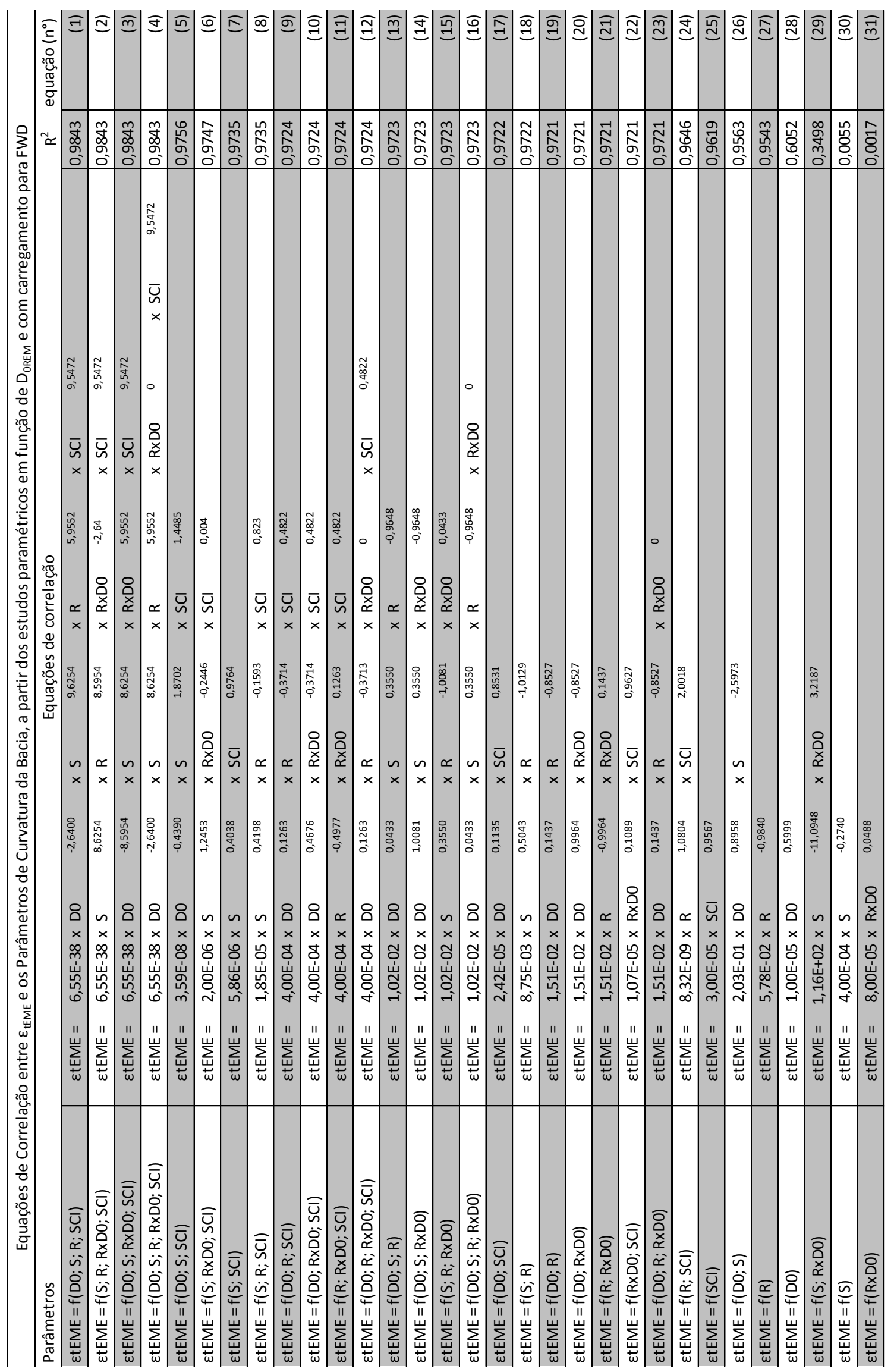




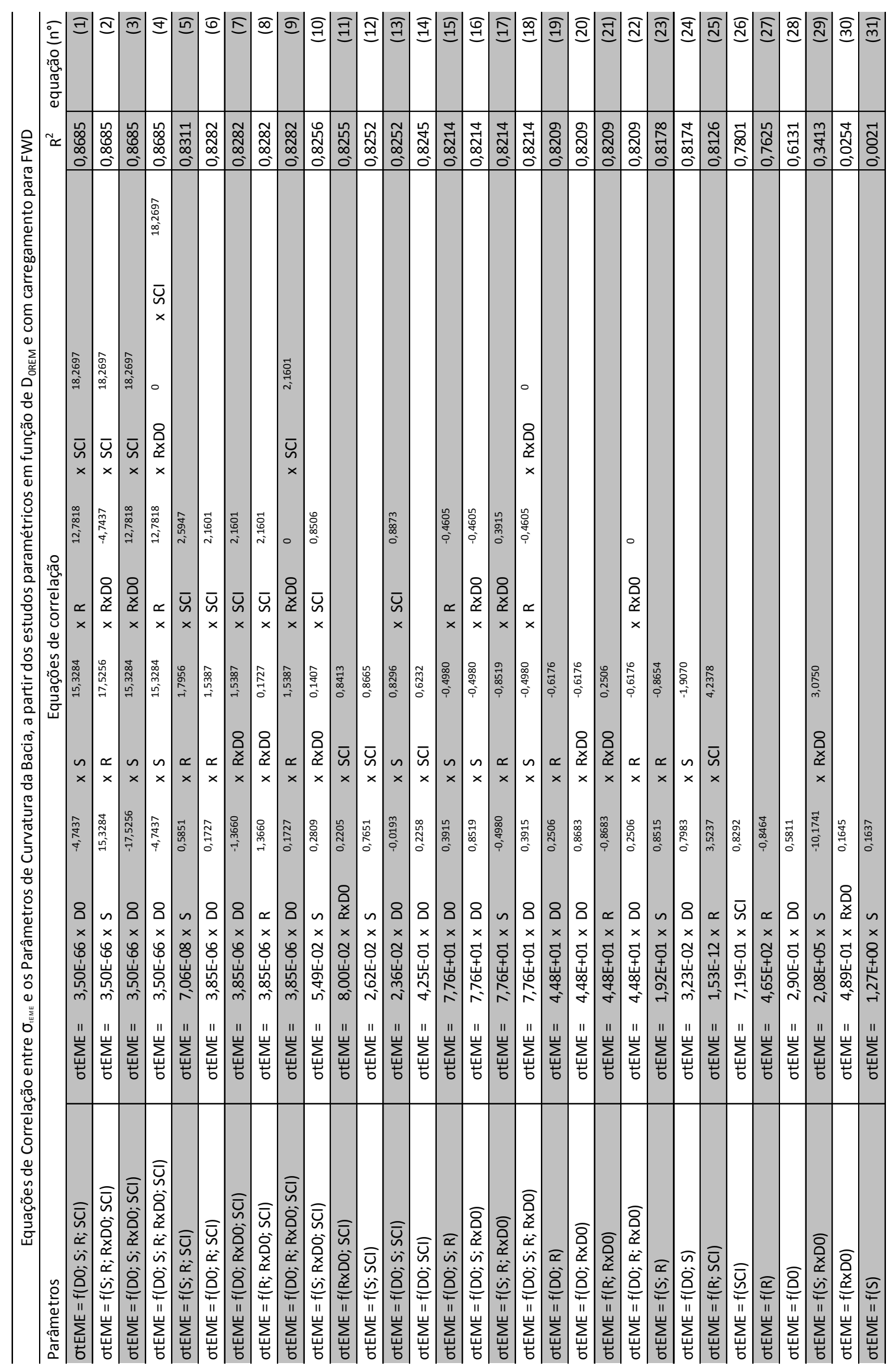




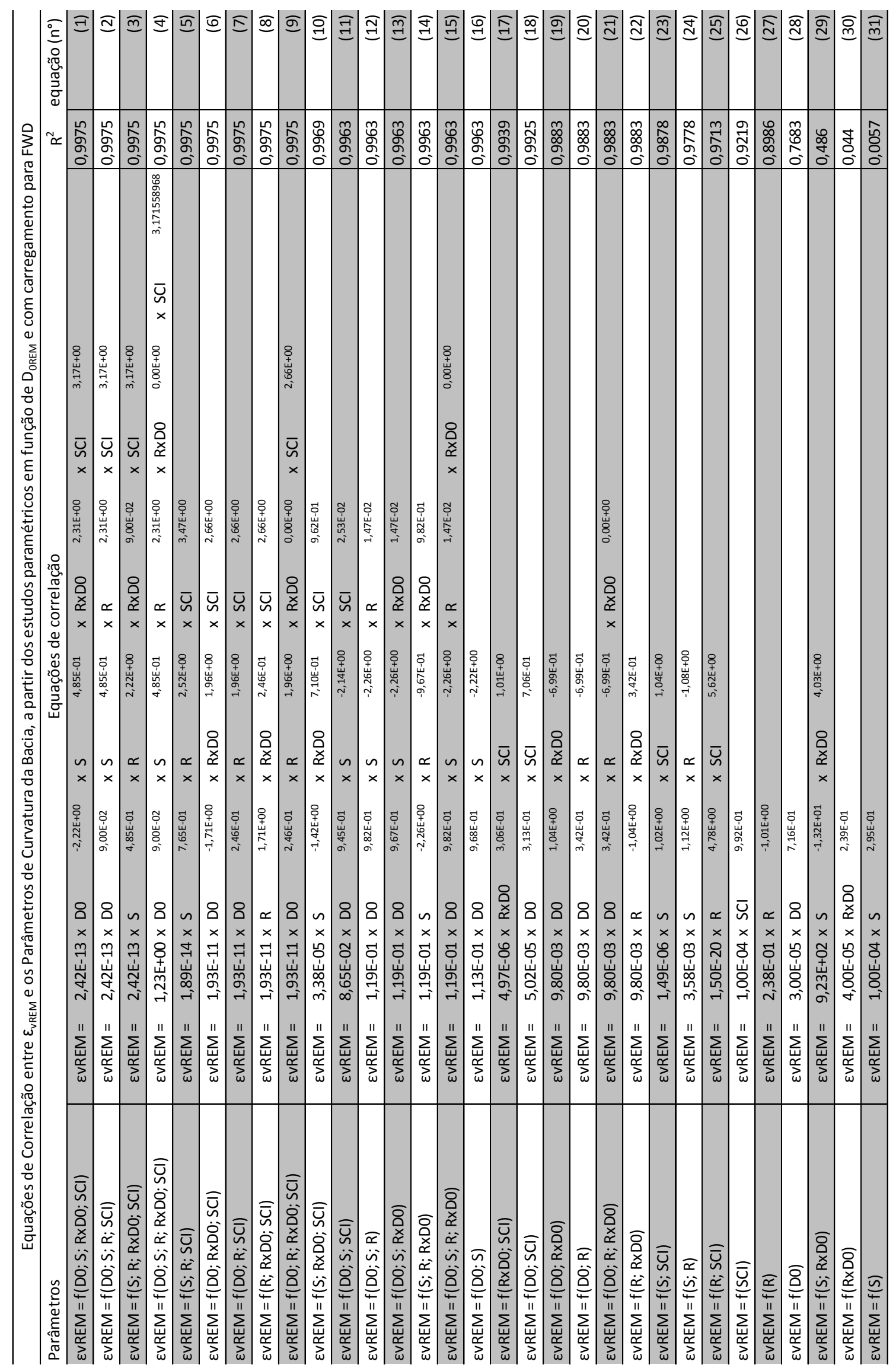




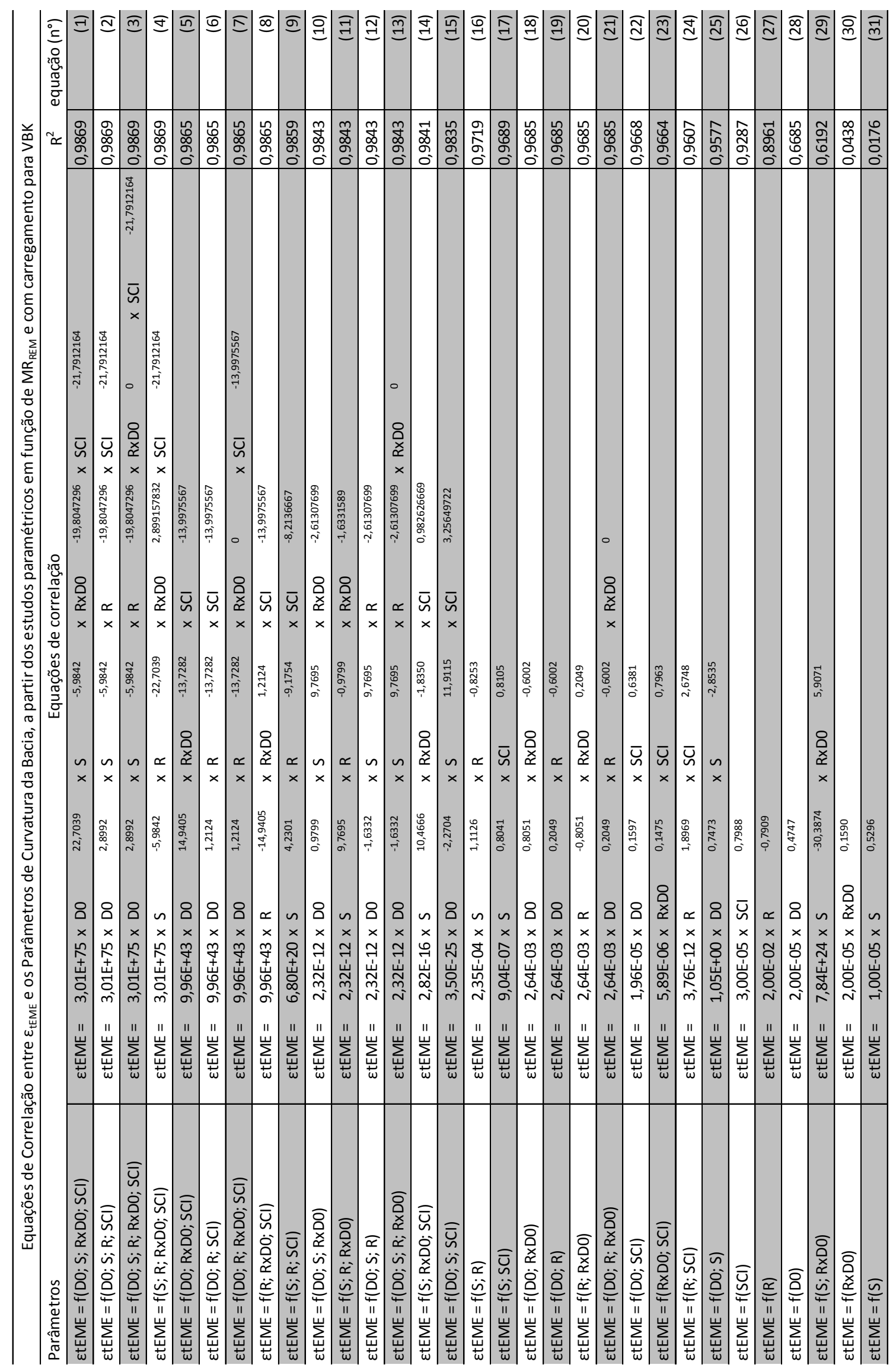




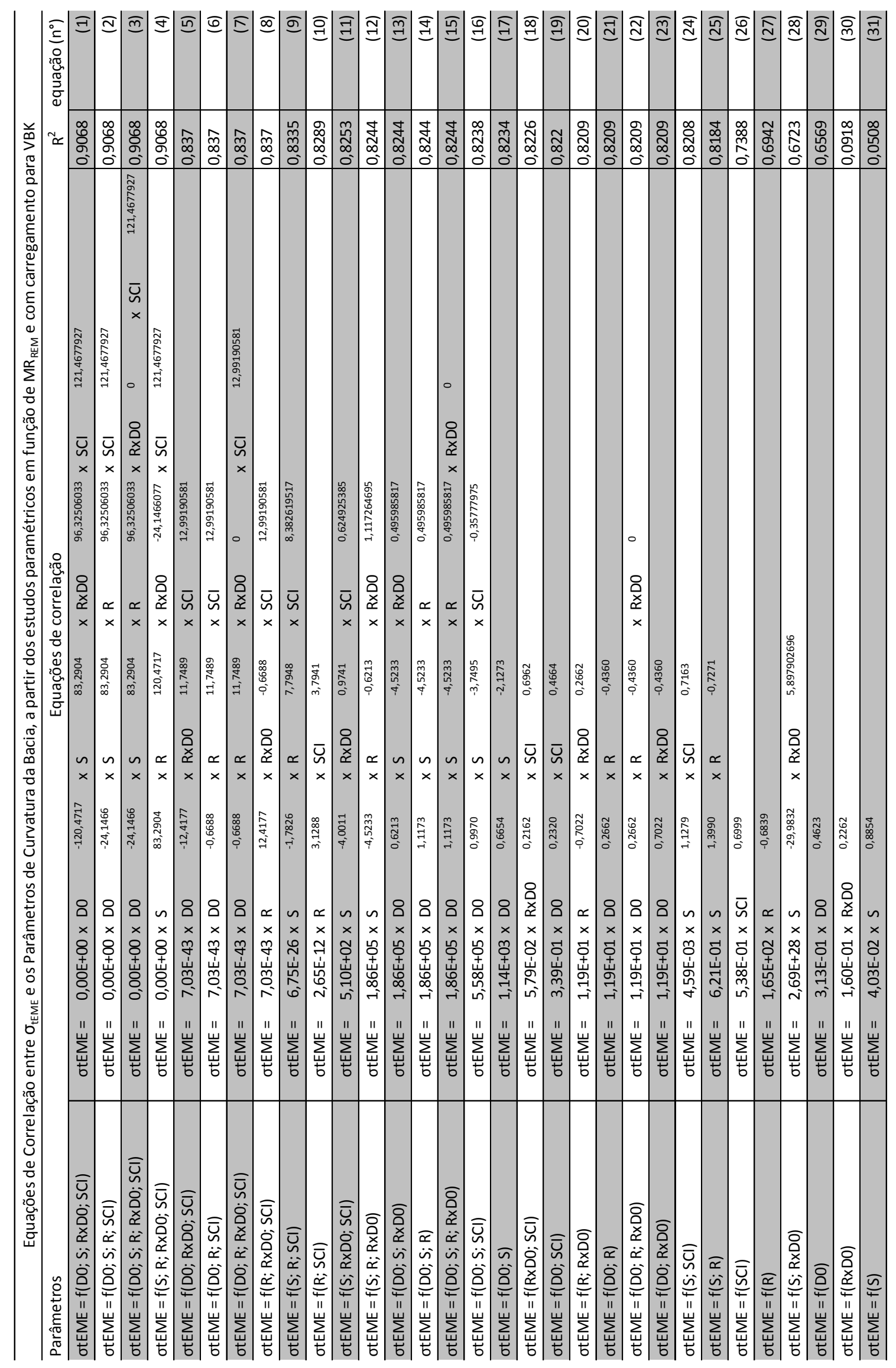




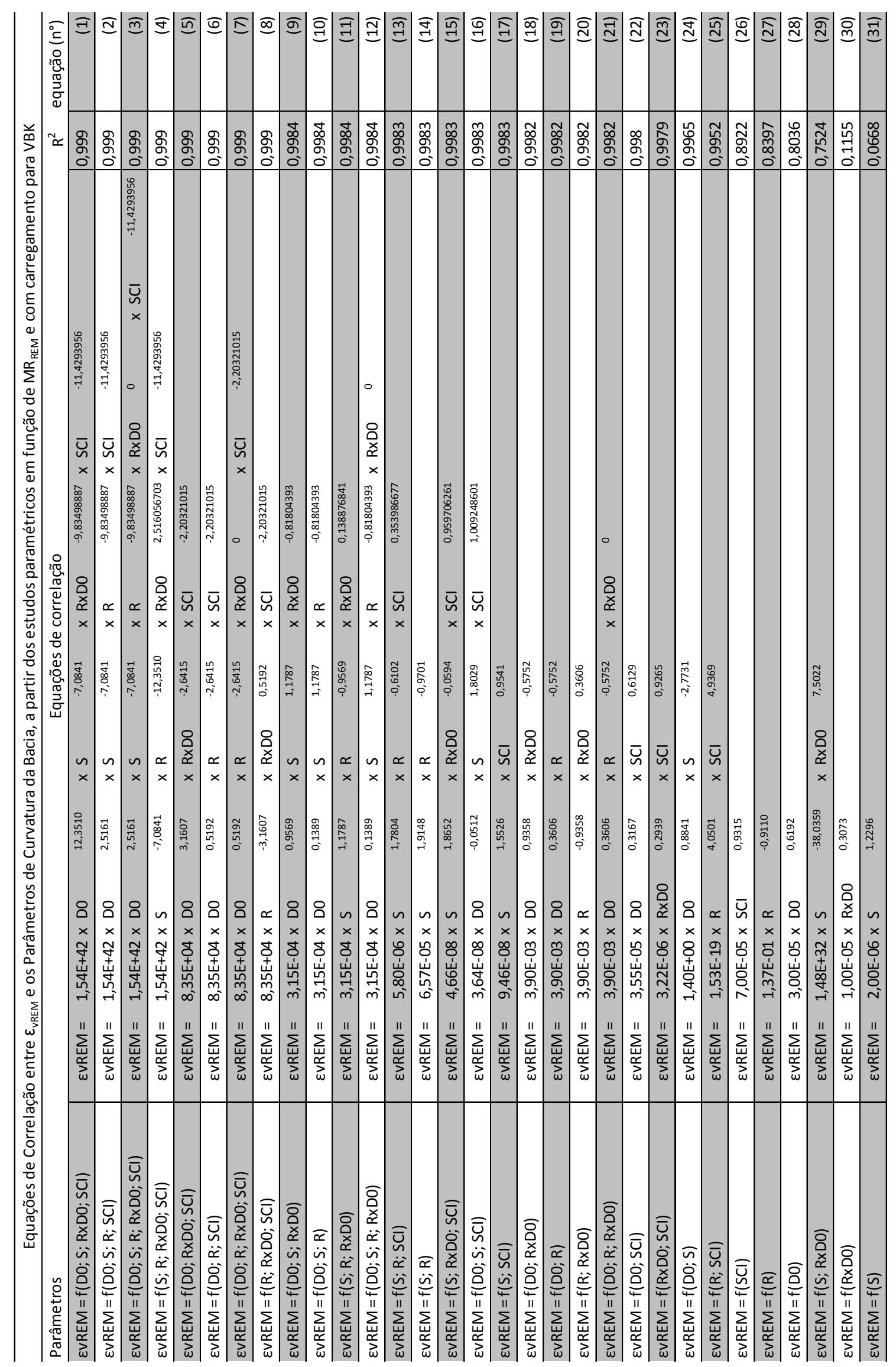




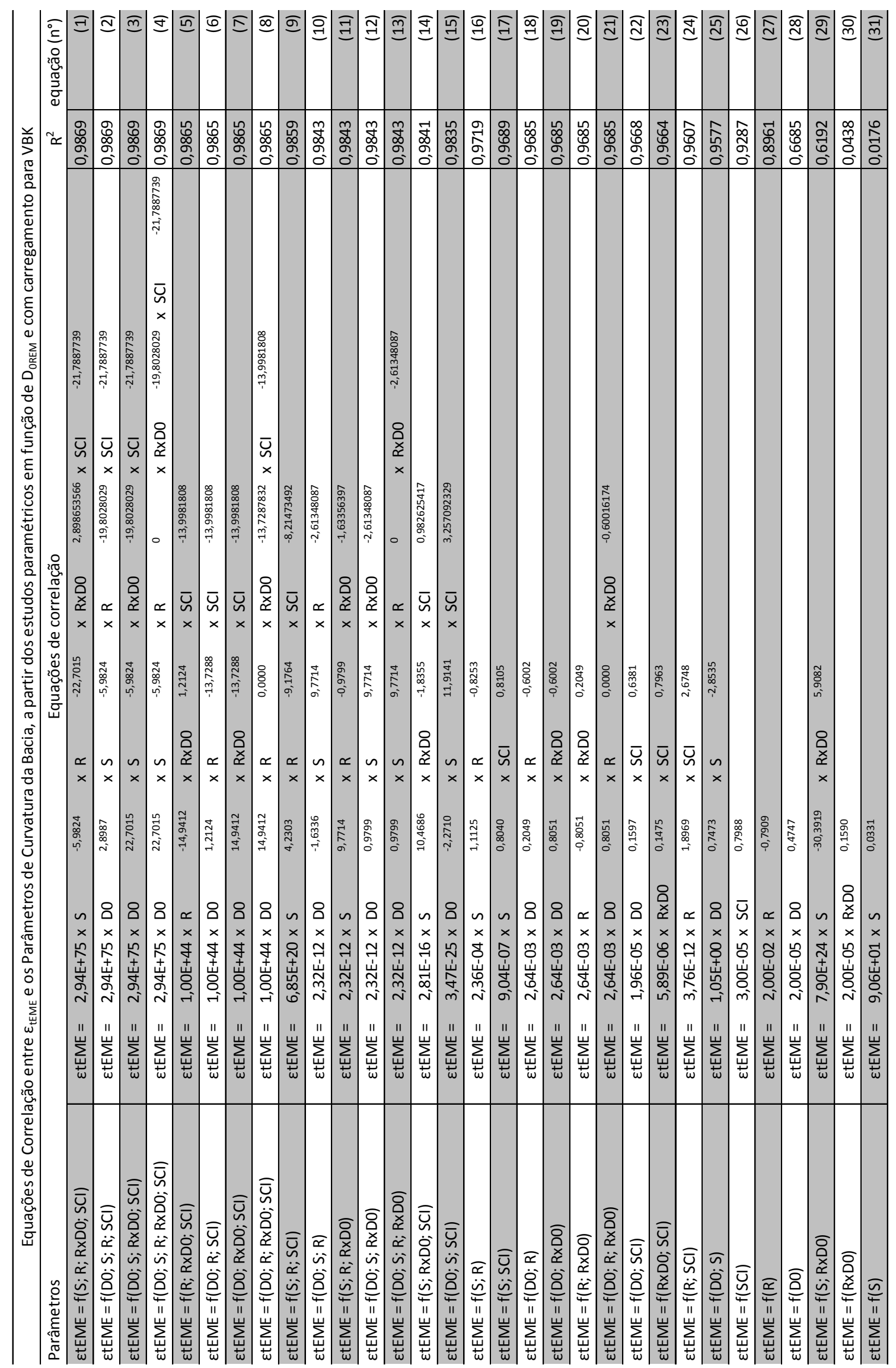




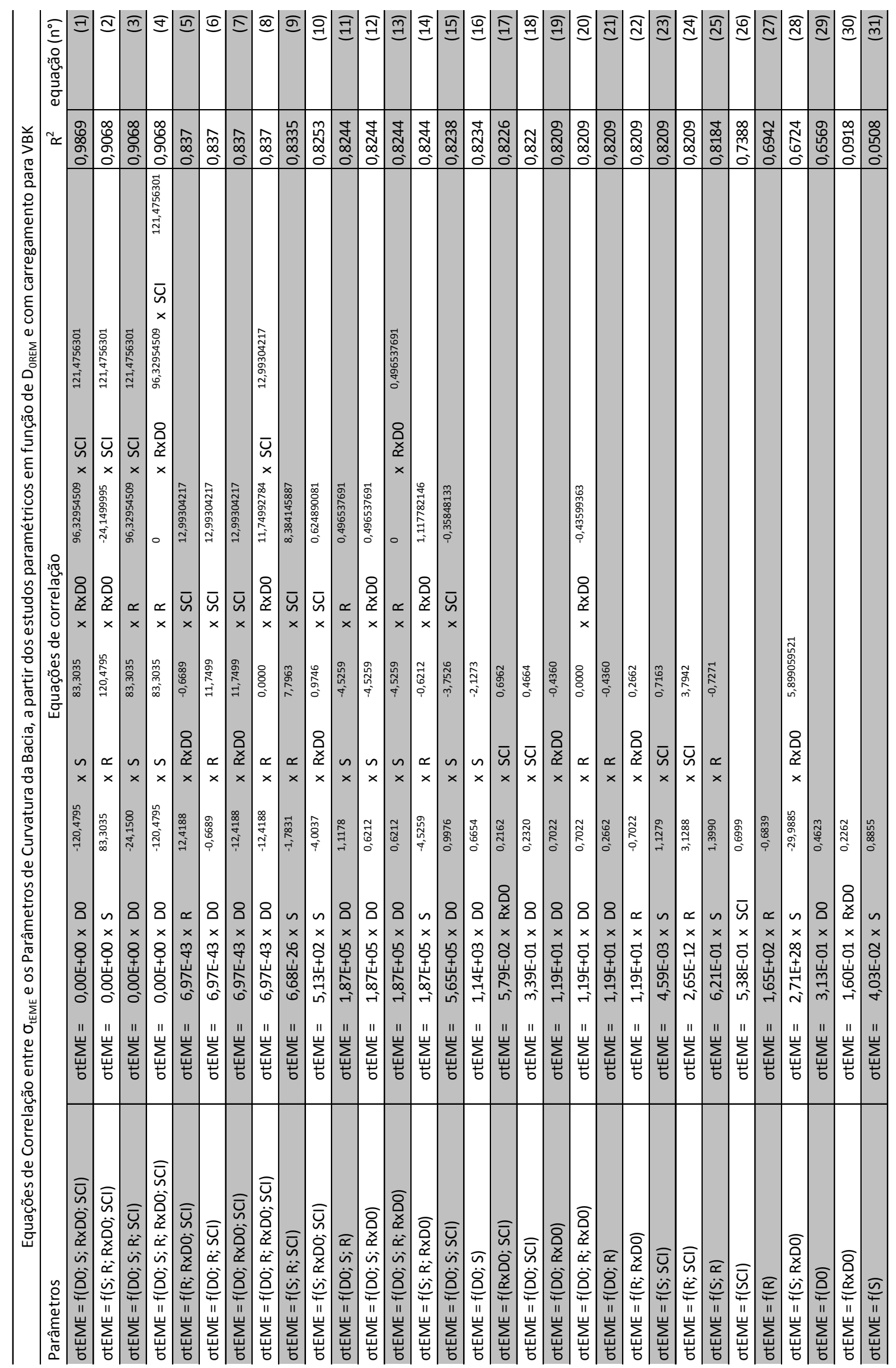




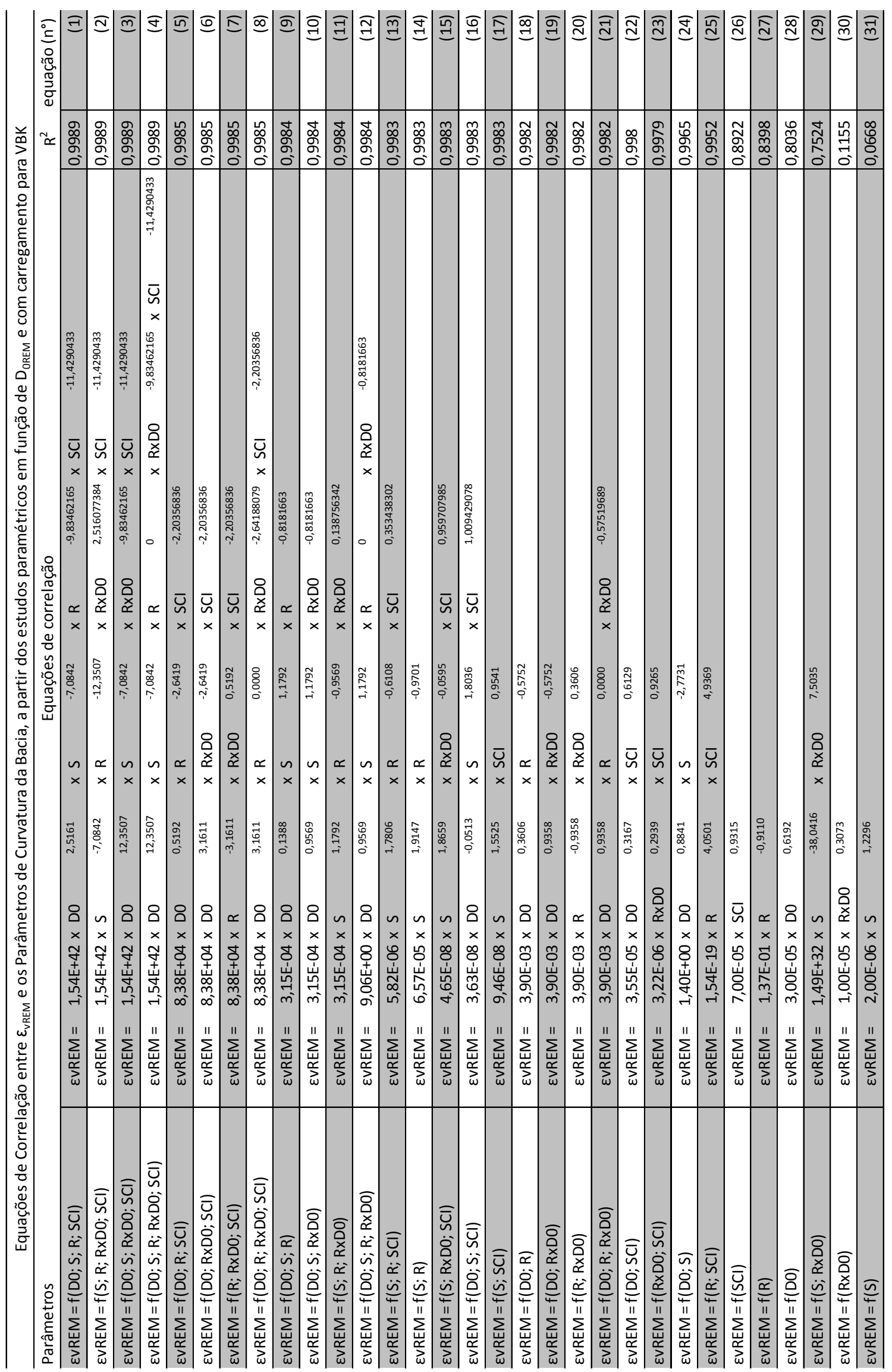



Rodovia: Presidente Dutra - BR-116 Pista: Norte (São Paulo) Sentido: Rio de Janeiro
Faixa: 2

Data: $29 / 06 / 2010$

\begin{tabular}{|c|c|c|c|c|c|c|c|c|c|c|c|}
\hline \multirow{2}{*}{$\mathrm{km}$} & \multirow{2}{*}{$\begin{array}{r}\text { Força } \\
\text { (kgf) }\end{array}$} & \multicolumn{7}{|c|}{ Deflexões $(0,01 \mathrm{~mm})$} & \multirow{2}{*}{$\begin{array}{l}\text { Temp. } \\
\operatorname{Ar}\left({ }^{\circ} \mathrm{C}\right)\end{array}$} & \multirow{2}{*}{$\begin{array}{l}\text { Temp. } \\
\text { Pav. }\left({ }^{\circ} \mathrm{C}\right)\end{array}$} & \multirow{2}{*}{ Obs } \\
\hline & & D0 & D200 & D300 & D450 & D600 & D900 & D1200 & & & \\
\hline 171,000 & 2100 & 40,6 & 28,1 & 20,5 & 11,6 & 7,4 & 4,0 & 2,9 & 9 & 20 & $\begin{array}{l}\text { seção de avaliação onde está } \\
\text { prevista RECONSTRUÇÃO }\end{array}$ \\
\hline 171,000 & 4100 & 61,7 & 47,0 & 35,9 & 23,3 & 15,5 & 7,9 & 5,9 & 9 & 20 & $\begin{array}{l}\text { seção de avaliação onde está } \\
\text { prevista RECONSTRUÇÃO }\end{array}$ \\
\hline 171,000 & 6500 & 85,2 & 68,4 & 53,8 & 37,7 & 26,4 & 13,5 & 9,9 & 9 & 20 & $\begin{array}{l}\text { seção de avaliação onde está } \\
\text { prevista RECONSTRUÇÃO }\end{array}$ \\
\hline 170,980 & 2100 & 22,6 & 17,7 & 15,0 & 11,5 & 9,3 & 5,7 & 3,7 & 9 & 20 & $\begin{array}{l}\text { seção de avaliação onde está } \\
\text { prevista RECONSTRUÇÃO }\end{array}$ \\
\hline 170,980 & 4100 & 43,5 & 35,2 & 30,0 & 23,7 & 19,1 & 11,4 & 7,9 & 9 & 20 & $\begin{array}{l}\text { seção de avaliação onde está } \\
\text { prevista RECONSTRUÇÃO }\end{array}$ \\
\hline 170,980 & 6500 & 65,7 & 54,0 & 46,6 & 38,1 & 31,2 & 18,9 & 13,3 & 9 & 20 & $\begin{array}{l}\text { seção de avaliação onde está } \\
\text { prevista RECONSTRUÇÃO }\end{array}$ \\
\hline 170,960 & 2100 & 19,6 & 16,4 & 13,8 & 10,6 & 8,8 & 5,4 & 3,5 & 9 & 20 & $\begin{array}{l}\text { seção de avaliação onde está } \\
\text { prevista RECONSTRUÇÃO }\end{array}$ \\
\hline 170,960 & 4100 & 39,9 & 33,8 & 28,8 & 22,5 & 18,6 & 10,6 & 7,1 & 9 & 20 & $\begin{array}{l}\text { seção de avaliação onde está } \\
\text { prevista RECONSTRUÇÃO }\end{array}$ \\
\hline 170,960 & 6500 & 62,8 & 53,2 & 45,8 & 37,1 & 30,6 & 17,6 & 11,8 & 9 & 20 & $\begin{array}{l}\text { seção de avaliação onde está } \\
\text { prevista RECONSTRUÇÃO }\end{array}$ \\
\hline 170,940 & 2100 & 16,3 & 13,4 & 11,2 & 8,6 & 6,9 & 3,9 & 2,9 & 9 & 20 & $\begin{array}{l}\text { seção de avaliação onde está } \\
\text { prevista RECONSTRUÇÃO }\end{array}$ \\
\hline 170,940 & 4100 & 33,3 & 27,8 & 23,5 & 18,3 & 14,7 & 8,6 & 6,0 & 9 & 20 & $\begin{array}{l}\text { seção de avaliação onde está } \\
\text { prevista RECONSTRUÇÃO }\end{array}$ \\
\hline 170,940 & 6500 & 52,4 & 44,1 & 37,7 & 30,3 & 24,4 & 14,3 & 10,0 & 9 & 20 & $\begin{array}{l}\text { seção de avaliação onde está } \\
\text { prevista RECONSTRUÇÃO }\end{array}$ \\
\hline 170,920 & 2100 & 33,6 & 22,2 & 18,3 & 13,7 & 10,7 & 5,8 & 3,8 & 9 & 20 & $\begin{array}{l}\text { seção de avaliação onde está } \\
\text { prevista RECONSTRUÇÃO }\end{array}$ \\
\hline 170,920 & 4100 & 57,1 & 42,7 & 35,5 & 27,3 & 21,8 & 11,8 & 7,6 & 9 & 20 & $\begin{array}{l}\text { seção de avaliação onde está } \\
\text { prevista RECONSTRUÇÃO }\end{array}$ \\
\hline 170,920 & 6500 & 81,9 & 63,8 & 53,9 & 42,7 & 34,4 & 19,3 & 12,9 & 9 & 20 & $\begin{array}{l}\text { seção de avaliação onde está } \\
\text { prevista RECONSTRUÇÃO }\end{array}$ \\
\hline 170,900 & 2100 & 8,9 & 7,5 & 6,8 & 6,1 & 5,2 & 3,3 & 2,9 & 9 & 20 & $\begin{array}{l}\text { seção de avaliação onde está } \\
\text { prevista RECONSTRUÇÃO }\end{array}$ \\
\hline 170,900 & 4100 & 16,8 & 14,7 & 13,3 & 11,5 & 10,1 & 7,0 & 5,4 & 9 & 20 & $\begin{array}{l}\text { seção de avaliação onde está } \\
\text { prevista RECONSTRUÇÃO }\end{array}$ \\
\hline 170,900 & 6500 & 27,3 & 24,0 & 21,7 & 19,1 & 17,0 & 11,7 & 8,9 & 9 & 20 & $\begin{array}{l}\text { seção de avaliação onde está } \\
\text { prevista RECONSTRUÇÃO }\end{array}$ \\
\hline 170,880 & 2100 & 14,4 & 11,5 & 9,6 & 7,2 & 6,0 & 3,7 & 2,7 & 10 & 20 & $\begin{array}{l}\text { seção de avaliação onde está } \\
\text { prevista RECONSTRUÇÃO }\end{array}$ \\
\hline 170,880 & 4100 & 31,3 & 25,0 & 20,9 & 16,3 & 13,0 & 7,9 & 5,5 & 10 & 20 & $\begin{array}{l}\text { seção de avaliação onde está } \\
\text { prevista RECONSTRUÇÃO }\end{array}$ \\
\hline 170,880 & 6500 & 50,4 & 40,8 & 34,4 & 27,5 & 22,1 & 13,2 & 9,3 & 10 & 20 & $\begin{array}{l}\text { seção de avaliação onde está } \\
\text { prevista RECONSTRUÇÃO }\end{array}$ \\
\hline 170,860 & 2100 & 30,9 & 24,8 & 18,0 & 12,0 & 9,7 & 6,8 & 3,4 & 10 & 20 & $\begin{array}{l}\text { seção de avaliação onde está } \\
\text { prevista RECONSTRUÇÃO }\end{array}$ \\
\hline 170,860 & 4100 & 54,8 & 45,5 & 35,4 & 24,9 & 20,1 & 12,1 & 7,4 & 10 & 20 & $\begin{array}{l}\text { seção de avaliação onde está } \\
\text { prevista RECONSTRUÇÃO }\end{array}$ \\
\hline 170,860 & 6500 & 76,6 & 64,9 & 51,9 & 38,5 & 30,8 & 18,8 & 11,5 & 10 & 20 & $\begin{array}{l}\text { seção de avaliação onde está } \\
\text { prevista RECONSTRUÇÃO }\end{array}$ \\
\hline 170,840 & 2100 & 13,7 & 12,1 & 10,0 & 7,5 & 5,6 & 3,9 & 2,7 & 10 & 20 & $\begin{array}{l}\text { seção de avaliação onde está } \\
\text { prevista RECONSTRUÇÃO }\end{array}$ \\
\hline 170,840 & 4100 & 27,4 & 24,1 & 20,3 & 15,5 & 11,6 & 7,3 & 5,3 & 10 & 20 & $\begin{array}{l}\text { seção de avaliação onde está } \\
\text { prevista RECONSTRUÇÃO }\end{array}$ \\
\hline 170,840 & 6500 & 43,0 & 37,7 & 32,1 & 25,8 & 19,7 & 12,3 & 8,8 & 10 & 20 & $\begin{array}{l}\text { seção de avaliação onde está } \\
\text { prevista RECONSTRUÇÃO }\end{array}$ \\
\hline 170,820 & 2100 & 18,0 & 15,1 & 13,0 & 10,4 & 8,2 & 5,1 & 3,3 & 10 & 20 & $\begin{array}{l}\text { seção de avaliação onde está } \\
\text { prevista RECONSTRUÇÃO }\end{array}$ \\
\hline 170,820 & 4100 & 34,6 & 29,2 & 25,8 & 21,2 & 17,0 & 10,1 & 7,0 & 10 & 20 & $\begin{array}{l}\text { seção de avaliação onde está } \\
\text { prevista RECONSTRUÇÃO }\end{array}$ \\
\hline 170,820 & 6500 & 51,9 & 44,3 & 39,4 & 33,4 & 27,2 & 16,6 & 11,7 & 10 & 20 & $\begin{array}{l}\text { seção de avaliação onde está } \\
\text { prevista RECONSTRUÇÃO }\end{array}$ \\
\hline 170,810 & 2100 & 12,9 & 10,9 & 9,7 & 7,4 & 6,3 & 4,7 & 2,8 & 10 & 20 & $\begin{array}{l}\text { seção de avaliação onde está } \\
\text { prevista RECONSTRUÇÃO }\end{array}$ \\
\hline 170,810 & 4100 & 28,1 & 23,7 & 20,8 & 16,8 & 13,7 & 8,6 & 5,8 & 10 & 20 & $\begin{array}{l}\text { seção de avaliação onde está } \\
\text { prevista RECONSTRUÇÃO }\end{array}$ \\
\hline 170,810 & 6500 & 45,1 & 38,2 & 33,6 & 27,5 & 22,6 & 14,0 & 9,4 & 10 & 20 & $\begin{array}{l}\text { seção de avaliação onde está } \\
\text { prevista RECONSTRUÇÃO }\end{array}$ \\
\hline 170,800 & 2100 & 30,5 & 26,6 & 22,7 & 16,9 & 12,1 & 5,1 & 3,3 & 10 & 20 & $\begin{array}{l}\text { seção de avaliação onde está } \\
\text { prevista RECONSTRUÇÃO }\end{array}$ \\
\hline 170,800 & 4100 & 33,6 & 29,5 & 25,3 & 19,5 & 14,6 & 7,5 & 5,0 & 10 & 20 & $\begin{array}{l}\text { seção de avaliação onde está } \\
\text { prevista RECONSTRUÇÃO }\end{array}$ \\
\hline
\end{tabular}


Rodovia: Presidente Dutra - BR-116 Pista: Norte (São Paulo) Sentido: Rio de Janeiro
Faixa: 2

Data: $29 / 06 / 2010$

\begin{tabular}{|c|c|c|c|c|c|c|c|c|c|c|c|}
\hline \multirow{2}{*}{$\mathrm{km}$} & \multirow{2}{*}{$\begin{array}{r}\text { Força } \\
\text { (kgf) }\end{array}$} & \multicolumn{7}{|c|}{ Deflexões $(0,01 \mathrm{~mm})$} & \multirow{2}{*}{$\begin{array}{l}\text { Temp. } \\
\operatorname{Ar}\left({ }^{\circ} \mathrm{C}\right)\end{array}$} & \multirow{2}{*}{$\begin{array}{l}\text { Temp. } \\
\text { Pav. }\left({ }^{\circ} \mathrm{C}\right)\end{array}$} & \multirow{2}{*}{ Obs } \\
\hline & & D0 & D200 & D300 & D450 & D600 & D900 & D1200 & & & \\
\hline 170,800 & 6500 & 40,9 & 35,6 & 30,3 & 24,0 & 18,8 & 10,9 & 7,3 & 10 & 20 & $\begin{array}{l}\text { seção de avaliação onde está } \\
\text { prevista RECONSTRUÇÃO }\end{array}$ \\
\hline 170,780 & 2100 & 37,4 & 28,9 & 23,7 & 16,6 & 12,3 & 5,5 & 3,2 & 11 & 20 & $\begin{array}{l}\text { seção de avaliação onde está } \\
\text { previsto } 14 \mathrm{~cm} \text { - EME }\end{array}$ \\
\hline 170,780 & 4100 & 37,8 & 30,6 & 25,7 & 19,5 & 15,0 & 8,3 & 5,5 & 11 & 20 & $\begin{array}{l}\text { seção de avaliação onde está } \\
\text { previsto } 14 \mathrm{~cm} \text { - EME }\end{array}$ \\
\hline 170,780 & 6500 & 43,0 & 36,3 & 31,1 & 24,6 & 19,7 & 11,7 & 8,5 & 11 & 20 & $\begin{array}{l}\text { seção de avaliação onde está } \\
\text { previsto } 14 \mathrm{~cm} \text { - EME }\end{array}$ \\
\hline 170,760 & 2100 & 35,0 & 29,6 & 25,6 & 19,2 & 13,9 & 6,0 & 2,4 & 11 & 20 & $\begin{array}{l}\text { seção de avaliação onde está } \\
\text { previsto } 14 \mathrm{~cm} \text { - EME }\end{array}$ \\
\hline 170,760 & 4100 & 40,9 & 34,6 & 30,0 & 23,1 & 17,6 & 8,9 & 5,0 & 11 & 20 & $\begin{array}{l}\text { seção de avaliação onde está } \\
\text { previsto } 14 \mathrm{~cm} \text { - EME }\end{array}$ \\
\hline 170,760 & 6500 & 51,3 & 43,5 & 37,7 & 29,4 & 22,7 & 13,0 & 8,1 & 11 & 20 & $\begin{array}{l}\text { seção de avaliação onde está } \\
\text { previsto } 14 \mathrm{~cm} \text { - EME }\end{array}$ \\
\hline 170,740 & 2100 & 19,3 & 16,3 & 13,9 & 10,5 & 8,1 & 3,3 & 2,6 & 11 & 20 & $\begin{array}{l}\text { seção de avaliação onde está } \\
\text { previsto } 14 \mathrm{~cm} \text { - EME }\end{array}$ \\
\hline 170,740 & 4100 & 25,9 & 21,8 & 18,7 & 14,4 & 11,3 & 6,1 & 4,1 & 11 & 20 & $\begin{array}{l}\text { seção de avaliação onde está } \\
\text { previsto } 14 \mathrm{~cm} \text { - EME }\end{array}$ \\
\hline 170,740 & 6500 & 35,6 & 29,4 & 25,1 & 20,3 & 16,0 & 9,5 & 6,2 & 11 & 20 & $\begin{array}{l}\text { seção de avaliação onde está } \\
\text { previsto } 14 \mathrm{~cm} \text { - EME }\end{array}$ \\
\hline 170,720 & 2100 & 12,9 & 10,7 & 9,5 & 7,0 & 5,7 & 2,5 & 1,9 & 12 & 20 & $\begin{array}{l}\text { seção de avaliação onde está } \\
\text { previsto } 14 \mathrm{~cm} \text { - EME }\end{array}$ \\
\hline 170,720 & 4100 & 18,7 & 15,7 & 13,5 & 10,8 & 8,6 & 5,0 & 3,4 & 12 & 20 & $\begin{array}{c}\text { seção de avaliação onde está } \\
\text { previsto } 14 \mathrm{~cm} \text { - EME }\end{array}$ \\
\hline 170,720 & 6500 & 26,3 & 22,7 & 19,2 & 15,3 & 12,6 & 7,8 & 5,0 & 12 & 20 & $\begin{array}{l}\text { seção de avaliação onde está } \\
\text { previsto } 14 \mathrm{~cm} \text { - EME }\end{array}$ \\
\hline 170,700 & 2100 & 41,2 & 32,4 & 27,5 & 20,6 & 13,8 & 4,0 & 1,2 & 12 & 20 & $\begin{array}{l}\text { seção de avaliação onde está } \\
\text { previsto } 14 \mathrm{~cm} \text { - EME }\end{array}$ \\
\hline 170,700 & 4100 & 49,1 & 39,4 & 32,8 & 24,2 & 17,8 & 8,2 & 4,3 & 12 & 20 & $\begin{array}{l}\text { seção de avaliação onde está } \\
\text { previsto } 14 \mathrm{~cm} \text { - EME }\end{array}$ \\
\hline 170,700 & 6500 & 55,9 & 44,8 & 37,6 & 27,6 & 20,8 & 10,6 & 5,7 & 12 & 20 & $\begin{array}{l}\text { seção de avaliação onde está } \\
\text { previsto } 14 \mathrm{~cm} \text { - EME }\end{array}$ \\
\hline 170,690 & 2100 & 12,4 & 10,5 & 9,3 & 7,2 & 5,8 & 3,5 & 2,1 & 10 & 20 & $\begin{array}{l}\text { seção de avaliação onde está } \\
\text { previsto } 14 \mathrm{~cm} \text { - EME }\end{array}$ \\
\hline 170,690 & 4100 & 25,6 & 21,9 & 19,2 & 15,3 & 12,2 & 7,2 & 4,2 & 10 & 20 & $\begin{array}{c}\text { seção de avaliação onde está } \\
\text { previsto } 14 \mathrm{~cm} \text { - EME }\end{array}$ \\
\hline 170,690 & 6500 & 41,0 & 35,2 & 30,8 & 25,0 & 20,0 & 12,0 & 7,0 & 10 & 20 & $\begin{array}{l}\text { seção de avaliação onde está } \\
\text { previsto } 14 \mathrm{~cm} \text { - EME }\end{array}$ \\
\hline 170,680 & 2100 & 17,0 & 13,2 & 10,6 & 7,5 & 5,4 & 2,5 & 1,3 & 11 & 20 & $\begin{array}{c}\text { seção de avaliação onde está } \\
\text { previsto } 14 \mathrm{~cm} \text { - EME }\end{array}$ \\
\hline 170,680 & 4100 & 34,9 & 27,7 & 22,6 & 16,8 & 12,1 & 5,6 & 2,7 & 11 & 20 & $\begin{array}{l}\text { seção de avaliação onde está } \\
\text { previsto } 14 \mathrm{~cm} \text { - EME }\end{array}$ \\
\hline 170,680 & 6500 & 52,5 & 42,2 & 34,9 & 26,3 & 19,5 & 9,2 & 4,6 & 11 & 20 & $\begin{array}{l}\text { seção de avaliação onde está } \\
\text { previsto } 14 \mathrm{~cm} \text { - EME }\end{array}$ \\
\hline 170,660 & 2100 & 16,5 & 12,8 & 10,0 & 6,8 & 4,7 & 2,1 & 1,1 & 10 & 20 & $\begin{array}{c}\text { seção de avaliação onde está } \\
\text { previsto } 14 \mathrm{~cm} \text { - EME }\end{array}$ \\
\hline 170,660 & 4100 & 33,2 & 26,1 & 20,7 & 14,8 & 10,3 & 4,4 & 2,2 & 10 & 20 & $\begin{array}{l}\text { seção de avaliação onde está } \\
\text { previsto } 14 \mathrm{~cm} \text { - EME }\end{array}$ \\
\hline 170,660 & 6500 & 50,6 & 40,1 & 32,3 & 23,8 & 17,0 & 7,6 & 3,7 & 10 & 20 & $\begin{array}{l}\text { seção de avaliação onde está } \\
\text { previsto } 14 \mathrm{~cm} \text { - EME }\end{array}$ \\
\hline 170,640 & 2100 & 14,5 & 12,2 & 10,1 & 7,2 & 5,4 & 2,6 & 1,4 & 10 & 20 & $\begin{array}{c}\text { seção de avaliação onde está } \\
\text { previsto } 14 \mathrm{~cm} \text { - EME }\end{array}$ \\
\hline 170,640 & 4100 & 30,2 & 25,7 & 21,6 & 16,2 & 12,3 & 5,9 & 3,0 & 10 & 20 & $\begin{array}{l}\text { seção de avaliação onde está } \\
\text { previsto } 14 \mathrm{~cm} \text { - EME }\end{array}$ \\
\hline 170,640 & 6500 & 46,8 & 40,0 & 33,9 & 26,3 & 20,3 & 9,9 & 5,2 & 10 & 20 & $\begin{array}{l}\text { seção de avaliação onde está } \\
\text { previsto } 14 \mathrm{~cm} \text { - EME }\end{array}$ \\
\hline 170,620 & 2100 & 16,5 & 13,3 & 11,0 & 7,9 & 6,0 & 3,0 & 1,5 & 10 & 20 & $\begin{array}{l}\text { seção de avaliação onde está } \\
\text { previsto } 14 \mathrm{~cm} \text { - EME }\end{array}$ \\
\hline 170,620 & 4100 & 34,5 & 28,3 & 23,8 & 17,8 & 13,3 & 6,4 & 3,4 & 10 & 20 & $\begin{array}{l}\text { seção de avaliação onde está } \\
\text { previsto } 14 \mathrm{~cm} \text { - EME }\end{array}$ \\
\hline 170,620 & 6500 & 53,3 & 43,9 & 37,1 & 28,6 & 21,9 & 10,7 & 5,8 & 10 & 20 & $\begin{array}{l}\text { seção de avaliação onde está } \\
\text { previsto } 14 \mathrm{~cm} \text { - EME }\end{array}$ \\
\hline 170,600 & 2100 & 28,3 & 19,8 & 14,7 & 8,2 & 5,8 & 2,1 & 0,8 & 10 & 20 & $\begin{array}{l}\text { seção de avaliação onde está } \\
\text { previsto } 14 \mathrm{~cm} \text { - EME }\end{array}$ \\
\hline 170,600 & 4100 & 50,0 & 37,4 & 28,5 & 17,5 & 12,4 & 4,4 & 1,5 & 10 & 20 & $\begin{array}{l}\text { seção de avaliação onde está } \\
\text { previsto } 14 \mathrm{~cm} \text { - EME }\end{array}$ \\
\hline 170,600 & 6500 & 71,2 & 54,9 & 42,8 & 28,4 & 20,4 & 7,6 & 2,5 & 10 & 20 & $\begin{array}{l}\text { seção de avaliação onde está } \\
\text { previsto } 14 \mathrm{~cm} \text { - EME }\end{array}$ \\
\hline 170,580 & 2100 & 28,8 & 20,7 & 15,8 & 9,0 & 5,7 & 2,2 & 0,8 & 10 & 20 & $\begin{array}{l}\text { seção de avaliação onde está } \\
\text { previsto } 11 \mathrm{~cm} \text { - EME }\end{array}$ \\
\hline
\end{tabular}


Rodovia: Presidente Dutra - BR-116 Pista: Norte (São Paulo) Sentido: Rio de Janeiro
Faixa: 2

Data: $29 / 06 / 2010$

\begin{tabular}{|c|c|c|c|c|c|c|c|c|c|c|c|}
\hline \multirow{2}{*}{$\mathrm{km}$} & \multirow{2}{*}{$\begin{array}{r}\text { Força } \\
\text { (kgf) }\end{array}$} & \multicolumn{7}{|c|}{ Deflexões $(0,01 \mathrm{~mm})$} & \multirow{2}{*}{$\begin{array}{l}\text { Temp. } \\
\operatorname{Ar}\left({ }^{\circ} \mathrm{C}\right)\end{array}$} & \multirow{2}{*}{$\begin{array}{l}\text { Temp. } \\
\text { Pav. }\left({ }^{\circ} \mathrm{C}\right)\end{array}$} & \multirow{2}{*}{ Obs } \\
\hline & & D0 & D200 & D300 & D450 & D600 & D900 & D1200 & & & \\
\hline 170,580 & 4100 & 51,6 & 40,5 & 31,8 & 20,5 & 13,2 & 5,0 & 1,9 & 10 & 20 & $\begin{array}{l}\text { seção de avaliação onde está } \\
\text { previsto } 11 \mathrm{~cm} \text { - EME }\end{array}$ \\
\hline 170,580 & 6500 & 74,8 & 60,8 & 49,1 & 34,1 & 22,9 & 8,8 & 3,5 & 10 & 20 & $\begin{array}{l}\text { seção de avaliação onde está } \\
\text { previsto } 11 \mathrm{~cm} \text { - EME }\end{array}$ \\
\hline 170,560 & 2100 & 28,5 & 19,0 & 13,5 & 8,6 & 5,5 & 2,9 & 1,5 & 10 & 20 & $\begin{array}{l}\text { seção de avaliação onde está } \\
\text { previsto } 11 \mathrm{~cm}-\text { EME }\end{array}$ \\
\hline 170,560 & 4100 & 50,4 & 38,2 & 28,7 & 20,4 & 13,4 & 6,9 & 3,6 & 10 & 20 & $\begin{array}{c}\text { seção de avaliação onde está } \\
\text { previsto } 11 \mathrm{~cm} \text { - EME }\end{array}$ \\
\hline 170,560 & 6500 & 72,6 & 57,9 & 45,0 & 33,8 & 23,0 & 12,1 & 6,5 & 10 & 20 & $\begin{array}{l}\text { seção de avaliação onde está } \\
\text { previsto } 11 \mathrm{~cm}-\text { EME }\end{array}$ \\
\hline 170,540 & 2100 & 24,8 & 16,4 & 12,1 & 7,8 & 5,7 & 2,7 & 1,4 & 10 & 20 & $\begin{array}{l}\text { seção de avaliação onde está } \\
\text { previsto } 11 \mathrm{~cm} \text { - EME }\end{array}$ \\
\hline 170,540 & 4100 & 43,6 & 32,3 & 24,9 & 17,4 & 12,5 & 5,8 & 2,9 & 10 & 20 & $\begin{array}{l}\text { seção de avaliação onde está } \\
\text { previsto } 11 \mathrm{~cm}-\text { EME }\end{array}$ \\
\hline 170,540 & 6500 & 63,1 & 48,8 & 39,0 & 28,4 & 21,0 & 10,2 & 5,4 & 10 & 20 & $\begin{array}{l}\text { seção de avaliação onde está } \\
\text { previsto } 11 \mathrm{~cm} \text { - EME }\end{array}$ \\
\hline 170,520 & 2100 & 20,1 & 16,5 & 12,0 & 7,7 & 4,8 & 1,6 & 0,8 & 11 & 20 & $\begin{array}{l}\text { seção de avaliação onde está } \\
\text { previsto } 11 \mathrm{~cm} \text { - EME }\end{array}$ \\
\hline 170,520 & 4100 & 38,4 & 32,5 & 24,3 & 16,4 & 10,3 & 3,4 & 1,6 & 11 & 20 & $\begin{array}{l}\text { seção de avaliação onde está } \\
\text { previsto } 11 \mathrm{~cm} \text { - EME }\end{array}$ \\
\hline 170,520 & 6500 & 55,7 & 47,2 & 36,3 & 25,4 & 16,5 & 5,8 & 2,5 & 11 & 20 & $\begin{array}{l}\text { seção de avaliação onde está } \\
\text { previsto } 11 \mathrm{~cm} \text { - EME }\end{array}$ \\
\hline 170,500 & 2100 & 29,2 & 19,7 & 13,8 & 8,0 & 4,6 & 1,2 & 0,4 & 11 & 20 & $\begin{array}{l}\text { seção de avaliação onde está } \\
\text { previsto } 11 \mathrm{~cm} \text { - EME }\end{array}$ \\
\hline 170,500 & 4100 & 45,0 & 33,1 & 24,5 & 15,2 & 8,9 & 2,5 & 0,7 & 11 & 20 & $\begin{array}{l}\text { seção de avaliação onde está } \\
\text { previsto } 11 \mathrm{~cm} \text { - EME }\end{array}$ \\
\hline 170,500 & 6500 & 58,8 & 44,8 & 34,0 & 22,1 & 13,6 & 4,0 & 1,3 & 11 & 20 & $\begin{array}{l}\text { seção de avaliação onde está } \\
\text { previsto } 11 \mathrm{~cm} \text { - EME }\end{array}$ \\
\hline 170,480 & 2100 & 20,0 & 14,7 & 11,6 & 7,7 & 5,3 & 2,2 & 1,0 & 11 & 20 & $\begin{array}{c}\text { seção de avaliação onde está } \\
\text { previsto } 11 \mathrm{~cm} \text { - EME }\end{array}$ \\
\hline 170,480 & 4100 & 39,8 & 30,0 & 24,2 & 16,9 & 11,4 & 4,7 & 2,2 & 11 & 20 & $\begin{array}{l}\text { seção de avaliação onde está } \\
\text { previsto } 11 \mathrm{~cm} \text { - EME }\end{array}$ \\
\hline 170,480 & 6500 & 60,7 & 46,6 & 38,0 & 27,6 & 18,9 & 8,1 & 3,8 & 11 & 20 & $\begin{array}{c}\text { seção de avaliação onde está } \\
\text { previsto } 11 \mathrm{~cm} \text { - EME }\end{array}$ \\
\hline 170,460 & 2100 & 15,0 & 9,9 & 7,3 & 4,6 & 3,5 & 1,7 & 1,0 & 11 & 20 & $\begin{array}{c}\text { seção de avaliação onde está } \\
\text { previsto } 11 \mathrm{~cm} \text { - EME }\end{array}$ \\
\hline 170,460 & 4100 & 29,0 & 20,0 & 15,2 & 10,6 & 7,7 & 3,6 & 1,9 & 11 & 20 & $\begin{array}{l}\text { seção de avaliação onde está } \\
\text { previsto } 11 \mathrm{~cm} \text { - EME }\end{array}$ \\
\hline 170,460 & 6500 & 44,0 & 31,0 & 24,2 & 17,4 & 13,0 & 6,2 & 3,4 & 11 & 20 & $\begin{array}{c}\text { seção de avaliação onde está } \\
\text { previsto } 11 \mathrm{~cm} \text { - EME }\end{array}$ \\
\hline 170,440 & 2100 & 29,8 & 18,7 & 13,3 & 7,8 & 4,3 & 1,5 & 0,8 & 11 & 20 & $\begin{array}{c}\text { seção de avaliação onde está } \\
\text { previsto } 11 \mathrm{~cm} \text { - EME }\end{array}$ \\
\hline 170,440 & 4100 & 49,6 & 35,1 & 26,5 & 16,1 & 9,5 & 3,4 & 1,7 & 11 & 20 & $\begin{array}{l}\text { seção de avaliação onde está } \\
\text { previsto } 11 \mathrm{~cm} \text { - EME }\end{array}$ \\
\hline 170,440 & 6500 & 68,2 & 50,9 & 39,4 & 25,3 & 15,2 & 5,8 & 2,7 & 11 & 20 & $\begin{array}{c}\text { seção de avaliação onde está } \\
\text { previsto } 11 \mathrm{~cm} \text { - EME }\end{array}$ \\
\hline 170,420 & 2100 & 24,2 & 16,2 & 12,0 & 7,9 & 5,5 & 2,4 & 1,2 & 11 & 20 & $\begin{array}{l}\text { seção de avaliação onde está } \\
\text { previsto } 11 \mathrm{~cm} \text { - EME }\end{array}$ \\
\hline 170,420 & 4100 & 46,5 & 32,9 & 25,5 & 17,4 & 12,1 & 5,2 & 2,4 & 11 & 20 & $\begin{array}{l}\text { seção de avaliação onde está } \\
\text { previsto } 11 \mathrm{~cm} \text { - EME }\end{array}$ \\
\hline 170,420 & 6500 & 67,0 & 48,5 & 38,3 & 26,9 & 19,1 & 8,3 & 3,8 & 11 & 20 & $\begin{array}{c}\text { seção de avaliação onde está } \\
\text { previsto } 11 \mathrm{~cm} \text { - EME }\end{array}$ \\
\hline 170,400 & 2100 & 11,1 & 8,7 & 7,1 & 5,1 & 4,0 & 1,9 & 0,9 & 11 & 20 & $\begin{array}{c}\text { seção de avaliação onde está } \\
\text { previsto } 11 \mathrm{~cm} \text { - EME }\end{array}$ \\
\hline 170,400 & 4100 & 24,2 & 19,6 & 16,3 & 12,3 & 9,4 & 4,5 & 2,3 & 11 & 20 & $\begin{array}{l}\text { seção de avaliação onde está } \\
\text { previsto } 11 \mathrm{~cm} \text { - EME }\end{array}$ \\
\hline 170,400 & 6500 & 39,3 & 32,0 & 26,9 & 20,7 & 16,0 & 7,9 & 4,0 & 11 & 20 & $\begin{array}{c}\text { seção de avaliação onde está } \\
\text { previsto } 11 \mathrm{~cm} \text { - EME }\end{array}$ \\
\hline 170,380 & 2100 & 25,2 & 18,2 & 13,6 & 9,2 & 6,6 & 2,9 & 1,4 & 11 & 20 & $\begin{array}{l}\text { seção de avaliação onde está } \\
\text { previsto } 8 \mathrm{~cm} \text { - EME }\end{array}$ \\
\hline 170,380 & 4100 & 42,7 & 32,3 & 25,3 & 17,9 & 13,0 & 5,7 & 2,8 & 11 & 20 & $\begin{array}{l}\text { seção de avaliação onde está } \\
\text { previsto } 8 \mathrm{~cm} \text { - EME }\end{array}$ \\
\hline 170,380 & 6500 & 59,3 & 45,7 & 36,5 & 26,9 & 19,8 & 9,1 & 4,5 & 11 & 20 & $\begin{array}{l}\text { seção de avaliação onde está } \\
\text { previsto } 8 \mathrm{~cm} \text { - EME }\end{array}$ \\
\hline 170,360 & 2100 & 29,1 & 13,9 & 10,8 & 7,1 & 5,3 & 2,9 & 2,1 & 11 & 20 & $\begin{array}{l}\text { seção de avaliação onde está } \\
\text { previsto } 8 \mathrm{~cm} \text { - EME }\end{array}$ \\
\hline 170,360 & 4100 & 49,0 & 27,3 & 21,2 & 14,5 & 10,7 & 5,9 & 4,1 & 11 & 20 & $\begin{array}{l}\text { seção de avaliação onde está } \\
\text { previsto } 8 \mathrm{~cm} \text { - EME }\end{array}$ \\
\hline 170,360 & 6500 & 71,8 & 42,2 & 33,2 & 23,2 & 17,4 & 9,7 & 7,0 & 11 & 20 & $\begin{array}{l}\text { seção de avaliação onde está } \\
\text { previsto } 8 \mathrm{~cm} \text { - EME }\end{array}$ \\
\hline
\end{tabular}


Rodovia: Presidente Dutra - BR-116 Pista: Norte (São Paulo) Sentido: Rio de Janeiro
Faixa: 2

Data: $29 / 06 / 2010$

\begin{tabular}{|c|c|c|c|c|c|c|c|c|c|c|c|}
\hline \multirow{2}{*}{$\mathrm{km}$} & \multirow{2}{*}{$\begin{array}{r}\text { Força } \\
\text { (kgf) }\end{array}$} & \multicolumn{7}{|c|}{ Deflexões $(0,01 \mathrm{~mm})$} & \multirow{2}{*}{$\begin{array}{l}\text { Temp. } \\
\operatorname{Ar}\left({ }^{\circ} \mathrm{C}\right)\end{array}$} & \multirow{2}{*}{$\begin{array}{l}\text { Temp. } \\
\text { Pav. }\left({ }^{\circ} \mathrm{C}\right)\end{array}$} & \multirow{2}{*}{ Obs } \\
\hline & & D0 & D200 & D300 & D450 & D600 & D900 & D1200 & & & \\
\hline 170,340 & 2100 & 18,2 & 15,2 & 12,8 & 9,5 & 7,5 & 3,9 & 2,5 & 10 & 20 & $\begin{array}{l}\text { seção de avaliação onde está } \\
\text { previsto } 8 \mathrm{~cm} \text { - EME }\end{array}$ \\
\hline 170,340 & 4100 & 36,8 & 31,2 & 26,7 & 20,8 & 16,2 & 8,6 & 5,0 & 10 & 20 & $\begin{array}{l}\text { seção de avaliação onde está } \\
\text { previsto } 8 \mathrm{~cm} \text { - EME }\end{array}$ \\
\hline 170,340 & 6500 & 56,3 & 48,1 & 41,7 & 33,4 & 26,4 & 14,3 & 8,5 & 10 & 20 & $\begin{array}{l}\text { seção de avaliação onde está } \\
\text { previsto } 8 \mathrm{~cm} \text { - EME }\end{array}$ \\
\hline 170,320 & 2100 & 27,4 & 20,5 & 16,5 & 11,6 & 8,5 & 4,4 & 2,7 & 10 & 20 & $\begin{array}{l}\text { seção de avaliação onde está } \\
\text { previsto } 8 \mathrm{~cm} \text { - EME }\end{array}$ \\
\hline 170,320 & 4100 & 51,5 & 40,0 & 32,6 & 23,8 & 17,6 & 9,2 & 5,7 & 10 & 20 & $\begin{array}{l}\text { seção de avaliação onde está } \\
\text { previsto } 8 \mathrm{~cm} \text { - EME }\end{array}$ \\
\hline 170,320 & 6500 & 73,0 & 57,4 & 47,4 & 36,0 & 26,9 & 14,3 & 8,8 & 10 & 20 & $\begin{array}{l}\text { seção de avaliação onde está } \\
\text { previsto } 8 \mathrm{~cm} \text { - EME }\end{array}$ \\
\hline 170,300 & 2100 & 21,1 & 17,0 & 14,4 & 11,0 & 8,9 & 5,2 & 3,8 & 10 & 20 & $\begin{array}{l}\text { seção de avaliação onde está } \\
\text { previsto } 8 \mathrm{~cm} \text { - EME }\end{array}$ \\
\hline 170,300 & 4100 & 41,7 & 34,1 & 28,8 & 21,9 & 17,2 & 9,2 & 6,0 & 10 & 20 & $\begin{array}{l}\text { seção de avaliação onde está } \\
\text { previsto } 8 \mathrm{~cm} \text { - EME }\end{array}$ \\
\hline 170,300 & 6500 & 64,6 & 53,2 & 45,4 & 35,2 & 27,7 & 14,8 & 9,8 & 10 & 20 & $\begin{array}{l}\text { seção de avaliação onde está } \\
\text { previsto } 8 \mathrm{~cm} \text { - EME }\end{array}$ \\
\hline 170,280 & 2100 & 26,6 & 22,7 & 18,2 & 13,5 & 10,2 & 5,4 & 3,7 & 9 & 20 & $\begin{array}{l}\text { seção de avaliação onde está } \\
\text { previsto } 8 \mathrm{~cm} \text { - EME }\end{array}$ \\
\hline 170,280 & 4100 & 48,5 & 42,2 & 34,5 & 26,1 & 19,7 & 10,5 & 6,8 & 9 & 20 & $\begin{array}{l}\text { seção de avaliação onde está } \\
\text { previsto } 8 \mathrm{~cm} \text { - EME }\end{array}$ \\
\hline 170,280 & 6500 & 72,1 & 62,7 & 52,3 & 41,6 & 32,0 & 17,8 & 12,3 & 9 & 20 & $\begin{array}{l}\text { seção de avaliação onde está } \\
\text { previsto } 8 \mathrm{~cm} \text { - EME }\end{array}$ \\
\hline 170,260 & 2100 & 18,3 & 14,3 & 11,8 & 8,8 & 6,9 & 3,7 & 2,4 & 10 & 20 & $\begin{array}{l}\text { seção de avaliação onde está } \\
\text { previsto } 8 \mathrm{~cm} \text { - EME }\end{array}$ \\
\hline 170,260 & 4100 & 37,0 & 29,5 & 24,6 & 19,0 & 14,4 & 7,4 & 4,5 & 10 & 20 & $\begin{array}{l}\text { seção de avaliação onde está } \\
\text { previsto } 8 \mathrm{~cm} \text { - EME }\end{array}$ \\
\hline 170,260 & 6500 & 58,1 & 47,4 & 40,2 & 31,4 & 24,7 & 13,4 & 8,5 & 10 & 20 & $\begin{array}{l}\text { seção de avaliação onde está } \\
\text { previsto } 8 \mathrm{~cm} \text { - EME }\end{array}$ \\
\hline 170,240 & 2100 & 26,2 & 20,2 & 16,1 & 10,8 & 8,0 & 4,5 & 3,1 & 10 & 20 & $\begin{array}{l}\text { seção de avaliação onde está } \\
\text { previsto } 8 \mathrm{~cm} \text { - EME }\end{array}$ \\
\hline 170,240 & 4100 & 48,6 & 39,2 & 32,9 & 23,2 & 17,1 & 9,4 & 6,3 & 10 & 20 & $\begin{array}{l}\text { seção de avaliação onde está } \\
\text { previsto } 8 \mathrm{~cm} \text { - EME }\end{array}$ \\
\hline 170,240 & 6500 & 72,7 & 60,3 & 51,9 & 38,3 & 28,5 & 15,7 & 10,5 & 10 & 20 & $\begin{array}{l}\text { seção de avaliação onde está } \\
\text { previsto } 8 \mathrm{~cm} \text { - EME }\end{array}$ \\
\hline 170,220 & 2100 & 15,6 & 12,3 & 10,2 & 7,7 & 6,4 & 3,8 & 2,7 & 9 & 20 & $\begin{array}{l}\text { seção de avaliação onde está } \\
\text { previsto } 8 \mathrm{~cm} \text { - EME }\end{array}$ \\
\hline 170,220 & 4100 & 33,4 & 26,3 & 22,0 & 17,5 & 13,8 & 7,8 & 5,4 & 9 & 20 & $\begin{array}{l}\text { seção de avaliação onde está } \\
\text { previsto } 8 \mathrm{~cm} \text { - EME }\end{array}$ \\
\hline 170,220 & 6500 & 52,9 & 42,3 & 36,0 & 28,8 & 23,1 & 13,2 & 9,0 & 9 & 20 & $\begin{array}{l}\text { seção de avaliação onde está } \\
\text { previsto } 8 \mathrm{~cm} \text { - EME }\end{array}$ \\
\hline 170,200 & 2100 & 26,2 & 19,6 & 15,5 & 10,6 & 8,1 & 4,3 & 2,7 & 9 & 20 & $\begin{array}{l}\text { seção de avaliação onde está } \\
\text { previsto } 8 \mathrm{~cm} \text { - EME }\end{array}$ \\
\hline 170,200 & 4100 & 51,2 & 39,9 & 32,3 & 23,3 & 17,3 & 8,8 & 5,2 & 9 & 20 & $\begin{array}{l}\text { seção de avaliação onde está } \\
\text { previsto } 8 \mathrm{~cm} \text { - EME }\end{array}$ \\
\hline 170,200 & 6500 & 76,9 & 61,0 & 50,1 & 37,9 & 28,5 & 14,7 & 8,9 & 9 & 20 & $\begin{array}{l}\text { seção de avaliação onde está } \\
\text { previsto } 8 \mathrm{~cm} \text { - EME }\end{array}$ \\
\hline 170,180 & 2100 & 15,1 & 12,6 & 11,0 & 9,0 & 7,6 & 4,9 & 3,6 & 9 & 20 & $\begin{array}{l}\text { seção de avaliação onde está } \\
\text { previsto } 8 \mathrm{~cm} \text { - EME }\end{array}$ \\
\hline 170,180 & 4100 & 31,5 & 26,9 & 23,6 & 19,6 & 16,4 & 10,4 & 7,4 & 9 & 20 & $\begin{array}{l}\text { seção de avaliação onde está } \\
\text { previsto } 8 \mathrm{~cm} \text { - EME }\end{array}$ \\
\hline 170,180 & 6500 & 50,6 & 43,3 & 38,3 & 32,2 & 27,2 & 17,2 & 12,2 & 9 & 20 & $\begin{array}{l}\text { seção de avaliação onde está } \\
\text { previsto } 8 \mathrm{~cm} \text { - EME }\end{array}$ \\
\hline 170,160 & 2100 & 11,9 & 9,5 & 8,0 & 6,3 & 5,4 & 3,6 & 2,8 & 9 & 20 & $\begin{array}{l}\text { seção de avaliação onde está } \\
\text { previsto } 8 \mathrm{~cm} \text { - CAP } 30 / 45\end{array}$ \\
\hline 170,160 & 4100 & 24,4 & 19,8 & 16,9 & 13,4 & 11,2 & 7,4 & 5,6 & 9 & 20 & $\begin{array}{l}\text { seção de avaliação onde está } \\
\text { previsto } 8 \mathrm{~cm} \text { - CAP } 30 / 45\end{array}$ \\
\hline 170,160 & 6500 & 40,3 & 32,6 & 28,1 & 23,3 & 19,1 & 12,6 & 9,8 & 9 & 20 & $\begin{array}{l}\text { seção de avaliação onde está } \\
\text { previsto } 8 \mathrm{~cm} \text { - CAP } 30 / 45\end{array}$ \\
\hline 170,140 & 2100 & 7,4 & 5,9 & 5,0 & 3,9 & 3,5 & 2,4 & 1,9 & 9 & 20 & $\begin{array}{l}\text { seção de avaliação onde está } \\
\text { previsto } 8 \mathrm{~cm} \text { - CAP } 30 / 45\end{array}$ \\
\hline 170,140 & 4100 & 14,6 & 11,3 & 9,7 & 7,8 & 6,8 & 4,6 & 3,6 & 9 & 20 & $\begin{array}{l}\text { seção de avaliação onde está } \\
\text { previsto } 8 \mathrm{~cm} \text { - CAP } 30 / 45\end{array}$ \\
\hline 170,140 & 6500 & 22,2 & 17,1 & 14,4 & 12,0 & 10,1 & 6,9 & 5,2 & 9 & 20 & $\begin{array}{l}\text { seção de avaliação onde está } \\
\text { previsto } 8 \mathrm{~cm} \text { - CAP } 30 / 45\end{array}$ \\
\hline 170,120 & 2100 & 13,1 & 9,9 & 7,9 & 5,8 & 4,6 & 2,5 & 1,7 & 9 & 20 & $\begin{array}{l}\text { seção de avaliação onde está } \\
\text { previsto } 8 \mathrm{~cm} \text { - CAP } 30 / 45\end{array}$ \\
\hline 170,120 & 4100 & 27,9 & 21,8 & 18,0 & 13,7 & 10,7 & 6,0 & 3,8 & 9 & 20 & $\begin{array}{l}\text { seção de avaliação onde está } \\
\text { previsto } 8 \mathrm{~cm} \text { - CAP } 30 / 45\end{array}$ \\
\hline
\end{tabular}


Rodovia: Presidente Dutra - BR-116

Pista: Norte (São Paulo)

Sentido: Rio de Janeiro
Faixa: 2

Data: $29 / 06 / 2010$

Trecho: Estrutura Primitiva

\begin{tabular}{|c|c|c|c|c|c|c|c|c|c|c|c|}
\hline \multirow{2}{*}{$\mathrm{km}$} & \multirow{2}{*}{$\begin{array}{l}\text { Força } \\
\text { (kgf) }\end{array}$} & \multicolumn{7}{|c|}{ Deflexões $(0,01 \mathrm{~mm})$} & \multirow{2}{*}{$\begin{array}{l}\text { Temp. } \\
\operatorname{Ar}\left({ }^{\circ} \mathrm{C}\right)\end{array}$} & \multirow{2}{*}{$\begin{array}{l}\text { Temp. } \\
\text { Pav. }\left({ }^{\circ} \mathrm{C}\right)\end{array}$} & \multirow{2}{*}{ Obs } \\
\hline & & D0 & D200 & D300 & D450 & D600 & D900 & D1200 & & & \\
\hline 170,120 & 6500 & 43,4 & 34,6 & 28,7 & 22,2 & 17,5 & 9,7 & 6,1 & 9 & 20 & $\begin{array}{l}\text { seção de avaliação onde está } \\
\text { previsto } 8 \mathrm{~cm} \text { - CAP } 30 / 45\end{array}$ \\
\hline 170,100 & 2100 & 12,5 & 9,1 & 6,6 & 4,8 & 3,9 & 2,2 & 1,6 & 9 & 20 & $\begin{array}{l}\text { seção de avaliação onde está } \\
\text { previsto } 8 \mathrm{~cm} \text { - CAP } 30 / 45\end{array}$ \\
\hline 170,100 & 4100 & 25,0 & 18,8 & 14,1 & 10,4 & 8,1 & 4,4 & 2,9 & 9 & 20 & $\begin{array}{l}\text { seção de avaliação onde está } \\
\text { previsto } 8 \mathrm{~cm} \text { - CAP } 30 / 45\end{array}$ \\
\hline 170,100 & 6500 & 39,0 & 29,8 & 23,1 & 17,3 & 13,9 & 7,8 & 5,2 & 9 & 20 & $\begin{array}{l}\text { seção de avaliação onde está } \\
\text { previsto } 8 \mathrm{~cm} \text { - CAP } 30 / 45\end{array}$ \\
\hline 170,080 & 2100 & 10,0 & 7,9 & 6,6 & 4,7 & 3,7 & 2,1 & 1,4 & 9 & 20 & $\begin{array}{l}\text { seção de avaliação onde está } \\
\text { previsto } 8 \mathrm{~cm} \text { - CAP } 30 / 45\end{array}$ \\
\hline 170,080 & 4100 & 20,6 & 16,6 & 13,8 & 10,4 & 8,0 & 4,4 & 2,6 & 9 & 20 & $\begin{array}{l}\text { seção de avaliação onde está } \\
\text { previsto } 8 \mathrm{~cm} \text { - CAP } 30 / 45\end{array}$ \\
\hline 170,080 & 6500 & 32,8 & 26,4 & 22,1 & 17,2 & 13,4 & 7,1 & 4,3 & 9 & 20 & $\begin{array}{l}\text { seção de avaliação onde está } \\
\text { previsto } 8 \mathrm{~cm} \text { - CAP } 30 / 45\end{array}$ \\
\hline 170,060 & 2100 & 15,5 & 11,0 & 8,3 & 5,6 & 4,2 & 1,9 & 1,2 & 10 & 20 & $\begin{array}{l}\text { seção de avaliação onde está } \\
\text { previsto } 8 \mathrm{~cm} \text { - CAP } 30 / 45\end{array}$ \\
\hline 170,060 & 4100 & 30,0 & 22,0 & 17,1 & 11,9 & 8,8 & 4,0 & 2,4 & 10 & 20 & $\begin{array}{l}\text { seção de avaliação onde está } \\
\text { previsto } 8 \mathrm{~cm} \text { - CAP } 30 / 45\end{array}$ \\
\hline 170,060 & 6500 & 44,4 & 33,1 & 26,0 & 18,8 & 13,9 & 6,4 & 3,7 & 10 & 20 & $\begin{array}{l}\text { seção de avaliação onde está } \\
\text { previsto } 8 \mathrm{~cm} \text { - CAP } 30 / 45\end{array}$ \\
\hline 170,040 & 2100 & 9,9 & 7,9 & 6,5 & 4,9 & 4,0 & 1,8 & 1,5 & 10 & 20 & $\begin{array}{l}\text { seção de avaliação onde está } \\
\text { previsto } 8 \mathrm{~cm} \text { - CAP } 30 / 45\end{array}$ \\
\hline 170,040 & 4100 & 20,9 & 17,1 & 14,5 & 11,4 & 8,8 & 5,0 & 3,1 & 10 & 20 & $\begin{array}{l}\text { seção de avaliação onde está } \\
\text { previsto } 8 \mathrm{~cm} \text { - CAP } 30 / 45\end{array}$ \\
\hline 170,040 & 6500 & 34,1 & 27,9 & 23,6 & 18,9 & 15,0 & 8,2 & 5,0 & 10 & 20 & $\begin{array}{l}\text { seção de avaliação onde está } \\
\text { previsto } 8 \mathrm{~cm} \text { - CAP } 30 / 45\end{array}$ \\
\hline 170,020 & 2100 & 12,2 & 10,0 & 8,3 & 6,1 & 5,0 & 2,9 & 2,0 & 10 & 20 & $\begin{array}{l}\text { seção de avaliação onde está } \\
\text { previsto } 8 \mathrm{~cm} \text { - CAP } 30 / 45\end{array}$ \\
\hline 170,020 & 4100 & 27,0 & 22,0 & 18,6 & 14,4 & 11,3 & 6,4 & 4,1 & 10 & 20 & $\begin{array}{l}\text { seção de avaliação onde está } \\
\text { previsto } 8 \mathrm{~cm} \text { - CAP } 30 / 45\end{array}$ \\
\hline 170,020 & 6500 & 44,1 & 36,5 & 30,9 & 24,4 & 19,5 & 11,0 & 7,0 & 10 & 20 & $\begin{array}{l}\text { seção de avaliação onde está } \\
\text { previsto } 8 \mathrm{~cm} \text { - CAP } 30 / 45\end{array}$ \\
\hline 170,000 & 2100 & 7,9 & 6,8 & 6,0 & 4,8 & 4,2 & 2,8 & 2,1 & 9 & 20 & $\begin{array}{l}\text { seção de avaliação onde está } \\
\text { previsto } 8 \mathrm{~cm} \text { - CAP } 30 / 45\end{array}$ \\
\hline 170,000 & 4100 & 18,6 & 16,0 & 14,2 & 11,9 & 10,0 & 6,4 & 4,5 & 9 & 20 & $\begin{array}{l}\text { seção de avaliação onde está } \\
\text { previsto } 8 \mathrm{~cm} \text { - CAP } 30 / 45\end{array}$ \\
\hline 170,000 & 6500 & 31,2 & 27,1 & 24,1 & 20,6 & 17,4 & 10,9 & 7,6 & 9 & 20 & $\begin{array}{l}\text { seção de avaliação onde está } \\
\text { previsto } 8 \mathrm{~cm} \text { - CAP } 30 / 45\end{array}$ \\
\hline
\end{tabular}


Rodovia: Presidente Dutra - BR-116 Pista: Norte (São Paulo)

Sentido: Rio de Janeiro
Faixa: 2

Trecho: Fundo da Caixa Fresada (Topo da Estrutura Remanescente)

\begin{tabular}{|c|c|c|c|c|c|c|c|c|c|c|c|}
\hline \multirow{2}{*}{$\mathrm{km}$} & \multirow{2}{*}{$\begin{array}{r}\text { Força } \\
\text { (kgf) }\end{array}$} & \multicolumn{7}{|c|}{ Deflexões $(0,01 \mathrm{~mm})$} & \multirow{2}{*}{$\begin{array}{l}\text { Temp. } \\
\operatorname{Ar}\left({ }^{\circ} \mathrm{C}\right)\end{array}$} & \multirow{2}{*}{$\begin{array}{l}\text { Temp. } \\
\text { Pav. }\left({ }^{\circ} \mathrm{C}\right)\end{array}$} & \multirow{2}{*}{ Obs } \\
\hline & & D0 & D200 & D300 & D450 & D600 & D900 & D1200 & & & \\
\hline 170,790 & 2100 & 39,2 & 26,8 & 18,1 & 10,5 & 6,5 & 3,5 & 2,6 & 10 & 20 & $\begin{array}{c}\text { data do levantamento: } \\
30 / 06 / 2010\end{array}$ \\
\hline 170,790 & 4100 & 63,1 & 44,9 & 32,1 & 20,1 & 13,5 & 6,8 & 5,0 & 10 & 20 & $\begin{array}{c}\text { data do levantamento: } \\
30 / 06 / 2010\end{array}$ \\
\hline 170,790 & 6500 & 91,6 & 66,0 & 48,7 & 32,2 & 21,7 & 11,3 & 8,5 & 10 & 20 & $\begin{array}{c}\text { data do levantamento: } \\
30 / 06 / 2010\end{array}$ \\
\hline 170,780 & 2100 & 45,2 & 31,8 & 21,0 & 11,4 & 6,4 & 3,3 & 2,7 & 10 & 20 & $\begin{array}{c}\text { data do levantamento: } \\
30 / 06 / 2010\end{array}$ \\
\hline 170,780 & 4100 & 67,4 & 48,8 & 34,5 & 20,6 & 12,7 & 6,5 & 5,1 & 10 & 20 & $\begin{array}{c}\text { data do levantamento: } \\
30 / 06 / 2010\end{array}$ \\
\hline 170,780 & 6500 & 93,8 & 69,2 & 50,6 & 32,6 & 20,6 & 10,9 & 8,2 & 10 & 20 & $\begin{array}{c}\text { data do levantamento: } \\
30 / 06 / 2010\end{array}$ \\
\hline 170,760 & 2100 & 63,2 & 39,8 & 24,4 & 11,3 & 5,2 & 3,0 & 2,7 & 11 & 20 & $\begin{array}{c}\text { data do levantamento: } \\
30 / 06 / 2010\end{array}$ \\
\hline 170,760 & 4100 & 105,7 & 66,9 & 43,2 & 21,7 & 11,0 & 5,8 & 5,4 & 11 & 20 & $\begin{array}{c}\text { data do levantamento: } \\
30 / 06 / 2010\end{array}$ \\
\hline 170,760 & 6500 & 146,7 & 94,7 & 63,1 & 34,4 & 18,6 & 9,7 & 8,9 & 11 & 20 & $\begin{array}{c}\text { data do levantamento: } \\
30 / 06 / 2010\end{array}$ \\
\hline 170,740 & 2100 & 29,4 & 19,5 & 13,8 & 7,8 & 4,6 & 2,2 & 1,7 & 11 & 20 & $\begin{array}{c}\text { data do levantamento: } \\
30 / 06 / 2010\end{array}$ \\
\hline 170,740 & 4100 & 51,4 & 34,7 & 24,9 & 15,2 & 9,3 & 4,3 & 3,3 & 11 & 20 & $\begin{array}{c}\text { data do levantamento: } \\
30 / 06 / 2010\end{array}$ \\
\hline 170,740 & 6500 & 74,9 & 51,2 & 37,3 & 23,6 & 14,8 & 6,9 & 5,3 & 11 & 20 & $\begin{array}{c}\text { data do levantamento: } \\
30 / 06 / 2010\end{array}$ \\
\hline 170,720 & 2100 & 36,5 & 23,2 & 16,1 & 9,3 & 5,6 & 2,0 & 1,3 & 11 & 20 & $\begin{array}{c}\text { data do levantamento: } \\
30 / 06 / 2010\end{array}$ \\
\hline 170,720 & 4100 & 54,1 & 35,8 & 25,9 & 16,0 & 10,0 & 4,0 & 2,6 & 11 & 20 & $\begin{array}{c}\text { data do levantamento: } \\
30 / 06 / 2010\end{array}$ \\
\hline 170,720 & 6500 & 72,9 & 49,3 & 36,6 & 23,6 & 15,4 & 6,6 & 4,2 & 11 & 20 & $\begin{array}{c}\text { data do levantamento: } \\
30 / 06 / 2010\end{array}$ \\
\hline 170,700 & 2100 & 54,4 & 37,4 & 25,6 & 13,4 & 6,9 & 2,2 & 1,4 & 11 & 20 & $\begin{array}{c}\text { data do levantamento: } \\
30 / 06 / 2010\end{array}$ \\
\hline 170,700 & 4100 & 72,5 & 52,5 & 37,8 & 21,7 & 11,9 & 4,3 & 2,7 & 11 & 20 & $\begin{array}{c}\text { data do levantamento: } \\
30 / 06 / 2010\end{array}$ \\
\hline 170,700 & 6500 & 94,4 & 70,2 & 52,2 & 32,1 & 18,5 & 7,3 & 4,6 & 11 & 20 & $\begin{array}{c}\text { data do levantamento: } \\
30 / 06 / 2010\end{array}$ \\
\hline 170,680 & 2100 & 44,2 & 29,0 & 19,8 & 9,7 & 4,7 & 1,2 & 0,7 & 9 & 20 & $\begin{array}{c}\text { data do levantamento: } \\
01 / 07 / 2010\end{array}$ \\
\hline 170,680 & 4100 & 59,9 & 40,9 & 29,4 & 15,6 & 8,1 & 2,3 & 1,4 & 9 & 20 & $\begin{array}{c}\text { data do levantamento: } \\
01 / 07 / 2010\end{array}$ \\
\hline 170,680 & 6500 & 77,0 & 54,2 & 39,8 & 22,2 & 12,4 & 3,7 & 2,3 & 9 & 20 & $\begin{array}{c}\text { data do levantamento: } \\
01 / 07 / 2010\end{array}$ \\
\hline 170,660 & 2100 & 34,9 & 22,5 & 14,3 & 6,6 & 3,2 & 1,1 & 0,7 & 9 & 20 & $\begin{array}{c}\text { data do levantamento: } \\
01 / 07 / 2010\end{array}$ \\
\hline 170,660 & 4100 & 55,3 & 37,0 & 25,1 & 12,8 & 6,6 & 2,2 & 1,3 & 9 & 20 & $\begin{array}{c}\text { data do levantamento: } \\
01 / 07 / 2010\end{array}$ \\
\hline 170,660 & 6500 & 79,1 & 54,1 & 37,9 & 20,8 & 11,0 & 3,9 & 2,4 & 9 & 20 & $\begin{array}{c}\text { data do levantamento: } \\
01 / 07 / 2010\end{array}$ \\
\hline 170,640 & 2100 & 42,7 & 26,4 & 17,0 & 8,6 & 4,4 & 1,1 & 0,6 & 10 & 20 & $\begin{array}{c}\text { data do levantamento: } \\
01 / 07 / 2010\end{array}$ \\
\hline 170,640 & 4100 & 64,4 & 40,8 & 28,7 & 15,9 & 8,2 & 2,8 & 1,4 & 10 & 20 & $\begin{array}{c}\text { data do levantamento: } \\
01 / 07 / 2010\end{array}$ \\
\hline 170,640 & 6500 & 90,4 & 58,4 & 42,7 & 25,1 & 13,6 & 4,8 & 2,5 & 10 & 20 & $\begin{array}{c}\text { data do levantamento: } \\
01 / 07 / 2010\end{array}$ \\
\hline 170,620 & 2100 & 47,2 & 29,5 & 17,8 & 8,5 & 4,2 & 1,4 & 0,9 & 9 & 20 & $\begin{array}{c}\text { data do levantamento: } \\
01 / 07 / 2010\end{array}$ \\
\hline 170,620 & 4100 & 68,0 & 46,2 & 30,8 & 17,0 & 9,2 & 3,2 & 2,0 & 9 & 20 & $\begin{array}{c}\text { data do levantamento: } \\
01 / 07 / 2010\end{array}$ \\
\hline 170,620 & 6500 & 94,5 & 66,2 & 46,3 & 27,6 & 16,0 & 6,0 & 3,7 & 9 & 20 & $\begin{array}{c}\text { data do levantamento: } \\
01 / 07 / 2010\end{array}$ \\
\hline 170,610 & 2100 & 31,5 & 19,9 & 13,7 & 7,0 & 4,0 & 1,4 & 0,7 & 9 & 20 & $\begin{array}{c}\text { data do levantamento: } \\
01 / 07 / 2010\end{array}$ \\
\hline 170,610 & 4100 & 57,1 & 38,3 & 27,5 & 15,7 & 8,8 & 3,0 & 1,5 & 9 & 20 & $\begin{array}{c}\text { data do levantamento: } \\
01 / 07 / 2010\end{array}$ \\
\hline 170,610 & 6500 & 83,0 & 58,1 & 42,8 & 26,0 & 15,0 & 5,3 & 2,6 & 9 & 20 & $\begin{array}{c}\text { data do levantamento: } \\
01 / 07 / 2010\end{array}$ \\
\hline 170,590 & 2100 & 42,6 & 25,5 & 17,3 & 9,2 & 5,0 & 1,1 & 0,5 & 11 & 20 & $\begin{array}{c}\text { data do levantamento: } \\
02 / 07 / 2010\end{array}$ \\
\hline 170,590 & 4100 & 65,0 & 43,3 & 31,5 & 18,6 & 10,5 & 3,0 & 1,0 & 11 & 20 & $\begin{array}{c}\text { data do levantamento: } \\
02 / 07 / 2010\end{array}$ \\
\hline
\end{tabular}


Rodovia: Presidente Dutra - BR-116 Pista: Norte (São Paulo)

Sentido: Rio de Janeiro
Faixa: 2

Trecho: Fundo da Caixa Fresada (Topo da Estrutura Remanescente)

\begin{tabular}{|c|c|c|c|c|c|c|c|c|c|c|c|}
\hline \multirow{2}{*}{$\mathrm{km}$} & \multirow{2}{*}{$\begin{array}{r}\text { Força } \\
\text { (kgf) }\end{array}$} & \multicolumn{7}{|c|}{ Deflexões $(0,01 \mathrm{~mm})$} & \multirow{2}{*}{$\begin{array}{l}\text { Temp. } \\
\operatorname{Ar}\left({ }^{\circ} \mathrm{C}\right)\end{array}$} & \multirow{2}{*}{$\begin{array}{l}\text { Temp. } \\
\text { Pav. }\left({ }^{\circ} \mathrm{C}\right)\end{array}$} & \multirow{2}{*}{ Obs } \\
\hline & & D0 & D200 & D300 & D450 & D600 & D900 & D1200 & & & \\
\hline 170,590 & 6500 & 88,4 & 62,0 & 46,6 & 29,4 & 17,3 & 5,3 & 1,9 & 11 & 20 & $\begin{array}{c}\text { data do levantamento: } \\
02 / 07 / 2010\end{array}$ \\
\hline 170,580 & 2100 & 44,4 & 29,2 & 20,8 & 12,0 & 6,9 & 2,1 & 0,8 & 11 & 20 & $\begin{array}{c}\text { data do levantamento: } \\
02 / 07 / 2010\end{array}$ \\
\hline 170,580 & 4100 & 68,6 & 48,7 & 36,6 & 23,1 & 13,9 & 4,6 & 1,4 & 11 & 20 & $\begin{array}{c}\text { data do levantamento: } \\
02 / 07 / 2010\end{array}$ \\
\hline 170,580 & 6500 & 95,9 & 71,0 & 55,4 & 37,0 & 23,4 & 8,2 & 2,6 & 11 & 20 & $\begin{array}{c}\text { data do levantamento: } \\
02 / 07 / 2010\end{array}$ \\
\hline 170,560 & 2100 & 40,5 & 28,8 & 20,8 & 11,8 & 6,9 & 2,1 & 0,9 & 11 & 20 & $\begin{array}{c}\text { data do levantamento: } \\
02 / 07 / 2010\end{array}$ \\
\hline 170,560 & 4100 & 72,4 & 54,4 & 41,8 & 26,1 & 16,0 & 5,2 & 2,0 & 11 & 20 & $\begin{array}{c}\text { data do levantamento: } \\
02 / 07 / 2010\end{array}$ \\
\hline 170,560 & 6500 & 105,4 & 81,4 & 64,6 & 42,6 & 27,3 & 9,4 & 3,5 & 11 & 20 & $\begin{array}{c}\text { data do levantamento: } \\
02 / 07 / 2010\end{array}$ \\
\hline 170,540 & 2100 & 42,0 & 30,2 & 21,9 & 12,9 & 7,7 & 2,5 & 1,0 & 11 & 20 & $\begin{array}{c}\text { data do levantamento: } \\
02 / 07 / 2010\end{array}$ \\
\hline 170,540 & 4100 & 65,4 & 50,1 & 38,5 & 25,3 & 15,8 & 5,7 & 2,3 & 11 & 20 & $\begin{array}{c}\text { data do levantamento: } \\
02 / 07 / 2010\end{array}$ \\
\hline 170,540 & 6500 & 90,7 & 71,7 & 56,9 & 39,4 & 25,5 & 10,1 & 4,3 & 11 & 20 & $\begin{array}{c}\text { data do levantamento: } \\
02 / 07 / 2010\end{array}$ \\
\hline 170,520 & 2100 & 42,1 & 24,0 & 16,2 & 7,8 & 4,1 & 1,0 & 0,4 & 13 & 20 & $\begin{array}{c}\text { data do levantamento: } \\
02 / 07 / 2010\end{array}$ \\
\hline 170,520 & 4100 & 56,6 & 36,6 & 26,1 & 13,7 & 7,4 & 1,8 & 0,8 & 13 & 20 & $\begin{array}{c}\text { data do levantamento: } \\
02 / 07 / 2010\end{array}$ \\
\hline 170,520 & 6500 & 73,4 & 50,4 & 37,3 & 20,4 & 11,6 & 3,0 & 1,4 & 13 & 20 & $\begin{array}{c}\text { data do levantamento: } \\
02 / 07 / 2010\end{array}$ \\
\hline 170,500 & 2100 & 30,6 & 20,3 & 13,5 & 6,0 & 2,8 & 0,4 & 0,3 & 12 & 20 & $\begin{array}{c}\text { data do levantamento: } \\
02 / 07 / 2010\end{array}$ \\
\hline 170,500 & 4100 & 47,0 & 32,4 & 22,5 & 10,9 & 5,3 & 0,8 & 0,4 & 12 & 20 & $\begin{array}{c}\text { data do levantamento: } \\
02 / 07 / 2010\end{array}$ \\
\hline 170,500 & 6500 & 63,8 & 44,8 & 31,9 & 16,1 & 8,0 & 1,3 & 0,6 & 12 & 20 & $\begin{array}{c}\text { data do levantamento: } \\
02 / 07 / 2010\end{array}$ \\
\hline 170,480 & 2100 & 41,0 & 26,8 & 18,4 & 9,8 & 4,7 & 1,0 & 0,4 & 12 & 20 & $\begin{array}{c}\text { data do levantamento: } \\
02 / 07 / 2010\end{array}$ \\
\hline 170,480 & 4100 & 58,3 & 40,1 & 28,8 & 16,5 & 8,6 & 2,1 & 0,8 & 12 & 20 & $\begin{array}{c}\text { data do levantamento: } \\
02 / 07 / 2010\end{array}$ \\
\hline 170,480 & 6500 & 76,9 & 54,5 & 40,3 & 24,2 & 13,4 & 3,6 & 1,4 & 12 & 20 & $\begin{array}{c}\text { data do levantamento: } \\
02 / 07 / 2010\end{array}$ \\
\hline 170,460 & 2100 & 20,2 & 13,8 & 10,6 & 6,7 & 4,1 & 1,4 & 0,7 & 12 & 20 & $\begin{array}{c}\text { data do levantamento: } \\
02 / 07 / 2010\end{array}$ \\
\hline 170,460 & 4100 & 35,0 & 24,6 & 19,5 & 13,0 & 8,2 & 2,8 & 1,3 & 12 & 20 & $\begin{array}{c}\text { data do levantamento: } \\
02 / 07 / 2010\end{array}$ \\
\hline 170,460 & 6500 & 49,5 & 35,6 & 28,7 & 19,8 & 12,9 & 4,6 & 2,2 & 12 & 20 & $\begin{array}{c}\text { data do levantamento: } \\
02 / 07 / 2010\end{array}$ \\
\hline 170,440 & 2100 & 37,9 & 23,3 & 15,9 & 8,1 & 4,4 & 1,2 & 0,6 & 13 & 20 & $\begin{array}{c}\text { data do levantamento: } \\
02 / 07 / 2010\end{array}$ \\
\hline 170,440 & 4100 & 62,9 & 41,3 & 29,4 & 16,5 & 9,0 & 2,4 & 1,1 & 13 & 20 & $\begin{array}{c}\text { data do levantamento: } \\
02 / 07 / 2010\end{array}$ \\
\hline 170,440 & 6500 & 88,7 & 59,9 & 43,8 & 25,7 & 14,3 & 3,8 & 1,7 & 13 & 20 & $\begin{array}{c}\text { data do levantamento: } \\
02 / 07 / 2010\end{array}$ \\
\hline 170,420 & 2100 & 52,1 & 33,1 & 22,6 & 11,7 & 6,0 & 1,4 & 0,6 & 13 & 20 & $\begin{array}{c}\text { data do levantamento: } \\
02 / 07 / 2010\end{array}$ \\
\hline 170,420 & 4100 & 70,8 & 47,2 & 33,3 & 18,1 & 9,8 & 2,4 & 1,1 & 13 & 20 & $\begin{array}{c}\text { data do levantamento: } \\
02 / 07 / 2010\end{array}$ \\
\hline 170,420 & 6500 & 89,0 & 60,8 & 43,7 & 24,8 & 13,6 & 3,7 & 1,8 & 13 & 20 & $\begin{array}{c}\text { data do levantamento: } \\
02 / 07 / 2010\end{array}$ \\
\hline 170,410 & 2100 & 17,0 & 12,1 & 8,9 & 5,3 & 3,2 & 1,0 & 0,4 & 14 & 20 & $\begin{array}{c}\text { data do levantamento: } \\
02 / 07 / 2010\end{array}$ \\
\hline 170,410 & 4100 & 31,7 & 23,4 & 17,5 & 11,0 & 6,7 & 2,1 & 0,7 & 14 & 20 & $\begin{array}{c}\text { data do levantamento: } \\
02 / 07 / 2010\end{array}$ \\
\hline 170,410 & 6500 & 46,2 & 34,2 & 26,1 & 16,7 & 10,5 & 3,2 & 1,1 & 14 & 20 & $\begin{array}{c}\text { data do levantamento: } \\
02 / 07 / 2010\end{array}$ \\
\hline 170,390 & 2100 & 32,2 & 22,0 & 15,6 & 9,5 & 5,4 & 1,3 & 0,6 & 12 & 20 & $\begin{array}{c}\text { data do levantamento: } \\
07 / 07 / 2010\end{array}$ \\
\hline 170,390 & 4100 & 52,2 & 36,6 & 27,1 & 16,9 & 9,9 & 3,0 & 0,9 & 12 & 20 & $\begin{array}{c}\text { data do levantamento: } \\
07 / 07 / 2010\end{array}$ \\
\hline 170,390 & 6500 & 68,5 & 49,2 & 36,9 & 23,5 & 14,1 & 3,9 & 1,7 & 12 & 20 & $\begin{array}{c}\text { data do levantamento: } \\
07 / 07 / 2010\end{array}$ \\
\hline 170,380 & 2100 & 32,9 & 21,5 & 14,9 & 8,7 & 5,1 & 0,9 & 0,7 & 12 & 20 & $\begin{array}{c}\text { data do levantamento: } \\
07 / 07 / 2010\end{array}$ \\
\hline
\end{tabular}


Rodovia: Presidente Dutra - BR-116 Pista: Norte (São Paulo)

Sentido: Rio de Janeiro
Faixa: 2

Trecho: Fundo da Caixa Fresada (Topo da Estrutura Remanescente)

\begin{tabular}{|c|c|c|c|c|c|c|c|c|c|c|c|}
\hline \multirow{2}{*}{$\mathrm{km}$} & \multirow{2}{*}{$\begin{array}{r}\text { Força } \\
\text { (kgf) }\end{array}$} & \multicolumn{7}{|c|}{ Deflexões $(0,01 \mathrm{~mm})$} & \multirow{2}{*}{$\begin{array}{l}\text { Temp. } \\
\operatorname{Ar}\left({ }^{\circ} \mathrm{C}\right)\end{array}$} & \multirow{2}{*}{$\begin{array}{l}\text { Temp. } \\
\text { Pav. }\left({ }^{\circ} \mathrm{C}\right)\end{array}$} & \multirow{2}{*}{ Obs } \\
\hline & & D0 & D200 & D300 & D450 & D600 & D900 & D1200 & & & \\
\hline 170,380 & 4100 & 54,8 & 37,5 & 27,1 & 16,6 & 10,1 & 2,3 & 1,6 & 12 & 20 & $\begin{array}{c}\text { data do levantamento: } \\
07 / 07 / 2010\end{array}$ \\
\hline 170,380 & 6500 & 70,5 & 49,7 & 36,5 & 23,0 & 14,5 & 3,9 & 2,3 & 12 & 20 & $\begin{array}{c}\text { data do levantamento: } \\
07 / 07 / 2010\end{array}$ \\
\hline 170,370 & 2100 & 12,3 & 6,6 & 4,4 & 3,1 & 2,4 & 0,6 & 0,5 & 12 & 20 & $\begin{array}{c}\text { data do levantamento: } \\
07 / 07 / 2010\end{array}$ \\
\hline 170,370 & 4100 & 21,8 & 12,5 & 8,8 & 6,1 & 4,4 & 1,7 & 1,5 & 12 & 20 & $\begin{array}{c}\text { data do levantamento: } \\
07 / 07 / 2010\end{array}$ \\
\hline 170,370 & 6500 & 31,4 & 18,9 & 13,8 & 9,9 & 7,4 & 3,1 & 2,9 & 12 & 20 & $\begin{array}{c}\text { data do levantamento: } \\
07 / 07 / 2010\end{array}$ \\
\hline 170,360 & 2100 & 12,6 & 6,8 & 5,1 & 3,9 & 3,2 & 1,4 & 1,3 & 12 & 20 & $\begin{array}{c}\text { data do levantamento: } \\
07 / 07 / 2010\end{array}$ \\
\hline 170,360 & 4100 & 24,2 & 14,2 & 11,2 & 8,8 & 7,2 & 4,1 & 3,6 & 12 & 20 & $\begin{array}{c}\text { data do levantamento: } \\
07 / 07 / 2010\end{array}$ \\
\hline 170,360 & 6500 & 35,8 & 22,2 & 17,9 & 14,3 & 11,7 & 6,5 & 5,7 & 12 & 20 & $\begin{array}{c}\text { data do levantamento: } \\
07 / 07 / 2010\end{array}$ \\
\hline 170,350 & 2100 & 32,0 & 20,5 & 14,6 & 8,4 & 5,1 & 1,8 & 1,2 & 12 & 20 & $\begin{array}{c}\text { data do levantamento: } \\
07 / 07 / 2010\end{array}$ \\
\hline 170,350 & 4100 & 54,3 & 36,0 & 26,3 & 16,0 & 9,9 & 3,6 & 2,6 & 12 & 20 & $\begin{array}{c}\text { data do levantamento: } \\
07 / 07 / 2010\end{array}$ \\
\hline 170,350 & 6500 & 74,0 & 50,0 & 37,7 & 24,1 & 15,6 & 6,3 & 4,4 & 12 & 20 & $\begin{array}{c}\text { data do levantamento: } \\
07 / 07 / 2010\end{array}$ \\
\hline 170,340 & 2100 & 38,6 & 26,7 & 20,0 & 12,0 & 7,4 & 2,2 & 1,9 & 12 & 20 & $\begin{array}{c}\text { data do levantamento: } \\
07 / 07 / 2010\end{array}$ \\
\hline 170,340 & 4100 & 65,3 & 47,0 & 36,8 & 23,6 & 15,3 & 5,7 & 4,0 & 12 & 20 & $\begin{array}{c}\text { data do levantamento: } \\
07 / 07 / 2010\end{array}$ \\
\hline 170,340 & 6500 & 87,2 & 64,9 & 52,0 & 35,4 & 23,9 & 10,2 & 6,9 & 12 & 20 & $\begin{array}{c}\text { data do levantamento: } \\
07 / 07 / 2010\end{array}$ \\
\hline 170,330 & 2100 & 30,5 & 21,2 & 16,5 & 10,4 & 7,3 & 2,3 & 2,0 & 13 & 20 & $\begin{array}{c}\text { data do levantamento: } \\
07 / 07 / 2010\end{array}$ \\
\hline 170,330 & 4100 & 54,3 & 38,4 & 29,9 & 19,8 & 13,1 & 5,4 & 3,7 & 13 & 20 & $\begin{array}{c}\text { data do levantamento: } \\
07 / 07 / 2010\end{array}$ \\
\hline 170,330 & 6500 & 73,5 & 53,4 & 42,4 & 29,0 & 19,8 & 8,9 & 6,2 & 13 & 20 & $\begin{array}{c}\text { data do levantamento: } \\
07 / 07 / 2010\end{array}$ \\
\hline 170,320 & 2100 & 41,2 & 28,7 & 21,9 & 13,6 & 10,1 & 2,9 & 2,3 & 12 & 20 & $\begin{array}{c}\text { data do levantamento: } \\
07 / 07 / 2010\end{array}$ \\
\hline 170,320 & 4100 & 66,7 & 48,4 & 37,4 & 24,5 & 16,0 & 6,0 & 4,3 & 12 & 20 & $\begin{array}{c}\text { data do levantamento: } \\
07 / 07 / 2010\end{array}$ \\
\hline 170,320 & 6500 & 89,4 & 66,2 & 52,3 & 36,0 & 24,7 & 11,0 & 7,7 & 12 & 20 & $\begin{array}{c}\text { data do levantamento: } \\
07 / 07 / 2010\end{array}$ \\
\hline 170,310 & 2100 & 39,2 & 27,3 & 19,6 & 12,7 & 4,6 & 2,6 & 2,5 & 12 & 20 & $\begin{array}{c}\text { data do levantamento: } \\
07 / 07 / 2010\end{array}$ \\
\hline 170,310 & 4100 & 64,5 & 47,3 & 36,2 & 24,1 & 15,6 & 7,0 & 5,0 & 12 & 20 & $\begin{array}{c}\text { data do levantamento: } \\
07 / 07 / 2010\end{array}$ \\
\hline 170,310 & 6500 & 87,4 & 65,6 & 51,6 & 36,1 & 24,3 & 11,7 & 8,4 & 12 & 20 & $\begin{array}{c}\text { data do levantamento: } \\
07 / 07 / 2010\end{array}$ \\
\hline 170,300 & 2100 & 39,9 & 27,2 & 19,4 & 12,1 & 7,6 & 2,1 & 2,0 & 12 & 20 & $\begin{array}{c}\text { data do levantamento: } \\
07 / 07 / 2010\end{array}$ \\
\hline 170,300 & 4100 & 69,9 & 50,5 & 37,5 & 23,9 & 14,3 & 5,4 & 4,6 & 12 & 20 & $\begin{array}{c}\text { data do levantamento: } \\
07 / 07 / 2010\end{array}$ \\
\hline 170,300 & 6500 & 99,5 & 72,7 & 55,0 & 36,5 & 23,2 & 10,2 & 8,1 & 12 & 20 & $\begin{array}{c}\text { data do levantamento: } \\
07 / 07 / 2010\end{array}$ \\
\hline 170,290 & 2100 & 36,2 & 24,8 & 18,2 & 11,3 & 10,3 & 3,1 & 2,9 & 12 & 20 & $\begin{array}{c}\text { data do levantamento: } \\
07 / 07 / 2010\end{array}$ \\
\hline 170,290 & 4100 & 59,5 & 44,7 & 34,2 & 22,9 & 15,7 & 8,3 & 5,7 & 12 & 20 & $\begin{array}{c}\text { data do levantamento: } \\
07 / 07 / 2010\end{array}$ \\
\hline 170,290 & 6500 & 84,9 & 65,8 & 51,9 & 36,4 & 25,9 & 13,8 & 10,4 & 12 & 20 & $\begin{array}{c}\text { data do levantamento: } \\
07 / 07 / 2010\end{array}$ \\
\hline 170,280 & 2100 & 35,7 & 25,8 & 19,2 & 13,2 & 7,0 & 3,9 & 3,3 & 12 & 20 & $\begin{array}{c}\text { data do levantamento: } \\
07 / 07 / 2010\end{array}$ \\
\hline 170,280 & 4100 & 61,7 & 46,4 & 36,8 & 25,7 & 18,0 & 8,8 & 6,7 & 12 & 20 & $\begin{array}{c}\text { data do levantamento: } \\
07 / 07 / 2010\end{array}$ \\
\hline 170,280 & 6500 & 86,4 & 66,4 & 54,1 & 39,3 & 28,4 & 15,3 & 11,4 & 12 & 20 & $\begin{array}{c}\text { data do levantamento: } \\
07 / 07 / 2010\end{array}$ \\
\hline 170,270 & 2100 & 40,4 & 27,1 & 19,6 & 12,4 & 7,5 & 3,0 & 2,9 & 10 & 20 & $\begin{array}{c}\text { data do levantamento: } \\
07 / 07 / 2010\end{array}$ \\
\hline 170,270 & 4100 & 66,9 & 48,1 & 36,7 & 24,3 & 16,5 & 7,2 & 5,7 & 10 & 20 & $\begin{array}{c}\text { data do levantamento: } \\
07 / 07 / 2010\end{array}$ \\
\hline 170,270 & 6500 & 93,2 & 70,3 & 55,4 & 38,4 & 26,8 & 12,7 & 9,9 & 10 & 20 & $\begin{array}{c}\text { data do levantamento: } \\
07 / 07 / 2010\end{array}$ \\
\hline
\end{tabular}


Rodovia: Presidente Dutra - BR-116 Pista: Norte (São Paulo)

Sentido: Rio de Janeiro
Faixa: 2

Trecho: Fundo da Caixa Fresada (Topo da Estrutura Remanescente)

\begin{tabular}{|c|c|c|c|c|c|c|c|c|c|c|c|}
\hline \multirow{2}{*}{$\mathrm{km}$} & \multirow{2}{*}{$\begin{array}{r}\text { Força } \\
\text { (kgf) }\end{array}$} & \multicolumn{7}{|c|}{ Deflexões $(0,01 \mathrm{~mm})$} & \multirow{2}{*}{$\begin{array}{l}\text { Temp. } \\
\operatorname{Ar}\left({ }^{\circ} \mathrm{C}\right)\end{array}$} & \multirow{2}{*}{$\begin{array}{l}\text { Temp. } \\
\text { Pav. }\left({ }^{\circ} \mathrm{C}\right)\end{array}$} & \multirow{2}{*}{ Obs } \\
\hline & & D0 & D200 & D300 & D450 & D600 & D900 & D1200 & & & \\
\hline 170,260 & 2100 & 32,4 & 22,5 & 16,9 & 11,1 & 8,5 & 3,4 & 2,1 & 10 & 20 & $\begin{array}{c}\text { data do levantamento: } \\
07 / 07 / 2010\end{array}$ \\
\hline 170,260 & 4100 & 55,2 & 40,8 & 31,8 & 21,6 & 14,7 & 6,6 & 4,0 & 10 & 20 & $\begin{array}{c}\text { data do levantamento: } \\
07 / 07 / 2010\end{array}$ \\
\hline 170,260 & 6500 & 77,8 & 59,3 & 47,3 & 33,8 & 23,6 & 10,3 & 6,5 & 10 & 20 & $\begin{array}{c}\text { data do levantamento: } \\
07 / 07 / 2010\end{array}$ \\
\hline 170,250 & 2100 & 33,4 & 23,7 & 17,1 & 10,7 & 7,6 & 2,7 & 2,2 & 11 & 20 & $\begin{array}{c}\text { data do levantamento: } \\
07 / 07 / 2010\end{array}$ \\
\hline 170,250 & 4100 & 56,5 & 42,6 & 32,6 & 21,8 & 14,7 & 6,5 & 4,7 & 11 & 20 & $\begin{array}{c}\text { data do levantamento: } \\
07 / 07 / 2010\end{array}$ \\
\hline 170,250 & 6500 & 81,9 & 63,2 & 49,6 & 34,7 & 24,2 & 11,4 & 8,0 & 11 & 20 & $\begin{array}{c}\text { data do levantamento: } \\
07 / 07 / 2010\end{array}$ \\
\hline 170,240 & 2100 & 38,4 & 26,8 & 19,9 & 12,8 & 8,0 & 3,9 & 2,8 & 11 & 20 & $\begin{array}{c}\text { data do levantamento: } \\
07 / 07 / 2010\end{array}$ \\
\hline 170,240 & 4100 & 66,7 & 50,1 & 38,7 & 26,1 & 18,0 & 8,8 & 5,6 & 11 & 20 & $\begin{array}{c}\text { data do levantamento: } \\
07 / 07 / 2010\end{array}$ \\
\hline 170,240 & 6500 & 97,0 & 74,7 & 59,1 & 41,2 & 29,2 & 15,0 & 9,6 & 11 & 20 & $\begin{array}{c}\text { data do levantamento: } \\
07 / 07 / 2010\end{array}$ \\
\hline 170,230 & 2100 & 19,7 & 14,2 & 11,1 & 7,9 & 5,4 & 2,6 & 2,4 & 11 & 20 & $\begin{array}{c}\text { data do levantamento: } \\
07 / 07 / 2010\end{array}$ \\
\hline 170,230 & 4100 & 39,0 & 29,1 & 23,0 & 16,6 & 12,4 & 6,1 & 5,0 & 11 & 20 & $\begin{array}{c}\text { data do levantamento: } \\
07 / 07 / 2010\end{array}$ \\
\hline 170,230 & 6500 & 58,6 & 45,3 & 36,8 & 27,3 & 20,6 & 10,7 & 8,4 & 11 & 20 & $\begin{array}{c}\text { data do levantamento: } \\
07 / 07 / 2010\end{array}$ \\
\hline 170,220 & 2100 & 27,3 & 18,5 & 14,6 & 9,4 & 6,1 & 3,5 & 2,4 & 10 & 20 & $\begin{array}{c}\text { data do levantamento: } \\
07 / 07 / 2010\end{array}$ \\
\hline 170,220 & 4100 & 53,8 & 38,2 & 30,2 & 20,5 & 14,2 & 7,1 & 4,7 & 10 & 20 & $\begin{array}{c}\text { data do levantamento: } \\
07 / 07 / 2010\end{array}$ \\
\hline 170,220 & 6500 & 80,6 & 59,0 & 47,3 & 33,1 & 23,4 & 12,4 & 7,9 & 10 & 20 & $\begin{array}{c}\text { data do levantamento: } \\
07 / 07 / 2010\end{array}$ \\
\hline 170,210 & 2100 & 34,8 & 23,6 & 17,4 & 10,8 & 6,7 & 2,6 & 2,5 & 10 & 20 & $\begin{array}{c}\text { data do levantamento: } \\
07 / 07 / 2010\end{array}$ \\
\hline 170,210 & 4100 & 61,1 & 43,9 & 33,7 & 21,9 & 14,7 & 6,7 & 5,0 & 10 & 20 & $\begin{array}{c}\text { data do levantamento: } \\
07 / 07 / 2010\end{array}$ \\
\hline 170,210 & 6500 & 86,3 & 64,3 & 51,0 & 35,0 & 24,2 & 11,8 & 8,4 & 10 & 20 & $\begin{array}{c}\text { data do levantamento: } \\
07 / 07 / 2010\end{array}$ \\
\hline 170,200 & 2100 & 45,9 & 31,0 & 22,3 & 13,0 & 7,7 & 2,8 & 2,2 & 11 & 20 & $\begin{array}{c}\text { data do levantamento: } \\
07 / 07 / 2010\end{array}$ \\
\hline 170,200 & 4100 & 76,4 & 55,3 & 41,9 & 26,2 & 16,3 & 6,5 & 4,3 & 11 & 20 & $\begin{array}{c}\text { data do levantamento: } \\
07 / 07 / 2010\end{array}$ \\
\hline 170,200 & 6500 & 103,3 & 77,1 & 59,8 & 39,3 & 25,5 & 10,6 & 7,4 & 11 & 20 & $\begin{array}{c}\text { data do levantamento: } \\
07 / 07 / 2010\end{array}$ \\
\hline 170,190 & 2100 & 45,6 & 31,8 & 22,9 & 14,2 & 10,2 & 4,3 & 2,6 & 10 & 20 & $\begin{array}{c}\text { data do levantamento: } \\
07 / 07 / 2010\end{array}$ \\
\hline 170,190 & 4100 & 76,4 & 56,7 & 43,3 & 28,4 & 18,9 & 8,3 & 5,3 & 10 & 20 & $\begin{array}{c}\text { data do levantamento: } \\
07 / 07 / 2010\end{array}$ \\
\hline 170,190 & 6500 & 104,8 & 80,4 & 63,4 & 44,4 & 30,4 & 14,3 & 9,1 & 10 & 20 & $\begin{array}{c}\text { data do levantamento: } \\
07 / 07 / 2010\end{array}$ \\
\hline 170,180 & 2100 & 33,2 & 23,7 & 18,4 & 12,9 & 8,3 & 4,0 & 3,3 & 10 & 20 & $\begin{array}{c}\text { data do levantamento: } \\
07 / 07 / 2010\end{array}$ \\
\hline 170,180 & 4100 & 60,1 & 45,8 & 36,9 & 26,8 & 18,9 & 10,1 & 6,9 & 10 & 20 & $\begin{array}{c}\text { data do levantamento: } \\
07 / 07 / 2010\end{array}$ \\
\hline 170,180 & 6500 & 86,9 & 67,8 & 55,8 & 41,8 & 30,5 & 16,3 & 11,6 & 10 & 20 & $\begin{array}{c}\text { data do levantamento: } \\
07 / 07 / 2010\end{array}$ \\
\hline 170,170 & 2100 & 31,4 & 22,0 & 17,6 & 12,3 & 9,5 & 4,5 & 3,4 & 10 & 20 & $\begin{array}{c}\text { data do levantamento: } \\
07 / 07 / 2010\end{array}$ \\
\hline 170,170 & 4100 & 59,5 & 44,4 & 36,2 & 26,1 & 19,3 & 10,6 & 7,2 & 10 & 20 & $\begin{array}{c}\text { data do levantamento: } \\
07 / 07 / 2010\end{array}$ \\
\hline 170,170 & 6500 & 86,5 & 66,3 & 55,3 & 40,9 & 31,1 & 17,5 & 12,0 & 10 & 20 & $\begin{array}{c}\text { data do levantamento: } \\
07 / 07 / 2010\end{array}$ \\
\hline 170,160 & 2100 & 19,8 & 14,3 & 11,6 & 8,6 & 7,0 & 3,4 & 2,5 & 12 & 20 & $\begin{array}{c}\text { data do levantamento: } \\
13 / 08 / 2010\end{array}$ \\
\hline 170,160 & 4100 & 40,4 & 30,2 & 24,9 & 19,1 & 14,4 & 8,2 & 4,5 & 12 & 20 & $\begin{array}{c}\text { data do levantamento: } \\
13 / 08 / 2010\end{array}$ \\
\hline 170,160 & 6500 & 61,6 & 47,4 & 39,8 & 30,9 & 23,7 & 13,3 & 8,7 & 12 & 20 & $\begin{array}{c}\text { data do levantamento: } \\
13 / 08 / 2010\end{array}$ \\
\hline 170,150 & 2100 & 16,9 & 9,9 & 7,0 & 4,9 & 3,9 & 2,5 & 2,5 & 12 & 20 & $\begin{array}{c}\text { data do levantamento: } \\
13 / 08 / 2010\end{array}$ \\
\hline 170,150 & 4100 & 31,0 & 18,9 & 13,6 & 9,9 & 7,8 & 5,1 & 4,1 & 12 & 20 & $\begin{array}{c}\text { data do levantamento: } \\
13 / 08 / 2010\end{array}$ \\
\hline
\end{tabular}


Rodovia: Presidente Dutra - BR-116 Pista: Norte (São Paulo)

Sentido: Rio de Janeiro
Faixa: 2

Data: $30 / 06 / 2010$ a $13 / 08 / 2010$

Trecho: Fundo da Caixa Fresada (Topo da Estrutura Remanescente)

\begin{tabular}{|c|c|c|c|c|c|c|c|c|c|c|c|}
\hline \multirow{2}{*}{$\mathrm{km}$} & \multirow{2}{*}{$\begin{array}{l}\text { Força } \\
\text { (kgf) }\end{array}$} & \multicolumn{7}{|c|}{ Deflexões $(0,01 \mathrm{~mm})$} & \multirow{2}{*}{$\begin{array}{c}\text { Temp. } \\
\operatorname{Ar}\left({ }^{\circ} \mathrm{C}\right)\end{array}$} & \multirow{2}{*}{$\begin{array}{l}\text { Temp. } \\
\text { Pav. }\left({ }^{\circ} \mathrm{C}\right)\end{array}$} & \multirow{2}{*}{ Obs } \\
\hline & & D0 & D200 & D300 & D450 & D600 & D900 & D1200 & & & \\
\hline 170,150 & 6500 & 44,8 & 28,2 & 20,6 & 14,9 & 12,1 & 8,4 & 7,0 & 12 & 20 & $\begin{array}{c}\text { data do levantamento: } \\
13 / 08 / 2010\end{array}$ \\
\hline 170,140 & 2100 & 11,8 & 8,0 & 6,6 & 4,8 & 4,0 & 2,1 & 2,1 & 12 & 20 & $\begin{array}{c}\text { data do levantamento: } \\
13 / 08 / 2010\end{array}$ \\
\hline 170,140 & 4100 & 21,6 & 15,0 & 12,2 & 9,1 & 7,3 & 4,8 & 3,0 & 12 & 20 & $\begin{array}{c}\text { data do levantamento: } \\
13 / 08 / 2010\end{array}$ \\
\hline 170,140 & 6500 & 31,5 & 22,6 & 18,4 & 14,1 & 11,1 & 6,8 & 5,9 & 12 & 20 & $\begin{array}{c}\text { data do levantamento: } \\
13 / 08 / 2010\end{array}$ \\
\hline 170,130 & 2100 & 10,9 & 10,9 & 6,8 & 5,5 & 4,3 & 2,5 & 2,4 & 12 & 20 & $\begin{array}{c}\text { data do levantamento: } \\
13 / 08 / 2010\end{array}$ \\
\hline 170,130 & 4100 & 21,2 & 16,0 & 13,5 & 10,6 & 8,3 & 4,7 & 2,6 & 12 & 20 & $\begin{array}{c}\text { data do levantamento: } \\
13 / 08 / 2010\end{array}$ \\
\hline 170,130 & 6500 & 32,5 & 24,8 & 20,9 & 16,4 & 13,0 & 7,9 & 6,5 & 12 & 20 & $\begin{array}{c}\text { data do levantamento: } \\
13 / 08 / 2010\end{array}$ \\
\hline 170,120 & 2100 & 20,0 & 12,8 & 9,7 & 6,6 & 4,3 & 2,0 & 1,8 & 12 & 20 & $\begin{array}{c}\text { data do levantamento: } \\
13 / 08 / 2010 \\
\end{array}$ \\
\hline 170,120 & 4100 & 38,5 & 26,1 & 20,1 & 14,3 & 10,2 & 4,5 & 2,9 & 12 & 20 & $\begin{array}{c}\text { data do levantamento: } \\
13 / 08 / 2010\end{array}$ \\
\hline 170,120 & 6500 & 55,3 & 38,6 & 30,6 & 22,1 & 16,4 & 8,1 & 5,7 & 12 & 20 & $\begin{array}{c}\text { data do levantamento: } \\
13 / 08 / 2010\end{array}$ \\
\hline 170,110 & 2100 & 18,2 & 11,2 & 8,3 & 5,5 & 3,5 & 1,9 & 1,9 & 12 & 20 & $\begin{array}{c}\text { data do levantamento: } \\
13 / 08 / 2010\end{array}$ \\
\hline 170,110 & 4100 & 33,8 & 22,0 & 16,7 & 11,1 & 7,7 & 3,4 & 3,0 & 12 & 20 & $\begin{array}{c}\text { data do levantamento: } \\
13 / 08 / 2010\end{array}$ \\
\hline 170,110 & 6500 & 48,8 & 33,1 & 25,9 & 17,4 & 12,4 & 6,6 & 6,1 & 12 & 20 & $\begin{array}{c}\text { data do levantamento: } \\
13 / 08 / 2010\end{array}$ \\
\hline 170,100 & 2100 & 23,8 & 13,7 & 10,0 & 6,4 & 4,2 & 1,8 & 1,8 & 12 & 20 & $\begin{array}{c}\text { data do levantamento: } \\
13 / 08 / 2010 \\
\end{array}$ \\
\hline 170,100 & 4100 & 42,4 & 26,2 & 19,6 & 12,5 & 7,8 & 3,4 & 1,4 & 12 & 20 & $\begin{array}{c}\text { data do levantamento: } \\
13 / 08 / 2010\end{array}$ \\
\hline 170,100 & 6500 & 62,0 & 39,7 & 30,3 & 19,7 & 12,6 & 5,3 & 4,4 & 12 & 20 & $\begin{array}{c}\text { data do levantamento: } \\
13 / 08 / 2010\end{array}$ \\
\hline 170,090 & 2100 & 15,1 & 10,2 & 7,9 & 5,2 & 3,6 & 1,8 & 1,8 & 13 & 20 & $\begin{array}{c}\text { data do levantamento: } \\
13 / 08 / 2010\end{array}$ \\
\hline 170,090 & 4100 & 31,5 & 22,3 & 17,4 & 11,7 & 8,1 & 3,6 & 2,6 & 13 & 20 & $\begin{array}{c}\text { data do levantamento: } \\
13 / 08 / 2010\end{array}$ \\
\hline 170,090 & 6500 & 45,5 & 32,8 & 25,9 & 17,9 & 12,4 & 5,9 & 5,1 & 13 & 20 & $\begin{array}{c}\text { data do levantamento: } \\
13 / 08 / 2010\end{array}$ \\
\hline 170,080 & 2100 & 24,2 & 16,2 & 11,6 & 7,6 & 5,0 & 1,9 & 1,9 & 12 & 20 & $\begin{array}{c}\text { data do levantamento: } \\
13 / 08 / 2010\end{array}$ \\
\hline 170,080 & 4100 & 47,3 & 32,6 & 24,3 & 15,8 & 10,2 & 3,8 & 2,0 & 12 & 20 & $\begin{array}{c}\text { data do levantamento: } \\
13 / 08 / 2010\end{array}$ \\
\hline 170,080 & 6500 & 66,2 & 46,4 & 34,9 & 23,1 & 15,3 & 5,5 & 5,2 & 12 & 20 & $\begin{array}{c}\text { data do levantamento: } \\
13 / 08 / 2010 \\
\end{array}$ \\
\hline 170,070 & 2100 & 22,4 & 15,0 & 11,0 & 6,9 & 4,9 & 1,6 & 1,6 & 12 & 20 & $\begin{array}{c}\text { data do levantamento: } \\
13 / 08 / 2010\end{array}$ \\
\hline 170,070 & 4100 & 40,2 & 28,0 & 21,3 & 13,8 & 8,8 & 3,1 & 1,9 & 12 & 20 & $\begin{array}{c}\text { data do levantamento: } \\
13 / 08 / 2010\end{array}$ \\
\hline 170,070 & 6500 & 56,0 & 40,1 & 31,0 & 20,4 & 13,1 & 4,6 & 3,3 & 12 & 20 & $\begin{array}{c}\text { data do levantamento: } \\
13 / 08 / 2010\end{array}$ \\
\hline 170,060 & 2100 & 32,1 & 18,0 & 12,7 & 7,5 & 4,7 & 1,6 & 1,2 & 12 & 20 & $\begin{array}{c}\text { data do levantamento: } \\
13 / 08 / 2010\end{array}$ \\
\hline 170,060 & 4100 & 50,7 & 30,3 & 22,1 & 13,3 & 8,2 & 2,9 & 1,3 & 12 & 20 & $\begin{array}{c}\text { data do levantamento: } \\
13 / 08 / 2010\end{array}$ \\
\hline 170,060 & 6500 & 73,5 & 45,2 & 33,3 & 20,7 & 12,8 & 4,8 & 4,5 & 12 & 20 & $\begin{array}{c}\text { data do levantamento: } \\
13 / 08 / 2010\end{array}$ \\
\hline 170,050 & 2100 & 32,4 & 21,0 & 15,6 & 9,8 & 6,2 & 2,2 & 1,7 & 12 & 20 & $\begin{array}{c}\text { data do levantamento: } \\
13 / 08 / 2010\end{array}$ \\
\hline 170,050 & 4100 & 55,0 & 37,5 & 28,9 & 18,6 & 12,1 & 4,5 & 1,6 & 12 & 20 & $\begin{array}{c}\text { data do levantamento: } \\
13 / 08 / 2010\end{array}$ \\
\hline 170,050 & 6500 & 73,2 & 50,9 & 39,7 & 26,1 & 17,2 & 7,0 & 3,3 & 12 & 20 & $\begin{array}{c}\text { data do levantamento: } \\
13 / 08 / 2010\end{array}$ \\
\hline 170,040 & 2100 & 32,1 & 21,3 & 16,4 & 10,9 & 7,7 & 2,9 & 1,3 & 12 & 20 & $\begin{array}{c}\text { data do levantamento: } \\
13 / 08 / 2010\end{array}$ \\
\hline 170,040 & 4100 & 59,2 & 41,4 & 32,6 & 22,0 & 14,9 & 5,8 & 2,8 & 12 & 20 & $\begin{array}{c}\text { data do levantamento: } \\
13 / 08 / 2010\end{array}$ \\
\hline 170,040 & 6500 & 82,5 & 58,8 & 46,9 & 32,2 & 22,2 & 8,6 & 4,9 & 12 & 20 & $\begin{array}{c}\text { data do levantamento: } \\
13 / 08 / 2010\end{array}$ \\
\hline 170,030 & 2100 & 34,8 & 22,1 & 16,4 & 10,4 & 7,2 & 3,2 & 2,5 & 12 & 20 & $\begin{array}{c}\text { data do levantamento: } \\
13 / 08 / 2010\end{array}$ \\
\hline
\end{tabular}


Levantamento Deflectométrico com FWD - Fundo da Caixa Fresada - Topo da Estrutura Remanescente (ESTAGIO 1)

Rodovia: Presidente Dutra - BR-116

Pista: Norte (São Paulo)

Sentido: Rio de Janeiro
Faixa: 2

Trecho: Fundo da Caixa Fresada (Topo da Estrutura Remanescente)

\begin{tabular}{|c|c|c|c|c|c|c|c|c|c|c|c|}
\hline \multirow{2}{*}{$\mathrm{km}$} & \multirow{2}{*}{$\begin{array}{r}\text { Força } \\
\text { (kgf) }\end{array}$} & \multicolumn{7}{|c|}{ Deflexões $(0,01 \mathrm{~mm})$} & \multirow{2}{*}{$\begin{array}{l}\text { Temp. } \\
\operatorname{Ar}\left({ }^{\circ} \mathrm{C}\right)\end{array}$} & \multirow{2}{*}{$\begin{array}{l}\text { Temp. } \\
\text { Pav. }\left({ }^{\circ} \mathrm{C}\right)\end{array}$} & \multirow{2}{*}{ Obs } \\
\hline & & D0 & D200 & D300 & D450 & D600 & D900 & D1200 & & & \\
\hline 170,030 & 4100 & 59,0 & 40,1 & 30,9 & 20,2 & 13,5 & 5,4 & 3,4 & 12 & 20 & $\begin{array}{c}\text { data do levantamento: } \\
13 / 08 / 2010\end{array}$ \\
\hline 170,030 & 6500 & 78,3 & 54,4 & 42,7 & 28,4 & 19,5 & 8,8 & 5,1 & 12 & 20 & $\begin{array}{c}\text { data do levantamento: } \\
13 / 08 / 2010\end{array}$ \\
\hline 170,020 & 2100 & 27,4 & 17,5 & 13,1 & 8,5 & 5,9 & 2,6 & 1,2 & 13 & 20 & $\begin{array}{c}\text { data do levantamento: } \\
13 / 08 / 2010\end{array}$ \\
\hline 170,020 & 4100 & 51,3 & 34,5 & 26,4 & 17,9 & 12,2 & 6,2 & 2,2 & 13 & 20 & $\begin{array}{c}\text { data do levantamento: } \\
13 / 08 / 2010\end{array}$ \\
\hline 170,020 & 6500 & 72,6 & 49,8 & 38,5 & 26,4 & 18,7 & 9,1 & 5,5 & 13 & 20 & $\begin{array}{c}\text { data do levantamento: } \\
13 / 08 / 2010\end{array}$ \\
\hline 170,018 & 2100 & 22,0 & 15,6 & 11,7 & 7,7 & 5,1 & 2,2 & 2,0 & 13 & 20 & $\begin{array}{c}\text { data do levantamento: } \\
13 / 08 / 2010\end{array}$ \\
\hline 170,018 & 4100 & 36,8 & 27,4 & 21,2 & 14,3 & 9,6 & 4,7 & 3,5 & 13 & 20 & $\begin{array}{c}\text { data do levantamento: } \\
13 / 08 / 2010\end{array}$ \\
\hline 170,018 & 6500 & 51,0 & 38,8 & 30,5 & 21,2 & 14,6 & 7,8 & 7,8 & 13 & 20 & $\begin{array}{c}\text { data do levantamento: } \\
13 / 08 / 2010\end{array}$ \\
\hline
\end{tabular}

Data: $30 / 06 / 2010$ a $13 / 08 / 2010$ 
Rodovia: Presidente Dutra - BR-116 Pista: Norte (São Paulo) Sentido: Rio de Janeiro
Faixa: 2

Data: $19 / 08 / 2010$

Trecho: Topo da Camada de EME

\begin{tabular}{|c|c|c|c|c|c|c|c|c|c|c|c|}
\hline \multirow{2}{*}{$\mathrm{km}$} & \multirow{2}{*}{$\begin{array}{r}\text { Força } \\
\text { (kgf) }\end{array}$} & \multicolumn{7}{|c|}{ Deflexões $(0,01 \mathrm{~mm})$} & \multirow{2}{*}{$\begin{array}{l}\text { Temp. } \\
\operatorname{Ar}\left({ }^{\circ} \mathrm{C}\right)\end{array}$} & \multirow{2}{*}{$\begin{array}{l}\text { Temp. } \\
\text { Pav. }\left({ }^{\circ} \mathrm{C}\right)\end{array}$} & \multirow{2}{*}{ Obs } \\
\hline & & D0 & D200 & D300 & D450 & D600 & D900 & D1200 & & & \\
\hline 171,000 & 2100 & 17,0 & 13,7 & 11,5 & 8,7 & 6,9 & 2,8 & 1,9 & 13 & 20 & $\begin{array}{c}\text { RECONSTRUÇÃO } \\
\text { (data da exec:13/08/2010) }\end{array}$ \\
\hline 171,000 & 4100 & 33,6 & 27,6 & 23,2 & 17,9 & 13,9 & 7,8 & 6,4 & 13 & 20 & $\begin{array}{c}\text { RECONSTRUÇÃO } \\
\text { (data da exec:13/08/2010) }\end{array}$ \\
\hline 171,000 & 6500 & 51,7 & 43,0 & 36,4 & 28,2 & 22,2 & 11,0 & 7,9 & 13 & 20 & $\begin{array}{c}\text { RECONSTRUÇÃO } \\
\text { (data da exec:13/08/2010) }\end{array}$ \\
\hline 170,990 & 2100 & 9,3 & 8,1 & 7,3 & 6,3 & 5,5 & 3,3 & 1,9 & 13 & 20 & $\begin{array}{c}\text { RECONSTRUÇÃO } \\
\text { (data da exec:13/08/2010) }\end{array}$ \\
\hline 170,990 & 4100 & 17,1 & 14,8 & 13,5 & 11,7 & 10,0 & 7,3 & 5,2 & 13 & 20 & $\begin{array}{c}\text { RECONSTRUÇÃO } \\
\text { (data da exec:13/08/2010) }\end{array}$ \\
\hline 170,990 & 6500 & 25,3 & 22,4 & 20,3 & 17,5 & 15,2 & 11,5 & 10,2 & 13 & 20 & $\begin{array}{c}\text { RECONSTRUÇÃO } \\
\text { (data da exec:13/08/2010) }\end{array}$ \\
\hline 170,980 & 2100 & 7,6 & 6,6 & 6,2 & 5,5 & 4,9 & 3,0 & 1,0 & 14 & 20 & $\begin{array}{c}\text { RECONSTRUÇÃO } \\
\text { (data da exec:13/08/2010) }\end{array}$ \\
\hline 170,980 & 4100 & 14,3 & 12,5 & 11,6 & 10,3 & 9,1 & 6,8 & 5,8 & 14 & 20 & $\begin{array}{c}\text { RECONSTRUÇÃO } \\
\text { (data da exec:13/08/2010) }\end{array}$ \\
\hline 170,980 & 6500 & 21,6 & 19,3 & 17,9 & 15,7 & 14,0 & 10,2 & 8,8 & 14 & 20 & $\begin{array}{c}\text { RECONSTRUÇÃO } \\
\text { (data da exec: } 13 / 08 / 2010 \text { ) }\end{array}$ \\
\hline 170,970 & 2100 & 7,9 & 7,3 & 6,7 & 5,8 & 5,1 & 3,0 & 2,0 & 14 & 20 & $\begin{array}{c}\text { RECONSTRUÇÃO } \\
\text { (data da exec:13/08/2010) }\end{array}$ \\
\hline 170,970 & 4100 & 14,4 & 13,0 & 11,9 & 10,5 & 9,2 & 6,8 & 5,3 & 14 & 20 & $\begin{array}{c}\text { RECONSTRUÇÃO } \\
\text { (data da exec: } 13 / 08 / 2010 \text { ) }\end{array}$ \\
\hline 170,970 & 6500 & 21,9 & 19,9 & 18,3 & 16,0 & 14,2 & 9,7 & 9,3 & 14 & 20 & $\begin{array}{c}\text { RECONSTRUÇÃO } \\
\text { (data da exec:13/08/2010) }\end{array}$ \\
\hline 170,960 & 2100 & 8,9 & 7,7 & 6,9 & 5,8 & 5,1 & 2,8 & 2,0 & 14 & 20 & $\begin{array}{c}\text { RECONSTRUÇÃO } \\
\text { (data da exec:13/08/2010) }\end{array}$ \\
\hline 170,960 & 4100 & 16,6 & 14,6 & 13,3 & 11,5 & 10,0 & 6,7 & 6,0 & 14 & 20 & $\begin{array}{c}\text { RECONSTRUÇÃO } \\
\text { (data da exec:13/08/2010) }\end{array}$ \\
\hline 170,960 & 6500 & 25,0 & 22,5 & 20,4 & 17,8 & 15,6 & 10,7 & 7,8 & 14 & 20 & $\begin{array}{c}\text { RECONSTRUÇÃO } \\
\text { (data da exec: } 13 / 08 / 2010 \text { ) }\end{array}$ \\
\hline 170,950 & 2100 & 8,9 & 7,6 & 7,1 & 6,1 & 5,3 & 3,0 & 2,0 & 14 & 20 & $\begin{array}{c}\text { RECONSTRUÇÃO } \\
\text { (data da exec:13/08/2010) }\end{array}$ \\
\hline 170,950 & 4100 & 16,4 & 14,3 & 13,1 & 11,4 & 10,0 & 6,8 & 3,8 & 14 & 20 & $\begin{array}{c}\text { RECONSTRUÇÃO } \\
\text { (data da exec: } 13 / 08 / 2010 \text { ) }\end{array}$ \\
\hline 170,950 & 6500 & 24,2 & 21,8 & 20,1 & 17,5 & 15,4 & 10,4 & 6,9 & 14 & 20 & $\begin{array}{c}\text { RECONSTRUÇÃO } \\
\text { (data da exec:13/08/2010) }\end{array}$ \\
\hline 170,940 & 2100 & 8,5 & 7,6 & 6,9 & 6,0 & 5,3 & 2,9 & 1,0 & 14 & 20 & $\begin{array}{c}\text { RECONSTRUÇÃO } \\
\text { (data da exec: } 13 / 08 / 2010 \text { ) }\end{array}$ \\
\hline 170,940 & 4100 & 15,4 & 13,8 & 12,8 & 11,3 & 9,9 & 7,0 & 5,9 & 14 & 20 & $\begin{array}{c}\text { RECONSTRUÇÃO } \\
\text { (data da exec:13/08/2010) }\end{array}$ \\
\hline 170,940 & 6500 & 22,8 & 20,6 & 19,1 & 16,7 & 14,5 & 10,8 & 9,4 & 14 & 20 & $\begin{array}{c}\text { RECONSTRUÇÃO } \\
\text { (data da exec: } 13 / 08 / 2010 \text { ) }\end{array}$ \\
\hline 170,930 & 2100 & 8,7 & 7,3 & 6,7 & 5,8 & 5,1 & 3,2 & 3,0 & 14 & 20 & $\begin{array}{c}\text { RECONSTRUÇÃO } \\
\text { (data da exec:13/08/2010) }\end{array}$ \\
\hline 170,930 & 4100 & 15,8 & 13,4 & 12,3 & 10,8 & 9,4 & 6,4 & 5,2 & 14 & 20 & $\begin{array}{c}\text { RECONSTRUÇÃO } \\
\text { (data da exec: } 13 / 08 / 2010 \text { ) }\end{array}$ \\
\hline 170,930 & 6500 & 23,5 & 20,6 & 18,9 & 16,5 & 14,6 & 10,6 & 8,9 & 14 & 20 & $\begin{array}{c}\text { RECONSTRUÇÃO } \\
\text { (data da exec:13/08/2010) }\end{array}$ \\
\hline 170,920 & 2100 & 7,9 & 6,9 & 6,4 & 5,6 & 4,9 & 2,5 & 2,0 & 14 & 20 & $\begin{array}{c}\text { RECONSTRUÇÃO } \\
\text { (data da exec: } 13 / 08 / 2010 \text { ) }\end{array}$ \\
\hline 170,920 & 4100 & 14,9 & 13,1 & 12,0 & 10,6 & 9,4 & 5,9 & 5,2 & 14 & 20 & $\begin{array}{c}\text { RECONSTRUÇÃO } \\
\text { (data da exec:13/08/2010) }\end{array}$ \\
\hline 170,920 & 6500 & 21,7 & 19,6 & 18,2 & 16,2 & 14,3 & 9,7 & 8,5 & 14 & 20 & $\begin{array}{c}\text { RECONSTRUÇÃO } \\
\text { (data da exec: } 13 / 08 / 2010 \text { ) }\end{array}$ \\
\hline 170,909 & 2100 & 8,5 & 7,5 & 6,9 & 5,9 & 5,3 & 3,2 & 2,5 & 15 & 20 & $\begin{array}{c}\text { RECONSTRUÇÃO } \\
\text { (data da exec:13/08/2010) }\end{array}$ \\
\hline 170,909 & 4100 & 15,4 & 13,6 & 12,4 & 10,8 & 9,5 & 6,9 & 5,2 & 15 & 20 & $\begin{array}{c}\text { RECONSTRUÇÃO } \\
\text { (data da exec: } 13 / 08 / 2010 \text { ) }\end{array}$ \\
\hline 170,909 & 6500 & 23,5 & 21,5 & 19,8 & 17,1 & 15,1 & 10,1 & 9,9 & 15 & 20 & $\begin{array}{c}\text { RECONSTRUÇÃO } \\
\text { (data da exec:13/08/2010) }\end{array}$ \\
\hline 170,900 & 2100 & 7,3 & 6,4 & 5,8 & 5,3 & 4,7 & 2,7 & 2,0 & 15 & 20 & $\begin{array}{c}\text { RECONSTRUÇÃO } \\
\text { (data da exec:13/08/2010) }\end{array}$ \\
\hline 170,900 & 4100 & 13,8 & 12,6 & 11,6 & 10,3 & 9,1 & 6,6 & 5,1 & 15 & 20 & $\begin{array}{c}\text { RECONSTRUÇÃO } \\
\text { (data da exec:13/08/2010) }\end{array}$ \\
\hline 170,900 & 6500 & 21,0 & 19,8 & 18,4 & 16,5 & 14,7 & 10,4 & 10,1 & 15 & 20 & $\begin{array}{c}\text { RECONSTRUÇÃO } \\
\text { (data da exec:13/08/2010) }\end{array}$ \\
\hline 170,890 & 2100 & 8,4 & 7,3 & 6,6 & 5,8 & 4,9 & 3,5 & 2,0 & 15 & 20 & $\begin{array}{c}\text { RECONSTRUÇÃO } \\
\text { (data da exec:13/08/2010) }\end{array}$ \\
\hline 170,890 & 4100 & 15,2 & 13,7 & 12,4 & 10,7 & 9,3 & 6,4 & 5,5 & 15 & 20 & $\begin{array}{c}\text { RECONSTRUÇÃO } \\
\text { (data da exec:13/08/2010) }\end{array}$ \\
\hline
\end{tabular}


Rodovia: Presidente Dutra - BR-116 Pista: Norte (São Paulo) Sentido: Rio de Janeiro
Faixa: 2

Data: $19 / 08 / 2010$

\begin{tabular}{|c|c|c|c|c|c|c|c|c|c|c|c|}
\hline \multirow{2}{*}{$\mathrm{km}$} & \multirow{2}{*}{$\begin{array}{r}\text { Força } \\
\text { (kgf) }\end{array}$} & \multicolumn{7}{|c|}{ Deflexões $(0,01 \mathrm{~mm})$} & \multirow{2}{*}{$\begin{array}{l}\text { Temp. } \\
\operatorname{Ar}\left({ }^{\circ} \mathrm{C}\right)\end{array}$} & \multirow{2}{*}{$\begin{array}{l}\text { Temp. } \\
\text { Pav. }\left({ }^{\circ} \mathrm{C}\right)\end{array}$} & \multirow{2}{*}{ Obs } \\
\hline & & D0 & D200 & D300 & D450 & D600 & D900 & D1200 & & & \\
\hline 170,890 & 6500 & 22,5 & 20,6 & 18,8 & 16,3 & 14,3 & 9,9 & 8,9 & 15 & 20 & $\begin{array}{c}\text { RECONSTRUÇÃO } \\
\text { (data da exec:13/08/2010) }\end{array}$ \\
\hline 170,880 & 2100 & 7,4 & 6,5 & 6,1 & 5,3 & 4,7 & 2,7 & 1,0 & 15 & 20 & $\begin{array}{c}\text { RECONSTRUÇÃO } \\
\text { (data da exec:13/08/2010) }\end{array}$ \\
\hline 170,880 & 4100 & 13,5 & 12,2 & 11,2 & 9,9 & 8,7 & 6,0 & 5,0 & 15 & 20 & $\begin{array}{c}\text { RECONSTRUÇÃO } \\
\text { (data da exec:13/08/2010) }\end{array}$ \\
\hline 170,880 & 6500 & 20,1 & 18,5 & 17,2 & 14,9 & 13,4 & 10,2 & 9,2 & 15 & 20 & $\begin{array}{c}\text { RECONSTRUÇÃO } \\
\text { (data da exec:13/08/2010) }\end{array}$ \\
\hline 170,870 & 2100 & 7,8 & 7,0 & 6,5 & 5,7 & 5,1 & 2,7 & 1,9 & 15 & 20 & $\begin{array}{c}\text { RECONSTRUÇÃO } \\
\text { (data da exec:13/08/2010) }\end{array}$ \\
\hline 170,870 & 4100 & 14,8 & 13,4 & 12,3 & 11,1 & 9,9 & 6,4 & 3,8 & 15 & 20 & $\begin{array}{c}\text { RECONSTRUÇÃO } \\
\text { (data da exec:13/08/2010) }\end{array}$ \\
\hline 170,870 & 6500 & 22,1 & 20,5 & 19,1 & 17,0 & 15,3 & 10,8 & 10,1 & 15 & 20 & $\begin{array}{c}\text { RECONSTRUÇÃO } \\
\text { (data da exec:13/08/2010) }\end{array}$ \\
\hline 170,860 & 2100 & 7,5 & 6,4 & 5,7 & 5,1 & 4,6 & 3,0 & 2,6 & 15 & 20 & $\begin{array}{c}\text { RECONSTRUÇÃO } \\
\text { (data da exec:13/08/2010) }\end{array}$ \\
\hline 170,860 & 4100 & 14,0 & 12,0 & 11,2 & 10,0 & 8,9 & 6,3 & 5,0 & 15 & 20 & $\begin{array}{c}\text { RECONSTRUÇÃO } \\
\text { (data da exec: } 13 / 08 / 2010 \text { ) }\end{array}$ \\
\hline 170,860 & 6500 & 21,3 & 18,4 & 17,2 & 15,3 & 13,7 & 10,2 & 9,6 & 15 & 20 & $\begin{array}{c}\text { RECONSTRUÇÃO } \\
\text { (data da exec:13/08/2010) }\end{array}$ \\
\hline 170,850 & 2100 & 8,5 & 7,4 & 7,0 & 6,0 & 5,4 & 3,8 & 2,0 & 15 & 20 & $\begin{array}{c}\text { RECONSTRUÇÃO } \\
\text { (data da exec:13/08/2010) }\end{array}$ \\
\hline 170,850 & 4100 & 15,5 & 13,6 & 12,8 & 11,4 & 10,1 & 7,7 & 5,6 & 15 & 20 & $\begin{array}{c}\text { RECONSTRUÇÃO } \\
\text { (data da exec: } 13 / 08 / 2010 \text { ) }\end{array}$ \\
\hline 170,850 & 6500 & 23,2 & 21,1 & 19,5 & 17,4 & 15,5 & 12,2 & 10,4 & 15 & 20 & $\begin{array}{c}\text { RECONSTRUÇÃO } \\
\text { (data da exec:13/08/2010) }\end{array}$ \\
\hline 170,840 & 2100 & 8,4 & 7,6 & 7,2 & 6,3 & 5,6 & 3,3 & 2,7 & 15 & 20 & $\begin{array}{c}\text { RECONSTRUÇÃO } \\
\text { (data da exec: } 13 / 08 / 2010 \text { ) }\end{array}$ \\
\hline 170,840 & 4100 & 15,0 & 14,0 & 12,9 & 11,6 & 10,2 & 7,0 & 5,5 & 15 & 20 & $\begin{array}{c}\text { RECONSTRUÇÃO } \\
\text { (data da exec:13/08/2010) }\end{array}$ \\
\hline 170,840 & 6500 & 22,7 & 20,9 & 19,5 & 17,3 & 15,3 & 11,7 & 9,4 & 15 & 20 & $\begin{array}{c}\text { RECONSTRUÇÃO } \\
\text { (data da exec:13/08/2010) }\end{array}$ \\
\hline 170,830 & 2100 & 8,5 & 7,6 & 7,1 & 6,3 & 5,7 & 2,9 & 1,0 & 15 & 20 & $\begin{array}{c}\text { RECONSTRUÇÃO } \\
\text { (data da exec:13/08/2010) }\end{array}$ \\
\hline 170,830 & 4100 & 14,8 & 13,4 & 12,6 & 11,3 & 10,2 & 7,0 & 5,6 & 15 & 20 & $\begin{array}{c}\text { RECONSTRUÇÃO } \\
\text { (data da exec: } 13 / 08 / 2010 \text { ) }\end{array}$ \\
\hline 170,830 & 6500 & 21,9 & 20,1 & 19,0 & 17,1 & 15,5 & 11,7 & 9,5 & 15 & 20 & $\begin{array}{c}\text { RECONSTRUÇÃO } \\
\text { (data da exec:13/08/2010) }\end{array}$ \\
\hline 170,820 & 2100 & 8,1 & 7,0 & 6,4 & 5,6 & 5,0 & 4,0 & 3,7 & 15 & 20 & $\begin{array}{c}\text { RECONSTRUÇÃO } \\
\text { (data da exec: } 13 / 08 / 2010 \text { ) }\end{array}$ \\
\hline 170,820 & 4100 & 15,1 & 12,7 & 11,7 & 10,4 & 9,2 & 7,3 & 5,6 & 15 & 20 & $\begin{array}{c}\text { RECONSTRUÇÃO } \\
\text { (data da exec:13/08/2010) }\end{array}$ \\
\hline 170,820 & 6500 & 21,9 & 19,3 & 17,7 & 15,7 & 13,9 & 11,1 & 9,7 & 15 & 20 & $\begin{array}{c}\text { RECONSTRUÇÃO } \\
\text { (data da exec: } 13 / 08 / 2010 \text { ) }\end{array}$ \\
\hline 170,810 & 2100 & 8,1 & 6,9 & 6,4 & 5,6 & 5,0 & 3,7 & 3,1 & 15 & 20 & $\begin{array}{c}\text { RECONSTRUÇÃO } \\
\text { (data da exec:13/08/2010) }\end{array}$ \\
\hline 170,810 & 4100 & 15,0 & 13,2 & 12,1 & 10,7 & 9,5 & 7,3 & 4,5 & 15 & 20 & $\begin{array}{c}\text { RECONSTRUÇÃO } \\
\text { (data da exec: } 13 / 08 / 2010 \text { ) }\end{array}$ \\
\hline 170,810 & 6500 & 22,1 & 20,0 & 18,6 & 16,5 & 14,7 & 11,6 & 9,9 & 15 & 20 & $\begin{array}{c}\text { RECONSTRUÇÃO } \\
\text { (data da exec:13/08/2010) }\end{array}$ \\
\hline 170,800 & 2100 & 14,1 & 11,5 & 9,7 & 7,1 & 5,6 & 4,4 & 3,1 & 15 & 20 & $\begin{array}{c}\text { RECONSTRUÇÃO } \\
\text { (data da exec: } 13 / 08 / 2010 \text { ) }\end{array}$ \\
\hline 170,800 & 4100 & 27,7 & 22,7 & 19,3 & 14,0 & 10,9 & 7,8 & 5,7 & 15 & 20 & $\begin{array}{c}\text { RECONSTRUÇÃO } \\
\text { (data da exec:13/08/2010) }\end{array}$ \\
\hline 170,800 & 6500 & 41,9 & 34,5 & 29,4 & 21,6 & 16,9 & 12,6 & 9,8 & 15 & 20 & $\begin{array}{c}\text { RECONSTRUÇÃO } \\
\text { (data da exec:13/08/2010) }\end{array}$ \\
\hline 170,790 & 2100 & 11,4 & 9,4 & 8,3 & 6,9 & 5,7 & 4,0 & 3,0 & 15 & 20 & $\begin{array}{c}14 c m-E M E \\
\text { (data da exec:30/06/2010) }\end{array}$ \\
\hline 170,790 & 4100 & 23,9 & 20,6 & 18,2 & 15,0 & 12,2 & 8,3 & 4,6 & 15 & 20 & $\begin{array}{c}14 c m-E M E \\
\text { (data da exec:30/06/2010) }\end{array}$ \\
\hline 170,790 & 6500 & 38,2 & 33,2 & 29,4 & 24,0 & 19,7 & 13,6 & 10,3 & 15 & 20 & $\begin{array}{c}14 c m-E M E \\
\text { (data da exec:30/06/2010) }\end{array}$ \\
\hline 170,780 & 2100 & 10,1 & 8,7 & 8,0 & 6,4 & 5,4 & 3,7 & 2,9 & 15 & 20 & $\begin{array}{c}14 \mathrm{~cm}-\mathrm{EME} \\
\text { (data da exec:30/06/2010) }\end{array}$ \\
\hline 170,780 & 4100 & 20,7 & 18,4 & 16,7 & 13,8 & 11,6 & 7,8 & 5,0 & 15 & 20 & $\begin{array}{c}14 c m-E M E \\
\text { (data da exec:30/06/2010) }\end{array}$ \\
\hline 170,780 & 6500 & 32,9 & 29,8 & 26,6 & 22,6 & 18,6 & 12,9 & 10,5 & 15 & 20 & $\begin{array}{c}14 \mathrm{~cm}-\mathrm{EME} \\
\text { (data da exec:30/06/2010) }\end{array}$ \\
\hline 170,770 & 2100 & 12,4 & 10,8 & 9,5 & 7,7 & 6,3 & 4,5 & 3,9 & 15 & 20 & $\begin{array}{c}14 \mathrm{~cm}-\mathrm{EME} \\
\text { (data da exec:30/06/2010) }\end{array}$ \\
\hline
\end{tabular}


Rodovia: Presidente Dutra - BR-116 Pista: Norte (São Paulo) Sentido: Rio de Janeiro
Faixa: 2

Data: $19 / 08 / 2010$

\begin{tabular}{|c|c|c|c|c|c|c|c|c|c|c|c|}
\hline \multirow{2}{*}{$\mathrm{km}$} & \multirow{2}{*}{$\begin{array}{r}\text { Força } \\
\text { (kgf) }\end{array}$} & \multicolumn{7}{|c|}{ Deflexões $(0,01 \mathrm{~mm})$} & \multirow{2}{*}{$\begin{array}{l}\text { Temp. } \\
\operatorname{Ar}\left({ }^{\circ} \mathrm{C}\right)\end{array}$} & \multirow{2}{*}{$\begin{array}{l}\text { Temp. } \\
\text { Pav. }\left({ }^{\circ} \mathrm{C}\right)\end{array}$} & \multirow{2}{*}{ Obs } \\
\hline & & D0 & D200 & D300 & D450 & D600 & D900 & D1200 & & & \\
\hline 170,770 & 4100 & 24,9 & 21,5 & 19,1 & 15,6 & 12,6 & 8,3 & 5,7 & 15 & 20 & $\begin{array}{c}14 \mathrm{~cm}-\mathrm{EME} \\
\text { (data da exec:30/06/2010) }\end{array}$ \\
\hline 170,770 & 6500 & 38,6 & 33,9 & 30,0 & 24,6 & 20,0 & 13,5 & 10,3 & 15 & 20 & $\begin{array}{c}\text { 14cm - EME } \\
\text { (data da exec:30/06/2010) }\end{array}$ \\
\hline 170,760 & 2100 & 9,2 & 7,7 & 6,8 & 5,5 & 4,6 & 3,3 & 2,9 & 15 & 20 & $\begin{array}{c}14 \mathrm{~cm}-\mathrm{EME} \\
\text { (data da exec:30/06/2010) }\end{array}$ \\
\hline 170,760 & 4100 & 18,9 & 16,3 & 14,2 & 11,8 & 9,6 & 6,7 & 4,5 & 15 & 20 & $\begin{array}{c}\text { 14cm - EME } \\
\text { (data da exec:30/06/2010) }\end{array}$ \\
\hline 170,760 & 6500 & 29,5 & 26,0 & 23,0 & 18,9 & 15,8 & 11,2 & 9,8 & 15 & 20 & $\begin{array}{c}14 \mathrm{~cm}-\mathrm{EME} \\
\text { (data da exec:30/06/2010) }\end{array}$ \\
\hline 170,750 & 2100 & 8,2 & 7,1 & 6,4 & 5,2 & 4,4 & 3,1 & 2,8 & 16 & 20 & $\begin{array}{c}\text { 14cm - EME } \\
\text { (data da exec:30/06/2010) }\end{array}$ \\
\hline 170,750 & 4100 & 15,6 & 13,8 & 12,5 & 10,5 & 8,9 & 6,6 & 4,3 & 16 & 20 & $\begin{array}{c}14 \mathrm{~cm}-\mathrm{EME} \\
\text { (data da exec:30/06/2010) }\end{array}$ \\
\hline 170,750 & 6500 & 23,6 & 21,2 & 19,1 & 16,1 & 13,7 & 9,9 & 9,6 & 16 & 20 & $\begin{array}{c}\text { 14cm - EME } \\
\text { (data da exec:30/06/2010) }\end{array}$ \\
\hline 170,741 & 2100 & 9,9 & 8,2 & 7,2 & 5,8 & 4,8 & 3,1 & 2,7 & 16 & 20 & $\begin{array}{c}14 \mathrm{~cm}-\mathrm{EME} \\
\text { (data da exec:30/06/2010) }\end{array}$ \\
\hline 170,741 & 4100 & 20,7 & 17,4 & 15,2 & 12,2 & 9,9 & 6,2 & 4,5 & 16 & 20 & $\begin{array}{c}14 \mathrm{~cm}-\text { EME } \\
\text { (data da exec:30/06/2010) }\end{array}$ \\
\hline 170,741 & 6500 & 32,3 & 27,5 & 24,1 & 19,5 & 15,6 & 10,2 & 9,7 & 16 & 20 & $\begin{array}{c}14 \mathrm{~cm}-\mathrm{EME} \\
\text { (data da exec:30/06/2010) }\end{array}$ \\
\hline 170,730 & 2100 & 7,2 & 5,9 & 5,2 & 4,1 & 3,6 & 2,3 & 1,0 & 16 & 20 & $\begin{array}{c}14 \mathrm{~cm}-\text { EME } \\
\text { (data da exec:30/06/2010) }\end{array}$ \\
\hline 170,730 & 4100 & 15,0 & 12,6 & 11,0 & 8,9 & 7,2 & 4,7 & 2,7 & 16 & 20 & $\begin{array}{c}14 \mathrm{~cm}-\mathrm{EME} \\
\text { (data da exec:30/06/2010) }\end{array}$ \\
\hline 170,730 & 6500 & 24,1 & 20,6 & 18,2 & 14,6 & 12,1 & 8,0 & 6,0 & 16 & 20 & $\begin{array}{c}14 \mathrm{~cm}-\mathrm{EME} \\
\text { (data da exec:30/06/2010) }\end{array}$ \\
\hline 170,720 & 2100 & 7,4 & 6,5 & 5,7 & 4,7 & 4,0 & 2,6 & 1,5 & 16 & 20 & $\begin{array}{c}14 \mathrm{~cm}-\mathrm{EME} \\
\text { (data da exec:30/06/2010) }\end{array}$ \\
\hline 170,720 & 4100 & 15,4 & 13,6 & 12,1 & 10,0 & 8,3 & 5,4 & 3,1 & 16 & 20 & $\begin{array}{c}14 \mathrm{~cm}-\mathrm{EME} \\
\text { (data da exec:30/06/2010) }\end{array}$ \\
\hline 170,720 & 6500 & 24,0 & 21,5 & 19,2 & 16,1 & 13,3 & 8,9 & 6,4 & 16 & 20 & $\begin{array}{c}14 \mathrm{~cm}-\mathrm{EME} \\
\text { (data da exec:30/06/2010) }\end{array}$ \\
\hline 170,710 & 2100 & 11,1 & 9,6 & 8,4 & 6,5 & 5,2 & 3,0 & 1,8 & 16 & 20 & $\begin{array}{c}14 c m-E M E \\
\text { (data da exec:30/06/2010) }\end{array}$ \\
\hline 170,710 & 4100 & 23,9 & 20,7 & 18,2 & 14,6 & 11,5 & 7,0 & 3,7 & 16 & 20 & $\begin{array}{c}14 \mathrm{~cm}-\mathrm{EME} \\
\text { (data da exec:30/06/2010) }\end{array}$ \\
\hline 170,710 & 6500 & 37,5 & 32,9 & 28,8 & 23,3 & 18,3 & 10,8 & 7,3 & 16 & 20 & $\begin{array}{c}14 c m-E M E \\
\text { (data da exec:30/06/2010) }\end{array}$ \\
\hline 170,700 & 2100 & 10,0 & 8,6 & 7,7 & 5,9 & 4,8 & 3,0 & 2,1 & 17 & 20 & $\begin{array}{c}14 \mathrm{~cm}-\mathrm{EME} \\
\text { (data da exec:30/06/2010) }\end{array}$ \\
\hline 170,700 & 4100 & 21,7 & 19,2 & 17,0 & 13,6 & 11,0 & 6,7 & 3,6 & 17 & 20 & $\begin{array}{c}14 \mathrm{~cm}-\mathrm{EME} \\
\text { (data da exec:30/06/2010) }\end{array}$ \\
\hline 170,700 & 6500 & 34,8 & 31,5 & 28,2 & 22,6 & 18,4 & 11,8 & 6,9 & 17 & 20 & $\begin{array}{c}14 \mathrm{~cm}-\mathrm{EME} \\
\text { (data da exec:30/06/2010) }\end{array}$ \\
\hline 170,690 & 2100 & 10,3 & 8,6 & 7,3 & 5,7 & 4,5 & 2,6 & 1,7 & 17 & 20 & $\begin{array}{c}14 c m-E M E \\
\text { (data da exec:01/07/2010) }\end{array}$ \\
\hline 170,690 & 4100 & 21,8 & 18,4 & 16,0 & 12,5 & 9,8 & 5,7 & 3,2 & 17 & 20 & $\begin{array}{c}14 \mathrm{~cm}-\mathrm{EME} \\
\text { (data da exec:01/07/2010) }\end{array}$ \\
\hline 170,690 & 6500 & 34,3 & 29,5 & 25,5 & 20,3 & 16,0 & 9,2 & 6,1 & 17 & 20 & $\begin{array}{c}14 c m-E M E \\
\text { (data da exec:01/07/2010) }\end{array}$ \\
\hline 170,680 & 2100 & 8,6 & 7,1 & 6,2 & 4,8 & 3,7 & 2,1 & 1,4 & 17 & 20 & $\begin{array}{c}14 c m-E M E \\
\text { (data da exec:01/07/2010) }\end{array}$ \\
\hline 170,680 & 4100 & 17,6 & 15,0 & 13,0 & 10,1 & 7,5 & 4,3 & 1,8 & 17 & 20 & $\begin{array}{c}14 c m-E M E \\
\text { (data da exec:01/07/2010) }\end{array}$ \\
\hline 170,680 & 6500 & 28,2 & 24,3 & 21,1 & 16,5 & 12,5 & 7,1 & 4,7 & 17 & 20 & $\begin{array}{c}14 \mathrm{~cm}-\mathrm{EME} \\
\text { (data da exec:01/07/2010) }\end{array}$ \\
\hline 170,670 & 2100 & 6,8 & 5,7 & 5,0 & 3,9 & 3,0 & 1,9 & 1,5 & 17 & 20 & $\begin{array}{c}14 c m-E M E \\
\text { (data da exec:01/07/2010) }\end{array}$ \\
\hline 170,670 & 4100 & 14,2 & 12,2 & 10,6 & 8,5 & 6,5 & 4,0 & 1,9 & 17 & 20 & $\begin{array}{c}14 c m-E M E \\
\text { (data da exec:01/07/2010) }\end{array}$ \\
\hline 170,670 & 6500 & 22,8 & 20,2 & 17,6 & 14,1 & 10,9 & 6,7 & 4,9 & 17 & 20 & $\begin{array}{c}14 \mathrm{~cm}-\mathrm{EME} \\
\text { (data da exec:01/07/2010) }\end{array}$ \\
\hline 170,660 & 2100 & 8,4 & 6,7 & 6,0 & 4,7 & 3,7 & 2,2 & 2,0 & 17 & 20 & $\begin{array}{c}14 c m-E M E \\
\text { (data da exec:01/07/2010) }\end{array}$ \\
\hline 170,660 & 4100 & 16,6 & 13,9 & 12,3 & 9,8 & 7,6 & 4,5 & 1,8 & 17 & 20 & $\begin{array}{c}14 \mathrm{~cm}-\mathrm{EME} \\
\text { (data da exec:01/07/2010) }\end{array}$ \\
\hline 170,660 & 6500 & 26,6 & 22,7 & 20,1 & 16,0 & 12,5 & 7,6 & 5,5 & 17 & 20 & $\begin{array}{c}14 \mathrm{~cm}-\mathrm{EME} \\
\text { (data da exec:01/07/2010) }\end{array}$ \\
\hline
\end{tabular}


Rodovia: Presidente Dutra - BR-116 Pista: Norte (São Paulo) Sentido: Rio de Janeiro
Faixa: 2

Trecho: Topo da Camada de EME
Data: $19 / 08 / 2010$

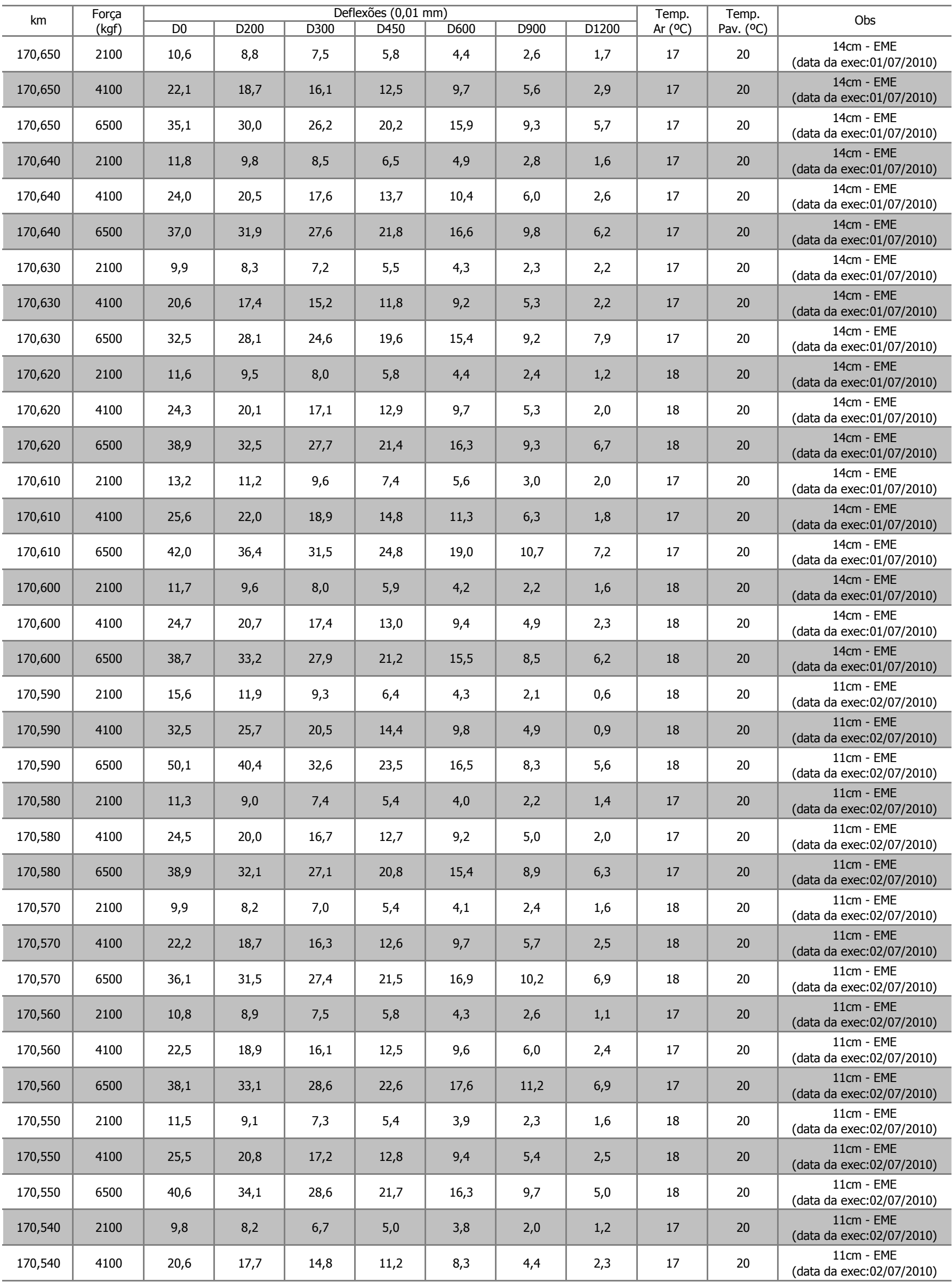


Rodovia: Presidente Dutra - BR-116 Pista: Norte (São Paulo)

Sentido: Rio de Janeiro
Faixa: 2

Data: $19 / 08 / 2010$

\begin{tabular}{|c|c|c|c|c|c|c|c|c|c|c|c|}
\hline \multirow{2}{*}{$\mathrm{km}$} & \multirow{2}{*}{$\begin{array}{r}\text { Força } \\
\text { (kgf) }\end{array}$} & \multicolumn{7}{|c|}{ Deflexões $(0,01 \mathrm{~mm})$} & \multirow{2}{*}{$\begin{array}{l}\text { Temp. } \\
\operatorname{Ar}\left({ }^{\circ} \mathrm{C}\right)\end{array}$} & \multirow{2}{*}{$\begin{array}{l}\text { Temp. } \\
\text { Pav. }\left({ }^{\circ} \mathrm{C}\right)\end{array}$} & \multirow{2}{*}{ Obs } \\
\hline & & D0 & D200 & D300 & D450 & D600 & D900 & D1200 & & & \\
\hline 170,540 & 6500 & 32,2 & 27,8 & 23,7 & 18,1 & 13,3 & 7,2 & 4,7 & 17 & 20 & $\begin{array}{c}11 \mathrm{~cm}-\mathrm{EME} \\
\text { (data da exec:02/07/2010) }\end{array}$ \\
\hline 170,530 & 2100 & 14,0 & 11,0 & 8,9 & 6,5 & 4,7 & 2,6 & 1,6 & 17 & 20 & $\begin{array}{c}11 \mathrm{~cm}-\mathrm{EME} \\
\text { (data da exec:02/07/2010) }\end{array}$ \\
\hline 170,530 & 4100 & 29,2 & 23,2 & 19,0 & 14,0 & 10,2 & 5,6 & 2,9 & 17 & 20 & $\begin{array}{c}11 \mathrm{~cm}-\mathrm{EME} \\
\text { (data da exec:02/07/2010) }\end{array}$ \\
\hline 170,530 & 6500 & 44,4 & 36,3 & 30,1 & 22,6 & 16,7 & 9,6 & 5,3 & 17 & 20 & $\begin{array}{c}11 \mathrm{~cm}-\mathrm{EME} \\
\text { (data da exec:02/07/2010) }\end{array}$ \\
\hline 170,520 & 2100 & 12,1 & 9,8 & 8,3 & 6,1 & 4,5 & 2,4 & 1,4 & 17 & 20 & $\begin{array}{c}11 \mathrm{~cm}-\mathrm{EME} \\
\text { (data da exec:02/07/2010) }\end{array}$ \\
\hline 170,520 & 4100 & 25,2 & 20,8 & 17,7 & 13,4 & 9,9 & 5,3 & 3,0 & 17 & 20 & $\begin{array}{c}11 \mathrm{~cm}-\mathrm{EME} \\
\text { (data da exec:02/07/2010) }\end{array}$ \\
\hline 170,520 & 6500 & 39,0 & 32,5 & 27,8 & 21,4 & 15,9 & 8,9 & 5,8 & 17 & 20 & $\begin{array}{c}11 \mathrm{~cm}-\mathrm{EME} \\
\text { (data da exec:02/07/2010) }\end{array}$ \\
\hline 170,510 & 2100 & 10,9 & 9,0 & 7,4 & 5,5 & 4,1 & 2,3 & 0,8 & 17 & 20 & $\begin{array}{c}11 \mathrm{~cm}-\mathrm{EME} \\
\text { (data da exec:02/07/2010) }\end{array}$ \\
\hline 170,510 & 4100 & 23,2 & 19,5 & 16,3 & 12,3 & 9,2 & 5,2 & 3,0 & 17 & 20 & $\begin{array}{c}11 \mathrm{~cm}-\text { EME } \\
\text { (data da exec:02/07/2010) }\end{array}$ \\
\hline 170,510 & 6500 & 36,1 & 30,7 & 26,1 & 19,9 & 15,1 & 8,8 & 5,2 & 17 & 20 & $\begin{array}{c}11 \mathrm{~cm}-\text { EME } \\
\text { (data da exec:02/07/2010) }\end{array}$ \\
\hline 170,500 & 2100 & 12,5 & 9,6 & 7,7 & 5,4 & 3,8 & 1,8 & 0,8 & 18 & 20 & $\begin{array}{c}11 \mathrm{~cm}-\text { EME } \\
\text { (data da exec:02/07/2010) }\end{array}$ \\
\hline 170,500 & 4100 & 25,9 & 20,5 & 16,7 & 11,9 & 8,4 & 4,3 & 2,4 & 18 & 20 & $\begin{array}{c}11 \mathrm{~cm}-\text { EME } \\
\text { (data da exec:02/07/2010) }\end{array}$ \\
\hline 170,500 & 6500 & 38,8 & 31,0 & 25,5 & 18,5 & 13,2 & 6,9 & 4,7 & 18 & 20 & $\begin{array}{c}11 \mathrm{~cm}-\mathrm{EME} \\
\text { (data da exec:02/07/2010) }\end{array}$ \\
\hline 170,490 & 2100 & 10,2 & 8,1 & 6,4 & 4,6 & 3,3 & 1,9 & 1,1 & 17 & 20 & $\begin{array}{c}11 \mathrm{~cm}-\mathrm{EME} \\
\text { (data da exec:02/07/2010) }\end{array}$ \\
\hline 170,490 & 4100 & 21,6 & 17,3 & 14,0 & 10,1 & 7,0 & 3,8 & 1,8 & 17 & 20 & $\begin{array}{c}11 \mathrm{~cm}-\text { EME } \\
\text { (data da exec:02/07/2010) }\end{array}$ \\
\hline 170,490 & 6500 & 33,9 & 27,6 & 22,5 & 16,4 & 11,6 & 6,0 & 4,3 & 17 & 20 & $\begin{array}{c}11 \mathrm{~cm}-\text { EME } \\
\text { (data da exec:02/07/2010) }\end{array}$ \\
\hline 170,480 & 2100 & 13,4 & 10,7 & 8,9 & 6,6 & 4,9 & 2,8 & 1,7 & 18 & 20 & $\begin{array}{c}11 \mathrm{~cm}-\text { EME } \\
\text { (data da exec:02/07/2010) }\end{array}$ \\
\hline 170,480 & 4100 & 27,8 & 22,8 & 19,0 & 14,1 & 10,5 & 6,0 & 3,5 & 18 & 20 & $\begin{array}{c}11 \mathrm{~cm}-\mathrm{EME} \\
\text { (data da exec:02/07/2010) }\end{array}$ \\
\hline 170,480 & 6500 & 42,6 & 35,4 & 29,5 & 22,4 & 16,8 & 9,8 & 6,6 & 18 & 20 & $\begin{array}{c}11 \mathrm{~cm}-\text { EME } \\
\text { (data da exec:02/07/2010) }\end{array}$ \\
\hline 170,470 & 2100 & 9,0 & 7,3 & 6,2 & 4,9 & 3,8 & 2,4 & 0,9 & 18 & 20 & $\begin{array}{c}11 \mathrm{~cm}-\mathrm{EME} \\
\text { (data da exec:02/07/2010) }\end{array}$ \\
\hline 170,470 & 4100 & 19,7 & 16,1 & 13,8 & 10,8 & 8,4 & 5,1 & 3,0 & 18 & 20 & $\begin{array}{c}11 \mathrm{~cm}-\mathrm{EME} \\
\text { (data da exec:02/07/2010) }\end{array}$ \\
\hline 170,470 & 6500 & 30,5 & 25,9 & 22,3 & 17,5 & 13,7 & 8,4 & 5,3 & 18 & 20 & $\begin{array}{c}11 \mathrm{~cm}-\text { EME } \\
\text { (data da exec:02/07/2010) }\end{array}$ \\
\hline 170,460 & 2100 & 10,6 & 8,6 & 7,0 & 5,1 & 3,5 & 2,1 & 1,1 & 18 & 20 & $\begin{array}{c}11 \mathrm{~cm}-\mathrm{EME} \\
\text { (data da exec:02/07/2010) }\end{array}$ \\
\hline 170,460 & 4100 & 22,2 & 18,1 & 14,7 & 10,8 & 7,6 & 4,0 & 2,2 & 18 & 20 & $\begin{array}{c}11 \mathrm{~cm}-\mathrm{EME} \\
\text { (data da exec:02/07/2010) }\end{array}$ \\
\hline 170,460 & 6500 & 34,3 & 28,1 & 23,2 & 17,1 & 12,1 & 6,1 & 3,6 & 18 & 20 & $\begin{array}{c}11 \mathrm{~cm}-\mathrm{EME} \\
\text { (data da exec:02/07/2010) }\end{array}$ \\
\hline 170,450 & 2100 & 9,4 & 7,6 & 6,1 & 4,7 & 3,4 & 2,0 & 1,6 & 18 & 20 & $\begin{array}{c}11 \mathrm{~cm}-\mathrm{EME} \\
\text { (data da exec:02/07/2010) }\end{array}$ \\
\hline 170,450 & 4100 & 20,3 & 16,5 & 13,6 & 10,2 & 7,4 & 4,1 & 3,1 & 18 & 20 & $\begin{array}{c}11 \mathrm{~cm}-\mathrm{EME} \\
\text { (data da exec:02/07/2010) }\end{array}$ \\
\hline 170,450 & 6500 & 32,1 & 26,5 & 22,1 & 16,8 & 12,3 & 7,0 & 5,1 & 18 & 20 & $\begin{array}{c}11 \mathrm{~cm}-\mathrm{EME} \\
\text { (data da exec:02/07/2010) }\end{array}$ \\
\hline 170,440 & 2100 & 10,0 & 8,0 & 6,4 & 4,6 & 3,3 & 2,1 & 1,2 & 18 & 20 & $\begin{array}{c}11 \mathrm{~cm}-\mathrm{EME} \\
\text { (data da exec:02/07/2010) }\end{array}$ \\
\hline 170,440 & 4100 & 21,3 & 17,3 & 14,2 & 10,1 & 7,2 & 3,7 & 2,9 & 18 & 20 & $\begin{array}{c}11 \mathrm{~cm}-\mathrm{EME} \\
\text { (data da exec:02/07/2010) }\end{array}$ \\
\hline 170,440 & 6500 & 34,3 & 28,2 & 23,4 & 16,9 & 12,2 & 6,0 & 5,1 & 18 & 20 & $\begin{array}{c}11 \mathrm{~cm}-\mathrm{EME} \\
\text { (data da exec:02/07/2010) }\end{array}$ \\
\hline 170,430 & 2100 & 14,9 & 12,9 & 10,8 & 8,0 & 6,0 & 3,5 & 2,8 & 18 & 20 & $\begin{array}{c}11 \mathrm{~cm}-\mathrm{EME} \\
\text { (data da exec:02/07/2010) }\end{array}$ \\
\hline 170,430 & 4100 & 30,5 & 26,5 & 22,4 & 17,0 & 12,5 & 7,2 & 4,1 & 18 & 20 & $\begin{array}{c}11 \mathrm{~cm}-\mathrm{EME} \\
\text { (data da exec:02/07/2010) }\end{array}$ \\
\hline 170,430 & 6500 & 46,3 & 40,5 & 34,5 & 26,4 & 19,6 & 11,8 & 7,6 & 18 & 20 & $\begin{array}{c}11 \mathrm{~cm}-\text { EME } \\
\text { (data da exec:02/07/2010) }\end{array}$ \\
\hline 170,420 & 2100 & 11,2 & 8,8 & 7,1 & 5,1 & 3,5 & 1,9 & 0,7 & 18 & 20 & $\begin{array}{c}11 \mathrm{~cm}-\mathrm{EME} \\
\text { (data da exec:02/07/2010) }\end{array}$ \\
\hline
\end{tabular}


Rodovia: Presidente Dutra - BR-116 Pista: Norte (São Paulo)

Sentido: Rio de Janeiro
Faixa: 2

Trecho: Topo da Camada de EME
Data: $19 / 08 / 2010$

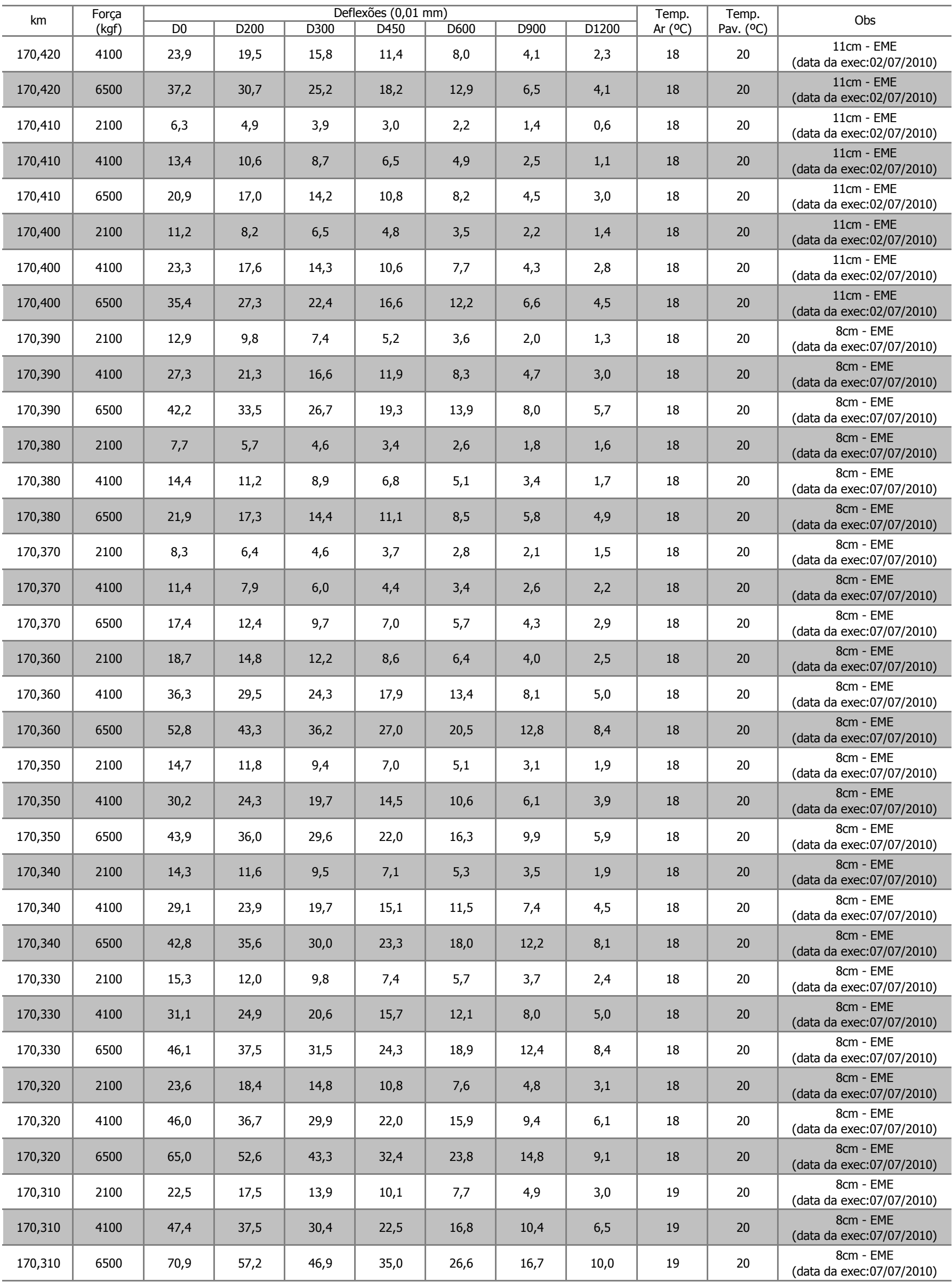


Rodovia: Presidente Dutra - BR-116 Pista: Norte (São Paulo)

Sentido: Rio de Janeiro
Faixa: 2

Trecho: Topo da Camada de EME
Data: $19 / 08 / 2010$

\begin{tabular}{|c|c|c|c|c|c|c|c|c|c|c|c|}
\hline \multirow{2}{*}{$\mathrm{km}$} & \multirow{2}{*}{$\begin{array}{r}\text { Força } \\
\text { (kgf) }\end{array}$} & \multicolumn{7}{|c|}{ Deflexões $(0,01 \mathrm{~mm})$} & \multirow{2}{*}{$\begin{array}{l}\text { Temp. } \\
\operatorname{Ar}\left({ }^{\circ} \mathrm{C}\right)\end{array}$} & \multirow{2}{*}{$\begin{array}{l}\text { Temp. } \\
\text { Pav. }\left({ }^{\circ} \mathrm{C}\right)\end{array}$} & \multirow{2}{*}{ Obs } \\
\hline & & D0 & D200 & D300 & D450 & D600 & D900 & D1200 & & & \\
\hline 170,300 & 2100 & 20,0 & 15,8 & 13,0 & 9,8 & 7,2 & 5,0 & 3,1 & 19 & 20 & $\begin{array}{c}\text { 8cm - EME } \\
\text { (data da exec:07/07/2010) }\end{array}$ \\
\hline 170,300 & 4100 & 40,2 & 32,3 & 26,8 & 20,1 & 15,1 & 9,9 & 6,5 & 19 & 20 & $\begin{array}{c}\text { 8cm - EME } \\
\text { (data da exec:07/07/2010) }\end{array}$ \\
\hline 170,300 & 6500 & 59,4 & 48,1 & 40,2 & 30,8 & 23,2 & 15,6 & 10,2 & 19 & 20 & $\begin{array}{c}\text { 8cm - EME } \\
\text { (data da exec:07/07/2010) }\end{array}$ \\
\hline 170,290 & 2100 & 22,6 & 17,5 & 14,1 & 10,3 & 7,5 & 4,7 & 4,3 & 18 & 20 & $\begin{array}{c}\text { 8cm - EME } \\
\text { (data da exec:07/07/2010) }\end{array}$ \\
\hline 170,290 & 4100 & 43,7 & 34,5 & 28,4 & 20,8 & 15,5 & 10,0 & 8,4 & 18 & 20 & $\begin{array}{c}\text { 8cm - EME } \\
\text { (data da exec:07/07/2010) }\end{array}$ \\
\hline 170,290 & 6500 & 61,7 & 49,9 & 41,7 & 31,3 & 23,9 & 15,7 & 13,9 & 18 & 20 & $\begin{array}{c}\text { 8cm - EME } \\
\text { (data da exec:07/07/2010) }\end{array}$ \\
\hline 170,280 & 2100 & 18,3 & 14,7 & 12,1 & 9,2 & 7,3 & 5,1 & 3,3 & 18 & 20 & $\begin{array}{c}8 \mathrm{~cm}-\mathrm{EME} \\
\text { (data da exec:07/07/2010) }\end{array}$ \\
\hline 170,280 & 4100 & 36,6 & 30,0 & 25,0 & 19,4 & 15,2 & 10,5 & 7,8 & 18 & 20 & $\begin{array}{c}\text { 8cm - EME } \\
\text { (data da exec:07/07/2010) }\end{array}$ \\
\hline 170,280 & 6500 & 53,4 & 44,8 & 38,0 & 30,1 & 23,7 & 17,2 & 12,5 & 18 & 20 & $\begin{array}{c}8 \mathrm{~cm} \text { - EME } \\
\text { (data da exec:07/07/2010) }\end{array}$ \\
\hline 170,270 & 2100 & 16,2 & 12,7 & 10,3 & 7,8 & 5,7 & 4,0 & 2,4 & 19 & 20 & $\begin{array}{c}\text { 8cm - EME } \\
\text { (data da exec:07/07/2010) }\end{array}$ \\
\hline 170,270 & 4100 & 33,2 & 26,8 & 21,9 & 16,2 & 12,1 & 7,8 & 5,5 & 19 & 20 & $\begin{array}{c}\text { 8cm - EME } \\
\text { (data da exec:07/07/2010) }\end{array}$ \\
\hline 170,270 & 6500 & 50,1 & 40,9 & 33,9 & 25,7 & 19,2 & 12,9 & 8,9 & 19 & 20 & $\begin{array}{c}\text { 8cm - EME } \\
\text { (data da exec:07/07/2010) }\end{array}$ \\
\hline 170,260 & 2100 & 15,7 & 12,3 & 10,2 & 7,7 & 5,9 & 3,9 & 2,9 & 19 & 20 & $\begin{array}{c}\text { 8cm - EME } \\
\text { (data da exec:07/07/2010) }\end{array}$ \\
\hline 170,260 & 4100 & 31,2 & 25,0 & 20,9 & 16,0 & 12,1 & 8,0 & 5,5 & 19 & 20 & $\begin{array}{c}\text { 8cm - EME } \\
\text { (data da exec:07/07/2010) }\end{array}$ \\
\hline 170,260 & 6500 & 45,6 & 37,5 & 31,8 & 24,7 & 18,8 & 12,5 & 8,2 & 19 & 20 & $\begin{array}{c}8 \mathrm{~cm} \text { - EME } \\
\text { (data da exec:07/07/2010) }\end{array}$ \\
\hline 170,250 & 2100 & 20,4 & 15,7 & 12,5 & 9,0 & 6,6 & 4,0 & 3,0 & 20 & 20 & $\begin{array}{c}\text { 8cm - EME } \\
\text { (data da exec:07/07/2010) }\end{array}$ \\
\hline 170,250 & 4100 & 39,4 & 31,4 & 25,5 & 18,8 & 13,7 & 8,5 & 5,3 & 20 & 20 & $\begin{array}{c}8 \mathrm{~cm} \text { - EME } \\
\text { (data da exec:07/07/2010) }\end{array}$ \\
\hline 170,250 & 6500 & 57,3 & 46,3 & 38,1 & 28,8 & 21,3 & 13,4 & 8,1 & 20 & 20 & $\begin{array}{c}\text { 8cm - EME } \\
\text { (data da exec:07/07/2010) }\end{array}$ \\
\hline 170,240 & 2100 & 15,3 & 12,2 & 9,9 & 7,6 & 6,1 & 4,4 & 3,1 & 21 & 20 & $\begin{array}{c}\text { 8cm - EME } \\
\text { (data da exec:07/07/2010) }\end{array}$ \\
\hline 170,240 & 4100 & 31,1 & 25,0 & 20,9 & 16,3 & 12,6 & 8,9 & 6,4 & 21 & 20 & $\begin{array}{c}\text { 8cm - EME } \\
\text { (data da exec:07/07/2010) }\end{array}$ \\
\hline 170,240 & 6500 & 47,0 & 38,8 & 33,0 & 26,0 & 20,6 & 14,9 & 9,7 & 21 & 20 & $\begin{array}{c}8 \mathrm{~cm}-\mathrm{EME} \\
\text { (data da exec:07/07/2010) }\end{array}$ \\
\hline 170,230 & 2100 & 12,4 & 9,7 & 8,1 & 6,4 & 5,1 & 3,8 & 2,8 & 19 & 20 & $\begin{array}{c}\text { 8cm - EME } \\
\text { (data da exec:07/07/2010) }\end{array}$ \\
\hline 170,230 & 4100 & 24,9 & 19,8 & 16,6 & 13,0 & 10,3 & 7,5 & 5,2 & 19 & 20 & $\begin{array}{c}8 \mathrm{~cm} \text { - EME } \\
\text { (data da exec:07/07/2010) }\end{array}$ \\
\hline 170,230 & 6500 & 37,6 & 30,7 & 26,0 & 20,6 & 16,6 & 12,0 & 7,2 & 19 & 20 & $\begin{array}{c}\text { 8cm - EME } \\
\text { (data da exec:07/07/2010) }\end{array}$ \\
\hline 170,220 & 2100 & 18,7 & 14,2 & 11,2 & 8,1 & 5,9 & 3,8 & 2,5 & 20 & 20 & $\begin{array}{c}8 \mathrm{~cm}-\text { EME } \\
\text { (data da exec:07/07/2010) }\end{array}$ \\
\hline 170,220 & 4100 & 36,9 & 28,8 & 23,3 & 17,0 & 12,3 & 7,7 & 5,0 & 20 & 20 & $\begin{array}{c}\text { 8cm - EME } \\
\text { (data da exec:07/07/2010) }\end{array}$ \\
\hline 170,220 & 6500 & 55,1 & 44,0 & 36,3 & 27,0 & 20,0 & 12,9 & 8,8 & 20 & 20 & $\begin{array}{c}8 \mathrm{~cm}-\text { EME } \\
\text { (data da exec:07/07/2010) }\end{array}$ \\
\hline 170,210 & 2100 & 18,7 & 14,4 & 11,7 & 8,5 & 6,5 & 4,4 & 2,9 & 20 & 20 & $\begin{array}{c}\text { 8cm - EME } \\
\text { (data da exec:07/07/2010) }\end{array}$ \\
\hline 170,210 & 4100 & 36,3 & 28,8 & 23,7 & 17,6 & 13,2 & 8,6 & 5,3 & 20 & 20 & $\begin{array}{c}\text { 8cm - EME } \\
\text { (data da exec:07/07/2010) }\end{array}$ \\
\hline 170,210 & 6500 & 52,5 & 42,3 & 35,3 & 26,6 & 20,2 & 13,4 & 8,5 & 20 & 20 & $\begin{array}{c}\text { 8cm - EME } \\
\text { (data da exec:07/07/2010) }\end{array}$ \\
\hline 170,200 & 2100 & 17,6 & 14,2 & 11,7 & 8,8 & 6,6 & 4,4 & 2,6 & 20 & 20 & $\begin{array}{c}8 \mathrm{~cm}-\text { EME } \\
\text { (data da exec:07/07/2010) }\end{array}$ \\
\hline 170,200 & 4100 & 36,6 & 30,3 & 25,1 & 19,1 & 14,4 & 9,1 & 5,5 & 20 & 20 & $\begin{array}{c}8 \mathrm{~cm}-\text { EME } \\
\text { (data da exec:07/07/2010) }\end{array}$ \\
\hline 170,200 & 6500 & 54,3 & 45,7 & 38,6 & 29,9 & 22,8 & 15,2 & 10,2 & 20 & 20 & $\begin{array}{c}8 \mathrm{~cm}-\text { EME } \\
\text { (data da exec:07/07/2010) }\end{array}$ \\
\hline 170,190 & 2100 & 18,7 & 14,8 & 12,1 & 8,9 & 6,6 & 4,4 & 2,5 & 20 & 20 & $\begin{array}{c}\text { 8cm - EME } \\
\text { (data da exec:07/07/2010) }\end{array}$ \\
\hline 170,190 & 4100 & 38,8 & 31,7 & 26,2 & 19,7 & 14,7 & 9,5 & 6,0 & 20 & 20 & $\begin{array}{c}\text { 8cm - EME } \\
\text { (data da exec:07/07/2010) }\end{array}$ \\
\hline
\end{tabular}


Rodovia: Presidente Dutra - BR-116 Pista: Norte (São Paulo) Sentido: Rio de Janeiro
Faixa: 2

Data: $19 / 08 / 2010$

\begin{tabular}{|c|c|c|c|c|c|c|c|c|c|c|c|}
\hline \multirow{2}{*}{$\mathrm{km}$} & \multirow{2}{*}{$\begin{array}{r}\text { Força } \\
\text { (kgf) }\end{array}$} & \multicolumn{7}{|c|}{ Deflexões $(0,01 \mathrm{~mm})$} & \multirow{2}{*}{$\begin{array}{l}\text { Temp. } \\
\operatorname{Ar}\left({ }^{\circ} \mathrm{C}\right)\end{array}$} & \multirow{2}{*}{$\begin{array}{l}\text { Temp. } \\
\text { Pav. }\left({ }^{\circ} \mathrm{C}\right)\end{array}$} & \multirow{2}{*}{ Obs } \\
\hline & & D0 & D200 & D300 & D450 & D600 & D900 & D1200 & & & \\
\hline 170,190 & 6500 & 56,9 & 47,3 & 39,5 & 30,3 & 22,8 & 15,0 & 10,2 & 20 & 20 & $\begin{array}{c}\text { 8cm - EME } \\
\text { (data da exec:07/07/2010) }\end{array}$ \\
\hline 170,180 & 2100 & 13,9 & 11,2 & 9,4 & 7,9 & 6,6 & 5,1 & 3,6 & 20 & 20 & $\begin{array}{c}\text { 8cm - EME } \\
\text { (data da exec:07/07/2010) }\end{array}$ \\
\hline 170,180 & 4100 & 28,9 & 23,8 & 20,5 & 16,9 & 13,9 & 10,5 & 7,3 & 20 & 20 & $\begin{array}{c}\text { 8cm - EME } \\
\text { (data da exec:07/07/2010) }\end{array}$ \\
\hline 170,180 & 6500 & 44,2 & 37,2 & 32,8 & 26,9 & 22,5 & 17,6 & 10,9 & 20 & 20 & $\begin{array}{c}\text { 8cm - EME } \\
\text { (data da exec:07/07/2010) }\end{array}$ \\
\hline 170,170 & 2100 & 12,9 & 10,8 & 9,3 & 7,5 & 6,1 & 4,7 & 4,0 & 19 & 20 & $\begin{array}{c}\text { 8cm - EME } \\
\text { (data da exec:07/07/2010) }\end{array}$ \\
\hline 170,170 & 4100 & 27,0 & 23,2 & 20,2 & 16,2 & 13,2 & 9,9 & 8,2 & 19 & 20 & $\begin{array}{c}\text { 8cm - EME } \\
\text { (data da exec:07/07/2010) }\end{array}$ \\
\hline 170,170 & 6500 & 41,6 & 36,1 & 31,8 & 25,8 & 21,2 & 15,8 & 12,6 & 19 & 20 & $\begin{array}{c}\text { 8cm - EME } \\
\text { (data da exec:07/07/2010) }\end{array}$ \\
\hline 170,160 & 2100 & 11,7 & 8,9 & 7,4 & 5,9 & 4,7 & 3,8 & 3,2 & 19 & 20 & $\begin{array}{c}\text { 8cm - CAP 30/45 } \\
\text { (data da exec: } 13 / 08 / 2010 \text { ) }\end{array}$ \\
\hline 170,160 & 4100 & 24,4 & 19,0 & 16,2 & 12,9 & 10,4 & 8,0 & 6,2 & 19 & 20 & $\begin{array}{c}\text { 8cm - CAP 30/45 } \\
\text { (data da exec: } 13 / 08 / 2010 \text { ) }\end{array}$ \\
\hline 170,160 & 6500 & 37,4 & 29,9 & 25,8 & 20,6 & 16,8 & 13,0 & 10,1 & 19 & 20 & $\begin{array}{c}8 \mathrm{~cm} \text { - CAP } 30 / 45 \\
\text { (data da exec: } 13 / 08 / 2010 \text { ) }\end{array}$ \\
\hline 170,150 & 2100 & 8,7 & 6,3 & 4,9 & 3,9 & 3,2 & 2,6 & 2,4 & 20 & 20 & $\begin{array}{c}\text { 8cm - CAP 30/45 } \\
\text { (data da exec: } 13 / 08 / 2010 \text { ) }\end{array}$ \\
\hline 170,150 & 4100 & 16,5 & 12,4 & 9,8 & 7,5 & 6,1 & 5,0 & 3,8 & 20 & 20 & $\begin{array}{c}8 \mathrm{~cm} \text { - CAP } 30 / 45 \\
\text { (data da exec: } 13 / 08 / 2010 \text { ) }\end{array}$ \\
\hline 170,150 & 6500 & 24,5 & 18,5 & 15,0 & 11,4 & 9,4 & 7,7 & 6,4 & 20 & 20 & $\begin{array}{c}\text { 8cm - CAP 30/45 } \\
\text { (data da exec: } 13 / 08 / 2010 \text { ) }\end{array}$ \\
\hline 170,140 & 2100 & 6,6 & 5,2 & 4,4 & 3,7 & 3,1 & 2,6 & 1,9 & 20 & 20 & $\begin{array}{c}\text { 8cm - CAP 30/45 } \\
\text { (data da exec: } 13 / 08 / 2010 \text { ) }\end{array}$ \\
\hline 170,140 & 4100 & 12,2 & 9,7 & 8,2 & 6,8 & 5,8 & 4,7 & 3,4 & 20 & 20 & $\begin{array}{c}\text { 8cm - CAP 30/45 } \\
\text { (data da exec: } 13 / 08 / 2010 \text { ) }\end{array}$ \\
\hline 170,140 & 6500 & 17,5 & 14,2 & 12,1 & 10,0 & 8,5 & 7,1 & 5,5 & 20 & 20 & $\begin{array}{c}8 \mathrm{~cm} \text { - CAP } 30 / 45 \\
\text { (data da exec: } 13 / 08 / 2010 \text { ) }\end{array}$ \\
\hline 170,130 & 2100 & 7,6 & 5,4 & 4,5 & 3,6 & 3,0 & 2,4 & 1,9 & 20 & 20 & $\begin{array}{c}\text { 8cm - CAP } 30 / 45 \\
\text { (data da exec: } 13 / 08 / 2010 \text { ) }\end{array}$ \\
\hline 170,130 & 4100 & 14,1 & 10,4 & 8,5 & 6,9 & 5,7 & 4,6 & 2,9 & 20 & 20 & $\begin{array}{c}8 \mathrm{~cm} \text { - CAP } 30 / 45 \\
\text { (data da exec: } 13 / 08 / 2010 \text { ) }\end{array}$ \\
\hline 170,130 & 6500 & 20,9 & 15,7 & 13,1 & 10,7 & 8,9 & 7,2 & 5,0 & 20 & 20 & $\begin{array}{c}8 \mathrm{~cm} \text { - CAP } 30 / 45 \\
\text { (data da exec: } 13 / 08 / 2010 \text { ) }\end{array}$ \\
\hline 170,120 & 2100 & 8,9 & 6,8 & 5,5 & 4,1 & 3,3 & 2,4 & 1,5 & 20 & 20 & $\begin{array}{c}8 \mathrm{~cm} \text { - CAP } 30 / 45 \\
\text { (data da exec: } 13 / 08 / 2010 \text { ) }\end{array}$ \\
\hline 170,120 & 4100 & 18,6 & 14,6 & 11,9 & 9,1 & 7,1 & 5,0 & 2,9 & 20 & 20 & $\begin{array}{c}\text { 8cm - CAP 30/45 } \\
\text { (data da exec: } 13 / 08 / 2010 \text { ) }\end{array}$ \\
\hline 170,120 & 6500 & 28,5 & 22,9 & 19,0 & 14,7 & 11,5 & 8,0 & 6,2 & 20 & 20 & $\begin{array}{c}8 \mathrm{~cm} \text { - CAP } 30 / 45 \\
\text { (data da exec: } 13 / 08 / 2010 \text { ) }\end{array}$ \\
\hline 170,109 & 2100 & 8,4 & 5,9 & 4,7 & 3,6 & 2,7 & 2,1 & 1,4 & 20 & 20 & $\begin{array}{c}\text { 8cm - CAP } 30 / 45 \\
\text { (data da exec: } 13 / 08 / 2010 \text { ) }\end{array}$ \\
\hline 170,109 & 4100 & 16,9 & 12,5 & 9,9 & 7,5 & 5,5 & 3,9 & 2,1 & 20 & 20 & $\begin{array}{c}8 \mathrm{~cm} \text { - CAP } 30 / 45 \\
\text { (data da exec: } 13 / 08 / 2010 \text { ) }\end{array}$ \\
\hline 170,109 & 6500 & 26,1 & 19,6 & 16,0 & 11,9 & 8,9 & 6,4 & 4,6 & 20 & 20 & $\begin{array}{c}8 \mathrm{~cm} \text { - CAP } 30 / 45 \\
\text { (data da exec: } 13 / 08 / 2010 \text { ) }\end{array}$ \\
\hline 170,100 & 2100 & 12,4 & 8,4 & 6,2 & 4,3 & 3,0 & 2,2 & 1,7 & 20 & 20 & $\begin{array}{c}8 \mathrm{~cm} \text { - CAP } 30 / 45 \\
\text { (data da exec: } 13 / 08 / 2010 \text { ) }\end{array}$ \\
\hline 170,100 & 4100 & 24,5 & 17,2 & 13,1 & 9,1 & 6,4 & 4,0 & 2,7 & 20 & 20 & $\begin{array}{c}8 \mathrm{~cm} \text { - CAP } 30 / 45 \\
\text { (data da exec: } 13 / 08 / 2010 \text { ) }\end{array}$ \\
\hline 170,100 & 6500 & 36,1 & 26,0 & 20,1 & 14,3 & 10,1 & 6,4 & 4,5 & 20 & 20 & $\begin{array}{c}8 \mathrm{~cm} \text { - CAP } 30 / 45 \\
\text { (data da exec: } 13 / 08 / 2010 \text { ) }\end{array}$ \\
\hline 170,090 & 2100 & 8,7 & 6,4 & 5,0 & 3,8 & 2,8 & 2,1 & 1,0 & 20 & 20 & $\begin{array}{c}\text { 8cm - CAP 30/45 } \\
\text { (data da exec: } 13 / 08 / 2010 \text { ) }\end{array}$ \\
\hline 170,090 & 4100 & 18,0 & 13,6 & 11,1 & 8,2 & 6,1 & 3,9 & 3,0 & 20 & 20 & $\begin{array}{c}8 \mathrm{~cm} \text { - CAP } 30 / 45 \\
\text { (data da exec: } 13 / 08 / 2010 \text { ) }\end{array}$ \\
\hline 170,090 & 6500 & 27,3 & 21,1 & 17,4 & 12,9 & 9,8 & 6,4 & 4,6 & 20 & 20 & $\begin{array}{c}8 \mathrm{~cm} \text { - CAP } 30 / 45 \\
\text { (data da exec: } 13 / 08 / 2010 \text { ) }\end{array}$ \\
\hline 170,080 & 2100 & 11,4 & 8,4 & 6,5 & 4,6 & 3,5 & 2,1 & 1,1 & 19 & 20 & $\begin{array}{c}8 \mathrm{~cm} \text { - CAP } 30 / 45 \\
\text { (data da exec: } 13 / 08 / 2010 \text { ) }\end{array}$ \\
\hline 170,080 & 4100 & 22,8 & 17,5 & 13,8 & 10,1 & 7,4 & 4,3 & 2,7 & 19 & 20 & $\begin{array}{c}8 \mathrm{~cm} \text { - CAP } 30 / 45 \\
\text { (data da exec: } 13 / 08 / 2010 \text { ) }\end{array}$ \\
\hline 170,080 & 6500 & 34,0 & 26,6 & 21,3 & 15,5 & 11,5 & 7,1 & 4,6 & 19 & 20 & $\begin{array}{c}8 \mathrm{~cm} \text { - CAP } 30 / 45 \\
\text { (data da exec: } 13 / 08 / 2010 \text { ) }\end{array}$ \\
\hline 170,070 & 2100 & 10,5 & 7,4 & 5,8 & 4,0 & 2,9 & 1,8 & 1,3 & 19 & 20 & $\begin{array}{c}8 \mathrm{~cm} \text { - CAP } 30 / 45 \\
\text { (data da exec: } 13 / 08 / 2010 \text { ) }\end{array}$ \\
\hline
\end{tabular}


Rodovia: Presidente Dutra - BR-116

Pista: Norte (São Paulo)

Sentido: Rio de Janeiro
Faixa: 2

Trecho: Topo da Camada de EME
Data: $19 / 08 / 2010$

\begin{tabular}{|c|c|c|c|c|c|c|c|c|c|c|c|}
\hline \multirow{2}{*}{$\mathrm{km}$} & \multirow{2}{*}{$\begin{array}{r}\text { Força } \\
\text { (kgf) }\end{array}$} & \multicolumn{7}{|c|}{ Deflexões $(0,01 \mathrm{~mm})$} & \multirow{2}{*}{$\begin{array}{l}\text { Temp. } \\
\operatorname{Ar}\left({ }^{\circ} \mathrm{C}\right)\end{array}$} & \multirow{2}{*}{$\begin{array}{l}\text { Temp. } \\
\text { Pav. }\left({ }^{\circ} \mathrm{C}\right)\end{array}$} & \multirow{2}{*}{ Obs } \\
\hline & & D0 & D200 & D300 & D450 & D600 & D900 & D1200 & & & \\
\hline 170,070 & 4100 & 21,8 & 16,0 & 12,6 & 8,9 & 6,3 & 3,8 & 2,3 & 19 & 20 & $\begin{array}{c}8 \mathrm{~cm} \text { - CAP } 30 / 45 \\
\text { (data da exec: } 13 / 08 / 2010 \text { ) }\end{array}$ \\
\hline 170,070 & 6500 & 32,6 & 24,2 & 19,4 & 13,9 & 10,0 & 5,9 & 4,3 & 19 & 20 & $\begin{array}{c}\text { 8cm - CAP } 30 / 45 \\
\text { (data da exec: } 13 / 08 / 2010 \text { ) }\end{array}$ \\
\hline 170,060 & 2100 & 11,3 & 8,0 & 6,0 & 4,2 & 3,0 & 2,1 & 1,5 & 19 & 20 & $\begin{array}{c}8 \mathrm{~cm} \text { - CAP } 30 / 45 \\
\text { (data da exec: } 13 / 08 / 2010 \text { ) }\end{array}$ \\
\hline 170,060 & 4100 & 22,9 & 16,9 & 12,9 & 9,0 & 6,3 & 3,7 & 2,5 & 19 & 20 & $\begin{array}{c}\text { 8cm - CAP } 30 / 45 \\
\text { (data da exec: } 13 / 08 / 2010 \text { ) }\end{array}$ \\
\hline 170,060 & 6500 & 34,7 & 26,0 & 20,0 & 14,3 & 10,0 & 6,1 & 4,1 & 19 & 20 & $\begin{array}{c}8 \mathrm{~cm} \text { - CAP } 30 / 45 \\
\text { (data da exec: } 13 / 08 / 2010 \text { ) }\end{array}$ \\
\hline 170,050 & 2100 & 12,5 & 9,3 & 7,3 & 5,3 & 4,0 & 2,5 & 1,3 & 19 & 20 & $\begin{array}{c}\text { 8cm - CAP 30/45 } \\
\text { (data da exec: } 13 / 08 / 2010 \text { ) }\end{array}$ \\
\hline 170,050 & 4100 & 25,3 & 19,5 & 15,5 & 11,4 & 8,5 & 5,0 & 2,1 & 19 & 20 & $\begin{array}{c}8 \mathrm{~cm} \text { - CAP } 30 / 45 \\
\text { (data da exec: } 13 / 08 / 2010 \text { ) }\end{array}$ \\
\hline 170,050 & 6500 & 37,2 & 29,2 & 23,6 & 17,6 & 13,2 & 8,1 & 4,2 & 19 & 20 & $\begin{array}{c}\text { 8cm - CAP } 30 / 45 \\
\text { (data da exec: } 13 / 08 / 2010 \text { ) }\end{array}$ \\
\hline 170,040 & 2100 & 12,6 & 9,5 & 7,9 & 5,9 & 4,5 & 3,3 & 2,2 & 20 & 20 & $\begin{array}{c}8 \mathrm{~cm} \text { - CAP } 30 / 45 \\
\text { (data da exec: } 13 / 08 / 2010 \text { ) }\end{array}$ \\
\hline 170,040 & 4100 & 26,3 & 20,1 & 16,8 & 12,6 & 9,4 & 6,5 & 3,6 & 20 & 20 & $\begin{array}{c}\text { 8cm - CAP 30/45 } \\
\text { (data da exec: } 13 / 08 / 2010 \text { ) }\end{array}$ \\
\hline 170,040 & 6500 & 39,6 & 31,0 & 26,1 & 19,7 & 14,9 & 10,1 & 5,9 & 20 & 20 & $\begin{array}{c}8 \mathrm{~cm} \text { - CAP } 30 / 45 \\
\text { (data da exec: } 13 / 08 / 2010 \text { ) }\end{array}$ \\
\hline 170,030 & 2100 & 13,6 & 9,9 & 7,9 & 5,7 & 4,3 & 2,8 & 1,5 & 20 & 20 & $\begin{array}{c}\text { 8cm - CAP 30/45 } \\
\text { (data da exec: } 13 / 08 / 2010 \text { ) }\end{array}$ \\
\hline 170,030 & 4100 & 28,3 & 21,5 & 17,3 & 12,8 & 9,6 & 6,1 & 3,3 & 20 & 20 & $\begin{array}{c}\text { 8cm - CAP } 30 / 45 \\
\text { (data da exec: } 13 / 08 / 2010 \text { ) }\end{array}$ \\
\hline 170,030 & 6500 & 41,6 & 32,4 & 26,5 & 19,8 & 15,0 & 9,9 & 5,5 & 20 & 20 & $\begin{array}{c}\text { 8cm - CAP } 30 / 45 \\
\text { (data da exec: } 13 / 08 / 2010 \text { ) }\end{array}$ \\
\hline 170,020 & 2100 & 12,3 & 9,1 & 7,1 & 5,2 & 4,0 & 2,6 & 2,1 & 20 & 20 & $\begin{array}{c}\text { 8cm - CAP 30/45 } \\
\text { (data da exec: } 13 / 08 / 2010 \text { ) }\end{array}$ \\
\hline 170,020 & 4100 & 25,7 & 19,8 & 15,9 & 11,8 & 9,0 & 5,8 & 3,1 & 20 & 20 & $\begin{array}{c}\text { 8cm - CAP 30/45 } \\
\text { (data da exec: } 13 / 08 / 2010 \text { ) }\end{array}$ \\
\hline 170,020 & 6500 & 38,7 & 30,8 & 25,1 & 18,9 & 14,8 & 10,0 & 8,0 & 20 & 20 & $\begin{array}{c}\text { 8cm - CAP } 30 / 45 \\
\text { (data da exec: } 13 / 08 / 2010 \text { ) }\end{array}$ \\
\hline
\end{tabular}


Rodovia: Presidente Dutra - BR-116

Pista: Norte (São Paulo)

Sentido: Rio de Janeiro
Faixa: 2

Data: $19 / 10 / 2010$

Trecho: Topo da Camada de Gap Graded

\begin{tabular}{|c|c|c|c|c|c|c|c|c|c|c|c|}
\hline \multirow{2}{*}{ km } & \multirow{2}{*}{$\begin{array}{l}\text { Força } \\
\text { (kgf) }\end{array}$} & \multicolumn{7}{|c|}{ Deflexões $(0,01 \mathrm{~mm})$} & \multirow{2}{*}{$\begin{array}{l}\text { Temp. } \\
\operatorname{Ar}\left({ }^{\circ} \mathrm{C}\right)\end{array}$} & \multirow{2}{*}{$\begin{array}{l}\text { Temp. } \\
\text { Pav. }\left({ }^{\circ} \mathrm{C}\right)\end{array}$} & \multirow{2}{*}{ Obs } \\
\hline & & D0 & D200 & D300 & D450 & D600 & D900 & D1200 & & & \\
\hline 171,000 & 2100 & 10,7 & 8,6 & 7,8 & 6,5 & 5,4 & 4,4 & 3,1 & 29 & 20 & $\begin{array}{l}\text { seção de avaliação onde foi } \\
\text { executada RECONSTRUÇÃO }\end{array}$ \\
\hline 171,000 & 4100 & 19,9 & 14,5 & 13,5 & 12,6 & 10,4 & 9,4 & 5,2 & 29 & 20 & $\begin{array}{l}\text { seção de avaliação onde foi } \\
\text { executada RECONSTRUÇÃO }\end{array}$ \\
\hline 171,000 & 6500 & 28,6 & 25,0 & 21,5 & 18,5 & 15,4 & 14,2 & 10,7 & 29 & 20 & $\begin{array}{l}\text { seção de avaliação onde foi } \\
\text { executada RECONSTRUÇÃO }\end{array}$ \\
\hline 170,990 & 2100 & 9,7 & 7,0 & 5,9 & 4,7 & 3,7 & 2,4 & 1,9 & 31 & 20 & $\begin{array}{l}\text { seção de avaliação onde foi } \\
\text { executada RECONSTRUÇÃO }\end{array}$ \\
\hline 170,990 & 4100 & 16,4 & 11,8 & 9,9 & 8,2 & 6,5 & 4,0 & 3,5 & 31 & 20 & $\begin{array}{l}\text { seção de avaliação onde foi } \\
\text { executada RECONSTRUÇÃO }\end{array}$ \\
\hline 170,990 & 6500 & 23,7 & 19,3 & 14,9 & 12,2 & 9,8 & 6,5 & 6,0 & 31 & 20 & $\begin{array}{l}\text { seção de avaliação onde foi } \\
\text { executada RECONSTRUÇÃO }\end{array}$ \\
\hline 170,980 & 2100 & 8,6 & 6,2 & 5,5 & 4,3 & 3,5 & 2,0 & 1,5 & 31 & 20 & $\begin{array}{l}\text { seção de avaliação onde foi } \\
\text { executada RECONSTRUÇÃO }\end{array}$ \\
\hline 170,980 & 4100 & 14,8 & 11,0 & 9,6 & 7,9 & 6,5 & 4,4 & 3,9 & 31 & 20 & $\begin{array}{l}\text { seção de avaliação onde foi } \\
\text { executada RECONSTRUÇÃO }\end{array}$ \\
\hline 170,980 & 6500 & 21,4 & 17,6 & 13,9 & 11,6 & 9,7 & 6,6 & 6,1 & 31 & 20 & $\begin{array}{l}\text { seção de avaliação onde foi } \\
\text { executada RECONSTRUÇÃO }\end{array}$ \\
\hline 170,970 & 2100 & 12,2 & 9,0 & 7,8 & 6,0 & 5,1 & 4,1 & 3,1 & 33 & 20 & $\begin{array}{l}\text { seção de avaliação onde foi } \\
\text { executada RECONSTRUÇÃO }\end{array}$ \\
\hline 170,970 & 4100 & 21,2 & 16,0 & 13,9 & 11,5 & 9,4 & 8,5 & 7,1 & 33 & 20 & $\begin{array}{l}\text { seção de avaliação onde foi } \\
\text { executada RECONSTRUÇÃO }\end{array}$ \\
\hline 170,970 & 6500 & 30,7 & 25,5 & 20,2 & 16,8 & 13,8 & 11,8 & 11,6 & 33 & 20 & $\begin{array}{l}\text { seção de avaliação onde foi } \\
\text { executada RECONSTRUÇÃO }\end{array}$ \\
\hline 170,960 & 2100 & 13,0 & 9,5 & 8,1 & 6,4 & 5,0 & 3,8 & 2,5 & 31 & 20 & $\begin{array}{l}\text { seção de avaliação onde foi } \\
\text { executada RECONSTRUÇÃO }\end{array}$ \\
\hline 170,960 & 4100 & 22,6 & 17,0 & 14,7 & 12,0 & 9,4 & 8,3 & 6,6 & 31 & 20 & $\begin{array}{l}\text { seção de avaliação onde foi } \\
\text { executada RECONSTRUÇÃO }\end{array}$ \\
\hline 170,960 & 6500 & 32,2 & 26,5 & 20,9 & 17,0 & 13,9 & 11,8 & 8,8 & 31 & 20 & $\begin{array}{l}\text { seção de avaliação onde foi } \\
\text { executada RECONSTRUÇÃO }\end{array}$ \\
\hline 170,950 & 2100 & 12,0 & 8,8 & 7,5 & 6,0 & 4,9 & 4,0 & 3,1 & 32 & 20 & $\begin{array}{l}\text { seção de avaliação onde foi } \\
\text { executada RECONSTRUÇÃO }\end{array}$ \\
\hline 170,950 & 4100 & 21,1 & 15,3 & 13,4 & 11,0 & 8,9 & 7,8 & 7,0 & 32 & 20 & $\begin{array}{l}\text { seção de avaliação onde foi } \\
\text { executada RECONSTRUÇÃO }\end{array}$ \\
\hline 170,950 & 6500 & 30,2 & 20,9 & 19,8 & 16,4 & 13,7 & 13,0 & 9,4 & 32 & 20 & $\begin{array}{l}\text { seção de avaliação onde foi } \\
\text { executada RECONSTRUÇÃO }\end{array}$ \\
\hline 170,940 & 2100 & 11,5 & 8,1 & 7,0 & 5,5 & 4,5 & 3,1 & 2,9 & 32 & 20 & $\begin{array}{l}\text { seção de avaliação onde foi } \\
\text { executada RECONSTRUÇÃO }\end{array}$ \\
\hline 170,940 & 4100 & 20,0 & 14,3 & 12,5 & 10,3 & 8,5 & 7,7 & 6,4 & 32 & 20 & $\begin{array}{l}\text { seção de avaliação onde foi } \\
\text { executada RECONSTRUÇÃO }\end{array}$ \\
\hline 170,940 & 6500 & 28,4 & 20,2 & 18,0 & 15,1 & 12,6 & 11,3 & 8,3 & 32 & 20 & $\begin{array}{l}\text { seção de avaliação onde foi } \\
\text { executada RECONSTRUÇÃO }\end{array}$ \\
\hline 170,930 & 2100 & 15,5 & 10,8 & 9,5 & 7,5 & 6,1 & 2,8 & 2,7 & 31 & 20 & $\begin{array}{l}\text { seção de avaliação onde foi } \\
\text { executada RECONSTRUÇÃO }\end{array}$ \\
\hline 170,930 & 4100 & 27,8 & 20,1 & 17,7 & 14,6 & 12,5 & 7,7 & 7,2 & 31 & 20 & $\begin{array}{l}\text { seção de avaliação onde foi } \\
\text { executada RECONSTRUÇÃO }\end{array}$ \\
\hline 170,930 & 6500 & 38,7 & 27,9 & 24,4 & 20,2 & 16,7 & 10,5 & 8,9 & 31 & 20 & $\begin{array}{l}\text { seção de avaliação onde foi } \\
\text { executada RECONSTRUÇÃO }\end{array}$ \\
\hline 170,920 & 2100 & 15,1 & 11,2 & 9,6 & 7,8 & 6,3 & 2,7 & 2,2 & 31 & 20 & $\begin{array}{l}\text { seção de avaliação onde foi } \\
\text { executada RECONSTRUÇÃO }\end{array}$ \\
\hline 170,920 & 4100 & 28,1 & 21,2 & 18,4 & 15,6 & 12,8 & 7,8 & 6,6 & 31 & 20 & $\begin{array}{l}\text { seção de avaliação onde foi } \\
\text { executada RECONSTRUÇÃO }\end{array}$ \\
\hline 170,920 & 6500 & 40,3 & 30,7 & 27,2 & 22,9 & 19,0 & 12,3 & 8,6 & 31 & 20 & $\begin{array}{l}\text { seção de avaliação onde foi } \\
\text { executada RECONSTRUÇÃo }\end{array}$ \\
\hline 170,910 & 2100 & 14,3 & 10,5 & 9,0 & 7,1 & 5,8 & 3,7 & 3,2 & 31 & 20 & $\begin{array}{l}\text { seção de avaliação onde foi } \\
\text { executada RECONSTRUÇÃO }\end{array}$ \\
\hline 170,910 & 4100 & 24,3 & 18,0 & 15,5 & 12,6 & 10,2 & 8,1 & 6,0 & 31 & 20 & $\begin{array}{l}\text { seção de avaliação onde foi } \\
\text { executada RECONSTRUÇÃO }\end{array}$ \\
\hline 170,910 & 6500 & 35,1 & 26,4 & 22,9 & 18,7 & 15,4 & 12,0 & 7,9 & 31 & 20 & $\begin{array}{l}\text { seção de avaliação onde foi } \\
\text { executada RECONSTRUÇÃO }\end{array}$ \\
\hline 170,900 & 2100 & 11,5 & 8,4 & 7,6 & 6,0 & 4,9 & 3,4 & 2,6 & 30 & 20 & $\begin{array}{l}\text { seção de avaliação onde foi } \\
\text { executada RECONSTRUÇÃo }\end{array}$ \\
\hline 170,900 & 4100 & 20,2 & 15,3 & 13,4 & 11,3 & 9,4 & 7,9 & 6,7 & 30 & 20 & $\begin{array}{l}\text { seção de avaliação onde foi } \\
\text { executada RECONSTRUÇÃO }\end{array}$ \\
\hline 170,900 & 6500 & 28,8 & 21,5 & 18,9 & 16,0 & 13,3 & 12,3 & 8,2 & 30 & 20 & $\begin{array}{l}\text { seção de avaliação onde foi } \\
\text { executada RECONSTRUÇÃo }\end{array}$ \\
\hline 170,890 & 2100 & 9,5 & 6,8 & 5,8 & 4,6 & 3,6 & 3,4 & 2,8 & 31 & 20 & $\begin{array}{l}\text { seção de avaliação onde foi } \\
\text { executada RECONSTRUÇÃO }\end{array}$ \\
\hline 170,890 & 4100 & 16,7 & 12,0 & 10,4 & 8,3 & 6,7 & 4,1 & 3,6 & 31 & 20 & $\begin{array}{l}\text { seção de avaliação onde foi } \\
\text { executada RECONSTRUÇÃO }\end{array}$ \\
\hline
\end{tabular}


Rodovia: Presidente Dutra - BR-116 Pista: Norte (São Paulo) Sentido: Rio de Janeiro
Faixa: 2

Data: $19 / 10 / 2010$

Trecho: Topo da Camada de Gap Graded

\begin{tabular}{|c|c|c|c|c|c|c|c|c|c|c|c|}
\hline \multirow{2}{*}{$\mathrm{km}$} & \multirow{2}{*}{$\begin{array}{r}\text { Força } \\
\text { (kgf) }\end{array}$} & \multicolumn{7}{|c|}{ Deflexões $(0,01 \mathrm{~mm})$} & \multirow{2}{*}{$\begin{array}{l}\text { Temp. } \\
\operatorname{Ar}\left({ }^{\circ} \mathrm{C}\right)\end{array}$} & \multirow{2}{*}{$\begin{array}{l}\text { Temp. } \\
\text { Pav. }\left({ }^{\circ} \mathrm{C}\right)\end{array}$} & \multirow{2}{*}{ Obs } \\
\hline & & D0 & D200 & D300 & D450 & D600 & D900 & D1200 & & & \\
\hline 170,890 & 6500 & 24,2 & 17,8 & 15,3 & 12,5 & 10,2 & 6,3 & 5,8 & 31 & 20 & $\begin{array}{l}\text { seção de avaliação onde foi } \\
\text { executada RECONSTRUÇÃO }\end{array}$ \\
\hline 170,880 & 2100 & 11,7 & 7,8 & 6,7 & 5,3 & 4,5 & 3,2 & 2,0 & 31 & 20 & $\begin{array}{l}\text { seção de avaliação onde foi } \\
\text { executada RECONSTRUÇÃO }\end{array}$ \\
\hline 170,880 & 4100 & 19,8 & 13,6 & 11,6 & 9,5 & 7,9 & 6,6 & 5,9 & 31 & 20 & $\begin{array}{l}\text { seção de avaliação onde foi } \\
\text { executada RECONSTRUÇÃO }\end{array}$ \\
\hline 170,880 & 6500 & 27,9 & 18,8 & 16,3 & 13,2 & 11,1 & 9,5 & 7,1 & 31 & 20 & $\begin{array}{l}\text { seção de avaliação onde foi } \\
\text { executada RECONSTRUÇÃO }\end{array}$ \\
\hline 170,870 & 2100 & 11,8 & 8,0 & 7,0 & 5,8 & 4,8 & 3,4 & 2,3 & 30 & 20 & $\begin{array}{l}\text { seção de avaliação onde foi } \\
\text { executada RECONSTRUÇÃOO }\end{array}$ \\
\hline 170,870 & 4100 & 20,4 & 14,3 & 12,5 & 10,5 & 8,8 & 7,5 & 6,1 & 30 & 20 & $\begin{array}{l}\text { seção de avaliação onde foi } \\
\text { executada RECONSTRUÇÃO }\end{array}$ \\
\hline 170,870 & 6500 & 28,8 & 20,5 & 18,0 & 15,0 & 12,7 & 10,5 & 7,9 & 30 & 20 & $\begin{array}{l}\text { seção de avaliação onde foi } \\
\text { executada RECONSTRUÇÃO }\end{array}$ \\
\hline 170,860 & 2100 & 12,1 & 8,8 & 7,4 & 6,0 & 4,9 & 4,1 & 2,6 & 31 & 20 & $\begin{array}{l}\text { seção de avaliação onde foi } \\
\text { executada RECONSTRUÇÃO }\end{array}$ \\
\hline 170,860 & 4100 & 21,3 & 15,5 & 13,4 & 11,1 & 9,0 & 8,1 & 5,5 & 31 & 20 & $\begin{array}{l}\text { seção de avaliação onde foi } \\
\text { executada RECONSTRUÇÃO }\end{array}$ \\
\hline 170,860 & 6500 & 30,6 & 22,4 & 19,6 & 16,0 & 13,2 & 10,7 & 8,4 & 31 & 20 & $\begin{array}{l}\text { seção de avaliação onde foi } \\
\text { executada RECONSTRUÇÃO }\end{array}$ \\
\hline 170,849 & 2100 & 11,8 & 8,6 & 7,6 & 6,0 & 4,8 & 2,9 & 2,3 & 31 & 20 & $\begin{array}{l}\text { seção de avaliação onde foi } \\
\text { executada RECONSTRUÇÃO }\end{array}$ \\
\hline 170,849 & 4100 & 20,9 & 15,5 & 13,9 & 11,4 & 9,3 & 7,8 & 5,3 & 31 & 20 & $\begin{array}{l}\text { seção de avaliação onde foi } \\
\text { executada RECONSTRUÇÃO }\end{array}$ \\
\hline 170,849 & 6500 & 30,1 & 22,6 & 20,1 & 16,5 & 13,7 & 11,0 & 8,4 & 31 & 20 & $\begin{array}{l}\text { seção de avaliação onde foi } \\
\text { executada RECONSTRUÇÃO }\end{array}$ \\
\hline 170,839 & 2100 & 11,3 & 8,2 & 7,2 & 6,0 & 5,1 & 3,7 & 3,0 & 30 & 20 & $\begin{array}{l}\text { seção de avaliação onde foi } \\
\text { executada RECONSTRUÇÃO }\end{array}$ \\
\hline 170,839 & 4100 & 19,9 & 14,7 & 13,3 & 11,1 & 9,4 & 8,3 & 6,2 & 30 & 20 & $\begin{array}{l}\text { seção de avaliação onde foi } \\
\text { executada RECONSTRUÇÃO }\end{array}$ \\
\hline 170,839 & 6500 & 28,2 & 21,0 & 18,9 & 15,7 & 13,4 & 11,5 & 8,8 & 30 & 20 & $\begin{array}{l}\text { seção de avaliação onde foi } \\
\text { executada RECONSTRUÇÃO }\end{array}$ \\
\hline 170,830 & 2100 & 11,6 & 8,2 & 7,1 & 5,7 & 4,7 & 4,3 & 3,2 & 29 & 20 & $\begin{array}{l}\text { seção de avaliação onde foi } \\
\text { executada RECONSTRUÇÃO }\end{array}$ \\
\hline 170,830 & 4100 & 21,1 & 15,3 & 13,4 & 11,3 & 9,4 & 7,8 & 6,3 & 29 & 20 & $\begin{array}{l}\text { seção de avaliação onde foi } \\
\text { executada RECONSTRUÇÃO }\end{array}$ \\
\hline 170,830 & 6500 & 29,8 & 21,9 & 19,2 & 16,2 & 13,5 & 11,6 & 7,1 & 29 & 20 & $\begin{array}{l}\text { seção de avaliação onde foi } \\
\text { executada RECONSTRUÇÃO }\end{array}$ \\
\hline 170,820 & 2100 & 8,6 & 6,1 & 5,2 & 4,0 & 3,2 & 3,0 & 2,1 & 29 & 20 & $\begin{array}{l}\text { seção de avaliação onde foi } \\
\text { executada RECONSTRUÇÃO }\end{array}$ \\
\hline 170,820 & 4100 & 14,6 & 10,6 & 9,1 & 7,3 & 5,8 & 3,7 & 3,2 & 29 & 20 & $\begin{array}{l}\text { seção de avaliação onde foi } \\
\text { executada RECONSTRUÇÃO }\end{array}$ \\
\hline 170,820 & 6500 & 20,6 & 15,2 & 13,0 & 10,5 & 8,6 & 5,5 & 5,0 & 29 & 20 & $\begin{array}{l}\text { seção de avaliação onde foi } \\
\text { executada RECONSTRUÇÃO }\end{array}$ \\
\hline 170,810 & 2100 & 8,8 & 6,4 & 5,5 & 4,4 & 3,6 & 3,2 & 2,8 & 29 & 20 & $\begin{array}{l}\text { seção de avaliação onde foi } \\
\text { executada RECONSTRUÇÃO }\end{array}$ \\
\hline 170,810 & 4100 & 15,0 & 11,2 & 9,9 & 8,0 & 6,4 & 4,1 & 3,6 & 29 & 20 & $\begin{array}{l}\text { seção de avaliação onde foi } \\
\text { executada RECONSTRUÇÃO }\end{array}$ \\
\hline 170,810 & 6500 & 21,6 & 16,4 & 14,3 & 11,7 & 9,6 & 6,0 & 5,5 & 29 & 20 & $\begin{array}{l}\text { seção de avaliação onde foi } \\
\text { executada RECONSTRUÇÃO }\end{array}$ \\
\hline 170,800 & 2100 & 15,5 & 11,3 & 9,1 & 6,2 & 4,4 & 3,4 & 1,9 & 28 & 20 & $\begin{array}{l}\text { seção de avaliação onde foi } \\
\text { executada RECONSTRUÇÃO }\end{array}$ \\
\hline 170,800 & 4100 & 29,8 & 22,7 & 18,5 & 13,1 & 9,5 & 7,5 & 4,2 & 28 & 20 & $\begin{array}{l}\text { seção de avaliação onde foi } \\
\text { executada RECONSTRUÇÃO }\end{array}$ \\
\hline 170,800 & 6500 & 43,8 & 35,9 & 28,0 & 20,2 & 15,1 & 11,9 & 8,5 & 28 & 20 & $\begin{array}{l}\text { seção de avaliação onde foi } \\
\text { executada RECONSTRUÇÃO }\end{array}$ \\
\hline 170,790 & 2100 & 11,2 & 8,0 & 6,7 & 5,1 & 3,9 & 3,2 & 2,1 & 29 & 20 & $\begin{array}{l}\text { seção de avaliação onde foi } \\
\text { executado } 14 \mathrm{~cm} \text { - EME }\end{array}$ \\
\hline 170,790 & 4100 & 22,9 & 17,1 & 14,5 & 11,3 & 8,5 & 8,4 & 5,1 & 29 & 20 & $\begin{array}{l}\text { seção de avaliação onde foi } \\
\text { executado } 14 \mathrm{~cm} \text { - EME }\end{array}$ \\
\hline 170,790 & 6500 & 34,9 & 23,8 & 22,9 & 17,6 & 13,7 & 12,4 & 7,2 & 29 & 20 & $\begin{array}{c}\text { seção de avaliação onde foi } \\
\text { executado } 14 \mathrm{~cm} \text { - EME }\end{array}$ \\
\hline 170,780 & 2100 & 12,1 & 8,7 & 7,3 & 5,3 & 4,0 & 3,2 & 2,3 & 29 & 20 & $\begin{array}{l}\text { seção de avaliação onde foi } \\
\text { executado } 14 \mathrm{~cm} \text { - EME }\end{array}$ \\
\hline 170,780 & 4100 & 24,3 & 18,4 & 15,6 & 11,5 & 8,7 & 6,5 & 6,0 & 29 & 20 & $\begin{array}{l}\text { seção de avaliação onde foi } \\
\text { executado } 14 \mathrm{~cm} \text { - EME }\end{array}$ \\
\hline 170,780 & 6500 & 36,7 & 25,4 & 23,9 & 18,0 & 13,5 & 11,5 & 8,1 & 29 & 20 & $\begin{array}{l}\text { seção de avaliação onde foi } \\
\text { executado } 14 \mathrm{~cm} \text { - EME }\end{array}$ \\
\hline 170,770 & 2100 & 16,3 & 12,3 & 10,3 & 7,6 & 5,6 & 3,9 & 2,7 & 28 & 20 & $\begin{array}{l}\text { seção de avaliação onde foi } \\
\text { executado } 14 \mathrm{~cm} \text { - EME }\end{array}$ \\
\hline
\end{tabular}


Rodovia: Presidente Dutra - BR-116 Pista: Norte (São Paulo) Sentido: Rio de Janeiro
Faixa: 2

Data: $19 / 10 / 2010$

Trecho: Topo da Camada de Gap Graded

\begin{tabular}{|c|c|c|c|c|c|c|c|c|c|c|c|}
\hline \multirow{2}{*}{$\mathrm{km}$} & \multirow{2}{*}{$\begin{array}{l}\text { Força } \\
\text { (kgf) }\end{array}$} & \multicolumn{7}{|c|}{ Deflexões $(0,01 \mathrm{~mm})$} & \multirow{2}{*}{$\begin{array}{l}\text { Temp. } \\
\operatorname{Ar}\left({ }^{\circ} \mathrm{C}\right)\end{array}$} & \multirow{2}{*}{$\begin{array}{l}\text { Temp. } \\
\text { Pav. }\left({ }^{\circ} \mathrm{C}\right)\end{array}$} & \multirow{2}{*}{ Obs } \\
\hline & & D0 & D200 & D300 & D450 & D600 & D900 & D1200 & & & \\
\hline 170,770 & 4100 & 30,8 & 24,0 & 20,3 & 15,2 & 11,2 & 9,5 & 5,6 & 28 & 20 & $\begin{array}{l}\text { seção de avaliação onde foi } \\
\text { executado } 14 \mathrm{~cm} \text { - EME }\end{array}$ \\
\hline 170,770 & 6500 & 43,7 & 36,7 & 29,7 & 22,7 & 17,0 & 14,3 & 8,7 & 28 & 20 & $\begin{array}{l}\text { seção de avaliação onde foi } \\
\text { executado } 14 \mathrm{~cm} \text { - EME }\end{array}$ \\
\hline 170,760 & 2100 & 11,2 & 7,9 & 6,3 & 4,4 & 3,4 & 2,8 & 2,4 & 28 & 20 & $\begin{array}{l}\text { seção de avaliação onde foi } \\
\text { executado } 14 \mathrm{~cm} \text { - EME }\end{array}$ \\
\hline 170,760 & 4100 & 22,1 & 16,3 & 13,3 & 9,4 & 6,8 & 6,1 & 3,6 & 28 & 20 & $\begin{array}{l}\text { seção de avaliação onde foi } \\
\text { executado } 14 \mathrm{~cm} \text { - EME }\end{array}$ \\
\hline 170,760 & 6500 & 33,6 & 25,1 & 20,7 & 14,6 & 10,7 & 8,6 & 6,8 & 28 & 20 & $\begin{array}{l}\text { seção de avaliação onde foi } \\
\text { executado } 14 \mathrm{~cm} \text { - EME }\end{array}$ \\
\hline 170,750 & 2100 & 10,0 & 6,9 & 5,8 & 4,3 & 3,4 & 2,7 & 2,0 & 28 & 20 & $\begin{array}{l}\text { seção de avaliação onde foi } \\
\text { executado } 14 \mathrm{~cm} \text { - EME }\end{array}$ \\
\hline 170,750 & 4100 & 17,9 & 12,9 & 10,8 & 8,3 & 6,4 & 6,1 & 4,0 & 28 & 20 & $\begin{array}{l}\text { seção de avaliação onde foi } \\
\text { executado } 14 \mathrm{~cm} \text { - EME }\end{array}$ \\
\hline 170,750 & 6500 & 26,2 & 19,1 & 16,1 & 12,6 & 9,9 & 6,7 & 6,2 & 28 & 20 & $\begin{array}{l}\text { seção de avaliação onde foi } \\
\text { executado } 14 \mathrm{~cm} \text { - EME }\end{array}$ \\
\hline 170,740 & 2100 & 16,3 & 11,8 & 9,3 & 6,3 & 4,2 & 2,7 & 1,8 & 28 & 20 & $\begin{array}{l}\text { seção de avaliação onde foi } \\
\text { executado } 14 \mathrm{~cm} \text { - EME }\end{array}$ \\
\hline 170,740 & 4100 & 30,3 & 22,6 & 18,1 & 12,3 & 8,3 & 6,0 & 3,4 & 28 & 20 & $\begin{array}{l}\text { seção de avaliação onde foi } \\
\text { executado } 14 \mathrm{~cm} \text { - EME }\end{array}$ \\
\hline 170,740 & 6500 & 42,9 & 34,6 & 26,3 & 18,1 & 12,6 & 8,5 & 4,3 & 28 & 20 & $\begin{array}{l}\text { seção de avaliação onde foi } \\
\text { executado } 14 \mathrm{~cm} \text { - EME }\end{array}$ \\
\hline 170,730 & 2100 & 10,2 & 6,9 & 5,4 & 3,9 & 2,9 & 2,2 & 1,7 & 28 & 20 & $\begin{array}{l}\text { seção de avaliação onde foi } \\
\text { executado } 14 \mathrm{~cm} \text { - EME }\end{array}$ \\
\hline 170,730 & 4100 & 20,5 & 14,5 & 11,7 & 8,4 & 6,0 & 4,6 & 2,8 & 28 & 20 & $\begin{array}{l}\text { seção de avaliação onde foi } \\
\text { executado } 14 \mathrm{~cm} \text { - EME }\end{array}$ \\
\hline 170,730 & 6500 & 30,6 & 22,2 & 18,2 & 12,9 & 9,6 & 6,9 & 3,0 & 28 & 20 & $\begin{array}{l}\text { seção de avaliação onde foi } \\
\text { executado } 14 \mathrm{~cm} \text { - EME }\end{array}$ \\
\hline 170,719 & 2100 & 16,0 & 11,6 & 9,1 & 6,0 & 4,0 & 2,2 & 1,4 & 27 & 20 & $\begin{array}{l}\text { seção de avaliação onde foi } \\
\text { executado } 14 \mathrm{~cm} \text { - EME }\end{array}$ \\
\hline 170,719 & 4100 & 29,7 & 22,1 & 17,6 & 12,1 & 7,9 & 5,3 & 3,9 & 27 & 20 & $\begin{array}{l}\text { seção de avaliação onde foi } \\
\text { executado } 14 \mathrm{~cm} \text { - EME }\end{array}$ \\
\hline 170,719 & 6500 & 41,0 & 27,8 & 24,9 & 17,2 & 11,7 & 7,8 & 5,1 & 27 & 20 & $\begin{array}{l}\text { seção de avaliação onde foi } \\
\text { executado } 14 \mathrm{~cm} \text { - EME }\end{array}$ \\
\hline 170,710 & 2100 & 15,9 & 11,6 & 9,4 & 6,7 & 4,7 & 2,9 & 2,3 & 28 & 20 & $\begin{array}{l}\text { seção de avaliação onde foi } \\
\text { executado } 14 \mathrm{~cm} \text { - EME }\end{array}$ \\
\hline 170,710 & 4100 & 29,8 & 22,6 & 18,6 & 13,5 & 9,4 & 6,4 & 2,6 & 28 & 20 & $\begin{array}{l}\text { seção de avaliação onde foi } \\
\text { executado } 14 \mathrm{~cm} \text { - EME }\end{array}$ \\
\hline 170,710 & 6500 & 41,8 & 28,0 & 26,8 & 19,6 & 14,1 & 9,7 & 4,0 & 28 & 20 & $\begin{array}{l}\text { seção de avaliação onde foi } \\
\text { executado } 14 \mathrm{~cm} \text { - EME }\end{array}$ \\
\hline 170,700 & 2100 & 12,9 & 9,4 & 7,8 & 5,6 & 4,0 & 2,7 & 1,2 & 28 & 20 & $\begin{array}{l}\text { seção de avaliação onde foi } \\
\text { executado } 14 \mathrm{~cm} \text { - EME }\end{array}$ \\
\hline 170,700 & 4100 & 26,5 & 20,2 & 16,9 & 12,4 & 9,1 & 6,1 & 2,2 & 28 & 20 & $\begin{array}{l}\text { seção de avaliação onde foi } \\
\text { executado } 14 \mathrm{~cm} \text { - EME }\end{array}$ \\
\hline 170,700 & 6500 & 39,2 & 28,2 & 25,8 & 19,4 & 14,3 & 9,8 & 6,4 & 28 & 20 & $\begin{array}{l}\text { seção de avaliação onde foi } \\
\text { executado } 14 \mathrm{~cm} \text { - EME }\end{array}$ \\
\hline 170,690 & 2100 & 11,6 & 8,3 & 6,6 & 4,6 & 3,1 & 2,0 & 1,4 & 29 & 20 & $\begin{array}{l}\text { seção de avaliação onde foi } \\
\text { executado } 14 \mathrm{~cm} \text { - EME }\end{array}$ \\
\hline 170,690 & 4100 & 22,3 & 16,5 & 13,5 & 9,4 & 6,4 & 4,3 & 3,0 & 29 & 20 & $\begin{array}{l}\text { seção de avaliação onde foi } \\
\text { executado } 14 \mathrm{~cm} \text { - EME }\end{array}$ \\
\hline 170,690 & 6500 & 30,2 & 22,8 & 18,8 & 13,4 & 9,3 & 6,1 & 3,6 & 29 & 20 & $\begin{array}{l}\text { seção de avaliação onde foi } \\
\text { executado } 14 \mathrm{~cm} \text { - EME }\end{array}$ \\
\hline 170,680 & 2100 & 9,9 & 6,9 & 5,5 & 3,7 & 2,5 & 1,4 & 1,2 & 30 & 20 & $\begin{array}{l}\text { seção de avaliação onde foi } \\
\text { executado } 14 \mathrm{~cm} \text { - EME }\end{array}$ \\
\hline 170,680 & 4100 & 19,2 & 14,1 & 11,4 & 7,8 & 5,2 & 3,6 & 2,6 & 30 & 20 & $\begin{array}{l}\text { seção de avaliação onde foi } \\
\text { executado } 14 \mathrm{~cm} \text { - EME }\end{array}$ \\
\hline 170,680 & 6500 & 27,1 & 20,3 & 16,6 & 11,7 & 8,1 & 4,9 & 1,8 & 30 & 20 & $\begin{array}{l}\text { seção de avaliação onde foi } \\
\text { executado } 14 \mathrm{~cm} \text { - EME }\end{array}$ \\
\hline 170,670 & 2100 & 9,4 & 6,9 & 5,5 & 3,9 & 2,7 & 1,6 & 1,4 & 28 & 20 & $\begin{array}{l}\text { seção de avaliação onde foi } \\
\text { executado } 14 \mathrm{~cm} \text { - EME }\end{array}$ \\
\hline 170,670 & 4100 & 18,7 & 14,2 & 11,5 & 8,3 & 5,7 & 4,4 & 3,1 & 28 & 20 & $\begin{array}{l}\text { seção de avaliação onde foi } \\
\text { executado } 14 \mathrm{~cm} \text { - EME }\end{array}$ \\
\hline 170,670 & 6500 & 27,9 & 21,4 & 17,7 & 12,8 & 9,0 & 6,3 & 3,5 & 28 & 20 & $\begin{array}{l}\text { seção de avaliação onde foi } \\
\text { executado } 14 \mathrm{~cm} \text { - EME }\end{array}$ \\
\hline 170,660 & 2100 & 12,1 & 9,3 & 7,4 & 5,1 & 3,5 & 1,9 & 1,8 & 31 & 20 & $\begin{array}{l}\text { seção de avaliação onde foi } \\
\text { executado } 14 \mathrm{~cm} \text { - EME }\end{array}$ \\
\hline 170,660 & 4100 & 23,1 & 18,1 & 14,7 & 10,3 & 6,9 & 4,5 & 1,6 & 31 & 20 & $\begin{array}{l}\text { seção de avaliação onde foi } \\
\text { executado } 14 \mathrm{~cm} \text { - EME }\end{array}$ \\
\hline 170,660 & 6500 & 34,2 & 27,3 & 22,5 & 16,1 & 11,1 & 7,3 & 2,5 & 31 & 20 & $\begin{array}{l}\text { seção de avaliação onde foi } \\
\text { executado } 14 \mathrm{~cm} \text { - EME }\end{array}$ \\
\hline
\end{tabular}


Rodovia: Presidente Dutra - BR-116 Pista: Norte (São Paulo) Sentido: Rio de Janeiro
Faixa: 2

Data: $19 / 10 / 2010$

Trecho: Topo da Camada de Gap Graded

\begin{tabular}{|c|c|c|c|c|c|c|c|c|c|c|c|}
\hline \multirow{2}{*}{$\mathrm{km}$} & \multirow{2}{*}{$\begin{array}{r}\text { Força } \\
\text { (kgf) }\end{array}$} & \multicolumn{7}{|c|}{ Deflexões $(0,01 \mathrm{~mm})$} & \multirow{2}{*}{$\begin{array}{l}\text { Temp. } \\
\operatorname{Ar}\left({ }^{\circ} \mathrm{C}\right)\end{array}$} & \multirow{2}{*}{$\begin{array}{l}\text { Temp. } \\
\text { Pav. }\left({ }^{\circ} \mathrm{C}\right)\end{array}$} & \multirow{2}{*}{ Obs } \\
\hline & & D0 & D200 & D300 & D450 & D600 & D900 & D1200 & & & \\
\hline 170,650 & 2100 & 12,4 & 9,2 & 7,4 & 5,3 & 3,7 & 2,6 & 1,2 & 28 & 20 & $\begin{array}{l}\text { seção de avaliação onde foi } \\
\text { executado } 14 \mathrm{~cm} \text { - EME }\end{array}$ \\
\hline 170,650 & 4100 & 23,9 & 18,4 & 15,1 & 10,7 & 7,5 & 5,0 & 2,6 & 28 & 20 & $\begin{array}{l}\text { seção de avaliação onde foi } \\
\text { executado } 14 \mathrm{~cm} \text { - EME }\end{array}$ \\
\hline 170,650 & 6500 & 34,8 & 27,2 & 22,6 & 16,5 & 11,6 & 7,9 & 3,2 & 28 & 20 & $\begin{array}{l}\text { seção de avaliação onde foi } \\
\text { executado } 14 \mathrm{~cm} \text { - EME }\end{array}$ \\
\hline 170,640 & 2100 & 13,7 & 10,4 & 8,3 & 5,8 & 3,9 & 2,2 & 1,4 & 28 & 20 & $\begin{array}{l}\text { seção de avaliação onde foi } \\
\text { executado } 14 \mathrm{~cm} \text { - EME }\end{array}$ \\
\hline 170,640 & 4100 & 25,1 & 19,6 & 15,9 & 11,6 & 7,9 & 5,7 & 2,8 & 28 & 20 & $\begin{array}{l}\text { seção de avaliação onde foi } \\
\text { executado } 14 \mathrm{~cm} \text { - EME }\end{array}$ \\
\hline 170,640 & 6500 & 36,0 & 28,4 & 23,5 & 16,9 & 12,0 & 7,3 & 2,9 & 28 & 20 & $\begin{array}{l}\text { seção de avaliação onde foi } \\
\text { executado } 14 \mathrm{~cm} \text { - EME }\end{array}$ \\
\hline 170,630 & 2100 & 13,2 & 10,2 & 8,4 & 5,7 & 4,1 & 2,1 & 1,6 & 29 & 20 & $\begin{array}{l}\text { seção de avaliação onde foi } \\
\text { executado } 14 \mathrm{~cm} \text { - EME }\end{array}$ \\
\hline 170,630 & 4100 & 25,4 & 20,1 & 17,0 & 12,2 & 8,7 & 6,5 & 2,8 & 29 & 20 & $\begin{array}{l}\text { seção de avaliação onde foi } \\
\text { executado } 14 \mathrm{~cm} \text { - EME }\end{array}$ \\
\hline 170,630 & 6500 & 37,2 & 29,7 & 25,3 & 18,4 & 13,4 & 8,6 & 3,8 & 29 & 20 & $\begin{array}{l}\text { seção de avaliação onde foi } \\
\text { executado } 14 \mathrm{~cm} \text { - EME }\end{array}$ \\
\hline 170,620 & 2100 & 19,3 & 13,9 & 11,0 & 7,6 & 5,2 & 2,7 & 1,5 & 28 & 20 & $\begin{array}{l}\text { seção de avaliação onde foi } \\
\text { executado } 14 \mathrm{~cm} \text { - EME }\end{array}$ \\
\hline 170,620 & 4100 & 35,8 & 26,7 & 21,6 & 15,0 & 10,4 & 6,0 & 3,8 & 28 & 20 & $\begin{array}{l}\text { seção de avaliação onde foi } \\
\text { executado } 14 \mathrm{~cm} \text { - EME }\end{array}$ \\
\hline 170,620 & 6500 & 50,9 & 41,3 & 31,7 & 22,5 & 16,3 & 9,8 & 4,7 & 28 & 20 & $\begin{array}{l}\text { seção de avaliação onde foi } \\
\text { executado } 14 \mathrm{~cm} \text { - EME }\end{array}$ \\
\hline 170,610 & 2100 & 16,9 & 12,8 & 10,3 & 6,9 & 4,6 & 2,0 & 1,6 & 28 & 20 & $\begin{array}{l}\text { seção de avaliação onde foi } \\
\text { executado } 14 \mathrm{~cm} \text { - EME }\end{array}$ \\
\hline 170,610 & 4100 & 31,0 & 24,3 & 20,0 & 14,2 & 9,8 & 5,7 & 3,0 & 28 & 20 & $\begin{array}{l}\text { seção de avaliação onde foi } \\
\text { executado } 14 \mathrm{~cm} \text { - EME }\end{array}$ \\
\hline 170,610 & 6500 & 44,5 & 31,8 & 29,3 & 21,6 & 15,1 & 8,6 & 3,7 & 28 & 20 & $\begin{array}{l}\text { seção de avaliação onde foi } \\
\text { executado } 14 \mathrm{~cm} \text { - EME }\end{array}$ \\
\hline 170,600 & 2100 & 21,2 & 14,4 & 10,7 & 6,6 & 4,2 & 1,9 & 1,8 & 27 & 20 & $\begin{array}{l}\text { seção de avaliação onde foi } \\
\text { executado } 14 \mathrm{~cm} \text { - EME }\end{array}$ \\
\hline 170,600 & 4100 & 39,3 & 27,7 & 21,1 & 13,8 & 8,7 & 5,0 & 2,5 & 27 & 20 & $\begin{array}{l}\text { seção de avaliação onde foi } \\
\text { executado } 14 \mathrm{~cm} \text { - EME }\end{array}$ \\
\hline 170,600 & 6500 & 55,1 & 32,6 & 30,7 & 20,3 & 13,2 & 6,8 & 2,8 & 27 & 20 & $\begin{array}{l}\text { seção de avaliação onde foi } \\
\text { executado } 14 \mathrm{~cm} \text { - EME }\end{array}$ \\
\hline 170,590 & 2100 & 21,2 & 14,9 & 11,6 & 7,4 & 4,9 & 2,6 & 1,5 & 27 & 20 & $\begin{array}{l}\text { seção de avaliação onde foi } \\
\text { executado } 11 \mathrm{~cm} \text { - EME }\end{array}$ \\
\hline 170,590 & 4100 & 40,8 & 30,5 & 24,1 & 16,4 & 11,1 & 6,4 & 3,8 & 27 & 20 & $\begin{array}{l}\text { seção de avaliação onde foi } \\
\text { executado } 11 \mathrm{~cm} \text { - EME }\end{array}$ \\
\hline 170,590 & 6500 & 58,2 & 34,6 & 29,9 & 25,2 & 17,5 & 9,9 & 4,2 & 27 & 20 & $\begin{array}{l}\text { seção de avaliação onde foi } \\
\text { executado } 11 \mathrm{~cm} \text { - EME }\end{array}$ \\
\hline 170,580 & 2100 & 15,3 & 11,2 & 8,7 & 5,6 & 3,9 & 1,9 & 1,1 & 27 & 20 & $\begin{array}{l}\text { seção de avaliação onde foi } \\
\text { executado } 11 \mathrm{~cm}-\text { EME }\end{array}$ \\
\hline 170,580 & 4100 & 31,1 & 23,2 & 18,6 & 12,9 & 8,7 & 5,3 & 3,0 & 27 & 20 & $\begin{array}{l}\text { seção de avaliação onde foi } \\
\text { executado } 11 \mathrm{~cm} \text { - EME }\end{array}$ \\
\hline 170,580 & 6500 & 45,6 & 33,4 & 28,2 & 19,6 & 13,7 & 7,9 & 3,5 & 27 & 20 & $\begin{array}{l}\text { seção de avaliação onde foi } \\
\text { executado } 11 \mathrm{~cm} \text { - EME }\end{array}$ \\
\hline 170,569 & 2100 & 14,1 & 10,5 & 8,5 & 6,0 & 4,3 & 2,6 & 2,3 & 28 & 20 & $\begin{array}{l}\text { seção de avaliação onde foi } \\
\text { executado } 11 \mathrm{~cm} \text { - EME }\end{array}$ \\
\hline 170,569 & 4100 & 28,0 & 21,8 & 18,0 & 13,0 & 9,4 & 6,7 & 2,6 & 28 & 20 & $\begin{array}{l}\text { seção de avaliação onde foi } \\
\text { executado } 11 \mathrm{~cm} \text { - EME }\end{array}$ \\
\hline 170,569 & 6500 & 44,5 & 33,3 & 29,6 & 21,7 & 16,1 & 10,3 & 4,8 & 28 & 20 & $\begin{array}{l}\text { seção de avaliação onde foi } \\
\text { executado } 11 \mathrm{~cm} \text { - EME }\end{array}$ \\
\hline 170,559 & 2100 & 16,5 & 12,4 & 9,9 & 6,7 & 4,6 & 2,5 & 1,1 & 29 & 20 & $\begin{array}{l}\text { seção de avaliação onde foi } \\
\text { executado } 11 \mathrm{~cm} \text { - EME }\end{array}$ \\
\hline 170,559 & 4100 & 33,8 & 26,5 & 21,8 & 15,3 & 10,6 & 6,8 & 3,1 & 29 & 20 & $\begin{array}{l}\text { seção de avaliação onde foi } \\
\text { executado } 11 \mathrm{~cm} \text { - EME }\end{array}$ \\
\hline 170,559 & 6500 & 49,8 & 34,0 & 29,1 & 24,1 & 17,1 & 10,5 & 6,7 & 29 & 20 & $\begin{array}{l}\text { seção de avaliação onde foi } \\
\text { executado } 11 \mathrm{~cm} \text { - EME }\end{array}$ \\
\hline 170,549 & 2100 & 23,3 & 16,1 & 12,0 & 7,7 & 4,8 & 2,3 & 2,2 & 29 & 20 & $\begin{array}{c}\text { seção de avaliação onde foi } \\
\text { executado } 11 \mathrm{~cm} \text { - EME }\end{array}$ \\
\hline 170,549 & 4100 & 43,4 & 31,7 & 24,6 & 16,6 & 10,7 & 5,5 & 2,4 & 29 & 20 & $\begin{array}{l}\text { seção de avaliação onde foi } \\
\text { executado } 11 \mathrm{~cm} \text { - EME }\end{array}$ \\
\hline 170,549 & 6500 & 60,7 & 48,4 & 36,2 & 25,3 & 16,9 & 8,9 & 3,6 & 29 & 20 & $\begin{array}{c}\text { seção de avaliação onde foi } \\
\text { executado } 11 \mathrm{~cm} \text { - EME }\end{array}$ \\
\hline 170,540 & 2100 & 13,8 & 10,4 & 8,1 & 5,5 & 3,6 & 1,8 & 1,2 & 28 & 20 & $\begin{array}{l}\text { seção de avaliação onde foi } \\
\text { executado } 11 \mathrm{~cm} \text { - EME }\end{array}$ \\
\hline 170,540 & 4100 & 26,6 & 20,4 & 16,5 & 11,8 & 7,9 & 4,9 & 3,3 & 28 & 20 & $\begin{array}{l}\text { seção de avaliação onde foi } \\
\text { executado } 11 \mathrm{~cm} \text { - EME }\end{array}$ \\
\hline
\end{tabular}


Rodovia: Presidente Dutra - BR-116 Pista: Norte (São Paulo) Sentido: Rio de Janeiro
Faixa: 2

Data: $19 / 10 / 2010$

Trecho: Topo da Camada de Gap Graded

\begin{tabular}{|c|c|c|c|c|c|c|c|c|c|c|c|}
\hline \multirow{2}{*}{$\mathrm{km}$} & \multirow{2}{*}{$\begin{array}{r}\text { Força } \\
\text { (kgf) }\end{array}$} & \multicolumn{7}{|c|}{ Deflexões $(0,01 \mathrm{~mm})$} & \multirow{2}{*}{$\begin{array}{l}\text { Temp. } \\
\operatorname{Ar}\left({ }^{\circ} \mathrm{C}\right)\end{array}$} & \multirow{2}{*}{$\begin{array}{l}\text { Temp. } \\
\text { Pav. }\left({ }^{\circ} \mathrm{C}\right)\end{array}$} & \multirow{2}{*}{ Obs } \\
\hline & & D0 & D200 & D300 & D450 & D600 & D900 & D1200 & & & \\
\hline 170,540 & 6500 & 39,2 & 30,8 & 25,4 & 18,4 & 12,8 & 7,1 & 1,9 & 28 & 20 & $\begin{array}{l}\text { seção de avaliação onde foi } \\
\text { executado } 11 \mathrm{~cm} \text { - EME }\end{array}$ \\
\hline 170,530 & 2100 & 18,0 & 12,3 & 9,4 & 5,9 & 3,7 & 1,8 & 1,3 & 28 & 20 & $\begin{array}{l}\text { seção de avaliação onde foi } \\
\text { executado } 11 \mathrm{~cm} \text { - EME }\end{array}$ \\
\hline 170,530 & 4100 & 32,0 & 22,8 & 18,1 & 12,2 & 7,9 & 4,3 & 2,5 & 28 & 20 & $\begin{array}{l}\text { seção de avaliação onde foi } \\
\text { executado } 11 \mathrm{~cm} \text { - EME }\end{array}$ \\
\hline 170,530 & 6500 & 45,2 & 33,5 & 27,1 & 18,9 & 12,7 & 6,7 & 3,5 & 28 & 20 & $\begin{array}{l}\text { seção de avaliação onde foi } \\
\text { executado } 11 \mathrm{~cm} \text { - EME }\end{array}$ \\
\hline 170,520 & 2100 & 15,3 & 11,7 & 9,3 & 6,5 & 4,4 & 2,5 & 1,7 & 27 & 20 & $\begin{array}{l}\text { seção de avaliação onde foi } \\
\text { executado } 11 \mathrm{~cm} \text { - EME }\end{array}$ \\
\hline 170,520 & 4100 & 29,7 & 23,3 & 18,9 & 13,6 & 9,6 & 5,9 & 3,0 & 27 & 20 & $\begin{array}{l}\text { seção de avaliação onde foi } \\
\text { executado } 11 \mathrm{~cm} \text { - EME }\end{array}$ \\
\hline 170,520 & 6500 & 42,8 & 34,2 & 28,2 & 20,7 & 14,9 & 9,4 & 4,4 & 27 & 20 & $\begin{array}{l}\text { seção de avaliação onde foi } \\
\text { executado } 11 \mathrm{~cm}-\text { EME }\end{array}$ \\
\hline 170,509 & 2100 & 13,3 & 9,6 & 7,6 & 5,0 & 3,4 & 1,7 & 1,5 & 28 & 20 & $\begin{array}{l}\text { seção de avaliação onde foi } \\
\text { executado } 11 \mathrm{~cm} \text { - EME }\end{array}$ \\
\hline 170,509 & 4100 & 25,0 & 18,9 & 15,5 & 10,5 & 7,1 & 4,4 & 1,9 & 28 & 20 & $\begin{array}{l}\text { seção de avaliação onde foi } \\
\text { executado } 11 \mathrm{~cm} \text { - EME }\end{array}$ \\
\hline 170,509 & 6500 & 35,7 & 27,2 & 22,5 & 15,6 & 10,8 & 6,3 & 2,7 & 28 & 20 & $\begin{array}{l}\text { seção de avaliação onde foi } \\
\text { executado } 11 \mathrm{~cm} \text { - EME }\end{array}$ \\
\hline 170,500 & 2100 & 17,8 & 12,9 & 10,2 & 6,5 & 4,2 & 2,0 & 1,7 & 28 & 20 & $\begin{array}{l}\text { seção de avaliação onde foi } \\
\text { executado } 11 \mathrm{~cm} \text { - EME }\end{array}$ \\
\hline 170,500 & 4100 & 33,0 & 24,5 & 19,5 & 13,0 & 8,5 & 4,3 & 2,1 & 28 & 20 & $\begin{array}{l}\text { seção de avaliação onde foi } \\
\text { executado } 11 \mathrm{~cm} \text { - EME }\end{array}$ \\
\hline 170,500 & 6500 & 45,2 & 32,8 & 27,3 & 18,6 & 12,2 & 5,9 & 3,6 & 28 & 20 & $\begin{array}{l}\text { seção de avaliação onde foi } \\
\text { executado } 11 \mathrm{~cm} \text { - EME }\end{array}$ \\
\hline 170,490 & 2100 & 14,3 & 10,3 & 8,1 & 5,2 & 3,3 & 1,7 & 1,6 & 28 & 20 & $\begin{array}{l}\text { seção de avaliação onde foi } \\
\text { executado } 11 \mathrm{~cm} \text { - EME }\end{array}$ \\
\hline 170,490 & 4100 & 27,6 & 20,3 & 15,9 & 10,7 & 7,1 & 4,4 & 1,7 & 28 & 20 & $\begin{array}{l}\text { seção de avaliação onde foi } \\
\text { executado } 11 \mathrm{~cm} \text { - EME }\end{array}$ \\
\hline 170,490 & 6500 & 38,6 & 28,6 & 22,9 & 15,7 & 10,5 & 6,3 & 2,7 & 28 & 20 & $\begin{array}{l}\text { seção de avaliação onde foi } \\
\text { executado } 11 \mathrm{~cm} \text { - EME }\end{array}$ \\
\hline 170,480 & 2100 & 21,1 & 15,8 & 12,5 & 8,9 & 6,1 & 3,6 & 2,0 & 28 & 20 & $\begin{array}{l}\text { seção de avaliação onde foi } \\
\text { executado } 11 \mathrm{~cm} \text { - EME }\end{array}$ \\
\hline 170,480 & 4100 & 40,5 & 31,1 & 25,4 & 18,6 & 13,1 & 8,4 & 4,9 & 28 & 20 & $\begin{array}{l}\text { seção de avaliação onde foi } \\
\text { executado } 11 \mathrm{~cm} \text { - EME }\end{array}$ \\
\hline 170,480 & 6500 & 56,5 & 36,9 & 32,0 & 27,2 & 19,7 & 12,2 & 7,0 & 28 & 20 & $\begin{array}{l}\text { seção de avaliação onde foi } \\
\text { executado } 11 \mathrm{~cm} \text { - EME }\end{array}$ \\
\hline 170,470 & 2100 & 15,0 & 10,8 & 8,2 & 5,5 & 3,6 & 1,9 & 1,0 & 28 & 20 & $\begin{array}{l}\text { seção de avaliação onde foi } \\
\text { executado } 11 \mathrm{~cm} \text { - EME }\end{array}$ \\
\hline 170,470 & 4100 & 27,4 & 20,5 & 16,1 & 11,2 & 7,6 & 4,6 & 1,1 & 28 & 20 & $\begin{array}{l}\text { seção de avaliação onde foi } \\
\text { executado } 11 \mathrm{~cm} \text { - EME }\end{array}$ \\
\hline 170,470 & 6500 & 37,1 & 28,0 & 22,6 & 16,1 & 11,2 & 6,7 & 4,1 & 28 & 20 & $\begin{array}{l}\text { seção de avaliação onde foi } \\
\text { executado } 11 \mathrm{~cm} \text { - EME }\end{array}$ \\
\hline 170,459 & 2100 & 17,4 & 12,4 & 9,8 & 6,9 & 4,8 & 2,7 & 1,8 & 27 & 20 & $\begin{array}{l}\text { seção de avaliação onde foi } \\
\text { executado } 11 \mathrm{~cm} \text { - EME }\end{array}$ \\
\hline 170,459 & 4100 & 30,8 & 22,5 & 18,2 & 12,9 & 9,3 & 5,7 & 2,4 & 27 & 20 & $\begin{array}{l}\text { seção de avaliação onde foi } \\
\text { executado } 11 \mathrm{~cm} \text { - EME }\end{array}$ \\
\hline 170,459 & 6500 & 43,3 & 32,2 & 26,3 & 18,9 & 13,8 & 8,2 & 4,9 & 27 & 20 & $\begin{array}{l}\text { seção de avaliação onde foi } \\
\text { executado } 11 \mathrm{~cm} \text { - EME }\end{array}$ \\
\hline 170,450 & 2100 & 14,2 & 10,8 & 8,4 & 5,5 & 3,7 & 1,8 & 1,2 & 26 & 20 & $\begin{array}{l}\text { seção de avaliação onde foi } \\
\text { executado } 11 \mathrm{~cm} \text { - EME }\end{array}$ \\
\hline 170,450 & 4100 & 27,9 & 21,8 & 17,5 & 12,2 & 8,2 & 3,8 & 1,5 & 26 & 20 & $\begin{array}{l}\text { seção de avaliação onde foi } \\
\text { executado } 11 \mathrm{~cm} \text { - EME }\end{array}$ \\
\hline 170,450 & 6500 & 40,5 & 32,1 & 26,2 & 18,5 & 12,8 & 6,6 & 3,9 & 26 & 20 & $\begin{array}{l}\text { seção de avaliação onde foi } \\
\text { executado } 11 \mathrm{~cm}-\text { EME }\end{array}$ \\
\hline 170,439 & 2100 & 30,8 & 21,9 & 16,2 & 10,0 & 6,0 & 2,2 & 1,6 & 26 & 20 & $\begin{array}{l}\text { seção de avaliação onde foi } \\
\text { executado } 11 \mathrm{~cm} \text { - EME }\end{array}$ \\
\hline 170,439 & 4100 & 48,6 & 35,7 & 27,0 & 17,8 & 11,1 & 4,9 & 2,4 & 26 & 20 & $\begin{array}{l}\text { seção de avaliação onde foi } \\
\text { executado } 11 \mathrm{~cm} \text { - EME }\end{array}$ \\
\hline 170,439 & 6500 & 63,4 & 39,9 & 36,5 & 24,7 & 15,9 & 7,8 & 3,4 & 26 & 20 & $\begin{array}{l}\text { seção de avaliação onde foi } \\
\text { executado } 11 \mathrm{~cm} \text { - EME }\end{array}$ \\
\hline 170,429 & 2100 & 19,4 & 14,5 & 11,2 & 7,4 & 5,0 & 2,0 & 1,2 & 25 & 20 & $\begin{array}{l}\text { seção de avaliação onde foi } \\
\text { executado } 11 \mathrm{~cm} \text { - EME }\end{array}$ \\
\hline 170,429 & 4100 & 37,6 & 28,5 & 22,7 & 15,1 & 10,1 & 5,3 & 2,8 & 25 & 20 & $\begin{array}{l}\text { seção de avaliação onde foi } \\
\text { executado } 11 \mathrm{~cm} \text { - EME }\end{array}$ \\
\hline 170,429 & 6500 & 52,6 & 39,2 & 32,3 & 21,8 & 14,6 & 7,0 & 3,3 & 25 & 20 & $\begin{array}{l}\text { seção de avaliação onde foi } \\
\text { executado } 11 \mathrm{~cm} \text { - EME }\end{array}$ \\
\hline 170,419 & 2100 & 12,2 & 8,9 & 6,7 & 4,3 & 2,7 & 1,0 & 0,8 & 26 & 20 & $\begin{array}{l}\text { seção de avaliação onde foi } \\
\text { executado } 11 \mathrm{~cm} \text { - EME }\end{array}$ \\
\hline
\end{tabular}


Rodovia: Presidente Dutra - BR-116 Pista: Norte (São Paulo) Sentido: Rio de Janeiro
Faixa: 2

Data: $19 / 10 / 2010$

Trecho: Topo da Camada de Gap Graded

\begin{tabular}{|c|c|c|c|c|c|c|c|c|c|c|c|}
\hline \multirow{2}{*}{$\mathrm{km}$} & \multirow{2}{*}{$\begin{array}{r}\text { Força } \\
\text { (kgf) }\end{array}$} & \multicolumn{7}{|c|}{ Deflexões $(0,01 \mathrm{~mm})$} & \multirow{2}{*}{$\begin{array}{l}\text { Temp. } \\
\operatorname{Ar}\left({ }^{\circ} \mathrm{C}\right)\end{array}$} & \multirow{2}{*}{$\begin{array}{l}\text { Temp. } \\
\text { Pav. }\left({ }^{\circ} \mathrm{C}\right)\end{array}$} & \multirow{2}{*}{ Obs } \\
\hline & & D0 & D200 & D300 & D450 & D600 & D900 & D1200 & & & \\
\hline 170,419 & 4100 & 22,8 & 16,9 & 13,3 & 8,8 & 5,6 & 2,2 & 1,5 & 26 & 20 & $\begin{array}{l}\text { seção de avaliação onde foi } \\
\text { executado } 11 \mathrm{~cm} \text { - EME }\end{array}$ \\
\hline 170,419 & 6500 & 32,5 & 24,5 & 19,8 & 13,5 & 9,1 & 4,1 & 4,0 & 26 & 20 & $\begin{array}{l}\text { seção de avaliação onde foi } \\
\text { executado } 11 \mathrm{~cm} \text { - EME }\end{array}$ \\
\hline 170,409 & 2100 & 15,1 & 10,8 & 8,2 & 5,2 & 3,4 & 2,0 & 0,8 & 25 & 20 & $\begin{array}{l}\text { seção de avaliação onde foi } \\
\text { executado } 11 \mathrm{~cm} \text { - EME }\end{array}$ \\
\hline 170,409 & 4100 & 30,4 & 22,8 & 17,9 & 12,1 & 7,9 & 5,2 & 2,1 & 25 & 20 & $\begin{array}{l}\text { seção de avaliação onde foi } \\
\text { executado } 11 \mathrm{~cm} \text { - EME }\end{array}$ \\
\hline 170,409 & 6500 & 43,5 & 33,3 & 26,6 & 18,2 & 12,4 & 6,8 & 3,2 & 25 & 20 & $\begin{array}{l}\text { seção de avaliação onde foi } \\
\text { executado } 11 \mathrm{~cm} \text { - EME }\end{array}$ \\
\hline 170,400 & 2100 & 17,7 & 12,3 & 9,3 & 5,8 & 3,8 & 1,8 & 1,1 & 24 & 20 & $\begin{array}{l}\text { seção de avaliação onde foi } \\
\text { executado } 11 \mathrm{~cm} \text { - EME }\end{array}$ \\
\hline 170,400 & 4100 & 32,5 & 22,9 & 17,8 & 11,6 & 7,6 & 3,8 & 2,3 & 24 & 20 & $\begin{array}{l}\text { seção de avaliação onde foi } \\
\text { executado } 11 \mathrm{~cm} \text { - EME }\end{array}$ \\
\hline 170,400 & 6500 & 44,4 & 31,7 & 25,1 & 16,8 & 11,3 & 5,3 & 3,2 & 24 & 20 & $\begin{array}{l}\text { seção de avaliação onde foi } \\
\text { executado } 11 \mathrm{~cm} \text { - EME }\end{array}$ \\
\hline 170,389 & 2100 & 17,9 & 12,5 & 9,1 & 5,5 & 3,6 & 1,9 & 1,3 & 25 & 20 & $\begin{array}{l}\text { seção de avaliação onde foi } \\
\text { executado } 8 \mathrm{~cm} \text { - EME }\end{array}$ \\
\hline 170,389 & 4100 & 33,5 & 24,8 & 18,6 & 11,8 & 7,8 & 4,5 & 3,0 & 25 & 20 & $\begin{array}{l}\text { seção de avaliação onde foi } \\
\text { executado } 8 \mathrm{~cm} \text { - EME }\end{array}$ \\
\hline 170,389 & 6500 & 46,4 & 34,9 & 26,9 & 17,5 & 11,8 & 6,2 & 4,8 & 25 & 20 & $\begin{array}{l}\text { seção de avaliação onde foi } \\
\text { executado } 8 \mathrm{~cm} \text { - EME }\end{array}$ \\
\hline 170,380 & 2100 & 11,4 & 6,1 & 3,8 & 2,1 & 1,6 & 1,4 & 0,9 & 26 & 20 & $\begin{array}{l}\text { seção de avaliação onde foi } \\
\text { executado } 8 \mathrm{~cm} \text { - EME }\end{array}$ \\
\hline 170,380 & 4100 & 18,8 & 10,7 & 7,2 & 4,4 & 3,1 & 2,5 & 2,4 & 26 & 20 & $\begin{array}{l}\text { seção de avaliação onde foi } \\
\text { executado } 8 \mathrm{~cm} \text { - EME }\end{array}$ \\
\hline 170,380 & 6500 & 25,5 & 15,2 & 10,3 & 6,7 & 5,0 & 4,0 & 3,2 & 26 & 20 & $\begin{array}{l}\text { seção de avaliação onde foi } \\
\text { executado } 8 \mathrm{~cm} \text { - EME }\end{array}$ \\
\hline 170,370 & 2100 & 15,9 & 7,4 & 4,8 & 3,2 & 2,9 & 2,2 & 2,0 & 25 & 20 & $\begin{array}{l}\text { seção de avaliação onde foi } \\
\text { executado } 8 \mathrm{~cm} \text { - EME }\end{array}$ \\
\hline 170,370 & 4100 & 27,5 & 13,6 & 9,1 & 6,4 & 5,4 & 4,2 & 3,6 & 25 & 20 & $\begin{array}{l}\text { seção de avaliação onde foi } \\
\text { executado } 8 \mathrm{~cm} \text { - EME }\end{array}$ \\
\hline 170,370 & 6500 & 38,3 & 19,8 & 14,0 & 10,2 & 8,6 & 6,9 & 5,9 & 25 & 20 & $\begin{array}{l}\text { seção de avaliação onde foi } \\
\text { executado } 8 \mathrm{~cm} \text { - EME }\end{array}$ \\
\hline 170,358 & 2100 & 21,6 & 13,4 & 9,6 & 6,0 & 3,9 & 2,6 & 1,6 & 26 & 20 & $\begin{array}{l}\text { seção de avaliação onde foi } \\
\text { executado } 8 \mathrm{~cm} \text { - EME }\end{array}$ \\
\hline 170,358 & 4100 & 37,9 & 24,6 & 18,2 & 11,8 & 7,9 & 5,2 & 2,1 & 26 & 20 & $\begin{array}{l}\text { seção de avaliação onde foi } \\
\text { executado } 8 \mathrm{~cm} \text { - EME }\end{array}$ \\
\hline 170,358 & 6500 & 51,5 & 34,1 & 25,7 & 17,5 & 11,9 & 7,4 & 4,7 & 26 & 20 & $\begin{array}{l}\text { seção de avaliação onde foi } \\
\text { executado } 8 \mathrm{~cm} \text { - EME }\end{array}$ \\
\hline 170,347 & 2100 & 18,7 & 12,9 & 10,0 & 6,8 & 4,9 & 2,9 & 2,4 & 25 & 20 & $\begin{array}{l}\text { seção de avaliação onde foi } \\
\text { executado } 8 \mathrm{~cm} \text { - EME }\end{array}$ \\
\hline 170,347 & 4100 & 34,6 & 25,1 & 19,7 & 14,1 & 10,4 & 6,6 & 4,7 & 25 & 20 & $\begin{array}{l}\text { seção de avaliação onde foi } \\
\text { executado } 8 \mathrm{~cm} \text { - EME }\end{array}$ \\
\hline 170,347 & 6500 & 47,6 & 35,3 & 28,6 & 21,3 & 15,8 & 11,2 & 8,2 & 25 & 20 & $\begin{array}{l}\text { seção de avaliação onde foi } \\
\text { executado } 8 \mathrm{~cm} \text { - EME }\end{array}$ \\
\hline 170,337 & 2100 & 22,2 & 15,2 & 11,6 & 7,7 & 5,4 & 2,7 & 2,5 & 24 & 20 & $\begin{array}{l}\text { seção de avaliação onde foi } \\
\text { executado } 8 \mathrm{~cm} \text { - EME }\end{array}$ \\
\hline 170,337 & 4100 & 39,6 & 28,7 & 22,4 & 15,8 & 11,0 & 7,1 & 4,6 & 24 & 20 & $\begin{array}{l}\text { seção de avaliação onde foi } \\
\text { executado } 8 \mathrm{~cm} \text { - EME }\end{array}$ \\
\hline 170,337 & 6500 & 54,9 & 40,4 & 32,6 & 23,6 & 16,7 & 11,4 & 7,6 & 24 & 20 & $\begin{array}{l}\text { seção de avaliação onde foi } \\
\text { executado } 8 \mathrm{~cm} \text { - EME }\end{array}$ \\
\hline 170,319 & 2100 & 24,3 & 17,1 & 13,3 & 9,1 & 6,4 & 3,5 & 2,3 & 25 & 20 & $\begin{array}{l}\text { seção de avaliação onde foi } \\
\text { executado } 8 \mathrm{~cm} \text { - EME }\end{array}$ \\
\hline 170,319 & 4100 & 44,5 & 32,6 & 26,1 & 18,4 & 13,3 & 8,4 & 4,6 & 25 & 20 & $\begin{array}{l}\text { seção de avaliação onde foi } \\
\text { executado } 8 \mathrm{~cm} \text { - EME }\end{array}$ \\
\hline 170,319 & 6500 & 58,1 & 43,4 & 35,2 & 25,7 & 18,8 & 12,0 & 6,2 & 25 & 20 & $\begin{array}{l}\text { seção de avaliação onde foi } \\
\text { executado } 8 \mathrm{~cm} \text { - EME }\end{array}$ \\
\hline 170,309 & 2100 & 23,8 & 16,5 & 12,8 & 8,7 & 6,1 & 3,1 & 2,8 & 24 & 20 & $\begin{array}{l}\text { seção de avaliação onde foi } \\
\text { executado } 8 \mathrm{~cm} \text { - EME }\end{array}$ \\
\hline 170,309 & 4100 & 46,1 & 33,4 & 26,7 & 18,7 & 13,3 & 9,1 & 5,9 & 24 & 20 & $\begin{array}{l}\text { seção de avaliação onde foi } \\
\text { executado } 8 \mathrm{~cm} \text { - EME }\end{array}$ \\
\hline 170,309 & 6500 & 63,3 & 46,0 & 38,4 & 27,9 & 20,1 & 13,3 & 7,8 & 24 & 20 & $\begin{array}{l}\text { seção de avaliação onde foi } \\
\text { executado } 8 \mathrm{~cm} \text { - EME }\end{array}$ \\
\hline 170,299 & 2100 & 23,7 & 16,0 & 12,6 & 8,5 & 6,3 & 3,8 & 2,3 & 24 & 20 & $\begin{array}{l}\text { seção de avaliação onde foi } \\
\text { executado } 8 \mathrm{~cm} \text { - EME }\end{array}$ \\
\hline 170,299 & 4100 & 43,3 & 31,4 & 25,0 & 17,8 & 13,2 & 8,3 & 6,3 & 24 & 20 & $\begin{array}{l}\text { seção de avaliação onde foi } \\
\text { executado } 8 \mathrm{~cm} \text { - EME }\end{array}$ \\
\hline 170,299 & 6500 & 60,8 & 45,4 & 37,0 & 27,2 & 20,4 & 13,5 & 10,4 & 24 & 20 & $\begin{array}{l}\text { seção de avaliação onde foi } \\
\text { executado } 8 \mathrm{~cm} \text { - EME }\end{array}$ \\
\hline
\end{tabular}


Rodovia: Presidente Dutra - BR-116 Pista: Norte (São Paulo) Sentido: Rio de Janeiro
Faixa: 2

Data: $19 / 10 / 2010$

Trecho: Topo da Camada de Gap Graded

\begin{tabular}{|c|c|c|c|c|c|c|c|c|c|c|c|}
\hline \multirow{2}{*}{$\mathrm{km}$} & \multirow{2}{*}{$\begin{array}{r}\text { Força } \\
\text { (kgf) }\end{array}$} & \multicolumn{7}{|c|}{ Deflexões $(0,01 \mathrm{~mm})$} & \multirow{2}{*}{$\begin{array}{l}\text { Temp. } \\
\operatorname{Ar}\left({ }^{\circ} \mathrm{C}\right)\end{array}$} & \multirow{2}{*}{$\begin{array}{l}\text { Temp. } \\
\text { Pav. }\left({ }^{\circ} \mathrm{C}\right)\end{array}$} & \multirow{2}{*}{ Obs } \\
\hline & & D0 & D200 & D300 & D450 & D600 & D900 & D1200 & & & \\
\hline 170,285 & 2100 & 24,3 & 17,4 & 14,0 & 9,8 & 7,4 & 4,0 & 3,5 & 23 & 20 & $\begin{array}{l}\text { seção de avaliação onde foi } \\
\text { executado } 8 \mathrm{~cm} \text { - EME }\end{array}$ \\
\hline 170,285 & 4100 & 43,6 & 32,8 & 26,7 & 19,6 & 14,5 & 10,6 & 7,2 & 23 & 20 & $\begin{array}{l}\text { seção de avaliação onde foi } \\
\text { executado } 8 \mathrm{~cm} \text { - EME }\end{array}$ \\
\hline 170,285 & 6500 & 60,3 & 45,4 & 38,9 & 29,4 & 22,3 & 15,2 & 10,7 & 23 & 20 & $\begin{array}{l}\text { seção de avaliação onde foi } \\
\text { executado } 8 \mathrm{~cm} \text { - EME }\end{array}$ \\
\hline 170,280 & 2100 & 23,8 & 16,6 & 13,1 & 9,0 & 6,7 & 3,7 & 3,3 & 23 & 20 & $\begin{array}{l}\text { seção de avaliação onde foi } \\
\text { executado } 8 \mathrm{~cm} \text { - EME }\end{array}$ \\
\hline 170,280 & 4100 & 44,6 & 32,7 & 26,5 & 19,2 & 14,2 & 10,0 & 6,4 & 23 & 20 & $\begin{array}{l}\text { seção de avaliação onde foi } \\
\text { executado } 8 \mathrm{~cm} \text { - EME }\end{array}$ \\
\hline 170,280 & 6500 & 62,9 & 46,5 & 39,4 & 29,3 & 22,1 & 15,0 & 11,1 & 23 & 20 & $\begin{array}{l}\text { seção de avaliação onde foi } \\
\text { executado } 8 \mathrm{~cm} \text { - EME }\end{array}$ \\
\hline 170,270 & 2100 & 21,4 & 14,9 & 11,4 & 7,9 & 5,9 & 3,3 & 1,5 & 23 & 20 & $\begin{array}{l}\text { seção de avaliação onde foi } \\
\text { executado } 8 \mathrm{~cm} \text { - EME }\end{array}$ \\
\hline 170,270 & 4100 & 39,7 & 28,7 & 22,6 & 15,2 & 10,9 & 6,7 & 2,2 & 23 & 20 & $\begin{array}{l}\text { seção de avaliação onde foi } \\
\text { executado } 8 \mathrm{~cm} \text { - EME }\end{array}$ \\
\hline 170,270 & 6500 & 53,7 & 40,4 & 32,6 & 23,7 & 17,3 & 11,1 & 8,2 & 23 & 20 & $\begin{array}{l}\text { seção de avaliação onde foi } \\
\text { executado } 8 \mathrm{~cm} \text { - EME }\end{array}$ \\
\hline 170,260 & 2100 & 21,1 & 15,1 & 11,7 & 8,0 & 5,8 & 3,7 & 0,5 & 23 & 20 & $\begin{array}{l}\text { seção de avaliação onde foi } \\
\text { executado } 8 \mathrm{~cm} \text { - EME }\end{array}$ \\
\hline 170,260 & 4100 & 39,3 & 29,5 & 23,7 & 16,5 & 12,1 & 8,1 & 4,1 & 23 & 20 & $\begin{array}{l}\text { seção de avaliação onde foi } \\
\text { executado } 8 \mathrm{~cm} \text { - EME }\end{array}$ \\
\hline 170,260 & 6500 & 53,7 & 41,6 & 34,2 & 25,1 & 18,8 & 13,0 & 8,6 & 23 & 20 & $\begin{array}{l}\text { seção de avaliação onde foi } \\
\text { executado } 8 \mathrm{~cm} \text { - EME }\end{array}$ \\
\hline 170,248 & 2100 & 21,9 & 16,1 & 12,5 & 8,4 & 6,1 & 3,5 & 2,8 & 23 & 20 & $\begin{array}{l}\text { seção de avaliação onde foi } \\
\text { executado } 8 \mathrm{~cm} \text { - EME }\end{array}$ \\
\hline 170,248 & 4100 & 43,2 & 33,1 & 26,3 & 18,5 & 13,3 & 8,5 & 4,9 & 23 & 20 & $\begin{array}{l}\text { seção de avaliação onde foi } \\
\text { executado } 8 \mathrm{~cm} \text { - EME }\end{array}$ \\
\hline 170,248 & 6500 & 62,4 & 48,9 & 39,9 & 29,0 & 21,4 & 13,4 & 10,7 & 23 & 20 & $\begin{array}{l}\text { seção de avaliação onde foi } \\
\text { executado } 8 \mathrm{~cm} \text { - EME }\end{array}$ \\
\hline 170,240 & 2100 & 15,7 & 11,9 & 9,7 & 7,1 & 5,6 & 3,5 & 3,0 & 23 & 20 & $\begin{array}{l}\text { seção de avaliação onde foi } \\
\text { executado } 8 \mathrm{~cm} \text { - EME }\end{array}$ \\
\hline 170,240 & 4100 & 30,4 & 23,9 & 20,0 & 14,8 & 11,5 & 8,1 & 6,0 & 23 & 20 & $\begin{array}{l}\text { seção de avaliação onde foi } \\
\text { executado } 8 \mathrm{~cm} \text { - EME }\end{array}$ \\
\hline 170,240 & 6500 & 44,0 & 35,2 & 29,7 & 22,6 & 17,7 & 12,5 & 9,7 & 23 & 20 & $\begin{array}{l}\text { seção de avaliação onde foi } \\
\text { executado } 8 \mathrm{~cm} \text { - EME }\end{array}$ \\
\hline 170,229 & 2100 & 22,0 & 15,6 & 12,1 & 8,4 & 6,0 & 3,2 & 2,4 & 23 & 20 & $\begin{array}{l}\text { seção de avaliação onde foi } \\
\text { executado } 8 \mathrm{~cm} \text { - EME }\end{array}$ \\
\hline 170,229 & 4100 & 41,5 & 31,1 & 24,7 & 17,4 & 12,5 & 8,1 & 5,7 & 23 & 20 & $\begin{array}{l}\text { seção de avaliação onde foi } \\
\text { executado } 8 \mathrm{~cm} \text { - EME }\end{array}$ \\
\hline 170,229 & 6500 & 58,8 & 45,0 & 36,6 & 26,6 & 19,5 & 12,7 & 10,1 & 23 & 20 & $\begin{array}{l}\text { seção de avaliação onde foi } \\
\text { executado } 8 \mathrm{~cm} \text { - EME }\end{array}$ \\
\hline 170,217 & 2100 & 22,9 & 16,8 & 13,5 & 9,0 & 6,4 & 3,9 & 1,6 & 22 & 20 & $\begin{array}{l}\text { seção de avaliação onde foi } \\
\text { executado } 8 \mathrm{~cm} \text { - EME }\end{array}$ \\
\hline 170,217 & 4100 & 42,6 & 32,5 & 26,4 & 18,3 & 13,2 & 8,4 & 4,7 & 22 & 20 & $\begin{array}{l}\text { seção de avaliação onde foi } \\
\text { executado } 8 \mathrm{~cm} \text { - EME }\end{array}$ \\
\hline 170,217 & 6500 & 60,0 & 46,7 & 38,7 & 27,9 & 20,6 & 13,3 & 8,1 & 22 & 20 & $\begin{array}{l}\text { seção de avaliação onde foi } \\
\text { executado } 8 \mathrm{~cm} \text { - EME }\end{array}$ \\
\hline 170,209 & 2100 & 24,5 & 18,7 & 15,0 & 10,5 & 7,3 & 4,8 & 2,8 & 22 & 20 & $\begin{array}{l}\text { seção de avaliação onde foi } \\
\text { executado } 8 \mathrm{~cm} \text { - EME }\end{array}$ \\
\hline 170,209 & 4100 & 47,8 & 37,6 & 30,6 & 21,8 & 15,4 & 9,1 & 5,3 & 22 & 20 & $\begin{array}{l}\text { seção de avaliação onde foi } \\
\text { executado } 8 \mathrm{~cm} \text { - EME }\end{array}$ \\
\hline 170,209 & 6500 & 67,4 & 49,4 & 44,1 & 32,6 & 23,4 & 13,7 & 8,1 & 22 & 20 & $\begin{array}{l}\text { seção de avaliação onde foi } \\
\text { executado } 8 \mathrm{~cm} \text { - EME }\end{array}$ \\
\hline 170,200 & 2100 & 26,4 & 19,6 & 15,3 & 10,3 & 7,2 & 4,3 & 3,0 & 22 & 20 & $\begin{array}{l}\text { seção de avaliação onde foi } \\
\text { executado } 8 \mathrm{~cm} \text { - EME }\end{array}$ \\
\hline 170,200 & 4100 & 49,1 & 37,9 & 30,3 & 21,0 & 14,9 & 9,5 & 6,7 & 22 & 20 & $\begin{array}{l}\text { seção de avaliação onde foi } \\
\text { executado } 8 \mathrm{~cm} \text { - EME }\end{array}$ \\
\hline 170,200 & 6500 & 68,7 & 50,1 & 44,0 & 31,6 & 23,3 & 14,4 & 8,3 & 22 & 20 & $\begin{array}{l}\text { seção de avaliação onde foi } \\
\text { executado } 8 \mathrm{~cm} \text { - EME }\end{array}$ \\
\hline 170,189 & 2100 & 17,8 & 13,6 & 11,5 & 8,7 & 6,9 & 4,6 & 3,0 & 22 & 20 & $\begin{array}{l}\text { seção de avaliação onde foi } \\
\text { executado } 8 \mathrm{~cm} \text { - EME }\end{array}$ \\
\hline 170,189 & 4100 & 34,6 & 27,6 & 23,7 & 18,3 & 14,5 & 10,1 & 6,8 & 22 & 20 & $\begin{array}{l}\text { seção de avaliação onde foi } \\
\text { executado } 8 \mathrm{~cm} \text { - EME }\end{array}$ \\
\hline 170,189 & 6500 & 51,3 & 41,2 & 35,7 & 27,8 & 22,5 & 15,7 & 10,0 & 22 & 20 & $\begin{array}{l}\text { seção de avaliação onde foi } \\
\text { executado } 8 \mathrm{~cm} \text { - EME }\end{array}$ \\
\hline 170,180 & 2100 & 18,9 & 14,0 & 11,8 & 8,3 & 6,5 & 4,5 & 3,4 & 21 & 20 & $\begin{array}{l}\text { seção de avaliação onde foi } \\
\text { executado } 8 \mathrm{~cm} \text { - EME }\end{array}$ \\
\hline 170,180 & 4100 & 39,9 & 31,0 & 25,9 & 19,2 & 15,0 & 10,2 & 6,9 & 21 & 20 & $\begin{array}{l}\text { seção de avaliação onde foi } \\
\text { executado } 8 \mathrm{~cm} \text { - EME }\end{array}$ \\
\hline
\end{tabular}


Rodovia: Presidente Dutra - BR-116 Pista: Norte (São Paulo) Sentido: Rio de Janeiro
Faixa: 2

Data: $19 / 10 / 2010$

Trecho: Topo da Camada de Gap Graded

\begin{tabular}{|c|c|c|c|c|c|c|c|c|c|c|c|}
\hline \multirow{2}{*}{$\mathrm{km}$} & \multirow{2}{*}{$\begin{array}{r}\text { Força } \\
\text { (kgf) }\end{array}$} & \multicolumn{7}{|c|}{ Deflexões $(0,01 \mathrm{~mm})$} & \multirow{2}{*}{$\begin{array}{l}\text { Temp. } \\
\operatorname{Ar}\left({ }^{\circ} \mathrm{C}\right)\end{array}$} & \multirow{2}{*}{$\begin{array}{l}\text { Temp. } \\
\text { Pav. }\left({ }^{\circ} \mathrm{C}\right)\end{array}$} & \multirow{2}{*}{ Obs } \\
\hline & & D0 & D200 & D300 & D450 & D600 & D900 & D1200 & & & \\
\hline 170,180 & 6500 & 60,8 & 48,0 & 41,1 & 30,9 & 24,3 & 15,7 & 11,2 & 21 & 20 & $\begin{array}{l}\text { seção de avaliação onde foi } \\
\text { executado } 8 \mathrm{~cm} \text { - EME }\end{array}$ \\
\hline 170,169 & 2100 & 12,5 & 8,9 & 7,2 & 5,6 & 4,7 & 3,6 & 2,9 & 21 & 20 & $\begin{array}{l}\text { seção de avaliação onde foi } \\
\text { executado } 8 \mathrm{~cm} \text { - CAP } 30 / 45\end{array}$ \\
\hline 170,169 & 4100 & 24,1 & 18,0 & 15,2 & 12,1 & 10,1 & 8,3 & 6,9 & 21 & 20 & $\begin{array}{l}\text { seção de avaliação onde foi } \\
\text { executado } 8 \mathrm{~cm} \text { - CAP } 30 / 45\end{array}$ \\
\hline 170,169 & 6500 & 34,8 & 26,6 & 22,7 & 18,6 & 15,4 & 12,2 & 8,5 & 21 & 20 & $\begin{array}{l}\text { seção de avaliação onde foi } \\
\text { executado } 8 \mathrm{~cm} \text { - CAP } 30 / 45\end{array}$ \\
\hline 170,160 & 2100 & 14,6 & 9,4 & 6,9 & 4,6 & 3,6 & 3,0 & 2,9 & 21 & 20 & $\begin{array}{l}\text { seção de avaliação onde foi } \\
\text { executado } 8 \mathrm{~cm} \text { - CAP } 30 / 45\end{array}$ \\
\hline 170,160 & 4100 & 25,3 & 17,1 & 13,1 & 9,0 & 7,0 & 5,6 & 3,9 & 21 & 20 & $\begin{array}{l}\text { seção de avaliação onde foi } \\
\text { executado } 8 \mathrm{~cm} \text { - CAP } 30 / 45\end{array}$ \\
\hline 170,160 & 6500 & 35,8 & 25,0 & 19,6 & 14,2 & 11,2 & 8,4 & 5,5 & 21 & 20 & $\begin{array}{l}\text { seção de avaliação onde foi } \\
\text { executado } 8 \mathrm{~cm} \text { - CAP } 30 / 45\end{array}$ \\
\hline 170,150 & 2100 & 10,4 & 7,3 & 5,8 & 4,3 & 3,4 & 2,8 & 2,4 & 22 & 20 & $\begin{array}{l}\text { seção de avaliação onde foi } \\
\text { executado } 8 \mathrm{~cm} \text { - CAP } 30 / 45\end{array}$ \\
\hline 170,150 & 4100 & 18,2 & 13,2 & 10,5 & 8,0 & 6,4 & 5,3 & 3,8 & 22 & 20 & $\begin{array}{l}\text { seção de avaliação onde foi } \\
\text { executado } 8 \mathrm{~cm} \text { - CAP } 30 / 45\end{array}$ \\
\hline 170,150 & 6500 & 25,4 & 18,4 & 15,0 & 11,3 & 9,3 & 7,8 & 5,8 & 22 & 20 & $\begin{array}{l}\text { seção de avaliação onde foi } \\
\text { executado } 8 \mathrm{~cm} \text { - CAP } 30 / 45\end{array}$ \\
\hline 170,140 & 2100 & 18,1 & 12,6 & 9,1 & 5,7 & 3,8 & 2,0 & 0,5 & 22 & 20 & $\begin{array}{l}\text { seção de avaliação onde foi } \\
\text { executado 8cm - CAP } 30 / 45\end{array}$ \\
\hline 170,140 & 4100 & 32,0 & 23,4 & 17,9 & 11,7 & 7,9 & 4,8 & 3,5 & 22 & 20 & $\begin{array}{l}\text { seção de avaliação onde foi } \\
\text { executado } 8 \mathrm{~cm} \text { - CAP } 30 / 45\end{array}$ \\
\hline 170,140 & 6500 & 45,2 & 34,3 & 26,6 & 18,1 & 12,4 & 7,2 & 5,3 & 22 & 20 & $\begin{array}{l}\text { seção de avaliação onde foi } \\
\text { executado } 8 \mathrm{~cm} \text { - CAP } 30 / 45\end{array}$ \\
\hline 170,130 & 2100 & 13,9 & 9,4 & 7,4 & 5,0 & 3,8 & 2,3 & 1,5 & 21 & 20 & $\begin{array}{l}\text { seção de avaliação onde foi } \\
\text { executado } 8 \mathrm{~cm} \text { - CAP } 30 / 45\end{array}$ \\
\hline 170,130 & 4100 & 27,3 & 19,8 & 15,9 & 11,3 & 8,2 & 5,2 & 2,8 & 21 & 20 & $\begin{array}{l}\text { seção de avaliação onde foi } \\
\text { executado } 8 \mathrm{~cm} \text { - CAP } 30 / 45\end{array}$ \\
\hline 170,130 & 6500 & 39,8 & 29,6 & 24,2 & 17,8 & 13,3 & 8,3 & 5,5 & 21 & 20 & $\begin{array}{l}\text { seção de avaliação onde foi } \\
\text { executado } 8 \mathrm{~cm} \text { - CAP } 30 / 45\end{array}$ \\
\hline 170,120 & 2100 & 14,9 & 9,0 & 6,2 & 3,9 & 2,6 & 1,8 & 1,2 & 22 & 20 & $\begin{array}{l}\text { seção de avaliação onde foi } \\
\text { executado } 8 \mathrm{~cm} \text { - CAP } 30 / 45\end{array}$ \\
\hline 170,120 & 4100 & 27,1 & 17,6 & 12,4 & 8,0 & 5,3 & 3,7 & 2,5 & 22 & 20 & $\begin{array}{l}\text { seção de avaliação onde foi } \\
\text { executado } 8 \mathrm{~cm} \text { - CAP } 30 / 45\end{array}$ \\
\hline 170,120 & 6500 & 39,1 & 26,3 & 19,5 & 12,7 & 8,8 & 5,3 & 3,2 & 22 & 20 & $\begin{array}{l}\text { seção de avaliação onde foi } \\
\text { executado 8cm - CAP } 30 / 45\end{array}$ \\
\hline 170,109 & 2100 & 21,0 & 12,3 & 8,4 & 4,7 & 3,1 & 1,7 & 1,2 & 22 & 20 & $\begin{array}{l}\text { seção de avaliação onde foi } \\
\text { executado } 8 \mathrm{~cm} \text { - CAP } 30 / 45\end{array}$ \\
\hline 170,109 & 4100 & 37,1 & 23,6 & 16,6 & 10,2 & 6,5 & 4,0 & 1,9 & 22 & 20 & $\begin{array}{l}\text { seção de avaliação onde foi } \\
\text { executado } 8 \mathrm{~cm} \text { - CAP } 30 / 45\end{array}$ \\
\hline 170,109 & 6500 & 51,0 & 33,1 & 24,3 & 15,1 & 10,0 & 5,7 & 3,5 & 22 & 20 & $\begin{array}{l}\text { seção de avaliação onde foi } \\
\text { executado } 8 \mathrm{~cm} \text { - CAP } 30 / 45\end{array}$ \\
\hline 170,100 & 2100 & 15,1 & 10,0 & 7,6 & 4,9 & 3,4 & 2,0 & 1,5 & 22 & 20 & $\begin{array}{l}\text { seção de avaliação onde foi } \\
\text { executado } 8 \mathrm{~cm} \text { - CAP } 30 / 45\end{array}$ \\
\hline 170,100 & 4100 & 27,0 & 19,1 & 14,9 & 10,1 & 7,0 & 4,3 & 2,3 & 22 & 20 & $\begin{array}{l}\text { seção de avaliação onde foi } \\
\text { executado } 8 \mathrm{~cm} \text { - CAP } 30 / 45\end{array}$ \\
\hline 170,100 & 6500 & 40,6 & 29,4 & 23,3 & 16,0 & 11,2 & 6,8 & 3,3 & 22 & 20 & $\begin{array}{l}\text { seção de avaliação onde foi } \\
\text { executado } 8 \mathrm{~cm} \text { - CAP } 30 / 45\end{array}$ \\
\hline 170,080 & 2100 & 21,0 & 13,4 & 9,4 & 5,4 & 3,5 & 3,0 & 1,9 & 22 & 20 & $\begin{array}{l}\text { seção de avaliação onde foi } \\
\text { executado } 8 \mathrm{~cm} \text { - CAP } 30 / 45\end{array}$ \\
\hline 170,080 & 4100 & 37,0 & 25,0 & 18,3 & 11,5 & 7,2 & 3,6 & 2,9 & 22 & 20 & $\begin{array}{l}\text { seção de avaliação onde foi } \\
\text { executado } 8 \mathrm{~cm} \text { - CAP } 30 / 45\end{array}$ \\
\hline 170,080 & 6500 & 50,6 & 35,3 & 26,6 & 17,3 & 11,2 & 5,1 & 2,3 & 22 & 20 & $\begin{array}{l}\text { seção de avaliação onde foi } \\
\text { executado } 8 \mathrm{~cm} \text { - CAP } 30 / 45\end{array}$ \\
\hline 170,061 & 2100 & 27,7 & 19,2 & 13,8 & 8,4 & 5,3 & 2,7 & 0,5 & 22 & 20 & $\begin{array}{l}\text { seção de avaliação onde foi } \\
\text { executado } 8 \mathrm{~cm} \text { - CAP } 30 / 45\end{array}$ \\
\hline 170,061 & 4100 & 48,2 & 34,1 & 25,1 & 16,1 & 10,1 & 4,7 & 2,7 & 22 & 20 & $\begin{array}{l}\text { seção de avaliação onde foi } \\
\text { executado } 8 \mathrm{~cm} \text { - CAP } 30 / 45\end{array}$ \\
\hline 170,061 & 6500 & 63,8 & 46,0 & 34,4 & 22,7 & 14,8 & 7,1 & 3,7 & 22 & 20 & $\begin{array}{l}\text { seção de avaliação onde foi } \\
\text { executado } 8 \mathrm{~cm} \text { - CAP } 30 / 45\end{array}$ \\
\hline 170,050 & 2100 & 21,4 & 14,5 & 10,7 & 7,1 & 4,6 & 3,0 & 1,1 & 21 & 20 & $\begin{array}{l}\text { seção de avaliação onde foi } \\
\text { executado } 8 \mathrm{~cm} \text { - CAP } 30 / 45\end{array}$ \\
\hline 170,050 & 4100 & 40,8 & 28,9 & 22,3 & 14,9 & 9,9 & 5,4 & 3,4 & 21 & 20 & $\begin{array}{l}\text { seção de avaliação onde foi } \\
\text { executado } 8 \mathrm{~cm} \text { - CAP } 30 / 45\end{array}$ \\
\hline 170,050 & 6500 & 57,1 & 41,1 & 32,5 & 22,4 & 15,2 & 8,5 & 5,3 & 21 & 20 & $\begin{array}{l}\text { seção de avaliação onde foi } \\
\text { executado } 8 \mathrm{~cm} \text { - CAP } 30 / 45\end{array}$ \\
\hline 170,039 & 2100 & 23,1 & 15,0 & 11,0 & 7,1 & 4,9 & 2,6 & 1,3 & 21 & 20 & $\begin{array}{l}\text { seção de avaliação onde foi } \\
\text { executado } 8 \mathrm{~cm} \text { - CAP } 30 / 45\end{array}$ \\
\hline
\end{tabular}


Levantamento Deflectométrico com FWD - Topo da Camada de Gap-Graded - $1^{\circ}$ Levantamento (ESTAGIO 3)

Rodovia: Presidente Dutra - BR-116

Pista: Norte (São Paulo)

Sentido: Rio de Janeiro
Faixa: 2

Data: $19 / 10 / 2010$

Trecho: Topo da Camada de Gap Graded

\begin{tabular}{|c|c|c|c|c|c|c|c|c|c|c|c|}
\hline \multirow{2}{*}{$\mathrm{km}$} & \multirow{2}{*}{$\begin{array}{r}\text { Força } \\
\text { (kgf) }\end{array}$} & \multicolumn{7}{|c|}{ Deflexões $(0,01 \mathrm{~mm})$} & \multirow{2}{*}{$\begin{array}{l}\text { Temp. } \\
\operatorname{Ar}\left({ }^{\circ} \mathrm{C}\right)\end{array}$} & \multirow{2}{*}{$\begin{array}{l}\text { Temp. } \\
\text { Pav. }\left({ }^{\circ} \mathrm{C}\right)\end{array}$} & \multirow{2}{*}{ Obs } \\
\hline & & D0 & D200 & D300 & D450 & D600 & D900 & D1200 & & & \\
\hline 170,039 & 4100 & 40,9 & 28,4 & 21,7 & 14,9 & 10,5 & 6,3 & 3,7 & 21 & 20 & $\begin{array}{l}\text { seção de avaliação onde foi } \\
\text { executado } 8 \mathrm{~cm} \text { - CAP } 30 / 45\end{array}$ \\
\hline 170,039 & 6500 & 58,7 & 42,0 & 32,8 & 23,0 & 16,5 & 9,5 & 5,9 & 21 & 20 & $\begin{array}{l}\text { seção de avaliação onde foi } \\
\text { executado } 8 \mathrm{~cm} \text { - CAP } 30 / 45\end{array}$ \\
\hline 170,030 & 2100 & 22,6 & 15,5 & 11,7 & 7,4 & 5,1 & 3,1 & 0,6 & 21 & 20 & $\begin{array}{l}\text { seção de avaliação onde foi } \\
\text { executado } 8 \mathrm{~cm} \text { - CAP } 30 / 45\end{array}$ \\
\hline 170,030 & 4100 & 44,5 & 32,3 & 24,9 & 16,8 & 11,3 & 6,6 & 3,5 & 21 & 20 & $\begin{array}{l}\text { seção de avaliação onde foi } \\
\text { executado } 8 \mathrm{~cm} \text { - CAP } 30 / 45\end{array}$ \\
\hline 170,030 & 6500 & 63,3 & 46,9 & 36,9 & 25,4 & 17,8 & 10,2 & 5,0 & 21 & 20 & $\begin{array}{l}\text { seção de avaliação onde foi } \\
\text { executado } 8 \mathrm{~cm} \text { - CAP } 30 / 45\end{array}$ \\
\hline 170,026 & 2100 & 13,3 & 10,0 & 8,1 & 5,9 & 4,5 & 3,2 & 2,8 & 21 & 20 & $\begin{array}{l}\text { seção de avaliação onde foi } \\
\text { executado } 8 \mathrm{~cm} \text { - CAP } 30 / 45\end{array}$ \\
\hline 170,026 & 4100 & 23,7 & 17,9 & 14,7 & 10,9 & 8,1 & 5,3 & 3,8 & 21 & 20 & $\begin{array}{l}\text { seção de avaliação onde foi } \\
\text { executado } 8 \mathrm{~cm} \text { - CAP } 30 / 45\end{array}$ \\
\hline 170,026 & 6500 & 34,2 & 26,3 & 21,7 & 16,2 & 12,3 & 8,1 & 5,9 & 21 & 20 & $\begin{array}{l}\text { seção de avaliação onde foi } \\
\text { executado } 8 \mathrm{~cm} \text { - CAP } 30 / 45\end{array}$ \\
\hline
\end{tabular}


Rodovia: Presidente Dutra - BR-116

Pista: Norte (São Paulo)

Sentido: Rio de Janeiro
Faixa: 2

Data: $26 / 04 / 2011$

Trecho: Topo da Camada de Gap Graded

\begin{tabular}{|c|c|c|c|c|c|c|c|c|c|c|c|}
\hline \multirow{2}{*}{$\mathrm{km}$} & \multirow{2}{*}{$\begin{array}{r}\text { Força } \\
\text { (kgf) }\end{array}$} & \multicolumn{7}{|c|}{ Deflexões $(0,01 \mathrm{~mm})$} & \multirow{2}{*}{$\begin{array}{l}\text { Temp. } \\
\operatorname{Ar}\left({ }^{\circ} \mathrm{C}\right)\end{array}$} & \multirow{2}{*}{$\begin{array}{l}\text { Temp. } \\
\text { Pav. }\left({ }^{\circ} \mathrm{C}\right)\end{array}$} & \multirow{2}{*}{ Obs } \\
\hline & & D0 & D200 & D300 & D450 & D600 & D900 & D1200 & & & \\
\hline 171,000 & 2100 & 8,7 & 7,7 & 7,1 & 6,4 & 5,7 & 4,4 & 3,3 & 21 & 20 & $\begin{array}{l}\text { seção de avaliação onde foi } \\
\text { executada RECONSTRUÇÃOO }\end{array}$ \\
\hline 171,000 & 4100 & 16,5 & 14,8 & 13,6 & 12,2 & 10,9 & 8,8 & 6,6 & 21 & 20 & $\begin{array}{l}\text { seção de avaliação onde foi } \\
\text { executada RECONSTRUÇÃO }\end{array}$ \\
\hline 171,000 & 6500 & 24,5 & 22,4 & 20,9 & 18,9 & 16,8 & 13,6 & 10,6 & 21 & 20 & $\begin{array}{l}\text { seção de avaliação onde foi } \\
\text { executada RECONSTRUÇÃO }\end{array}$ \\
\hline 170,990 & 2100 & 9,0 & 7,5 & 7,0 & 5,8 & 5,0 & 3,8 & 3,1 & 21 & 20 & $\begin{array}{l}\text { seção de avaliação onde foi } \\
\text { executada RECONSTRUÇÃOO }\end{array}$ \\
\hline 170,990 & 4100 & 16,7 & 14,3 & 12,9 & 11,1 & 9,7 & 7,4 & 6,0 & 21 & 20 & $\begin{array}{l}\text { seção de avaliação onde foi } \\
\text { executada RECONSTRUÇÃO }\end{array}$ \\
\hline 170,990 & 6500 & 24,4 & 21,5 & 19,5 & 17,0 & 14,8 & 12,6 & 9,6 & 21 & 20 & $\begin{array}{l}\text { seção de avaliação onde foi } \\
\text { executada RECONSTRUÇÃOO }\end{array}$ \\
\hline 170,980 & 2100 & 8,7 & 7,1 & 6,3 & 5,4 & 4,8 & 3,7 & 2,9 & 21 & 20 & $\begin{array}{l}\text { seção de avaliação onde foi } \\
\text { executada RECONSTRUÇÃO }\end{array}$ \\
\hline 170,980 & 4100 & 15,9 & 13,2 & 11,8 & 10,0 & 8,8 & 6,7 & 5,5 & 21 & 20 & $\begin{array}{l}\text { seção de avaliação onde foi } \\
\text { executada RECONSTRUÇÃO }\end{array}$ \\
\hline 170,980 & 6500 & 23,3 & 19,5 & 17,4 & 15,4 & 13,3 & 11,1 & 8,9 & 21 & 20 & $\begin{array}{l}\text { seção de avaliação onde foi } \\
\text { executada RECONSTRUÇÃO }\end{array}$ \\
\hline 170,970 & 2100 & 9,1 & 7,6 & 6,7 & 5,7 & 5,0 & 3,6 & 2,8 & 22 & 20 & $\begin{array}{l}\text { seção de avaliação onde foi } \\
\text { executada RECONSTRUÇÃO }\end{array}$ \\
\hline 170,970 & 4100 & 17,2 & 14,5 & 12,9 & 11,1 & 9,6 & 7,2 & 5,6 & 22 & 20 & $\begin{array}{l}\text { seção de avaliação onde foi } \\
\text { executada RECONSTRUÇÃO }\end{array}$ \\
\hline 170,970 & 6500 & 25,5 & 21,8 & 19,5 & 17,1 & 14,8 & 11,2 & 8,9 & 22 & 20 & $\begin{array}{l}\text { seção de avaliação onde foi } \\
\text { executada RECONSTRUÇÃO }\end{array}$ \\
\hline 170,960 & 2100 & 10,1 & 8,7 & 7,5 & 6,6 & 5,4 & 3,9 & 2,9 & 22 & 20 & $\begin{array}{l}\text { seção de avaliação onde foi } \\
\text { executada RECONSTRUÇÃO }\end{array}$ \\
\hline 170,960 & 4100 & 18,6 & 15,8 & 14,2 & 12,1 & 10,2 & 7,4 & 5,7 & 22 & 20 & $\begin{array}{l}\text { seção de avaliação onde foi } \\
\text { executada RECONSTRUÇÃO }\end{array}$ \\
\hline 170,960 & 6500 & 27,0 & 23,6 & 21,2 & 18,4 & 15,6 & 11,8 & 9,4 & 22 & 20 & $\begin{array}{l}\text { seção de avaliação onde foi } \\
\text { executada RECONSTRUÇÃO }\end{array}$ \\
\hline 170,949 & 2100 & 8,0 & 7,0 & 6,3 & 5,6 & 4,8 & 3,8 & 3,1 & 22 & 20 & $\begin{array}{l}\text { seção de avaliação onde foi } \\
\text { executada RECONSTRUÇÃO }\end{array}$ \\
\hline 170,949 & 4100 & 15,4 & 13,5 & 12,2 & 10,7 & 9,5 & 8,5 & 6,3 & 22 & 20 & $\begin{array}{l}\text { seção de avaliação onde foi } \\
\text { executada RECONSTRUÇÃO }\end{array}$ \\
\hline 170,949 & 6500 & 22,3 & 19,4 & 17,7 & 15,7 & 13,7 & 10,7 & 8,9 & 22 & 20 & $\begin{array}{l}\text { seção de avaliação onde foi } \\
\text { executada RECONSTRUÇÃO }\end{array}$ \\
\hline 170,940 & 2100 & 7,4 & 6,3 & 5,8 & 5,2 & 4,4 & 3,2 & 2,6 & 22 & 20 & $\begin{array}{l}\text { seção de avaliação onde foi } \\
\text { executada RECONSTRUÇÃO }\end{array}$ \\
\hline 170,940 & 4100 & 13,5 & 12,0 & 11,0 & 9,5 & 8,3 & 6,1 & 5,3 & 22 & 20 & $\begin{array}{l}\text { seção de avaliação onde foi } \\
\text { executada RECONSTRUÇÃo }\end{array}$ \\
\hline 170,940 & 6500 & 20,7 & 18,5 & 16,9 & 15,2 & 13,4 & 10,8 & 8,7 & 22 & 20 & $\begin{array}{l}\text { seção de avaliação onde foi } \\
\text { executada RECONSTRUÇÃo }\end{array}$ \\
\hline 170,929 & 2100 & 7,9 & 6,8 & 6,1 & 5,3 & 4,6 & 3,0 & 2,6 & 22 & 20 & $\begin{array}{l}\text { seção de avaliação onde foi } \\
\text { executada RECONSTRUÇÃO }\end{array}$ \\
\hline 170,929 & 4100 & 15,1 & 12,9 & 11,7 & 10,1 & 8,7 & 6,2 & 5,1 & 22 & 20 & $\begin{array}{l}\text { seção de avaliação onde foi } \\
\text { executada RECONSTRUÇÃo }\end{array}$ \\
\hline 170,929 & 6500 & 22,5 & 19,7 & 17,9 & 15,5 & 13,7 & 9,9 & 8,1 & 22 & 20 & $\begin{array}{l}\text { seção de avaliação onde foi } \\
\text { executada RECONSTRUÇÃO }\end{array}$ \\
\hline 170,920 & 2100 & 8,0 & 6,6 & 6,1 & 5,2 & 4,4 & 2,9 & 2,5 & 22 & 20 & $\begin{array}{l}\text { seção de avaliação onde foi } \\
\text { executada RECONSTRUÇÃo }\end{array}$ \\
\hline 170,920 & 4100 & 15,0 & 12,8 & 11,7 & 10,1 & 8,7 & 6,3 & 5,0 & 22 & 20 & $\begin{array}{l}\text { seção de avaliação onde foi } \\
\text { executada RECONSTRUÇÃo }\end{array}$ \\
\hline 170,920 & 6500 & 22,0 & 19,1 & 17,4 & 15,3 & 13,4 & 10,3 & 7,8 & 22 & 20 & $\begin{array}{l}\text { seção de avaliação onde foi } \\
\text { executada RECONSTRUÇÃo }\end{array}$ \\
\hline 170,910 & 2100 & 7,8 & 6,8 & 6,1 & 5,2 & 4,5 & 3,2 & 2,5 & 22 & 20 & $\begin{array}{l}\text { seção de avaliação onde foi } \\
\text { executada RECONSTRUÇÃO }\end{array}$ \\
\hline 170,910 & 4100 & 14,5 & 12,3 & 11,1 & 9,5 & 8,2 & 5,4 & 4,5 & 22 & 20 & $\begin{array}{l}\text { seção de avaliação onde foi } \\
\text { executada RECONSTRUÇÃo }\end{array}$ \\
\hline 170,910 & 6500 & 22,1 & 19,1 & 17,5 & 15,2 & 13,2 & 10,0 & 8,1 & 22 & 20 & $\begin{array}{l}\text { seção de avaliação onde foi } \\
\text { executada RECONSTRUÇÃO }\end{array}$ \\
\hline 170,900 & 2100 & 7,6 & 6,5 & 6,0 & 5,2 & 4,6 & 3,2 & 2,7 & 23 & 20 & $\begin{array}{l}\text { seção de avaliação onde foi } \\
\text { executada RECONSTRUÇÃo }\end{array}$ \\
\hline 170,900 & 4100 & 14,1 & 12,3 & 11,1 & 9,8 & 8,5 & 6,3 & 5,1 & 23 & 20 & $\begin{array}{l}\text { seção de avaliação onde foi } \\
\text { executada RECONSTRUÇÃO }\end{array}$ \\
\hline 170,900 & 6500 & 20,8 & 18,3 & 16,8 & 14,8 & 12,9 & 10,5 & 8,2 & 23 & 20 & $\begin{array}{l}\text { seção de avaliação onde foi } \\
\text { executada RECONSTRUÇÃo }\end{array}$ \\
\hline 170,890 & 2100 & 7,4 & 6,3 & 5,7 & 4,9 & 4,3 & 3,3 & 2,7 & 22 & 20 & $\begin{array}{l}\text { seção de avaliação onde foi } \\
\text { executada RECONSTRUÇÃO }\end{array}$ \\
\hline 170,890 & 4100 & 13,4 & 11,5 & 10,4 & 9,0 & 7,9 & 6,0 & 4,9 & 22 & 20 & $\begin{array}{l}\text { seção de avaliação onde foi } \\
\text { executada RECONSTRUÇÃO }\end{array}$ \\
\hline
\end{tabular}


Rodovia: Presidente Dutra - BR-116 Pista: Norte (São Paulo) Sentido: Rio de Janeiro
Faixa: 2

Data: $26 / 04 / 2011$

Trecho: Topo da Camada de Gap Graded

\begin{tabular}{|c|c|c|c|c|c|c|c|c|c|c|c|}
\hline \multirow{2}{*}{$\mathrm{km}$} & \multirow{2}{*}{$\begin{array}{r}\text { Força } \\
\text { (kgf) }\end{array}$} & \multicolumn{7}{|c|}{ Deflexões $(0,01 \mathrm{~mm})$} & \multirow{2}{*}{$\begin{array}{l}\text { Temp. } \\
\operatorname{Ar}\left({ }^{\circ} \mathrm{C}\right)\end{array}$} & \multirow{2}{*}{$\begin{array}{l}\text { Temp. } \\
\text { Pav. }\left({ }^{\circ} \mathrm{C}\right)\end{array}$} & \multirow{2}{*}{ Obs } \\
\hline & & D0 & D200 & D300 & D450 & D600 & D900 & D1200 & & & \\
\hline 170,890 & 6500 & 20,2 & 17,7 & 16,0 & 14,0 & 12,3 & 10,6 & 8,2 & 22 & 20 & $\begin{array}{l}\text { seção de avaliação onde foi } \\
\text { executada RECONSTRUÇÃO }\end{array}$ \\
\hline 170,880 & 2100 & 7,3 & 6,1 & 5,5 & 4,9 & 4,2 & 3,3 & 2,4 & 22 & 20 & $\begin{array}{l}\text { seção de avaliação onde foi } \\
\text { executada RECONSTRUÇÃO }\end{array}$ \\
\hline 170,880 & 4100 & 13,6 & 11,2 & 10,2 & 8,9 & 7,8 & 5,8 & 4,7 & 22 & 20 & $\begin{array}{l}\text { seção de avaliação onde foi } \\
\text { executada RECONSTRUÇÃO }\end{array}$ \\
\hline 170,880 & 6500 & 19,6 & 16,6 & 15,2 & 13,3 & 11,6 & 9,0 & 7,4 & 22 & 20 & $\begin{array}{l}\text { seção de avaliação onde foi } \\
\text { executada RECONSTRUÇÃO }\end{array}$ \\
\hline 170,870 & 2100 & 7,0 & 6,1 & 5,5 & 4,9 & 4,3 & 3,2 & 2,6 & 22 & 20 & $\begin{array}{l}\text { seção de avaliação onde foi } \\
\text { executada RECONSTRUÇÃOO }\end{array}$ \\
\hline 170,870 & 4100 & 12,9 & 11,2 & 10,2 & 9,0 & 8,0 & 6,2 & 5,1 & 22 & 20 & $\begin{array}{l}\text { seção de avaliação onde foi } \\
\text { executada RECONSTRUÇÃO }\end{array}$ \\
\hline 170,870 & 6500 & 19,0 & 16,8 & 15,4 & 13,8 & 12,1 & 9,7 & 8,1 & 22 & 20 & $\begin{array}{l}\text { seção de avaliação onde foi } \\
\text { executada RECONSTRUÇÃO }\end{array}$ \\
\hline 170,860 & 2100 & 7,5 & 6,3 & 5,8 & 5,1 & 4,4 & 3,3 & 2,6 & 22 & 20 & $\begin{array}{l}\text { seção de avaliação onde foi } \\
\text { executada RECONSTRUÇÃO }\end{array}$ \\
\hline 170,860 & 4100 & 13,6 & 11,8 & 10,8 & 9,3 & 8,3 & 6,2 & 5,1 & 22 & 20 & $\begin{array}{l}\text { seção de avaliação onde foi } \\
\text { executada RECONSTRUÇÃO }\end{array}$ \\
\hline 170,860 & 6500 & 19,9 & 17,8 & 16,1 & 14,4 & 12,7 & 10,2 & 8,0 & 22 & 20 & $\begin{array}{l}\text { seção de avaliação onde foi } \\
\text { executada RECONSTRUÇÃO }\end{array}$ \\
\hline 170,850 & 2100 & 7,9 & 6,6 & 6,1 & 5,3 & 4,6 & 3,3 & 2,7 & 22 & 20 & $\begin{array}{l}\text { seção de avaliação onde foi } \\
\text { executada RECONSTRUÇÃO }\end{array}$ \\
\hline 170,850 & 4100 & 14,7 & 12,5 & 11,3 & 9,9 & 8,6 & 6,4 & 5,2 & 22 & 20 & $\begin{array}{l}\text { seção de avaliação onde foi } \\
\text { executada RECONSTRUÇÃO }\end{array}$ \\
\hline 170,850 & 6500 & 21,6 & 18,8 & 17,2 & 15,1 & 13,3 & 10,3 & 8,3 & 22 & 20 & $\begin{array}{l}\text { seção de avaliação onde foi } \\
\text { executada RECONSTRUÇÃO }\end{array}$ \\
\hline 170,840 & 2100 & 7,2 & 6,2 & 5,5 & 5,1 & 4,5 & 3,5 & 2,7 & 23 & 20 & $\begin{array}{l}\text { seção de avaliação onde foi } \\
\text { executada RECONSTRUÇÃO }\end{array}$ \\
\hline 170,840 & 4100 & 13,2 & 11,4 & 10,6 & 9,3 & 8,2 & 6,0 & 5,1 & 23 & 20 & $\begin{array}{l}\text { seção de avaliação onde foi } \\
\text { executada RECONSTRUÇÃO }\end{array}$ \\
\hline 170,840 & 6500 & 19,4 & 17,0 & 15,8 & 14,0 & 12,5 & 10,0 & 8,1 & 23 & 20 & $\begin{array}{l}\text { seção de avaliação onde foi } \\
\text { executada RECONSTRUÇÃO }\end{array}$ \\
\hline 170,830 & 2100 & 7,3 & 6,1 & 5,5 & 4,9 & 4,3 & 3,1 & 2,6 & 22 & 20 & $\begin{array}{l}\text { seção de avaliação onde foi } \\
\text { executada RECONSTRUÇÃO }\end{array}$ \\
\hline 170,830 & 4100 & 13,9 & 11,8 & 10,7 & 9,4 & 8,3 & 6,4 & 5,2 & 22 & 20 & $\begin{array}{l}\text { seção de avaliação onde foi } \\
\text { executada RECONSTRUÇÃO }\end{array}$ \\
\hline 170,830 & 6500 & 20,6 & 17,7 & 16,2 & 14,3 & 12,7 & 10,1 & 8,4 & 22 & 20 & $\begin{array}{l}\text { seção de avaliação onde foi } \\
\text { executada RECONSTRUÇÃO }\end{array}$ \\
\hline 170,820 & 2100 & 8,0 & 6,7 & 5,9 & 5,2 & 4,4 & 3,5 & 2,8 & 23 & 20 & $\begin{array}{l}\text { seção de avaliação onde foi } \\
\text { executada RECONSTRUÇÃO }\end{array}$ \\
\hline 170,820 & 4100 & 14,4 & 12,1 & 10,9 & 9,2 & 8,0 & 6,4 & 5,1 & 23 & 20 & $\begin{array}{l}\text { seção de avaliação onde foi } \\
\text { executada RECONSTRUÇÃO }\end{array}$ \\
\hline 170,820 & 6500 & 21,0 & 18,3 & 16,4 & 14,4 & 12,3 & 10,5 & 8,3 & 23 & 20 & $\begin{array}{l}\text { seção de avaliação onde foi } \\
\text { executada RECONSTRUÇÃO }\end{array}$ \\
\hline 170,810 & 2100 & 8,3 & 7,3 & 6,7 & 5,8 & 4,9 & 4,0 & 3,2 & 23 & 20 & $\begin{array}{l}\text { seção de avaliação onde foi } \\
\text { executada RECONSTRUÇÃO }\end{array}$ \\
\hline 170,810 & 4100 & 15,5 & 13,7 & 12,5 & 10,9 & 9,4 & 7,5 & 6,0 & 23 & 20 & $\begin{array}{l}\text { seção de avaliação onde foi } \\
\text { executada RECONSTRUÇÃO }\end{array}$ \\
\hline 170,810 & 6500 & 22,7 & 20,3 & 18,4 & 15,8 & 14,0 & 11,9 & 9,3 & 23 & 20 & $\begin{array}{l}\text { seção de avaliação onde foi } \\
\text { executada RECONSTRUÇÃO }\end{array}$ \\
\hline 170,800 & 2100 & 11,2 & 9,0 & 7,6 & 6,1 & 4,8 & 3,1 & 2,3 & 23 & 20 & $\begin{array}{l}\text { seção de avaliação onde foi } \\
\text { executada RECONSTRUÇÃO }\end{array}$ \\
\hline 170,800 & 4100 & 24,1 & 20,3 & 17,6 & 13,8 & 10,7 & 6,9 & 4,8 & 23 & 20 & $\begin{array}{l}\text { seção de avaliação onde foi } \\
\text { executada RECONSTRUÇÃO }\end{array}$ \\
\hline 170,800 & 6500 & 38,7 & 33,0 & 28,8 & 22,8 & 18,0 & 11,9 & 8,2 & 23 & 20 & $\begin{array}{l}\text { seção de avaliação onde foi } \\
\text { executada RECONSTRUÇÃO }\end{array}$ \\
\hline 170,790 & 2100 & 9,3 & 7,8 & 6,9 & 5,8 & 4,8 & 3,3 & 2,6 & 22 & 20 & $\begin{array}{l}\text { seção de avaliação onde foi } \\
\text { executado } 14 \mathrm{~cm} \text { - EME }\end{array}$ \\
\hline 170,790 & 4100 & 19,4 & 16,8 & 14,7 & 12,5 & 10,1 & 7,2 & 5,1 & 22 & 20 & $\begin{array}{l}\text { seção de avaliação onde foi } \\
\text { executado } 14 \mathrm{~cm} \text { - EME }\end{array}$ \\
\hline 170,790 & 6500 & 31,0 & 27,1 & 24,3 & 20,2 & 16,7 & 11,9 & 8,7 & 22 & 20 & $\begin{array}{c}\text { seção de avaliação onde foi } \\
\text { executado } 14 \mathrm{~cm} \text { - EME }\end{array}$ \\
\hline 170,780 & 2100 & 9,6 & 8,2 & 7,1 & 6,2 & 5,0 & 3,6 & 2,7 & 23 & 20 & $\begin{array}{l}\text { seção de avaliação onde foi } \\
\text { executado } 14 \mathrm{~cm} \text { - EME }\end{array}$ \\
\hline 170,780 & 4100 & 19,5 & 17,4 & 15,4 & 12,7 & 10,5 & 7,2 & 5,2 & 23 & 20 & $\begin{array}{l}\text { seção de avaliação onde foi } \\
\text { executado } 14 \mathrm{~cm} \text { - EME }\end{array}$ \\
\hline 170,780 & 6500 & 31,0 & 27,8 & 24,5 & 20,9 & 17,2 & 12,6 & 8,8 & 23 & 20 & $\begin{array}{l}\text { seção de avaliação onde foi } \\
\text { executado } 14 \mathrm{~cm} \text { - EME }\end{array}$ \\
\hline 170,770 & 2100 & 11,4 & 9,5 & 8,3 & 6,7 & 5,4 & 3,6 & 2,8 & 23 & 20 & $\begin{array}{l}\text { seção de avaliação onde foi } \\
\text { executado } 14 \mathrm{~cm} \text { - EME }\end{array}$ \\
\hline
\end{tabular}


Rodovia: Presidente Dutra - BR-116 Pista: Norte (São Paulo) Sentido: Rio de Janeiro
Faixa: 2

Data: $26 / 04 / 2011$

Trecho: Topo da Camada de Gap Graded

\begin{tabular}{|c|c|c|c|c|c|c|c|c|c|c|c|}
\hline \multirow{2}{*}{$\mathrm{km}$} & \multirow{2}{*}{$\begin{array}{l}\text { Força } \\
\text { (kgf) }\end{array}$} & \multicolumn{7}{|c|}{ Deflexões $(0,01 \mathrm{~mm})$} & \multirow{2}{*}{$\begin{array}{l}\text { Temp. } \\
\operatorname{Ar}\left({ }^{\circ} \mathrm{C}\right)\end{array}$} & \multirow{2}{*}{$\begin{array}{l}\text { Temp. } \\
\text { Pav. }\left({ }^{\circ} \mathrm{C}\right)\end{array}$} & \multirow{2}{*}{ Obs } \\
\hline & & D0 & D200 & D300 & D450 & D600 & D900 & D1200 & & & \\
\hline 170,770 & 4100 & 23,2 & 19,8 & 17,3 & 14,0 & 11,2 & 7,8 & 5,5 & 23 & 20 & $\begin{array}{l}\text { seção de avaliação onde foi } \\
\text { executado } 14 \mathrm{~cm} \text { - EME }\end{array}$ \\
\hline 170,770 & 6500 & 35,6 & 31,0 & 27,3 & 22,0 & 17,9 & 12,6 & 9,0 & 23 & 20 & $\begin{array}{l}\text { seção de avaliação onde foi } \\
\text { executado } 14 \mathrm{~cm} \text { - EME }\end{array}$ \\
\hline 170,760 & 2100 & 8,2 & 6,7 & 5,7 & 5,0 & 4,1 & 2,9 & 2,4 & 23 & 20 & $\begin{array}{l}\text { seção de avaliação onde foi } \\
\text { executado } 14 \mathrm{~cm} \text { - EME }\end{array}$ \\
\hline 170,760 & 4100 & 17,1 & 14,6 & 12,8 & 10,2 & 8,4 & 6,3 & 4,9 & 23 & 20 & $\begin{array}{l}\text { seção de avaliação onde foi } \\
\text { executado } 14 \mathrm{~cm} \text { - EME }\end{array}$ \\
\hline 170,760 & 6500 & 27,6 & 23,6 & 20,6 & 17,2 & 13,9 & 10,3 & 7,7 & 23 & 20 & $\begin{array}{l}\text { seção de avaliação onde foi } \\
\text { executado } 14 \mathrm{~cm} \text { - EME }\end{array}$ \\
\hline 170,750 & 2100 & 8,4 & 7,0 & 6,2 & 5,2 & 4,3 & 2,9 & 2,3 & 22 & 20 & $\begin{array}{l}\text { seção de avaliação onde foi } \\
\text { executado } 14 \mathrm{~cm} \text { - EME }\end{array}$ \\
\hline 170,750 & 4100 & 16,0 & 13,8 & 12,1 & 10,0 & 8,3 & 5,9 & 4,5 & 22 & 20 & $\begin{array}{l}\text { seção de avaliação onde foi } \\
\text { executado } 14 \mathrm{~cm} \text { - EME }\end{array}$ \\
\hline 170,750 & 6500 & 24,3 & 21,4 & 18,9 & 15,6 & 13,1 & 9,8 & 7,6 & 22 & 20 & $\begin{array}{l}\text { seção de avaliação onde foi } \\
\text { executado } 14 \mathrm{~cm} \text { - EME }\end{array}$ \\
\hline 170,740 & 2100 & 9,5 & 7,8 & 6,6 & 5,5 & 4,3 & 2,9 & 1,8 & 22 & 20 & $\begin{array}{l}\text { seção de avaliação onde foi } \\
\text { executado } 14 \mathrm{~cm} \text { - EME }\end{array}$ \\
\hline 170,740 & 4100 & 19,7 & 16,7 & 14,5 & 11,4 & 8,9 & 5,7 & 4,0 & 22 & 20 & $\begin{array}{l}\text { seção de avaliação onde foi } \\
\text { executado } 14 \mathrm{~cm} \text { - EME }\end{array}$ \\
\hline 170,740 & 6500 & 30,9 & 26,5 & 23,0 & 18,2 & 14,3 & 9,7 & 6,4 & 22 & 20 & $\begin{array}{l}\text { seção de avaliação onde foi } \\
\text { executado } 14 \mathrm{~cm} \text { - EME }\end{array}$ \\
\hline 170,730 & 2100 & 6,3 & 5,1 & 4,3 & 3,6 & 2,8 & 1,9 & 1,4 & 22 & 20 & $\begin{array}{l}\text { seção de avaliação onde foi } \\
\text { executado } 14 \mathrm{~cm} \text { - EME }\end{array}$ \\
\hline 170,730 & 4100 & 13,5 & 11,3 & 9,7 & 7,8 & 6,3 & 4,1 & 3,0 & 22 & 20 & $\begin{array}{l}\text { seção de avaliação onde foi } \\
\text { executado } 14 \mathrm{~cm} \text { - EME }\end{array}$ \\
\hline 170,730 & 6500 & 22,0 & 18,7 & 16,3 & 12,9 & 10,4 & 6,8 & 4,9 & 22 & 20 & $\begin{array}{l}\text { seção de avaliação onde foi } \\
\text { executado } 14 \mathrm{~cm} \text { - EME }\end{array}$ \\
\hline 170,720 & 2100 & 7,8 & 6,3 & 5,6 & 4,4 & 3,6 & 2,4 & 1,6 & 22 & 20 & $\begin{array}{l}\text { seção de avaliação onde foi } \\
\text { executado } 14 \mathrm{~cm} \text { - EME }\end{array}$ \\
\hline 170,720 & 4100 & 15,7 & 13,2 & 11,6 & 9,4 & 7,5 & 4,9 & 3,4 & 22 & 20 & $\begin{array}{l}\text { seção de avaliação onde foi } \\
\text { executado } 14 \mathrm{~cm} \text { - EME }\end{array}$ \\
\hline 170,720 & 6500 & 24,8 & 21,3 & 18,5 & 15,3 & 12,4 & 8,7 & 5,7 & 22 & 20 & $\begin{array}{l}\text { seção de avaliação onde foi } \\
\text { executado } 14 \mathrm{~cm} \text { - EME }\end{array}$ \\
\hline 170,710 & 2100 & 10,6 & 8,7 & 7,4 & 6,0 & 4,5 & 2,7 & 1,6 & 22 & 20 & $\begin{array}{l}\text { seção de avaliação onde foi } \\
\text { executado } 14 \mathrm{~cm} \text { - EME }\end{array}$ \\
\hline 170,710 & 4100 & 22,1 & 18,7 & 16,2 & 12,8 & 10,0 & 6,3 & 3,9 & 22 & 20 & $\begin{array}{l}\text { seção de avaliação onde foi } \\
\text { executado } 14 \mathrm{~cm} \text { - EME }\end{array}$ \\
\hline 170,710 & 6500 & 34,7 & 29,7 & 25,7 & 20,6 & 15,9 & 10,0 & 6,1 & 22 & 20 & $\begin{array}{l}\text { seção de avaliação onde foi } \\
\text { executado } 14 \mathrm{~cm} \text { - EME }\end{array}$ \\
\hline 170,700 & 2100 & 10,2 & 8,5 & 7,4 & 6,1 & 4,8 & 3,0 & 1,8 & 22 & 20 & $\begin{array}{l}\text { seção de avaliação onde foi } \\
\text { executado } 14 \mathrm{~cm} \text { - EME }\end{array}$ \\
\hline 170,700 & 4100 & 22,1 & 18,7 & 16,5 & 13,3 & 10,7 & 6,5 & 4,0 & 22 & 20 & $\begin{array}{l}\text { seção de avaliação onde foi } \\
\text { executado } 14 \mathrm{~cm} \text { - EME }\end{array}$ \\
\hline 170,700 & 6500 & 35,2 & 30,3 & 26,8 & 22,0 & 17,6 & 11,5 & 7,0 & 22 & 20 & $\begin{array}{l}\text { seção de avaliação onde foi } \\
\text { executado } 14 \mathrm{~cm} \text { - EME }\end{array}$ \\
\hline 170,690 & 2100 & 10,3 & 8,2 & 7,0 & 5,4 & 4,0 & 2,5 & 1,6 & 22 & 20 & $\begin{array}{l}\text { seção de avaliação onde foi } \\
\text { executado } 14 \mathrm{~cm} \text { - EME }\end{array}$ \\
\hline 170,690 & 4100 & 22,2 & 18,2 & 15,2 & 11,9 & 9,0 & 5,2 & 3,2 & 22 & 20 & $\begin{array}{l}\text { seção de avaliação onde foi } \\
\text { executado } 14 \mathrm{~cm} \text { - EME }\end{array}$ \\
\hline 170,690 & 6500 & 34,7 & 29,0 & 24,5 & 19,1 & 14,7 & 9,0 & 5,3 & 22 & 20 & $\begin{array}{l}\text { seção de avaliação onde foi } \\
\text { executado } 14 \mathrm{~cm} \text { - EME }\end{array}$ \\
\hline 170,680 & 2100 & 7,8 & 6,2 & 5,2 & 4,3 & 3,2 & 2,0 & 1,1 & 22 & 20 & $\begin{array}{l}\text { seção de avaliação onde foi } \\
\text { executado } 14 \mathrm{~cm} \text { - EME }\end{array}$ \\
\hline 170,680 & 4100 & 16,1 & 13,3 & 11,3 & 8,6 & 6,5 & 3,6 & 2,2 & 22 & 20 & $\begin{array}{l}\text { seção de avaliação onde foi } \\
\text { executado } 14 \mathrm{~cm} \text { - EME }\end{array}$ \\
\hline 170,680 & 6500 & 25,2 & 21,4 & 18,2 & 14,2 & 10,8 & 6,6 & 3,7 & 22 & 20 & $\begin{array}{l}\text { seção de avaliação onde foi } \\
\text { executado } 14 \mathrm{~cm} \text { - EME }\end{array}$ \\
\hline 170,670 & 2100 & 6,8 & 5,4 & 4,6 & 3,2 & 2,9 & 1,6 & 1,1 & 22 & 20 & $\begin{array}{l}\text { seção de avaliação onde foi } \\
\text { executado } 14 \mathrm{~cm} \text { - EME }\end{array}$ \\
\hline 170,670 & 4100 & 14,7 & 12,2 & 10,3 & 8,1 & 6,1 & 3,8 & 2,3 & 22 & 20 & $\begin{array}{l}\text { seção de avaliação onde foi } \\
\text { executado } 14 \mathrm{~cm} \text { - EME }\end{array}$ \\
\hline 170,670 & 6500 & 23,7 & 20,2 & 17,3 & 13,6 & 10,4 & 6,6 & 3,9 & 22 & 20 & $\begin{array}{l}\text { seção de avaliação onde foi } \\
\text { executado } 14 \mathrm{~cm} \text { - EME }\end{array}$ \\
\hline 170,660 & 2100 & 7,1 & 5,9 & 5,1 & 4,2 & 3,2 & 2,0 & 1,1 & 21 & 20 & $\begin{array}{l}\text { seção de avaliação onde foi } \\
\text { executado } 14 \mathrm{~cm} \text { - EME }\end{array}$ \\
\hline 170,660 & 4100 & 14,5 & 12,4 & 10,8 & 8,5 & 6,5 & 3,8 & 2,4 & 21 & 20 & $\begin{array}{l}\text { seção de avaliação onde foi } \\
\text { executado } 14 \mathrm{~cm} \text { - EME }\end{array}$ \\
\hline 170,660 & 6500 & 23,3 & 20,5 & 17,7 & 14,4 & 10,9 & 7,0 & 4,0 & 21 & 20 & $\begin{array}{l}\text { seção de avaliação onde foi } \\
\text { executado } 14 \mathrm{~cm} \text { - EME }\end{array}$ \\
\hline
\end{tabular}


Rodovia: Presidente Dutra - BR-116 Pista: Norte (São Paulo) Sentido: Rio de Janeiro
Faixa: 2

Data: $26 / 04 / 2011$

Trecho: Topo da Camada de Gap Graded

\begin{tabular}{|c|c|c|c|c|c|c|c|c|c|c|c|}
\hline \multirow{2}{*}{$\mathrm{km}$} & \multirow{2}{*}{$\begin{array}{r}\text { Força } \\
\text { (kgf) }\end{array}$} & \multicolumn{7}{|c|}{ Deflexões $(0,01 \mathrm{~mm})$} & \multirow{2}{*}{$\begin{array}{l}\text { Temp. } \\
\operatorname{Ar}\left({ }^{\circ} \mathrm{C}\right)\end{array}$} & \multirow{2}{*}{$\begin{array}{l}\text { Temp. } \\
\text { Pav. }\left({ }^{\circ} \mathrm{C}\right)\end{array}$} & \multirow{2}{*}{ Obs } \\
\hline & & D0 & D200 & D300 & D450 & D600 & D900 & D1200 & & & \\
\hline 170,650 & 2100 & 9,7 & 7,8 & 6,8 & 5,2 & 3,8 & 2,2 & 1,2 & 22 & 20 & $\begin{array}{l}\text { seção de avaliação onde foi } \\
\text { executado } 14 \mathrm{~cm} \text { - EME }\end{array}$ \\
\hline 170,650 & 4100 & 20,3 & 17,0 & 14,7 & 11,6 & 8,5 & 5,0 & 2,8 & 22 & 20 & $\begin{array}{l}\text { seção de avaliação onde foi } \\
\text { executado } 14 \mathrm{~cm} \text { - EME }\end{array}$ \\
\hline 170,650 & 6500 & 32,5 & 27,4 & 23,9 & 18,8 & 14,1 & 8,3 & 4,5 & 22 & 20 & $\begin{array}{l}\text { seção de avaliação onde foi } \\
\text { executado } 14 \mathrm{~cm} \text { - EME }\end{array}$ \\
\hline 170,640 & 2100 & 11,5 & 9,3 & 7,9 & 6,1 & 4,7 & 2,8 & 1,5 & 21 & 20 & $\begin{array}{l}\text { seção de avaliação onde foi } \\
\text { executado } 14 \mathrm{~cm} \text { - EME }\end{array}$ \\
\hline 170,640 & 4100 & 23,4 & 19,3 & 16,7 & 12,9 & 9,8 & 5,5 & 3,3 & 21 & 20 & $\begin{array}{l}\text { seção de avaliação onde foi } \\
\text { executado } 14 \mathrm{~cm} \text { - EME }\end{array}$ \\
\hline 170,640 & 6500 & 35,9 & 30,2 & 26,0 & 20,5 & 15,8 & 9,7 & 5,4 & 21 & 20 & $\begin{array}{l}\text { seção de avaliação onde foi } \\
\text { executado } 14 \mathrm{~cm} \text { - EME }\end{array}$ \\
\hline 170,630 & 2100 & 9,9 & 8,1 & 6,8 & 5,3 & 3,9 & 2,2 & 1,7 & 21 & 20 & $\begin{array}{l}\text { seção de avaliação onde foi } \\
\text { executado } 14 \mathrm{~cm} \text { - EME }\end{array}$ \\
\hline 170,630 & 4100 & 19,8 & 16,9 & 14,3 & 11,0 & 8,4 & 4,7 & 2,6 & 21 & 20 & $\begin{array}{l}\text { seção de avaliação onde foi } \\
\text { executado } 14 \mathrm{~cm} \text { - EME }\end{array}$ \\
\hline 170,630 & 6500 & 31,0 & 26,5 & 22,7 & 17,7 & 13,5 & 8,0 & 4,1 & 21 & 20 & $\begin{array}{l}\text { seção de avaliação onde foi } \\
\text { executado } 14 \mathrm{~cm} \text { - EME }\end{array}$ \\
\hline 170,620 & 2100 & 10,8 & 8,8 & 7,3 & 5,6 & 4,1 & 2,4 & 1,1 & 21 & 20 & $\begin{array}{l}\text { seção de avaliação onde foi } \\
\text { executado } 14 \mathrm{~cm} \text { - EME }\end{array}$ \\
\hline 170,620 & 4100 & 23,2 & 18,6 & 16,0 & 12,1 & 9,0 & 5,0 & 2,8 & 21 & 20 & $\begin{array}{l}\text { seção de avaliação onde foi } \\
\text { executado } 14 \mathrm{~cm} \text { - EME }\end{array}$ \\
\hline 170,620 & 6500 & 36,4 & 30,1 & 25,8 & 20,0 & 14,9 & 8,8 & 4,9 & 21 & 20 & $\begin{array}{l}\text { seção de avaliação onde foi } \\
\text { executado } 14 \mathrm{~cm} \text { - EME }\end{array}$ \\
\hline 170,610 & 2100 & 13,4 & 11,3 & 9,4 & 7,3 & 5,3 & 2,9 & 1,4 & 21 & 20 & $\begin{array}{l}\text { seção de avaliação onde foi } \\
\text { executado } 14 \mathrm{~cm} \text { - EME }\end{array}$ \\
\hline 170,610 & 4100 & 27,7 & 23,7 & 20,0 & 15,7 & 11,6 & 6,3 & 3,2 & 21 & 20 & $\begin{array}{l}\text { seção de avaliação onde foi } \\
\text { executado } 14 \mathrm{~cm} \text { - EME }\end{array}$ \\
\hline 170,610 & 6500 & 42,8 & 37,0 & 31,5 & 24,8 & 18,7 & 10,7 & 5,4 & 21 & 20 & $\begin{array}{l}\text { seção de avaliação onde foi } \\
\text { executado } 14 \mathrm{~cm} \text { - EME }\end{array}$ \\
\hline 170,600 & 2100 & 12,0 & 9,6 & 7,9 & 5,9 & 4,2 & 2,2 & 0,9 & 21 & 20 & $\begin{array}{l}\text { seção de avaliação onde foi } \\
\text { executado } 14 \mathrm{~cm} \text { - EME }\end{array}$ \\
\hline 170,600 & 4100 & 25,6 & 21,1 & 17,7 & 13,2 & 9,4 & 5,0 & 2,4 & 21 & 20 & $\begin{array}{l}\text { seção de avaliação onde foi } \\
\text { executado } 14 \mathrm{~cm} \text { - EME }\end{array}$ \\
\hline 170,600 & 6500 & 39,9 & 33,4 & 28,0 & 21,4 & 15,4 & 8,3 & 3,9 & 21 & 20 & $\begin{array}{l}\text { seção de avaliação onde foi } \\
\text { executado } 14 \mathrm{~cm} \text { - EME }\end{array}$ \\
\hline 170,590 & 2100 & 13,1 & 10,1 & 7,8 & 5,7 & 3,8 & 2,1 & 1,0 & 21 & 20 & $\begin{array}{l}\text { seção de avaliação onde foi } \\
\text { executado } 11 \mathrm{~cm}-\text { EME }\end{array}$ \\
\hline 170,590 & 4100 & 28,1 & 22,2 & 17,6 & 12,7 & 8,8 & 4,5 & 2,2 & 21 & 20 & $\begin{array}{l}\text { seção de avaliação onde foi } \\
\text { executado } 11 \mathrm{~cm} \text { - EME }\end{array}$ \\
\hline 170,590 & 6500 & 44,3 & 35,8 & 29,2 & 21,4 & 15,2 & 8,1 & 4,0 & 21 & 20 & $\begin{array}{l}\text { seção de avaliação onde foi } \\
\text { executado } 11 \mathrm{~cm} \text { - EME }\end{array}$ \\
\hline 170,579 & 2100 & 10,3 & 8,2 & 6,6 & 4,9 & 3,6 & 2,1 & 0,9 & 21 & 20 & $\begin{array}{c}\text { seção de avaliação onde foi } \\
\text { executado } 11 \mathrm{~cm} \text { - EME }\end{array}$ \\
\hline 170,579 & 4100 & 22,8 & 18,7 & 15,6 & 11,4 & 8,3 & 4,5 & 2,4 & 21 & 20 & $\begin{array}{l}\text { seção de avaliação onde foi } \\
\text { executado } 11 \mathrm{~cm} \text { - EME }\end{array}$ \\
\hline 170,579 & 6500 & 36,8 & 30,8 & 26,0 & 19,7 & 14,4 & 8,1 & 4,2 & 21 & 20 & $\begin{array}{l}\text { seção de avaliação onde foi } \\
\text { executado } 11 \mathrm{~cm} \text { - EME }\end{array}$ \\
\hline 170,570 & 2100 & 9,8 & 8,0 & 6,6 & 5,3 & 4,0 & 2,4 & 1,3 & 21 & 20 & $\begin{array}{l}\text { seção de avaliação onde foi } \\
\text { executado } 11 \mathrm{~cm} \text { - EME }\end{array}$ \\
\hline 170,570 & 4100 & 22,3 & 18,8 & 16,0 & 12,6 & 9,6 & 5,6 & 3,3 & 21 & 20 & $\begin{array}{l}\text { seção de avaliação onde foi } \\
\text { executado } 11 \mathrm{~cm} \text { - EME }\end{array}$ \\
\hline 170,570 & 6500 & 36,2 & 31,1 & 26,9 & 21,4 & 16,6 & 10,4 & 6,0 & 21 & 20 & $\begin{array}{l}\text { seção de avaliação onde foi } \\
\text { executado } 11 \mathrm{~cm} \text { - EME }\end{array}$ \\
\hline 170,560 & 2100 & 10,3 & 8,5 & 7,3 & 5,7 & 4,4 & 2,7 & 1,4 & 21 & 20 & $\begin{array}{c}\text { seção de avaliação onde foi } \\
\text { executado } 11 \mathrm{~cm} \text { - EME }\end{array}$ \\
\hline 170,560 & 4100 & 23,4 & 20,1 & 17,5 & 13,6 & 10,4 & 6,1 & 3,6 & 21 & 20 & $\begin{array}{l}\text { seção de avaliação onde foi } \\
\text { executado } 11 \mathrm{~cm} \text { - EME }\end{array}$ \\
\hline 170,560 & 6500 & 38,4 & 33,3 & 29,1 & 23,5 & 18,3 & 11,8 & 6,7 & 21 & 20 & $\begin{array}{l}\text { seção de avaliação onde foi } \\
\text { executado } 11 \mathrm{~cm} \text { - EME }\end{array}$ \\
\hline 170,550 & 2100 & 13,4 & 10,0 & 7,8 & 5,5 & 4,1 & 1,4 & 1,2 & 21 & 20 & $\begin{array}{l}\text { seção de avaliação onde foi } \\
\text { executado } 11 \mathrm{~cm} \text { - EME }\end{array}$ \\
\hline 170,550 & 4100 & 29,5 & 23,0 & 18,4 & 13,6 & 9,9 & 5,0 & 3,1 & 21 & 20 & $\begin{array}{l}\text { seção de avaliação onde foi } \\
\text { executado } 11 \mathrm{~cm} \text { - EME }\end{array}$ \\
\hline 170,550 & 6500 & 46,0 & 36,8 & 30,0 & 22,5 & 16,9 & 8,7 & 5,3 & 21 & 20 & $\begin{array}{l}\text { seção de avaliação onde foi } \\
\text { executado } 11 \mathrm{~cm} \text { - EME }\end{array}$ \\
\hline 170,540 & 2100 & 10,5 & 8,4 & 6,6 & 4,9 & 3,5 & 1,9 & 0,8 & 21 & 20 & $\begin{array}{l}\text { seção de avaliação onde foi } \\
\text { executado } 11 \mathrm{~cm} \text { - EME }\end{array}$ \\
\hline 170,540 & 4100 & 21,3 & 17,6 & 14,4 & 10,2 & 7,1 & 3,6 & 1,9 & 21 & 20 & $\begin{array}{l}\text { seção de avaliação onde foi } \\
\text { executado } 11 \mathrm{~cm} \text { - EME }\end{array}$ \\
\hline
\end{tabular}


Rodovia: Presidente Dutra - BR-116 Pista: Norte (São Paulo) Sentido: Rio de Janeiro
Faixa: 2

Data: $26 / 04 / 2011$

Trecho: Topo da Camada de Gap Graded

\begin{tabular}{|c|c|c|c|c|c|c|c|c|c|c|c|}
\hline \multirow{2}{*}{$\mathrm{km}$} & \multirow{2}{*}{$\begin{array}{r}\text { Força } \\
\text { (kgf) }\end{array}$} & \multicolumn{7}{|c|}{ Deflexões $(0,01 \mathrm{~mm})$} & \multirow{2}{*}{$\begin{array}{l}\text { Temp. } \\
\operatorname{Ar}\left({ }^{\circ} \mathrm{C}\right)\end{array}$} & \multirow{2}{*}{$\begin{array}{l}\text { Temp. } \\
\text { Pav. }\left({ }^{\circ} \mathrm{C}\right)\end{array}$} & \multirow{2}{*}{ Obs } \\
\hline & & D0 & D200 & D300 & D450 & D600 & D900 & D1200 & & & \\
\hline 170,540 & 6500 & 33,0 & 27,7 & 22,8 & 17,0 & 12,2 & 7,0 & 3,3 & 21 & 20 & $\begin{array}{l}\text { seção de avaliação onde foi } \\
\text { executado } 11 \mathrm{~cm} \text { - EME }\end{array}$ \\
\hline 170,530 & 2100 & 20,8 & 13,8 & 10,3 & 7,3 & 5,0 & 2,3 & 1,4 & 21 & 20 & $\begin{array}{l}\text { seção de avaliação onde foi } \\
\text { executado } 11 \mathrm{~cm} \text { - EME }\end{array}$ \\
\hline 170,530 & 4100 & 38,2 & 27,3 & 21,1 & 15,2 & 10,4 & 5,4 & 2,9 & 21 & 20 & $\begin{array}{l}\text { seção de avaliação onde foi } \\
\text { executado } 11 \mathrm{~cm} \text { - EME }\end{array}$ \\
\hline 170,530 & 6500 & 54,3 & 39,8 & 31,2 & 23,3 & 16,5 & 9,2 & 4,7 & 21 & 20 & $\begin{array}{l}\text { seção de avaliação onde foi } \\
\text { executado } 11 \mathrm{~cm}-\text { EME }\end{array}$ \\
\hline 170,520 & 2100 & 11,4 & 9,5 & 7,8 & 6,3 & 4,4 & 2,7 & 1,5 & 21 & 20 & $\begin{array}{l}\text { seção de avaliação onde foi } \\
\text { executado } 11 \mathrm{~cm} \text { - EME }\end{array}$ \\
\hline 170,520 & 4100 & 23,9 & 20,2 & 17,1 & 13,1 & 9,7 & 5,3 & 2,9 & 21 & 20 & $\begin{array}{l}\text { seção de avaliação onde foi } \\
\text { executado } 11 \mathrm{~cm} \text { - EME }\end{array}$ \\
\hline 170,520 & 6500 & 37,0 & 31,6 & 26,8 & 20,9 & 15,7 & 9,3 & 5,0 & 21 & 20 & $\begin{array}{l}\text { seção de avaliação onde foi } \\
\text { executado } 11 \mathrm{~cm} \text { - EME }\end{array}$ \\
\hline 170,510 & 2100 & 9,9 & 7,8 & 6,4 & 4,9 & 3,6 & 1,2 & 1,1 & 21 & 20 & $\begin{array}{l}\text { seção de avaliação onde foi } \\
\text { executado } 11 \mathrm{~cm} \text { - EME }\end{array}$ \\
\hline 170,510 & 4100 & 21,7 & 17,4 & 14,6 & 11,2 & 8,2 & 4,2 & 2,5 & 21 & 20 & $\begin{array}{l}\text { seção de avaliação onde foi } \\
\text { executado } 11 \mathrm{~cm} \text { - EME }\end{array}$ \\
\hline 170,510 & 6500 & 34,2 & 28,0 & 23,8 & 18,2 & 13,9 & 7,5 & 4,4 & 21 & 20 & $\begin{array}{l}\text { seção de avaliação onde foi } \\
\text { executado } 11 \mathrm{~cm} \text { - EME }\end{array}$ \\
\hline 170,500 & 2100 & 11,6 & 9,2 & 7,6 & 5,6 & 3,8 & 2,0 & 0,9 & 21 & 20 & $\begin{array}{l}\text { seção de avaliação onde foi } \\
\text { executado } 11 \mathrm{~cm} \text { - EME }\end{array}$ \\
\hline 170,500 & 4100 & 24,9 & 20,0 & 17,0 & 12,3 & 8,7 & 4,3 & 2,1 & 21 & 20 & $\begin{array}{l}\text { seção de avaliação onde foi } \\
\text { executado } 11 \mathrm{~cm} \text { - EME }\end{array}$ \\
\hline 170,500 & 6500 & 38,3 & 31,0 & 26,3 & 19,6 & 13,9 & 7,5 & 3,5 & 21 & 20 & $\begin{array}{l}\text { seção de avaliação onde foi } \\
\text { executado } 11 \mathrm{~cm} \text { - EME }\end{array}$ \\
\hline 170,490 & 2100 & 9,4 & 7,7 & 6,2 & 4,5 & 3,2 & 1,60 & 0,8 & 21 & 20 & $\begin{array}{l}\text { seção de avaliação onde foi } \\
\text { executado } 11 \mathrm{~cm} \text { - EME }\end{array}$ \\
\hline 170,490 & 4100 & 21,0 & 17,4 & 14,3 & 10,4 & 7,3 & 3,0 & 1,9 & 21 & 20 & $\begin{array}{l}\text { seção de avaliação onde foi } \\
\text { executado } 11 \mathrm{~cm} \text { - EME }\end{array}$ \\
\hline 170,490 & 6500 & 33,9 & 28,2 & 23,4 & 17,5 & 12,4 & 5,6 & 3,2 & 21 & 20 & $\begin{array}{l}\text { seção de avaliação onde foi } \\
\text { executado } 11 \mathrm{~cm}-\text { EME }\end{array}$ \\
\hline 170,480 & 2100 & 16,5 & 11,4 & 9,1 & 7,0 & 5,1 & 2,2 & 2,1 & 21 & 20 & $\begin{array}{l}\text { seção de avaliação onde foi } \\
\text { executado } 11 \mathrm{~cm} \text { - EME }\end{array}$ \\
\hline 170,480 & 4100 & 32,3 & 23,4 & 19,0 & 14,3 & 10,3 & 5,3 & 4,9 & 21 & 20 & $\begin{array}{l}\text { seção de avaliação onde foi } \\
\text { executado } 11 \mathrm{~cm} \text { - EME }\end{array}$ \\
\hline 170,480 & 6500 & 47,1 & 34,6 & 28,6 & 21,9 & 16,0 & 10,60 & 8,6 & 21 & 20 & $\begin{array}{l}\text { seção de avaliação onde foi } \\
\text { executado } 11 \mathrm{~cm} \text { - EME }\end{array}$ \\
\hline 170,470 & 2100 & 9,0 & 7,3 & 6,0 & 4,6 & 3,5 & 1,40 & 1,2 & 21 & 20 & $\begin{array}{l}\text { seção de avaliação onde foi } \\
\text { executado } 11 \mathrm{~cm} \text { - EME }\end{array}$ \\
\hline 170,470 & 4100 & 18,8 & 16,0 & 13,4 & 10,4 & 7,8 & 3,2 & 2,8 & 21 & 20 & $\begin{array}{l}\text { seção de avaliação onde foi } \\
\text { executado } 11 \mathrm{~cm} \text { - EME }\end{array}$ \\
\hline 170,470 & 6500 & 29,4 & 25,2 & 21,7 & 16,8 & 13,0 & 6,7 & 4,7 & 21 & 20 & $\begin{array}{l}\text { seção de avaliação onde foi } \\
\text { executado } 11 \mathrm{~cm}-\text { EME }\end{array}$ \\
\hline 170,460 & 2100 & 10,6 & 8,7 & 7,0 & 5,2 & 3,6 & 1,1 & 0,8 & 21 & 20 & $\begin{array}{l}\text { seção de avaliação onde foi } \\
\text { executado } 11 \mathrm{~cm} \text { - EME }\end{array}$ \\
\hline 170,460 & 4100 & 22,7 & 18,8 & 15,5 & 11,0 & 7,9 & 3,2 & 1,8 & 21 & 20 & $\begin{array}{l}\text { seção de avaliação onde foi } \\
\text { executado } 11 \mathrm{~cm} \text { - EME }\end{array}$ \\
\hline 170,460 & 6500 & 35,1 & 29,5 & 24,6 & 18,2 & 12,9 & 5,9 & 3,2 & 21 & 20 & $\begin{array}{l}\text { seção de avaliação onde foi } \\
\text { executado } 11 \mathrm{~cm} \text { - EME }\end{array}$ \\
\hline 170,449 & 2100 & 11,3 & 9,2 & 7,5 & 5,8 & 4,0 & 1,7 & 1,0 & 21 & 20 & $\begin{array}{l}\text { seção de avaliação onde foi } \\
\text { executado } 11 \mathrm{~cm} \text { - EME }\end{array}$ \\
\hline 170,449 & 4100 & 24,1 & 20,1 & 16,5 & 12,4 & 8,8 & 4,1 & 2,1 & 21 & 20 & $\begin{array}{l}\text { seção de avaliação onde foi } \\
\text { executado } 11 \mathrm{~cm} \text { - EME }\end{array}$ \\
\hline 170,449 & 6500 & 37,2 & 31,3 & 26,2 & 19,8 & 14,4 & 7,4 & 3,8 & 21 & 20 & $\begin{array}{l}\text { seção de avaliação onde foi } \\
\text { executado } 11 \mathrm{~cm} \text { - EME }\end{array}$ \\
\hline 170,440 & 2100 & 11,2 & 8,7 & 7,2 & 5,5 & 3,9 & 1,60 & 1,1 & 21 & 20 & $\begin{array}{l}\text { seção de avaliação onde foi } \\
\text { executado } 11 \mathrm{~cm} \text { - EME }\end{array}$ \\
\hline 170,440 & 4100 & 23,7 & 19,0 & 15,8 & 11,9 & 8,6 & 3,0 & 2,3 & 21 & 20 & $\begin{array}{l}\text { seção de avaliação onde foi } \\
\text { executado } 11 \mathrm{~cm} \text { - EME }\end{array}$ \\
\hline 170,440 & 6500 & 36,5 & 30,0 & 25,3 & 19,4 & 14,0 & 6,2 & 3,6 & 21 & 20 & $\begin{array}{c}\text { seção de avaliação onde foi } \\
\text { executado } 11 \mathrm{~cm} \text { - EME }\end{array}$ \\
\hline 170,430 & 2100 & 13,5 & 12,0 & 10,3 & 7,8 & 5,5 & 3,01 & 1,5 & 21 & 20 & $\begin{array}{l}\text { seção de avaliação onde foi } \\
\text { executado } 11 \mathrm{~cm} \text { - EME }\end{array}$ \\
\hline 170,430 & 4100 & 28,1 & 25,3 & 21,7 & 16,8 & 12,1 & 4,7 & 3,0 & 21 & 20 & $\begin{array}{c}\text { seção de avaliação onde foi } \\
\text { executado } 11 \mathrm{~cm} \text { - EME }\end{array}$ \\
\hline 170,430 & 6500 & 42,8 & 38,5 & 33,5 & 26,1 & 19,2 & 8,7 & 5,2 & 21 & 20 & $\begin{array}{l}\text { seção de avaliação onde foi } \\
\text { executado } 11 \mathrm{~cm} \text { - EME }\end{array}$ \\
\hline 170,420 & 2100 & 9,6 & 8,1 & 6,6 & 5,2 & 3,8 & 1,66 & 0,9 & 21 & 20 & $\begin{array}{l}\text { seção de avaliação onde foi } \\
\text { executado } 11 \mathrm{~cm} \text { - EME }\end{array}$ \\
\hline
\end{tabular}


Rodovia: Presidente Dutra - BR-116 Pista: Norte (São Paulo) Sentido: Rio de Janeiro
Faixa: 2

Data: $26 / 04 / 2011$

Trecho: Topo da Camada de Gap Graded

\begin{tabular}{|c|c|c|c|c|c|c|c|c|c|c|c|}
\hline \multirow{2}{*}{$\mathrm{km}$} & \multirow{2}{*}{$\begin{array}{l}\text { Força } \\
\text { (kgf) }\end{array}$} & \multicolumn{7}{|c|}{ Deflexões $(0,01 \mathrm{~mm})$} & \multirow{2}{*}{$\begin{array}{l}\text { Temp. } \\
\operatorname{Ar}\left({ }^{\circ} \mathrm{C}\right)\end{array}$} & \multirow{2}{*}{$\begin{array}{l}\text { Temp. } \\
\text { Pav. }\left({ }^{\circ} \mathrm{C}\right)\end{array}$} & \multirow{2}{*}{ Obs } \\
\hline & & D0 & D200 & D300 & D450 & D600 & D900 & D1200 & & & \\
\hline 170,420 & 4100 & 20,6 & 17,7 & 15,0 & 11,4 & 8,4 & 3,3 & 2,4 & 21 & 20 & $\begin{array}{l}\text { seção de avaliação onde foi } \\
\text { executado } 11 \mathrm{~cm} \text { - EME }\end{array}$ \\
\hline 170,420 & 6500 & 32,5 & 28,4 & 24,3 & 18,9 & 14,1 & 6,3 & 4,0 & 21 & 20 & $\begin{array}{l}\text { seção de avaliação onde foi } \\
\text { executado } 11 \mathrm{~cm} \text { - EME }\end{array}$ \\
\hline 170,410 & 2100 & 7,8 & 6,0 & 4,7 & 3,3 & 2,3 & 0,71 & 0,6 & 22 & 20 & $\begin{array}{l}\text { seção de avaliação onde foi } \\
\text { executado } 11 \mathrm{~cm} \text { - EME }\end{array}$ \\
\hline 170,410 & 4100 & 15,4 & 11,9 & 9,5 & 6,5 & 4,5 & 1,0 & 0,9 & 22 & 20 & $\begin{array}{l}\text { seção de avaliação onde foi } \\
\text { executado } 11 \mathrm{~cm} \text { - EME }\end{array}$ \\
\hline 170,410 & 6500 & 23,4 & 18,7 & 15,1 & 10,7 & 7,4 & 2,3 & 1,7 & 22 & 20 & $\begin{array}{l}\text { seção de avaliação onde foi } \\
\text { executado } 11 \mathrm{~cm} \text { - EME }\end{array}$ \\
\hline 170,400 & 2100 & 12,2 & 9,3 & 7,1 & 5,2 & 3,7 & 1,66 & 1,0 & 22 & 20 & $\begin{array}{l}\text { seção de avaliação onde foi } \\
\text { executado } 11 \mathrm{~cm} \text { - EME }\end{array}$ \\
\hline 170,400 & 4100 & 25,7 & 20,1 & 16,1 & 11,5 & 8,3 & 3,2 & 2,5 & 22 & 20 & $\begin{array}{l}\text { seção de avaliação onde foi } \\
\text { executado } 11 \mathrm{~cm} \text { - EME }\end{array}$ \\
\hline 170,400 & 6500 & 38,8 & 30,8 & 25,0 & 18,2 & 13,2 & 6,2 & 3,9 & 22 & 20 & $\begin{array}{l}\text { seção de avaliação onde foi } \\
\text { executado } 11 \mathrm{~cm} \text { - EME }\end{array}$ \\
\hline 170,390 & 2100 & 10,0 & 8,0 & 6,6 & 5,0 & 3,6 & 0,8 & 0,3 & 21 & 20 & $\begin{array}{l}\text { seção de avaliação onde foi } \\
\text { executado } 8 \mathrm{~cm} \text { - EME }\end{array}$ \\
\hline 170,390 & 4100 & 21,9 & 17,8 & 14,9 & 11,1 & 8,2 & 3,4 & 2,5 & 21 & 20 & $\begin{array}{l}\text { seção de avaliação onde foi } \\
\text { executado } 8 \mathrm{~cm} \text { - EME }\end{array}$ \\
\hline 170,390 & 6500 & 34,0 & 28,2 & 23,6 & 17,8 & 13,5 & 6,1 & 4,3 & 21 & 20 & $\begin{array}{l}\text { seção de avaliação onde foi } \\
\text { executado } 8 \mathrm{~cm} \text { - EME }\end{array}$ \\
\hline 170,379 & 2100 & 6,7 & 5,0 & 3,9 & 3,2 & 2,2 & 0,83 & 0,8 & 21 & 20 & $\begin{array}{l}\text { seção de avaliação onde foi } \\
\text { executado } 8 \mathrm{~cm} \text { - EME }\end{array}$ \\
\hline 170,379 & 4100 & 12,6 & 9,6 & 7,6 & 5,5 & 4,1 & 2,07 & 1,9 & 21 & 20 & $\begin{array}{l}\text { seção de avaliação onde foi } \\
\text { executado } 8 \mathrm{~cm} \text { - EME }\end{array}$ \\
\hline 170,379 & 6500 & 18,9 & 14,3 & 11,4 & 8,4 & 6,3 & 3,1 & 2,8 & 21 & 20 & $\begin{array}{l}\text { seção de avaliação onde foi } \\
\text { executado } 8 \mathrm{~cm} \text { - EME }\end{array}$ \\
\hline 170,370 & 2100 & 8,6 & 5,3 & 3,8 & 3,0 & 2,1 & 0,89 & 0,9 & 22 & 20 & $\begin{array}{l}\text { seção de avaliação onde foi } \\
\text { executado } 8 \mathrm{~cm} \text { - EME }\end{array}$ \\
\hline 170,370 & 4100 & 16,1 & 10,0 & 7,3 & 5,3 & 4,1 & 2,31 & 2,0 & 22 & 20 & $\begin{array}{l}\text { seção de avaliação onde foi } \\
\text { executado } 8 \mathrm{~cm} \text { - EME }\end{array}$ \\
\hline 170,370 & 6500 & 23,4 & 15,1 & 11,5 & 8,4 & 6,6 & 3,2 & 3,0 & 22 & 20 & $\begin{array}{l}\text { seção de avaliação onde foi } \\
\text { executado } 8 \mathrm{~cm} \text { - EME }\end{array}$ \\
\hline 170,360 & 2100 & 16,0 & 12,2 & 9,6 & 7,1 & 5,3 & 2,0 & 1,9 & 21 & 20 & $\begin{array}{l}\text { seção de avaliação onde foi } \\
\text { executado } 8 \mathrm{~cm} \text { - EME }\end{array}$ \\
\hline 170,360 & 4100 & 34,0 & 26,8 & 22,0 & 16,3 & 12,3 & 6,8 & 4,3 & 21 & 20 & $\begin{array}{l}\text { seção de avaliação onde foi } \\
\text { executado } 8 \mathrm{~cm} \text { - EME }\end{array}$ \\
\hline 170,360 & 6500 & 51,6 & 41,6 & 34,4 & 26,3 & 19,9 & 11,6 & 7,8 & 21 & 20 & $\begin{array}{l}\text { seção de avaliação onde foi } \\
\text { executado } 8 \mathrm{~cm} \text { - EME }\end{array}$ \\
\hline 170,350 & 2100 & 12,1 & 9,7 & 7,8 & 5,8 & 4,4 & 1,77 & 1,5 & 21 & 20 & $\begin{array}{l}\text { seção de avaliação onde foi } \\
\text { executado } 8 \mathrm{~cm} \text { - EME }\end{array}$ \\
\hline 170,350 & 4100 & 25,1 & 20,4 & 16,9 & 12,6 & 9,4 & 3,6 & 3,2 & 21 & 20 & $\begin{array}{l}\text { seção de avaliação onde foi } \\
\text { executado } 8 \mathrm{~cm} \text { - EME }\end{array}$ \\
\hline 170,350 & 6500 & 38,2 & 31,4 & 26,3 & 20,1 & 15,1 & 6,7 & 5,5 & 21 & 20 & $\begin{array}{l}\text { seção de avaliação onde foi } \\
\text { executado } 8 \mathrm{~cm} \text { - EME }\end{array}$ \\
\hline 170,340 & 2100 & 11,5 & 9,4 & 7,8 & 6,3 & 4,8 & 3,2 & 2,2 & 22 & 20 & $\begin{array}{l}\text { seção de avaliação onde foi } \\
\text { executado } 8 \mathrm{~cm} \text { - EME }\end{array}$ \\
\hline 170,340 & 4100 & 24,5 & 20,2 & 17,1 & 13,2 & 10,5 & 6,8 & 4,7 & 22 & 20 & $\begin{array}{l}\text { seção de avaliação onde foi } \\
\text { executado } 8 \mathrm{~cm} \text { - EME }\end{array}$ \\
\hline 170,340 & 6500 & 37,6 & 31,7 & 27,2 & 21,7 & 17,0 & 11,2 & 7,8 & 22 & 20 & $\begin{array}{l}\text { seção de avaliação onde foi } \\
\text { executado } 8 \mathrm{~cm} \text { - EME }\end{array}$ \\
\hline 170,330 & 2100 & 16,1 & 12,3 & 9,8 & 7,1 & 5,5 & 2,80 & 2,2 & 22 & 20 & $\begin{array}{l}\text { seção de avaliação onde foi } \\
\text { executado } 8 \mathrm{~cm} \text { - EME }\end{array}$ \\
\hline 170,330 & 4100 & 32,8 & 26,1 & 21,5 & 16,1 & 12,3 & 5,7 & 4,9 & 22 & 20 & $\begin{array}{l}\text { seção de avaliação onde foi } \\
\text { executado } 8 \mathrm{~cm} \text { - EME }\end{array}$ \\
\hline 170,330 & 6500 & 48,9 & 39,6 & 33,4 & 25,6 & 19,6 & 10,4 & 8,2 & 22 & 20 & $\begin{array}{l}\text { seção de avaliação onde foi } \\
\text { executado } 8 \mathrm{~cm} \text { - EME }\end{array}$ \\
\hline 170,320 & 2100 & 19,8 & 15,5 & 12,6 & 9,3 & 6,8 & 2,8 & 2,5 & 22 & 20 & $\begin{array}{l}\text { seção de avaliação onde foi } \\
\text { executado } 8 \mathrm{~cm} \text { - EME }\end{array}$ \\
\hline 170,320 & 4100 & 40,7 & 32,9 & 27,4 & 20,2 & 15,2 & 8,2 & 5,7 & 22 & 20 & $\begin{array}{l}\text { seção de avaliação onde foi } \\
\text { executado } 8 \mathrm{~cm} \text { - EME }\end{array}$ \\
\hline 170,320 & 6500 & 58,9 & 48,2 & 40,7 & 30,9 & 23,3 & 13,8 & 9,1 & 22 & 20 & $\begin{array}{l}\text { seção de avaliação onde foi } \\
\text { executado } 8 \mathrm{~cm} \text { - EME }\end{array}$ \\
\hline 170,310 & 2100 & 17,8 & 14,0 & 11,5 & 8,6 & 6,4 & 3,69 & 3,1 & 22 & 20 & $\begin{array}{l}\text { seção de avaliação onde foi } \\
\text { executado } 8 \mathrm{~cm} \text { - EME }\end{array}$ \\
\hline 170,310 & 4100 & 38,9 & 31,7 & 26,4 & 20,0 & 15,0 & 7,4 & 6,1 & 22 & 20 & $\begin{array}{l}\text { seção de avaliação onde foi } \\
\text { executado } 8 \mathrm{~cm} \text { - EME }\end{array}$ \\
\hline 170,310 & 6500 & 59,8 & 49,7 & 41,9 & 32,6 & 24,6 & 13,5 & 10,1 & 22 & 20 & $\begin{array}{l}\text { seção de avaliação onde foi } \\
\text { executado } 8 \mathrm{~cm} \text { - EME }\end{array}$ \\
\hline
\end{tabular}


Rodovia: Presidente Dutra - BR-116 Pista: Norte (São Paulo) Sentido: Rio de Janeiro
Faixa: 2

Data: $26 / 04 / 2011$

Trecho: Topo da Camada de Gap Graded

\begin{tabular}{|c|c|c|c|c|c|c|c|c|c|c|c|}
\hline \multirow{2}{*}{$\mathrm{km}$} & \multirow{2}{*}{$\begin{array}{r}\text { Força } \\
\text { (kgf) }\end{array}$} & \multicolumn{7}{|c|}{ Deflexões $(0,01 \mathrm{~mm})$} & \multirow{2}{*}{$\begin{array}{l}\text { Temp. } \\
\operatorname{Ar}\left({ }^{\circ} \mathrm{C}\right)\end{array}$} & \multirow{2}{*}{$\begin{array}{l}\text { Temp. } \\
\text { Pav. }\left({ }^{\circ} \mathrm{C}\right)\end{array}$} & \multirow{2}{*}{ Obs } \\
\hline & & D0 & D200 & D300 & D450 & D600 & D900 & D1200 & & & \\
\hline 170,300 & 2100 & 19,1 & 15,1 & 12,3 & 9,5 & 7,1 & 4,10 & 3,1 & 22 & 20 & $\begin{array}{l}\text { seção de avaliação onde foi } \\
\text { executado } 8 \mathrm{~cm} \text { - EME }\end{array}$ \\
\hline 170,300 & 4100 & 39,8 & 32,3 & 27,1 & 20,3 & 15,7 & 7,9 & 6,5 & 22 & 20 & $\begin{array}{l}\text { seção de avaliação onde foi } \\
\text { executado } 8 \mathrm{~cm} \text { - EME }\end{array}$ \\
\hline 170,300 & 6500 & 59,5 & 49,4 & 41,9 & 32,0 & 24,9 & 14,4 & 10,9 & 22 & 20 & $\begin{array}{l}\text { seção de avaliação onde foi } \\
\text { executado } 8 \mathrm{~cm} \text { - EME }\end{array}$ \\
\hline 170,290 & 2100 & 25,4 & 18,8 & 15,1 & 10,8 & 8,0 & 3,90 & 3,2 & 22 & 20 & $\begin{array}{l}\text { seção de avaliação onde foi } \\
\text { executado } 8 \mathrm{~cm} \text { - EME }\end{array}$ \\
\hline 170,290 & 4100 & 48,6 & 37,1 & 30,2 & 22,3 & 16,4 & 7,8 & 6,4 & 22 & 20 & $\begin{array}{l}\text { seção de avaliação onde foi } \\
\text { executado } 8 \mathrm{~cm} \text { - EME }\end{array}$ \\
\hline 170,290 & 6500 & 68,5 & 53,5 & 44,2 & 33,5 & 25,2 & 13,8 & 10,3 & 22 & 20 & $\begin{array}{l}\text { seção de avaliação onde foi } \\
\text { executado } 8 \mathrm{~cm} \text { - EME }\end{array}$ \\
\hline 170,280 & 2100 & 16,5 & 13,2 & 11,1 & 9,0 & 6,9 & 4,8 & 3,4 & 22 & 20 & $\begin{array}{l}\text { seção de avaliação onde foi } \\
\text { executado } 8 \mathrm{~cm} \text { - EME }\end{array}$ \\
\hline 170,280 & 4100 & 33,7 & 27,6 & 23,6 & 18,7 & 14,7 & 9,8 & 7,2 & 22 & 20 & $\begin{array}{l}\text { seção de avaliação onde foi } \\
\text { executado } 8 \mathrm{~cm} \text { - EME }\end{array}$ \\
\hline 170,280 & 6500 & 49,2 & 41,5 & 35,8 & 28,6 & 22,9 & 16,2 & 11,5 & 22 & 20 & $\begin{array}{l}\text { seção de avaliação onde foi } \\
\text { executado } 8 \mathrm{~cm} \text { - EME }\end{array}$ \\
\hline 170,270 & 2100 & 14,8 & 11,8 & 9,6 & 7,3 & 5,5 & 2,80 & 2,5 & 22 & 20 & $\begin{array}{l}\text { seção de avaliação onde foi } \\
\text { executado } 8 \mathrm{~cm} \text { - EME }\end{array}$ \\
\hline 170,270 & 4100 & 31,1 & 25,4 & 21,0 & 16,0 & 12,2 & 5,9 & 5,2 & 22 & 20 & $\begin{array}{l}\text { seção de avaliação onde foi } \\
\text { executado } 8 \mathrm{~cm} \text { - EME }\end{array}$ \\
\hline 170,270 & 6500 & 47,0 & 39,2 & 33,1 & 25,7 & 19,6 & 10,5 & 8,4 & 22 & 20 & $\begin{array}{l}\text { seção de avaliação onde foi } \\
\text { executado } 8 \mathrm{~cm} \text { - EME }\end{array}$ \\
\hline 170,260 & 2100 & 13,5 & 10,6 & 8,8 & 7,1 & 5,4 & 3,3 & 2,5 & 22 & 20 & $\begin{array}{l}\text { seção de avaliação onde foi } \\
\text { executado } 8 \mathrm{~cm} \text { - EME }\end{array}$ \\
\hline 170,260 & 4100 & 27,7 & 22,3 & 19,0 & 14,6 & 11,5 & 7,6 & 5,1 & 22 & 20 & $\begin{array}{l}\text { seção de avaliação onde foi } \\
\text { executado } 8 \mathrm{~cm} \text { - EME }\end{array}$ \\
\hline 170,260 & 6500 & 41,8 & 34,6 & 29,6 & 23,3 & 18,5 & 12,1 & 8,5 & 22 & 20 & $\begin{array}{l}\text { seção de avaliação onde foi } \\
\text { executado } 8 \mathrm{~cm} \text { - EME }\end{array}$ \\
\hline 170,250 & 2100 & 18,5 & 14,8 & 11,9 & 9,0 & 6,5 & 2,5 & 2,5 & 22 & 20 & $\begin{array}{l}\text { seção de avaliação onde foi } \\
\text { executado } 8 \mathrm{~cm} \text { - EME }\end{array}$ \\
\hline 170,250 & 4100 & 38,3 & 31,3 & 25,4 & 19,2 & 14,2 & 7,7 & 5,6 & 22 & 20 & $\begin{array}{l}\text { seção de avaliação onde foi } \\
\text { executado } 8 \mathrm{~cm} \text { - EME }\end{array}$ \\
\hline 170,250 & 6500 & 57,6 & 47,5 & 39,4 & 30,1 & 22,8 & 13,2 & 9,0 & 22 & 20 & $\begin{array}{l}\text { seção de avaliação onde foi } \\
\text { executado } 8 \mathrm{~cm} \text { - EME }\end{array}$ \\
\hline 170,239 & 2100 & 14,9 & 11,4 & 9,3 & 7,2 & 5,5 & 3,5 & 2,3 & 22 & 20 & $\begin{array}{l}\text { seção de avaliação onde foi } \\
\text { executado } 8 \mathrm{~cm} \text { - EME }\end{array}$ \\
\hline 170,239 & 4100 & 31,6 & 25,6 & 21,5 & 16,8 & 13,1 & 8,6 & 6,4 & 22 & 20 & $\begin{array}{l}\text { seção de avaliação onde foi } \\
\text { executado } 8 \mathrm{~cm} \text { - EME }\end{array}$ \\
\hline 170,239 & 6500 & 47,8 & 39,1 & 33,0 & 26,3 & 20,7 & 14,1 & 9,9 & 22 & 20 & $\begin{array}{l}\text { seção de avaliação onde foi } \\
\text { executado } 8 \mathrm{~cm} \text { - EME }\end{array}$ \\
\hline 170,230 & 2100 & 13,2 & 10,2 & 8,3 & 6,5 & 5,2 & 3,7 & 2,8 & 22 & 20 & $\begin{array}{l}\text { seção de avaliação onde foi } \\
\text { executado } 8 \mathrm{~cm} \text { - EME }\end{array}$ \\
\hline 170,230 & 4100 & 27,1 & 21,9 & 18,2 & 14,2 & 11,4 & 8,1 & 6,0 & 22 & 20 & $\begin{array}{l}\text { seção de avaliação onde foi } \\
\text { executado } 8 \mathrm{~cm} \text { - EME }\end{array}$ \\
\hline 170,230 & 6500 & 41,2 & 33,6 & 28,2 & 22,4 & 17,8 & 12,3 & 8,7 & 22 & 20 & $\begin{array}{l}\text { seção de avaliação onde foi } \\
\text { executado } 8 \mathrm{~cm} \text { - EME }\end{array}$ \\
\hline 170,220 & 2100 & 15,8 & 12,7 & 10,4 & 7,7 & 5,8 & 3,7 & 2,5 & 22 & 20 & $\begin{array}{l}\text { seção de avaliação onde foi } \\
\text { executado } 8 \mathrm{~cm} \text { - EME }\end{array}$ \\
\hline 170,220 & 4100 & 31,7 & 26,1 & 21,6 & 16,2 & 12,3 & 7,5 & 5,2 & 22 & 20 & $\begin{array}{l}\text { seção de avaliação onde foi } \\
\text { executado } 8 \mathrm{~cm} \text { - EME }\end{array}$ \\
\hline 170,220 & 6500 & 48,0 & 40,4 & 33,8 & 26,1 & 19,9 & 13,1 & 8,8 & 22 & 20 & $\begin{array}{l}\text { seção de avaliação onde foi } \\
\text { executado } 8 \mathrm{~cm} \text { - EME }\end{array}$ \\
\hline 170,210 & 2100 & 15,1 & 12,1 & 9,9 & 7,4 & 5,5 & 3,5 & 2,3 & 22 & 20 & $\begin{array}{l}\text { seção de avaliação onde foi } \\
\text { executado } 8 \mathrm{~cm} \text { - EME }\end{array}$ \\
\hline 170,210 & 4100 & 31,4 & 25,8 & 21,4 & 16,3 & 12,3 & 7,8 & 5,3 & 22 & 20 & $\begin{array}{l}\text { seção de avaliação onde foi } \\
\text { executado } 8 \mathrm{~cm} \text { - EME }\end{array}$ \\
\hline 170,210 & 6500 & 47,2 & 39,5 & 33,3 & 25,9 & 19,9 & 12,7 & 8,7 & 22 & 20 & $\begin{array}{l}\text { seção de avaliação onde foi } \\
\text { executado } 8 \mathrm{~cm} \text { - EME }\end{array}$ \\
\hline 170,200 & 2100 & 19,3 & 15,2 & 12,6 & 9,4 & 7,2 & 4,3 & 3,0 & 22 & 20 & $\begin{array}{l}\text { seção de avaliação onde foi } \\
\text { executado } 8 \mathrm{~cm} \text { - EME }\end{array}$ \\
\hline 170,200 & 4100 & 37,9 & 30,9 & 26,1 & 20,0 & 15,3 & 9,8 & 6,3 & 22 & 20 & $\begin{array}{l}\text { seção de avaliação onde foi } \\
\text { executado } 8 \mathrm{~cm} \text { - EME }\end{array}$ \\
\hline 170,200 & 6500 & 55,9 & 46,6 & 39,6 & 31,0 & 24,0 & 15,4 & 10,2 & 22 & 20 & $\begin{array}{l}\text { seção de avaliação onde foi } \\
\text { executado } 8 \mathrm{~cm} \text { - EME }\end{array}$ \\
\hline 170,190 & 2100 & 19,8 & 15,6 & 12,8 & 9,8 & 7,5 & 4,4 & 3,5 & 22 & 20 & $\begin{array}{l}\text { seção de avaliação onde foi } \\
\text { executado } 8 \mathrm{~cm} \text { - CAP } 30 / 45\end{array}$ \\
\hline 170,190 & 4100 & 39,7 & 32,2 & 26,8 & 20,5 & 15,7 & 9,9 & 6,5 & 22 & 20 & $\begin{array}{l}\text { seção de avaliação onde foi } \\
\text { executado } 8 \mathrm{~cm} \text { - CAP } 30 / 45\end{array}$ \\
\hline
\end{tabular}


Rodovia: Presidente Dutra - BR-116 Pista: Norte (São Paulo) Sentido: Rio de Janeiro
Faixa: 2

Data: $26 / 04 / 2011$

Trecho: Topo da Camada de Gap Graded

\begin{tabular}{|c|c|c|c|c|c|c|c|c|c|c|c|}
\hline \multirow{2}{*}{$\mathrm{km}$} & \multirow{2}{*}{$\begin{array}{r}\text { Força } \\
\text { (kgf) }\end{array}$} & \multicolumn{7}{|c|}{ Deflexões $(0,01 \mathrm{~mm})$} & \multirow{2}{*}{$\begin{array}{l}\text { Temp. } \\
\operatorname{Ar}\left({ }^{\circ} \mathrm{C}\right)\end{array}$} & \multirow{2}{*}{$\begin{array}{l}\text { Temp. } \\
\text { Pav. }\left({ }^{\circ} \mathrm{C}\right)\end{array}$} & \multirow{2}{*}{ Obs } \\
\hline & & D0 & D200 & D300 & D450 & D600 & D900 & D1200 & & & \\
\hline 170,190 & 6500 & 58,0 & 48,0 & 40,5 & 31,6 & 24,6 & 15,7 & 10,6 & 22 & 20 & $\begin{array}{l}\text { seção de avaliação onde foi } \\
\text { executado } 8 \mathrm{~cm} \text { - CAP } 30 / 45\end{array}$ \\
\hline 170,170 & 2100 & 13,3 & 11,1 & 9,3 & 7,6 & 5,9 & 4,2 & 3,2 & 22 & 20 & $\begin{array}{l}\text { seção de avaliação onde foi } \\
\text { executado } 8 \mathrm{~cm} \text { - CAP } 30 / 45\end{array}$ \\
\hline 170,170 & 4100 & 28,2 & 23,7 & 20,3 & 16,3 & 13,0 & 9,0 & 6,6 & 22 & 20 & $\begin{array}{l}\text { seção de avaliação onde foi } \\
\text { executado } 8 \mathrm{~cm} \text { - CAP } 30 / 45\end{array}$ \\
\hline 170,170 & 6500 & 43,2 & 37,2 & 32,1 & 26,2 & 20,9 & 15,0 & 10,9 & 22 & 20 & $\begin{array}{l}\text { seção de avaliação onde foi } \\
\text { executado } 8 \mathrm{~cm} \text { - CAP } 30 / 45\end{array}$ \\
\hline 170,160 & 2100 & 12,6 & 9,7 & 8,2 & 6,3 & 5,2 & 3,5 & 0,5 & 22 & 20 & $\begin{array}{l}\text { seção de avaliação onde foi } \\
\text { executado } 8 \mathrm{~cm} \text { - CAP } 30 / 45\end{array}$ \\
\hline 170,160 & 4100 & 25,9 & 20,6 & 17,4 & 13,7 & 10,9 & 7,5 & 5,7 & 22 & 20 & $\begin{array}{l}\text { seção de avaliação onde foi } \\
\text { executado } 8 \mathrm{~cm} \text { - CAP } 30 / 45\end{array}$ \\
\hline 170,160 & 6500 & 39,6 & 32,2 & 27,5 & 22,0 & 17,7 & 12,7 & 9,3 & 22 & 20 & $\begin{array}{l}\text { seção de avaliação onde foi } \\
\text { executado } 8 \mathrm{~cm} \text { - CAP } 30 / 45\end{array}$ \\
\hline 170,150 & 2100 & 12,6 & 9,3 & 7,4 & 5,7 & 4,2 & 3,1 & 2,1 & 22 & 20 & $\begin{array}{l}\text { seção de avaliação onde foi } \\
\text { executado } 8 \mathrm{~cm} \text { - CAP } 30 / 45\end{array}$ \\
\hline 170,150 & 4100 & 24,9 & 18,9 & 15,3 & 11,2 & 8,6 & 5,7 & 4,4 & 22 & 20 & $\begin{array}{l}\text { seção de avaliação onde foi } \\
\text { executado } 8 \mathrm{~cm} \text { - CAP } 30 / 45\end{array}$ \\
\hline 170,150 & 6500 & 37,3 & 29,0 & 23,8 & 18,0 & 13,9 & 9,6 & 7,1 & 22 & 20 & $\begin{array}{l}\text { seção de avaliação onde foi } \\
\text { executado } 8 \mathrm{~cm} \text { - CAP } 30 / 45\end{array}$ \\
\hline 170,140 & 2100 & 8,2 & 6,0 & 4,9 & 3,9 & 3,1 & 1,8 & 1,6 & 22 & 20 & $\begin{array}{l}\text { seção de avaliação onde foi } \\
\text { executado } 8 \mathrm{~cm} \text { - CAP } 30 / 45\end{array}$ \\
\hline 170,140 & 4100 & 15,0 & 11,6 & 9,4 & 7,5 & 6,0 & 4,3 & 3,4 & 22 & 20 & $\begin{array}{l}\text { seção de avaliação onde foi } \\
\text { executado } 8 \mathrm{~cm} \text { - CAP } 30 / 45\end{array}$ \\
\hline 170,140 & 6500 & 22,2 & 17,3 & 14,3 & 11,4 & 9,4 & 6,8 & 5,5 & 22 & 20 & $\begin{array}{l}\text { seção de avaliação onde foi } \\
\text { executado } 8 \mathrm{~cm} \text { - CAP } 30 / 45\end{array}$ \\
\hline 170,130 & 2100 & 12,9 & 8,9 & 6,9 & 5,1 & 3,7 & 2,8 & 1,8 & 21 & 20 & $\begin{array}{l}\text { seção de avaliação onde foi } \\
\text { executado } 8 \mathrm{~cm} \text { - CAP } 30 / 45\end{array}$ \\
\hline 170,130 & 4100 & 24,9 & 17,2 & 13,7 & 9,9 & 7,7 & 5,1 & 3,8 & 21 & 20 & $\begin{array}{l}\text { seção de avaliação onde foi } \\
\text { executado } 8 \mathrm{~cm} \text { - CAP } 30 / 45\end{array}$ \\
\hline 170,130 & 6500 & 37,0 & 26,1 & 20,9 & 15,6 & 11,7 & 8,7 & 6,2 & 21 & 20 & $\begin{array}{l}\text { seção de avaliação onde foi } \\
\text { executado } 8 \mathrm{~cm} \text { - CAP } 30 / 45\end{array}$ \\
\hline 170,120 & 2100 & 9,6 & 7,1 & 5,7 & 4,3 & 3,2 & 2,2 & 1,5 & 21 & 20 & $\begin{array}{l}\text { seção de avaliação onde foi } \\
\text { executado } 8 \mathrm{~cm} \text { - CAP } 30 / 45\end{array}$ \\
\hline 170,120 & 4100 & 20,4 & 15,6 & 12,9 & 9,8 & 7,5 & 4,8 & 3,2 & 21 & 20 & $\begin{array}{l}\text { seção de avaliação onde foi } \\
\text { executado } 8 \mathrm{~cm} \text { - CAP } 30 / 45\end{array}$ \\
\hline 170,120 & 6500 & 31,3 & 24,4 & 20,3 & 16,0 & 12,2 & 8,2 & 5,4 & 21 & 20 & $\begin{array}{l}\text { seção de avaliação onde foi } \\
\text { executado } 8 \mathrm{~cm} \text { - CAP } 30 / 45\end{array}$ \\
\hline 170,110 & 2100 & 11,3 & 7,9 & 5,9 & 4,3 & 2,9 & 2,0 & 1,3 & 21 & 20 & $\begin{array}{l}\text { seção de avaliação onde foi } \\
\text { executado } 8 \mathrm{~cm} \text { - CAP } 30 / 45\end{array}$ \\
\hline 170,110 & 4100 & 22,8 & 16,4 & 12,8 & 8,9 & 6,3 & 3,8 & 0,5 & 21 & 20 & $\begin{array}{l}\text { seção de avaliação onde foi } \\
\text { executado } 8 \mathrm{~cm} \text { - CAP } 30 / 45\end{array}$ \\
\hline 170,110 & 6500 & 34,1 & 25,1 & 19,8 & 14,1 & 10,2 & 6,2 & 4,0 & 21 & 20 & $\begin{array}{l}\text { seção de avaliação onde foi } \\
\text { executado } 8 \mathrm{~cm} \text { - CAP } 30 / 45\end{array}$ \\
\hline 170,100 & 2100 & 14,0 & 9,3 & 7,0 & 4,8 & 3,3 & 1,9 & 1,2 & 21 & 20 & $\begin{array}{l}\text { seção de avaliação onde foi } \\
\text { executado } 8 \mathrm{~cm} \text { - CAP } 30 / 45\end{array}$ \\
\hline 170,100 & 4100 & 27,1 & 19,3 & 14,8 & 10,3 & 7,0 & 4,0 & 2,6 & 21 & 20 & $\begin{array}{l}\text { seção de avaliação onde foi } \\
\text { executado } 8 \mathrm{~cm} \text { - CAP } 30 / 45\end{array}$ \\
\hline 170,100 & 6500 & 39,7 & 29,0 & 22,8 & 16,4 & 11,4 & 6,6 & 4,0 & 21 & 20 & $\begin{array}{l}\text { seção de avaliação onde foi } \\
\text { executado } 8 \mathrm{~cm} \text { - CAP } 30 / 45\end{array}$ \\
\hline 170,090 & 2100 & 11,7 & 8,2 & 6,4 & 4,5 & 3,1 & 1,9 & 1,3 & 22 & 20 & $\begin{array}{l}\text { seção de avaliação onde foi } \\
\text { executado } 8 \mathrm{~cm} \text { - CAP } 30 / 45\end{array}$ \\
\hline 170,090 & 4100 & 22,8 & 16,7 & 13,3 & 9,5 & 6,6 & 3,7 & 2,3 & 22 & 20 & $\begin{array}{l}\text { seção de avaliação onde foi } \\
\text { executado } 8 \mathrm{~cm} \text { - CAP } 30 / 45\end{array}$ \\
\hline 170,090 & 6500 & 33,4 & 25,2 & 20,5 & 15,0 & 10,7 & 6,3 & 4,0 & 22 & 20 & $\begin{array}{l}\text { seção de avaliação onde foi } \\
\text { executado } 8 \mathrm{~cm} \text { - CAP } 30 / 45\end{array}$ \\
\hline 170,080 & 2100 & 22,3 & 14,3 & 9,9 & 6,4 & 4,0 & 2,1 & 1,2 & 22 & 20 & $\begin{array}{l}\text { seção de avaliação onde foi } \\
\text { executado } 8 \mathrm{~cm} \text { - CAP } 30 / 45\end{array}$ \\
\hline 170,080 & 4100 & 40,1 & 27,4 & 19,7 & 12,9 & 8,4 & 4,2 & 2,3 & 22 & 20 & $\begin{array}{l}\text { seção de avaliação onde foi } \\
\text { executado } 8 \mathrm{~cm} \text { - CAP } 30 / 45\end{array}$ \\
\hline 170,080 & 6500 & 54,8 & 38,6 & 28,5 & 19,5 & 12,9 & 6,8 & 3,8 & 22 & 20 & $\begin{array}{l}\text { seção de avaliação onde foi } \\
\text { executado } 8 \mathrm{~cm} \text { - CAP } 30 / 45\end{array}$ \\
\hline 170,070 & 2100 & 19,5 & 12,3 & 8,5 & 5,6 & 3,5 & 2,1 & 0,8 & 21 & 20 & $\begin{array}{l}\text { seção de avaliação onde foi } \\
\text { executado } 8 \mathrm{~cm} \text { - CAP } 30 / 45\end{array}$ \\
\hline 170,070 & 4100 & 34,2 & 23,3 & 16,9 & 11,3 & 7,4 & 3,4 & 1,9 & 21 & 20 & $\begin{array}{l}\text { seção de avaliação onde foi } \\
\text { executado } 8 \mathrm{~cm} \text { - CAP } 30 / 45\end{array}$ \\
\hline 170,070 & 6500 & 47,5 & 33,4 & 24,8 & 17,3 & 11,6 & 6,2 & 3,2 & 21 & 20 & $\begin{array}{l}\text { seção de avaliação onde foi } \\
\text { executado } 8 \mathrm{~cm} \text { - CAP } 30 / 45\end{array}$ \\
\hline 170,060 & 2100 & 19,7 & 13,0 & 9,5 & 6,3 & 4,1 & 2,2 & 1,2 & 21 & 20 & $\begin{array}{l}\text { seção de avaliação onde foi } \\
\text { executado } 8 \mathrm{~cm} \text { - CAP } 30 / 45\end{array}$ \\
\hline
\end{tabular}


Levantamento Deflectométrico com FWD - Topo da Camada de Gap-Graded - $2^{\circ}$ Levantamento (ESTAGIO 4)

Rodovia: Presidente Dutra - BR-116

Pista: Norte (São Paulo)

Sentido: Rio de Janeiro
Faixa: 2

Data: $26 / 04 / 2011$

Trecho: Topo da Camada de Gap Graded

\begin{tabular}{|c|c|c|c|c|c|c|c|c|c|c|c|}
\hline \multirow{2}{*}{$\mathrm{km}$} & \multirow{2}{*}{$\begin{array}{r}\text { Força } \\
\text { (kgf) }\end{array}$} & \multicolumn{7}{|c|}{ Deflexões $(0,01 \mathrm{~mm})$} & \multirow{2}{*}{$\begin{array}{l}\text { Temp. } \\
\operatorname{Ar}\left({ }^{\circ} \mathrm{C}\right)\end{array}$} & \multirow{2}{*}{$\begin{array}{l}\text { Temp. } \\
\text { Pav. }\left({ }^{\circ} \mathrm{C}\right)\end{array}$} & \multirow{2}{*}{ Obs } \\
\hline & & D0 & D200 & D300 & D450 & D600 & D900 & D1200 & & & \\
\hline 170,060 & 4100 & 37,4 & 25,9 & 19,7 & 13,3 & 8,9 & 4,5 & 2,4 & 21 & 20 & $\begin{array}{l}\text { seção de avaliação onde foi } \\
\text { executado } 8 \mathrm{~cm} \text { - CAP } 30 / 45\end{array}$ \\
\hline 170,060 & 6500 & 52,3 & 37,5 & 28,9 & 20,3 & 13,9 & 7,3 & 4,0 & 21 & 20 & $\begin{array}{l}\text { seção de avaliação onde foi } \\
\text { executado } 8 \mathrm{~cm} \text { - CAP } 30 / 45\end{array}$ \\
\hline 170,050 & 2100 & 20,0 & 13,0 & 9,5 & 6,8 & 4,4 & 2,8 & 1,5 & 22 & 20 & $\begin{array}{l}\text { seção de avaliação onde foi } \\
\text { executado } 8 \mathrm{~cm} \text { - CAP } 30 / 45\end{array}$ \\
\hline 170,050 & 4100 & 37,1 & 26,0 & 19,9 & 14,1 & 9,7 & 5,1 & 3,0 & 22 & 20 & $\begin{array}{l}\text { seção de avaliação onde foi } \\
\text { executado } 8 \mathrm{~cm} \text { - CAP } 30 / 45\end{array}$ \\
\hline 170,050 & 6500 & 52,3 & 37,7 & 29,7 & 21,8 & 15,2 & 8,8 & 4,8 & 22 & 20 & $\begin{array}{l}\text { seção de avaliação onde foi } \\
\text { executado } 8 \mathrm{~cm} \text { - CAP } 30 / 45\end{array}$ \\
\hline 170,040 & 2100 & 15,7 & 11,2 & 8,3 & 6,1 & 4,4 & 2,8 & 1,7 & 22 & 20 & $\begin{array}{l}\text { seção de avaliação onde foi } \\
\text { executado } 8 \mathrm{~cm} \text { - CAP } 30 / 45\end{array}$ \\
\hline 170,040 & 4100 & 30,7 & 22,8 & 17,6 & 13,0 & 9,3 & 5,5 & 3,3 & 22 & 20 & $\begin{array}{l}\text { seção de avaliação onde foi } \\
\text { executado } 8 \mathrm{~cm} \text { - CAP } 30 / 45\end{array}$ \\
\hline 170,040 & 6500 & 45,1 & 34,4 & 27,0 & 20,3 & 14,8 & 9,1 & 5,4 & 22 & 20 & $\begin{array}{l}\text { seção de avaliação onde foi } \\
\text { executado } 8 \mathrm{~cm} \text { - CAP } 30 / 45\end{array}$ \\
\hline 170,030 & 2100 & 15,3 & 11,5 & 9,1 & 6,6 & 4,6 & 3,0 & 1,7 & 22 & 20 & $\begin{array}{l}\text { seção de avaliação onde foi } \\
\text { executado } 8 \mathrm{~cm} \text { - CAP } 30 / 45\end{array}$ \\
\hline 170,030 & 4100 & 31,7 & 24,5 & 19,9 & 14,5 & 10,4 & 5,9 & 3,7 & 22 & 20 & $\begin{array}{l}\text { seção de avaliação onde foi } \\
\text { executado } 8 \mathrm{~cm} \text { - CAP } 30 / 45\end{array}$ \\
\hline 170,030 & 6500 & 46,7 & 37,0 & 30,3 & 22,5 & 16,6 & 10,3 & 6,2 & 22 & 20 & $\begin{array}{l}\text { seção de avaliação onde foi } \\
\text { executado } 8 \mathrm{~cm} \text { - CAP } 30 / 45\end{array}$ \\
\hline 170,020 & 2100 & 15,9 & 11,9 & 9,4 & 6,4 & 4,3 & 2,5 & 1,8 & 22 & 20 & $\begin{array}{l}\text { seção de avaliação onde foi } \\
\text { executado } 8 \mathrm{~cm} \text { - CAP } 30 / 45\end{array}$ \\
\hline 170,020 & 4100 & 28,8 & 22,5 & 18,0 & 12,7 & 8,7 & 5,2 & 3,4 & 22 & 20 & $\begin{array}{l}\text { seção de avaliação onde foi } \\
\text { executado } 8 \mathrm{~cm} \text { - CAP } 30 / 45\end{array}$ \\
\hline 170,020 & 6500 & 40,1 & 32,1 & 26,3 & 19,0 & 13,4 & 8,3 & 5,4 & 22 & 20 & $\begin{array}{l}\text { seção de avaliação onde foi } \\
\text { executado } 8 \mathrm{~cm} \text { - CAP } 30 / 45\end{array}$ \\
\hline
\end{tabular}

